
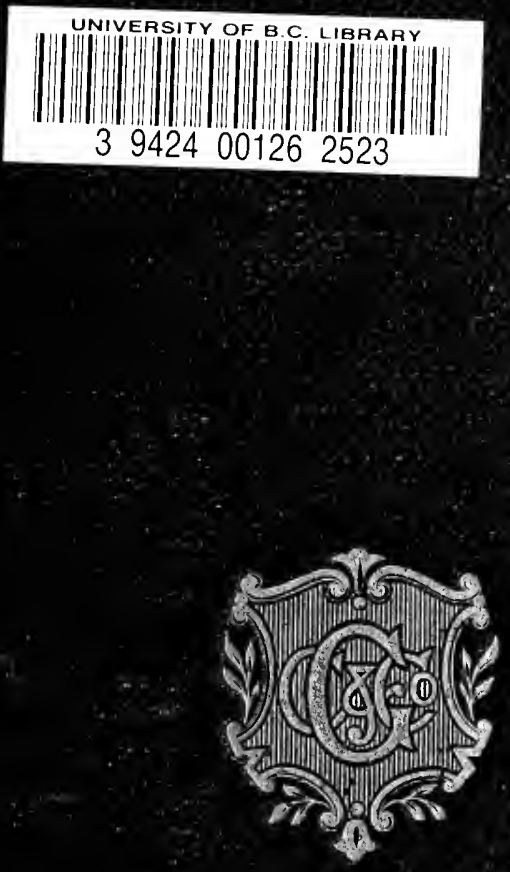

NTOAAGE I TLA

PKUCLSSHNG-CNA

LF $1-113$

U.B.C. LIBRARY 


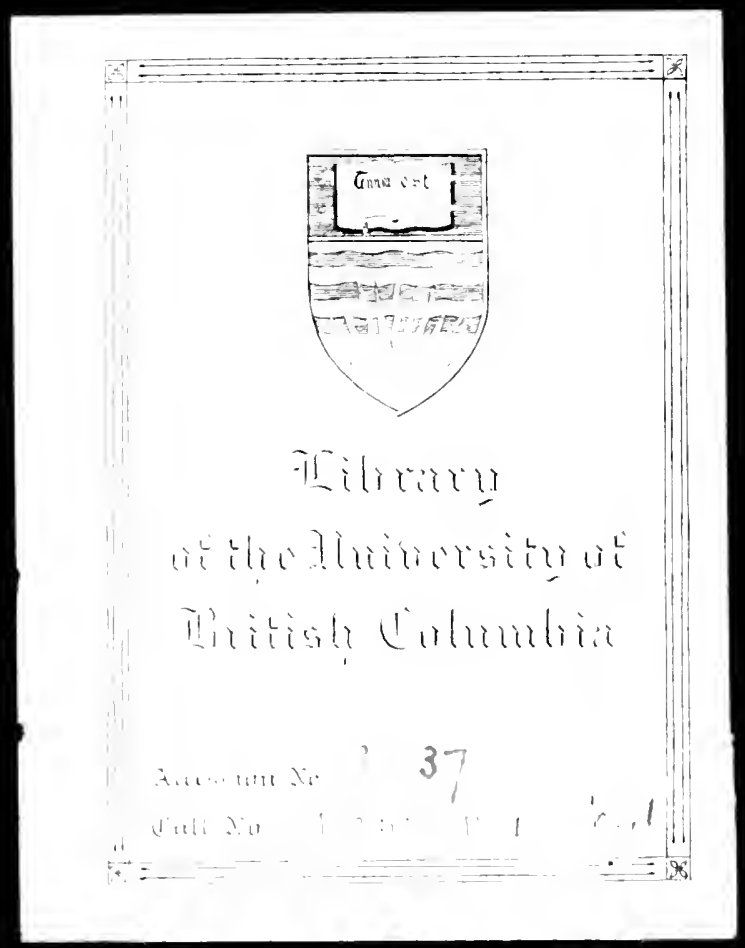




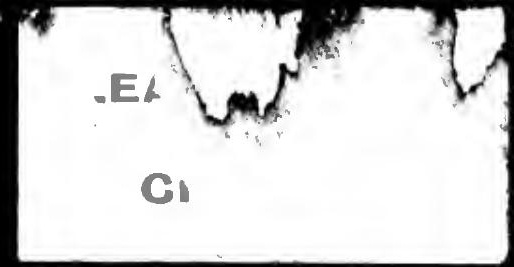

s 
Digitized by the Internet Archive in 2010 with funding from University of British Columbia Library 
DAIRY CHEMISTRY. 


\section{WORKS PUBLISHED BY CHARLES GRIFFIN \& CO.}

FOODS : Theip Composition and Analysis. By A. Writer Bryti,

M.R.C.S., F.C.S., Harrister-at-Law, Public Analyst for the County of Devon, and

Bedical Officer of Ienlth for. St. Marylelone. Witl Elaborate Tables, Folding

Litho.Plate, and Photographic Frontispicce. Fourth Edition, Revised and En-

larged. 21s.

AN AJMIPABLE IIGEST of the most recent state of knowledge. . . . Intcresting even to lay readers." -Chemical Nev's.

AGRICULTURAL CHEMISTRY AND ANALYSIS: A Practical

llandbouk for the Use of Aqricultural Stuments. By J. M. II. MUsro, D.Se.,

Professor of Chemistry, Downton College of Arriculture. (Friffin's Techaological Honuals.)

[In preparation.

Now ReAly. In Jarge 8\%o. Handsome Cloth, with Plate and Numerous Illitstrations. 21s.

B上正WING:

THE PRINCIPLES AND PRACTICE OF.

A TEXT-BOOK FOR THE USE OF STUDENTS AND PRACTICAL MEN.

BY WALTER J. SIKES, M.I., W.P.H., F.I.C., Exlitor of the Analyst.

"We consider it one of THE MUST COMPLETE IN COSTESTS and NoVEL IX ARRAXgE. MENT that has yet been published."-Breuers'Joumal.

Now Reauy, Vol. I., Complete in itself. $15 \mathrm{~s}$.

\section{TECHNICAL MYCOLOGY:}

THE UTILIZATION OF MICRO-ORGANISMS IN THE ARTS AND MANUFACTURES.

A Practical Handbook for Bacteriologists, Analysts, and others.

BY PROF. FRANZ; LAFAR, of TrEx.A.

THASLATED BY CHAS. SALTEP.

In two rols., large Sro, with Plate aurl Illustritions.

"The chajters TEFM WIтH IXTEREstixg MATTEk from beginning to end. . . The Jlatn is atmigrable, the classification simple, the style genol, and the tendency of the whole volume is tri eronvey SCRE INForistTos to the reader." -Lancet.

FIXED OILS, FATS, BUTTERS, AND WAXES: Their Preparation and J'roperties, and the Branufacture therefrom of Candles, Soaps, and other Products. By C. R. AbIFR WhighT, D.Sc., F.H.,., Late leeturer on Chemistry, st. MIary's Hosjital Medical School. In large ovo, lanisome cloth, with 144 Illustrations. $2 \mathrm{~s}$.

"Jr. WRIGIT'S work wjl] be found ABSULCTELY WNISIYX:ABLE hy every Ch mist. Trass with information valuable alike to the Analyst and tle "Techincal chenist."the inalyxi.

FOOD SUPPLY. Bir PonERT BACCE, Agricultural superintendent to the Rogal Dublin Soeiely. With Amendix on PliEsERVEH FoObs. Py C. A.

BItcili.f, l:.A., F.I.t. With many Engravings frum Photographs illustrating the Chief lireeds of Cattle, Slieep, l'jes, Poulty, dic. Cloth, 4s. Gd.

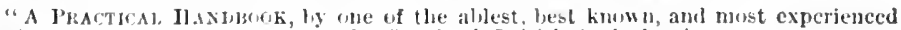
agricultural writers of tle juesent tay. "- Surth Dritish Alpriculturist.

PRACTICAL SANITATION. A Handbook for Sanitary Inspectors

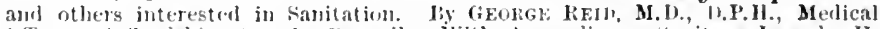

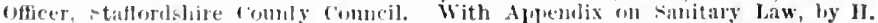

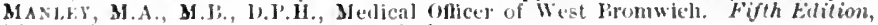

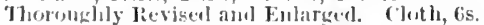

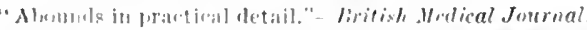

CHEMISTRY FOR ENGINEERS AND MANUFACTURERS. By

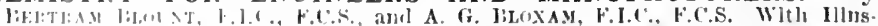

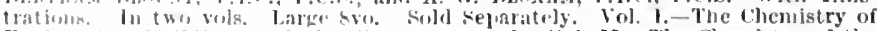

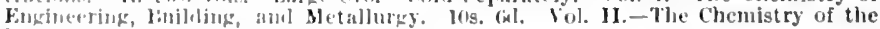
Manufacturing Proeseses. $16 \mathrm{~s}$.

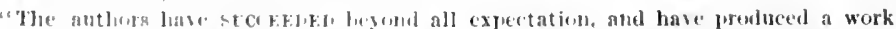

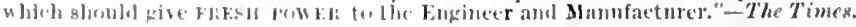

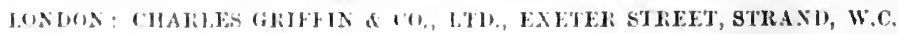




\section{DAIRY CHEMISTRY:}

$\widetilde{H}$ Practical 可andbook

FOR

DAIRY CHEMISTS AND OTHERS HAVING CONTROL OF DAIRIES.

BY

HENRY DROOP RICHMOND, F.I.C., ANALYST TO THE AYLESBURY LAIRY COMPANY, LIMITED.

rattb Namerous Cables ano 22 Fllugtrationg.

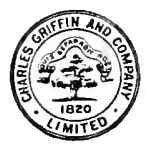

L O N D O N :

CHARLES GRIFFIN AND COMPANY, LIMITED;

EXETER STREET, STRAND.

1899.

[All Rights Reserved.] 



\section{PREFA CE.}

THE object of this work is to provide dairy chemists with a guide for the chemical control of dairy operations, the assumption being that a knowledge of dairying is already possessed; and public analysts, medical officers, dairy farmers, and Students with a practically useful manual.

The plan adopted is (1) to describe the chemical properties of the constituents of milk: (2) to make use of these properties in the practical analysis of the various milks and milk products; and (3) to apply analytical methods to the control of dairy operations.

In carrying out this work the author would especially notice that its value nay be largely attributed to two factors. The first is that Dr. Paul Vieth (now Professor in and Director of the Dairy Institute at Hameln) during his twelve years occupation as Analyst to the Aylesbury Dairy Company, accumulated a large number of observations, which, as he remarked, contained very little theory, but a good deal of fact. This valuable material was handed over to me as his successor, and has been made full use of in this work. The second factor is that the autbor owes much of his training as a dairy chemist to Mr. Otto Hehner, who enjoys so high a reputation in connection with butter analysis.

It may also be stated that Mr. L. K. Boseley has kindly read the Section on the Analytical Characters of Sterilised Milk, that Mr. F. R. O'Shaughnessy has revised the mathematical portions of the book, and that Mr. A. W. Stokes has supplied the information respecting those methods which bear his name. 



\section{CONTENTS.}

Chapter I.-Introductory-The Constituents of Milk.

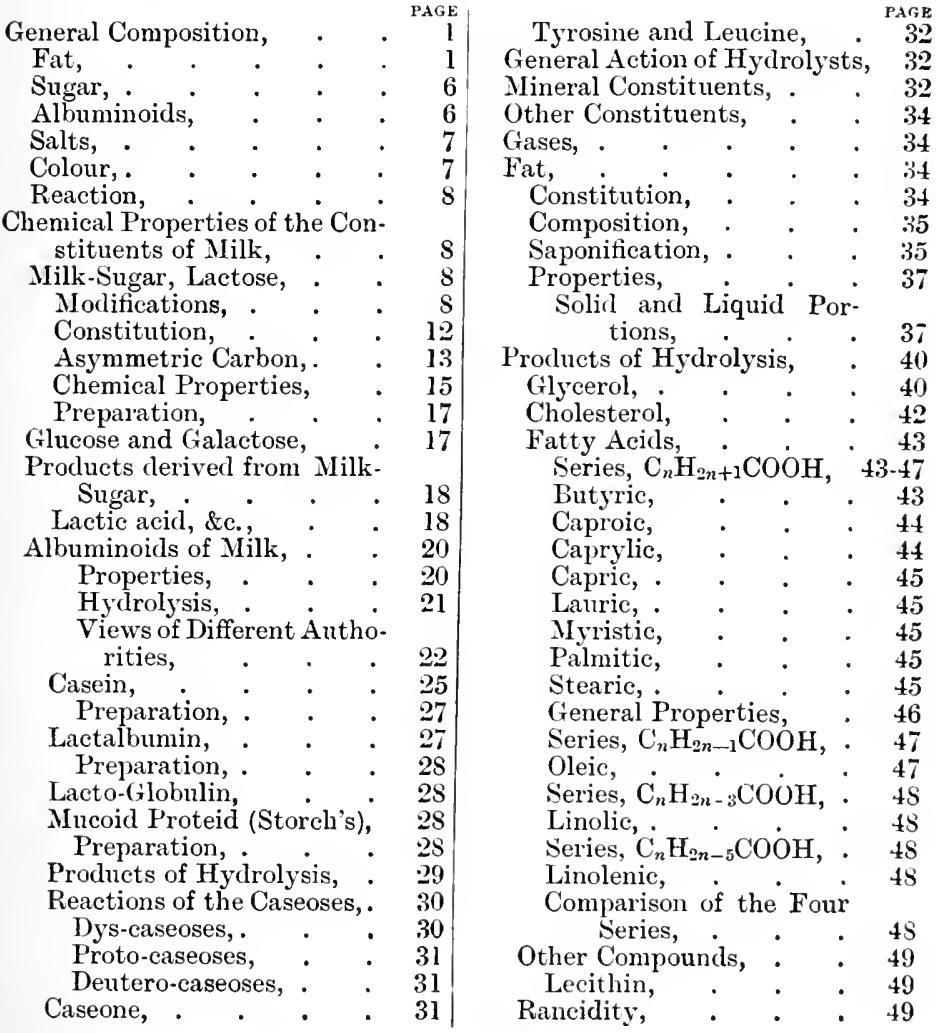


CHAPTER II.-ThE Axalysis of MiLK.

Specific Gravity;

\begin{tabular}{|c|c|c|c|}
\hline 51 & & & \\
\hline $\begin{array}{l}51 \\
51\end{array}$ & $\begin{array}{l}\text { Fstimation of Fat, } \\
\text { Gravimetric JIethods, }\end{array}$ & & \\
\hline $\begin{array}{l}51 \\
53\end{array}$ & $\begin{array}{l}\text { Gravmetric Methods, } \\
\text { by Adams, }\end{array}$ & & \\
\hline 55 & by Bell (Somerset $\mathrm{Hc}$ & ouse), & \\
\hline & by Storch, . & & \\
\hline 61 & lyy Soxllet, & & \\
\hline & by Werner-Schmid, & & \\
\hline 6 & beock (asbestos & s), & 100 \\
\hline 61 & lausen, . & . & \\
\hline 67 & Methods, & & \\
\hline 6 & Iethods, & 102 & \\
\hline 0 & hods, & . & \\
\hline & Cream & & \\
\hline & Iethod, & & \\
\hline 6 & Estimation of Proteids, & & \\
\hline 7 & From Nitrogen and & Total & \\
\hline & s, & & \\
\hline$\pi$ & Kjeldahl, & & \\
\hline 61 & en, & & \\
\hline I. & etric, $\cdot$ & & \\
\hline 27 & of Casein a & and Al- & \\
\hline & n, Hoppe-S & eyler,. & \\
\hline & sen, & & \\
\hline 7 & and Werl, & & \\
\hline & . & & \\
\hline 3 & Duclau & & \\
\hline & Den & & \\
\hline 8: & tric, . & . & \\
\hline$S_{2}$ & of Casein, & & \\
\hline & y Lehmann & & \\
\hline S & $a n$ & & \\
\hline & & & \\
\hline 80 & ion of Total & Acidity & \\
\hline 87 & Lactic Acid, & & \\
\hline & Analysis of the Milh & k Pro- & \\
\hline & 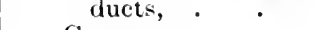 & & \\
\hline Si & & & \\
\hline 89 & & & \\
\hline 89 & ed Milk. & & \\
\hline & ed Milk, & & \\
\hline & I Milk, & & \\
\hline & & & \\
\hline
\end{tabular}

Modes of Expression, . . . $\quad 5$

Variation, . . . . 55

Formulæ, . . . 5

Milk Scale, . . . . 61

Specific Volune, . . . 63

Molle of Averaging, . . 64

As altered by Temperature, . standing,

Estimation of Total Solids,

Wanklyn's Method,

Society of Public Analysts' Mlethod,

Babcock's Method,

Macfarlane's ,

Adams:

Drying, Apparatus,

Estimation of Ash.

Estimation of Citric Acid,

Estimation of Milk-Sugar,

Metlod by Alcohol, .

Wiley, $\cdot$.
Wiley-Ewell, : $\quad$.

Richmond-Boseley, .

Jeniges, . . . . 8

Fehling's Solution, . . S2

O'Sullivan, . . . 83

Wein, . . . . S 4

Volumetric, . . . 85

Pary's Solution, . . 86

Estimation of Cane-Sugar, . 87

Nethor by Muter, . . S7

Stokes-Bodmer, . . ss

Invertase, . . . . 88

Other Methorls, . . . 89

Cotton's Method of Detecting, 89

Estimation and Detection of

Starch,

Buttermilk and Whey, . 119

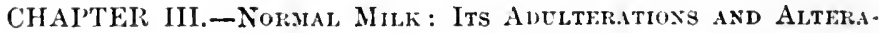
THONS, AND THELE DETECTION.

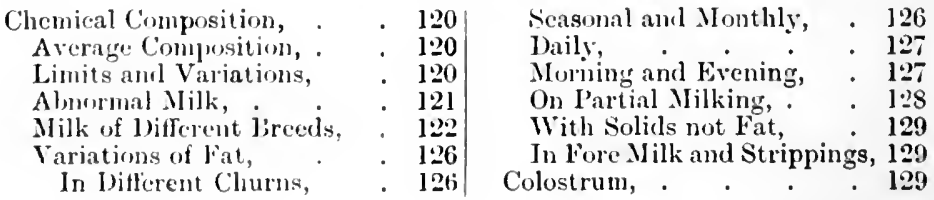


Change of, to Normal Milk, 131

Limits and Stanclards, . . 132 Society of Public Analysts' Standard,

Triple Standard,

Variations of Fat in Milk on

Standing,

Conrt of Queen's Bench Decision,

Practical Allowance, $\quad 13 \tilde{5}$

Appeal to the Cow, . . 136

Aclulterations, . $\quad . \quad$. 136

Added WVater, . . . 136

Cane-Sugar, \&c., . . . . 137

Glycerine, . . . . 137

Starch,. . . . . 137

Brains and Mammary Tissue, 138

Fat Abstracted,

Preservatives, .

Objections, .

Advantages, .
Detection, PAGk:

Boric Acid and Borax, $\quad 140$

Salicylic Acid, . . . 141

Fluorides, . . . 141

Formalchyde, . $\quad 142$

Preservation of Samples, . 144

Action of Heat, . . . 145

Condensed Milk, . • . $\quad \mathbf{1} \$ 6$

Composition of Sweetened IIilk, . . . 146

Unsweetened, . . . 147

Dilution, . . . . 148

Food Talue, . . . . . 148

Milk Powders, . . . 149

Sterilised Milk, . • . 149

Analytical Characters, . 150

Detection of, in New Milk, 152

Action of Cold, . . . 154

Composition, . . . 154

Of Melted Frozen Milk, . 156

Chapter IV.-The Chemical Coytrol of the Dairy.

Duties of the Dairy Chemist, . 158

Samples and Sampling, . 159

Testing, . . . . 161

Sample cans, $\quad \cdot \quad \cdot 162$

Analysis of Samples, . . 163

Testing, . . . . . 164

Determination of Specific

Gravity, . . . 164

Lactometers, . . . 164

Use of, . . . . 165

Estimation of Total Solids, . 167

Weighing, . . . 169

Stokes' Kapid Method, . 170

Estimation of Fat, . . 170

Babcock Method, . . 170

Measuring, . . . 171

New Milk, . . . 172

Cream, . . . 172

Separated Milk, : • 173

Acid, . . . . 173

Cleaning Test Bottles, . 173

Working and Oiling, . 173

Revolving Disc, . . 173

Leffmann-Beam Method, . 174

Beimling Machine, . 174

Apparatus, . . . 175

Chemicals, . . . 177

The Process, . . : 177

Testing Milk, \&c., . 177

Cream, . . 178

Sour Milk, : . 179
Clotted Cream,

Cheese, and Butter, 180

Failures and their Probable

Causes, . . . 180

Modifications, . . . 180

Gerber's Acido-butyrometric Nethod, . 180

Gaertmer and Hugershoff's Tester, . . 181

Excelsior Gearing, $\quad 182$

Rapid Gearing, . . 183

The Lister Machine, . 184

Apparatus, \&c., • . 184

Chemicals, . . . 185

Modes of Operation, . 185

Milk, Skin Milk, Whey, and Buttermilk, . 185

Reading the Fatty Layer, 186

Creanı, . . 187

Sour Milk, . . 188

Clotted Cream, Butter, Cheese. \&c., . 188

Cleaning Bottles, . 188

Butyrometer with two openings, . . 188

Cream, . . . 189

Butter, . . . 189

Cheese, . . . 189

Calculation of Results, 189

Water Estimation in Butter, \&c., - 159 
Stokes Modification, . I'ISI Soxhlet's Areometric Process, Control of Milk during Delivery, 195 Solution of Analytical Problems, Low Specific Gravity, . . High Sweet Taste," . 200 "Poor" llilk, . . . 200 Unusual Taste anı Smell, . 201 Sour Milk, • • • 203 Thick llilk, . . . 204 Siediment, : : 204 Skim Milk, . . . . 205
Distinction from Separated Milk, . . . . 205 Rising of Fat rilobules, . 205 Composition, . . . 209 Control of Separators, . . 209 Separator Slime, . . . 210 Separators, . . . . 211 Cream, . . . . 214 Composition, . . . 214 Ash, . . . . . 216 Density, . . . . 217 Clotted Cream, : $\quad$ : 219 Thickness of Cream, - $\quad 221$ Artificial Thiekening of Cream, 224

\section{CHAPTER Y.-Biological aNd Saxitary Matters.}

Micro-organisms and the Decomposition of Mlilk,

Classification,

Action on ylilk, $\cdot$.

Lactic Fermentation,

Alcoholic

Curdling Organisms,

Currlling and Peptonising Organisms,

Chromogenic Organisms, . Nonlels.

Pathogenic Organisms, : Conveyance of Disease through Mlilk, . .

Conreyance of Disease through Contaminated llilk,

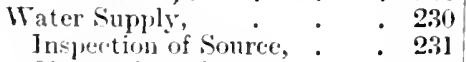

Chemical Analysis, . . $\mathbf{2 3 1}$

Taking of Samples, . . 231

Colour and Simell, . : 231
Analytical Figures, . . 232

Total Solids, . . . 232

Loss on Ignition, . . 232

Chlorine, . . . 232

Free and Albuminoid Ammonia, . . 232

Nitric Acid, . . . 234

Nitrites, . . . . 234

Oxygen Absorbed from Permanganate, . . 2:55

Pliosphates, . . . 235

Interpretation of Results, . 236

Bacteriologieal Examinations,. 237

Preparation of Nutrient Media, 237

229 Procedure, . . 238

Interpretation of Results, . 238

Summary of Sanitary Precau. tions, . 239

Produets formed from Milk bi

Organisms, . . . 240

Kiomiss, . . . . 241

Kephir, . . . . 243

Mazoum, . . . . 244

\section{CHAPTEI: V*I.-BCTTEK.}

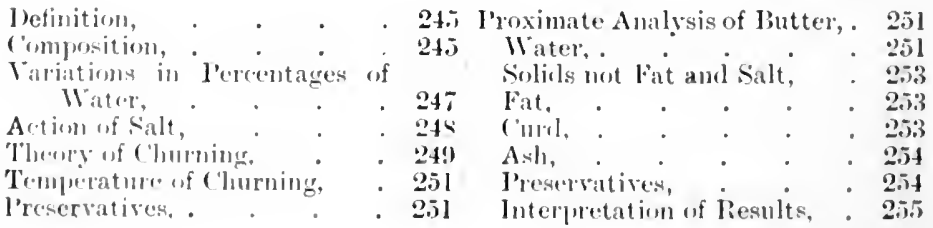


Analysis of Butter Fat,
Preparation for Analysis,
Recapitulation of Properties,
Estimation of Volatile Fatty
Acids, . . .
Reichert Process, .
Kreis' Modification,
Theory of Reichert's Pro.
cess, .

Estimation of Saponification Equivalent,

Kottstorfer's Method,

Estimation of Soluble and Insoluble Fatty Acids,

Hehner and Angell Method, 268 Modification by American Association of Agricultural Chemists, .

Johnstone, . . . Blunt, . . . . Morse and Burton, Specific Colour Tests for Adulterants, . .

Baudouin's, : $\quad$ : 272

Becchi's, . . . 272

Wellmann's, . - 272

Behaviour of Butter Fat with Solvents,

Critical Temperature of Solution,

Valenta's Method, : .

Iodine and Bromine Absorp-

$\begin{array}{lll}\text { tion, } & \text { • } & 274 \\ \text { Von Hubl's Method,. } & \cdot & 274\end{array}$

Bromine Absorption, . 276
PAGR

257

257

$25 \mathrm{~s}$

258

262

263

266

266

268

269

271

271

271

272

273

273

273

274
274
276
Gravimetric Method of Helner, . . 276

Thermometric Method, . 276

Heat Evolved by Hydrolysis, 277

Manmené Test, . . 277

Thompson and Ballantyne's Modification, 277

Richmond Modification, 278

Physical Examination of Butter

Fat, . . . . . 279

with Polarised Light, . $\quad$. 279

Density, . . . . 281

Expansion, . . . 281

Mode of Expressing Results, 382

Determination,. . . 283

Molecular Specific Volumes, $\mathbf{2 8 5}$

Refractive Index, . . 285

Oleo-refractometer, . . 2S5

Butyro-refractometer, . 287

Viscosity, . . . 290

Behaviour of Butter on Melt. ing, . . . 290

Melting point of Fat, . . $\quad 291$

Detection of Adulteration, . 291

Margarine, . . . . 292

Influence of Keeping on the

Analytical Properties, . 292

Buttermilk, . . . . 296

Definition, . . . . 296

Composition, . . . 296

Variations of Fat, $\quad$. $\quad 296$

Ash, . . . . 296

Chemical Control of Churning

Operations, $\quad . \quad .297$

\section{CHAPter VII.-Other Milk Products.}

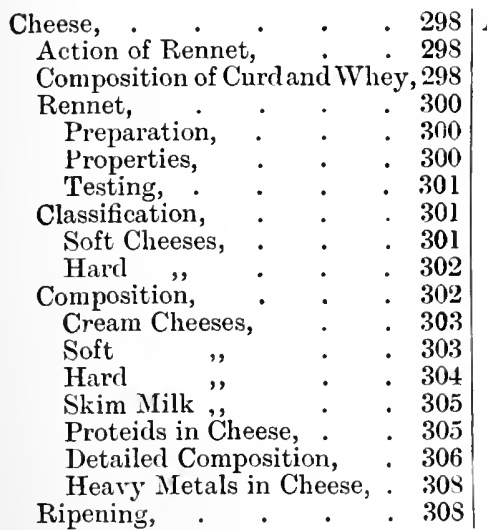

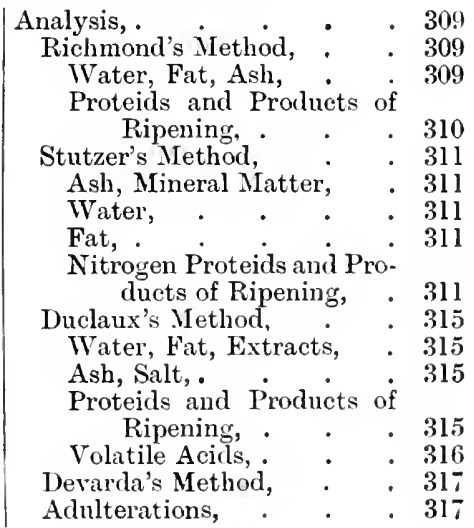




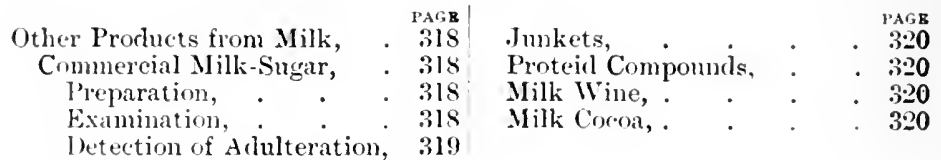

\section{CHAPTER VIII. - THe MiLK of Mammals Other thas} THE COW.

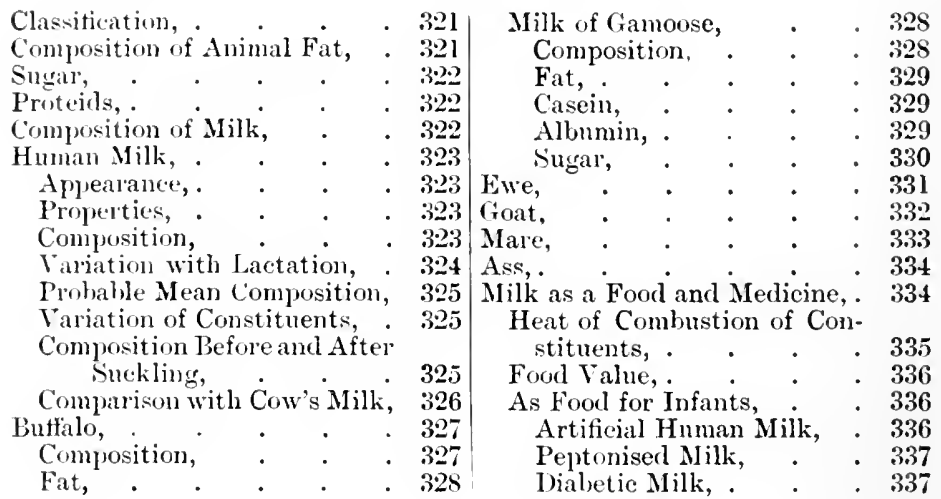

APPENDIX A.- Experinental Evidexce that the Fat in Cream is holfo at low Temperatures, . • 338-341

APIENDIX B.-STANDARdisation AND Calibhation of APPaRatus,

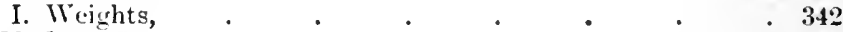

II. Burettes, . . . . . . . 344

III. I'ipettes, $\quad . \quad$. $\quad . \quad$. $\quad . \quad . \quad .345$

IY. Flasks, . . . . . . . 345

$\checkmark$. Leflinann-Beam or fierber Bottles, . . . . 345

VI. Lactometers, . $\quad . \quad$. $\quad . \quad$. $\quad .346$

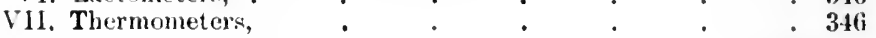

APPENdix C.-Useful Tames, . . . . $347-356$

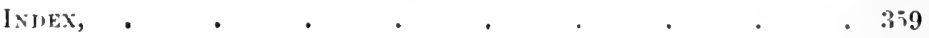




\section{LIST OF ILLUSTRATIONS.}

FIG.

1. Milk Scale,

PAGE

2. Diagrammatic View of Air-bath, . . . . . 72

3. Stokes' Tube,

4. Thermo-lactometer,

5. Soxhlet's Lactometer, . . . . . . 165

6. Glass Jar, .

7. Lister-Babcock Milk Tester, . . . . . 171

8. Beimling's Separator, . . . . . . . $17 t$

9. Automatic Burette, . . . . . . 176

10. Neck of Bottle, . . . . . . . . 178

11. Gaertner and Hugershoff's Milk 'Tester, . . . 182

12. Milk Tester (steam driven), . . . . . 152

13. The Lister Machine, . . . . . . . 184

14. Neck of Bottle, . . . . . . . . 186

15. Lister-Stokes Machine, . $\quad$ • $\quad$. $\quad$. $\quad$. 191

16. Soxhlet's Apparatus for Examination of Milk, . • . 193

17. Alexandra Separator, . . . . . facing 212

18. Burmeister and Wain Separator, . . . . 212

19. Alpha Separator, . . . . . . . 213

20. Oleo-refractometer, . . . . . . . . . . . 256

21. Butyro-refractometer, . . . . . . 288

22. Curves of Specific Volume, . . . . . . 340 



\section{LIST OF T A L E S.}

TABLE

Composition of Mneoid Proteid.

I. Change of Rotation of a-Mlilk-sugar in Solution, . 10

Composition of Casein, . . . . . . $\quad 26$

,2 Pepto-caseoses, . . . . 29

," Trypto-caseoses, . . . . 30

", Hydrolo-caseoses, . . . . 30

"Chymo-caseoses, . $\quad . \quad 30$

" Asli of Nilk, . $\quad . \quad$. $\quad . \quad 32$

", Salts of Milk, . . . . . 33

," Fat of Milk, . $\quad . \quad$. $\quad 35$

II. Properties of Milk Fat (Richmont), . . . . 3 . 3 -

III.

,

(Pizzi), . . . . 37

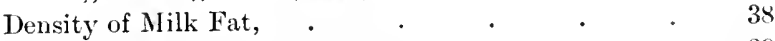

Speeific Gravities and Volumes of Fat, . . $\quad 39$

Solubility of Calcimm Butyrate,. . . . 44

IV. Properties of the Acids of Series $\mathrm{C}_{n} \mathrm{H}_{2 n+1} \mathrm{COOH}, \quad$. $\quad 46$

V. Comparison of the Four Typieal Fatty Acirls, . $\quad 49$

VI. Specific Gravity of Water, . . . . . 51

Variation of Specifie Gravity of Milk on Dilution, . 57

VII. Specific Gravity and Volume of Milk, . • • • 64

VIII. Expansion of Milk, . $\quad$ • $\quad$ • $\quad$. $\quad . \quad 66$

IX. For Correcting Specific Gravity of Separated Milk to $60^{\circ} \mathrm{F} ., 67$

$\mathrm{X}$. For Caleulating the Amomt of Milk-sugar from the Quantities of Copper Reduced, . . . $\quad 85$

Comparison of Percentage of Fat by Dry and Wet Ether, • $\quad 94$

Comparison of Percentage of Fat by Bell and Adams'

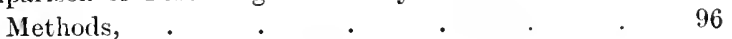

Comparison of Percentage of Fat by Ritthausen and

Composition of Milk after Filtration through Paper, . 104

XI. Estimation of Milk Solicts by Densimetric Method, . 104

XII. For Caleulating Percentages of Proteids in Nilk, . $10 \mathrm{~s}$

Acidity of Milk on Stanling, . 114

, , to Litmus and l'henolphthalein, . 115

XIII. Alcohol Tables (Hehner), . . . . . 118

Average Composition of Milk, . . . . 120

Limits for Milk, . . . . . . 120 
TURLE

XIV. Percentage of Asl in Milk,

XT. Analyses of Abomal Milks, . . . . . 102

XYI. Percentage of Solirls not Fat in Mixed Milk, . . 122

SVII. ('mposition of Milk of Inifferent Breeds of Cattle (Fat), 123 Analysis of Samples Higlest and Lowest in Fat, . 123

XVIII. Composition of Milk of Different Breeds of Cattle (Siolicls not Fat), . . . . . 124

XIX. Variations in Solicls not Fat in Milk of the same Cow, 125

XX. Solirls in Milk of Cows of Different Breeds (Tieth), . I25

XXI. Composition of Milk of Different IBreerls of Cattle, . $\quad 125$

XXII. Solids in Milk of Cows of J)ifferent Breeds (Bell), . 126

Variations of Fat in lifferent Clums, . . . 126

XXII. Mean Monthly Averages of Milk, . . . 127

Daily Tariations, . . . . . 127

XXIV. Composition of Morning and Evening Milk, . . 128

Variations on Partial Milking, . . . . 128

Variations of Fat with Solids not Fat, . . . 129

Composition of Viscons aml Non-Viscous Secretions

lefore Parturition, . $\quad$. $\quad$. $\quad . \quad$. 129

Composition of Ash of Colostrum, . . . 130

Average Composition of Colostrum, . • . 130

Change of Colostrum after l'arturition, . . I3I

XXY. C'hange of Colostrum to Normal Hilk, . . . 131

XXYI. Composition of Colostrum, . . . . 131

XXYII. Variations in Composition of Milk on Standing (Large

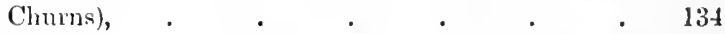

XXYII. Variations in Composition of Milk on Standing (Small

Churns), . $\quad$. $\quad$. $\quad$. $\quad$. $\quad$. 134

XXIX. Tariations in Composition of Milk on Standing (Pan), 135

XXX. Composition of Sweetened Milk, . . . 147

XXXi. , Unsweetener Milk, . . . 147

bilution of Conclenserl Milk, . . . . 145

Composition of Milk l'owiters, . . . . . 149

XXXII. Composition of Sterilised Milk (Six Hours), . . 151

XXXll. , , , (Twenty-four Hours), . 151

XXXll. ", New Milk, . . . 151

XXXV. Percentage of Alhumin in Milk at Varions Temperatures, 154

XXXVI. Comparative Analyes of Mixed Fresh and Sterilised

Nlilks, . . . . . 154

XXXV1I. ('ompresition of the sollid and Liquid Portions of Frozen

Mlilk, . . . . . . 155

XXXYII. Comprostion of Fromen Milk (Companative), . . 156

XXXIX , , "

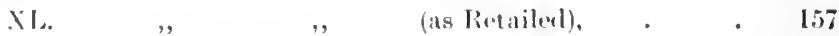

Stremgth of Sulphuric Acial, . . . . 177

XII. For Estimating liat in Crean, . . . , 179 
XLII. For Calculating Fat in Cream, .

Calculation of Fat in Separaterl Yilk,

Composition of Separated Milk, . . . 209

, Separator Slime, . . . 210

,, Ash of Separator Slime, . . 211

XLIII. Composition of Cream, . . . . . 215

, Ash of Cream, . . . . . 217

XLIV. Calculation of Fat in Cream, . . . . $21 \mathrm{~s}$

Density of Cream at Different Temperatures, . . 219

Composition of Froth of Cream, . . . 219

XLV. ", Clotted Cream, . . . . 219

XLVI. Ratio of Fat to Total Solids in Cream, . . . 2:20

Relation between Fat and Viscosity in Cream, . 22:2

Results obtained with Various Separators, . . $\quad 221$

Average Results of Water Analysis, . . . $\quad 236$

Composition of Mare's Milk Konmiss, . . . 241

,, Cow's Milk Koumiss, . . 2 24l-243

, American Koumiss, . . . . $2 \notin 3$

, Kephir, . . . . . . 243

, , Grains, . . . . . 244

, , Powcler, . . . . 244

, Mazoum. . . . . . 244

XLVII. Composition of Butter, . . . . . $\quad 245$

XLVIII. $\quad, \quad$. $\quad . \quad \ldots \quad$. $\quad . \quad 246$

XLIX. ,, Butter's, . . . . . 246

L. Variations of Water in Butter, . . . . 247

LI. $\quad, \quad$,,$\quad$ (Ful,er), . $\quad 247$

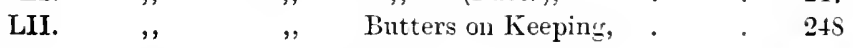

Temperature of Churning, . . . . $\quad$ 251

Characteristics of Butter, . . . . . $\quad \mathbf{2 5 6}$

Results with Reichert Process, . . . . $\quad 259$

, Reichert-Meissl Process, . . . 260

," Reichert-Wollny Process, . . $\quad 262$

Distillation of Volatile Acids of Butter (Two Tables) . 26.5

Variations of Critical Temperature with Insoluble

Fatty Acids, : . . . . . $\quad 273$

Maumené Figures with Acids of Different Strengths, . 27s

Heat Equivalent of A pparatus, . . . . $\quad 279$

Expansion of Butter and Margarine, . • . 282

Density of Butter Fat, • . . . . 254

, Oils and Fats, . . . . . 254

Muter's Relation of Refractive Index to Reichert

Figures, . . . . . . 2S7

Values of Butyro-refractometer Degrees, . . 255 
TABLE

Variations of Butyro-refractometer Degrees with

Temperature, . . . . . . $\quad . \quad 289$

Variations of Insoluble Fatty Acids on Keeping Butter, 293

Properties of Old Butter Fat (Allen and Moor), . 294

,, $\quad, \quad$ (Clayton), . . 294

LIII. The Reichert-Wollny Figures of Butters (Besana), $\quad 295$

," ", (Yieth), . 295

Composition of Butter Milk from Sweet Cream, . $\quad 296$

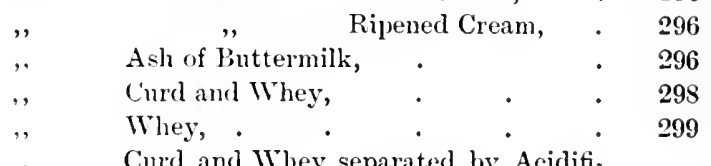

,, Curd and Whey separated by Acidification, . $\quad . \quad$. 299

,, Sour Milk Whey, . $\quad$. $\quad 300$

Action of Remmet at Different Temperatures, . $\quad 300$

LIV. Cream Cheeses, . $\quad$. $\quad$. $\quad$. $\quad$. 303

LV. Soft Cheeses, . $\quad$. $\quad$. $\quad$. $\quad$. $\quad .303$

LVI. Harl Cheeses, . . . . . . 304

LVII. Skim Milk Cheeses, . $\quad$. $\quad$. $\quad$. 305

Porpuefort Cheese, $\quad$. $\quad$. $\quad$. $\quad$. $\quad 305$

LVIII. Detailed Composition of Cheeses, . . $\quad 306,307$

," Roruefort Cheese, . . 308

LIX. Analyses of Cheese (stutier), . . . . . $\quad 314$

," $\quad$, $\quad($ Duclaux $), \quad$. $\quad$. $\quad$. $\quad 316$

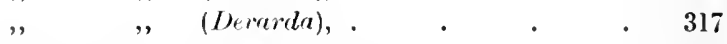

Limits of Conmercial Milk-Sugar, . $\quad$ • $\quad 319$

LX. Analyses of Sugars, . . . . . . 320

Composition of Nilk Cocoa, . $\quad$. $\quad$. $\quad 320$

LXI. Size of Fat (ilobules in Mammalian Milk, . . 321

LXII. Properties of Mammalian Fats, . • . . . $\quad 322$

LAIII. Comprosition of Mammalian Milk, . $\quad$. $\quad 323$

LXIY. Mean Composition of Human Milk, . . . 324

LXV. Variations in Composition of Human Milk during

Lactation, . $\quad$. $\quad$. $\quad$. $\quad 324$

I'rohable Mean Composition of Human Milk, . . $\quad 325$

Varjation of Constituents of Human Milk, . 325

('ompustion Before aurl After Suekling, . . 325

,, , , , (Maxima and

Minima), . $\quad 326$

Comprestion of Milk agrering Well and Badly, . 326

, Ash of Human Milk, . . . 327

., the Milk of the Butlito, . . 328

. ". Ciamose, . . 325

"the Fat of Ciamoose Milk, . . 3:9

", the Sugar of tiamouse Milk, . . 330 
LXVI. Composition of Ewe's Milk, . . . . . 331

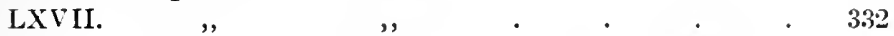

Correction of Specific Gravity of Ewe's Milk for

Temperature, $\quad . \quad$. $\quad . \quad$. $\quad . \quad 332$

LXVIII. Composition of Goat's Milk, . $\quad$ • $\quad$ • $\quad 332$

LXIX. ,, Mare's Milk, . . . . 333

" Ass's Milk, . . . . $\quad 334$

", Constituents of Milk, . $\quad$. $\quad$. 334

Heats of Combustion, . $\quad$ - . . $\quad 335$

Composition of Peptonised Milk, . . . $\quad 337$

Diabetic Nilk, • $\quad \cdot \quad$ • $\quad . \quad 337$

Expansion of Cream, . . . . . . $33 \mathrm{~s}$

, Separated Milk, . . . . $33 \mathrm{~s}$

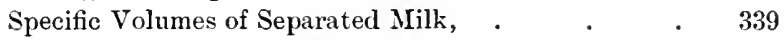

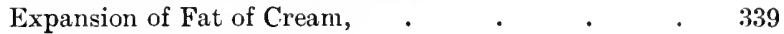

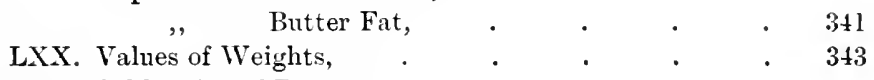

LXXI. Calibration of Burette, • . $\quad$ • . $\quad$ • 345

LXXII. Boiling Point of Water under Different Pressures, . $\quad 347$

LXXIII. For the Correction of Specific Gravity of Milk, Op. $p .34 \mathrm{~S}$

LXXIV. For the Calculation of Total Solids from Fat and

Specific Gravity, . . . . . Op. $p .348$

LXXV. For the Calculation of Total Solids from Fat and

Specific Gravity, . . . . . Op. p. 348

LXXVI. For the Calculation of Total Solids from Fat and Specific Gravity, . . . . . . $\quad$. 345

LXXVII. For the Calculation of Total Solids from Fat and Specific Gravity, . $\quad$. $\quad$. $\quad$. 350

LXXVIII. For the Calculation of Total Solids of Skim Milk, $\quad 352$

LXXIX. Soxhlet's Areometric Method, . . . . Op. p. 352

LXXX. For the Conversion of Thermometric Scales, . . 352

LXXXI. Weights and Measures, . . . . $\quad$ • 354

LXXXII. For the Conversion of Barn Gallons into Imperial Gallons, . . . . . . $35 \overline{5}$

LXXXIII. Weights of Dairy Products, • • • • 356

LXXXIV. For the Calculation of the Weight of Butter in Pounds obtained on Churning Cream, . . O Op. p. 356 



\title{
DAIRY CHEMISTRY.
}

\author{
C H A P T E R I.
}

INTRODUCTORY-THE CONSTITUENTS OF MILK.

Contents. - General Composition - Fat - Sugar - Albuminoids - SaltsColour - Reaction - Milk-Sugar - Glucose - Products derived from Milk-Sugar-The Albuminoids of Milk-Products of HydrolysisGeneral Action of Hydrolysis-Mineral Constituents-Other Constituents of Milk-The Gases of Milk-The Fat of Milk-Products of Hydrolysis-Fatty Acids-Other Compounds-Rancidity.

General Composition.-Milk is the normal secretion of the mammary glands of a mammal; the milk of all mammals has a similar composition, consisting of fat, sugar, albuminoids, mineral constituents, and small quantities of other compounds. The milk of the cow has been studied in greater detail than that of any other animal on account of the extended use of this animal's milk and the products derived from it as human food; the greater portion of this work will, therefore, be devoted to the consideration of the chemical properties of cow's milk, and the expressions "milk," "butter," \&c., must be taken as applying to the products derived from the cow, unless described to the contrary. Much, however, that is stated with regard to the cow may be taken as applying equally to the inilk of other animals; but our knowledge of the chemical composition of the milk of any animal, except the cow, is very incomplete. Studies, more or less incomplete, have been made of the milk yielded by woman, the goat, the ass, the mare, the gamoose, and the sheep, and analyses, few in number, have been made of the milk of other mammals, both terrestrial and marine. It is probable that there exist wider differences than are yet recognised between the milk yielded by different animals.

Fat.-The fat in milk is of peculiar and complex composition; it differs from all other fats in that it contains compound glycerides partly built up of fatty acids of low molccular weight. It exists in milk in the form of small globules. Many have thought that a true membrane surrounds each globule, and Béchamp considers this view as proved by the behaviour of milk when treated with ether. He finds that milk is capable of 
dissolving a very large quantity of ether, much more than would be dissolved in the aqueous portion of the milk, and he explains this by the theory that the ether is dissolved by the fat contained in the membranes. His theory assumes that the ether has passed into the membrane by the process known as "endosmose," and that the endosmose is stopped only when the pressure exerted by the distended membrane is equal to the osmotic pressure; the presence of fit to small amount in the excess of ether which separates is explainel as partly due to a process of exosmose of the fat within the membrane concurrently with the endosmose, and partly to the bursting of a number of the globules. The opponents of his theory urge that the amount of fat in the excess of ether which separates, if this be great, is too large to be explained by assuming exosmose, or the bursting of the globules, which should not take place to a greater degree with a large excess of ether than with a small.

Storch has recently put forward the view that no real membrane exists round the fat globules, but that a gelatinous "mucoid" membrane (slim-membran, in Danish) surrounds them; this consists, according to him, of a combination of 6 parts of a "mucoid" proteid with 94 parts of water (membran-slim). $\mathrm{He}$ bases his view-

(1) On the fact of the existence of this mucoid substance in eream and butter, and therefore presumably in milk; he proves its existence, and, in fact, isolates it, by washing eream with water and separating the layer of globules till milk-sugar, casein, dc., are all removed.

(2) On the behaviour of milk with ether; his experience differs from that of Béchamp, as, while the latter finds that ether expands the globules to several times their normal size, Storch states that they are not swollen.

(3) On the appearance of the fat globules under the microscope when the milk has been stained by ammoniacal picrocarmine, and the layer of eream treated with successive quantities of water till all the milk-sugar has been removed; he notices that a stained layer is present round each fat globule.

There is much to be said in favour of Storch's reasoning, and other evidence may be adduced in favour of it. Butter, in which the slohules are certainly more naked than in milk, can be prepared with ahout 85 to $\$ 6$ per cent. of fat; this is solid, because the solid fat globules are in close proximity ; cream, on the other hand, camnot be prepared with more than about 72 per cent. of fat, and as this has the same consistency as butter at the same temperature, it may he assumed that the globules are in equally close proximity. This would agree with the view that each globule was surrounded by a layer, which inereased the effective size. Storch has adduced evidence, based on the property of ether to emulsify this mucoid substance, that butter- 
milk contains a larger amount than milk, and on this has based a theory that churning consists of rubbing off the membrane, with the effect that the glubules coalesce. The author has experimentally proved the fact that buttermilk is richer in mucoid substance than milk by separating it with a cream separator. Storch considers this as confirmatory evidence of the presence of a membrane.

The evidence is, however, inadequate to settle the question, and in some respects may be held to show that, a membrane does not exist. As the author has succeeded in isolating the proteid, he has no doubt of its existence; by estimating in butter and buttermilk the water, fat, milk-sugar, proteids, and ash, Storch finds that there is much less milk-sugar and more proteids in proportion to the water in butter than in buttermilk; he calculates the proportion of proteids and water equivalent to the milk-sugar in butter on the supposition that the milk-sugar is an index of the buttermilk left in the butter, and finds a residue of the following percentage composition in three series of experiments :-

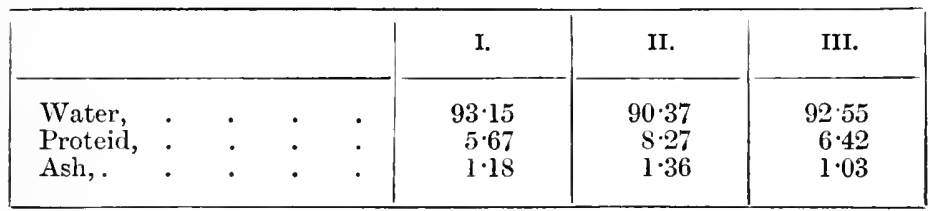

The results from the three experiments agree very well, considering the smallness of the actual quantities.

From the results of experiments, in which cream was treated with a 33 per cent. solution of cane-sugar (used to promote the separation of the layer of fat globules), and the fatty layer separated, and the procedure repeated several times, Storch deduces the proportion of mucoid substance to fat as 38.4 to 100 .

From these experiments it is evident that cream containing 50 per cent. of fat should contain 19 per cent. of mucoid substance, and only 31 per cent. of the other constituents of milk; in other words, cream containing 50 per cent. of fat should, if Storch's hypothesis be true, only contain $\frac{31}{100}$ of the milk-sugar in the skim milk. Analysis, however, shows that it actually contains $\frac{50}{100}$.

If a membrane be present, the ratio of solids not fat to water in cream should differ from the ratio found in milk (except in the case that the ratio of solids to water in the membrane is the same as that in milk); the author has shown, and is confirmed by Smith and Leonard, that the ratio remains the same.

The experiments of Storch and Béchamp on the mixing of ether with milk are capable of an explanation quite different from that which they attach to it when the laws governing the 
distribution of a substance between two immiscible solvents are taken into account. We may regard milk as a mixture of an aqueous solution with a large number of fat globules; on gently shaking up with ether it is evident that very few, if any, of the fat globules come into contact with the ether, but only with an aqueous solution of ether. According to the law, the ether should distribute itself between the fat and the aqueous solution in proportion to the solubility in each ; if the fat is liquid we should expect a large proportion of the ether to yass into the globules, and they would naturally swell; if, on the other hand, the fat is solid we would not expect it to take up any appreciable proportion of ether, and the globules would remain the same size. In neither case would any appreciable amount of fat pass into the excess of ether which separates, as fat is very little soluble in an aqueous solution of ether.

It appears highly probable, though not explicitly stated, that Béchamp used milk which had not been strongly cooled, but which was freshly drawn, and cooled simply by radiation. Under these conditions the author has obtained evidence that the fat globules are liquid. Storch gires no indication as to the condition of the milk used by him, but it is the common practice in Denmark to cool all milk to a very low temperature with ice immediately after milking. These conditions, according to the author's experience, facilitate the solidification of the fat. It is not improbable that the apparent discrepancy between Béchamp and Storch is due to a difference of conditions.

In concluding that the staining of a layer round the fat globules proved the presence of a solid membrane, Storch appears to have overlooked the surface energy of small particles, which would cause a layer composed wholly of liquid to be formed round each globuje. The appearance noticed by Storch is quite explicable without the assumption that a membrane exists, and, indeed, is somewhat at variance with this view. If there were a solid or mucoill layer it should have a sharply defined outer edge. According to Storch's description this is wanting; the staining is deepest nearest to the globule, and fades imperceptibly away, an appearance quite compatible with the' view that a condensed liquid layer is present.

Though data do not exist for calculating the force with which a semi-solid layer would be held by surface energy, it appears reasonable to supnose that it would be impossible to remove this by churning-i.e., friction between globules-therefore butter could not be made were Storch's hypothesis correct.

Nilk is regarded by others as an emulsion, and they see no reason why an emulsion of fat containing ether should not exist of the same nature as that of fat alone; these regard the fact that while a small quantity of ether does not extract the fat to any extent from milk, a large quantity does so with a much nearer 
approach to completeness, to favour the idea that a membrane does not exist round the globules. If milk is precipitated with a solution of nitrate of mercury, which coagulates all the albuminoids of milk, the whole of the fat is removed from suspension, even if it exceeds the albuminoids in weight many times. That this is not due to the precipitation of substances distributed throughout the solution, and the enclosing of the fat therein, is shown by the fact that when the casein, which is equally distributed throughout the solution, is precipitated by means of rennet a considerable proportion of the fat is not enclosed. This fact can hardly be used as an argument that a membrane exists, as the two modes of precipitation differ essentially; the mercury precipitate commences to settle immediately, leaving the solution clear, while rennet gradually reduces the milk to a semi-solid mass, which does not yield a precipitate until the whole has received considerable agitation. As a strong argument against the existence of a membrane may be cited the possibility of preparing artificial emulsions of fats in a finely divided state with milk from which the natural fat has been removed; these emulsions partake very largely of the character of milk. Emulsions of a similar nature can be prepared with other substances, and their behaviour in a great number of respects resembles that of milk. The general consensus of opinion among chemists who may be regarded as authorities on this point is that the fat in milk is not surrounded by a membrane, and, therefore, that it is a true emulsion; further evidence is necessary before the point can be definitely settled. There is very little doubt that a layer exists round each fat globule; this is probably formed by an attraction due to a force akin to that which causes the phenomenon known as capillary attraction. Much of the evidence which has been taken as proof of the existence of a membrane round the globules is only evidence of the presence of a layer of some sort, but not necessarily membranous.

A study of the composition of cream does not, on the whole, favour the theory that a membrane exists round each globule; if this were the case, not only should cream contain a larger proportion of albuminoids, but a ricl cream should contain a greater proportionate amount than a thin one; careful determinations do not fully bear out the latter assumption.

The author has obtained evidence, which is detailed in Appendix I., that the fat globules in milk solidify when cooled below their melting point; the solidification is, however, a process which takes a considerable amount of time (some hours), and it appears probable that an apparent reversal of the laws of nature takes place. When a substance cools heat is given out or energy is evolved. When a very small globule cools it contracts, and the surface energy is increased-that is to say, 
energy is absorbed. As this energy can only be supplied as heat abstracted from the aqueous portion of the milk, it follows that, as the fat globules and aqueous portion are at approximately the same temperature, the passage of energy from one to the other will be slow, and, therefore, that solidification of the globules will be but a slow process.

Sugar. - The sugar in milk is of a peculiar nature; that of cow's milk is called "lactose," or, more commonly, sugar of milk. It is generally assumed that all milks contain the same sugar, but of this there is some doubt. The author, in conjunction with Pappel, has identitied in the milk of the "gamoose," or Egyptian buffalo, a sugar distinct from lactose, to which the name of "tewfikose" has been given. The sugar of the milk of the mare has the property of easily undergoing alcoholic fermentation, a property not possessed by lactose. According to the experiments of Carter and the author, the sugar of human milk is not identical with that of the milk of the cow.

The sweetness of milk is entirely due to the sugar contained in it; the sugar of milk has not the same sweetness as cane sugar, it being many times less sweet. It is very easy of digestion, even by young children.

Albuminoids. - In the albuminoids the milk of different. animals differ greatly. They may be divided broadly into two classes-those which give a curd on the addition of an acill, and those which do not. In the first class are included the milk yielded by the cow, the goat, the gamoose, \&c.; and in the second human milk, that of the mare, and that of the ass may be cited as examples. In the first class the curd is composed of casein, which is combined with phosphates of the alkaline earths; while in the second this is replaced by a similar albuminoid, which is not, however, combined with phosphates. It is possible that the difference between the albuminoids of the two classes is simply dependent on the presence or absence of the phosphates; but the chemistry of these bodies is only in its infancy, and it would be premature to offer an opinion at the present time. Besides casein, or a similar body, there exists in all milks a second albuminoil called albumin; this difters from casein by not being precipitated by acids, and by being coagulated by heat. Other albuminoids have been described in milk, but many of them are only decomposition products of casein or albumin, which were formed during the process adopted for the removal of the other albuminoids. Evidence has been adduced of a third albuminoid in milk; Storch's proteid has already been referred to. Béchamp has deseribed a starch-liquefying enzyme, and lately Babcock and Russell have separated a proteolytic enzyme.

The casein in milk is not in a state of true solution; it is probably in the state described recently by Picton and Linder 
as "pseudo-solution." They have shown that this state is due to the existence of particles in the solution not sufticiently large to settle under the influence of gravity, but which will interfere with the passage of light; they can also be separated by a current of electricity, or by passage of the solution through a porous jar. They show also that there is no sharp dividing line between crystalloids and colloids in solution, substances in pseudo-solution, and substances in suspension. In milk we have the four states represented-the fat is in suspension, the casein in pseudo-solution, the albumin in solution as a colloid, and the milk-sugar in solution as a crystalloid; these four states are probably due to the size of the conglomerates of molecules or particles.

Salts. - The salts of milk are not yet fully studied; the presence of chlorides, phosphates, and sulphates of sodium, potassium, calcium, and magnesium is generally admitted. Salts of organic acids are also present; Henkel has described citric acid, and Béchamp acetic acid, but this result is not universally accepted. Béchamp also maintains that the casein and albumin exist in milk as salts of alkalies; there is much to recommend this view. A solution creatly resembling milk can be prepared in which casein undoubtedly exists combined with an alkali, while it has not been found possible to dissolve casein to an appreciable extent unless an alkali is present; milk does not taste sour until an appreciable acidity has developed; at about the same point it curdles on heating; it is far from improbable that this is due to the acid developed displacing the casein from its compound of alkali, and, when this is wholly accomplished, to the free acid manifesting its properties. It is also found inpossible to coagulate the albumin in milk unless a certain amount of free acid is added, and this fact accords well with the theory of Béchamp. Söldner has also adduced evidence in proof of this view.

Besides the constituents enumerated above, milk contains traces of other compounds; among these may be mentioned urea and other bases, an odoriferous principle, and a colouringmatter; these two latter occur in very small amount, and are of unknown composition.

Colour. - The colour of milk is nearly white, due not to the presence of the colouring-matter just mentioned, which accumulates in the fat, but to the interference with the passage of light by the casein in pseudo-solution. When milk is riewed in thin layers, especially if the bulk of the fat has been remored, it has a bluish tint : the bluish tint can hardly be called a colour; it partakes more of the nature of a fluorescence, and the transmitted light is polarised to a slight degree.

The fat globules, being very much lighter than the medium in which they are suspended and being of sufficient mass to over- 
come the viscosity of the fluid, have a tendency to rise and form a laver of cream on the surface of the milk when left to rest.

Reaction.-Nilk has always, when fresh, an amphioteric reaction-i.e., it turns blue litnus paper sliglitly red and turmeric paper slightly brown. A similar reaction is possessed by certain phosphate solutions, and it is probally to the presence of such in milk that this reaction is dise. Much has been written on this subject, but it is a point which more properly belongs to the chemistry of litmus and turmeric than to the chemistry of milk. This reaction has acquired a false importance owing to the erroneous idea that neutrality as measured by the action of litmus is chemical neutrality; with the recognition of the fallacy of this idea the importance of the amplioteric reaction vanishes.

\section{The Chemical Properties of the Constituexts of Milk.}

Milk-Sugar, Lactose (Lacton or Lacto-biose), $\mathrm{C}_{12} \mathrm{H}_{22} \mathrm{O}_{11} \cdot \mathrm{OH}_{2}$. -Properties.--This sugar is found in the milk of the cow and probably in that of most other mammals. It is a hexa-biose, and belongs to the class of aldehydes (aldoses), or rather aldehydrols. It has the constitution of a galactose-glucoside, and on hydrolysis by acids yielus a mixture of galactose and glucose: Fisclier assigns the following constitution to it:-

$$
\mathrm{CH}_{2} \mathrm{OH} \cdot \pm(\mathrm{CHOH}) \mathrm{CH} \quad \mathrm{OCH}_{3}
$$

\section{OCH3 $(\mathrm{CHOH}) \mathrm{COH}$.}

The aldehyde group of the galactose has been eliminated in milk-sugar, while that of the glucose remains. This is shown by the reactions of several derivatives of milk-sugar; by heating rnilk-sugar with phenylhydrazine and acetic acid, phenyl-lactosazone is formed, which yields an osone on treatment with strong hydrochloric acid ; this, by boiling with hydrochloric acid, yields a mixture of galactose and glucosone. By treatment again with phenylhydrazine, the glucosone forms phenylglucosazone almost immediately, and, on warming, phenylgalactosazone is precipitated. A clear demonstration is thus afforded that the aldehyde group of the glucose only remains.

By oxidation with bromine, lactobionic acid is formed, which is hydrolyzed by acids to gluconic acid and galactose; again showing that the galactose group is modified.

The reactions of milk-sugar, which are all displayed in solution, are those of an aldehyde, but from its formation of stable hydrated compounds it appears more correct to regard it as an aldehydrol.

Modifications.-Milk-sugar exists in several modifications which are distinguished from each other chiefly by their behaviour towards polarised light. 
The best known modification is the hydrated $a$-milk-sugar, usually known as crystallised milk-sugar; this is the form in which it crystallises from water. The $\alpha$-modification exhibits multi-rotation -i.e., when dissolved in water it has a much higher specific rotation than that which it attains after a lapse of time. The author has found that when dissolved in water it causes a lowering of the temperature of the solution by about degree C. By shaking up the finely powdered sug,tr with water, a solution is obtained containing about $7 \cdot 5$ grammes per 100 c.c. at $15^{\circ} \mathrm{C}$., the quantity dissolved increasing roughly about $\cdot 1$ gramme per 100 c.c. for each degree above $15^{\circ} \mathrm{C}$. No thermal change was detected in this solution by a thermometer reading to $01^{\circ} \mathrm{C}$., but the temperature rose steadily till it attained that of the surrounding atmosphere, which was kept constant; the rate of rise was identical with thit of a previously prepared solution of milk-sugar of the same strength, which had been cooled to the same temperature. Brown and Pickering have, however, shown that a slight thermal change takes place with change of rotatory power $(+0.19$ calorie per gramme). No change in density or molecular weight indicated by freezing point determination was observed on keeping solutions of milksugar, though the specific rotation varied very widely.

It is usually stated that a freshly prepared solution of $\alpha$-milk sugar contains 14.55 per cent. at $10^{\circ} \mathrm{C}$.; while by long standing in contact with milk-sugar, or by boiling, a saturated solution containing $21 \cdot 64$ per cent. can be obtained. The author is unable to confirm the figure for the freshly prepared solution.

The density of well formed crystals is 1.545 at $\frac{15 \cdot 5^{\circ}}{15 \cdot 5^{\circ}}$, bad crystals-i.e., those which are strained, have, however, a lower density.

The hydrated $\alpha$-modification is practically insoluble in alcohol, ether (in ether saturated with water it dissolves to the extent of 00075 gramme per 100 c.c.), chloroform, benzene, and other organic solvents. It is slightly, but distinctly, soluble in amyl alcohol on boiling, but is probably dehydrated.

It is unaffected by heating to $100^{\circ} \mathrm{C}$., but the water of hydration is given off at $130^{\circ} \mathrm{C}$.; at $170^{\circ}$ a change takes place with formation of lacto-caramel, and it melts at $213 \cdot 5^{\circ} \mathrm{C}$.

When dissolved in water the specific rotatory power remains constant for a short period, 3 minutes at $20^{\circ} \mathrm{C}$., 6 minutes at $15^{\circ} \mathrm{C}$., and 15 minutes at $10^{\circ} \mathrm{C}$.; the rotation then gradually falls.

The following series of observations (Table I.) will show the nature of the change in rotation:- 
TaBle I.-Change of Rotation of $\alpha$-MIllk-Sugar in Solution.

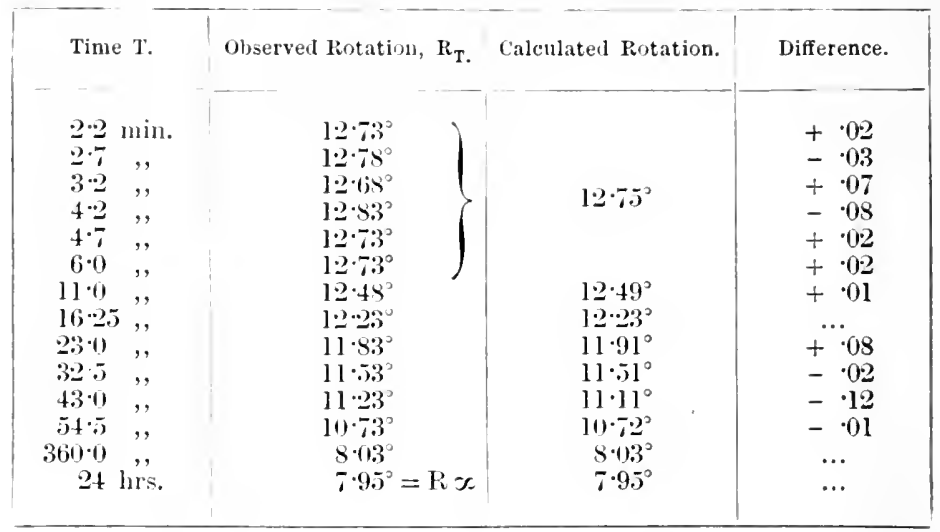

The solution used was examined in a $198.4 \mathrm{~mm}$. tube using the sodium light; two determinations gave 7.090 and 7.072 per cent. of anhydrous milk-sugar, and, as the solution had a density of 1.0265 at $17^{\circ}$ (the temperature of observation), it contained $7 \cdot 651$ grammes of hydrated milk-sugar per 100 c.c.

It is seen that the rotation is approximately constant for the first 6 minutes, and averages $12.75^{\circ}$, which corresponds to $[\alpha]_{\nu}=83.99^{\circ}$. After 24 hours the rotation is constant at $7 \cdot 95^{\circ}$, which corresponds to $[\alpha]_{\mathrm{r}}=52 \cdot 37^{\circ}$.

The figures given in the "calculated" column are deduced by the formula-

$$
\log \left(R_{T}-R x_{0}\right)=\cdot 68124-00491(T-6) .
$$

The fact that the fall in rotation is expresserl by a logarithmic curve shows that the rate of change is proportional to the amount of unchanged substance in solution; this is Harcourt's law of simple chemical change.

'The ratio between the initial rotation and the final rotation, which may be called the bi-rotation ratio, is $\frac{83 \cdot 99}{52 \cdot 37}=1 \cdot 604$.

The mean of several determinations has led to the value for $[\alpha]_{\mathrm{r}}$ of the hydrated $\alpha$-modification $=84 \cdot 0^{\circ}$, and the bi-rotation ratio $1 \cdot 6$; these are the figures giren by Schmoeger, who, however, assigned to them an approximate value only.

The small amount of thermal change during change of rotation and absence of change in density and freezing point show, with a considerable degree of probability, that the change manifested by alteration in rotation is intra-molecular. It is probably 
caused by the migration of the water of hydration from one carbon atom to another.

The anhydrous modification of the a-modification is obtained by heating the liydrated modification to $130^{\circ} \mathrm{C}$. It is hygroscopic and dissolves in water with evolution of heat; the solubility is much greater than that of the hydrated modification. The optical properties are stated by Schmoeger to be the same as those of the hydrated modification.

The $\beta$-modification is the one to which all others are converted on dissolving in water. Schmoeger gives the specific rotatory power $[\alpha]_{\mathrm{D}}$ as $52.53^{\circ}$ at $20^{\circ} \mathrm{C}$., diminishing $075^{\circ}$ for each degree C. above this and increasing for lower temperatures. The author can absolutely confirm these numbers. It has never been prepared pure in the solid state, though considerable evidence of its existence, both in the hydrated and anhydrous modifications, has been obtained by the author.

By the addition of alcohol or, better, ether to a very highly supersaturated hot solution of milk-sugar, it sets to a solid mass, which may be dried in vacuo, and does not then lose weight at $100^{\circ} \mathrm{C}$, but which contains, however, a certain amount-2 to 4 per cent. - of water of hydration which is lost at $130^{\circ} \mathrm{C}$. There is no appreciable change in rotation on dissolving this product in water and taking readings at intervals; as some of the readings obtained have been above, and some below, that ultimately obtained, it is probable that the very slight differences noticed were due to errors of observation.

By precipitating less strong solutions of milk sugar by alcohol, products can be obtained which contain very nearly, if not quite, the same percentage of water as the hydrated $\alpha$-modification, but which have a much smaller, but not constant, bi-rotation ratio. These also give a constant rotation for a few minutes on dissolving in water and behave as mixtures of the $\alpha$ and $\beta$ hydrated modifications. They have a less density than the a-modification, but it is not certain whether this may not be due to the very imperfect crystallisation which takes place, the products appearing nearly amorphous.

By evaporating aqueous solutions of milk-sugar on the water bath, an anhydrous sugar can be obtained, which has a very slight bi-rotation ratio, which is not constant. As this varies from 1.09 to 1.02 , such sugar probably consists of the anhydrous $\beta$-modification, mixed with a small amount of the $\alpha$-modification. A specimen having a bi-rotation ratio of 1.03 had a density of 1.585 at $\frac{15 \cdot 5^{\circ}}{15 \cdot 5^{\circ}}$ and dissolved in water with a slight evolution of heat.

There is some evidence that the hydrated $\beta$-modification dissolves in water with a greater absorption of heat than the a-modification, as the mixtures obtained by precipitation with 
alcohol cause a greater lowering of temperature than the $u$-modification. The solubility appears to be greater.

There exists also a $\gamma$-modification, which is obtained in the anhydrous form by the rapid evaporation of aqueous solutions in metallic vessels. Schmoeger states that it has a bi-rotation ratio of $\frac{1}{1 \cdot 6}$, which Tanret confirms.

By the adclition of ammonia, the change which the $\alpha$ - and $\gamma$ modifications slowly undergo on solution in water becomes almost instantaneous. By raising the temperature, the rate of change is increased and is practically instantaneous on boiling.

Constitution.-The author proposes the following formulæ to explain the existence of the three modifications:-

Taking the constitution given above-

$\mathrm{CH}_{2} \mathrm{OH}, 4(\mathrm{CHOH}) \mathrm{CH}$

$\mathrm{OCH}_{2}$

$\mathrm{OCH} 3(\mathrm{CHOH}) \mathrm{COH}$,

we see that the end groups are represented $-C_{-}^{-}-C_{H}$ as an
aldehyde.

Now, an aldehydrol is a combination of this with water. It $\mathrm{OH}$

does not appear probable that the group $-{ }_{\mathrm{H}}^{\mathrm{COH}}$ is present in an aldehydrol, but the molecule $\mathrm{OH}_{0}$ appears to eombine as a radicle of small valency, which may be conveniently represented thus (11\%)

The aldehydrol is represented thus<smiles>CC(O)C=O</smiles><smiles>c1ccccc1</smiles>
$\mathrm{HI}$ $\mathrm{OH} \mathrm{OH}$ Taking the form $-\mathrm{C}-\mathrm{C}-\mathrm{OH}$ as an unstable modification of this, it is sern that this might form the group $-\mathrm{C}-\mathrm{C}-\mathrm{OH}$
which is a liydrated anlyydride.

OH $\mathrm{OH}$

The group $-\mathrm{C}=\mathrm{C}-\mathrm{H}$ could equally well be formed.

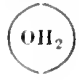


Of these three formulæ the aldehydrol and aldehyde represent the $\beta$ hydrated and anhydrous modifications respectively. The anhydride formation probably can be assigned to the $\alpha$-modifications, as the anhydrous $\alpha$-modification has the properties of an anhydride-e.g., it is hygroscopic. The ethylenic configuration would be left for the $\gamma$-modification; the hydrated form of this modification would probably be formed with great difficulty, if it exists at all ; the evidence of the existence of a hydrated $\gamma$-modification is very weak.

In the ethylenic formula the carbon atom next the end would be either non-asymmetric or opposite to that in the aldehyde; when this passes to the aldellyde formation, it becomes asymmetric, containing the groups $\mathrm{H}$ and $\mathrm{OH}$ opposed to each other: The anhydride formula contains this carbon atom as an asym-

metric one with the groups $\mathrm{H}$ and $\mathrm{O}\left(\mathrm{OH}_{2}\right.$ opposed.

Calling the combined effect on rotatory power of the other asymmetric carbon atoms $x$, and the effect of the opposed groups

$\mathrm{H}$ and $\mathrm{OH} a$, the effect of the groups $\mathrm{H}$ and $\mathrm{O}\left(\mathrm{OH}_{2}\right)$ may be

taken as greater than $a$, say $a+b$. We have, then, the total effect of the asymmetric carbon atoms as $x+a+b$ in the $\alpha$-modification, $x+a$ in the $\beta$-modification, and $x$ or $(x-c)$ in the $\gamma$-modification. It is evident that the rotatory power of the $\beta$-modification is intermediate between the other two.

Asymmetric Carbon.-An asymmetric carbon atom is one which is combined with four different radicles thus-<smiles>[Y]C([2H])([2H])[10BH2]</smiles>

It is probable that the atoms do not lie in the same plane, but are symmetrically grouped round the carbon atom as at the four corners of a regular tetrahedron thus-

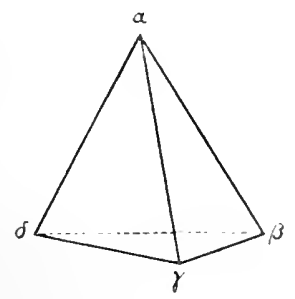

or

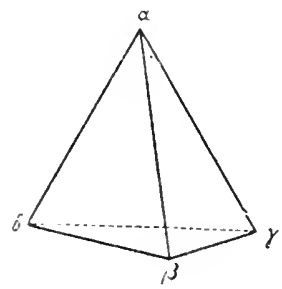


If we take up a regular tetrahedron and hold it by the corners $\alpha$ and $\beta$, we see that there are two possible arrangements; in one, $\gamma$ is towards us; in the other, $\partial$. It is found that compounds containing an asymmetric carbon atom exist in two modifications closely resembling each other, but differing in their effect on polarised light; both affect the ray to the same extent, but in opposite directions.

If we take a regular tetrahedron, and weight the corners, and spin it round the centre, we find that as long as two of the corners are weighted equally we can always find such a position that those two corners follow the same path when the system is in equilibrium ; if all the four corners are weighted unequally, it is impossible to tind a position in which two corners follow the same patl.

Looking at right angles to the axis of rotation we may represent the paths as straight lines; thus, for a non-asymmetric system, the sequence of appearance of the corners at any point

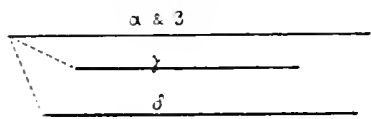

will be $\alpha, \gamma, \beta$, $\hat{o}$ or $\alpha, \delta, \beta, \gamma$, and the apparent path of the sequence will be denoted by the dutted lines, which are the same whicherer sequence is adopted or whether $y$ and $\delta$ are transposed.

With an asymmetric system we have

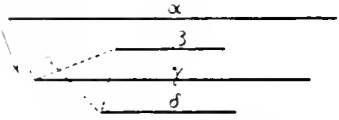

The sequence $\alpha, \gamma, \beta$, o moves apparently in one direction.

By transposing $\alpha$ and $\beta$, the paths of the corners are

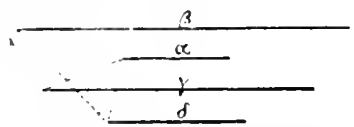

The sequence $\alpha, \gamma, \beta, \delta$ moves aplarently in the opposite direction to that previous to transposition.

The nature of polarised light and the effect of molecules thereon is not fully elucidated, but the above illustration is given to clemonstrate how a right-and left-handed effect may be produced from what is probahly the best representation of an asymmetric carlon atom.

If we have more than one asymmetric carbon atom in a molecule, each will produce its combined eflect. A molecule 
containing two asymmetric oarbon atoms may exist in three modifications; one, in which both atoms show a right-luanded effect; a second, in which both show a left-handed effect; a third, in which one shows a right-handed and one a left-handed effect. It is convenient to suppose that the effect is produced on the centre of the molecule, thus-

the compound

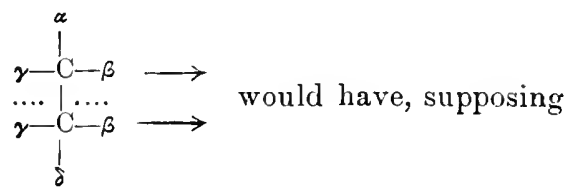

$\beta$ to be the greater radicle, an effect produced in the directions of the arrows, and the effects of the two asymmetric atoms on the centre would be opposite.

We may represent the three modifications thus-

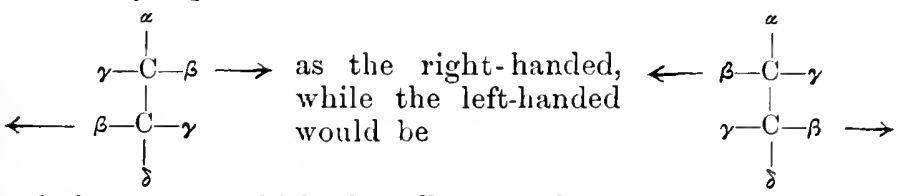

and the one in which the effects of the two atoms tended to neutralise each other would be that given above.

The solubility of milk-sugar in water is small compared with the solubilities of other carbohydrates; owing to the tendency of milk-sugar to form supersaturated solutions it is difficult to determine its exact solubility, but the mother liquors from which crystals have deposited usually contain about 21 per cent. The $\alpha$-modification crystallises in wedge-shaped forms which often have the face at the end of the wedge greatly prolonged. The $\gamma$-modification crystallises in needles.

The taste of the c-modification is not sweet, and from its comparative insolubility it appears to be gritty. In solution the $\beta$-modification has a sweet taste of about a quarter the sweetness of cane-sugar.

As already stated, on heating to $170^{\circ} \mathrm{C}$. it turns brown, and lacto-caramel is formed; a similar change takes place by leating an aqueous solution to $100^{\circ} \mathrm{C}$. for some hours; the presence of small amounts of alkali greatly increase the browning of the solution. The rotatory power is greatly diminished.

Chemical Properties. - Milk-sugar, in common with other aldoses and ketoses, reduces alkaline solutions of copper, silver, and mercury, forming cuprous oxide, and metallic silver and mercury respectively. On this fact the well-known Fehling's test for sugar is based. The amount of reduction is constant for fixed amounts of milk-sugar under the same conditions, and is nearly proportional to the amount of milk-sugar. Each sugar 
shows a definite amount of reduction in the same way, and a valuable method for distinguishing them is thus available. The difference between reduction by various sugars is not due to any difference in the reaction with the metallic salt, but depends on their relative stability towards allsalies.

On warming with dilute nitric acid (sp. gr. 1.2) an energetic action takes place, mucic acid, together with saccharic, oxalic, and other acids being formed; the mucic acid, which can be separated by its relative insolubility, amounts to about 35 per cent. of the weight of the milk-sugar. This is due to the galactose portion of the nilk-sugar. Strong nitric acid (sp. gr. 1.5) mixed with sulphuric acid, to absorb the water formed in the reaction, gives rise to the formation of tri- and pentanitrates; both these compounds have explosive properties. The penta-nitrate is a constituent of certain high explosives.

On heating with an excess of precipitated copper oxide gummy acids are formed, such as galactinic and pecto-galactinic acids, compounds which are also formed from galactose.

By oxidation with bromine lacto-bionic acid is formed, in which the $\mathrm{COH}$ group is converted into COOH. Potassium permanganate in acid solution oxidises it to carbonic acid, but the reaction is not complete, not more than 80 per cent. of the theoretical quantity of carbon clioxide being obtained.

By lreating with phenylhydrazine acetate two compounds are formed; one of these-phenyl-lactosizone-is sparingly soluble in cold water, but readily in hot, from which it separates on cooling in yellow needles melting at $197^{\circ} \mathrm{C}$. with decomposition. It is also soluble in alcoliol and ether; the latter solvent extracts it from aqueous solution. The second compound is an anhydride of phenyl-lactosazone, and is almost insoluble in hot water; but can be crystallised from lot dilute alcohol in yellow weedles which melt at $218^{\circ}$. Milk-sugar is distinguished from other sugars by its osazone forming an anhydride.

By treating with strong cold liydrochloric acid the phenylhydrazine groups are removed, and lactosone is formed.

The relation between these compounds is shown by the following formule: :-<smiles>N#CC([18OH])C#N</smiles>

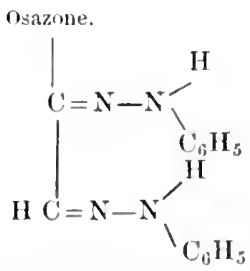

Osone.<smiles>CC=O</smiles>

The osone is readily reconverted into the osazone by treatment with phenylhydrazine acetate. 
By reduction with sodium amalgam a mixture of mannitol and dulcitol, hexahydric alcohols of the formula $\mathrm{C}_{6} \mathrm{H}_{14} \mathrm{O}_{6}$, with lactic acid and methyl, iso-propyl and hexyl alcohols is formed.

On heating with acetic anhydride and sodium acetate an octacetyl-lactose is formed. This crystallises in stout prisms from a mixture of alcohol and chloroform, and has an ill-defined melting point about $90^{\circ} \mathrm{C}$. Its solution in chloroform is optically inactive, or very slightly lævo-rotatory.

Milk-sugar dissolves lime, baryta, lead, copper, and mercuric oxides, and probably forms compounds with them. No compound with sodium chloride is known.

Ammoniacal lead acetate precipitates milk-sugar from an aqueous solution.

It is not fermentable by ordinary yeast, and is unacted on by invertase, diastase, rennet, pepsin, and trypsin. There exists, however, an enzyme, which has been called lactase, which is found in fresh kephir grains, which hydrolyses it to glucose and galactose. The enzume does not appear to be present in dried kephir grains, but is probably found in other substances.

The action of acids generally is to convert it into glucose and galactose. Some organic acids, such as citric, are, however, without action on milk-sugar.

Preparation.-Milk-sugar is prepared on a large scale by evaporating whey in vacuo, after neutralisation of any acid with lime and clarification with alum or other means, and allowing it to crystallise. The product is purified by re-solution, treatment with animal charcoal and re-crystallisation. In countries where alcohol used in manufacturing purposes is free from duty the sugar is precipitated from solution by this means instead of being crystallised from water.

On a small scale, it is best to precipitate the proteids from milk or whey by as small a quantity of acid mercuric nitrate (p. 78) as possible. The clear filtrate is neutralised with dilute caustic soda solution till a very faint tinge is given with phenolphthalein; it is filtered from the precipitate thus produced, which consists of mercury salts. Sulphuretted hydrogen is passed through the clear solution to remove the mercuric oxide dissolved by the sugar, and, after tiltration from mercuric sulphide, the sulphuretted hydrogen is expelled by boiling. On evaporating the solution, milk-sugar crystallises out; crystallisation may be hastened by vigorously stirring the concentrated solution while it is being rapidly cooled.

Glucose and Galactose.-These are two isomeric sugars of the monose type. Both are aldoses or aldehydrols, and have been obtained in three modifications. 
Their constitution is given by E. Fischer as<smiles>O=C(O)C(O)C(O)C(O)C(O)C(O)CO</smiles>

Wohl and List have confirmed the constitution of galactose.

They are thus isomeric sugars differing only in the third asymmetric carbon atom from the aldehyde group.

It is not known whether these sugars on dissolving them in water give a constant rotation for a short time as in the case of milk-sugar. Their specific rotatory powers $[\alpha]_{\mathrm{D}}$ are

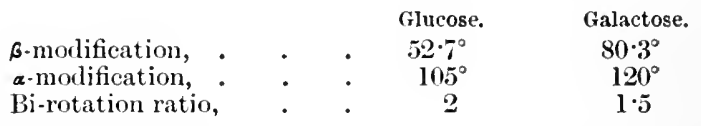

Both sugars give, on treatment with phenylhydrazine acetate, nearly insoluble osazones. These are converted into osones by treatinent with strong cold hydrochloric acid.

Products derived from Milk-Sugar. - The most important of these products is formed by the action of certain microorganisms on milk-sugar during the so-called lactic fermentation. By their action the milk-sugar is split up into lactic or oxypropionic acid almost quantitatively, a certain portion, however, being converted into other products, of which carbon dioxide is the most important. The micro-organisms which produce lactic acid are acter on inimically by acids, so that not much more than 1 per cent. of lactic acid is formed, unless the solution is kept nentralised by chalk or other means.

Its formula as usually given is $\mathrm{CH}_{3}-\mathrm{C}_{-}^{-}-\mathrm{COOH}$, so that it contains an asymmetric carhon atom; it is not, however, optically active, though the isomeric sarcolactic acid possesses this property. It appears to be a racemoid compound intermediate betwcen sarcolactic acid and the dextrolactic acid discovered by Purdie. It has a remarkable tendency to form compounds which contain less water.

On evaporating aqueous solutions of lactic acid, dehydrolactic acid is formed, $\mathrm{C}_{6} \mathrm{H}_{10} \mathrm{O}_{5}$, which, by further evaporation (especially at a high temperature), gives lactide, $\mathrm{C}_{6} \mathrm{H}_{8} \mathrm{O}_{4}$. 
Lactic acid acts as a monobasic acid; while dehydrolactic acid behaves as a monobasic acid, monohydric alcohol and an ethereal salt at the same time; lactide is a neutral substance.

Sarcolactic acid gives the same lactide, which, on boiling with water, is converted into the inactive modification.

To explain the fact that lactic acid is inactive and easily forms anhydrides, the author proposes to assign the following formulæ to

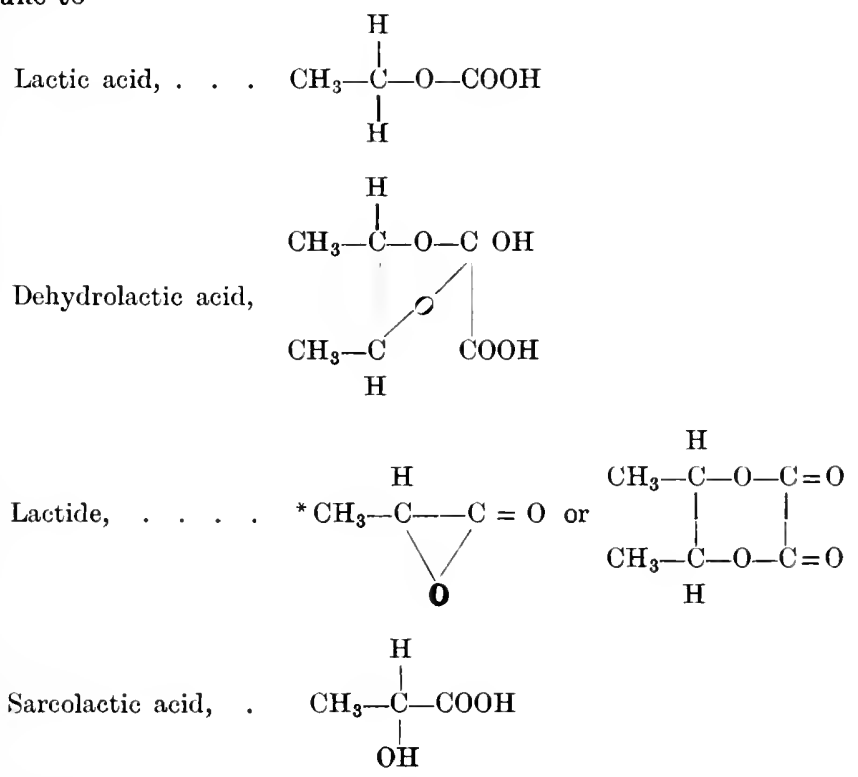

The so-called syrupy lactic acid is a mixture of lactic and dehydrolactic acids with probably a little lactide. Wislicenus has shown that by direct titration with alkali lactic, and dehydrolactic acids are estimated, while by further boiling with excess of alkali one molecule of lactic acid is produced for each molecule of dehydrolactic acid, and two for each molecule of lactide. Dehydrolactic acid has not been obtained pure, but appears to be amorphous and nearly insoluble in water.

Lactide can be prepared by subliming syrupy lactic acid at $150^{\circ}$ in a current of dry air. It is insoluble in water, but can be crystallised from alcohol in colourless rhombic plates melting at $124.5^{\circ} \mathrm{C}$. It boils at $255^{\circ} \mathrm{C}$.

Syrupy lactic acid is said to have a specific gravity of $1 \cdot 2485$. Lactic acid is not appreciably volatile in dilute solution, but

* The second formula is probably the more correct, as Henry has found its vapour density to agree with the formula $\mathrm{C}_{6} \mathrm{H}_{8} \mathrm{O}_{4}$. The first formula is introduced to show its derivation from sarcolactic acid. 
passes over with water to a slight extent as the solution becomes concentrated.

Lactic acid is soluble in and miscible in all proportions with water, alcohol, ether, and glycerol. It is insoluble in petroleum ether. Fats also dissolve it. It is probable that the lactic acid present in milk is, partially at all events, dissolved in the fat.

As milk almost immerliately after milking contains organisms which produce lactic acid, it may be considered as a normal constituent of milk ; indeed Béchamp has held that it is produced from milk by organisms (micro-zymes) derived from the udder itself. That this view is erroneous is shown by the fact that Lister, Pohl, Warington, and other's have succeeded in preserving milk, drawn direct into sterilisel vessels, for a considerable length of time without the development of acidity.

Lactic acid probably exists in milk, not in the free state, but as a salt, at all events until the acidity is sufficient to curdle the milk on boiling.

The Albuminoids of Milk-Properties. - Our present knowledge of the albuminoicls of milk is far from complete, though much work has been done on the subject. This is due to the fact that it is extremely difficult to obtain these compounds in anything like a state of purity. The method of crystallisation, which is so largely depended on in the case of other bodies, being unavailable, and as albuminoids are altered in their essential properties by very many reagents, the choice of methods of purification is limited. The difficulty is still further increased by the peculiar behaviour of casein in retaining calcium salts, if once it has been brought into contact with them, as is the case in milk. The albuminoids of milk have been prepared in as pure a state as possible by the general method of precipitating them by some leagent, dissoiving them, reprecipitating as many times as may be thought necessary, and, tinally, by eliminating such impurities as nay have been introduced during the process. As there is no means of knowing when all the impurities have been eliminated, it is possible that we are yet unacquainted with the albuminoids of milk in a state of purity. This should not be forgotten during the study of the milk albuminoids.

The milk albuminoids are bodies of complex composition containing carbon, oxygren, nitrogen, hydrogen, phosphorus, and sulphur. The way in which these elements are combined is not known, but some light is thrown on the constitution of albuminoirls by the production of amilo-acids (leucine or amido-caproic acid, for instance) by the action of acids or other substances (e.y., certain enzymes) as a far advanced decomposition product; the xantlio-protein reaction-the production of a yellow colour by evaporating with nitric acid and treatment with ammonia is characteristic of leucine, and the fact of albuminoids giving 
this reaction is further evidence of their being derivatives of this body. The action of alkalies on albuminoids is to procluce, amongst other substances, oxalic acid and ammonia. The molecule of albuminoids is very complex, as is evident by their being indiffusible bodies. By the action of acids and certain enzymes, e.g., peptase (pepsin), they are resolved into simpler bodies which become nore and more diffusible as the decomposition advances. During the simplification just mentioned evidence is afforded of the splitting off of portions by the fact that some of the decomposition products are free from sulphur.

Hydrolysis of Albuminoids.-Albuminoids are easily hydrolysed by the action of heat, acids, and various enzymes. The products, which are called "albumoses" and "peptones," are numerous and cannot be separated with certainty from each other. They are classed as follows:-

Proto-albumoses: precipitated from solution by saturation with sodium chloride.

Deutero-albumoses (I.): precipitated from the sodium chloride saturated solution by acetic acid.

Deutero-albumoses (II.) : precipitated by saturation with ammonium sulphate.

Peptones; unprecipitated by saturation with ammonium sulphate or sodium chloride with or without the addition of acetic acid.

Dys-peptones (Dys-albumoses) are bodies produced by the action of enzymes; they are insoluble.

The products of hydrolysis obtained by different means are not identical; thus the albumoses produced by pepsin and trypsin have not the same composition.

To distinguish between the products of hydrolysis the author proposes a nomenclature which shall indicate the means by which the product has been obtained. If an enzyme is the hydrolytic agent, it is proposed to use a pretix indicating the enzyme; for pepsin (peptase), trypsin (tryptase), and rennet (chymase) the author uses the pretixes, "pepto-," "trypto-," and "chymo-" respectively. For acid hydrolysis, the pretix "hydrolo-" seems most convenient.

As an example, the products obtained from casein would be called as follows :-

$$
\begin{array}{cc}
\begin{array}{c}
\text { Hydrolysing } \\
\text { Agent. } \\
\text { Acids, . . }
\end{array} & \multicolumn{1}{c}{\text { Products of Hydrolysis. }} \\
\text { Pepsin, . . Proto-hydrolo-caseose, Dentero-hydrolo-caseose, } \\
\text { and Hydrolo-caseone. }
\end{array}
$$

The prefix "hetero" is often used instead of "hydrolo," 
"auti-" for "pepto-," and "amphi-" for "trypto-." The author, however, believes that the above nomenelature is more convenient and expressive.

It is extremely probable that there exists more than one proto-albumose and, similarly, several deutero-albumoses.

The hydrolysis of albuminoids can be carried beyond the stage of peptones; tyrosine, leucine, and other amido-compounds are formed.

During hydrolysis, the hydrolysts are not destroyed, or are destroyed with extreme slowness, and appear to be able to act on a relatively enormous quantity of the hydrolyte. The time taken to produce a given change on a given quantity of hydrolyte is inversely proportional to the quantity of hydrolyst. Each hydrolyst has a certain optimum temperature at which it acts most rapidly, the action being diminished at both higher and lower temperatures. Certain substances-e.g., acids-affect the rate of hydrolysis; their influence, however, follows laws which are not fully known. This may be perhaps due to the hydrolysing effects of the acid combined with those of other hydrolysts taking a course influenced by both of them.

Views of Different Authorities.-The number of albuminoids present in milk (of the cow) has been variously stated at from one to eight by different observers. The most recent work has tended to reduce the number to not more than four, the larger number deseribed having been obtained by faulty methods of separating these bodies or by the action of some reagent used on the albuminoid. Many of the products described are now known to be mixtures of one or more of the albuminoids with various impurities, or decomposition products obtained during the separation of the albuminoids one from another.

The theories of leading observers are briefly given as follows:-

Duclaux maintains that there is only one albuminoid in milk, which exists in two forms-the coagulable and non-coagulable; he gives to this albuminoid the name of casein. 'The first modification is not in a state of solution, and can be separated by filtration throngh a porous jar; it is combined with the phosphates of the alkaline earths, and this causes it to differ in its properties from the other modification, which is in a state of true solution and passes through the porous jar. Were this view correct, the coagulable modifieation should gradually lose its distinctive properties as it is purified from phosphates; and, on the other hand, the non-corgulable modification should be capable of being converted into the other by associating it with phosphates; neither alternative has as yet been found possible, and, as two albuminoids having distinet properties can be separated from milk, Duelaux's view is hardly tenable.

Hammarsten deseribes two albuminoids; one, casein, corresponding to Duclaux's coagulable casein : the other, lact- 
albumin, corresponding to Duclaux's non-coagulable casein. He shows that lact-albumin has the properties of a true albumin, approaching very closely to serum-albumin, but differing from it in certain physical constants, which entitles it to rank as a distinct body. Sebelein has shown that there exist in milk traces of a globulin, in addition to the casein and albumin of Hammarsten.

Halliburton describes the albuminoids of milk as caseinogen and lacto-albumin; there is no essential difference between the casein of Hammarsten and the caseinogen of Halliburton, except a difference of name. He reserves the name casein for the curd produced by the action of rennet.*

Hewlett, a pupil of Halliburton, has confirmed Sebelein's statement as to the existence of globulin in milk, though he has shown that Sebelein's globulin was probably contaminated with small amounts of casein.

Musso and Menozzi have claimed the presence in milk of a body midway between casein and albumin; this is probably the globulin of Sebelein in an impure state, as their description is in fair accordance with a statement of the properties of the latter.

Radenhausen and Danilewsky have described many albuminoids in milk. Hammarsten and-later-Chittenden and Painter have shown that their view that casein is a mixture of two compounds is untenable, while the various lacto-protein

* The author dissents strongly from Halliburton's nomenclature "caseinogen" and "casein" for the following reasons :-

1. Casein is derived from the Latin caseum, and the termination oyen from the Greek root $\gamma \epsilon \nu$.

2. $\gamma \varepsilon \nu$ means " to beget." In the words hydrogen, oxygen, chromogen, \&c., this meaning is preserverl, and they mean that hydrogen, oxygen, and chromogen are essential constitnents which, with others, make water, acids, and colour respectively. In fibrinogen and caseinogen this meaning is not preserved; the termination means that these bodies are substances which are split up into fibrin and casein with other substances.

3. The action of remnet does not appear to differ materially from that of other proteolytic enzymes. Thus, the action of pepsin on casein is strictly analogous; pepsin, as it only acts in acid solution, cannot act on a solution of casein, but splits it up into soluble caseoses and the insoluble dyscasein-peptone (dys-pepto-caseose). It appear's from recent researches that the insolubility of dys-pepto-caseose is dne to its combination with calcium salts (chiefly phosphate). Rennet, which acts in nentral solution, splits up casein into soluble chymo-caseoses and an insoluble dys-chymo-caseose (cnrd); this likewise owes its insolubility to a combination with calcium salts (preferably phosphate). If calcium salts be completely removed, no insoluble dys-caseose is prodnced in either case.

4. The name "casein" has probably been given by Halliburton to the dys-caseose on account of its being used largely in cheese. It is not, however, essential for cheese. The casein precipitated by acicls can also be made into good cheese.

5. "Casein" has priority over " caseinogen," for the albuminoid of milk, and, except by Halliburton and his school, is univel'sally accepterl. 
bodies lave been shown to be the result of their method of separating casein and albumin.

Wynter Blyth has described a body called galactin in milk; this is essentially lacto-protein, perhaps contaminated with some organic salts, and has wo real existence in milk, being portions of the casein and albumin which had escaped separation, together with products of their decomposition during the process used for their removal.

Béchamp supposes that the albuminoids of milk number three -casein, albumin, and a body having the properties of an enzyme, which he calls galacto zymase; this enzyme he finds liquefies starch paste, evidently not its normal function in milk; his results have not been confirmed. He also supposes the casein and albumin to exist in milk in combination with bases (soda, lime, or potash).

Biel has described syntonin as a normal constituent of milk, but the existence of this must be considered doubtful at present.

Paim has stated that albumoses are found in milk; this is probably not wholly correct; it is possible that traces of albnmoses are formed during the decomposition to which milk is prone, but no other olserver has identified more than traces, while Palm gives 1.5 per cent. as occurring in milk. 'I'rue peptone has been proved to be absent. Storch's researches have been referred to (p. 2). Babcock has found very small amounts of nuclein, and the same observer has with Russell separated a proteolytic enzyme.

From the above list of the various albuminoids described as existing in milk we may select the four of whose existence we have the strongest evirlence; these are casein, lact-albumin, lacto-globulin, and Storch's mucoid ; the last two, however, are only found in traces in milk, and, practically, the albuminoids may be reduced to the former two. Of the other albuminoids described, the syntonin of Biel and the galacto-zymase of Bechamp must be considered to have a doubtful existence, though there is some probability of their being present. The other compounds described are hypothetical.

The main reactions that distinguish the four albuminoids of milk are as follows:-Casein is precipitated by saturating the solution with sodium chloride, magnesium sulphate, and ammonium snlphate; globulin is soluble in a saturated solution of sodium chloride, but is precipitated by nagnesinm and ammonium sulphates; albumin is soluble in saturated solutions of sorlinm chloride and mianesimu sulphate, but is precipitated by saturation with ammonium sulphate, while Storch's mucoid is not in solution; albumin is, however, precipitated from a saturated solution of magnesium sulphate by acidifying slightly, and is redissolved by neutralisation of the solution. Casein and slobulin are precipitated by the addition of acid, while albumin 
(and globulin, if much salt is present) is not so precipitated. Casein has the remarkable property of being acted on by chymase, the enzyme of rennet, with the formation of an insoluble product; albumin is coagulated by the action of heat, the raising of the solution to about $70^{\circ} \mathrm{C}$. being sufficient to precipitate a great portion. Casein (and globulin?) are removed from solution by filtration through a porous cell, while albumin remains dissolved. Properties conmon to the three albuminoids are solubility in alkalies, insolubility of their copper, mercury, and other salts, insolubility in alcohol; all are precipitated by tannin and plıspho-tungstic acid.

Casein.-This albuminoid, when pure, is a white amorphous body without taste or smell; it is practically insoluble in water, lissolving in this menstruum to the extent of about 0.1 per cent.; it is quite insoluble in alcohol and ether. Very dilute acids seem to diminish the solubility; but it is soluble in stronger acids, becoming, however, changed; a solution of casein in acetic acid has been used as glue; it is completely soluble in caustic alkaline solutions even when very dilute; the solutions of the carbonates, bi-carbonates, and phosphates of the alkalies also dissolve it, and from these solutions, as well as those of the alkalies, it is precipitated unchanged by the addition of sufficient acid to neutralise the alkali. It has the property of forming an opalescent solution when it is dissolved in the least possible excess of sodium phosphate, and the addition of small quantities of calcium chloride is made; it gives then a solution having the appearance of milk. It is highly probable that milk contains casein in this form. Casein has a peculiar affinity for calcium salts, especially the phosphate. It is extremely difficult to free it from this boly, the purest preparations that have been prepared having always been contaminated with small amounts of this compound. Casein yields a compratively small amount of sulphide if boiled with an alkali, and contains less of this element than either glohulin or albumin; it also differs from these compounds by containing phosphorus; on analysis, like other albuminoids, it does not yield rery concordant results; the most probable composition is as follows :-

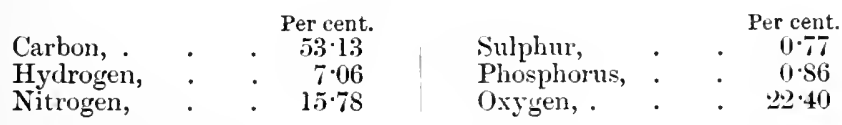

The formula and constitution of casein are not known. The composition of casein is variously stated by different authorities. The following are the most reliable results :- 


\begin{tabular}{|c|c|c|c|c|c|}
\hline Authrority. & Hanmarsten. & chittenden. & Strilmann. & Lehmann. & Ritthansen. \\
\hline C & $\begin{array}{c}\text { Per cent. } \\
52 \cdot 96\end{array}$ & $\begin{array}{c}\text { Per cent. } \\
53.311\end{array}$ & $\begin{array}{c}\text { Per cent. } \\
54.0 \mathrm{~S}\end{array}$ & $\begin{array}{c}\text { Per cent. } \\
54^{\circ} \cdot 00\end{array}$ & $\begin{array}{c}\text { Per cent. } \\
54 \div 22\end{array}$ \\
\hline $\mathrm{H}$ & $=.0 .5$ & 7.07 & $7 \cdot 0.9$ & $7 \cdot 04$ & $7 \cdot 17$ \\
\hline$N$ & $15 \cdot 65$ & $1.5 \cdot 91$ & 15.57 & $1.5 \cdot 60$ & $15 \cdot 49$ \\
\hline $\mathrm{S}$ & $7 \cdot 2$ & .82 & 77 & .75 & .91 \\
\hline $\mathrm{P}$ & 5.5 & 87 & $\ldots$ & $\cdot 85$ & $\ldots$ \\
\hline 0 & $2.2 \cdot-8$ & $2.2 \cdot 0.3$ & $\ldots$ & $21 \cdot 70$ & $\begin{array}{l}\cdots \\
\cdots\end{array}$ \\
\hline
\end{tabular}

The author has calculated the two following formulæ as possible for casein; the first agrees with the results of Hammarsten, and Chittenden and Painter, while the second represents the figures obtained by Stohmann, Lehmann, and Ritthausen :-

\begin{tabular}{|c|c|c|}
\hline & $\mathrm{C}_{172} \mathrm{H}_{234} \mathrm{I}_{44}^{\mathrm{S}} \mathrm{SPO}_{55}$. & $\mathrm{C}_{1 ; 0} \mathrm{H}_{269} \stackrel{\text { II. }}{42}_{42} \mathrm{SPO}_{5 \mathrm{l}}$. \\
\hline $\mathrm{C}$ & $\begin{array}{c}\text { Per cent. } \\
52 \cdot 96\end{array}$ & $\begin{array}{c}\text { Per cent. } \\
54.04\end{array}$ \\
\hline $\mathrm{H}$ & 7.03 & $7 \cdot 10$ \\
\hline$N$ & $15 \cdot 81$ & $15 \cdot 56$ \\
\hline$S$ & 52 & $\cdot 84$ \\
\hline$P$ & $\cdot 80$ & 82 \\
\hline 0 & $22 \cdot 32$ & $21 \cdot 60$ \\
\hline
\end{tabular}

Hammarsten and Chittenden puritied their casein by solution in alkali and reprecipitation several times; Ritthausen worked on the copper salt; and Lehmann used what he designated "renuine" casein, which was separated from milk by the use of a porous plate.

Lehmann found that in "genuine" casein 1.45 to $1 \cdot 75$ parts of lime were combined with 100 parts of casein; one molecule $\mathrm{CaO}$ to one molecule $\mathrm{C}_{170} \mathrm{H}_{26,5}, \mathrm{~N}_{42}, \mathrm{PO}_{51}$ requires a proportion $1 \cdot 49$. Sïldner has also shown that two lime compounds exist containing $1.5 \%$ and 2.39 per cent. $\mathrm{CaO}$, respectively, which correspond with $\mathrm{CaO}$ and $2 \mathrm{CaO}$ to one molecule of cascin.

It is noticed that the sulphur is lower than that calculated from either of the above formulae. By treating easein with alkalies a pretion of the sulphur is remover as sulphide. It is possible that in the purification of the cascin by solution in dilute alkali and precipitation hy acids that a small amount of decomposition sets in.

When dissolved in dilute alkali it has a lavo-rotary action on polarised light, the rotatory power $[\alpha]_{1}$, being, according to HoppeSeyler, about $69^{\circ}$ to the left; Bechamp gives it as $106^{\circ}$. It is completely precipitated from milk by copper sulphate; if the 
solution be neutral, a definite compound containing about 1 per cent. of copper is obtained; basic compounds are probably obtained if the solution be alkaline. Mercury salts precipitate casein completely, even in acid solution; it is also precipitated by meta-phosphoric acid. Béchamp maintains that casein is a weak dibasic acid, forming acid and neutral alkaline salts, an observation which Söldner confirms. Casein has probably a higher molecular weight than the other albuminoids existing in milk.

Preparation of Casein.-Casein is prepared from milk l,y diluting to about five times its volume, and adding sufficient acetic acid to give 0.1 per cent. of the acid in the solution; the casein is precipitated, carrying down with it the fat; the precipitate is well washed by decantation some ten times, collected on a cloth filter, washed on the filter, and then dried, as far as possible, by pressure. This precipitate is dissolved in the least. possible excess of ammonia, the solution allowed to stand for some time (to allow the fat to rise), then syphoned off and filtered, and the filtrate precipitated, as before, by acetic acid; the precipitate washed and redissolved in ammonia; and this treatment repeated three or four times. The casein is now rubbed up in a mortar with 80 per cent. alcohol, and the alcohol poured off; the treatment with alcohol is repeated several times, using, finally, absolute alcohol; it is then treated two or three times with ether in the same manner, and then extracted for some hours in a Soxhlet extractor to remove the fat, and the ether evaporated off at as low a temperature as possible. This casein may, if a very pure product is required, be redissolved, reprecipitated, and the treatment with alcohol and ether repeated; the casein is finally dried at $100^{\circ}$ to $105^{\circ} \mathrm{C}$., and is then a white amorphous powder; if casein containing water is dried it forms horny masses.

Lactalbumin.-This albuminoid has the property characteristic of albumins of being coagulated by raising the temperature of its solution to $70^{\circ} \mathrm{C}$.; the precipitation is never complete, since as much as 12 per cent. may be left in solution, according to Sebelein.

Lactalbumin, like other albumins, is not precipitated by saturating its solution with magnesium sulphate; on the addition of acetic acid to the solution a precipitate of albumin is obtained, and this is redissolved on neutralisation of the acid. It is, like other albumins, precipitated by sodium sulphate added to saturation, and also by ammonium sulphate. It is also precipitatel by tannin, phospho-tungstic acid, and other general reagents. The salts of albumin with copper, mercury, and lead are insoluble. Alcohol precipitates it and the precipitated albumin is soluble in water. It has a specific rotatory power $[\alpha]_{D}$ of $-67.5^{\circ}$ (Béchamp). 
Lactalbumin has the following composition, according to Sebelein :-

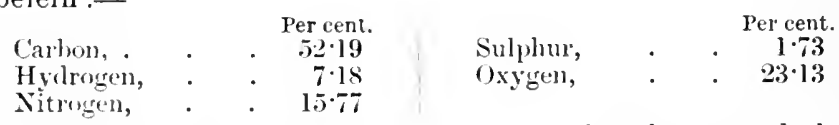

It difiers from casein by containing no phosphorus and about twice as much sulphur. When boiled with an alkaline solution of lead acetate it gives a very strong sulphur reaction. There appears to be no difference in composition between soluble and coagulated albumin.

Preparation of Lactalbumin. - Milk is saturated with magnesium sulphate and filtered. To the clear filtrate is added as much acetic acid as will give $\frac{1}{4}$ per cent. of acetic acid; lactalbumin is precipitated, and is filtered off. The precipitate, with the filter, is stirred up with water, and the acid neutralised; the lactalbumin dissolves. The solution is filtered, and reprecipitated by saturating with magnesium sulphate and adding per cent. of acetic acid; this is repeated three or four times; the solution of lactalbumin is then dialysed to remove salts. The solution is precipitated by alcolool, the precipitate washed with alcohol and ether and, finally, dried at a low temperature. Lactallumin, prepared in this way, is a white powder without taste, and completely soluble in water

Lacto-Globulin.- This albuminoid is coagulated by heat and precipitated by neutral sulphates, tannin, $\mathcal{d}$ c.; reunet does not coagulate it. It only occurs in traces in milk. It is not known whether it differs chemically from serum-globulin. Its chief eharacteristic is its solnbility in sodium chloride solutions even when acidified.

Storch's Mucoid Proteid. - The following properties are given by Storch:- Washed with alcolıol and afterwards with ether, and dried in air at the ordinary temperature, it forms a loose, fine, hygroscopic powder of a greyish-white colour. It is insoluble in dilute ammonia and acetic or hydrochloric acids; it swells considerably without dissolving in weak solutions of alkalies, and is only partly soluble in dilute potassium or sodium hydroxide. It gives the reactions of albuminoids-i.e, red coloration with MIillon's reagent, brown colour with iodine and yellow with nitric acid and ammonia (xantho-protein reaction) When heated with dilute hydrochloric acid it yields a substance which reduces Fehling's solution; the amount of copper reduced is 6.5 parts for each 100 parts of dry ash-free substance. It gives also the biuret reaction.

It contains 14.76 per cent. of nitrogen and $2 \cdot 2$ per cent. of sulphur, of which only a small portion is removed by hoiling with alkalies.

Preparation of Mucoid Proteid.-(i.) The author has found the ensiest method is to centrifugalise sweet butter milk and 
wash the deposit several times witl water made faintly alkaline with ammonia, the deposit being separated each time by centrifugal action. The mass is treated with strong alcohol, and afterwards with ether, and dried $i_{\text {" v vacuo. }}$

(ii.) Storch has prepared it from butter, by melting 1 to $2 \mathrm{lbs}$. at a low temperature; the fat is carefully decanted; and the liquid rinsed twice with benzene, diluted with distilled water and mixed with one and a half times its volume of strong alcohol. The precipitate is washed with 60 per cent. alcohol and extracted with ether till all fat is removed, and air dried.

(iii.) Fresh cream (about 30 per cent. fat) is diluted with four times its volume of a 33 per cent. solution of cane sugar and placed in a large separating funnel; after a day's repose, the sugar solution is drawn off, and the remaining cream again mixed with four times its volume of the sugar solution; this process is repeated four times and the washed cream is sliaken with an equal volume of strong alcolıol, and $t$ wice as much ether and some benzene are added. A gelatinous precipitate separates from the clear ethereal solution, which is separated by filtration, washed with strong alcohol and afterwards with ether, and dried in the air at the ordinary temperature. Storch found that if the cream was mixed with water at $35^{\circ} \mathrm{C}$. and separated in a cream separator, and this process repeated several times, the proteid could be prepared from the washed cream. This method was, however, more difficult than that involving the use of cane sugar solution.

The density of the mucoid substance containing 6.42 per cent. of mucoid proteid and 1.03 per cent. ash was found to be 1.0228 at $15^{\circ} \mathrm{C}$.

This substance appears to be identical with a product described some years ago as $\beta$-casein by Struve; he separated it from his $\alpha$-casein by dissolving in ammonia, when the $\beta$-casein was left; it only was found in traces in milk.

Products of Hydrolysis.-The following composition is given by Chittenden and Painter to the products of hydrolysis of casein :-

Pepto-caseoses (produced by the action of pepsin).

\begin{tabular}{|c|c|c|c|c|c|c|c|}
\hline & \multirow{2}{*}{ Casein. } & \multirow{2}{*}{$\begin{array}{c}\text { Dys- } \\
\text { Caseose. }\end{array}$} & \multicolumn{2}{|c|}{ Proto-Caseose. } & \multicolumn{3}{|c|}{ Deutero-Caseoses. } \\
\hline & & & $\begin{array}{l}\text { Weak } \\
\text { Pepsin. }\end{array}$ & $\begin{array}{l}\text { Strong } \\
\text { Yepsin. }\end{array}$ & Mixed. & $\propto$ & $\beta$ \\
\hline $\mathrm{C}$ & $\begin{array}{c}\text { Per cent. } \\
53 \cdot 30\end{array}$ & $\begin{array}{l}\text { Per cent. } \\
51 \cdot 16\end{array}$ & $\begin{array}{l}\text { Per cent. } \\
52 \cdot 89\end{array}$ & $\begin{array}{c}\text { Per cent. } \\
5 t: 40\end{array}$ & $\begin{array}{c}\text { Per cent. } \\
51.79\end{array}$ & $\begin{array}{c}\text { Per cent. } \\
5200\end{array}$ & $\begin{array}{c}\text { Per cent. } \\
4 \cdot \cdot 61\end{array}$ \\
\hline $\mathrm{H}$ & $7 \cdot 07$ & $7 \cdot 07$ & $7 \cdot 10$ & $7 \cdot 04$ & $7 \cdot 05$ & 694 & $6 \cdot 76$ \\
\hline $\mathrm{N}$ & $15 \cdot 91$ & $15 \cdot 31$ & $15 \cdot 94$ & $15 \cdot 84$ & $16 \cdot 00$ & $15 \cdot 95$ & $15 \cdot 95$ \\
\hline $\mathrm{S}$ & $\cdot 82$ & 72 & .95 & .95 & $1 \cdot 17$ & $\ldots$ & $\ldots$ \\
\hline $\mathrm{P}$ & $\cdot 87$ & none & $\ldots$ & $\ldots$ & $\ldots$ & $\ldots$ & $\ldots$ \\
\hline $\mathrm{O}$ & $22 \cdot 03$ & $25 \cdot 74$ & $\ldots$ & $\ldots$ & $\ldots$ & $\ldots$ & $\ldots$ \\
\hline
\end{tabular}


Trypto-Caseoses (produced by the action of trypsin).

\begin{tabular}{|c|c|c|c|c|}
\hline & C'asein. & $\begin{array}{c}\alpha \text {-Dentero- } \\
\text { casense. }\end{array}$ & $\begin{array}{l}\text { s-Deutero- } \\
\text { caseose. }\end{array}$ & Caseone. \\
\hline $\begin{array}{l}\mathrm{C} \\
\mathrm{H} \\
\mathrm{N} \\
\mathrm{S}\end{array}$ & $\begin{array}{c}\text { Per cent. } \\
.33: 30 \\
7007 \\
15 \cdot 91 \\
52\end{array}$ & $\begin{array}{c}\text { Per cent. } \\
.3617 \\
6 \cdot 90 \\
14 \cdot 80 \\
\ldots\end{array}$ & $\begin{array}{c}\text { Per cent. } \\
.3 \cdot 56 \\
6 \cdot 70 \\
15 \cdot 07 \\
\cdot 93\end{array}$ & $\begin{array}{c}\text { Per cent. } \\
50 \cdot 28 \\
6.53 \\
15.95 \\
.78 *\end{array}$ \\
\hline
\end{tabular}

Hydrolo-CAseoses (produced by the action of acids).

\begin{tabular}{|c|c|c|c|c|c|}
\hline & Casein. & Dys-casense. & Proto-caserse. & $\begin{array}{c}\alpha \text {-Dentero- } \\
\text { caseose. }\end{array}$ & $\begin{array}{l}\text { B-Deutero- } \\
\text { caseose. }\end{array}$ \\
\hline $\begin{array}{l}\mathrm{C} \\
\mathrm{H} \\
\mathrm{N}\end{array}$ & $\begin{array}{c}\text { Per cent. } \\
53 \cdot 30 \\
7 \cdot(17 \\
15 \cdot 91\end{array}$ & $\begin{array}{c}\text { Per cent. } \\
54 \cdot 40 \\
6 \cdot 80 \\
14 \cdot 80\end{array}$ & $\begin{array}{c}\text { Per cent. } \\
56 \cdot 20 \\
7 \cdot 08 \\
1.5 \cdot 36\end{array}$ & $\begin{array}{c}\text { Per cent. } \\
54 \cdot 5.5 \\
6 \cdot 84 \\
15 \cdot 3.3\end{array}$ & $\begin{array}{c}\text { Per cent. } \\
52 \cdot 93 \\
6 \cdot 87 \\
15 \cdot 66\end{array}$ \\
\hline
\end{tabular}

Chymo-Caseoses (produced by the action of rennet). Hammarsten gives the following composition:-

\begin{tabular}{|c|c|c|c|}
\hline & Casein. & Dys-caseose. & $\begin{array}{l}\text { Caseoses. } \\
\text { (Jixed). }\end{array}$ \\
\hline $\begin{array}{l}\mathrm{H} \\
\mathrm{H}\end{array}$ & $\begin{array}{c}\text { Per cent. } \\
52 \cdot 96 \\
7 \cdot 0.5 \\
15 \cdot 6.5\end{array}$ & $\begin{array}{c}\text { Per cent. } \\
52 \cdot 85 \\
7 \cdot(0) \\
1.5 \cdot 84\end{array}$ & $\begin{array}{c}\text { Per cent. } \\
50 \cdot 33 \\
7 \cdot 00 \\
13 \cdot 25\end{array}$ \\
\hline
\end{tabular}

\section{Reactions of the Caseoses.}

Dys-caseoses. - These products in the pure state are soluble in water; they combine with calcium salts, especially phosphates, to form insoluble compounds.

The following reactions are given by dys-pepto-caseose; the other dys-caseoses behave similarly.

Acetic acid in moderate excess gives an insoluble white precipitate, soluble in large excess on heating.

Hydrochloric and sulphuric acirl give precipitates, also soluble in large excess on heating. Even $\cdot 2$ per cent. hydrochloric acid produces complete precipitation.

Nitric acid rrives a precipitate far more easily soluble in excess of acid. On warming, the solution turus yellow, and, with aminonia, gives the orange-yellow colour of the xantho-protein reaction.

- The figure 68 ocrurs in the ariginal ; from the weighings given it is evident that 'on is the correct tignre. 
With a little copper sulpluate and an excess of caustic potash the violet colour of the biuret reaction is given.

Cupric sulphate and ferric chloride precipitate dys-caseose.

Anmonium sulphate added to saturation precipitates dyscaseose, but sodium chloride does not. Addition of acetic acid, however, to the salt-saturated fluid gives the usual precipitate of dys-caseose.

The insoluble compound with lime salts is dissolved with more or less readiness by an alkaline trypsin solution, giving finally a caseone, presumably trypto-caseone.

Proto-caseoses.-Proto-caseoses are soluble in water, and precipitated incompletely by the addition of acetic, hydrochloric, sulphuric, and nitric acids. They are soluble in 4 per cent. hydrochloric acid, but are precipitated by stronger solutions. The portion not precipitated by acetic acid gives a precipitate on saturation with salt solution and with potassium ferrocyanide.

Copper sulphate gives a heavy precipitate, as does ferric chloride, but the latter is soluble in excess of the reagent. They give the xantho-protein reaction with nitric acid.

Proto-caseoses are precipitated by saturation with sodium chloride.

$\alpha$-Deutero-caseoses are soluble in water, not precipitated by acids nor by saturation of a neutral solution with sodium chloride; on adding acetic acid to the salt-saturated solution, $\alpha$-deutero-caseose is incompletely precipitated ; it is precipitated by saturation with ammonium sulphate in the cold.

$\beta$-deutero-caseose is precipitated by saturation of the solution with ammonium sulphate and boiling.

Cupric sulphate gives a precipitate with $\alpha$-deutero-caseose soluble in excess, but none with $\beta$-deutero-caseose.

Potassium ferrocyanide in acetic acid solution gives a precipitate with both deutero-caseoses.

Caseone.-Only the trypto-caseone has been prepared; it is not precipitated by acids; nor by saturation of its solution by sodium chloride; nor by ammonium sulphate, even on boiling; nor by zinc sulphate. Caseone and peptones generally are very hygroscopic. Caseone is dialysable and only precipitated by such reagents as tannin and phospho-tungstic acid.

All the caseoses and caseones give the biuret reaction with copper sulphate and caustic potash.

It must be remembered that the separation of the caseoses is by no means sharp; thus proto-caseose is not completely precipitated by sodium chloride and the residue is obtained with the $\alpha$-deutero-caseose.

Besides the above products another caseose, resembling protocaseose, but soluble only in dilute acid and salt solutions, is also formed ; this is called hetero-caseose and is precipitated by dialysis.

The albumoses are bodies analogous to the caseoses; they are 
not, however, precipitated by acids, and are less readily precipitated by copper sulphate.

Tyrosine and Leucine.-By the further action of hydrolysts on the proteidis of milk amido-compounds are forned; the best known of these are tyrosine and leucine.

Tyrosine, $\mathrm{C}_{3} \mathrm{H}_{11} \mathrm{NU}_{3}$, is an oxyphenyl derivative of amidopropionic acid. It crystallises in fine glistening needles usually grouped in bundles, soluble in about 150 parts of boiling water. It gives a red precipitate with a solution of mercuric nitrate containing nitrous acid, and is capable of forming metallic salts.

Leucine, $\mathrm{C}_{6} \mathrm{H}_{23} \mathrm{NO}_{2}$, is an amido-caproic acid; it is moderately soluble in water, and crystallises in soft nacreous scales consisting of concentrically groujed rhombic prisms.

By tryptic digestion more tyrosine is produced than leucine: other hydrolytic actions produce greater quantities of leucine.

General Action of Hydrolysts. - The figures given above show that the percentage composition of the proteicls is not very greatly different from that of the products of hydroiysis.

It is practically certain that hydrolysis is a process of splitting up the proteids into substances of lower molecular weight; the nature of the constitution of proteirls is unknown, but as they are very complex, it is easy to imagine that the splitting up may give rise to different products according to the hycholyst used. It will be noticed generally that as the hydrolysis proceeds, the percentage of carbon becomes less; hydrogen and nitrogen become in some series less and in others more, but always a fairly regular change is noticed.

Mineral Constituents. - On burning milk a white ash is left; this contains the mineral constituents of milk, altered, however, to some extent by the oxilation of some of the compounds present in milk: thus the phosphorus and sulphur of the proteids give rise to phosphoric and sulphuric acids; and carbonic acid is also formed by the oxidation of organic carbon. 'The ash does not truly represent the mineral constituents of milk.

The average composition of the ash of milk is-

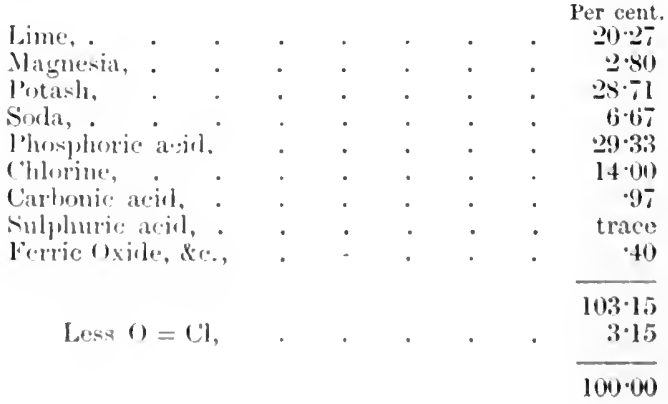


About 8 per cent. of the phosphoric acid present in the ash is derived from the phosphorus of the casein; the traces of sulphuric acid as also the carbonic acid present are not true mineral constituents of the milk.

Deducting these, we have a considerable excess of bases over acids; in the milk these bases are combined partly with the proteids to form soluble salts, and partly with citric acid to form citrates.

Söldner deduces the following composition as nost probable for the salts existing in milk:-

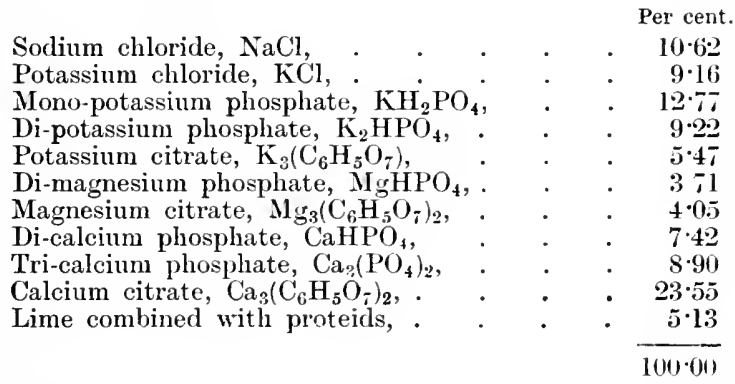

The mineral salts, as stated above, would amount to 90 per cent., as against 75 per cent. of ash obtained.

According to Söldner 36 to 56 per cent. of the phosphoric acid and 53 to 7.2 per cent. of the lime are not in solution, but are in the colloidal form.

The amount of insoluble ash-i.e., ash insoluble in hot wateramounts to about 52 per cent. of the milk; and the soluble ash to $\cdot 23$ per cent. The soluble ash consists mainly of the chlorides of the alkalies, with a little carbonateand a mere trace of phosphates.

The insoluble ash is mainly composed of donble phosphates of the formula $\mathrm{CaK} \mathrm{PO}_{4}$, the lime being partially replaced by magnesia and the potash by soda; double carbonates of the formula $\mathrm{CaNa}_{2}\left(\mathrm{CO}_{3}\right)_{2,}$ also exist in traces; these compounds are insoluble in water, and this accounts for the fact that the insoluble ash is always higher than the sum of the calcium and magnesium phosphates.

An ash of this composition is only formed when the milk is homogeneous; if it is curdled, by natural souring or by the addition of acids, the precipitated lumps do not contain sufficient alkali metals to form these componnds, and much calcium and magnesium phosphates are formeri ; on dissolving in water, soluble alkaline phosphates go into solution, and calcium and magnesium phosphates, together with varying proportions of double phosphates, are left insoluble. Curdled milk gives the same total proportion of ash as fresh milk, but the soluble ash is higher and the insoluble ash lower. 
Other Constituents of Milk.-- Besides the constituents mentioned, minute traces of silica, iodine, fluorine, acetates, and thio-cyanates have been described.

None of the salts of milk require a detailed description. They, together with the acids and bases composing them, are described in any elementary book on chemistry.

Among the other substances present in traces in milk the following have been described:- Urea, hypoxanthine and other nitrosenous basic substances, a colouring-matter; odorous substances and alcohol (described by Béchamp, but certainly not ordinarily present).

Béchamp has described a starch-liquefying enzyme as present in milk; and Babcock and Russell have adduced evidence showing the presence of a proteolytic enzyme.

The Gases of Milk. - It is extremely probable that the gases of milk are derived from the air by absorption during and after milking. Oxygen, nitrogen (probably argon), and carbon tlioxide are present in fresh milk. As the milk is kept the amount of oxysen decreases and that of the carbon dioxide increases; this is probably due to ärobic micro-organisms, which absorb the oxygen and give out carbon dioxide.

The gases of milk may also include products of decomposition; thus in decomposed milk, volatile sulphur compounds of evil odour are present. If such, as is probably the case in dirty surroundings, were present during milking they would be absorhed to some extent hy the milk.

The gases have no practical importance.

Milk is sometimes charged with earbon dioxide under high pressure to form an effervescing drink. In this case, and in koumiss and kephir, products of fermentation of milk, the carbon dioxide is an important constituent.

\section{THe Fat of MiLK.}

Constitution.- The fat in milk is found in the shape of small globules varying in size, according to Besana, Fleischuann and other anthorities, from $01 \mathrm{~mm}$. to $.0016 \mathrm{~mm}$. in diameter. There is some probability that the total weight of globules of any size is equal to the total weight of globules of any other size.

The fat consists of a mixture of grlycerides-i.e., ethereal salts of glycerol. It appears most probable that there are three acid radicles in combination with each glycerol residue, thus-

$$
C_{3} \mathrm{H}_{5}\left\{\begin{array}{l}
\mathrm{C}_{4} \mathrm{H}_{5} \mathrm{O}_{2} \\
\mathrm{C}_{18} \mathrm{H}_{33} \mathrm{O}_{2} \\
\mathrm{C}_{18} \mathrm{H}_{35} \mathrm{O}_{2}
\end{array}\right.
$$

which represents glyceryl butyro-oleo-stearate. This view has bern formed from the following facts:-(1) Were the fat a 
mixture of glyceryl tributyrate with other glycerides, it would be possible to dissolve out the glyceryl tributyrate by means of alcohol, leaving nearly the whole of the other glycerides behind. This is not the case. The portion soluble in alcohol contains a notable quantity of the higher glycericles.

(2) If glyceryl tributyrate existed as such in milk fat it should be possible to distil it off under reduced pressure, but this cannot be done.

We know nothing of the way in which the fatty acids are combined with glycerol ; it is convenient, however, to state the composition as if each glyceride existed separately.

Composition.-The average composition of the fat of milk appears to be, from the mean results obtained by different observers, as follows:-

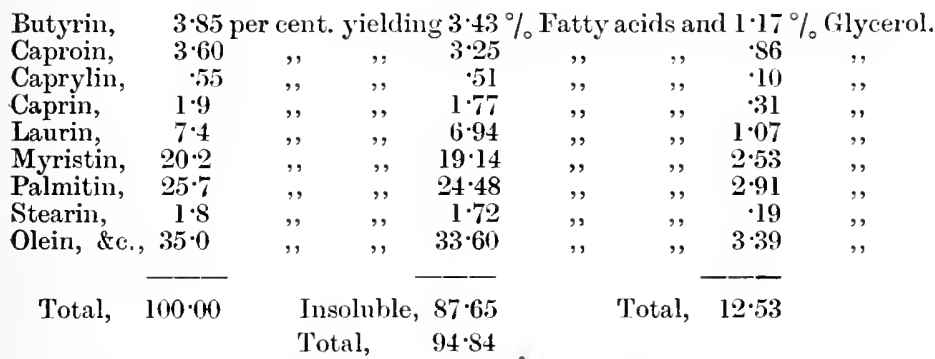

In this table, butyric, caproic, and caprylic acids have been classed as soluble in water, and the others insoluble; this is not, strictly speaking, correct, as capric and, probably, lauric acids are also slightly soluble; on the other hand, caprylic acid possesses so slight a solubility in water that it probably is not wholly dissolved.

The figure 87.65 per cent. is, however, a near approximation to the mean found for the insoluble fatty acids. The figure for the total amount of glycerol 12.53 also agrees with that found.

Besides the constituents enumerated above, there also exist in the fat of milk traces of cholesterol (which doubtless replaces a portion of the glycerol), lecithin, a colouring-matter, and possibly, also a hydrocarbon.

Saponification.-On boiling with a solution of caustic alkali, the fat undergoes hydrolysis, thus-

$$
\mathrm{C}_{3} \mathrm{H}_{5}\left\{\begin{array}{l}
\mathrm{R} \\
\mathrm{R},+3 \mathrm{NaOH}=\mathrm{C}_{3} \mathrm{H}_{5}(\mathrm{OH})_{3}+\mathrm{NaR}+\mathrm{NaR},+\mathrm{NaR}, \\
\mathrm{R}_{\text {u }}
\end{array}\right.
$$

$R, R$, and $R$ " representing radicles of the fatty acids.

If the hydrolysis be carried out in presence of alcohol a 
portion of the caustic alkali is converted into an alkali ethoxide (alcoholate) thus-

$$
\mathrm{NaOH}+\mathrm{C}_{2} \mathrm{H}_{5} \mathrm{OH}=\mathrm{C}_{2} \mathrm{H}_{5} \mathrm{ONa}+\mathrm{H}_{2} \mathrm{O} \text {. }
$$

This acts in a slightly different manner to the hydroxide, though the ultimate products of hydrolysis are identical.

The actions are probably as follows:-

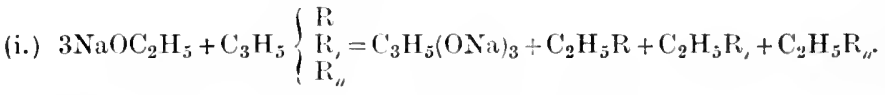

(ii.) $\mathrm{C}_{3} \mathrm{H}_{5}(\mathrm{ONa})_{3}+3 \mathrm{OH}_{2}=\mathrm{C}_{3} \mathrm{H}_{5}(\mathrm{OH})_{3}+3 \mathrm{NaOH}$.

(iii.) $3 \mathrm{NaOH}+\mathrm{C}_{2} \mathrm{H}_{5} \mathrm{R}+\mathrm{C}_{2} \mathrm{H}_{5} \mathrm{P}_{4}+\mathrm{C}_{2} \mathrm{H}_{5} \mathrm{P}_{v^{\prime \prime}}$

$$
=3 \mathrm{C}_{2} \mathrm{H}_{5} \mathrm{OH}+\mathrm{NaP}+\mathrm{NaP}_{,}+\mathrm{NaR}_{/ \prime} \text {. }
$$

In the first stage, sodium ethoxide and fat form sodium glyceroxide and ethyl salts (esters).

In the second, the glyceroxide is decomposed by the water present into glycerol and sodium hydroxide; while, in the third, the esters are liydrolysed by the hydroxide into alcohol and sodium salts of the fatty acils (soaps).

The action between the sodium hydroxide and the alcohol is never complete, and it is probable that the formation of esters is only partial ; evidence of the formation of ethyl butyrate can be obtained by warming a little of the fat with alcoholic soda, when the characteristic pine-apple odour of ethyl butyrate is at once developerl. By carefully avoiding any excess of alkali and distilling the ethyl butyrate as soon as possible, Wanklyn and Fox have succeeded in obtaining about 3 per cent. of rolatile acid (probably chiefly butyric) in the form of ester.

It is probable that the equation (ii.) may not represent the way in which sodium glyceroxide acts on the substances present; a portion may follow this equation-

$$
\text { (iv.) } \mathrm{C}_{3} \mathrm{H}_{5}(\mathrm{ONa})_{3}+3 \mathrm{C}_{2} \mathrm{H}_{5} \mathrm{OH}=\mathrm{C}_{3} \mathrm{H}_{5}(\mathrm{OH})_{3}+3 \mathrm{C}_{2} \mathrm{H}_{5} \mathrm{ONa} \text {. }
$$

The glyceroxide may act on alcohol forming ethoxile, instead of on water forming hydroxide.

Allen and Homfray have shown that by the action of a very small quintity of caustic sorla on acetin (glyceryl tri-acetate), a very large proportion of ethyl acetate is formed, many molecules of "thyl acetate being produced by each molecule of sodium ethoxide; this can only be explained by the action shown in equation (iv.).

Duffy has shown that ethyl and amyl stearate may be produced from slyceryl stearate and sodium ethoxide and amoxide respectively.

'The action of sodium ethoxile on milk fat has a practical bearing on butter analysis, owing to the volatility of ethyl butyrate, which, unless precautions are taken, is liable to cause loss of butyric acid on saponification. 
From their sodium salts the acids may be set at liberty by the addition of a mineral acid.

Properties.-Milk fat is insoluble in water, but dissolves about .2 per cent. of this substance. It is not volatile, though when heated to $100^{\circ} \mathrm{C}$. a loss of weight is noticed owing to the dissolved water being volatilised. On further heating at this temperature, in a current of hydrogen, no change is noticed; but if oxygen be allowed access a gradual increase of weight, due to oxidation, is found ; if the heating be prolonged, say for a week, the weight again decreases, and profound changes, the nature of which has not been elucidlated, take place.

Solid and Liquid Portions.--The fat of milk being an undoubted mixture has no sharply defined melting point. If rapidly cooled to a low temperature it becomes solid, and melts on warming at from $29.5^{\circ}$ to $33^{\circ} \mathrm{C}$. By slow cooling it does not solidify as a whole, but behaves as a solution of fat of a high melting point in fat of a low melting point.

The author obtained the following figures (Table II.) by allowing a sample to cool down gradually to about $25^{\circ} \mathrm{C}$, and separating the liquid portion from the deposited solid :

TABLE II.-Properties of Milk Fat (Richmond).

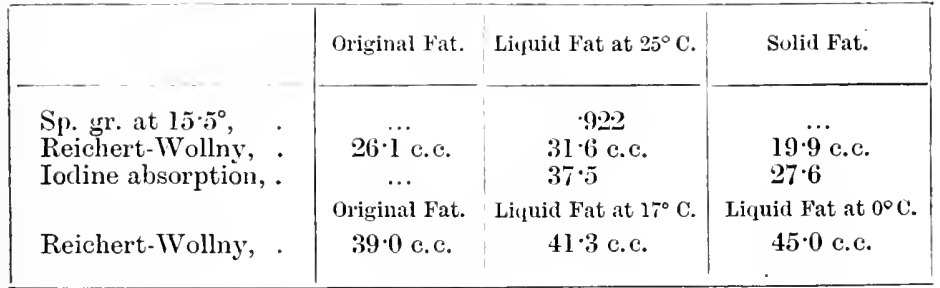

Pizzi has also recorded the following experiments (Table III.) :-

TABLE III.-Properties of Milk Fat (Pizzi).

\begin{tabular}{|c|c|c|c|c|c|c|c|c|}
\hline & Original & $\begin{array}{l}\text { Liquid } \\
\text { at } 262^{\circ}\end{array}$ & $\begin{array}{l}\text { Liquid } \\
\text { at } 21^{\circ} 2^{\circ}\end{array}$ & $\begin{array}{l}\text { Liquid } \\
\text { at } 17 \cdot 0^{\circ}\end{array}$ & $\begin{array}{l}\text { Liquid } \\
\text { at } 12 \cdot 4^{\circ}\end{array}$ & $\begin{array}{l}\text { Liquid } \\
\text { at } 11 \cdot 0^{\circ}\end{array}$ & $\begin{array}{l}\text { Liquid } \\
\text { at } 6.5^{\circ}\end{array}$ & $\begin{array}{c}\text { Solid at } \\
26^{\circ} 2^{\circ}\end{array}$ \\
\hline Sp. gr. at $26 \cdot 2^{\circ}$, & $\cdot 908$ & .912 & $\cdot 916$ & 923 & 927 & $\ldots$ & $\ldots$ & \\
\hline Melting point, & $36^{\circ}$ & $\ldots$ & $\ldots$ & $\ldots$ & $\ldots$ & $\ldots$ & $\ldots$ & $44^{\circ}$ \\
\hline Solidifying ,. & $25^{\circ}$ & $\ldots$ & $\ldots$ & $\ldots$ & $\ldots$ & $\ldots$ & $\ldots$ & $35^{\circ}$ \\
\hline & c.c. & c.c. & c.c. & c.c. & c.c. & c.c. & c.c. & c.c. \\
\hline $\left.\begin{array}{l}\text { Reichert- } \\
\text { Wollny, }\end{array}\right\}$ & $26 \cdot 96$ & $28 \cdot 05$ & $29 \cdot 81$ & $31 \cdot 57$ & $30 \cdot 36$ & $32 \cdot 34$ & $34 \cdot 10$ & $19 \cdot 91$ \\
\hline $\begin{array}{c}\text { Iodine absorp- } \\
\text { tion, } .\end{array}$ & $32 \cdot 96$ & $34 \cdot 50$ & $38 \cdot 80$ & $40 \cdot 75$ & $42 \cdot 75$ & $52 \cdot 25$ & $58 \cdot 50$ & $25 \cdot 38$ \\
\hline
\end{tabular}




\begin{tabular}{|c|c|c|c|c|c|}
\hline & $\begin{array}{l}\text { Solid Fat } \\
\text { deposited } \\
\text { from Liquid } \\
\text { at } 26^{\circ} 2^{\circ} \text { ty } \\
\text { cooling to } \\
211^{\circ} \text {. }\end{array}$ & $\begin{array}{l}\text { Solid fat } \\
\text { cleposited } \\
\text { from Liquial } \\
\text { at } 21 \cdot 2^{\circ} \text { by } \\
\text { cooling to } \\
17 \cdot 0^{\circ} \text {. }\end{array}$ & $\begin{array}{l}\text { Solid Fat } \\
\text { derosited } \\
\text { from Liquid } \\
\text { at } 170^{\circ} \text { ly } \\
\text { cooling to } \\
124^{\circ} \text {. }\end{array}$ & 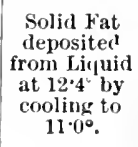 & $\begin{array}{c}\text { Solid Fat } \\
\text { deposited } \\
\text { from Liquid } \\
\text { at } 11 \cdot 0^{\circ} \text { by } \\
\text { cooling to } \\
6.5^{\circ} \text {. }\end{array}$ \\
\hline $\begin{array}{l}\text { Melting point, } \\
\text { Solidifying, }\end{array}$ & $\begin{array}{l}43 \cdot 5^{6} \\
21^{\circ}\end{array}$ & $\begin{array}{l}31^{\circ} \\
16.5^{\circ}\end{array}$ & $\begin{array}{l}18^{\circ} \\
13^{\circ}\end{array}$ & $17^{\circ}$ & $\begin{array}{r}10 \cdot 5^{\circ} \\
8.5^{\circ}\end{array}$ \\
\hline $\left.\begin{array}{l}\text { Reichert. } \\
\text { Wollny, }\end{array}\right\}$ & $20 \cdot 13$ c.c. & 27.59 с.с. & $29 \cdot 70$ c.c. & 29.37 c.c. & $3 l \cdot 02 \mathrm{c.c}$. \\
\hline $\begin{array}{c}\text { Iodinealisorp- } \\
\text { tion, . }\end{array}$ & $28 \cdot 13$ & $35 \cdot 70$ & $41 \cdot 25$ & $45 \cdot 50$ & $50 \cdot 5$ \\
\hline
\end{tabular}

The above figures all show that the liquid fat is somewhat richer in both volatile and unsaturated acids than the original fat, while the solic portion is correspondingly poorer in these constituents. There is, however, no sharp separation.

The density of the fat of milk is as follows :-

\begin{tabular}{|c|c|c|c|}
\hline Temperature. & Mean. & Limits. & Authorities. \\
\hline $\begin{array}{l}15 \\
15\end{array}$ & 9307 (solid) & $\cdots$ & Fleisehmann. \\
\hline$\frac{37 \cdot 8^{\circ}}{37 \cdot 8^{\circ}}$ & 9118 (liquid) & $\cdot 9094-9140$ & $\left\{\begin{array}{l}\text { Bell, Allen, } \\
\text { Muter, \&c. }\end{array}\right.$ \\
\hline $\begin{array}{l}39 \cdot \%^{\circ} \\
39 \cdot 5^{\circ}\end{array}$ & $9113(,, \quad)$ & $.9104-9117$ & Author. \\
\hline$\frac{160^{\circ}}{15 \cdot 5^{\circ}}$ (in gliass) & $\cdot 8667(,, \quad)$ & $\cdot 8650-8685$ & Numerous. \\
\hline
\end{tabular}

The last figure is not a true clensity, as it is not corrected for the expansion of glass between $15.5^{\circ}$ and $100^{\circ}$; it has been assumed that the volume of the glass instrument used to determine the density is the same at $100^{\circ}$ is at $155^{\circ}$. The error has no practical importance when the figures thus obtained for diffrent samples are compared, as they are all subject to the same correction.

From the average specitic gravities given ahove the author has calculated the true specific gravities and specific volumes; these are- 


\begin{tabular}{|c|c|cc|}
\hline Temperature. & Specific Gravity. & Specific Volume. & Calculation. \\
\hline$\frac{15^{\circ}}{4^{\circ}}$ & $\cdot 9300$ & $1 \cdot 0753$ & $1 \cdot 0844$ \\
$\frac{37 \cdot 8^{\circ}}{4^{\circ}}$ & -9057 & $1 \cdot 1041$ & $1 \cdot 1041$ \\
$\frac{39 \cdot 5^{\circ}}{4^{\circ}}$ & -9045 & $1 \cdot 1056$ & $1 \cdot 1056$ \\
$\frac{100^{\circ}}{4^{\circ}}$ & $\cdot 8637$ & $1 \cdot 1578$ & $1 \cdot 1578$ \\
\hline
\end{tabular}

The figures calculated are based on the assumption that the expansion is regular between $15^{\circ}$ and $100^{\circ}$, and that it averages .000863 for each degree Centigrade; on this assumption the specific volume of liquid tat at $15^{\circ}$ is higher, and the specific gravity is lower than that of the solid.

The specific gravity of liquid fat at $\frac{15 \cdot 5^{\circ}}{15 \cdot 5^{\circ}}$ (calculated) is $\cdot 922$.

It is interesting to note that the specific gravity of the liquid fat obtained by the author (above) had a specitic gravity of .922 . The specific gravities of the liquid fats obtained by Pizzi appear to have been taken at the temperatures at which the fat was separated, and on calculating to $15^{\circ}$ have values from 921 to 925 .

On the whole the evidence available appears to show that the specific gravity of solid fat is greater than that of liquid fat at the same temperature.

In connection with this, it may be mentioned that E. W. T. Jones has shown that the specitic gravity of other fats is greater when partially solidified at $37.8^{\circ}$ than when liquid at this temperature.

The index of refraction of the fat of milk averages 1.4566 at $35^{\circ}$, and the limits observed have been $1 \cdot 4550$ to $1 \cdot 4586$.

Stohmann has determined the heat of combustion of butter fat as 9.231 small calories per gramme, while Atwater found from $9 \cdot 320$ to $9 \cdot 362$ calories in three samples of butter, which appear from the analytical results of Schweinitz and Emery to have been of doubtful purity.

The fat of milk is soluble in all hydrocarbons which are liquid at the ordinary temperature, in their halogen derivatives, in ether, carbon bisulphide, nitro-benzene, and acetone. It is slightly soluble in alcohol and to a considerable extent in amyl alcohol when cold, but in all proportions when hot. Glycerol, when hot, dissolves it to a very small extent. It appears to mix in all proportions with esters. Fatty acids have a limited solvent effect, those of higher molecular weight dissolving more than 
the lower homologues. Phenol also dissolves it to some extent. On cooling : strong solution of the fat in any solvent, the portion deposited has not the same composition as the original fat, but is of the same nature as the solid portion olbtained by slow cooling of the melted fat.

The molecular weight of the fat has been determined by Ciarelli and Carcano by Raoult's cryoscopic method in benzene solution to be from 696 to 716 . That calculated from the amount of alkali necessury for saponification is 720 to 740 .

\section{ProdeCts of HYDROLYsis.}

Glycerol.-This is the simplest tri-hydric alcohol and has the constitution-- $\quad \mathrm{CHOH}_{2}$. It was discoverer ly Scheele in

$1779 \mathrm{in}$ olive oil, and was first recognised in butter in 1784 .

The anhydrous product is a thick syrupy liquid, which can be obtained in crystals by cooling to a low temperature; the melting point of the solid glycerol is given as $17^{\circ} \mathrm{C}$. by Henniger and $20^{\circ} \mathrm{C}$. by Nitsche. It boils at $290^{\circ} \mathrm{C}$. under the ordinary pressure, but undergoes slight decomposition; it can be readily distilled without change under reduced pressure. It is not volatile with steam. An aqueous solution containing less than 75 per cent. glycerol ean be boiled without loss ; but from solutions containing more than 75 per cent. glycerol it is somewhat volatile (l/eliner). Anhyrlrous glycerol volatilises slowly at $100^{\circ} \mathrm{C}$. When heated above $150^{\circ} \mathrm{C}$. it is inflammable.

'The rensity at $15.5^{\circ}$ is 12675 ; the refractive index at the same temperature is $1 \cdot 4+78$.

When heated to its boiling point, especially if not pure, various products, of which acrolein $\left(\mathrm{C}_{3} \mathrm{H}_{4} \mathrm{O}\right)$ is the most important, are given off. Di- and tri-glyeeric aleohols are also formed.

By the action of acid oxidising agents-e.g., chromic acid and potassium permanganate in acid solution-it is wholly converted into carlon dioxide and water. Alkaline permanganate converts it quantitatively into oxalic acid. By the action of bromine in the cold glycerose is formed, which is an aldehyde; by further oxidation with bromine at a high temperature, or by boiling with

dilute nitricacid, slyceric acid (OHOH is produced. 
Tartronic acid $\stackrel{\mathrm{CHOH}}{\mathrm{COOH}}_{\mathrm{C}}^{\mathrm{COOH}}$

produced together with glycolic, glyoxylic, oxalic, and formic acids.

Glyceric acid appears to have a constitution similar to lactic acid (q.v.), from which it differs only by containing the group $\mathrm{CH}_{2}(\mathrm{OH})$ in place of $\mathrm{CH}_{3}$. It forms a lactone and a dehydroderivative, and contains an asymmetric carbon atom.

By the action of fuming nitric acid (mixed with sulphuric acid to preserve its strength) glyceryl tri-nitrate (nitro-glycerine), usually mixed with small quantities of di- and mono-nitrates, is formed. This is a heavy explosive liquid of specific gravity 1.6 and of limited solubility in water. It has been proposed to estimate glycerol as "nitro-glycerine." This compound is best known as a powerful explosive.

With strong sulphuric and phosphoric acids glyceryl monohydrogen sulphate and mono-glyceryl di-hydrogen phosphate are produced. These have the composition-

$\mathrm{SO}_{2}(\mathrm{OH}) \mathrm{OC}_{3} \mathrm{H}_{5}(\mathrm{OH})_{2}$ and

$\mathrm{PO}(\mathrm{OH})_{2} \mathrm{OC}_{3} \mathrm{H}_{5}(\mathrm{OH})_{2}$ respectively.

When glycerol is heated with alkalies above $250^{\circ} \mathrm{C}$. a variety of products are formed; among these are formic, acetic, acrylic, and lactic acids. The oxygen of the air seems to play an important part in these changes, as all the products coutain more oxygen and less hydrogen. No change takes place below $250^{\circ}$, especially in the absence of air.

Several glyceroxides are known-i.e., bodies in which the hydrogen of the hydroxyl groups is replaced by metals. By heating lead oxide with glycerol, lead glyceroxide is formed. Glycerol also dissolves lead oxide.

By treating glycerol with sodium dissolved in alcohol a crystalline deposit of the composition $\mathrm{C}_{3} \mathrm{H}_{7} \mathrm{NaO}_{3}, \mathrm{C}_{2} \mathrm{H}_{6} \mathrm{O}$ is formed, which, when heated at $100^{\circ}$ in a current of hydrogen, loses alcohol. It is a white amorphous powder, very hygroscopic and immediately decomposed by water. Calcium, strontium, and barium hydroxides are freely soluble in glycerol, and form glyceroxides, which may be dissolved in water; the aqueous solutions do not give precipitates with carbonic anhydride.

By the action of hydrochloric and hydrobromic acids. monoand dichlor-hydrin and mono- and dibrom-hydrin are produced. There are two possible mono-chlor- and mono-brom-hydrins: thus-

$\begin{array}{lll}\mathrm{CH}_{2} \mathrm{Cl} & & \mathrm{CH}_{2}(\mathrm{OH}) \\ \mathrm{CHOH}_{2} \text { and } & \mathrm{CHCl}_{2}(\mathrm{OH})\end{array}$


and similarly two di-hydrins: thus-

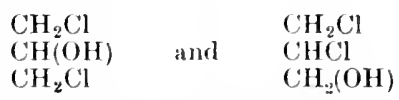

Botlı compounds are simultaneously produced.

By the action of alkalies on both the dichlor-hydrins, epichlor$\mathrm{C}^{\prime} \mathrm{H}_{2} \mathrm{C} \cdot \mathrm{l}$

hydrin $\left.{ }_{(}^{(} \mathrm{CH}_{2}-\mathrm{O}\right)$ is produced.

A mono-iod-hydrin also appears to be produced by the action ot liydriodic acici.

The penta-chloride and penta-bromide of phosphorus produce trichlor- and tribrom-liydrins, which are the $\alpha$-trichlor- and u-tribrom-derivatives of propane.

Phosphorus tri-iodide or concentrated hydriodic acid produce a mixture of allyl and iso-propyl iodides with propylene.

By the action of dehydrating agents acrolein, acrylic aldehyde, $\mathrm{C}_{3} \mathrm{H}_{4} \mathrm{O}$ is formed.

Glycerol is very soluble in water and alcohol, but insoluble in ether and chloroform.

Cholesterol, $\mathrm{C}_{2, ;} \mathrm{H}_{43} \mathrm{OH}$, is a mono-hydric alcohol, containing one unsaturated bond. This is shown by its combination with two atoms of bromine to form dibrom-cholesterol, $\mathrm{C}_{26} \mathrm{H}_{43} \mathrm{Br}_{2} \mathrm{OH}$. It has a melting point of $144^{\circ}$ to $146^{\circ} \mathrm{C}$, and may he sublimed unchanged. It is levo-rotatory, having an $[\alpha]_{\mathrm{i}}-36 \cdot 6$ (Dragendor:ff) or $-31 \cdot 6$ (Lindenmeyer).

It is easily soluble in hot alcohol, crystallising out on cooling in characteristic plates; oecasionally from alcohol and more often from ether it is obtained in needles.

Cholesteryl acetate, melting point $92^{\circ}$, is obtained by the aetion of acetic anhydride on cholesterol. The benzoate is obtained by lirating cholesterol with benzoic acid under pressure, and melts at $150^{\circ}$ to $151^{\circ} \mathrm{C}$.

The most characteristic reaction is the following, due to Salkowski:- Ahout 10 milligrammes of cholesterol are dissolved in : c.e. of chloroform, and the solution shaken with an equal measure of strong sulphuric acid in a corked test tube. The cliloroform layer becomes blood-red, passing to cherry-red and purple, the last colour being permanent for several days. 'T'he sulpliuric acid accpuires a well-markel green fluorescence. If the test tube be not corlied, or if the chloroform solution be poured into a basin, the colour chinges to blur, green, and, finally, yellow, probally due to moisture. On aldition of water the solution hecrmes paler, then blue, and, finally, nearly colourless, while showing a fine green fluorescence.

liv cautiously leating cholesterol with a drop of strong nitric acil and alding anmonia before the product has cooled completcly. a yellowish-red coloration is produced. 
If a mixture of 3 measures of concentrated hydrochloric acid and 1 of a solution of ferric chloride be evaporated with a little cholesterol, a reddish-violet coloration changing to blue is produced. By substituting sulphuric acid for hydrochloric acid, a carmine colour is produced, passing gradually to violet, which is changed to scarlet on treatment with ammonia.

\section{Fatty Acids.}

Acids of the Series, $\mathrm{C}_{n} \mathrm{H}_{2 n+1} \mathrm{COOH}$.-As far as is known, only the normal acids of this series, in which $n$ is an odd number, occur in the fat of milk.

Butyric Acid, $\mathrm{CH}_{3} \mathrm{CH}_{2} \mathrm{CH}_{2} \mathrm{COOH}$.-Grunzweig has proved that the butyric acid of the fat of nilk is normal. This acid is a liquid with a characteristic smell, which is specially developed in dilute solution; the anlydrous acid has a sharp acid smell, the characteristic smell being hardly perceptible.

The acid solidifies at $-19^{\circ} \mathrm{C}$. The solidified acid melts at $-2^{\circ}$ to $+2^{\circ} \mathrm{C}$. according to Linnemann, and at $-45^{\circ}$ to $-2^{\circ} \mathrm{C}$. according to Zander. The boiling point is variously stated according to different authorities. Thus-

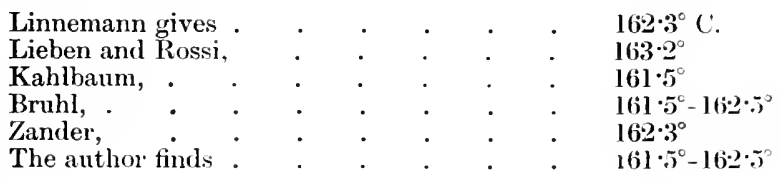

The density is given as 9587 at $\frac{20^{\circ}}{4^{\circ}}$ by Bruhl, 9746 at $0^{\circ}$ by Zander, and 9886 at $0^{\circ}$ by Linnemann.

It is very difficult to prefare the anhydrous acid by distillation alone, the last traces of water being retained with great obstinacy; dehydrating agents remove this water, and the acid is somewhat hygroscopic. It is soluble in all proportions in water, but is separated as an oily layer on saturating the solution with calcium chloride. It is extracted from aqueous solution by ether.

Fronl dilute solutions it distils twice as fast as water-i.e., the vapour arising from a dilute solution contains donble the proportion of butyric acid contained in the solution. Its solubility in the mixture of higher fatty acids of milk fat is very small.

By the action of strong chromic acid at the boiling point it is oxidised to a mixture of carbon dioxide and water, but dilute solutions are unaffected. Alkaline pernanganate oxidises it to carbon dioxirle; Jolnstone states that oxalic acid is formed from 
butyric acid by the action of alkaline permanganate, but other observers are unamimous in denying this.

The salts of butyric acid are all soluble in water. When ignited they leave a residue of the carbonate of the metal (except the silver and mercury salts, which leave metallic silver and no residue, respectively). The calcinm salt has the following solukility :-

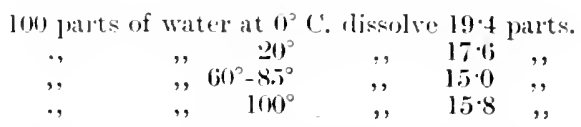

A cold saturated solution is precipitated by heat. It erystallises in rhombic needles from cold solutions, and in rhombic prisms from lot solutions.

The barium salt is much used for determining the molecular weight of the acid ; it cannot be dried at $100^{\circ} \mathrm{C}$. without slight loss of butyric acid, but is quite permanent at $90^{\circ} \mathrm{C}$. One thousind parts of absolute alcohol dissolve 11.7 parts at $30^{\circ}$ and $2 \cdot 45$ parts at $14^{4}$ according to Luck, who has used this method of separating it from barium formate, acetate, dr.

Silver butyrate crystallises by cooling a lot solution in needles, lut by spontaneous evaporation in monoclinic prisms. 100 parts of water at $16^{\circ}$ dissolve 413 part.

Both the acid and calcium salt form molecular eompounds with calcium chloride.

Butyric acid occurs in the free state in perspiration and as thyl salt in the oils of Heracleum gigantenm and II. spondylium, hexyl butyrate being also present in the latter; the oil from the seeds of the parsnip (I'astinace sretiva) consists chiefly of octyl butyrate. Ethyl l,utyrate is a volatile liquid of a smell recalling the orlour of pine apples.

Caproic Acid, $\mathrm{CH}_{3,} \mathrm{CH}_{2 .} \cdot \mathrm{CH}_{2} \cdot \mathrm{CH}_{2 .} \mathrm{CH}_{2} \mathrm{COOH}$ - Kofoed has proved that the calnoic acid of the fat of milk is normal. This acid is an oily liquid with an nupleasant goat-like smell. It brils at $205^{\circ} \mathrm{C}$, solidifies at $-15^{\circ} \mathrm{C}$, and melts at $-1 \cdot 5^{\circ}$. Its density at $0^{\circ}$ is 9446 accorling to Zander.

It hardly mixes with water, is extracted by ether from an aqueous solution, and possesses considerable solubility in the mixed higher fatty acils of milk fiat. From a dilute aqueous solution it distils four times as fast as water.

The calcium salt diflers from calcium butyrate by increasing in solubility on lieating; 100 parts of water dissolve at $11^{\circ}$ to $12^{\circ} 2.36$ parts, at $17.5^{\circ} 2.5 \mathrm{~s}^{\circ}$ parts, and at $18 \cdot 5^{\circ} \div .71$ parts of calcium caproate. It crystallises in needles. The barium salt alissolves in 100 parts of water to the extent of 12 parts at $11^{\circ}$ to $12^{\circ}$, and the solubility decreases on huating.

Caprylic Acid, $\mathrm{C}_{-} \mathrm{H}_{15} \mathrm{COOH}$.- This acid crystallises in plates 
or needles melting at $16.5^{\circ} \mathrm{C}$, and boils at about $236^{\circ} \mathrm{C}$. It has a faint unpleasant odour of sweat, and a sharp rancid taste ; it is difficultly soluble even in hot water, from which it crystal. lises in plates. From dilute solutions it distils eight times as fast as water.

Barium caprylate crystallises in anlydrous plates, and is soluble to the extent of 6 parts in 100 parts of water at $20^{\circ} \mathrm{C}$. The calcium salt crystallises in long thin needles, and is less soluble than the barium salt-.6 part per 100 .

Capric Acid, $\mathrm{C}_{9} \mathrm{H}_{19} \mathrm{COOH}$.- This acil has a faint goat-like odour and is only very slightly soluble in water. It crystallises in brilliant plates, melting at $30^{\circ} \mathrm{C}$; ; it boils at $268^{\circ}$ to $-70^{\circ}$. The barium and calcium salts are nearly insoluble in water, even on boiling, and the salts of the alkalies are the unly ones appreciably soluble.

Lauric Acid, $\mathrm{C}_{11} \mathrm{H}_{23} \mathrm{COOH}$. - The acid is solid at ordinary temperatures and is not soluble to any extent in water ; it passes over to a very appreciable extent when distilled with stean. It crystallises from alcohol in needles, melting at $43 \cdot 6^{\circ} \mathrm{C}$. It cannot be distilled without decomposition at the atmospheric pressure, but at $100 \mathrm{~mm}$. it has a boiling point of $225^{\circ} \mathrm{C}$. The salts of the alkali metals yielded by the acids previously described are soluble in strong salt solution; the laurates of sodium and potassium are, however, precipitated by strong sodium chloride solutions, but not by weaker ones. Lauric acid is a leading constituent of cocoa-nut and palm-nut oils.

Myristic Acid, $\mathrm{C}_{12} \mathrm{H}_{27} \mathrm{COOH}$.-This acid crystallises in lamine melting at $53.8^{\circ} \mathrm{C}$. and boils at $250.5^{\circ}$ under $100 \mathrm{~mm}$. pressure; it cannot be distilled alone. The acid is insoluble in water and its salts of the alkali metals are precipitated by salt.

Palmitic Acid, $\mathrm{C}_{15} \mathrm{H}_{20} \mathrm{COOH}$. - The acid is quite insoluble in water; it crystallises from alcohol in tufts of finely crystallised needles; and the melted acid solidifies on cooling to a pearly crystalline mass. The melting point is $62^{\circ} \mathrm{C}$. and it boils under $100 \mathrm{~mm}$. pressure at $271 \cdot 5^{\circ} \mathrm{C}$; it cannot be distilled under atmospleric pressure without decomposition.

According to Hehner and Mitchell a saturated solution of palmitic acid in alcohol of specific gravity 8183 contains from 1.32 to 1.03 grammes per 100 c.c. at $0^{\circ} \mathrm{C}$. 100 parts of absolute alcohol at $19.5^{\circ}$ dissolve 9.32 parts; it is, however, readily soluble in boiling alcohol and crystallises out on cooling.

Stearic Acid, $\mathrm{C}_{17} \mathrm{H}_{33} \mathrm{COOH}$. - This acid is quite insoluble in water; it crystallises from alcohol in white, nacreous, lamine melting at $69 \cdot 2^{\circ}$ (Heintz) or $68.5^{\circ}$ (Hehner and Mitchell) to a colourless liquid, which on cooling solidifies to a crystalline whitish mass. Under $100 \mathrm{~mm}$. pressure it boils at $291^{\circ} \mathrm{C}$. It cannot 
be distilled under the atmospheric pressure without decomposition.

Hehner and Nitchell have shown that at $0^{\circ} \mathrm{C}$. a saturated solution in alcohol of 8183 specific gravity contains from 142 to 158 gramme per 100 c.c. Absolute alcohol dissolves about 25 grammes per 100 c.c.

The salts of stearic acid are, with the exception of those of the alkali metals (soaps', insoluble in water and almost insoluble in alcohol. The salts of ralmitic acid resemble them very much. The most narked difference between these two acids is the difference of solnbility of the masnesium salt; that of stearic acid is practically insoluble in cold alcohol, while that of palmitic acid possesses a slight, but appreciable, solubility; the presence of magnesium plalmitate causes, lowever, appreciable solubility of magnesium stearate.

All salts of stearic acid (and palmitic acid) are partly decomposerl by water into basic and acid salts; the salts of the alkali metals (soals) cannot be dissolved without becoming appreciably alkaline. They are, however, soluble in hot alcohol without decomposition, forming solutions which gelatinise on cooling.

Soaps of stearic and palmitic acids are quite insoluble in 12 per cent. solution of sodium chloride.

General Properties of Acids of the Series, $\mathrm{C}_{n} \mathrm{H}_{2 n+1} \mathrm{COOH}$. -The following table (IV.) gives a summary of the leading properties of these acids :-

\section{TABLE IV.--Properties of tile Acids of Series}

$$
\mathrm{C}_{n} \mathrm{H}_{2 n+1} \mathrm{CUOH} \text {. }
$$

\begin{tabular}{|c|c|c|c|c|c|c|}
\hline Acill. & $\begin{array}{l}\text { Wol. } \\
\text { Wt. }\end{array}$ & $\therefore$ s. (ir. & l) & 1. P. & $\begin{array}{l}\text { Solulility of } \\
\text { Calcium Salt. }\end{array}$ & $\begin{array}{c}\text { Rate of } \\
\text { Distilla- } \\
\text { tion } \\
\text { Water }=1 .\end{array}$ \\
\hline Butyrir, & 86 & (17tian $0^{2}$ & $162^{3}$ & -2 & $17 \cdot\left(6\right.$ at $20^{\circ}$ & 2 \\
\hline Caproie. & $116 i$ & 9446 at 0 & $2015^{\circ}$ & $-1.5^{\circ}$ & 2.7 at $18.5^{\circ}$ & 4 \\
\hline Caprulic, & 144 & $(1271)$ at $11^{\circ}$ & $336^{\circ}$ & $16 \% i^{\circ}$ & f at $20^{\circ}$ & 8 \\
\hline (atprice, & 172 & 8993 at $330^{\circ}$ & $269^{\circ}$ & $30^{\circ}$ & $\cdot 1$ at $20^{\circ}$ & $?$ \\
\hline Lamris, & $2(1) 0$ & - 875 at 4306 & at $1(1,1) \operatorname{mm}$ & $43 \cdot 66^{\circ}$ & (033) at $15^{\circ}$ & ? \\
\hline Myristic, & היב2. & 86022 at -3.38 & $2.515^{\circ}$ & $.33 \cdot 8^{\circ}$ & insoluble & $\ldots$ \\
\hline Palmitic, & 2.56 & 8.527 at $62^{\circ}$ & $271 \%$ & $\begin{array}{c}62^{\circ} \\
(65 \%)^{\circ}\end{array}$ & " & $\cdots$ \\
\hline Stearie, & $2 \times 4$ & .8154 at $71^{\circ}$ & 291 & $\left\{\begin{array}{c}t 0 \\
(6 !) \cdots 2\end{array}\right.$ & , & $\ldots$ \\
\hline
\end{tabular}




\begin{tabular}{|c|c|c|c|c|c|}
\hline Acid. & & & $\begin{array}{l}\text { Solubility in } \\
\text { Water. }\end{array}$ & $\begin{array}{l}\text { At } 0^{\prime} \\
\text { Solubility in Alcohol } \\
\text { Sp. Gr. 'sl } 183 \text {. }\end{array}$ & $\begin{array}{c}\text { Yiscosity. } \\
\text { Dynes luer sil cm. } \\
\text { at } \ddot{y}^{2} 1^{3} \text {. }\end{array}$ \\
\hline $\begin{array}{l}\text { Butyric, } \\
\text { Caproic, } \\
\text { Caprylic, } \\
\text { Capric, } \\
\text { Lauric, } \\
\text { Myristic, } \\
\text { Palmitic, } \\
\text { Stearic, }\end{array}$ & • & . & $\begin{array}{c}\text { all proportions } \\
\text { soluble } \\
\cdot 25 \% \text { at I00 } \\
\cdot 1 \text {. } \\
\text { very slight } \\
\text { insoluble } \\
\text {," }\end{array}$ & $\begin{array}{c}\text { all proportions } \\
,, \\
\text { very soluble } \\
\text { soluble } \\
1 \% 2 \% \\
\cdot 1.5 \%\end{array}$ & $\begin{array}{l}\cdot 1634 \\
.3263 \\
-7860 \\
\ldots \\
\ldots \\
\ldots \\
\cdots \\
\ldots\end{array}$ \\
\hline
\end{tabular}

None of the acids of this series absorb iodine or bromine, as they are saturated compounds, and are not appreciably attacked by strong sulphuric acid or fused alkalies; the lead, copper, and zinc salts of the lower members of the series (up to lauric) are soluble in ether, but lead, copper, and zinc myristate, palmitate, and stearate are not very soluble in this menstrum.

Acids of the Series, $\mathrm{C}_{n} \mathrm{H}_{2 n-1} \mathrm{COOH}-$ Oleic Acid.-This acid is probably a constituent of butter; it is extraordinarily difficult to prepare it in the state of purity, as it is altered by exposure to the air, and no well-defined stable compound is known. It is extremely doubtful whether it has ever been isolated; the formula given for the acid is to some extent a matter of conjecture, as there is great probability that the analyses from which it was deduced were made on impure products. For the same reason there is some doubt as to its properties.

The following properties are assigned to oleic acid:-A colourless liquid free from smell, which moistens the skin, solidifies at $4^{\circ} \mathrm{C}$, and melts at $14^{\circ} \mathrm{C}$. Specific gravity at $14^{\circ}$ C. $\cdot 898$, and at $100^{\circ}$ C. $\cdot 876$. It cannot be distilled under atmospheric pressure, but boils under $100 \mathrm{~mm}$. pressure at $286^{\circ}$ C. It can be easily distilled below $270^{\circ}$ in a current of superheated steam.

Oleic acid is insoluble in water, but very soluble in alcohol even if considerably diluted. To a solution of 1 c.c. of oleic acid in 95 per cent. alcohol $2 \cdot 2$ c.c. of a mixture of equal parts of acetic acid and water can be added without causing precipitation; further quantities, however, throw the oleic acid out of solution.

On exposure to the air it turns yellowish, and becomes rancid; it then reddens blue litmus paper, while pure oleic acid is said not to do so.

By the oxidation of oleic acid hydroxyoleic acid is formed.

By the action of bromine di-brom-stearic acid is formed; this is a heavy yellow oil, which has not been erystallised. By reduction with zinc and hydrochloric acid oleic acid is again 
formed. Oleic acid also absorls iolline from Hübl's reagent, and is said to form chlor-iodo-stearic acid.

Strong sulphuric acid acts on oleic acid, forming stearo-sulphonic acid or sulpho-stearic acid; on hoiling with water, sulphuric acid is split off and hydroxystearic acid is formed, with other products.

When oxidised by alkaline potassium permanganate dihydroxystearic acid is formed.

The salts of oleic acid behave with water in much the same way as the salts of stearic and palmitic acids. All the oleates are soluble in alcohol, and those of copper, lead, and zinc are soluble in ether.

By the action of fused alkalies oleic acid is split up into salts of acetic and palmitic acids.

Nitrous fumes act on oleic acid in a characteristi ' manner; the liquid oleic acid is transformed into the isomeric solid elaidic acid melting at $45^{\circ}$ and boiling at $288^{\circ} \mathrm{C}$. at $100 \mathrm{~mm}$. pressure.

Baruch has proposed the following formula for oleic and elairlic acids :-
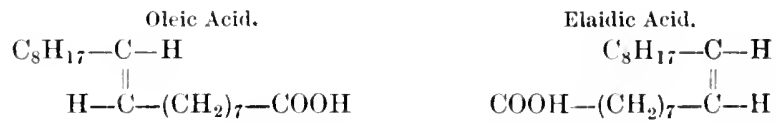

Acids of the Series, $\mathrm{C}_{n} \mathrm{H}_{2 n-3} \mathrm{COOH}$-Linolic Acid, $\mathrm{C}_{17} \mathrm{H}_{31} \mathrm{COOH}$.- It is not known whether this acid exists normally in hutter fat; if so, the proportion is probably not large. It, however, is present in many vegetahle oils, and will thus be a constituent of malrgarine.

Linolic acid is an oily substance of slight yellow colour, having a faint acid reaction; it dissolves readily in alcohol and ether. It remains fluid at low temperatures.

'The salts of linolic acid resemble those of oleic acid, but are more soluble in alcohol and ether. Nitrous acid does not produes a solid acid. Both the acid and its salts readily absorb oxygen from the air, and form resinons substances.

Linolic acid absorbs 4 atoms of bromine, forming tetra-bromstearic acid, which is a crystalline substance melting at $114^{\circ}$ to $115^{\circ}$; from this linolic acis can be prepared by reduction with zinc in a solution of hydrochloric acid in alcohol.

Acids of the Series, $\mathrm{C}_{n} \mathrm{H}_{2 n-5} \mathrm{COOH}$-Linolenic Acid.This occur's in vegetahle oils. It is a liquid, even at very low temperatures, and has a fishy orlour. It forms a hexa-bromcomponmel melting at $177 \mathrm{C}$.

Comparison of the Acids of the four Series.-The following table (V.) will show the main diflerences between stearic, oleic, linolic, and linolenic acids, the corresponding members of the four series:- 
TABLE V.-Comparison of the Four Typical Fatty Acins.

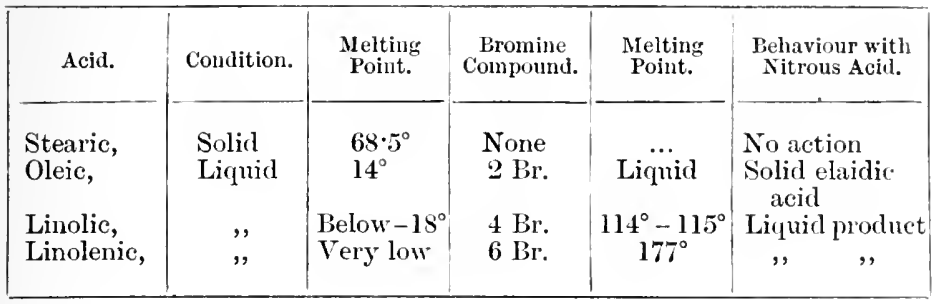

\begin{tabular}{|c|c|c|c|c|}
\hline Acid. & $\begin{array}{l}\text { Behaviour with } \\
\text { Sulphuric Acid. }\end{array}$ & $\begin{array}{l}\text { Product formed } \\
\text { by Alkaline } \\
\text { Permanganate. }\end{array}$ & $\begin{array}{l}\text { Melting } \\
\text { Point. }\end{array}$ & Character of Product. \\
\hline Stearic, & No action & $\begin{array}{l}\text { No character- } \\
\text { istic product }\end{array}$ & $\ldots$ & .. \\
\hline Oleic, & $\begin{array}{l}\text { Sulphonic } \\
\text { acid formed }\end{array}$ & $\begin{array}{l}\text { Dihydroxy- } \\
\text { stearic acid }\end{array}$ & $134^{\circ}$ & $\begin{array}{l}\text { Insoluble in cold } \\
\text { water. Very little } \\
\text { soluble in ether. }\end{array}$ \\
\hline Linolic, & Great action & Sativic acid & $172^{\circ}$ & $\begin{array}{l}\text { Soluble in hot } \\
\text { water. Insoluble } \\
\text { in ether. }\end{array}$ \\
\hline Linolenic, & , & Lmusic acid & $204^{\circ}$ & $\begin{array}{l}\text { More soluble in } \\
\text { lot water than } \\
\text { sativic acid. In- } \\
\text { soluble in ether. }\end{array}$ \\
\hline
\end{tabular}

Other Compounds. - Lecithin, $\mathrm{C}_{44} \mathrm{H}_{90} \mathrm{O}_{9} \mathrm{PN}$, exists in small quantities in butter fat; on saponification it gives glyceryl phosphoric acid, fatty acids and choline; it contains 3.84 per cent. of phosphorus and gives $8 \cdot \&$ per cent. of $\mathrm{P}_{2} \mathrm{O}_{5}$ on oxidation. The quantity does not exceed 5 per cent. of the fat. There is also a colouring-matter of unknown composition and an odoriferous principle.

Rancidity-Products of Decomposition.-But little is known of the real nature of the changes which take place when butter becomes rancid. The following statement will give an idea of the probable nature of the changes :-

The first action seems to be hydrolysis of the fat, splitting it up into fatty acids and glycerol; the latter, perhaps, is not liberated as such, but is oxidised, yielding aldeliydes and acids soluble in water, but not so volatile as the soluble acids o butter; the volatile acids are liberated, and the smell of these can be detected in rancid butter. The odoriferous principle is destroyed. The unsaturated fatty acids are oxidised to form hydroxy acids, which are perhaps slightly soluble in water, but 
not volatile; the total capacity for combining with bromine is reduced by this cause. It is probable that the fatty acids of the series, $\mathrm{C}_{n} \mathrm{H}_{2 n+1} \mathrm{COOH}$, are but slightly affected.

The effect of rancidity is-

(I) To diminish the glycerol produced on saponification.

(2) To increase the soluble acids.

(3) To increase slightly the volatile acids.

(4) To decrease the insoluble acids.

(5) To increase the total molecnlar proportion of acichs.

(6) To greatly increase the free acirls.

(7) To diminish the unsaturated acirls by

(s) The formation of hydroxy acids.

If the change takes place in the presence of water, some of the products are soluble therein; hence the fat separated from the water will not have the same characters as fat which has become rancid alone. If freely exposed to the air, some of the products may be volatile. 
CHAPTER II.

\author{
ANALYSIS OF MILK.
}

Contexts. - Specific Gravity of Milk-Estimation of Total Solids-of Ash-of Citric Acid-of Milk-Sugar-of Cane-Sugar-of Starch-of Fat and Cream-of Proteirls-of Total Acidity-Analysis of Milk Products.

The Specific Gravity of Milk-Modes of Expression.Specific gravity is the weight of a unit of volume. The unit of volume is a cubic centimetre, the unit of weight one gramme, and the specific gravity of any substance is the weight of one cubic centimetre in grammes. As one cubic centimetre of water at $4^{\circ} \mathrm{C}$. weighs one gramme, the specific gravity of water at $4^{\circ} \mathrm{C}$. is exactly 1 ; at temperatures higher and lower than $4^{\circ} \mathrm{C}$. water expands, and therefore has a specific gravity less than 1. Table VI. gives the specific gravity of water at different temperatures :-

TABLE VI.-Specific Gravity of Water.

\begin{tabular}{|c|c|c|c|}
\hline Temperature. & Specific Gravity. & T'emperature. & Specific Gravity. \\
\hline$r^{\circ} \mathrm{C}$. & .0998s & $40^{\circ}$ & .99237 \\
\hline $4^{\circ}$ & $1 \cdot 000000$ & $50^{\circ}$ & 98817 \\
\hline $10^{\circ}$ & .09975 & $60^{\circ}$ & .98343 \\
\hline $1.5 \cdot 55^{\circ}\left(60^{\circ} \mathrm{F}.\right)$ & .99910 & $71^{\circ}$ & 97794 \\
\hline $20^{\circ}$ & $.998: 26$ & $80^{\circ}$ & $9-193$ \\
\hline $30^{\circ}$ & 99575 & $90^{\circ}$ & .96 .561 \\
\hline $37 \cdot 78^{\circ}\left(100^{\circ} \mathrm{F}.\right)$ & 99313 & $100^{\circ}$ & .9 .5865 \\
\hline
\end{tabular}

As at $4^{\circ} \mathrm{C}$. one cubic centimetre of water weighs one gramme, a practical method of ascertaining the specific gravity at this temperature is to take the weight of any volume of the liquid and to compare it with the weight of an equal bulk of water. To ascertain the specific gravity at any other temperature-say, for example, $30^{\circ}$ C.- the weight of any volume of liquid is ascertained and compared with the weight of water at that temperature divided by the specific gravity at that temperature-in the case taken $\cdot 99575$. 
The following formula may he used for determining specific gravity :-

$$
\text { Sp. gr. }=\frac{\text { wt. of a known vol. of liquill } \times \text { sp. gr. of water at same temp. }}{\text { wt. of same volume of water at same temperature. }}
$$

In practice it is customary to assume that water at $15.55^{\circ} \mathrm{C}$. $\left(60^{\circ} \mathrm{F}\right.$.) has the specific gravity $\mathrm{l}$.

Thus, to ascertain the specitic gravity at $15.555^{\circ} \mathrm{C} .\left(60^{\circ} \mathrm{F}\right.$.) it is customary to weigh a known volume of liquid, and to compare it with the weight of an equal volume of water at that temperature. All specific gravities in this volume are stated in this way unless otherwise mentioned. In order to avoid confusion the symbol specific gravity at $\frac{15 \cdot 55^{\circ}}{15 \cdot 55^{\circ}}$ is often used to express this mole of expression. This means that the weight of a volume of liquid at $15.55^{\circ}$ is compared with the weight of an equal volume of water at $15.55^{\circ}$.

Similarly, the expression specific gravity at $\frac{15.55^{\circ}}{4^{\circ}}$ or $\frac{20^{\circ}}{4^{\circ}}$ is used to express the true specific gravities at $15.55^{\circ}$ and $20^{\circ}$ respectively.

It is occasionally convenient to compare the weight of a liquid at some other temperature with the weight of water at the same temprature; thus the specific gravity of fats is taken sometimes at $100^{\circ} \mathrm{C}$, and the expression specific gr.uvity at $\frac{100^{\circ}}{100^{\circ}}$ is used to express the value obtained by dividing the weight of a volume of fat at $100^{\circ} \mathrm{C}$. by the weight of an equal volume of water at $100^{\circ} \mathrm{C}$.

If we ascertain the weight of water held by a certain ressel at a definite temperature, we can ascertain the specific gravity of any liquirl by tilling it with the liquid at the same temperature ani weighing it. If we fill the vessel with the liquid at any other temperature, the volume contained will not be the same as that of the water, owing to the expansion of the ressel itself altering the capacity. Nevertheless, specitic gravity is frequently ascertained on the assumption that the vessel does not alter in capacity by change of temperature. As the ressel is usually mate of glass, this mode of expression of specific gravity may be termed the "applinent specific gravity in glass at $\frac{20^{\circ}}{1555^{\circ}}$ " (or whatever the temperature maty br).

As a matter of fict. specific gravities of milk are usually determined as "apparent spreeific gravities in glass at $15.55^{\circ}$ " 
Determination of Specific Gravity.-There are two methods of determining specific gravity, which is, as above stated, the weight of unit volume, or, expressed as an equation-

$$
\mathrm{s}=\frac{\mathrm{W}}{\mathrm{V}} \text {. }
$$

We may either determine the weight of a known rolume, or the volume of a known weight. Both methods are used in practice, the first in two ways:-

(1) A vessel of known rolume is filled with the liquid and its weight taken.

(2) A plummet of known volume is immersed completely in the liquid, and the loss of weight due to the displacement of an equal volume of liquid noterl.

The second method is applitd (3) by immersing a float of known weight, and noting the volume immersed; the volume immersed will be equal to a volume of the liquid of weight equal to that of the float.

Determinations of specific gravity by method (1) are made by specific gravity bottles and Sprengel tubes, by method (2) by a Westphal balance, and by method (3) by hydrometers, of which lactometers are special forms of limited range suited for milk.

For exact determinations of the specific gravity of milk, a Sprengel tube presents many advantages. It is a $U$-shaped tube with narrow capillary ends bent outwards at right angles, one being rather smaller than the other; the wider of the two has a fine line etched round it, to which the liquid in the tube may be adjusted, the $U$ and the other capillary being completely filled.

The weight of the dry and empty tube is first ascertained, the tube is then filled with pure distilled water, and immersed in water at exactly $15.55^{\circ} \mathrm{C} .\left(60^{\circ} \mathrm{F}\right.$.) ; when it is seen that no further expansion or contraction takes place, the water should be arljusted to the line on the wider capillary by the cautious application of a piece of blotting paper to the end of the narrow capillary; the tube is then wiped dry and weighed. The difference in the two weights gives the weight of the water contained in it. The tube is then filled with milk and immersed in water at $15.55^{\circ} \mathrm{C} .\left(60^{\circ} \mathrm{F}\right.$.), and the milk similarly adjusted to the line; the weight of mill divided by the weight of water gives the specific gravity of the milk at $\frac{15 \cdot 55^{\circ}}{15 \cdot 55^{\circ}}$.

A specific gravity bottle is used in a similar manner; the liquid, after inserting the stopper and immersing the bottle in water at $15.55^{\circ}$, is adjusted to the line by drawing out the excess with a very fine tube.

A Sprengel tube of 10 to 20 c.c. capacity is the most suit- 
able size; it is a disalvantage to use a larger one, as the time taken for the milk to assume the temperature of the surrounding water is so much increased that there is danger of a portion of the cream separating.

The advantages of a Sprengel tube over a speeific gravity bottle are :-

(1) Greater surface for a given volume; and therefore the temperature is adjusted quicker.

(2) There is no stopper to fit; consequently, no error can be due to difference of position owing to inaccuracy of fit.

The Westphal balance consists of a balance of the "steel-yard" type, carrying a glass plummet at one end; it is so arljusted that the pointer is at zero when the plummet hangs in air, and is provided with a weight, which, when hooked on to the end, causes the pointer to be at zero when the plummet is immersed in water at $15.55^{\circ} \mathrm{C}$. The beam is divided into ten parts, each indicated by a notch, and riders weighing the same, $\frac{1}{10}, \frac{1}{100}$, and $\frac{1}{1000}$ of the weiglit are provided.

To take the specific gravity, the plummet is immersed in milk at $15.55^{\circ}$, and riders are placed on the notches of the beam till the pointer is at zero. If the $\frac{1}{1} \overline{0}$ rider is on notch 3 , the specific gravity is 1.03 ; if, in aldition, the $\frac{1}{10} 0$ rider has to be placed on notch 2 , the specific gravity is 1.032; and if, in addition, the $\frac{1}{100 \pi}$ rider has to be placed on notch 4 the specific gravity is 1.0324 . If a rider is already on a notch, and it is desired to place another thereon, it may be hung on the turned up end of the rider alrearly in position.

A rule may be given as follows:-Count 1 for the weight hung on the end, the first place of decimals from the notch on which the ${ }_{1}^{2}$ rider is hung, the second place from the notch on which the $\frac{1}{10}$ rider is hung, the third place from the $\frac{1}{100}$ rider, and the fourth place from the $\frac{1}{1000}$ rider.

This methor has the alvantage of being somewhat more rapid than the use of the Sprengel tube, but is not quite so accurate, as the arjustment of riders and balance cannot practically be performed with very great accuracy.

In lairy work the litetometer is generally used. From a strictly scientifie point of view, there are many objections to lactoneters, but their practical convenience is so great that they are instruments of extreme value.

The faults of lactometers are:-(1) They do not indicate true specific gravities, but the inverse of this-specific volumes; consequently, the seile is not divided into equal parts. The divergenee from equility is, however, so small in a lnetometer, which has only a limited range, as to render it practically armissible to treat the smaller divisions as equal.

(2) The exact point at which the lewel of the liquill cuts the stem of the lactometor caunot be ascertained, as, owing to 
surface energy, the liquid is attracted to a higher level round the stem of the lactometer than the surface of the liquid ; moreover, the height to which the liquid is attracted varies with the nature of the liquid. As milk has always the same composition within narrow limits, there is no practical difference in the height to which it is attracted round the stem; the eye soon becomes trained in making the proper allowance for this.

(3) Lactometers are only correct at the temperature at which they are graduated; at other temperatures their volume varies; no inconvenience on this account is felt in practice, as this is allowed for in the tables given for correcting the specific gravity to a temperature of $15.55^{\circ} \mathrm{C}$. $\left(60^{\circ} \mathrm{F}\right.$.).

Practical instructions for the use of lactometers will be given later under the "Testing of Milk."

Variation in Milk.-The specific gravity of the milk of individual cows varies from 1.0135 to $1 \cdot 0397$; when the mixed milk of a herd is tested it rarely falls outside the limits of 1.030 and 1.034 . The average specific gravity of milk is 1.0322 .

The specific gravity is dependent on two causes-the amount of solids not fat, which, being dissolved in water, raises the specific gravity; and the fat, which, being lighter than water, lowers it. By removing the fat (with a small proportion of other constituents) as cream the specific gravity of the milk is raised. By the addition of water the specific gravity is lowered. The specific gravity has been-and is-largely used as a test for the addition of water to milk; for the detection of large amounts of water to milk it has some value.

That it is a test of the ronghest kind is shown by the following facts :-

(1) The variations in specific gravity are from 1.0135 to 1.0397 - i.e., nearly twice its bulk of water could be added to milk of the highest specific gravity to reduce it to the lowest. These, of course, are exceptional cases, and the specific gravity of the mixed milk of a herd is nearly always between 1.030 and 1.034. At least 10 per_cent. of water could be added to milk of 1.034 specific gravity before it would be suspected by this test.

(2) A milk of 1.032 specific gravity, if the cream is all removed, would give a product of about 1.036 specific gravity; and an addition of rather more than 10 per cent. of water would bring the specific gravity back to 1.032 .

(3) If to milk of 1.032 specific gravity sufficient cream be added to raise the percentage of fat 4 per cent., the specific gravity will be found to be about 1.028. The same result would be arrived at were the milk allowed to stand, and the upper portion removed.

As an absolute test the specific gravity is liable to be greatly misleading; as a preliminary test it is of the greatest importance, and should never be neglected. 
As stated above, the specific gravity is raised by the solids not fat, and lowered by the fat. This fact is not only true qualitatively, but also, as the following demonstration will show, guantitatively.

Brour definition that specific gravity (S) is the weight (W) of the unit of volume (V), we get the equation-

$$
\therefore=\frac{\mathrm{Wr}}{\mathrm{V}}
$$

Let us suppose we have a mixture (having the specific gravity S) of two substances, $A$ and $B$, of differing specific gravities $S_{A}$ and $S_{B}$.

Let us suppose thit the respective weights are $\mathrm{A}$ and $\mathrm{B}$, and let $\mathrm{A}+\mathrm{B}=\mathrm{I} 00$.

Then by (1)

Volume of $A=\frac{A}{S_{A}}$, volume of $B=\frac{B}{S_{B}}$, and wolume of mixture $=\frac{100}{S}$.

Then

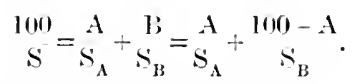

$$
\begin{aligned}
& s=\frac{A\left(s_{B}-S_{A}\right)}{S_{A} S_{B}}+\frac{100}{S_{B}} \text {. } \\
& \frac{100}{S}-\frac{100}{S_{B}}=A\left(\frac{S_{B}-S_{A}}{S_{A} S_{B}}\right) \text {. }
\end{aligned}
$$

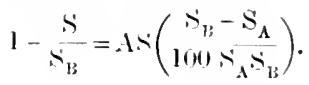

$$
\begin{aligned}
& S=S_{B}+A S\left(\begin{array}{c}
S_{A}-S_{B} \\
100
\end{array}\right) \text {. }
\end{aligned}
$$

Now in the same way

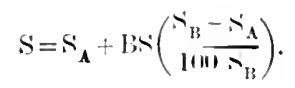

As both $S_{A}$ and $S_{B}$ are constants, we may write

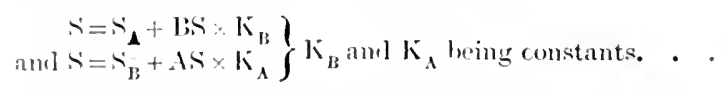

Now, ats $A+B=100, A$ is the pereentage by weight of this sulistance: and as $100 \times s$ expresses the total number of gl:mmmes in 100 e.c. of the mixtme, $A S$ is the number of erammes of this sut stance in 100 c.e.

lirom the equations above given we can deduce the law that "if two sulstances of differing specific gravity be mixed, the specific gravity of the mixture will he equal to the specific gravity 
of one of the substances plus the number of grammes of the other per 100 c.c. of the mixture multiplied by a constant factor."

Regarding milk as a mixture of fat and a solution of solids not fat in water, we can say that the specific gravity of a milk is equal to the specific gravity of the solution of solids not fat plus the number of grammes of fat per 100 c.c. multiplied by a constant.

In the solution of solids not fat we have in 100 c.c. of it $x$ grammes of solids not fat; let us assume that their density is $y$. Then $x$ grammes will occupy a volume $\frac{x}{y}$. $\mathrm{I}_{4}$ et the specific gravity of the solution be S. The 100 c.c. weigh $100 \mathrm{~S}$ grammes, and the water in this weighs $100 \mathrm{~S}-x$ grammes; it also measures $100-\frac{x}{y}$ c.c. Now, as the specitic gravity of water is 1 ,

$$
\begin{aligned}
100 \mathrm{~s}-x & =100-\frac{x}{y} \\
100 \mathrm{~s} & =100+x-\frac{x}{y} \\
\mathrm{~s} & =1+x \frac{y-1}{100 y} .
\end{aligned}
$$

Now, $\frac{y-1}{100 y}$ is a constant, provided that $y$ remains constant. Putting the equation into words we find " that the specific gravity of a solution of solids not fat is equal to 1 plus the number of grammes of solids not fat in 100 c.c. multiplied by a constant." It is known, however, that the specific gravity of substances in solution is not quite constant, but varies slightly with dilution.

The following figures will show that in milk the law just enumerated holds good within the limits of experimental error.

\begin{tabular}{|c|c|c|}
\hline Total Solids per Cent. & Specific Gravity. & Constant. \\
\hline $9 \cdot 280$ & $1 \cdot 03 i n+4$ & $00368 s$ \\
\hline 3.758 & 103343 & .003693 \\
\hline s.31s & $1 \cdot 03170$ & .003694 \\
\hline 7.776 & $1 \cdot 1.2950$ & .003684 \\
\hline $7 \cdot 456$ & $1 \cdot(0) 28: 29$ & .003690 \\
\hline $6 \cdot 455$ & $1 \cdot(1)+439$ & .003688 \\
\hline
\end{tabular}
A poor skim milk was diluted with water, and the total solids and specific gravity at $15.55^{\circ}$ estimated :-

From the laws expressed by equations (2) and (3) we see that the specific gravity of an agueous liquid containing a substance in solution or in admixture can be expressed equally as a direct 
multiple of the number of grammes per 100 c.c.; for if we suppose that the substance $A$ is water, $S_{A}$ will equal 1 , and equation (2) can then be writter-

$$
S-1+\mathrm{BS} \times \mathrm{K}_{\mathrm{B}}
$$

which is practically equation (3).

Formulæ for Calculations.-In order to deduce a formula expressing the relation between specific gravity and percentage by weight of fat and solids not fat, let us call the specific gravity (for convenience) $1+S$, the percentage by weight of fat $F$, and of solids not fat $\mathrm{N}$.

Then the number of grammes of fat per 100 c.c. will be $F \times(1+s)$ and of solids not fat $N \times(1+S)$.

The weight of the water in 100 c.c. is then

and its volume $100 \times(1+S)-\mathrm{N} \times(1+S)-\mathrm{F} \times(1+S)$ c.c.

$$
100 \times(1+S)-N \times(1+s)-F \times(1+s) \text { grammes: }
$$

The volume of fat and solirls not fat in 100 c.c. is therefore

$$
100-(100) \times(1+S)-\mathrm{N} \times(1+S)-\mathrm{F} \times(1+S)) \text { c.c. }
$$

which equals

$$
\mathrm{N} \times(1+S)+\mathbf{F} \times(1+S)-100 \mathrm{~S} . . .
$$

Let $"$ s assume that the specific gravity of fat is $f$ and of solids not fat $n$.

Then the volume of fat in 100 c.c. is $\frac{\mathrm{F} \times(1+\mathrm{S})}{f}$ and of solids not fat $\frac{N \times(1+S)}{n}$; therefore

$$
\begin{gathered}
N \times(1+S)+F \times(1+S)-1 m s=\frac{F \times(1+S)}{f}+\frac{N \times(1+S)}{n} \\
\text { or } \quad l(n) s=N \times(1+s)-\frac{N \times(1+S)}{\prime \prime}+F \times(1+S)-\frac{F \times(1+S)}{f}
\end{gathered}
$$$$
\text { or } \quad(10) \leq N \times(1+s)\left(\begin{array}{c}
n-1 \\
n
\end{array}\right)+\mathrm{F} \times(1+s)\left(\begin{array}{c}
f-1 \\
f
\end{array}\right) \text {. }
$$

$\mathrm{Now}$, as $n$ and $f$ are constant, we may write for $\left(\frac{n-1}{n}\right), a$; and for $\left(\begin{array}{c}f-1 \\ f\end{array}\right), b$.

Then the equation stands

$$
10 x+s=0 \mathrm{~N}+b \mathbf{F}
$$

It is usual, howerer, to estimatr total solids ('T) and fat in an analysis.

T $\mathbf{N}+\vec{r}$, and, therefore, $\mathbf{N}-\mathrm{T}-\mathbf{F}$. 
The equation (5) may be written

or

$$
\begin{aligned}
& 100 \mathrm{~S}=a(\mathrm{~T}-\mathrm{F})+b \mathrm{~F} \\
& 1+\mathrm{S}=a \mathrm{~S}=a \mathrm{~T}+(b-a) \mathrm{F} \\
& 100) \mathrm{S}=a
\end{aligned}
$$

In expressing the specific gravity of milk it is usual to do so in lactometer degrees, which are the specitic gravity nultiplied by 1000 minus 1000 .

Thus if the specitic gravity be 1.032 , the lactometer degrees are $1.032 \times 1000-1000=32$.

Let us express lactometer degrees by the symbol $G$.

Then $\mathrm{G}=1000 \mathrm{~S}$, and, substituting this in $(6)$, we get

$$
\frac{1 \mathrm{r}}{1+\mathrm{S}}=10 r \mathrm{~T}+10(1,-a) \mathrm{F} \text {. }
$$

The specitic gravity was expressed as $1+\mathrm{S}$ for ease in calculation; it is better, however, to substitute the symbol $D$ in the formula, which then stands as

or

$$
\begin{aligned}
& \frac{\mathrm{B}}{\mathrm{b}}=10 a \mathrm{~T}+10(1,-a) \mathrm{F} \\
& \mathrm{T}=\frac{1}{10 a} \times \frac{\mathrm{B}}{\mathrm{D}}-\left(\frac{1-a}{a}\right) \mathrm{F} .
\end{aligned}
$$

As, by the definition above, $a=\frac{n-1}{n}$ and $b=\frac{f-1}{f}$, we could calculate a formula, did we know the specific gravities of solids not fat and fat, but we do not know both of these. Fleischmann has determined the specific gravity of the fat of milk to be .9307 at $15^{\circ} \mathrm{C}$. , but it is impossible to determine the specific gravity of solids not fat in solution. Moreover, Fleischmann's determination of the specific gravity was made on fat in the solid state, and it is possible that in milk it may have a different specific gravity.

By transforming equation (7) into the form

$$
1=\frac{1}{10 u} \times \frac{(i}{\mathrm{T} I)}-\left(\frac{l-a}{a}\right) \times \frac{\mathrm{F}}{\mathrm{T}}
$$

and making a large number of determinations of $\frac{G}{D}$, T, and $F$ in different milks, we can form each pair of results into simultaneous equations and solve them. In this way we can get a large number of values for $a$ and $b$, and, from the mean of these, we can calculate the specific gravities of fat and solids not fat respectively. This method is not wholly free from objection, as, unless there is a considerable difference between the figures actually determined, the figures from which $a$ and $b$ are calcu- 
laterl are so small as to be greatly affected by experimental "rror; while, if the difference be large (as in the case of analyses of cream and skim milk), it is found that the experimental error is also increaserl. For this reason, and also for the reason that the specific gravity of fat and solids not fat are themselves liable to slicht variations, it is necessary to deduce the formula from a great many determinations, which means much labour in calculating.

In or ler to ascertain the specific gravities of fat and solids not fat in milk, the author has calculated their value from over 200 analyses made by the mos ${ }^{+}$exact methods at his command, and finds the following figures:-

$$
\begin{aligned}
& \text { Specific gravity of fat, . . . . . . } 93 \\
& \text { " ," solirls not fat, : : } \quad .1616
\end{aligned}
$$

It is seen that the author's figure, calculated from actual analyses, atrees with Fleisc'mann's determination of the specitic gravity of fat.

As the speeific gravity of milk does not vary much, it will not make an appreciable error if, instead of $\frac{G}{D}$, the expression 1.032.2 be used ; this form of calcnlation is much easier.

The irlea of deducing a relation between specific gravity, fat, and total solids appear's to liave arisen with Behrend and IIorgen, who published a table. Shortly afterwards Clauznitzer and Mayer, and Hehner published formule, but as they were foumled on inaccurate data, they are now abandoned.

Fleischmann and Morgen next published a formula in which the sprecific sravity of fat was assumed to be 94 ; this was corrected hy Fleisehmann after his determination of the specific sravity of fat as 93 . His formula is

$$
\mathrm{T}=\cdot 266.5)_{1}^{\prime}+1 \cdot 2 \mathrm{r} \text {. }
$$

Ifehner and the author deduced the formulat

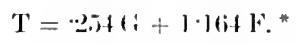

This is in the less scientifically eorrect, but more convenient form: as it was found that milk dillering appreciably in specitic alavity from 1.032.2 did not give results which agreed well with the formula, varions approximations have ben made to this.

'The anthor has calculaterl a formula which gives practically the same results, but is more seientifically correct, and which does not repuire the "pllication of approximations. 'This is

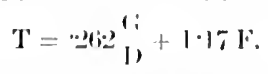

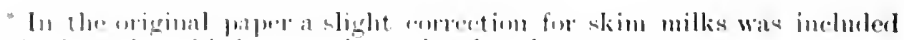

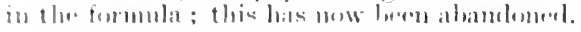


As the previous formule were deduced from analyses to which objection could be taken, the author has deduced a new formula from the results of analyses made as exactly as possible.

$$
\mathrm{T}=\cdot 2625 \frac{\mathrm{G}}{\mathrm{D}}+\mathrm{I} 2 \mathrm{~F} .
$$

This has been found to be expressed by the simpler formula $\mathrm{T}=\frac{\mathrm{G}}{4}+\frac{6}{5} \mathrm{~F}+\cdot 14$ within very small limits if the specific gravity lies between 1.020 and 1.036 .

The formula $\mathrm{T}=\frac{\mathrm{G}}{4}+\frac{6}{5} \mathrm{~F}$ also approximates closely to that of Hehner and the author.

Other formulæ lave been devised by J. K. Brown, Babcock, and others.

Of the above formule, that of Fleischmann agrees best with the results when Soxhlet's method of fat estimation is used; that of Hehner and the author when the Society of Public Analysts' methods are employed; while if the methods mentioned later as most exact in the author's opinion be employed, the author's formula gives the most satisfactory results.

The fat calculated from the specific gravity and total solids almost invariably agrees within $\cdot 2$ per cent. with the determination made by the appropriate method.

Milk Scale - In order to save calculation the author has devised a slide rule, known as the "milk scale" (Fig. 1), from which the percentage of fat can be read off directly from the specific gravity and percentage of total solids. On one side a scale is placed indicating total solids, 1 per cent. of total solids being represented by 1 inch; on the other side the fat is shown by a scale of 1.164 ( $1 \frac{1}{6}$ inches) to 1 per cent.; the slide carries the specific gravity scale, $1^{\circ}$ being equal to .254 inch. The line indicating the specitic gravity found is placed against the total solids estimated; an arrow then gives the fat as calculated by the formula

$$
\mathrm{T}=\cdot 254 \mathrm{G}+1 \cdot 164 \mathrm{~F} \text {. }
$$

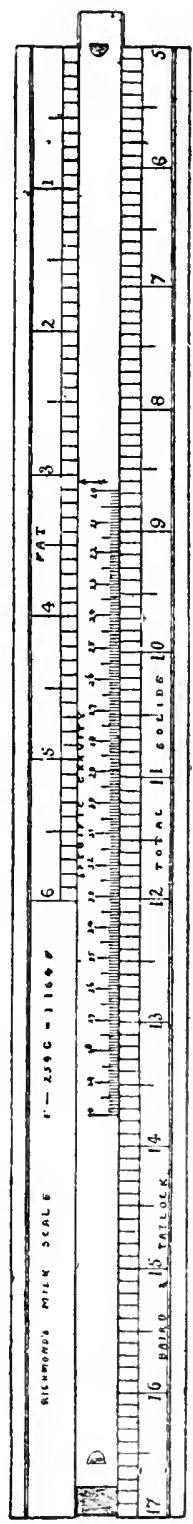

Fig. 1. Milk Scale. 
A seale is also made to express the formula

$$
\mathrm{T}=2 . \mathrm{s}+1 \cdot 2 \mathrm{~F}+\cdot 14 \text {. }
$$

In this case the total solids scale is 1 inch to 1 ler cent., the fat scale $1 \cdot 2$ inches to 1 per cent, and the specifie gravity $\cdot 25 \quad\left(\frac{1}{4}\right.$ inch) to $1^{\circ}$. The arrow is placed $\cdot 14$ inch lower than in the case of the other scale.

To facilitate reading, Cassal and Gerrans propose to add two sliding pointers, one on the total solids scale, and one on the specitic gravity slicle, which are first placed against the part of the scales corresponding to total solids and specific gravity found respectively, and the two pointers are then adjusted. This arrangement prevents the possibility of error in adjusting the slide.

The author has also employed a runner made out of a piece of brass bent round the milk scale, in which two holes are cut, leaving a narrow bar between them; this bar partially covers both the total solid and specific gravity scales, and has a fine line drawn upon it at right angles to the scales. By adjusting this lin to the total solids, and the specitic gravity to the line, the olject sought by Cassal and Gerrans is attained. The idea of the rumer is clue to Lieutenant Mannheim of the French Artillery, who, in 1851, devised it for a logarithmie slide rule.

The scales are divided into tenths, huudredths being estimated by the eye; a decimal scale, or, better, a vernier, as suggested by Sykes, can be applied to the runner, rendering it easier to read the second place of decimals. 'This, however, is not necessary, the error due to unavoidable circumstances being greater than the error of computation of the hundredths.

Tables are griven from which the fat calculated from different percentares of total solids and speeifie gravities can be read off.

by our definitions

$$
u=\frac{n-1}{n} \text { and } \quad b=\frac{i-1}{i}
$$

and from the values given above in the formula mentioned, $a$ and $b$ can be calculated.

Thus, taking the formula $\mathrm{T}=.2625 \frac{\mathrm{G}}{1}+1.2 \mathrm{~F}$,

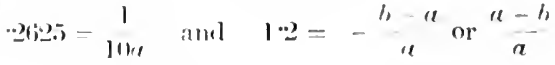

$$
\begin{aligned}
& "=: 341 \text { aml } \quad l=-11702 \text {; } \\
& n=\frac{1}{1-1} \text { and } i=\frac{1}{1-10} \text { : }
\end{aligned}
$$

and, therefore, $\quad n=1$.

$$
i=930 \quad,, \quad ., \quad \text { filt. }
$$


From the mode of deducing equation ( 7 ) we see that $a$ is the number of grammes that the weight of 100 c.c. of milk is greater than the weight of 100 c.c. of water, when 1 gramme per 100 c.c. of solids not fat is contained therein; the density being, by definition, the weight of 1 c.c., $\frac{a}{100}$ and $\frac{b}{100}$ are respectively the difference in specific gravity due to 1 gramme per 100 c.c. of solids not fat and fat.

It is also apparent that we may calculate from any analysis the amount that 1 gramme of total solids per 100 c.c. has raised the specific gravity, and, from this, the specific gravity of the total solids.

Thus, using the same symbols as before,

$$
\mathrm{T}=\frac{\mathrm{G}}{\mathrm{D}} \times \frac{\mathrm{l}}{10 x}, \text { and } \quad t=\frac{1}{1-x}
$$

( $t$ here representing the specific gravity of the total solids).

Thus, if a milk has a specific gravity of 1.032 and contains 12 per cent. of total solids,

$$
12=\frac{3.2}{1 \cdot 032} \times \frac{1}{10 x} \text { and } \quad x=2.584
$$

and

$$
t=1 \cdot 348 \text {. }
$$

It is occasionally useful to calculate the specific gravity of the total solids of a milk, as the total solids of skimmed milk have a considerably higher specific gravity than those of whole milk.

Specific Volume.-By our definition of specific gravity, we write $\mathrm{S}=\frac{\mathrm{W}}{\mathrm{V}}$; we may also write, $\frac{\mathrm{l}}{\mathrm{S}}=\frac{\mathrm{V}}{\mathrm{V}}$; or, in words, 1 $\overrightarrow{\mathrm{S}}$

volume. The expression $\frac{G}{D}$ is, therefore, a mode of indicating specific volumes; as G (degrees of specific gravity) is 1000 times the specific gravity minus 1000 , so $\frac{G}{D}$ (degrees of specific volume) is 1000 minus 1000 times the specific volıme.

In Table VII. the values of degrees of specific rolume for each half degree of specific gravity from 20 to 36 are giren.

It is seen from the formule above, that 1 per cent. by weight lowers the specific volume to the same extent as 1 gramme per 100 c.c. raises the specific gravity-i.e., specific volume, not specific gravity, varies directly as percentage by weight. 
TABLE VII.--Specific Gravity axd Voluae of Milk.

\begin{tabular}{|c|c|c|c|}
\hline $\begin{array}{c}\text { Defrees of } \\
\text { Specitic Gravity. }\end{array}$ & $\begin{array}{c}\text { Degrees of } \\
\text { specitic Volume. }\end{array}$ & $\begin{array}{c}\text { Degrees of } \\
\text { Specific Gravity. }\end{array}$ & $\begin{array}{c}\text { Degrees of } \\
\text { Specific Volume. }\end{array}$ \\
\hline $\begin{array}{l}20 \cdot 0 \\
2010 \\
21 \cdot 0 \\
21 \cdot 5 \\
22 \cdot 0 \\
2.2 \cdot 5 \\
2.3 \cdot 0 \\
2.3 \cdot 5 \\
24 \cdot 0 \\
24 \cdot 5 \\
2.5 \cdot 0 \\
2.5 \cdot 5 \\
26 \cdot 0 \\
26 \cdot 5 \\
27 \cdot 0 \\
27.5\end{array}$ & 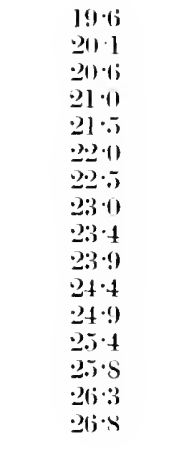 & $\begin{array}{l}25 \cdot 0 \\
25 \cdot \pi \\
2 ! 9 \cdot 11 \\
29.5 \\
30 \cdot 0 \\
31 \cdot \% \\
31 \cdot 0 \\
31 \cdot 5 \\
32 \cdot 0 \\
32 \cdot 0 \\
33 \cdot 0 \\
33 \cdot 0 \\
34 \cdot 0 \\
34 \cdot \pi \\
35 \cdot 0 \\
35 \cdot 5 \\
36 \cdot 0\end{array}$ & $\begin{array}{l}27 \cdot 2 \\
27 \cdot 7 \\
28 \cdot 2 \\
28 \cdot 7 \\
29 \cdot 1 \\
29 \cdot 6 \\
30 \cdot 1 \\
30 \cdot 5 \\
31 \cdot 0 \\
31 \cdot 5 \\
31 \cdot 9 \\
32 \cdot 4 \\
3 \cdot 2 \cdot 9 \\
33 \cdot 4 \\
33 \cdot 8 \\
34 \cdot 3 \\
34 \cdot 7\end{array}$ \\
\hline
\end{tabular}

Mode of Averaging Specific Gravities.-It is not, therefore, correct in averaging milk analyses, where specific gravities and percentages by weight are expressed, to obtain the average specific gravity by adding the specific gravities together and dividing by the total number, but specifie gravities must be first calculated to specific volumes, and these averaged, and the average specific gravity deduced from the average specific volume.

Thus, to average the following analyses:-

sperific gravity, . . 1.022 Total solids, . . . 900

$$
\text { , : } 1.0315 \text { Total }
$$

The average total solids is $20+10=15$; but the average specific gravity is not $\frac{1 \cdot 02 \cdot 2+1 \cdot 0.36}{2}=1 \cdot 029$, but $\frac{1}{\frac{.9785+\cdot 9653}{2}}$ $=\frac{1}{9719}=1 \cdot 0289$

The error is, however, small if the specific gravities do not differ greatly, and may very frequently be negleeted.

On the other hand, if, instrad of areraging perentages of total solids hy weight, we average the number of grammes per 100 c.e., we obtain correct results by areraging the specitic gravities. 
The following rules may be stated :-

(1) If equal volumes of different milks be mixed, the specific gravity of the mixture will be the mean of the specific gravities of the milks.

(2) If equal weights of different milks be mixed, the specific volume of the mixture will be the mean of the specific volumes of the milks.

Instead of taking the solids not fat as one substance, we may consider its constituents-lactose, proteids, and mineral matter - separately.

Calling the percentage of fat F, lactose $\mathrm{L}$, proteids $\mathrm{P}$, and mineral matter $\mathrm{A}$, we may write

$$
\frac{\mathrm{G}}{\overline{\mathrm{D}}}=10 b \mathrm{~F}+10 e \mathrm{~L}+10 d \mathrm{P}+10 e \mathrm{~A} \text {. }
$$

by the same reasoning employed in deducing formula (5).

The author has deduced from the mean of many analyses the formula

$$
\frac{\mathrm{G}}{\mathrm{D}}=-761 \mathrm{~F}+4 \mathrm{~L}+2 \cdot 5714 \mathrm{P}+7 \cdot 5715 \mathrm{~A} .
$$

From these factors the following specific gravities are deduced, as previously shown:-

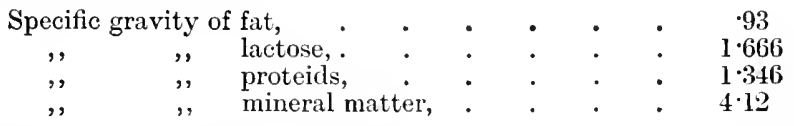

Using these specitic gravities, together with Vieth's estimate of the proportions of lactose, proteids, and mineral matter$13: 9: 2-$-we can calculate what the specific gravity of solids not fat should be. As Vieth's proportions are by weight, we must transform specific gravities into specific volumes.

$$
\begin{aligned}
\text { Specific volume of lactose } & =\frac{1}{1 \cdot 666}=\cdot 6 \\
, \quad \quad, \quad \text { proteids } & =\frac{1}{1 \cdot 346}=\cdot 743 \\
, \quad, \quad \text { mineral matter } & =\frac{1}{4 \cdot 12}=\cdot 243
\end{aligned}
$$

Then specific gravity of S.n.F. $=\frac{1}{\frac{13 \times 6+9 \times \cdot 743+2 \times \cdot 243}{24}}=\frac{1}{624}=1 \cdot 603$.

which is in approximate agreement with that given above, 1.616 -i.e., within 1 per cent.

It is a useful check on an analysis to calculate the specific gravity from the percentage of milk-sugar, proteids, fat, and 
mineral matter; this should agree within small limits with that found.

The Alteration of Specific Gravity by Change of Temperature.-Milk, like most other substances, alters in specific gravity by change of temperature.

Though it contains a large amount of water, it does not share the anomaly which this substance possesses of attaining its maximum specific gravity at $4^{\circ} \mathrm{C}$. $\left(39^{\circ} \mathrm{F}\right.$.). It decreases in specific gravity when heated from its freezing point $-55^{\circ} \mathrm{C}$. $\left(31^{\circ}\right.$ F.).

The following figures (Table VIII.) show the average apparent expansion of milk in glass :-

\section{TABLE VIII.-Expaxsion of Milk.}

\begin{tabular}{|c|c|c|c|}
\hline $\begin{array}{c}\text { Temperature in } \\
{ }_{0} \mathrm{~F} \text {. }\end{array}$ & Volume. & Temperature in & Volume. \\
\hline $\begin{array}{l}31 \\
35 \\
40 \\
45 \\
50 \\
5.5\end{array}$ & $\begin{array}{l}1 \cdot(1) 00000 \\
1 \cdot(10016 \\
1 \cdot 00041 \\
1 \cdot 00074 \\
1 \cdot 00114 \\
1 \cdot 00164\end{array}$ & $\begin{array}{l}60 \\
65 \\
70 \\
75 \\
80\end{array}$ & $\begin{array}{l}1 \cdot 00229 \\
1 \cdot 00298 \\
1 \cdot 00372 \\
1 \cdot 00451 \\
1 \cdot 00549\end{array}$ \\
\hline
\end{tabular}

The expansion is greater with rich milk than with poor milk; the above figures referring to milk having a specific gravity of 1.032 and containing 3.8 per cent. fat.

Table LXXIII. in Appendix $\mathrm{C}$ affords a means of correcting to $60^{\circ} \mathrm{F}$. the specific gravity of milk when taken by a lactometer at any temperature from $33^{\circ} \mathrm{F}$. to $85^{\circ} \mathrm{F}$. The table gives specific gravities from $1 .(120$ (20 degrees) to 1.036 (36 degrees) and is applicalble to whole milk only. The portion from $45^{\circ} \mathrm{F}$. to $75^{\circ} \mathrm{F}$. is, with a few alterations, due to Vieth; this has been repeatedly checked by the author, and in a few places slightly changed in accordance with the results obtained. The other portion has been ealculated by the author.

The table is used by looking up the degrees of specific gravity found (or the nearest whole degree) in a horizontal line, and the temperature in a vertical line; the figure at the intersection of the two lines is the specifie gravity corrected to $60^{\circ} \mathrm{F}$.

The specific gravity of separated milk may be corrected to $60^{\circ} \mathrm{F}$. by the following table. As the expansion is practically uniform for the variations in quality met with, the table is given in a simpler form. 
THE RISE OF SPECIFIC GRAVITY OF IILK ON STANDING.

\section{TABLE IX.-For Correcting Specific Gravity of Separated Milk tu $60^{\circ} \mathrm{F}$.}

\begin{tabular}{|c|c|c|c|c|c|}
\hline Temp. & Take off. & Temp. & Add on. & Temp. & Add on. \\
\hline $\begin{array}{c}{ }^{\circ} \mathbf{F} \\
50 \\
51 \\
52 \\
53 \\
54 \\
55 \\
56 \\
57 \\
58 \\
59\end{array}$ & $\begin{array}{r}1 \cdot 1 \\
1 \cdot 0 \\
\cdot 9 \\
\cdot 8 \\
\cdot 7 \\
\cdot 5 \\
4 \\
\cdot 3 \\
\cdot 2 \\
\cdot 1\end{array}$ & $\begin{array}{c}{ }^{\circ} \mathrm{F} . \\
60 \\
61 \\
62 \\
63 \\
64 \\
65 \\
66 \\
67 \\
68 \\
69\end{array}$ & $\begin{array}{r}\cdot 0 \\
\cdot 1 \\
\cdot 3 \\
\cdot 4 \\
\cdot 5 \\
\cdot 6 \\
\cdot 8 \\
\cdot 9 \\
1 \cdot 1 \\
1 \cdot 2\end{array}$ & $\begin{array}{c}{ }^{\circ} \mathrm{F} . \\
70 \\
71 \\
72 \\
73 \\
74 \\
75 \\
76 \\
77 \\
78 \\
79\end{array}$ & $\begin{array}{l}1 \cdot 4 \\
1 \cdot 6 \\
1 \cdot 8 \\
1 \cdot 9 \\
2 \cdot 0 \\
2 \cdot 2 \\
2 \cdot 3 \\
2 \cdot 4 \\
2 \cdot 6 \\
2 \cdot 7\end{array}$ \\
\hline
\end{tabular}

The author has devised a scale for correcting the specific gravity of milk to $60^{\circ} \mathrm{F}$. It is usually engraved on the "milk-scale," and is used by adjusting the specific gravity found (on the slide) to the arrow at $60^{\circ} \mathrm{F}$. The corrected specific gravity is found opposite the temperature at which the determination was made.

The corrected specific gravities obtained by the "milk-scale" agree generally within $\cdot 1$ of those taken from the table. At very low temperatures, however, there is sometimes a larger difference.

The Rise of Specific Gravity of Milk on Standing.-Milk drawn from the udder contains a large number of air bubbles, and its specific gravity cannot be taken; after the expiration of an hour or so these have disappeared, and a specific gravity determination is possible. It was first observed by Recknagel that the specific gravity taken after the expiration of one hour was lower than the specific gravity subsequently obtained. $\mathrm{He}$ found the rise in specific gravity to be regular, more rapid at low temperatures than high ones, and to amount on the average to 001 . He attributed the change to an alteration in the volume of the casein.

Vieth completely confirmed Recknagel's observation, and found the average rise to be $\cdot 0013$; Bourcart also observed the phenomenon.

The author has studied Recknagel's phenomenon (as this change in specific gravity has been called). In about 70 per cent. of his experiments the rise in specific gravity has been observed, varying from 0015 to $\cdot 0003$, and averaging 0006 , while in 30 per cent. of the observations no rise in specific gravity was indicated.

The experiences of Babcock and Farrington agree with that of the author.

The author's experiments have confirmed the statement of 
Recknagel, that the rise is more rapid when the temperature is low than when high; the same ultimate specific gravity is attained whatever the temperature.

Recknagel's phenomenon appears to be unconnected with the milk-sugar ; it is possibly enzymic, as in one experiment the author found that the addition of a trace of salicylic acid delayed the rise, though, as the milk had to be well shaken to dissolve the salicylic acid, too much reliance cannot be placed on this result. It is possible that Recknagel's explanation is the correct one, and that an intra-molecular change takes place in the casein. An analogous change, manifested in a different manner, is kuown to take place in the fibrin of the blood. It is, however, difficult to reconcile the idea that it is enzymic, with the fact that the rise is more rapid at low than high temperatures.

The author's experiments on the change of density of cream by heating (Appendix A.) have rendered it probable that Recknagel's phenomenon is due largely to the increase of clensity of the fat on solidification.

Contrary to the author's former conjecture, there seem to be no particular periods of the year in which Recknagel's phenomenon is observed or not. Samples have been found at all seasons which show a marked change in specific gravity, while others examined almost simultaneously have shown no change.

It must be mentioned that Recknagel's phenomenon has been denied by some. Smetham attributes the change in specific gravity solely to the presence of air bubbles. The weight of evidence is, however, greatly against this view ; it is inconceivable that air bubbles generated by nilking a cow slıould be persistent for twelve hours, while if they are formed in the milk by other means, say by running through a separator, they disappear in one hour.

The final specific gravity is always taken as the true specific gravity of milk, and the term is so used in this volume.

The Estimation of Total Solids. - The total solids of milk are estimated by evaporating the water and weighing the residue.

Wanklyn's Method.-Wanklyn proposed to linit the time of drying to three hours at the temperature of boiling water; he weigherl 5. grammes in a platinum basin, kept it for three hours on a briskly boiling water-bath, and, after cooling in a desiccator, weigherl the resilue. This method has now entirely fallen into disuse, as the residne thus oblained still contained a quantity of water, which eould be driven ofl by further evaporation.

Method of Society of Public Analysts.-A rery obvious modification of this is to continue the drying on a water-bath or in an oven at $100^{\circ} \mathrm{C}$. till the weight is constant. This method has been adrepted ly the Society of Public Analysts. It is not, however, possible to attain alssolute constancy, as a decomposition 
due to heating takes place, and the weight continually slightly diminishes on further heating; for this reason the weight is usually considered constant when less than 1 milligramme per hour is lost on further drying. The method gives very good results, and duplicates agree closely ; but it is doubtful whether the results represent accurately the true total solids of the milk. First, an absolutely constant weight is not attained; and, next, the residue is markedly brown, indicating decomposition; the point taken as constancy is really a point where it may be assumed that the bulk of the water is driven off, and comparatively little decomposition has taken place.

The author has found by taking smaller quantities of milk -about 1 gramme-and spreading this over a large surface during evaporation, that a nearly white residue is obtained, and constancy of weight can be attained. It appears probable that the decomposition to which the browning is due takes place during the heating of the milk before evaporation is concluded. In support of this view it may be noted that Cazenenve and Haddon have observed that formic acid is produced by heating milk to the temperature of boiling water, and Johnstone has found that formic acid added to milk had an enormous influence on the results. The results obtained by the estimation of total solids by the evaporation of 1 gramine spread over a large surface, from which the water was very quickly driven off, were always slightly higher than when 5 grammes were used, when evaporation was very much slower.

In order to secure rapid evaporation, the milk has been spread over a large surface by the use of sea sand and other granular substances. Vieth has found that evaporation on sand gives practically the same results as direct evaporation in a basin.

Babcock's Method.-Babcock has used asbestos as a medium for spreading the milk over. The method as adopted by the Association of Official Agricultural Analysts (of America) is described on p. 100. The author has found Babcock's method most satisfactory, and finds it convenient to operate as follows:Place about 3 grammes of fine asbestos fibres in a small platinum basin, and ignite strongly (preferably in a muftle); after weighing, add about 5 grammes of milk, and again weigh as quickly as possible to the nearest milligramme. Place the basin for an hour or two on a water bath, and dry in a water-oven till constant in weight.

The residue thus obtained shows no signs of browning, and a constant weight, which shows no appreciable change on prolonged drying, can be obtained. The "total solids" by this method are somewhat hygroscopic, and care must be exercised. in weighing. 
Macfarlane's Method.-Macfarlane uses "chrysotile" or Canadian asbestos for this purpose; this substance cannot be ignited, being a hyclrated mineral, and for some reason, which is at present obscure, dloes not seem to be so satisfactory as the Italian asbestos. The residue obtained by drying on "chrysotile" is very distinetly brown, and the results are much lower than those given by other methorls.

Adams' Method.-Adams uses a paper coil, which is first dried at $100^{\circ} \mathrm{C}$. and weighed, for the estimation of total solids. The results thus obtained are frequently low.

Duclaux has proposed the use of sponge, and Ganntner of wood fibre; but these substances have never come into general use.

Drying, - The author has found that by evaporation in vacuo over sulphuric acid good results are obtained if the milk be spread on blotting paper or on asbestos; the result is slightly higher than when the drying is performed at $100^{\circ} \mathrm{C}$.

In order to shorten the time of drying, Gerber and Radenhauson experimented with acetic acid and alcohol. They found that by coagulating the casein with these substances a skin no longer formed on lieating, and the time of evaporation was materially shortened. For this reason the use of acetic acid, or alcohol, or a mixture of the two, has been largely adopted for the estimation of total solids. A much greater browning of the total solids takes place, and constant results are quite impossible of attainment when acetic acid or alcohol is used; by a somewhat close adherence to arbitrary conditions as to time of drying very fair results may, however, be obtained in this way in a short time, but the method cannot be recommended where accuracy is of importance.

If the smell be not objected to, it is better to use butyric acid in place of acetic.

It may sometimes be of importance to estimate the water driven off, instead of deducing it from the difference between the percentage of total solids and 100. To accomplish this, about 4 grammes of asbestos should be placed in a U-tube, and, after drying by passing a current of dry air, this should be weigher. About 5 grammes of milk should be weighed in, and the $U$-tube suspended in a beaker of water. This is connected with another weighed $U$-tube filled with pumice moistened with strong sulphuric acid, and provided with a bulb in which the bulk of the water can condense. A current of air (or preferably, hydrogen) Iried hy sulphurie acid should be passed through the tubes, and the water in the beaker boiled. After about three hours heating, the sulphurie acid tube should be removed, and, after cooling, weighed. The increase of weight of the sulphuric acid tube will give the weight of the water in the milk taken.

It is not advisable to dry the total solids at temperatures 
exceeding $100^{\circ} \mathrm{C}$., as the decomposition of the residue by heat is increased at higher temperatures.

Drying Apparatus.-For the drying of total solids the following conditions may be laid down for the drying apparatus :-

(1) The temperature must not exceed $100^{\circ} \mathrm{C} .\left(212^{\circ} \mathrm{F}.\right)$.

(2) The moisture must be removed as soon as it is converted into vapour.

The usual form of water-oven used consists of a water-jacketed metal box with a door to it; very little provision is made for the removal of the moisture, as no current of air is allowed to circulate through the whole of the interior.

Various forms of air-baths, with a regulator for maintaining a constant temperature of $100^{\circ} \mathrm{C} .\left(212^{\circ} \mathrm{F}\right.$.), have been proposed; of these, the best are those of Griffin and Adams. These do not give quite satisfactory results for milk analysis, because the temperature for which they are regulated is the temperature of the air in the bath, while the basins in which the milk is dried are heated to a somewhat higher temperature by conduction.

The following figures were obtained with a Griffin's air-bath ; a porcelain capsule filled with mercury was placed on various shelves in the bath, and the temperature of the mercury noted. The air had a constant temperature of $100^{\circ} \mathrm{C}$ : :-

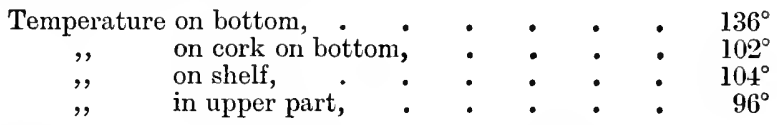

Constancy of temperature cannot be depended upon in an airbath; it is, therefore, preferable to use a water-oven. The author has devised a water-oven for milk analysis, which has given highly satisfactory results.

It consists of a jacketed copper box, opening only at the top, and closed with a movable lid; on the lid is a chimney about 1 foot high. The bottom portion of the jacket contains four 8-foot coils of thin copper tubing, which communicate with the exterior by four holes at the side of the bath, and with the interior by four holes, one in each corner. The jacket is closed, except for one opening, in which a condenser is placed. About 1 inch from the bottom a sheet of copper is fixed, in which is a round hole of diameter equal to half the width of the interior.

The jacket is filled with distilled water, which is heated either by a steam coil or a gas flame; perforated copper shelves are used to support the basins, \&c., containing the substances to be dried. The heating is chiefly done by conduction from the sides of the bath through the shelves; a current of hot air, approaching in temperature to that of boiling water, is always passing through the bath, and rapidly removes the vapour.

The condenser is supplied with cold water, and prevents loss 
of water. It conduces greatly to the efficiency of the bath to use distilled water, as no scale is produced on the coils and sides of the oven. To prevent loss of heat the oven may be lagged with felt, asbestos, or kieselguhr.

The most efficient condenser has been found to be a spiral coil of tubinc (preferably copper), which fits rather closely into a tube. The cold water enters at the top, and passes by a straight portion of the tubing to the lowest coil, whence it circulates upwards, and finds an exit at the top.

A diagrammatic figure of the bath will assist comprehension of the details (Fig. 2).

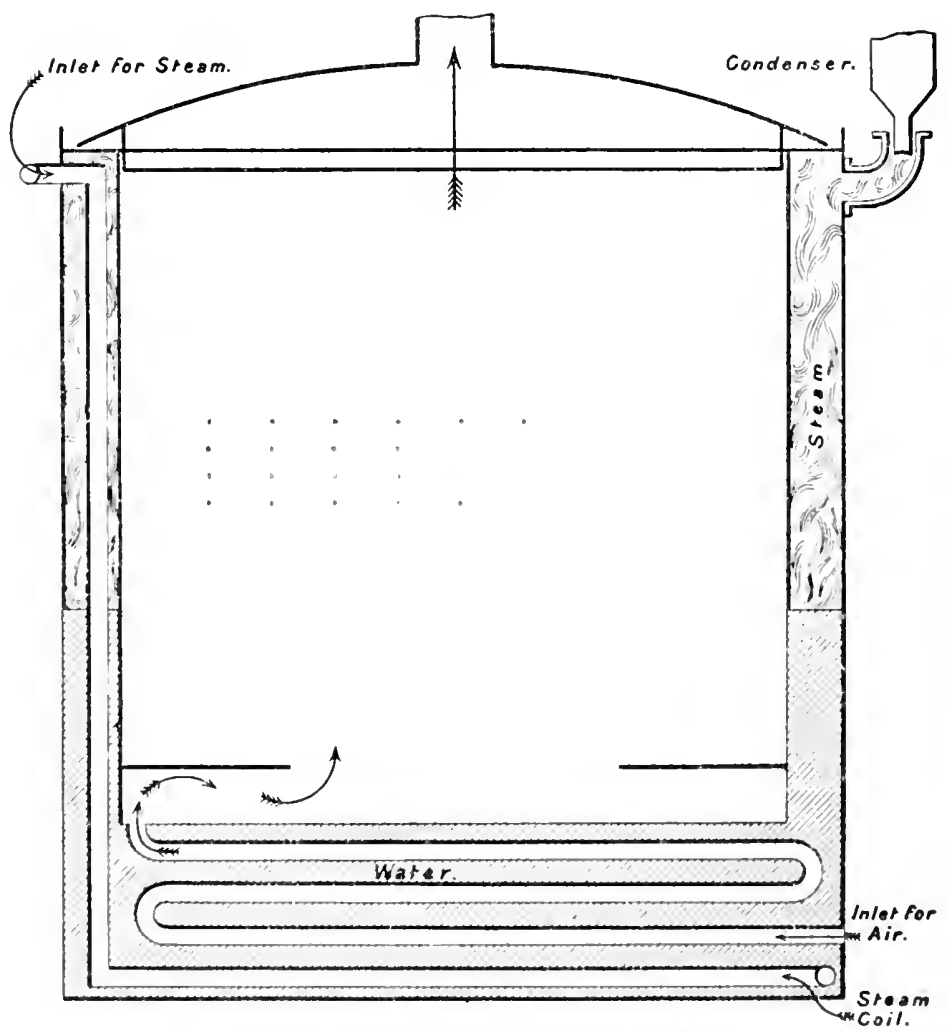

Fig. 2. -Diagrammatic View of Air-bath.

A very convenient water-hath for milk analysis is that devised by Vieth; the chief advantage of this lies in the lid, which, instead of merely having holes made in it in which the basins fit, has a copper ring fastened into each. This enables 
the basins to be taken off without contact between the fingers and the hot lid. This bath may be heated by a steam coil or a gas flame, and is conveniently supplied with water by a constant level apparatus.

If dry steam is available it is very convenient to use steam coils to heat the bath, and to condense the steam after it has passed the coils. The condensed steam can be used as distilled water, and is usually pure enough for all purposes. It is liable, however, to contain traces of copper, if this metal is employed in the construction of the coils, condenser, \&c.; if the boilers prime to any extent, it will also contain impurities (salts, scalepreventing composition, \&c.), derived from the boiler.

Estimation of Ash.-The residue of total solids serves excellently for the determination of the ash. By igniting over a small Bunsen flame, or an Argand burner, or in a muffle, a white ash can be obtained. The temperature must not be allowed to rise above a barely perceptible red heat, or distinct volatilisation of alkaline chlorides may occur. If the asbestos method of total solid estimation has been used, a somewhat higher temperature may be employed than if simple evaporation in platinum has been resorted to.

A more exact determination is obtained by evaporating a larger quantity of milk than is usually taken for total solid estimation-25 to 50 grammes-and gently igniting till thoroughly charred; the mass is extracted with hot water and filtered, the insoluble portion and the filter being (after washing) ignited at a red heat till white; this will give the insoluble ash.

By evaporating the filtrate and cautiously igniting at a low temperature, the soluble ash is obtained. The sum of the soluble and insoluble ash gives the total ash; the results obtained in this way are usually slightly higher (about 02 per cent.) than the ash obtained by ignition of the total solid residue.

If it be desired to further examine the ash, it is desirable to keep the insoluble ash separate from the soluble portion.

In the solution of the soluble ash the alkalinity may be determined by titration with $\frac{\mathrm{N}}{10}$ acid, methyl orange being used as an indicator; and the chlorine, by titration with standard nitrate of silver, using potassium chromate as indicator.

The insoluble ash is dissolved in a slight excess of dilute hydrochloric acid and the solution heated to boiling; a cold saturated solution of ammonium oxalate is dropped in slowly till the addition of a further drop gives no more precipitate. The precipitate is filtered off, washed, and ignited at a low temperature to convert the oxalate into carbonate; it is best to moisten the ignited precipitate with ammonium carbonate solution and re-ignite at a very low temperature. The precipitate, after weighing, is dissolved in dilute hydrochloric acid, keeping 
the bulk small; ammonia is added to alkaline reaction, and the small precipitate of calcium phosphate collected, ignited, and weighed. Its weight is subtracted from the previous weight, and the difference gives the weight of the calcium carbonate, which, multiplied by 4 , gives the calcium, or by 56 the lime, contained in it; the weight of the calcium phosphate multiplied by 3571 gives the calcium, or by 5419 the lime, contained in it. The total calcium or lime is the sum of the two.

The filtrite is made strongly ammoniacal by the addition of - 880 anmonia and allowed to stand twenty-four hours. The precipitated magnesium-ammonium phosphate is filtered off, washed with dilute ammonia, ignited, and the magnesium pyro-phosphate weighed. Its weight multiplied by $\cdot 21622$ will give the magnesium, and by $\cdot 36036$ the magnesia contained in it.

To the filtrate from this, magnesia mixture is added. The precipitate of magnesium-ammonium phosphate is filtered off after twenty-four hours and treated as above.

From the total weight of the two quantities of magnesium pyro-phosphate the phosphoric anhydride is calculated by multiplying by $\cdot 63964$; to this is added the phosphoric anhydride in the calcium phosphate calculated by multiplying the weight by .4581 .

The above method has proved satisfactory in the author's hands, though it takes no account of the traces of iron present, which is precipitated with the calcium phosphate, or the magnesium-ammonium phosphate. If desired, this may be estimater by dissolving up the precipitate of calcium phosphate and the first nagnesium-ammonium phosphate precipitate in dilute hydrochloric acid, and determining the iron colorimetrically as sulphide, ferrocyanide, or thio-cyanate.

To estimate alkalies, another portion of milk is ignited, as before, and the total ash dissolved in dilute hydrochloric acid and boiled; a few drops of barium chloride solution are added containing not more that $\cdot 1$ gramme of barium to 100 grammes of milk, and the boiling continued for some minutes. After some hours the precipitate of barium sulphate is filtered off, ignited, and weighed; its weight multiplied by 34335 will give the sulphuric anhydride in the milk. If an excess of barium chloride has been added, a little phosphoric acid, or ammonium phosphate, may now be dropped into the filtrate, though it is not necessary if the quantity of barium chloride given above has been employed. A quantity of ferric chloride solution sufficient to colour the solution brown is added, and the filtrate made alkaline with ammonia. 'The precipitate is well washed, and the filtrate evaporated and very cautiously ignited; the weight will give the alkaline chlorides. The residue is dissolved in water, and the solution shonld he quite clear; if it is not so, 
a little ammonium carbonate is added, the liquid evaporated to dryness, and the residue cautiously ignited ; the residue is again taken up witl water, the solution filtered and evaporated, and the residue cautiously ignited and weighed.

The cllorine in this may be titrated by standard silver nitrate, using potassium chromate as indicator. The potassium and sodium are calculated by the following formula :-

Let $\mathrm{IV}=$ weight of alkaline chlorides

and $\mathrm{C}=$ weight of chlorine therein.

The weight of sodium $=2.997 \mathrm{C}-1.4254 \mathrm{~W}$.

,,, potassium $=2 \cdot 4254 \mathrm{~W}-3 \cdot 997 \mathrm{C}$.

The potassium may be directly estimated by evaporating the solution of alkaline chlorides with an excess of platinum tetrachloride solution almost to dryness; the pasty residue is treated with 80 per cent. alcohol containing about 5 per cent. of ether, and washed repeatedly with this; the alcohol is passed through a weighed filter or, preferably, a Gooch crucible, and the precipitate is finally transferred to this and washed with ether. It is then dried at $100^{\circ} \mathrm{C}$. and weighed; the weight multiplied by .3056 will give the potassium chloride; this subtracted from the weight of the alkaline chlorides will give the sodium chloride.

The potassium chloride multiplied by 5244 will give potassium and by 6314 potash. The sodium chloride multiplied by 3932 will give sodium and by $\cdot 5299$ soda.

The above scheme of analysis has been worked ont so as to use as little milk as possible, as the anount available is sometimes linited. Many obvious modifications are available and will readily suggest themselves to analysts; thus the chlorine may be gravimetrically estimated, and, if the amount of milk be sufficient, the phosphoric acid may be separated from another portion by the molybdic acid method. Such modifications will be found in works on inorganic analysis, and need not be described in detail.

If boric acid be present, it will be found to interfere with the results of the analysis, as a portion of this remains in the insoluble ash; this may be removed by evaporating the acid solution to dryness and repeatedly evaporating with small portions of methyl alcohol. It will also interfere with the estimation of alkalinity in the soluble ash, as the alkali shown by methyl orange will be due to borax; the chlorine is best estimated in this case gravimetrically as silver chloride.

Boric acid is detected by slightly acidifying the ash with hydrochloric acid and dipping a piece of turmeric paper into the solution; on drying, this will assume a pinkish-brown coloration, turned a very dark green-almost black-on moistening with a solution of sodium bicarbonate. Or the ash may be moistened with dilute sulphuric acid and strong alcohol added; if boric 
acid be present, the alcohol will burn with a greenish flame on applying a match.

If boric acid be present, 25 to 50 grammes of milk should be taken for estimation. After addition of about 2 gramme caustic soda, the milk is eraporated and thoroughly charred by ignition; the residue is extracted by dilnte acetic acid, and well washed with as small a quantity of water as possible; the solution is tiltered into a small flask, to which a condenser is fitted, and distilled to dryness into about 10 c.c. of strong ammonia; eight successive portions of 10 c.c. each of methyl alcohol are added and distilled off.

About 1 gramme of lime is ignited in a capacious platinum basin in a muftle at the highest temperature attainable, and the basin and lime weighed. The ammoniacal distillate is now added and the liquid evaporated on the water bath; the basin is again ignited in a muffle and weighed. The increase of weight represents the boric anliydride.

Hehner prefers the use of a measured quantity of sodium phosphate solution of known strength for fixing the boric acid instead of ammonia and lime. He distils directly into the sodium phosphate solution, evaporates and cautionsly ignites. The weight of the residue of pyro-phosphate obtained from an equal measure of sodium phosphate solution is subtracted from the weight of the residue; the difference represents boric anhydride. It is necessary, however, to ignite very cautiously, as sodium phosphate is liable to spurt.

Thompson has shown that boric acid may be titrated with caustic alkali, using phenol-phthalein as indicator, provided at least 30 per cent. of glycerol be present. His directions are: 1 or 2 grammes of caustic sodia are added to 100 c.c. of milk and the whole evaporated to dryness in a platinum dish. The residue is thoroughly charred, heated with 20 c.c. of water and hydrochloric acill added drop by drop till all hut carbon is dissolved. The whole is transferred to a 100 c.c. flask, the bulk not being allowed to get above 50 to 60 c.c., and half a gramme of dry calcinm chloride added. To this mixture a few drops of phenol-phthalein solution are added, then a 10 per cent. solution of caustic soda, till a permanent pink colour is perceptible, and, finally, 25 c.c. of lime water. In this way all the phosphoric acid is precipitated as calcium phosphate. The mixture is made up to 100 c.c., mixed, and filtered through a dry filter. To 50 c.c. of the filtrate ( $=50$ c.c. milk) normal sulphuric acid is added till the pink colour is gone, then a few drops of methyl orange, and the addition of acid continued until the yellow is just changed to pink. $\frac{N}{5}$ caustic soda solution is added till the liquid assumes a yellow tinge, excess of sorla being aroided. At this stage all acids likely to be present exist as salts neutral to 
phenol-phthalein, except horic acid and a little carbonic acid, which last is expelled by a few minutes boiling. The solution is cooled, a little more phenol-phthalein added, and as much glycerin as will give at least 30 per cent. of that substance in the final solution, and titrated with $\frac{\mathrm{N}}{5}$ caustic soda till a permanent pink colour is produced. Each c.c. of $\frac{N}{5}$ caustic soda solution is equal to 0124 gramme crystallised boric acid or 0070 gramme boric anhydride.

Phosphoric acid can be separated from boric acid by precipitation as calcium phosphate, if not more than 2 per cent. of crystallised boric acid be present.

As excessive heating is apt to drive off boric acid, it is necessary to carry the charring so far only as will give a colourless solution.

Estimation of Citric Acid in Milk.-The proteids are precipitated by acid mercuric nitrate (p. 78) and a measured volume of the clear filtrate exactly neutralised with dilute caustic soda solution, using phenol-phthalein as indicator. A white precipitate of mercury and calcium phosphate and citrate is thrown down, collected on a filter and washed with water; it is removed from the filter, suspended in water, and a little dilute hydrochloric acid added; sulphuretted hydrogen is passed through to precipitate the mercury as mercuric sulphide. After filtration, the solution is boiled to remove sulphuretted hydrogen, a little calcium chloride added, and cooled. It is then carefully neutralised, phenol-phthalein being used as indicator; the precipitate of calcium phosphate is filtered off, and the solution boiled and concentrated to a small bulk; the calcium citrate is thus precipitated. This should be washed with boiling water, collected on a small filter and ignited. To the ignited residue an excess of standard hydrochloric acid is added and the excess titrated back with standard alkali, methyl orange being the best indicator. Each cubic centimetre of $\frac{\mathrm{N}}{10}$ hydrochloric acid used represents $.006+$ gramme of citric acid.

The result must be corrected for the volume of the fat and proteids thrown down as directed under milk-sugar.

Estimation of Milk-Sugar.-Milk-sugar is generally estimated indirectly, as it is not possible to isolate it quantitatively from milk in a state of purity. The following method may, however, be used to obtain an approximate determination of the milk-suga:" :-

By Alcohol.-To 10 c.c. of milk add 20 c.c. of 90 per cent. alcohol, well mix and filter; of the filtrate take 10 or 15 c.c., evaporate to dryness on a water-bath and dry at $100^{\circ} \mathrm{C} .\left(212^{\circ} \mathrm{F}\right.$.) 
till the weight is constant. Ignite the residue and weigh the ash. The weight of the residue less the weight of the ash will give the weight of the milk-sugar. The volume of the aqueous portion $m u<t$ be calculated; on mixing alcohol and water a contraction takes place; this with the quantities given is 4 c.c.; the rolume oecupied by the proteids is on the average .25 c.c.; the volume of the fat is olstained by multiplying the percentage by weight by 111 .

The jercentage of milk-sugar is ohtained by the following formula:-

$$
\mathrm{M}=\frac{30-(\cdot 6.5+\cdot 11] \mathrm{F})}{x} \times(\mathrm{R}-\mathrm{A}) \times 10 \times \frac{1}{\mathrm{U}}
$$

where

$$
\begin{aligned}
& y=\text { number of c.c. taken for estimation of residue. } \\
& 1)=\text { specific gravity of milk. } \\
& F=\text { percentage of fat in milk. } \\
& \mathrm{R}=\text { weight of residue. } \\
& \mathrm{A}=\text { a } \\
& \mathrm{M}=\text { wercentage of milk-sugar. }
\end{aligned}
$$

'l'his method has a tendency to yield too high results.

By the Polariscope.-The quickest metlod of milk-sugar estimation is hy the polariscope; before the milk can be polarised it is necessary to completely remove the fat and allouminoids, which intrere either by making the solution too opraque for reading or by polarising to the left.

Wiley's Method.-The investigations of Wiley have shown that mercury compounds are the most efficient for this purpose, of which "acid mercuric nitrate" is the most convenient This is prepared as follows:- Mercury is dissolved in twice its weight of nitric acid of sprecific gravity $1 \cdot 42$, and, after solution, an equal bulk of water is alded.

Basic lead acetate has also been used to remove fat and proteids, but Wiley has proved that the results are not accurate, owing to the incomplete removal of proteids. Still more inaccurate is the use of acetic acid, followed by boiling, which has been recently recommended ly lilyth.

Wiley-Ewell Method.-Wiley and Ewell give the following method as the lest for estimating milk-sugar by the polariscope :Thoy user a Schmilt \& Hansel polarimeter, with which 200 millimetres of a solution of $3 \cdot 2 \cdot 91$ grammes of milk-sugar in 100 c.e. ruat 100 divisions of the scale. They take $65 \cdot 82$ grammes of milk, ackl lo e.c. of acid mercuric nitrate solution (in this case the solution of moreury in nitric acid is diluted with 5 rolumes of water), and dilute to 100 c.c. A similar quantity of milk is taken, 10 c.c. of acid mercuric nitrate afleded and diluted to 200 c.c. Each of these solutions is woll mixed, filtered, and polarised in a $100 \mathrm{~mm}$. tubse.

Calling the realing of the solution obtained from 100 c.c. $x$, 
and that obtained from 200 c.c. $y$, the true percentage of milksugar is $\frac{x y}{4(x-y)}$.

The double dilution does away with any correction for the volume of the precipitated fat and proteids. The rationale of the process lies in the fact, that while the percentage of milksugar and the volume of the precipitate are constant, the total volume varies.

Let $m$ be the percentage of milk-sugar, and $v$ the volume of precipitate ;

then

$$
x=4 m \times \frac{100}{100-v} \text {. . . . . . . . }
$$

and

$$
y=2 m \times \frac{200}{200-v} \cdot . . . . . .
$$

$$
\begin{aligned}
\text { Now } \quad \frac{x y}{4(x-y)}=\frac{8 m^{2} \times \frac{100 \times 200}{(100-v)(200-v)}}{4\left(4 m \times \frac{100}{100-v}-2 m \times \frac{200}{200-v}\right)} \\
=\frac{8 m^{2} \times 100 \times 200}{4(4 m \times(200-v) \times 100-2 m \times(100-v) \times 200)} \\
=\frac{8 m^{2} \times 100 \times 200}{4(4 m \times 100 \times 200-2 m \times 100 \times 200-4 m \times 100 v+2 m \times 200 v)} \\
=\frac{8 m^{2}}{8 m}=m .
\end{aligned}
$$

The volume may be calculated thus :-From (1) we see that

or

$$
\begin{aligned}
100-v & \quad \frac{4 m \times 100}{x} \\
v & =100-\frac{4 m \times 100}{x} \\
= & 100-\frac{4 x y \times 100}{4 x(x-y)} \\
= & 100-\frac{y \times 100}{x-y} \\
= & \frac{100 x-200 y}{x-y}
\end{aligned}
$$

which may be similarly deduced from (2).

This method not only allows of an accurate estimation of milk-sugar to be made in milk without correction of any kind, but enables the volume of the precipitate of fat and proteids to be calculated.

The author, in conjunction with Boseley, has shown that the experimental error of Wiley and Ewell's method is, however, very appreciable ; and, though correct in principle, it is not so accurate in practice as originally claimed. 
The greatest delieacy of Wiley and Ewell's method-i.e, the point at which the influence of unavoidable errors in reading is least-is obtained when the volume of water added to the more dilute solution is equal to the volume of the milk taken, less that of the fat and preeipitated proteids.

Vieth Method.--Vieth, when using the small Mitscherlich half-shadow polariscope made by Schmidt and Hrensch, prefers to add the stronger mereurie nitrate solution, deseribed above, direet to the milk, and to polarise the resulting filtrate. He finds the volume of preeipitated proteids from 100 c.e. of milk to amount on the average to 3 e.c., and, consequently, adds 3 c.c. of acil mereuric nitrate solution to allow for this. The method is earried out as follows:--Measure 50 c.c. of milk into a small flask, add 1.5 c.c. of acid mereuric nitrate, and well mix by shaking violently; pour the mixture on to a filter, and fill a polarimeter tulse with the filtrate; polarise, and correct the reading for that obtained in a blank reading-i.e., by reading a tube filled with water.

As the $[\alpha]_{\mathrm{D}}$ of milk-sugar is $52.5^{\circ}$, the reading, if in angular degrees, ean be eonverted into percentages of milk-sugar by the following formula-

$$
m=\frac{100 \times 100}{52 . \overline{5} \times 1} \times r .
$$

Where $m=$ number of grammes of milk-sugar per 100 c.c. of solution polarised.

$I=$ length of tube in millimetres.

$r=$ rearling in angular degrees.

If a tube of 198.4 millimetres be used (these tubes are supplied with the instrument used by Vieth), the formula becomes

$$
m=\frac{r}{1 \cdot 042^{\circ}}
$$

If the length of the tube be 200 millimetres, the formula is

$$
m=\frac{r}{1 * 1.5}
$$

The resulting figure representing milk-sugar in the solution polarised must be submitted to correetion.

The volume of the liquirl from which the fat and proteids have been precipitated is the volume of the milk plus that of the moreuric nitrate mimus that of the proteid precipitate and fat.

As the volume of the mercuric nitrate was purposely made equal to that of the proteids, both of these may be neglected, one compensating for the other.

Taking the volume of the milk as 100 e.e., the volume of fat in this will be the perecntage by weight of fat multiplied by the specific gravity of the milk, divided by the specific gravity of the fat. 
The milksugar may be either calculated as hydrated or anhydrous sugar; it is usual to calculate it in milk analysis as anhydrous sugar.

The following formula expresses the percentage of anhydrous milk-sugar in the milk :-

$$
\begin{aligned}
m^{1} & =\underset{1 \cdot 042}{r} \times \frac{100-\frac{\mathrm{F} d}{993}}{100} \times \frac{1}{d} \times 95, \\
m^{1} & =\text { percentage of anhydrous milk-sugar by weight, } \\
r & =\text { reading, } \\
\mathrm{F} & =\text { percentage of fat by weight }, \\
d & =\text { specific gravity of milk. }
\end{aligned}
$$

For the expression $\frac{\mathrm{F} d}{.93}$ it is usually exact enough to employ the expression $\mathrm{F} \times 1 \cdot 11$.

As an example let us suppose that

$$
\begin{aligned}
r & =5 \cdot 5^{\circ} \\
\mathrm{F} & =4 \cdot 1 \\
d & =1 \cdot 032 \\
m^{1} & =\frac{5 \cdot 5}{1 \cdot 042} \times \cdot 9545 \times \frac{1}{1 \cdot 032} \times \cdot 95=4.58 \text { per cent. }
\end{aligned}
$$

Vieth states that when cream is analysed by this method, it is necessary to dilute with an equal bulk of water, the results being of course doubled.

Richmond-Boseley Method.-The author, in conjunction with Boseley, has shown that the calculation necessary in Vieth's method can be elininated by adding to 100 c.c. of milk

(a) A quantity of water in c.c. equal to $\frac{1}{10}$ degree of specific gravity.

,", ,",

$$
\begin{aligned}
& , \text { the fat } \times 1 \cdot 11 \text {. } \\
& \text { of milk-sngar. }
\end{aligned}
$$

(d) 3 c.c. of acid mercuric nitrate.

The percentage of milk-sugar can be read off directly in scale readings.

The values of $c$ are:-For polariscopes reading angular degrees-

With $198 \cdot 4$ mm. tube, $10 \cdot 0$ c.c.

$$
\text { , } 200 \quad, \quad \text {, } \quad 10 \cdot 85 \text {,", (divide readings by } 2.5 \text { ). }
$$

For the Laurent sugar scale $\left(100^{\circ}=21.67\right.$ angular degrees $)$ -

With $200 \mathrm{~mm}$. tube, $2 \cdot 33$ c.c. (divide readings by 5 ).

$$
\begin{aligned}
& \text {, } 400 \quad, \quad 2 \cdot 33,, \quad \text { ( , , , } 10 \text { ). } \\
& \text { " } 500 \quad, \quad 2 \cdot 33,,(\quad,, \quad, \quad 12 \cdot 5)
\end{aligned}
$$

For the Ventzke scale $\left(100^{\circ}=34 \cdot 64\right.$ angular degrees $)$ -

With $200 \mathrm{~mm}$. tube, 6.65 c.c. (divide readings by 3 ).

$$
\begin{aligned}
& \text { " } 400 \quad, \quad 6 \cdot 65,, \quad \text { ( , , , } 6 \text { ). }
\end{aligned}
$$

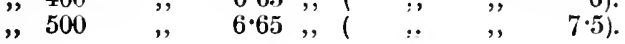


Deniges' Method.-Deniges objects to the use of mercuric nitrate because it necessitates the use of a glass polarimeter tube, brass being attacked by the solution, and prefers the use of meta-phosphoric acid to precipitate the proteids. His method is as follows:- Prepare sodium meta-phosphate by carefully heating sodium-ammonium-hydrogen phosphate (microcosmic salt) in a platinum dish, till it is completely fused and no longer evolves gas. Pour on a cool plate, break up, and preserve in a stoppered bottle. Prepare a 5 per cent. aqueous solution by boiling $5 \cdot 7$ grammes of the finely powdered salt with $50 \mathrm{c} \mathrm{c}$. of water for five minutes, at the expiration of which time solution should be complete. Add immediately 50 c.c. of cold water, cool uniler a jet of water, and make up to 100 c.c. Twelve per cent. of the meta-phosphate is converted into ortho-phosphate by the boiling, and this is allowed for by taking $5 \cdot 7$ grammes instead of 5 grammes.

Add 25 c.c. of this freshly prepared solution to 10 c.c. of milk, then 60 c.c. of water, and 3 c.c. of acetic acid ; mike up to 100 c.c. and filter; after rejecting the first few drops, fill a polarisation tube with the filtrate. A $500 \mathrm{~mm}$. tube is to be used, if possible, in preference to one of less length. It is hardly necessary to make any correction for the volume of the precipitate on account of the great dilution. As only 10 c.c. of milk are taken and diluted to 100 c.c., a very good polariscope must be used if accuracy is required. Unless glass polarisation tubes are unobtainable, the use of mercuric nitrate is preferable; an advantage of employing mercuric nitrate is that citric acid can be estimated in the same solution.

Fehling's Solution Method.-Another method, which is largely employed for the estimation of milk-sugar, depends on the oxidation of the sugar by alkaline cupric solution, and the consequent reduction of the copper to the state of cuprous oxide.

The alkaline cupric solution cannot be applied direct to milk, as the proteils are somewhat attacked by the alkaline solution.

The solution usually employed is Fehling's cupric tartrate solution, which is prepared by dissolving $\mathbf{3 4 . 6 3 9}$ grammes of pure, crystallised copper sulphate in water, and diluting to 500 c.c.; 173 grammes of pure sodium-potassium tartrate (Rochelle sait), and 51 to 55 grammes of sodium hydroxide of good quality are also dissolved in water and made up to 500 c.c. Equal parts of these solutions are mixed (preferably at the time of making the test) to form Fehling's solution. It is convenient to use a 50 per cent. solution of eaustic sorla solution, which has been filtered clear through asbestos, for making the alkaline tartrate solution. The percentuge of sodium hydroxide is estimated in this hy titration, and such a quintity is weighed out as will give 51 grammes. Most of the impurities in ordinary 
caustic sodi are insoluble in a 50 per cent. solution, so that this affords a ready means of purification.

Before estimating the milk-sugar in milk, the fat and proteids must be removed; this may be accomplished by the following methods :-

(1) By diluting 10 c.c. of milk to about 100 c.c., adding $1 \cdot j$ c.c. of 10 per cent. acetic acid solution and boiling; after cooling, the whole is made up to 100 c.c. (Citric acid may be substituted for acetic acid.)

(2) Add to 25 c.c. of milk about 200 c.c. of water and 10 c.c. of copper sulphate solution, as above; carefully neutralise with dilute caustic alkali solution, and make up to 250 c.c. This solution contains a small amount of copper.

(3) Carefully neutralise 10 c.c. of the filtrate from the milk which has been treated with acid mercuric nitrate with caustic alkali till exactly neutral to phenolphthalein, filter, and pass sulphuretted hydrogen through the filtrate; filter, to separate the precipitated mercuric sulphides, and boil the filtrate to expel sulphuretted hydrogen. Make up to 100 c.c. (The mercury may be precipitated by pù sphoric acid; add a small quantity of phosphoric acid or a soluble phosphate to the filtrate from mercuric nitrate; exactly neutralise, filter and wash the precipitate, and make up to 100 c.c.)

(4) Deniges' method, as above described.

Each of the methods of separating the fat and proteids gives a solution, of wiich 50 c.c. contains the milk-sugar in 5 c.c. of milk, which, in a normal milk, contains about $\frac{1}{4}$ gramme of milk-sugar.

The following modes of manipulation are among those in use:-

(1) O'Sullivan's Method.-Measure 50 c.c. of the filtrate into a beaker, and place this in a briskly-boiling water bath; dilute a mixture of 30 c.c. of the copper solution, and 30 c.c. of the alkaline tartrate solution, with about twice its volume of water, and boil over a flame. When the milk-sugar solution has attained the temperature of the water-bath, pour into it the Fehling's solution, and keep on the water-bath for 13 to 15 minutes. Filter through a small tilter, or, preferably, through a Gooch crucible, leaving the cuprous oxide as much as possible in the beaker; immediately the last drops of solution have been poured on the filter, pour boiling well-boiled water on the precipitate, and wash several times by decantation. Finally, transfer tlie precipitate to the filter, and wash well with boiling water. If a filter is used, transfer it to a small crucible, and ionite over a very small flame till the filter is thoroughly charred, and then gradually increase the flame till the lighest available temperature is obtained. It is better to use a porcelain crucible than a platinum one, because platinum is permeable to reducing gases from the flame, and complete oxidation cannot be obtained. If 
a Gooch crucible is used it should be ignited in a muffle, and the cuprous oxide thus converted into cupric oxide. The weight of the cupric oxide multiplied by 6024 will give the weight of hydrated milk-sugar. If a filter is used, the weight of the ash must, of course, be deducted ; this should be obtained by igniting filters of the same kind, which have been treated in exactly the same manner as in the estimation of milk-sugar, using the same quantity of Fehling's solution, but omitting the milk-sugar. 'This is necessary, because the filter takes up mineral matter from the Fehling's solution. If this precaution is taken, filtration through paper is satisfactory.

The author finds it far more satisfactory, instead of employing an arbitrary factor, which is not of absolute exactitude, to weigh out a quantity of pure milk-sugar, approximating as nearly as possible to that contained in the solution to be tested, and to estimate the copper oxide obtained by treating it side by side with the actual estimation. The extra trouble is nominal, and the slight variations in the factor, due to dilution, dc., are thereby compensated.

(2) Mein's Method.-The same quantities of solutions are used, but the Feliling's solution, instead of being diluted with water, is mixed directly with the milk-sugar solution, placed over a naked tlame, and raised as rapidly as possible to boiling; boiling is continued for exactly four minutes. The solution is filtered throum a tube about $1 \mathrm{~cm}$. widc, constricted at the end, and plugged witlı asbestos. This tube is weighed, after having been gently ignited, and the filtration is hastened by means of a water pump; a small fumnel is used to pour the solution into the tubc. 'The precipitate of cuprons oxide is washed with boiling well-boiled water, and transferred to the tube When the precipitate is well washed, the tube is sucked as dry as possible by the pump. It is then detached from the filter pum], and connected with a hydrogen apparatus, being clamped in a horizontal position. A gentle current of hydrogen is passed through, and the tube cautiously heated by a small flame till all the cuprous oxide is reducel to metallic copper, and the tube is dry; it is allowed to cool while the hydrogen is passed slowly through, and weighed. The increase of weight gives the amount of copper reduced. Table $X$. should be used to ealculate the amount of liyclrated milk-sugar from the copper.

The lable is used as follows:-Look up in the table the weinht of copper (fxpressed in milligrammes) nearest to the weight oltained, and calculate trom this, by a proportion sum, the corresponding weight of milk-sugir.

Thus, if the weight of copp'r is $33.4 \cdot 1$ milligrammes, take the weight of milk-sugar corresponding to 335 milligrammes.

$$
335=251 \cdot 6.33441=251 \cdot 6 \times \frac{334 \cdot 1}{335}=250 \cdot 9 .
$$


By taking a weight of milk-sugar as nearly as possible equal to that in the solution, and estimating the copper reduced by this, the calculation can be made in a similar manner from this.

The cuprous oxide may be reduced in a Gooch crucible by placing it in a muttle, and passing in a current of hydrogen.

Table X.-For Calculating the Amount of Milk-Sugar from the Quantities of Copper Reduced.

This table is due to Wein.

\begin{tabular}{|c|c|c|c|c|c|}
\hline Copper. & Mrilk-Sugar. & Copper. & Milk-sugar. & Copper. & Milk-Sugar. \\
\hline 120 & $86 \cdot 4$ & 215 & $158 \cdot 2$ & 310 & $232 \cdot 2$ \\
\hline 125 & $90 \cdot 1$ & 220 & $161 \cdot 9$ & 315 & $236 \cdot 1$ \\
\hline 130 & $93 \cdot 8$ & 225 & $165 \cdot 7$ & 320 & $240 \cdot 0$ \\
\hline 135 & $97 \cdot 6$ & 230 & $169 \cdot 4$ & 325 & $243 \cdot 9$ \\
\hline 140 & 1013 & 235 & $173 \cdot 1$ & 330 & $247 \cdot 7$ \\
\hline 145 & $105 \cdot 1$ & 240 & 176.9 & 335 & $251 \cdot 6$ \\
\hline 150 & $108 \cdot 8$ & 245 & $180 \cdot 8$ & 340 & $255 \cdot 7$ \\
\hline 155 & $112 \cdot 6$ & 250 & $184 \cdot 8$ & 345 & $259 \cdot 8$ \\
\hline 160 & $116 \cdot 4$ & 255 & $188 \cdot 7$ & 350 & $263 \cdot 9$ \\
\hline 165 & 1202 & 260 & $192 \cdot 5$ & 355 & $268 \cdot 0$ \\
\hline 170 & $123 \cdot 9$ & 265 & $196 \cdot 4$ & 360 & $272 \cdot 1$ \\
\hline 175 & $127 \cdot 8$ & 270 & $200 \cdot 3$ & 365 & 276.2 \\
\hline 180 & $131 \cdot 6$ & 275 & $204 \cdot 3$ & 370 & $280 \cdot 5$ \\
\hline 185 & $135 \cdot 4$ & 280 & $208 \cdot 3$ & 375 & $284 \cdot 8$ \\
\hline 190 & $139 \cdot 3$ & 285 & $212 \cdot 3$ & 380 & $289 \cdot 1$ \\
\hline 195 & $143 \cdot 1$ & 290 & $216 \cdot 3$ & 385 & $293 \cdot 4$ \\
\hline 200 & $146 \cdot 9$ & 295 & $220 \cdot 3$ & 390 & $297 \cdot 7$ \\
\hline 205 & $150 \cdot 7$ & 300 & $224 \cdot 4$ & 395 & $302 \cdot 0$ \\
\hline 210 & $154 \cdot 5$ & 305 & $225: 3$ & 400 & $306 \cdot 3$ \\
\hline
\end{tabular}

Volumetric Method.-Instead of weighing the copper reduced, the determination may be made volumetrically. The estimation is carried out as follows:-Place the solution obtained by removing the proteids by Methods 1,3 , or 4 (given above) in a burette graduated to $\frac{1}{10}$ c.c. Place in a small flask 10 c.c. of Fehling's solution accurately measured (or 5 c.c. of each of the copper and alkaline tartrate solutions), diluted with 30 c.c. of water, and bring this to the boil by means of a small flame. Run in the sugar solution, adding 2 c.c. at a time, and boiling between each addition. When the blue colour of the liquid has nearly disappeared the sugar solution should be added in smaller amounts, but the titration should not be unduly prolonged. The end of the reaction is reached when, on removing the flame, and allowing the cuprous oxide to settle, the supernatant liquid appears colourless or faintly yellow when viewed against a white surface. To make sure that the copper is all reduced a few drops of the liquid may be filtered through a small filter into acetic acid, and potassium ferrocyanide added. 
If copper be still present, a brown coloration will be observed. It is advisahle to repeat the titration, using $\cdot 2$ c.c. less of the milk-sugar solution, which may be all adched at once, and the boiling continued for four minutes; a small excess of copper should be present, and this is reduced by small additions of the sugar solution. Should no copper be present, the experiment must be repeated, using a still smaller amount of liquid. Ten c.c. of Fehling's solution is reduced by 0676 gramme of hydrated milk-sugar; this quantity is, therefore, contained in the volume of sugar solution used for titration.

For example, $10 \cdot 260$ grammes of milk were, after removal of proteids, made up to 100 c.c. Ten c.c. of Fehling's solution required $13 \cdot 0$ and $13 \cdot 1$ c.c. of this in two experiments, mean $13 \cdot 05$ c.c.; therefore,

$\begin{array}{ll}13 \cdot 0.5 \text { c.c. contain } & .0676 \text { gramme milk-sugar. } \\ \text { and } 1100 \text { c.c. contain } & .518 \\ 10.260 \text { grammes nilk contain } .518 & , \\ =5.05 \text { per cent. hydrated milk-sugar. } \\ =4.80 \text { per cent. anhydrons milk-sugar. }\end{array}$

It is advisable to titrate a solution of pure milk-sugar containing about 5 gramme per 100 c.c. to obtain the exact value of 10 c.c. of Fehling's solution.

Pavy's Solution Method.-Pavy's ammoniacal cupric solution may be substituted for Fehling's solution. This is prepared by mixing 120 c.c. of Fehling's solution, 400 c.c. of 12 per cent. caustic soda solution, and 300 c.c. of strong ammonia (specific gravity $\cdot 880)$, and diluting the whole to a litre.

One luundred c.c. of this solution are placed in a small flask, which is closed by an indit-rubber stopper with two holes; through one passes the nozzle of a Mohr's burette. and through the other a bent tube, which dips into a flask containing cold water to absorb the ammonia given off. Hydrogen or coal gas may be passed through the flask containing the Pary solution.

The solution is brought to boiling, and the sugar solution run in gradually, till the blue colour of the liquid is destroyed, the boiling being maintained the whole time, and the sugar solution run in slowly towards the end.

As the reaction takes place somewhat slowly, boiling must be continued for a few minutes hefore it can be finally lecided that the blue colour is permanent.

It is necessary to repeat the titration, adding a little less of the solution, as with Fehling's solution. This may be advantageously added all at once, ind the boiling continued for five minutes. If the boiling be unduly prolonged, the ammonia may be boiled ofl, and cuprous nxide will then begin to deposit; in order to avoid this, Shenstone places a tapped funnel in the cork, by menns of which an addition of strong ammonia can be made if necessary. 
Stokes and Bodmer strongly recommend this method, and state that the reducing power of milk-sugar is 52 per cent. of that of glucose-i.e., 100 c.c. of Pavy solution $=\cdot 0961$ gramme of milk-sugar.

It is advisable to standardise the Pavy's solution on a solution of pure milk-sugar containing $\cdot 5$ granme per 100 c.c.

Hehner has shown that by varying the proportion of salts in solution, such as alkaline tartrates and carbonates, the accuracy of the results is affected; by standardising the solution at the time of using with a solution of pure milk-sugar, the results are, however, reliable enough for estimating the milk-sugar in milk.

Allen has modified the procedure by placing a layer of petroleum over the Pavy solution, and dispensing with the cork. This enables an ordinary burette, or even pipette, to be used.

Estimation of Cane Sugar in Milk. - Cane sugar is sometimes added as an adulterant of milk, but the determination is more often required in the case of condensed milks.

An approximate estimation may be made by estimating the sugar by precipitation with alcohol, and the milk-sugar by Fehling or Pavy solution; the difference between the two will not be far from the cane sugar.

Muter Method.-Muter estimates as follows: 10 grammes of milk are evaporated to dryness on 4 grammes of hydrated calcium sulphate with frequent stirring, so that nothing sticks to the basin. The dry residue is powdered, placed in a dried filter, and extracted with ether in a Soxhlet apparatus. The residue, together with the filter, is transferred to a beaker, 20 c.c. of hot (not boiling) water added, and the whole well stirred; 30 c.c. of rectified spirit $\left(60^{\circ}\right.$ overproof, sp. gr. $\left.\cdot 825\right)$ are then added, and the mixture allowed to cool, stirring occasionally. When cool it is thrown on a fiiter and washed with proof spirit till the filtrate measures 120 c.c. 60 c.c. are evaporated in a dish on the water-bath and the residue weighed; the residue is then ignited and the ash weighed, the weight of the residue less that of the ash being the total sugar. In the other 60 c.c., the milk-sugar is estimated by Felıling's or Pary's solution; the difference between this and the total sugar is cane sugar. A deduction should be made from this of

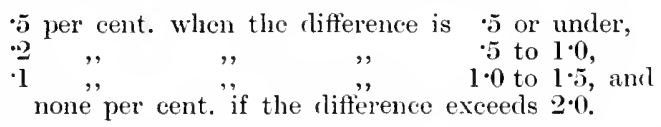

This method is stated to give fair results with percentages of cane sugar exceeding a half per cent.

The cane sugar may also be estimated by determining the total polarisation of the sample as directed for milk-sugar, and by estimating the milk-sugar gravimetrically or volumetrically by Pavy's or Fehling's solution. The difference between the 
percentage of anhydrous milk-sugar found by reduction of copper and that deduced from the polarisation divided by 1.217 will give the percentage of cane sugar. This method yiclds excellent results with mixtures of fresh milk and cane sugar, and with many samples of sweetened condensed milks, but is apt to lead to figures below the truth, if the milk has been much heated, owing to the reduction in the rotatory power of milk-sugar under these conditions.

Stokes-Bodmer Method.-Stokes and Bodmer prefer to estimate the milk-sugar by titration with Pavy's solution (Fehling's solution can be substituted for this), to invert the cane sugar by hoiling with 2 per cent. of citric acid for ten minutes, and then to estimate the combined milk-sugar and resulting mixture of glucose and fructose by titration; the difference between the two figures will be due to the products of hydrolysis of cane sugar. In this case it is advisable to standardise the solution on a mixture of milk-sugar and inverted cane sugar in about the same proportions as found in the milk. The determinations may also be made gravimetrically.

By Invertase. - The best method of estimating cane sugar depends on the hydrolysis of cane sugar by invertase, the enzyme of yeast. This is carried out as follows:-Estimate the rotation due to milk and cane sugar by polarisation of the solution obtainerl by precipitation with mercuric nitrate (100 c.c. of milk should be taken). 25 c.c. of the solution are placed in a flask, a drop or two of phenol-phthalein added, and dilute caustic soda solution run in till neutral. 'This solution is fiitered into a 50 c.c. flask, and the precipitate washed with water till the filtrate and washings measure about 45 c.c. 05 gramme of invertase, or 1 gramme of yeast, is added, together with a drop of acetic acid and a few drops of tolucne, and the whole made up to 51) e.c. The flask is corked and allowed to remain at about $55^{\circ}\left(131^{\circ} \mathrm{F}\right.$.) for tive hours. A little alumina cream is added and the whole made up to 55 c.c., tiltered, and polarised; the temperature at which the solution is polarised should be noted. The realing should be multiplied by $\frac{5.5}{2.5}=2 \cdot 2$; the reading due to cane sugar is fouml by the formula

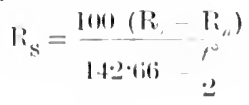

$$
\begin{aligned}
& l_{s}=\text { rotation due to smereste. } \\
& R,=\text {, lefore insersion. }
\end{aligned}
$$

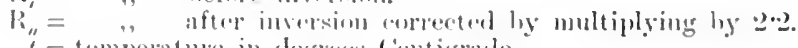

$$
\begin{aligned}
& i=\text { temperature in tegress centigrale. }
\end{aligned}
$$

The percentage of canc sugar is calculated from the rotation doducerl from this formula by the method giren for milli-sugar, 
bearing in mind that the $[\alpha]_{D}$ of cane sugar is $66.5^{\circ}$ instead of $52.5^{\circ}$, and that it does not require to be converted into anhydrous sugar.

Other Methods.-An approximation to the percentage of cane sugar can be obtained by determining the total polarisation, and deducing the milk-sugar by multiplying the ash by 6.5 . This method serves for controlling the preparation of condensed milk, but is of course of ouly approximate accuracy.

Another method, which gives fair approximate results, is to calculate the solids not tat $(a)$ from the specific gravity and percentage of fat, $(b)$ from the percentage of ash by multiplying by 12. The cane sugar will be represented by $a-b$.

Cotton's Method of Detecting Cane Sugar.-Cotton gives the following test for cane sugar in milk:-10 c.c. of the milk are mixed with 5 gramme of powdered ammonium molybdate and 10 c.c. of dilute hydrochloric acid $(1: 10)$. In a second tube 10 c.c. of milk of known purity, or 10 c.c. of a 6 per cent. solution of lactose, are similarly treated. The two tubes are placed in the water-bath and the temperature gradually raised. At about $80^{\circ} \mathrm{C}$. the milk, if aclulterated with saccharose, assumes an intense blue colour, whilst the genuine milk, or solution of lactose, remains practically unaltered. On boiling, these also turn blue, but to a less extent than the adulterated milk.

This test will detect $\cdot 1$ per cent. of cane sugar, but if this substance be added to milk, larger quantities are almost invariably added.

\section{Detection and Estimation of Starch in Milk.-Starch} is occasionally added to milk as an adulterant, and can be detected by the blue colour given by iodine; the iodine test is best applied to the whey, as the proteids of milk somewhat interfere.

Starch cannot be estimated with any great exactitude, as it becomes partly converted into other bodies in milk, either by means of an enzyme or by micro-organisms.

To estimate it, the milk should be raised to boiling and cooled; the milk-sugar should be estimated by one of the gravimetric methods given above, preferably by that of Wein. 20 c.c. of milk should be diluted to about 95 c.c., 3 c.c. of 10 per cent. acetic acid added, and the whole warmed to abont $80^{\circ} \mathrm{C}$, cooled and made up to 100 c.c. 50 c.c. of the filtrate should be carefully neutralised, and warmed to $65^{\circ} \mathrm{C} .\left(150^{\circ} \mathrm{F}\right.$.) ; 2 c.c. of a diastase solution (containing the diastase from 2 grammes of malt) should be added, and the solution kept at $65^{\circ} \mathrm{C}$. for two hours. At the expiration of that time it should be raised to boiling and evaporated on the water-bath to less than 25 c.c.; a little alumina cream should be added, if the solution be not clear, and the total made up to 25 c.c. This should be filtered and polarised. The 
copper reduced by 10 c.e. of this solution should be estimated by Wein's method.

The results should be calculated as follows:-Multiply the polarisation by 25 ; the result will be the polarisation due to milk-suњar, maltose, and dextrin; ealculate, from this and the determination of milk-sugar, the polarisation due to maltose and dextrin.

Calculat" the colper reduced from the 10 c.e. of diluted filtrate $=4$ c.c. of milk by the table on p. 8.5 , and subtract from this the milk-sugar present in this as ealculated from the first estimation; the difference multiplied by $1 \cdot 2$ will represent maltose. The polarisation lue to maltose can be ealculated, using the value $137^{\circ}$ for the $[\alpha]_{D}$, and the difference will be due to rlextrin. From this the percentage of dextrin can be ealeulated, using the value for $[\alpha]_{D}$ of $200^{\circ}$.

The percentage of dextrin p/us that of the maltose divided by 1.0 .56 will give that of the stareh.

An approxinate estimation may be made by subtracting from the solids not fat the ash multiplied by 1 ?

The estimation of starch is unsatisfactory, even if no other foreign sumar be present; if other sugars have also been added, it is nearly impossible to estimate them.

The Estimation of Fat.-More attention has perhaps been paid to the estimation of fat in milk than of any other constituent. The methods are very numerous, and may conveniently be divided into three classes:-

(1) Cravimetric methods, in which the fat is separated from the milk by a suitable solvent, and weighed after evaporation of the solvent.

(2) Volumotrie methods, in which the fat is separated from the milk by suitable means, and its rolume measured.

(:) Indirect methods, in which the amount of fat is deduced from the determination of some physical property.

of these methods the gravimetrie methods are undoubtedly the most accurate, though they are all to a certain extent tedious and not capable of use by unskilled persons.

The solvent chirfly used for extracting the fat is ether, which is convenient on account of the low boiling point and heat of volatilisation, its sleat solvent power for fat, and its comparative great miscibility with water, which renlers it unnecessary to have the milk solids in a state of alosolute dryness.

Petrolenm ether, chloroform, carbm disulphide, benzene, earbon tetrachloride, and anyl alcohol haw also heen used, but, though they give thr sane results, are not so conbenient.

\section{(1) Gravimetric Methods.}

The leading gravimetric methols are diseussel in the following pages; on the whole the Adams method is the best, though those 
due to Storch, Werner-Schmidt, and Bell are little, if at all, inferior in accuracy.

The Adams Method.-Dr. M. A. Adams, Public Analyst for Kent, was led to devise this method from his observation that when milk was dropped on blotting-paper, it spread out to a mucl greater extent than was possible in a basin, flask, or even on a flat surface of glass; he was of opinion that extraction of fat by ether would be much more complete.

As originally designed, the method was as follows:- Strips of white blotting-paper, "mill 428 ," $2 \frac{1}{2}$ inches wide by 22 inches long, were coiled up loosely and held by having a brass ring slipped over them. These were dried at $100^{\circ} \mathrm{C}$. to constant weight, the weighings being performed in a weighing bottle to prevent absorption of moisture from the atmosphere. 5 c.c. of milk was pipetted out into a small beaker and the weight noted; one of the coils was dropped in and the milk absorbed as completely as possible by the blotting-paper. When absorption was complete, the coil was carefully removed and stood, dry end downwards, on a glass plate, the beaker being again weighed and the quantity of milk taken up by the coil found from the difference of the two weights. The coil was transferred to a drying oven at $100^{\circ} \mathrm{C}$, and left therein till it ceased to lose weight. The original method was thus available for the determination of total solids as well as of fat. The dry coil was placed in a Soxhlet extractor, and the fat separated from the solids not fat by ether. The total extract, after evaporation of the ether and drying at $100^{\circ} \mathrm{C}$., was regarded as fat.

Allen and Chattaway modified this method by rolling up a piece of string with the coil, so that the layers of paper were kept from touching each other; they also wrapped a piece of filter paper around it, in order that no milk might escape when a weighed quantity was poured thereon.

Thompson also modified it by hanging up a strip by one end and running the milk on to it from a pipette, afterwards noting the weight of milk delivered by the pipette. He preferred to use filter paper instead of the blotting-paper recommended by Adams.

Vieth, immediately after the publication of the method, subjected it to an exhaustive test, and criticised it somewhat severely. He showed that blotting-paper contained matter soluble in ether, and that, as Adams had ignored this, the fat estimations made by Adams were too high; he also showed that the substance in filter paper soluble in ether was extracted with comparative slowness by this solvent. Faber later sloowed the same thing.

Notwithstanding these criticisms, the Nilk Committee appointed by the Society of Public Analysts recommended its adoption by their members; it was indeed recommended that the papers should be previously extracted, but nothing was said 
of the difficulty of completely removing the matter soluble in ether, it being implied that twelve siphonings were sufficient to wfect this. The recommendation of the Ililk Committee was adopterl at a General Meeting of the Society, and it thus became il quasi-olficial method. The use of this method for determining total solids was abandoned.

Notwithstanding the recommendation of the Milk Committee that the coils should be extracted previously to use, it became the general practice to omit this, and to use unextracted eoils, making a deduction, from the weight of total extract, of the weight of the extract obtained from a coil when extracted alone for the same length of time.

The author showed that this last modification was not free from error; the matter soluble in ether was found chiefly to consist of a calcium salt of resinous acids, which was only of limited solubility in ether; the acids themselves were much more soluble, and when these were liberated by acids-even the small amount of acid found in milk-a greater extract was obtained in a given time. As the time usually allowed for extraction (1 1 hours) was not sufficient to remove the whole of the soluble matter from the blotting-paper-as much as ten hours being necessary - it followed that the matter extracted by ether from the coil was greater whon a milk (containing sinall amounts of acid) was placed on a coil than when the coil was extracted alone. The difference was represented by the amount of resinous acids equivalent to the acidity of the nilk, and was naturally not constant.

He found that alcohol completely extracted the coils-a fact also noted almost simultaneously by Soxhlet-but preferred the use of alcohol containing 10 per cent. of acetic acid. Ether containing acetic acirl was also efficacious.

As the result of Soxhlet's researehes, Schleicher and Schül llaced a "fat-free" paper on the market, and this is very scencrally employed.

Waller and Jiebermann objected to the use of ether as a solvent for fat, on the ground that other substances contained in milk were soluble in this menstrum. The author has found, howerre, that, provided the coil is well dried provious to "xtraction, chloroform, lensene, and petroleum ether wive the same results as inhydrous ether; ordinary ether, which contains suall amounts of water and alcohol, grives, howerer. slightly higher results, especialiy if the coils aro allowed meroly to aildry. The cror introluced by the use of opdinary ether is sumall, and is very frepluently neirlected.

schleicher and Schüll's "fat-fire" pajuer grives a small ether "xtruct consisting chinfly of loose tibres; this does not, as a rule, rxeerd on milligrommes, a weight which may in many eises be neglected as within the limits of experimentil cror. 
Attempts have been made to substitute other substances for the blotting-paper; Abraham, indeed, before Adams published his method, had used "Parker's fibre lint." Wiley, and also Johnstone, tried asbestos paper, but the results were not satisfactory.

The action of the blotting-paper appears to be slightly different from that supposed by Adams. Undoubtedly he was correct in supposing that the nilk was spread out over a large surface; the author's experiments showed that when milk was filtered through blotting-paper the filtrate contained the solids not fat, but only a small anount of fat. This view was found by Vieth not to be entirely correct; he found that a portion of the casein was also removed from the milk by blotting-paper. When milk is spread on blotting-paper the portion which soaks in consists of the whole of the water, milk-sugar, and salts, and a considerable proportion of the proteids, together with a small amount of fat; the bulk of the fat, together with a proportion of the casein, is left on the surface, and is very easily extracted by the ether.

The following mode of procedure is considered most correct by the author:-

Hang up a convenient number of strips of Schleicher and Schüll's "fat-free" paper (or blotting-paper, from which the ether-soluble matter has been extracted by acid-alcohol or other means) from clamps (letter-clips are very serviceable). Run on, from a pipette, 5 c.c. of each of the samples to be tested in a slow stream, so as to spread the milk well over the paper; the strip should be held by its free end, so as to be nearly horizontal. The weight of the milk delivered by the pipette should be noted, care being taken that it is delivered into the weighing vessel at the same rate and in the same manner as it was run on to the paper. The papers are allowed to hang up till apparently dry; flies must not be permitted to settle on the surface of the paper, as they consume portions of the fat.

When the strips are dry enough to handle they should be rolled up in loose coils of a diameter such that they will easily go into the Soxhlet extractors ( $\frac{3}{4}$ to 1 inch), and these should be fastened either by a brass ring, a piece of cotton, or a small pin. A number, or other mark serving to identify the sample, should be placed on each, and a blank coil-i.e., one containing no milk - should also be rolled up. The coils should be dried at $100^{\circ} \mathrm{C}$. for about an hour.

A sufficient number of wide-necked flasks should be carefully cleaned, and allowed to stand for fifteen minutes inside the balance case. The lightest of these should be placed on the right-hand pan of the balance as a tare, and the others successively weighed against it, the weights required to produce equality being noted. The coils should be placed in the Soxhlet extractors, the flasks 
fitter, and a measured volume of dry ether, sufficient to fill the extractor well above the upper portion of the siphon, poured into each. The blank coil should be placed in a Soxhlet extractor, and extracted into the "tare." The Soxhlet extractors are connected to npright condensers, and the ether male to boil by partially immersing the flasks in water at $50^{\circ}$ to $60^{\circ} \mathrm{C}$. Extraction should be continued for tive hours.

The ether should be distilled off', and the flasks placed, side downwards, in a drying oven at $100^{\circ} \mathrm{C}$. for abont twenty minutes, being rotated, and air being blown in every five minutes to remove the vapour of ether. This time is suttieient to dry them if dry ether has heen used.

After cooling for fifteen minutes the flasks should be weighed, the "tare" being again plaeed on the right-hand pan of the balance, and the pereentage of fat ealculated from the increase of weight.

The "tare" is used to correet for the small quantity of "extract" obtained from the paper, and to neutralise the effect of any cluange of weight of the flasks due to handling.

The connection between the flasks and the extractors and between the extractors and condensers may be made by corks, provided they have been well extracted by ether.

The tare and the drying of the coils may be omitted, and ordinary ether used in place of dry ether without greatly aflecting the results.

Dry ether is prepared by washing the commercial preparation witl water, shaking the washed ether with caleium chloride, and, after allowing it to stand over ealcium ehloride for a day or two, distilling.

Ether sufficiently pure for most purposes may be obtained by ristilling (from a water-bath not execeding $40^{\circ} \mathrm{C}$. in temperature) the commercial product from a flask to which Glynsky's bulhs are fitted. The first fractions boiling below $34 \cdot 3^{\circ} \mathrm{C}$. and the last boiling above $34.8^{\circ} \mathrm{C}$. should be rejected.

The following figures show the amount of ditference that may be expectel between the two modes of procedure:-

\section{Percentage of Fat.}

\begin{tabular}{|c|c|c|c|c|c|c|c|c|}
\hline bry "ther, sec., & $.4 \cdot 49$ & $4 \cdot 59$ & $\cdot 1 ! 9$ & $2 \cdot(i)$ & $3 \cdot 190$ & $3 \cdot 4 \cdot 2$ & $3 \cdot 0.5$ & $4 \cdot 21$ \\
\hline ()rlinany ether, de., & $1 \therefore$ & $f(i)$ & היב" & $2 \cdot i s$ & $3 \cdot 13$ & 3.45 & $3 \cdot 0.5$ & $4 \cdot 34$ \\
\hline Ditfirences, & 1)! (1) & (1): & (1)!9 & $11 \%$ & 04 & 913 & $\ldots$ & $\cdot 13$ \\
\hline
\end{tabular}

The average difference is fommel to be 910 .

Tho Boll Method (often called the Somorsot Houso Method).-Jr. James Bell, when Principal of the Inland lievenue Iaboratory at Somerset House, on being appointed 
referee under the "Sale of Food and Drugs Act" devised this method for the estimation of fat and solids not fat in milk. His directions for the analysis of fresh milk (slightly abridged) are as follows :- 10 grammes of milk are weighed in a platinum capsule, 3 inches in diameter and 1 inch in depth, containing a glass stirrer. The capsule is placed on a water bath and its contents evaporated almost to dryness, the milk being well stirred during evaporation. The residue should be neither too moist nor too dry, as either condition tends to prevent the complete extraction of the fat. When the proper point has been reached, the mass is treated repeatedly with ether, the stirrer being each time used to pulverise the solid matter which, in order to ensure that no portion escapes the action of the solvent, should assume a fine state of division. The ether is used warm for the last three treatments. After each washing the ethereal solution of the fat is carefully poured through a small filter. To remove the last traces of fat from the filter, the upper part is cut off, livider into small pieces, which are placed in the remaining portion of the filter in the funnel, and washed with a little ether. The filtrates are received into a tared beaker, from which the ether is gently evaporated, and the fatty residue finally dried in a water-oven till the weight is constant.

The capsule containing the non-fatty residue is dried at $100^{\circ} \mathrm{C}$. until a constant weight is arrived at.

Though the directions are not very explicit the author has found no difficulty in working the method. Twelve portions of 25 c.c. each of ether are sufficient to completely extract the fat. A wide-mouthed flask may be conveniently substituted for the beaker directed to be used, and the ether may be distilled off after each two treatments, the distilled ether being used again. Though requiring a good deal of attention, the method is fairly rapid, two hours being sufficient for the estimation of fat.

When the ether is poured upon the pasty residue, it becomes solid in a very short time, and can be easily pounded to a fine powder. This appears to be due to two causes--the coagulation of the casein, and the crystallisation of the milk-sugar; as is pointed out in the chapter on Milk-Sugar (p. 11), the crystals have the composition of a mixture of hydrated and anhydrous milk-sugar in indefinite proportions, and, as hydrated milk-sugar does not lose its water of hydration at $100^{\circ} \mathrm{C}$., it follows that the solids not fat obtained by this method contain a proportion of the milk-sugar in this modification. It follows, therefore, that the estimation of solids not fat is not very accurate, hence this method should not be employed if an exact determination of solids not fat be desired. The determination of fat has proved in the author's hands to be accurate, as is shown by the following 
figures of determinations of fat by the Bell and Adams methods respectively :-

$$
\begin{array}{cccccccccc}
\text { Fat, Bell, } & 4 \cdot 28 & 4 \cdot 61 & \cdot 19 & 2 \cdot 69 & 3 \cdot 13 & 3 \cdot 45 & 3 \cdot 00 & 8 \cdot 03 & 4 \cdot 16 \\
,, \text { Adams, } 4 \cdot 29 & 4 \cdot 59 & \cdot 30 & 2 \cdot 61 & 3 \cdot 09 & 3 \cdot 4 \cdot 2 & 3 \cdot 05 & 8 \cdot 21 & 4 \cdot 21
\end{array}
$$

This method is also applied to sour milk; the portion taken for analysis should be first neutralised with decinormal sodinm hydroxide solution (Bell does not say what indicator is to be used, but the author prefers delicate litmus paper*), and the evaporation should be carried rather further than in the case of fresh milk, Bell directing that the residue attain the condition of a firm paste. The analysis is otherwise conducted as directed for fresh milk. For each cubic centimetre of decinormal soda added, a deduction from the weight of the solids not fat should be marle for the increase of weight due to the sorla arlded.

Contrary to Bell's statement the author has found that, if the milk be very sour, it is impossible to properly powder the residue, and in these cases the fat has a tendency to be lower than that found in the fresh milk. If the milk be not very sour a powdery residue can be obtained, and the fat estimated in the freslı milk and that determined in the sour milk slow a satisfactory arreement. This is in accord with the riew expressed above as to the cause of the solidification of the residue on the addition of ether; if a considerable portion of the milk-sugar has been ehanged to lactic acid, which is converted into sodium lactate (a salt not easily crystallising) on the addition of soda, the crystallisation cannot take place.

It is directed to dry the solids not fat to constant weight; this in the author's hands has proved impossible. An attempt was made to dry to such an extent that less than 1 milligramme per hour should be lost; this may be interpreted in more than one sense, either that in the space of one hour less than 1 milligramme should be lost, or that in the space of (say) three hours less than 3 milligrammes should be lost. Such a trifling difference of procedure led, however, to a difference of more than 1 per cent. in the weight of solisls not fat. It is evident that to obtain anything like comparable results, a very rigid mode of procedure must be laid down; as this has not been done ontside the Government Laboratory, the author can only consider Bell's methorl for the estimation of the solids not fat of sour milk valueless and unreliable.

The Storch Mothod.-The essential point of this method consists in drying the milk on pumice (or other medium) and extracting with ether after finely grinding in a mortar.

As originally designed by Storeh, 10 grammes of milk were dried at $100^{\circ} \mathrm{C}$. on about an equal weight of pumice in pieces

" 'The inclicator used is a mattor of some importance, as the results differ somewhat if phenol-phthalein be substituterl for litmus. 
about the size of a small pea; the pumice was ground in a mortar to a very fine powder, which was then transferred to a conical tube, and ether allowed to percolate through it till no more fat was extracted, the ether being received in a tarel flask. The pumice was removed and reground, and percolation again continued; and this treatment was repeated till no more fat was extracted. The method was somewhat tedious, though very exact.

In order to avoid the troublesome grinding of a hard substance like pumice and to economise time, the author prefers to use kieselguhr in place of pumice; the method is performed as follows :-

About 3 or 4 grammes of ignited kieselguhr or fossil meal are placed in a porcelain basin, a cavity being made in the centre, and 10 grammes of milk allowed to flow in, care being taken that none is permitted to fall on the sides of the basin. The kieselguhr is dried on a gently-boiling water bath, being stirred occasionally as drying proceeds; after about an hour's drying the kieselguhr can be powdered in the basin with a small pestle. The powder is transferred to a wide test tube, with a hole at the bottom, containing a half-inch plug of cotton wool, which has previously been well extracted with ether; both basin and pestle should be scraped, and the basin should be rinsed two or three times with kieselguhr, the pestle being used to grind up the rinsings with any portions adhering to the sides. The rinsings are added to the tube, and a circular piece of filter paper, of such size as to fit the tube, placed over the kieselguhr. The tube is placed in a Soxhlet extractor and extracted with ether for thiee hours; care must be taken that the top of the tube is well above the top of the siphon and that the ether is not distilled at such a rate that it fills and overflows the upper portion of the tube. After three hours' extraction the tube is removed from the extractor, the kieselguhr emptied out into the basin, and, after allowing the ether to evaporate, again powdered, and re-extracted for another three hours; the quantity obtained in the second extraction is very small.

The ether is then evaporated and the fat dried at $100^{\circ} \mathrm{C}$. in a tared flask; after weighing, the fat should be dissolved in a little ether, when any kieselguhr which may have run through will be detected; this should not be the case, if the plug of cotton wool was properly packed.

Schleicher and Schüll's thimbles may be used instead of the glass tube.

Other media, such as kiolin, plaster of Paris, \&c., may be substituted for pumice or kieselguhr, and, as long as the essential point of the method, fine grinding, is adhered to, the results are independent of the medium.

Kieselguhr is, however, the most convenient. 
The Soxhlet Gravimetric Method.-This method was long considered the best for the estimation of fat in milk. It was worked as follows :-About 20 grammes of plaster of Paris were placed in a porcelain basin, a cavity being made in the centre of the heap, and 10 grammes of milk carefully poured upon it. The basin was placed on a gently-boiling water-bath, and when the plaster began to set, it was stirred with a glass rod; this prevented the formation of liard lumps and enabled the plaster to be completely removed from the basin. When quite dry, the plaster was roughly crushed to a coarse powder, and placed in a "cartridge," made by rolling a strip of filter paper round a ruler and folding the ends, and extracted in a Soxhlet extractor* for two hours; no further extract was obtained by longer extraction.

The author found that by applying Storch's principle of fine grinding, that appreciably higher results could be obtained, and Vieth showed that, by placing only 5 grammes of milk on 20 grammes of plaster instead of 10 grammes, an increased extract was also furnished.

These observations prove that Soxhlet's method did not furnish accurate results. This is due to the fact that the plaster, in setting, encloses portions of the milk solids, and the fat is thereby protected from the action of the ether; when fine grinding is resorted to, the ether is enabled to penetrate the whole mass, and the last traces of fat are dissolved; in this case, the method is essentially that of Storch. When less milk is used, it is spread over a greater surface, and setting does not take place so readily.

This method is now very rarely usel, having been supplanted by the Adams and Werner-Schmid methods.

The Werner-Schmid Method.-This method differs from most other's, in that the milk is not reduced to a solid state by evaporation previous to the extraction of the fat by ether. In order to render the casein, which hinders the extraction of the fat from milk, solul,le, Werner-Schmid heated the milk with an equal bulk of hydrochloric acid till the fat floated in a nearly clear layer at the top, shook the resulting solution with ether, and drew oll an aliquot portion of the ethereal layer.

Stokes has devoted much attention to this method and has studied the effect of slight modifications.

Werner-Schnil's directions are:-Take a test tube of about 50 c.c. eapacity, uraduated in tentlis of a c.c., and introduce 10 c.c. of milk; add 10 e.c. of hylrochlorie acid, boil, with shaking, until the liquid turns dark-l,rown, and cool by placing the tube

- Thr Soxhlet extractor was really devised ly szombathy; it was

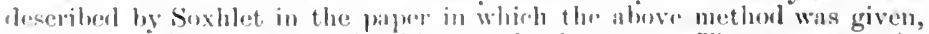

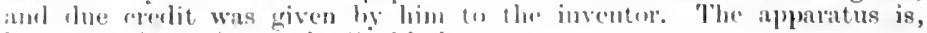
however, always known by biohlet s name. 
in cold water; add 30 c.c. of ether, sliake round and let stand; then measure the volume of the ethereal solution, draw off 10 c.c. with a pipette, evaporate the ether, and dry the fat at $100^{\circ} \mathrm{C}$.

Stokes prefers not to boil, but to plunge the test tube containing the mixture of milk and acid in boiling water for five or ten minutes. He recommends the use of washed ether.

T. E. Hill has also examined the method, and considers that the milk should be weighed, not measured. Hill notices that a fluffy-looking stratum is formed beneath the ether, and, following Stokes, adds three-fourths of this to the bulk of the ethereal layer for calculating purposes. He also points out that Werner-Schmid's method is not applicable to the determination of fat in milk to which cane sugar has been added, a conclusion confirmed later by Dyer and Roberts, who showed that by boiling cane sugar with hydrochloric acid a substance soluble in ether was formed.

Stokes later introduced a new form of tube, in which the middle portion is narrowed for greater accuracy of measurement of the ethereal layer (Fig. 3).

Allen proposed to draw off as much ether as possible, to add a further supply, to draw that off as completely as could be done, and to continue washing in this way till all the fat was separated from the aqueous layer.

Molinari and Stokes have both described form Stokes' apparatus in which the ethereal solution can be completely removed from the aqueous layer without the necessity for pipetting it off: These apparatus offer no special advantage and are not used.

The author prefers to dilute the milk with an equal bulk of water before heating with hydrochloric acid, as there is then no tendency for the formation of a fluffy-looking layer at the point of junction. He finds that it is necessary to wait for ten minutes at least atter the ether has apparently separated from the aqueous layer, in order to allow the fine globules of water to settle out of the ether.

Analysts who have used this method are generally agreed that it gives results practically identical with that of Adams; it is a question whether the drawing off of an aliquot portion of the ether is to be preferred to the extraction of the whole of the fat. In the first case, there is a tendency to be slightly low, owing to the fact that the ether, which dissolves in the aqueous portion, retains a minute proportion of fat; in the other, the tendency is to be somewhat high, as the water which dissolves in the ether dissolves a small amount of substances other than fat; in either case, however, the error introduced is very small and may usually be neglected. 
This method is eminently adapted for the estimation of fat in sour milk. A weighed portion of the well-mixed milk should be placed in a graduated tube, and diluted with an equal bulk of water; a quantity of hydrochloric acid, slightly greater than the total rolume of the diluted milk, shonld be added, and the whole boiled till clear. After cooling, ether should be added, the tube shaken, and the ether allowed to settle for ten minutes. Hefore taking ont the stopper of the tube, it is an advantage to cool the upper portion of the tube to as low a temperature as possible, so that any ether which may have collected round the stopper may be drawn inwards. An aliquot portion of the ether should be drawn off, and evaporated and the fat weighed. Owing to the presence of lactic acid in sour milk, which is soluble in ether, and gives a non-volatile lactone on heating, the results have a tendency to be slightly high. For this reason also, the whole of the fat should not be extracted hy repeated shaking with ether, as a greater amount of lactic acid is thereby extracted; the ethereal layer may be, however, washed with water to remove this.

This method has the advantage of being more rapid than the Adams process, though it requires rather more personal attention; it is not, however, quite so accurate, but can nevertheless be recommended for ordinary work.

Smetham has devised an extractor on a similar principle to Soxhlet's for extracting liquids with ether; the fat may be removed in this apparatus after boiling with hydrochloric acid.

Babcock's Asbestos Method.-Babcock has used asbestos as a medium for eraporation of the milk previous to extraction with ether. Originally it was contained in a glass tube and dried in a current of air, but he has modified it by the use of a perforated metal cylinder.

The following is the method as arlopted by the Association of Official Agricultural Chemists (of Ameriea) :-Provide a hollow cylinder of perforated sheet metal, $60 \mathrm{~mm}$. long and $20 \mathrm{~mm}$. in diameter, closed $5 \mathrm{~mm}$. from one end by a disc of the same material. The perforations should be about $0.7 \mathrm{~mm}$. in diameter and about $0.7 \mathrm{~mm}$. apart. Fill loosely with 1.5 to 2.5 grammes of freshly-ignited woolly asbestos, free from fine and brittle material; corl in a desiccator and weigh. Introduce a weighed quantity of milk (3 to 5 rammes) and iry at $100^{\circ} \mathrm{C}$. to constant weingt for the determination of total solids. Extract with anhydrous etlier until fat is removed, evaporate the ether, dry the fat at $100^{\circ}$ ( . and weigh. The fat may also be determined by difference, drying the extracted cylinders at $100^{\circ} \mathrm{C}$.

This method has been studied by the Association and has been found to give the same results as the Adams method. It has the advantage that fat, solids not fitt, and total solids are direetly estimated. 
Macfarlane has described a method essentially the same, but uses chrysotile or Canadian asbestos for the purpose; this being a hydrated mineral cannot be ignited. He uses a cup-shaped glass tube with a hole at the bottom, and operates with 10 grammes of milk.

The author finds that this method gives practically identical results for fat with the Aclams method, but the solids not fat and total solids are low. It is used to a considerable extent in Canada for official work.

The Ritthausen Method.-If milk is diluted with water, a solution of copper sulphate added, and the acid neutralised, the whole of the proteids are precipitated as copper salts; these carry down with them the whole of the fat. After washing, to remove milk-sugar, \&c., and drying, the fat may be extracted with ether; or a little strong alcohol may be poured on the precipitate to remove water, after which ether will extract the fat; the ethereal and alcoholic solutions are evaporated together and the fat weighed.

The fat may be similarly extracted from the casein precipitated by the addition of acetic acid to the diluted milk.

The results agree well with the Adams method, except in the case of very highly skimmed milks, when there is a tendency to be low.

This method has the advantage that the fat can be determined on the same portion of milk used for the estimation of proteids and milk-sugar.

The following comparative figures will show the results which may be expected :-

$\begin{array}{lllllll}\text { Fat by Ritthausen, . } & . & 4 \cdot 93 & 2 \cdot 87 & 1 \cdot 38 & 4 \cdot 00 & 0.04 \\ \text { Fat by Adams, } & . & 4.97 & \mathbf{2} \cdot 89 & 1 \cdot 43 & 3.99 & 0.17\end{array}$

This method is also suitable for the estimation of fat in condensed milks.

Other Methods of Gravimetric Fat Determination.-The other methods for the estimation of fat in milk are very numerous; a few of those which have been proposed may be britfly noticed.

Wanklyn's method consists in extracting the fat from the solids of milk dried per se. The totality of the fat is never obtained, as, owing to the hard, horny character of the residue, a considerable proportion of the fat is protected from the ether. This method attained considerable notoriety, owing to its semiofficial adoption by the Society of Public Analysts more than twenty years ago, but has now fallen into almost complete disuse. It has been modified by stirring the residue during evaporation so as to obtain a more granular residue, and by evaporating in a conical flask so as to expose a large surface to 
the ether, but the results, even with these modifications, have been unsatisfactory.

Hoppe-Seyler ani, later, Liebermann have proposed to shake the milk with potash (to dissolve the casein), and then to extract with ether, but the separation of the ether is so slow as to render this method impracticable.

Morse, Piggott, and Burton add the milk to anhydrous copper sulphate, which combines with the water, giving a dry residue at once; they then extract with petroleum ether.

Baynes proposes to dry the milk on powdered glass, a method essentially the same as that of Storch. Sand has also been largely used in Germany; but as it is very difficult to grind this up, its use is not to be recommended.

Marpmann has proposed the use of cotton-wool, Ganntter of wood-fibre, and Duclaux of sponge; the principle of these methods is the same as that of Adams.

Fernandez-Krug and Hampe mix a measured volume of milk with a finely-divided mineral substance-usually 5 c.c. of milk with 7 grammes of washed and dried kaolin-and add 5 grammes of finely-powdered anhydrous sodium sulphate. The sodium sulphate absorbs the water contained in the milk, and, after well stirring, the residue is quite dry; this is transferred to a Hlask holding 100 c.c. and 25 c.c. of ether added; after shaking for tive minutes, an aliquot portion is withdrawn by a pipette, over the point of which a piece of cotton wool is wrapped, and the fat estimated by evaporation and weighing.

Froidevaux precipitates the casein and fat with a solution containing 35 grammes of calcium phosphate and 6 c.e. acetic acid per litre; 90 c.c. of this solution are mixed with 10 e.c. of milk, and the fat determined as in the Ritthausen process.

\section{(2) Volumetric Methods.}

These, being suitable for use in the rapid testing of milk, will be more conveniently considered in the chapter on "The Testing of Milk."

\section{(3) Indirect Methods.}

Estimation of Cream.-One of the earliest and simplest metloods of estimating the fat in milk is to allow the milk to stand, and to measure the volume of cream thrown up. For this purpose a creanometer or cylindrical vessel, the upper portion of which is diviled into spaces, each representing the $\frac{1}{100}$ th part of the total volume up to the highest line, is employed. It is filled up to the mark, and allowed to stand at rest for some time-six, eight, twelve, or twenty-four hoursand the volume of cream measured. $\Lambda$ gool milk should throw up abrout 10 per cent. of its cream in eight hours. 
The method is of very slight value for a determination of the fat in milk, as comparatively slight variations in the conditions make enormous variations in the volume of cream. Thus, the author has found that a milk-freshly drawn and not cooledcontaining 5.3 per cent. of fat threw up 25 per cent. of cream in six hours, while another milk with the same percentage of fat, which had been raised to the boiling point and cooled, only threw up 2 per cent. of cream in the same time. These, of course, are extreme instances, and it is found in a majority of cases that the percentage of cream thrown up in six to eight hours divided by 3 will give an approximation to the percentage of fat.

It has been proposed to modify this method by raising the cream by centrifugal force, and apparatus have been made to fit on to the spindle of cream separators; though more concordant results are thus obtained, these methods have not the accuracy of many of the volumetric methods, by which they have been superseded as practical methods.

Faber has, however, shown that very accurate results may be obtained by measuring the volume of cream thrown up from skim milk, after whirling in the lactocrite for one hour, and dividing by 3 .

It has been proposed to deduce the percentage of fat in milk from the opacity of the sample. Various forms of "lactoscope" have been proposed which measure either the thickness of the layer of milk which obscures a given light, or the amount of light passing through a given layer of milk.

The accuracy of the lactoscope is approximate only, and the instrument is now rarely used.

The calculation of the fat from the specific gravity and total solids has already been described.

The author has tried an expansion method, which depends on the difference of the expansion by heat of fat and milk serum-that of the former being about three times that of the latter.

Densimetric Method of Fat Estimation.-By placing abont 200 c.c. on a pleated filter and collecting such portions as run through in the first quarter of an hour, the milk serum-i.e., a solution of the solids not fat in water-may be separated without much change in composition. A series of experiments by the author showed that the solids not fat in the filtered milk were, after correcting for the volume of the fat removed, on the average $\cdot 12$ per cent. lower than in the unfiltered milk.

Vieth gives the following experiment:-200 c.c. of milk were filtered; after one hour 50 c.c. of milk had run through; after four and a half hours more, 26 c.c. were collected; and 108 c.c. were poured ont from the filtrate.

The results of analyses of these four milks were- 


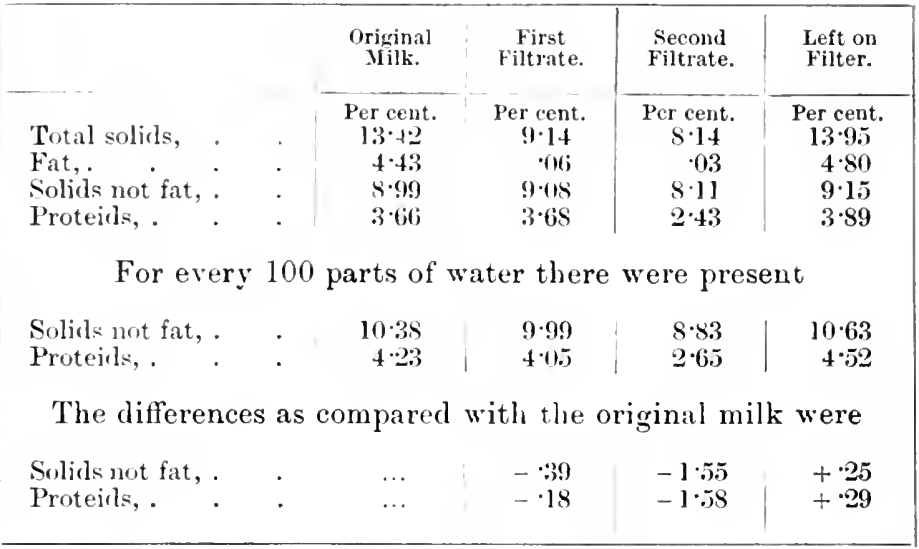

This experiment shows that a portion of the proteids is removed with the fat, and corroborates the author's conclusion that when the portion run through in the first fifteen minutes is taken, there is only a slight loss of solids not fat.

The author has found that if the specific gravity of the filtered milk less 1 be divided by 004 , and the difference between the specific gravities of the milk before and after filtration be divided by 0008 , the figures so obtained very fairly represent the solids not fat and fit respectively. The following figures (Table XI.) will show the agreement that may be expected:-

\section{TABLE XI.-Estimation of Milk Solids by Dexsimetric METIIOD.}

\begin{tabular}{|c|c|c|c|c|c|c|}
\hline \multicolumn{3}{|c|}{ Specific Gravity. } & \multicolumn{2}{|c|}{ Solids not Fat. } & \multicolumn{2}{|c|}{ Eat. } \\
\hline Pefore Filtration. & After Filtration. & Differences. & Found. & Calc. & Fonnd. & Calc. \\
\hline $1 \cdot(1,301,5$ & $1 \cdot 0.340)$ & (111:302 & $\begin{array}{c}\text { Per et. } \\
S \cdot 6: 3\end{array}$ & $\begin{array}{c}\text { Per ct. } \\
S \cdot 50)\end{array}$ & $\begin{array}{c}\text { Per ct. } \\
3 \cdot 94\end{array}$ & $\begin{array}{c}\text { Per ct. } \\
4.0\end{array}$ \\
\hline 1.318.31 & $1 \cdot 03.48$ & (1)1:30) & 871 & 8.70 & $3 \cdot 3.5$ & $3 \cdot 7$ \\
\hline $1 \cdot(1.31 \mathrm{ti}$ & $1 \cdot 18.34 .5$ & (F) & $s \cdot 63$ & $s \cdot 63$ & $3 \cdot 61$ & $3 \cdot 6$ \\
\hline $1 \cdot(10298$ & $1 \cdot 18320$ & י & $8 \cdot 18$ & $8 \cdot 15$ & $3 \cdot 80$ & $3 \cdot 5$ \\
\hline $1 \cdot(1.31 .5$ & $1 \cdot(183: 31$ & $\cdot(1) 16$ & $s \cdot 36$ & $8 \cdot 27$ & $1 \cdot 99$ & $2 \cdot 0$ \\
\hline
\end{tabular}

Great accuracy cannot be expected from this method, but it has the advantage of not requiring chemical apparatus. Determinations can be made with a small delicate lactometer, and an irlea of the quality of a milk obtained in a short time. 
The Estimation of Proteids.-Proteids may be either estimated collectively as total proteids, or separate determinations of casein and albumin can be performed.

From Total Nitrogen and Total Proteids. - The determinations of total proteids is generally performed either by making an estimation of total nitrogen in milk, and multiplying this by $6.38\left(=\frac{100}{15.7}\right.$, as both casein and albumin contain this amount of nitrogen), or by precipitating the proteids as copper salts by Ritthausen's method.

Kjeldahl's Method.-To determine total nitrogen the method of Kjeldahl is the most convenient. Five granmes of milk are weighed in to a round bottomed hard glass flask of about 1.50 c.c. capacity, and 20 c.c. of pure sulphuric acid added. This is placed over a small flame and heated till it is thoroughls charred, the water being evaporated during this heating; the flame is now removed, and about 10 grammes of potassium bisulphate added, and a small drop of mercury. A funnel or pear-shaped bulb with an elongated projection is placed in the neck of the flask, and heat applied, the flame being gradually increased as frothing ceases. In about half an hour the liquid becomes colourless; it is allowed to cool, diluted with water, and transferred to the distillation flask. This may conveniently be of copper or brass, and, for ease of manufacture, can be in the form of a bottle; the digestion flask is well washed with water, care being taken that any white crystals which form on cooling, and become yellow on dilution, are transferred to the distillation flask. A cork carrying a dropping funnel with stopcock, and a wide tube with one or more bulbs blown on it, which are loosely packed with asbestos, is fitted; one end of the tube is connected with a condenser, while the other end is made to dip just below the surface of 50 c.c. of $\frac{\mathrm{N}}{10}$ sulphuric acid.

One hundred c.c. (more or less) of a 20 per cent. solution of caustic soda, followed by 10 c.c. of a 10 per cent. solution of potassium sulphide are added through the dropping funnel, and the contents of the flask mixed by rotatory shaking; a flame is placed beneath the distillation flask, cold water run through the condenser, and the contents distilled till about 200 c.c. have passed over. The tap of the dropping funnel is opened, the flame removed, and the flask disconnected from the condenser; after washing the latter into the flask containing the distillate, it should be removed. The distillate is titrated with $\mathrm{N}$ 10 alkali solution, using litmus or cochineal as indicator. An amount of acid equivalent to the alkali used is subtracted from the amount of acid originally added; the difference represents 
the acid nentralised by the ammonia distilled. From this figure should be subtracted the figure obtained in a blank experiment-i.e., an experiment performed without the addition of milk, but in other respects exactly the same. Each c.c. of $\frac{\mathrm{N}}{10}$ acid neutralised by the ammonia produced is equal to 0014 gramme of nitrogen. 'The percentage of nitrogen multiplied by 6.38 will give the percentage of total proteids.

This method may be modified in many ways. The potassium bisulphate may be omitted, but the digestion then takes longer. Copper oxide or sulphate may be substituted for the mercury; if this be done, the potassium sulphide solution may be replaced by an equal bulk of Soxhlet's alkaline tartrate solution (see Estimation of .Milli-Sugar).

The tube with two bulbs can be replaced by any other form of apparatus having for its object the prevention of splashing; for the copper flask a Jena or other glass flask, or even a tin bottle, may be used. If a tin flask is employed, it must be remembered that " nust" contains ammonia, and the tin must be boiled with strong soda solution before use; for this reason a tin flask cannot be recommended.

For the estimation of nitrogen the methods of Varrentrap and Will and of Dumas may be employed, but they are not so generally convenient. In large laboratories where many determinations are made the method of Dumas is perhaps more convemient than that of Kjeldahl ; these methods will be found described in manuals devoted to analytical chemistry. The method of Kjeldahl is, however, the most generally employed in milk analysis.

Ritthausen's method is performed as follows:-Ten grammes of milk are diluted to about 100 c.c. and 5 c.c. of Soxhlet's copper sulphate solution (see Estimation of M/llk Sugar) added; a solution of caustic soda ( 25 grammes per litre) is added, drop by drop, till the solution is nearly neutral. The precipitate settles rapidly, an excess of alkali being avoided, as it prevents precipitation of the proteids. The precipitate is allowed to settle, and the supernatant liquicl poured off through a tared filter. The precipitate is washed several times by decantation, and then transferred to the filter, the portions adhering to the beaker being remored by a "policeman." It is washed a few more times with water, and the filter allowed to drain.

The filter is washed once with strong alcohol, and then several times with ether, preferably in a Soxhlet extractor; it is then washed again with strong alcohol from a small wash bottle, using the jet to distrihute the precipitate over the filter.

The filter and its contents and the tare are dried in an air oven at a temperature of $130^{\circ} \mathrm{C}$. and weighed; the filter and precipitate are incinerated in a porcelain capsule in a muftle, 
going up to as high a temperature as possible. The weight of the residue, minus that of the ash of the filter, is subtracted from the weight of the dried precipitate, the difference being the proteids.

The author and Boseley have obtained good results by neutralising the milk, using phenolphthalein as indicator, previous to the addition of the copper sulphate solution; the quantity of the latter may also be reduced to 2.5 c.c.

This method gives good results with all milk products, except whey; this is due to the fact that the copper saits of albumoses are not insoluble in water. There is a slight tendency for the results to be high, owing to copper hydroxide, which is always co-precipitated, not being entirely dehydrated at $130^{\circ}$; there is also a tendency to be low, because the phosphorus of the casein is converted into phosphoric acid on ignition, and this swells the amount of ash. These two errors usually compensate each other to a greater or less extent.

The washing with alcohol and ether may be omitted, and the precipitate weighed as proteids and fat, the fat, estimated by other methods, being subtracted from the weiglit.

Instead of a tared filter, a Gooch crucible may be employed with advantage.

Volumetric Determination of the Proteids in Milk.Deniges has worked out a process which depends on the estimation of the amount of mercury necessary to combine with the proteids; it is worked as follows :-

Twenty-five c.c. of the milk are mixed with 5 c.c. of a saturated solution of ammonium oxalate, 20 c.c. of $\frac{\mathrm{N}}{10}$ mercuric potassium iodide (13.55 grammes mercuric chloride and 36 grammes potassium iodide per litre) and 2 c.c. of acetic acid, the volume made up to 200 c.c. and the liquid filtered. To 100 c.c. of the clear filtrate are added 10 c.c. of a solution of potassium cyanide equivalent to a decinormal solution of silver nitrate and 12 or 15 c.c. of ammonia. The liquid is then titrated with $\frac{N}{10}$ silver nitrate solution until there is a permanent turbidity. The number of c.c. used $=q$.

A blank determination is made to determine the exact value of the silver nitrate solution. $10 \mathrm{c}$. of the cyanide solution, 12 to 15 c.c. of ammonia, and 10 c.c. of the mercuric-potassium iodide solution are mixed with 100 c.c. of water and titrated, as before, with the silver nitrate. The number of c.c. used (which with $\frac{N}{10}$ silver nitrate should be $4 \cdot 8$ c.c) $=c$. The percentage of proteids is calculated from the value $q-c$ by means of Table XII. 
Table Xil.-Fur Calculatixg Percextage of Proteids IN MILK.

\begin{tabular}{|c|c|c|c|c|c|c|c|}
\hline$\eta-c$ & Proteils. & $q-c$. & Proteirls. & $I-c$. & Proteils. & $q-c$. & Proteids. \\
\hline 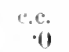 & $\begin{array}{c}\text { Per cent. } \\
1) \cdot 0\end{array}$ & $\begin{array}{l}\text { c.c. } \\
1 \cdots 2\end{array}$ & $\begin{array}{c}\text { Per cent. } \\
1.11\end{array}$ & $\begin{array}{l}\text { c.c. } \\
2 \cdot 4\end{array}$ & $\begin{array}{l}\text { Per cent. } \\
2.2 .25\end{array}$ & $\begin{array}{l}\text { c.c. } \\
3 \cdot 6\end{array}$ & $\begin{array}{c}\text { Per cent. } \\
3 \cdot 9\end{array}$ \\
\hline$\cdot 1$ & 'II) & $1 \cdot 3$ & $1 \cdot 1$ & $2 \cdot \pi$ & $2 \cdot 35$ & $3 \cdot 7$ & $4 \cdot 05$ \\
\hline$\because 2$ & $\cdot 17$ & $1+4$ & $1 \cdots 2$ & $2 \cdot 6$ & 2.475 & $3 \cdot \mathrm{s}$ & $4 \cdot 275$ \\
\hline 3 & 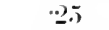 & 1.5 & $1 \cdot 3$ & $2 \cdot 7$ & $2 \cdot 6$ & $3 \cdot 9$ & $4 \cdot 5$ \\
\hline-4 & 30 & $1 \cdot 6$ & $1 \cdot 4$ & $2 \cdot 5$ & $2 \cdot 7$ & $4 \cdot 0$ & $4 \cdot 7$ \\
\hline$\cdot 5$ & 37. & 1.7 & $1 \%$ & $2 \cdot 9$ & 28 & $4 \cdot 1$ & $4 \cdot 9$ \\
\hline 6 & 4.7 & $1 \cdot 8$ & $1 \cdot 6$ & $3 \cdot 0$ & $2 \cdot 9.35$ & $4 \cdot 2$ & $5 \cdot 15$ \\
\hline$\tau$ & 5 & $1 \cdot 9$ & 1.7 & $3 \cdot 1$ & 3015 & $4 \cdot 3$ & $5 \cdot 4$ \\
\hline 's & 63 & $\cdot 2 \cdot 0$ & 1.8 & $3 \cdot 2$ & $3 \cdot 2$ & $4 \cdot 4$ & $5 \cdot 72$ \\
\hline$\cdot 9$ & 715 & $2 \cdot 1$ & $1 \cdot 9$ & $3 \cdot 3$ & 33.5 & 4.5 & $6 \cdot 0$ \\
\hline $1 \cdot 0$ & $\cdot s$ & $2 \cdots 2$ & $2 \cdot 11$ & $3+4$ & $3 \cdot \pi$ & $4 \cdot 6$ & $6 \cdot 25$ \\
\hline $1 \cdot 1$ & -9 & $2 \cdot 3$ & $2 \cdot 1$ & $3 \cdot 5$ & $3 \cdot 7$ & $\ldots$ & $\ldots$ \\
\hline
\end{tabular}

Estimation of Casein and Albumin.

Hoppe-Seyler's Method consists in diluting 10 grammes of milk with about 100 c.c. of water and precipitating the casein hy the addition of dilnte acetic acid; carbon dioxide is passed into the solution in order to complete the precipitation. The precipitate is allowed to settle, and the liquid decanted throngh a tared filter and treated in exactly the same manner as the copper precipitate in Rithausen's method. The casein. after drying, is ignited, and the weight of the ash, less the weight of the ash of the filter, subtracted from the total weight.

Ritthausen prefers to precipitate the casein at a temperature of $40^{\circ} \mathrm{C}$, omitting the passage of the carbon dioxide. Van slyke has compared these two methods, and finds that the results are identical; he gives the preference to that of Ritthausen, as being carried out with greater facility, and operates as follows :Dilute 10 grammes of inilk with 90 c.c. of water at $42^{\circ}$ to $43^{\circ} \mathrm{C}$, add 1.5 c.c. of 10 per cent. acetic acid solution, stirring well; after the expiration of five minutes, filter, and proceed as above lescribed.

Frenzel and Weyl have proposed the use of sulphuric acid, but $V$ an Slyke has found that either a slight deficiency or excess of acid canses inaccuracy. He, therefore, does not recommend the method.

Instead of weighing the casein, the nitrogen in the precipitate may be estimated by Kjeldahl's method, and multiplied by 6.38 . In this case it is not necessaly to dry the casein, but the precipitate with the filter may be iropper into a digestion flask, the acid added, and the method performed as directed for total nitrogren. 
Maissen and Musso have proposed the use of rennet for pre. cipitation of the casein, but this is not accurate.

As casein is not entirely insoluble in water, especially in the presence of acid, the results have a tendency to be low, especially if the nitrogen be estimated. On the other hand, it is difficult to wash the casein absolntely free from other milk solids (? calcium citrate); hence the weight of the "casein" obtained by precipitation is thus raised. In practice, the two errors have a tendency to compensate one another.

Albumin is estimated by boiling the filtrate from the casein; the filtrate is raised just to boiling over a small flame, and digested on the water-bath for fifteen minutes; the albumin separates in a pulverulent form. It is collected on a tared filter or, preferably, in a Gooch crucible, and dried at $100^{\circ} \mathrm{C}$.; the nitrogen may be estimated by the Kjeldahl method, and multiplied by 6.38 . The albumin is precipitated practically in a state of purity, and no correction for the ash need be made, but, owing to the precipitation not being complete, the results are slightly low; if the casein has not been completely precipitated, a portion may be found with the albumin.

A small quantity of so-called "lacto-protein" remains in solıtion after precipitation of the casein and albumin; this chiefly consists of the unprecipitated portions of casein and albumin. It may be estimated by precipitation as copper salt by Ritthausen's method, as described above; by precipitation by tannin and estimation of the nitrogen in the precipitate by Kjeldahl's method; or by evaporation of the solution and estimation of the nitrogen.

Segelein's method, though more tedious, is preferable to the above; to 10 grammes of milk, 20 c.c. of a saturated solution of magnesium sulphate are added. Solid magnesium sulphate in the form of powder is then added in small quantities at a time till no more is disso'ved. The solution is allowed to stand for twelve hours and filtered; it is washed four or five times with a saturated solution of magnesium sulphate, an operation which takes some time. The filter and its contents are dropped into a Kjeldahl digestion flask, 30 c.c. of sulphuric acirl added, and the nitrogen estimated, as jreviously described; an increased volume of soda solution to neutralise the 30 c.c. of acid used must be employed. The nitrogen multiplied by 6.38 will give the weight of casein.

The magnesium sulphate must be free from sodium sulphate, commercial "Epsom salts" often containing this impurity. If distinct acidity be developed in the milk, this shonld be neutralised previous to the addition of magnesium sulphate.

The albumin is separated by diluting the filtrate and precipitating by the addition of tannin, or plosphotungstic acid; the precipitate is collected on a filter, and the nitrogen therein 
estimated by Kjeldall's method. The albumin may be less exactly estimated hy boiling the filtrate after dilution and addition of a small quantity of acetic acid; it is collected on a tared filter and weighed as such.

In order to avoid the tedious washing with a saturated solution of mannesium sulphate, Leffmann and Beam take a larger quantity of milk (say 20 grammes), dilute with twice its bulk of saturated magnesium sulphate solution, add powdered magnesium sulphate till saturated, and make up to a definite volume with saturated magnesium sulphate solution in a graduated cylinder. The solution is allowed to stand and the lower clear portion is removed by a pipette; this is filtered and an aliquot portion taken; the albumin is estimated in this, as directed above. The casein is retermined by subtracting the albumin nitrogen from the total nitrogen and multiplying the difference by $6 \cdot 38$.

Sodium ehloride, to which a little calcium chloride has been added, can be substituted for magnesium sulphate; the precipitate is less easy to treat, owing to the formation of hydrogen chloride on heating the precipitate with sulphuric acid.

Duclaux las devised an ingenious method, which can be applied to the determination of casein and albumin. A quantity of milk is placed in a beaker, and a porous cell (the opening of which is closed by a cork, through which a tube passes) is immerserl in it. The tulse is connected to a water-pump and a vacuum maintained in the porous cell; the serum, containing in solution the milk-sugar, albumin and salts, filters through the porous cell, while the easein and fat together with a portion of the salts remain behind. A Berkefeld filter may be substituted for the porous cell. Filtration is hastened if the outside of the filter be rubbed from time to time with a rubber.tipped rod, which removes the closely adherent casein layer.

'The author has attempted to remove the casein by the addition of 2 c.c. of glacial acetic acid, and 1 c.e. of "alumina cream" to $100 \mathrm{c.c}$ warmel to $40^{\circ} \mathrm{C}$. ; the srrum is filtered through a filter, the filtrate being poured back till it becomes clear, or through a Gooch crucible.

Densimetric Methods.--The specific gravity of the serum obtained by either method may be determined and the casein deduced from the diflerence in sperific gravity between the milk and the serum. The serum may be polarised and the albumin deduced from the difference belween the reading obtained and that due to the milk-susar. The solids, milk-sugar, and ash may be estimated in the serum, and the total solids and fat in the milk; from these data the casein and albumin can be derluced.

The calculations in Duclinux's method are somewhat complisated :- 
Let $S m$ be the specific gravity of the milk.

Tm , total solids of the milk in grammes per 100 e.c.

$\mathrm{Fm}$, , fat of the milk in grammes per 100 c.c.

$A m,, \quad$ ash of the milk in grammes per 100 c.c.

Ss ,, specific gravity of the serum.

T. , total solids of the serum in grammes per 100 e.c.

As ," ash of the serum in grammes per 100 c.c.

Ms ," milk-sugar of the serum in grammes per 100 c.c.

Then $100 \mathrm{~S} m-\mathrm{T} m$ is the weight of the water in 100 c.c. of milk, and

$100 \mathrm{~S} s-\mathrm{T} s$ the weight of water in 100 c.c. of serum.

For 100 grammes of water there are

$$
\begin{aligned}
& \frac{\mathrm{T} m \times 100}{100 \mathrm{~S} m-\mathrm{T} m} \text { grammes of total solids, } \\
& \frac{\mathrm{F} m \times 100}{100 \mathrm{~S} m-\mathrm{T} m} \\
& \frac{\mathrm{A} m \times 100}{100 \mathrm{~S} m-\mathrm{T} m} \quad, \quad \text { fat, } \\
& \frac{\mathrm{T} s \times 100}{100 \mathrm{~S} s-\mathrm{T} s} \\
& \begin{array}{ll}
\mathrm{A} s \times 100 \\
100 \mathrm{~S} s-\mathrm{T} s
\end{array} \quad, \quad \text { ash, }
\end{aligned}
$$

The casein is equal to

$$
\frac{\mathrm{T} m \times 100}{100 \mathrm{~S} m-\mathrm{T} m}+\frac{\mathrm{A} s \times 100}{100 \mathrm{~S} s-\mathrm{T} s}-\left(\frac{\mathrm{F} m \times 100}{100 \mathrm{~S} m-\mathrm{T} m}+\begin{array}{c}
\mathrm{A} m \times 100 \\
100 \mathrm{~S} m-\mathrm{T} m
\end{array}+\frac{\mathrm{T} s \times 100}{100 \mathrm{~S} s-\mathrm{T} s}\right)
$$

This is expressed as grammes in 100 grammes of water, and must be multiplied by $\frac{100 \mathrm{~S} m-\mathrm{T} m}{100}$ to obtain grammes per 100 c.c. of milk, or by $\frac{100 \mathrm{~S} m-\mathrm{T} m}{100 \mathrm{~S} m}$ to obtain percentages.

If total solids, fat, \&c., are estimated as percentages by weight, the expressions $\frac{\mathrm{T} m \times 100}{100-\mathrm{T} m}$ must be substituted for $\frac{\mathrm{T} m \times 100}{100 \mathrm{~S} m-\mathrm{T} m}, \frac{\mathrm{T} s \times 100}{100-\mathrm{T}_{s}}$ for $\frac{\mathrm{T} s \times 100}{100 \mathrm{~S} s-\mathrm{T} s}$, and so on.

To obtain the albumin:-

Let the symbols be as before, then for 100 grammes of water there are

$\mathrm{T} s \times 100$ $100 \mathrm{~S} s-\mathrm{T}_{s}$ grammes of sernm solids.

$$
\begin{aligned}
& \text { ds } \times 100 \\
& 100 \mathrm{ss}-\mathrm{Ts} \quad,, \quad \text { ash. } \\
& \frac{\mathrm{M} * \times 100}{100 \mathrm{~S} s-\mathrm{T} s} \quad, \quad, \text { milk-sugar. }
\end{aligned}
$$

The albumin is equal to

$\frac{\mathrm{T} s \times 100}{100 \mathrm{~S} s-\mathrm{T} s}-\left(\frac{\mathrm{A} s \times 100}{100 \mathrm{~S} s-\mathrm{T} s}+\begin{array}{c}\mathrm{M} s \times 100 \\ 100 \mathrm{~S} s-\mathrm{T} s\end{array}\right)$ grms. in 100 grms. of water. 
To obtain grammes per 100 c.e. of milk, this must be multiplied by $\frac{100 \mathrm{Sm}-\mathrm{Tm}}{100}$, and to obtain percentage by $\frac{100 \mathrm{Sm}-\mathrm{Tm}}{100 \mathrm{Sm}}$.

If the milk-sngar be expressed as grammes per 100 c.e. of the milk ( $\mathrm{Mm}$ ), the expression $100 \mathrm{Sm} \times \mathbf{\mathrm { m } m}-\mathrm{T} m$ must be substituted for $\frac{\mathrm{M} s \times 100}{100 \mathrm{~s} s-\mathrm{T} s}$

If it be desired to deduce the amount of casein from the difference of speeifie glavity between the milk and the serum obtained by the author's method, the following formula must be nsed :-

Let
and $m$ be the specific gravity of the milk,
Fs , speeifie gravity of the serum,
Am the fat in grames per 100 e.c.,
As , ash of the milk in grammes per 100 c.c.,

the earein is equal to

$$
\frac{100 \times \frac{1000 \mathrm{Sm}-1000+\mathrm{Fm} \times 7 \mathrm{~F}}{100-\mathrm{Fm}}-(\mathrm{Am}-\mathrm{A} s) \times 7 \cdot 5-1000 \mathrm{~S} s+1000}{2.55}
$$

srammes per 100 c.c.

This involves the assumptions that the volume of the precipitated casein is equal to the volume of 2 c.c. of acetic acid +1 c.e. of alumina cream, and that the specific sravity is unchanged by this dilution; the assumptions are nearly correct. For expression $(A m-A s) \times 7.5$ the figure 1.0 may be used without much error.

Polarimetric Methods.-If the albumin is to be deduced from the polarisation of the serum, it is best to calculate the reading to percentage of milk-sugar, as directed under the estimation of milk-sugar. The difference between the alpparent percentage of milk-sugar thus found, and the true percentage multiplied by the factor 74 , will give the percentage of albumin. The factor is obtained by dividing the specific rotatory power of milk-sugar by that of albumin. As albumin polarises to the left, and milk-sugar to the right, the apparent percentage of milk-sugar deduced from polarisation of the serum will be less than the true percentage.

The polarisation methorl sulfers from the disadvantage that the serum is apt to be somewhit dark in colour, and the readings are conseguently not very sharp; still, if an estimation be required in a short time, it is a fuirly good method.

Estimation of Casein.-Lehmann's Method.-Lehmann has devised a method for the estimation of casein in milk by means of unglazed porcelain plates; the plate is wetted with water, and 5 grammes of milk diluted with 5 grammes of water placed in the centre. After about an hour and a half the serum is separated, and the casein, together with the fat, is removed with a spatula; the last traces of easein are removed by setting the plate in water. The fat is removed by extraction with 
ether, the casein being ground up to extract the last traces; the casein is dried at $100^{\circ} \mathrm{C}$. on it weighed filter, and weigher ; from the weight is deducted the weight of the ash left on incineration.

The results are said to be very accurate. The casein is obtained in the state in which it exists in the milk.

Schlossman's Method.-Schlossman proposes to estimate casein by warming 10 c.c. of milk mixed with 3 to 5 parts of water to $40^{\circ}$, and adding 1 c.c. of a concentrated solution of alun. Should the flocculent precipitate not subside rapidly an additional 0.5 c.c. of alum solution may be added, since a slight excess (up to 1 c.c.) does not affect the results. The precipitate is allowed to stand for some minutes, and is then filtered. After having been washed with water and dried, the filter and its contents are extracted with ether in a Soxhlet extractor (an estimation of fat being thereby obtained); the nitrogen determined by Kjeldahl's method, and multiplied by 6.38 , gives the weight of the casein.

Richmond's Method.-The albumin in milk, which has been raised to the boiling point, behaves with all methods as casein. An approximate estimation of real casein in milk, which has been heated, can be made as follows:-Twenty-tive grammes of milk are evaporated to dryness, ignited, and the phosphoric acid estimated in the ash, as directed on p. 74 . Twenty-five c.c. of the filtrate, produced by adding 3 c.c. of acid mercuric nitrate to 100 c.c. of milk, are taken, made alkaline, and, without removing the precipitate, evaporated down, and ignited: the phosphoric acid is estimated in the ash.

The casein is calculated from the following formula :-

Let $\mathrm{P}_{1}=\mathrm{P}_{2} \mathrm{O}_{5}$ obtained from 25 grammes of milk,

$\mathrm{P}_{2}=\mathrm{P}_{2} \mathrm{O}_{5}$ obtained from 25 c.c. of filtrate,

$\mathbf{F}=$ percentage of fat,

and $S=$ the specific gravity.

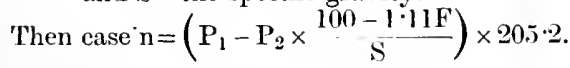

The coagulated albumin is deduced by subtracting this figure from the apparent percentage of casein estimated by one of the methods previously described.

Determination of Total Acidity-Lactic Acid.-One hundred c.c. are placed in a beaker; a little phenolphthalein (5 c.c. of a 1 per cent. solution) is added, and the milk titrated with $\frac{\mathrm{N}}{10}$ alkali till a faint pink colour is obtained.

Storch uses a solution of lime (lime-water), containing solid lime, in place of standard soda solutions, as it remains constant in composition, and is almost exactly twentieth normal. The strength of the solution remains constant, as if any of the lime 
is removed by carbon dioxide, more is dissolved ; its strength is l,ut little affected by ordinary variations of temperature.

It is to be recommended for dairy use, as no precaution, except to have an excess of lime in the bottle, is necessary.

Generally spreaking, about 20 c.c. of $\frac{\mathrm{N}}{10}$ alkali is required; each cubic centimetre of $\frac{\mathrm{N}}{10}$ alkali is called $1^{\circ}$ of acidity, hence a milk requiring 20 c.c. will have $20^{\circ}$ of acidity.

It is a frequent practice to calculate the acidity as lactic acid; this practice is, however, to be deprecated, as freshly-drawn milk has a very distinct acidity, though lactic acid is in all probability absent. The acidity of milk to phenolphthalein is due partly to the mono- and di-basic phosphates, and partly to the dissolved carbonic acid.

The following figures by Smetham and Ashworth are instructive :-

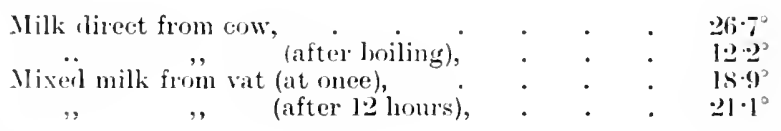

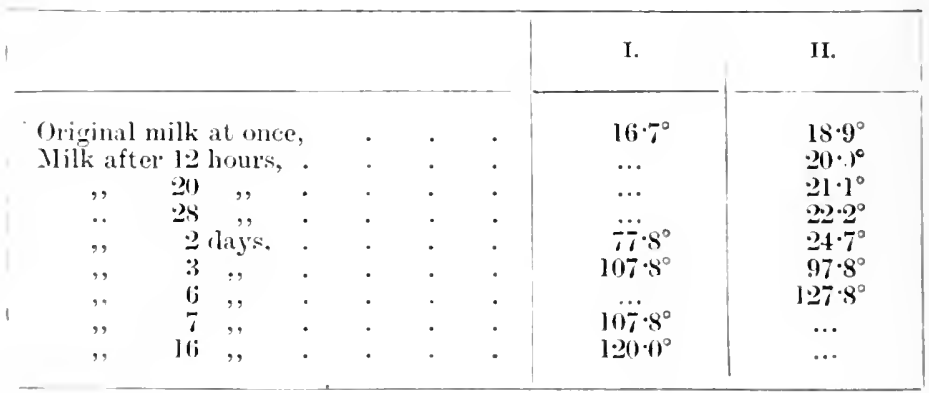

The gradual rise of acidity, on keeping, is well marked; this is, of course, due to the production of lactic and carbonic acids.

It is interesting to note the diminution of acidity in milk on boiling; this is probably due partly to the deposition of calcium salts having an acid reaction, and partly to the expulsion of carbonic acid.

Instead of using phenolplithalein, delicate neutral litums paper may be amployed; milk is practically neutral to this. 'The acidity can be titrated with fair accuracy, though the end point of the titration is not well marked. There is more justitication for calculating the acidity to litmus as lactic acid, as both the salts of milk and carbonic acid are not appreciably acid to litmus paper. 
The following figures obtained by the author on sour milks will show the enormous difference in the two results; the figures have in both cases been calculated to lactic acid:-

$$
\begin{array}{cccccc} 
& \text { I. } & \text { II. } & \text { III. } & \text { IV. } & \text { V. } \\
\text { Acidity (to phenolphthalein), } & 1 \cdot 24 & 1 \cdot 89 & 1 \cdot 82 & 1 \cdot 52 & 1 \cdot 32 \\
,, \quad \text { (to litmus paper), } & .65 & 1 \cdot 14 & 1.28 & .56 & .56
\end{array}
$$

There is no good method for the quantitative determination of lactic acid; the results of the titration with litmus give approximate results. An approximation nearer the trutl may be made by distilling some of the milk into a little $\frac{\mathrm{N}}{10}$ alkali, titrating back the alkali with $\frac{\mathrm{N}}{10}$ acid, using litmus paper as indicator, and subtracting the volatile acidity from the total acidity ; the non-volatile acidity is taken as lactic acid.

An estimation of lactic acid is rarely, if ever, required in practice, the determination of the total acidity serving for almost all purposes.

The Analysis of Milk Products.-For the analysis of milk products, the methods described above can generally be used. The following notes will show where it is advisable to depart from them or employ modifications.

Cream. - The methods given above may be employed in the analysis of cream. The following method of determining total solids, fat (by difference), solids not fat, and ash is convenient.

4 to 5 grammes are weighed in a wide platinum basin, which is placed in a water-oven, till the water has apparently evaporated and the solids not fat stick to the bottom of the basin ; when this occur's-after about an hour's drying-the basin is inclined so that the fat runs down to the side away from the solids not fat. Under these conditions drying is completed in about five hours.

After weighing the total solids, the basin is replaced in the water-oven for a few minutes to melt the fat; 25 c.c. of amyl alcohol are poured on, the basin again placed in the water-oven for ten minutes, and the amyl alcohol solution of fat carefully decanted while still hot; with care, none of the solids not fat passes away with the amyl alcohol. This process is repeated eight times more, the basin being allowed to stand all night between the fourth and fifth treatments. After the last treatment, the amyl alcohol is drained off as far as possible, and the basin and its contents dried for three hours in the water-oven. The residue is weighed as solids not fat. This is now burnt over a low flame, and the residue weighed as ash. Ether or chloroform may be substituted for amyl alcohol, but the latter is cheaper and less volatile.

For the determination of milk-sugar by polarisation, the 
cream should be diluted with water; 50 grammes may be mate up to 100 c.c., and 1 c.c. of acid mercuric nitrate added.

If total nitrogen is determined, the cream should be eraporated in a wide-mouthed flask, and the bulk of the fat extracterl, as, otherwise, great charring of the fat takes place (if the cream be treated by the K.jeldahl method), and mucli carbon, difficult to dissolve, is produced.

Skim Milk.-The methods of milk analysis may be applied; the fat is rather more difficult of extraction. If Ritthausen's method he used for proteid determination, it is not necessary to extract the fat, hut to dry and weigh the copper precipitate, and afterwards to sulbtract the percentage of fat found from the percentage of proteicls plus fat.

Condensed Milk.-About 30 to 35 grammes of the wellmixed milk should be weighed into a 100 c.c. flask, dilnted with 50 to 60 c.c. of water, and the solution raised to the boiling point ; this is cooled, made up to 100 c.c., and the total weight taken. The diluted solution is analysed as a milk. The fat is rather more difficult to extract than from ordinary milk, and longer extraction should be given; if cane sugar is present, the Werner-Sclimid process must not be used for the estimation of the fat, as cane sugar yields a substance soluble in ether. When soluble albumin is estimated, a fresh portion which has not been boiled is employed.

Decomposed Milk-Preparation of 'Sample.-The whole contents of the bottle are turned out into a beaker and whisked for a minute or two with a brush made of fine wire; the inside of the bottle is scraped with a wire all over, some of the milk is poured back, and the contents shaken; this is now emptied into the beaker and again whisked. Portions of about 5 grammes are weighed out for total solids and ash, fat, and total nitrogen.

Estimation of Acidity.-Twenty grammes of milk (if this quantity can be spared) are placed in a beaker, and titrated with $\frac{\mathrm{N}}{10}$ canstic soda solution, nsing delicate litmus paper as indicator.

To the prortion weighed ont for total solids, which should be in a wide flat-hottomed basin, a quantity of $\frac{\mathrm{N}}{10}$ soda solution, calculated from the determination of the acidity, should be added. The basin is placed on the water-bath and evaporated to dryness; when apparently dry, it is placed in the water-oven for two hours, weighed, then replaced, and re-weighed after one hour's interval ; this is repeated till the loss is less than 1 milligramme. From the final weight of total solids a quantity equal to the number of c.e. of $\frac{N}{10}$ sorla alded $\times \cdot 002.2$ is subtracted, and the remainder represents the total solids. 
The residue in the basin is ignited, and the residue weighed; from the weight a quantity equal to the number of c.c. of $\begin{gathered}\mathrm{N} \\ 10\end{gathered}$ soda added $\times .0053$ is subtracted; the remainder represents the ash.

The fat is best estimated by the Werner-Schmid method; an aliquot portion of the ether should be measured off and evaporated, as, if an attempt be made to extract the whole of the fat, a considerable proportion of lactic acid will be extracted; if, however, an aliquot portion of the ether be taken, the amount of lactic acid dissolved does not seriously affect the results. Fat may be estimated with about equal accuracy by one of the Leffmann-Beam methods ; a portion of the milk, as nearly equal to that normally employed as possible, is weighed into a bottle, and the fat read off in the usual manner ; the reading should be corrected by multiplying by 15.25 (if 15 c.c. be used) or 11.22 (if 11 c.c. be used), and dividing by the weight taken.

The other estimations are made as for milk.

Fermented Milk--Kephir and Koumiss.-Estimation of Alcohol.-100 grammes of milk are weighed into a flask, and about 50 c.c. are carefully distilled, and received into another flask; the distillate is mixed with a little baryta water, to render the solution alkaline, and again distilled; about 30 c.c. are collected and weighed. The density of the second distillate is carefully taken, and the percentage of alcohol in the distillate is deduced from Table XIII. (due to Hehner). The percentage of alcohol in the milk is found by multiplying the weight of the distillate by its percentage of alcohol, and dividing by the weight of the milk taken.

To the residue in the flask from which the milk was distilled, 25 c.c. of water are added, and 25 c.c. distilled off; this treatment is repeated several times until the last 25 c.c. are approximately neutral. The mixed distillates are added to the portion which had previously been made alkaline with baryta, and the solution titrated with baryta water (or sulphuric acid) till neutrial to phenolphthalein. The liquid is filtered, and evaporated to dryness, and the residue, consisting of the barium salts of volatile acids, weighed; a little sulphuric acid is added and the basin ignited; the weight of the barium sulphate, multiplied by 5803 , is subtracted from the total weiglit; the remainder represents the weight of the volatile acids ; this, multiplied by 116.75 and divided by the weight of the barium sulphate, will give their equivalent.

Estimation of Proteids. - The proteids precipitated by the acid developed in the milk are filtered off, and either weighed, or the nitrogen is determined in them; the filtrate is boiled, and the precipitate weighed as albumin; in the filtrate from this, 
TABLE XiII.-Alconol Tables (Heliner).

\begin{tabular}{|c|c|c|c|c|c|}
\hline $\begin{array}{l}\text { Spccific } \\
\text { Gravity at } \\
60^{\circ} \mathrm{F} \\
60^{\circ} \mathrm{F}\end{array}$ & $\begin{array}{l}\text { Alcobol } \\
\text { per cent. ly } \\
\text { Wcight. }\end{array}$ & 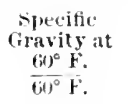 & $\begin{array}{l}\text { Alerhol } \\
\text { per cent. by } \\
\text { Weight. }\end{array}$ & $\begin{array}{l}\text { Specific } \\
\text { (iravity at } \\
60^{\circ} \mathrm{F} \\
60 \\
600^{\circ} \mathrm{F}\end{array}$ & $\begin{array}{l}\text { Alcohol } \\
\text { per cent. by } \\
\text { Weight. }\end{array}$ \\
\hline •99999 & $0(1.5$ & •996!) & $1 \%$ & •9939 & 3.47 \\
\hline 8 & $\cdot 11$ & 8 & 181 & 8 & $3 \cdot 53$ \\
\hline 7 & $\cdot 16$ & 7 & $1 \cdot 87$ & 7 & $3 \cdot 59$ \\
\hline (; & 21 & 6 & $1 \cdot 94$ & (j & $3 \cdot 6.5$ \\
\hline $\bar{j}$ & 20 & $\pi$ & 2.00 & 5 & $3 \cdot 71$ \\
\hline 4 & $: 32$ & 4 & $2 \cdot 106$ & 4 & $3 \cdot 76$ \\
\hline 3 & 37 & 3 & $2 \cdot 11$ & 3 & $3 \cdot 82$ \\
\hline$\because$ & 42 & 2 & $2 \cdot 17$ & 2 & $3 \cdot 85$ \\
\hline 1 & 47 & l & $2 \cdot 2 \cdot 2$ & 1 & $3 \cdot 94$ \\
\hline 0 & .33 & 0 & $2 \cdot 28$ & 0 & 4.00 \\
\hline 9989 & 5 & -99.59 & $2 \cdot 33$ & .9929 & $4 \cdot 06$ \\
\hline $\mathrm{s}$ & 63 & S & $2 \cdot 39$ & 8 & $4 \cdot 12$ \\
\hline 7 & - 65 & 7 & $2 \cdot 44$ & 7 & $4 \cdot 19$ \\
\hline 6 & 74 & 6 & $2 \cdot \pi 0$ & 6 & $4 \cdots 2.5$ \\
\hline 5 & 79 & 5 & $2 \cdot 56$ & 5 & $4 \cdot 31$ \\
\hline 4 & $\cdot 8 t$ & 4 & $2 \cdot 61$ & 4 & $4 \cdot 37$ \\
\hline ;3 & ‘99 & 3 & $2 \cdot 67$ & 3 & $4 \cdot 4 t$ \\
\hline 2 & 9.5 & 2 & $2 \cdot 72$ & 2 & $4 \cdot 50$ \\
\hline 1 & $1 \cdot 00$ & 1 & 2.78 & 1 & $+\cdot 56$ \\
\hline 0 & $1 \cdot 01 ;$ & 0 & $2 \cdot 8.3$ & 0 & +62 \\
\hline 9979 & $1 \cdot 12$ & 9949 & $2 \cdot 8 ! 1$ & .9919 & $4 \cdot 69$ \\
\hline 8 & $1 \cdot 19$ & 8 & $2 \cdot 94$ & 8 & 4.75 \\
\hline 7 & ; & 7 & 3.00 & 7 & $4 \cdot 81$ \\
\hline ij & $1: 31$ & 6 & $3 \cdot 66$ & ij & 4.87 \\
\hline$\overline{ }$ & $1 \cdot 37$ & $\bar{j}$ & $3 \cdot 12$ & J & 4.94 \\
\hline 4 & $1 \cdot 4$ & 4 & $3 \cdot 18$ & 4 & $5 \cdot 00$ \\
\hline 3 & $1 \cdot 51\}$ & 3 & $3 * 24$ & 3 & $5 \cdot 06$ \\
\hline$y$ & 1.56 & 2 & $3 \cdot 29$ & 2 & $5 \cdot 12$ \\
\hline 1 & $1 \cdot 62$ & 1 & $3 \cdot 3 \pi$ & 1 & $5 \cdot 19$ \\
\hline 0 & $1 \cdot 69$ & (1) & $3 \cdot 41$ & 0 & $\tilde{5} \cdot 2.5$ \\
\hline
\end{tabular}

allumoses are estimated by precipitation with tannin or phosphotungstic acid, and determining the nitrogen in the precipitate.

The total acidity to litmus paper may be calculated as lactic acii; from this an amount equivalent to the volatile acids is subtracted.

Carbonic acid can only he estimated if the koumiss or kephir was in a corked hottle. The worm of a champagne tap is carefully turned off to leave a perfectly smooth stem ; the tap is also carefully re-ground to make sure that it fits.

A drying and alsorbing apparatus is fitted up, consisting of (a), a U tube containing pumice and sulphuric acid, (b) a U-tube containing soda lime immersed in a beaker of cold water, $(c)$ a $U$-tube filled half with soda lime and half with caleium chloride. 'These are connected in the order named, and the end of $(a)$ is 
connected by a short piece of indiarubber tubing to the champagne tap.

(b) and (c) are weighed, and the tap (closed) carefully forced through the cork of the bottle; the tap is slightly opened and the carbon dioxide allowed to slowly escape ; when the escape of gas becomes slack the bottle may be slightly warmed, by placing it in warm water, and shaken to promote further escape. When no more gas comes off the tap is disconnected, a soda lime tube substituted, and a current of air drawn through the apparatus.

$(b)$ and $(c)$ are dried, cooled and again weighed; the increase represents the amount of carbon dioxide which has escaped from the bottle. The total contents of the bottle are now weighed and the percentage calculated.

There still remains a little carbon dioxide dissolved; this can be best estimated by titrating a weighed amount with $\frac{\mathrm{N}}{10}$ baryta water, using phenolphthalein as indicator; the difference between the acidity thus estimated and that estimated as previously described under Decomposed milk, will represent, without great error, the carbon dioxide ( 1 c.c. $\frac{\mathrm{N}}{10}$ alkali $=0022$ gramme $\mathrm{CO}_{2}$ ). This should be added to the amount estimated by absorption.

Buttermilk and whey are analysed by the methods given for milk; the total proteids of whey cannot be determined by Ritthausen's method, and the total nitrogen must be estimated. 


\title{
CHAPTER III.
}

\author{
NORMAL MILK : ITS ADULTERATIONS AND ALTERATIONS, \\ AND THEIR DETECTIONS.
}

Costexts. - Chemical Composition of Milk-Colostrum-Limits and Standlards of Milk - Adulterations of Milk - Preservatives - The Action of Heat on Milk-Condensed Milk-Sterilised MilkThe Aetion of Cold on Milk.

The Chemical Composition of Milk-Average Composition.-The milk of the cow has, on the average, the following composition (deduced from about 200,000 analyses made in the Laboratory of the Aylesbury Dairy Company, Limited) :-

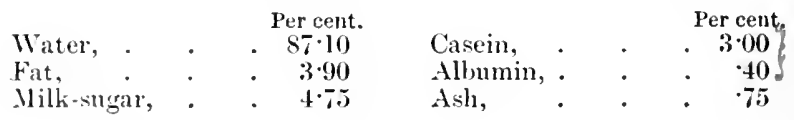

It is essentially an aqueous solution of milk-sugar, albumin, and certain salts, holding in suspension globules of fat and, in a state of semi-solution, casein, together with mineral matter. sumall quantities of other substances are also found, which have been referred to (Chap. I.).

When evaporated, a resilue is left, which is known as the solids of milk; these are empirically divided into fat and solids not fat. It was first pointed out by Wanklyn that the solids not fat in milk show comparatively small variations. Though this rule is by no means absolute, it is to a great extent borne out in practice, especially in dealing with the mixed milk of several cows.

Limits and Variations.-The following are the maximum and minimum percentages which have come under the author's notice; the highest fat is recorded by Bannister, the lighest and lowest solids not fat and the lowest fat were observed in the Aylesbury Dairy Company's Jaboratory :-

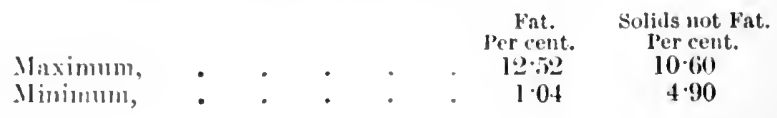


Vieth gives the average proportion between milk-sugar, proteids and ash in milk as $13: 9: 2$.

The author has found that this ratio is marvellously exact, the average being

Nilk-sugar, $52 \cdot 8 \%$ as against $54 \cdot 2$ caleulated from Vieth's ratio.

$\begin{array}{lrrrrr}\text { Proteids, } & 37 \cdot 5 & , & 37 \cdot 5 & , & \text {,, } \\ \text { Ash, } & 8 \cdot 3 & , & 8 \cdot 3 & , & \text {, }\end{array}$

Table XIV. will give the percentage of ash (calculated on the solids not fat) found in milks containing the percentages of solids not fat named.

TABLE XIV.-Percentage of Ash in Milk.

\begin{tabular}{|c|c|c|c|}
\hline \multirow{2}{*}{ Solids not Fat. } & \multirow{2}{*}{ No. of Samples. } & \multicolumn{2}{|c|}{$\begin{array}{l}\text { Percentage of Ash on the } \\
\text { Solids not Fat. }\end{array}$} \\
\hline & & Linlits. & Average. \\
\hline $\begin{array}{r}10 \cdot 5 \\
9 \cdot 7 \\
9 \cdot 6 \\
9 \cdot 5 \\
9 \cdot 4 \\
9 \cdot 3 \\
9 \cdot 2 \\
9 \cdot 1 \\
9 \cdot 0 \\
8 \cdot 9 \\
8 \cdot 8 \\
8 \cdot 7 \\
8 \cdot 6 \\
8 \cdot 5 \\
8 \cdot 4 \\
8 \cdot 3 \\
8 \cdot 2 \\
8 \cdot 1 \\
8 \cdot 0 \\
7 \cdot 7\end{array}$ & $\begin{array}{r}1 \\
1 \\
1 \\
1 \\
2 \\
2 \\
1 \cdot 2 \\
33 \\
43 \\
53 \\
36 \\
15 \\
11 \\
8 \\
10 \\
5 \\
7 \\
7 \\
4 \\
1 \\
253\end{array}$ & $\begin{array}{cc}\ldots & \\
\ldots & \\
\ldots & \\
\ldots & \\
8 \cdot 1 \text { to } & 8 \cdot 5 \\
8 \cdot 0,, & 8 \cdot 6 \\
8 \cdot 0,, & 8 \cdot 6 \\
7 \cdot 9,, & 9 \cdot 1 \\
7 \cdot 9,, & 8 \cdot 8 \\
7 \cdot 9,, & 8 \cdot 7 \\
8 \cdot 0,, & 8 \cdot 9 \\
7 \cdot 9,, & 8 \cdot 0 \\
8 \cdot 0,, & 8 \cdot 6 \\
8 \cdot 1,, & 8 \cdot 7 \\
8 \cdot 3,, & 9 \cdot 5 \\
8 \cdot 5,, & 8 \cdot 9 \\
86,, & 9 \cdot 1 \\
8 \cdot 8,, & 9 \cdot 4 \\
8 \cdot 8,, & 10 \cdot 0 \\
\ldots & \end{array}$ & $\begin{array}{l}8 \cdot 1 \\
8 \cdot 1 \\
8 \cdot 1 \\
8 \cdot 4 \\
8 \cdot 3 \\
8 \cdot 3 \\
8 \cdot 3 \\
8 \cdot 3 \\
8 \cdot 2 \cdot 5 \\
8 \cdot 3 \\
8 \cdot 25 \\
8 \cdot 3 \\
8 \cdot 3 \\
8 \cdot 4 \\
8 \cdot 6 \\
8 \cdot 7 \\
8 \cdot 9 \\
9 \cdot 0 \\
9 \cdot 2 \\
9 \cdot 1 \\
8 \cdot 3\end{array}$ \\
\hline
\end{tabular}

All the above samples were undoubtedly genuine.

Abnormal Milk.-Samples which differ greatly from the mean percentage of solids not fat almost invariably show a proportion of milk-sugar, proteids, or ash very markedly varying from the average. The following analyses (Table XV.) of abnormal milks will show this :- 
TABLE $\mathrm{XV}$ - Axalyes of A bxormal Milks.

\begin{tabular}{|c|c|c|c|c|c|c|c|c|}
\hline Ẍn. & Water. & Fat. & sugar. & Proteirls. & Ash. & liotal. & $\begin{array}{l}\text { solids } \\
\text { not f'at. }\end{array}$ & Anialyst. \\
\hline 1 & $\begin{array}{l}\text { Per } \\
\text { cent. } \\
\text { sig.(ui) }\end{array}$ & $\begin{array}{l}\text { Per } \\
\text { cent. }\end{array}$ & $\begin{array}{l}\text { Per } \\
\text { cent. } \\
1 \cdot 9 !\end{array}$ & $\begin{array}{l}\text { Per } \\
\text { cent. } \\
3 \cdot 3 .\end{array}$ & $\begin{array}{l}\text { Per } \\
\text { cent. } \\
. \$ 6\end{array}$ & $\begin{array}{c}\text { Per cent. } \\
\text { low }(102\end{array}$ & Per cent. & rintl \\
\hline 2 & 8.720 & 7.40 & $3 \cdot 13$ & $3 \cdot 3 \cdot 2$ & $\cdot 76$ & $1(k) \cdot 2)$ & $6 \cdot 60$ & , \\
\hline 3 & $8.5 \cdot 3$ & $9 \cdot 4$ & $\cdots$ & $\ldots$ & $7 s$ & $x$ & $4 \cdot 9$ & , \\
\hline+ & $\therefore: 3 \cdot 3$ & $111 \%$ & & & 76 & $\ldots$ & $6 \cdot 2$ & ,", \\
\hline$\pi$ & $S(j \cdot] 4$ & $3 \cdot 6 \cdot 2$ & $4 \cdot 6 i$ & 4.58 & $\$ 2$ & $99 \cdot 82$ & $10 \cdot 24$ & \\
\hline ii & $\ldots$ & $3 \cdot 14$ & $2 \cdot 59$ & $3 \cdot 7$ & 85 & $\cdots$ & $\ldots$ & Borlmer. \\
\hline 7 & $\ldots$ & $2 \cdot 79$ & & 10 & 94 & $\ldots$ & $6 \cdot 04$ & Lowe. \\
\hline$s$ & $87 \cdot 24$ & $4 \cdot 3 \cdot 3$ & +19 & 347 & 78 & $1010 \cdot 00$ & 8.44 & Lloyd. \\
\hline
\end{tabular}

There appears to be grood evidence of authentication in the case of all these samples; the table conld easily be extended, but the author has chosen those milks which show a very marked departure from the average.

Solids not Fat.-From the observations at his disposal, which exceed a million. the author has calculated (Table XVI.) the probable number of samples of the mixed milk of a herd of cows which will be found between the percentages named per 100,000 examined.

\section{TABLE XVI.-Percentage of Solids not Fat in Mixed MILk.}

\begin{tabular}{|c|c|}
\hline Percentage of Solids not fitt. & Number of Simples. \\
\hline$s \cdot t$ to 5.5 & 1.592 \\
\hline$x: 3,54$ & 042 \\
\hline$s \approx, \quad s: 3$ & 27 \\
\hline$s \cdot 1,,, \quad$, & $2 \cdot 2$ \\
\hline 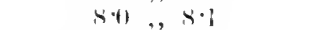 & 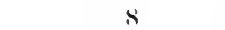 \\
\hline Below s.ll & $\ddot{2}$ \\
\hline
\end{tabular}

Composition of Milk of Different Breeds of Cattle.'lables XVII. and XVIII, give the mumber of samples which are found to fill between the pereentages named of fit and solids not fint respectively for the milk of single cows. Diflerent breeds are kept sepilmat". 
Tables XVII. to XX. are chiefly compiled from analyses by Vieth.

TABLE XVII.-Composition of Milk of Different Brefos of Cattle (Fat).

\begin{tabular}{|c|c|c|c|c|c|c|c|}
\hline $\begin{array}{c}\text { Percentage } \\
\text { of Fat. }\end{array}$ & $\begin{array}{c}\text { Dairy } \\
\text { Sliorthorn. }\end{array}$ & $\begin{array}{l}\text { Pedigree } \\
\text { Shorthor'n. }\end{array}$ & Kerry. & Jersey. & $\begin{array}{c}\text { Redl } \\
\text { Polledl. }\end{array}$ & $\begin{array}{c}\text { Other } \\
\text { Breerls. }\end{array}$ & 'Total. \\
\hline Above 10 & l & $\ldots$ & 2 & & $\ldots$ & ... & 3 \\
\hline 8 to 10 & 10 & $\cdots$ & 6 & 11 & $\ldots$ & l & $2 s$ \\
\hline 7,8 & 11 & 3 & 17 & 36 & $\ldots$ & 4 & 71 \\
\hline 6,7 & 76 & $s$ & 111 & 113 & $\dddot{b j}$ & 21 & 33.5 \\
\hline $5 \%$ & 382 & 91 & 408 & 136 & 41 & 45 & 1103 \\
\hline 4,5 & 1313 & 594 & 659 & 89 & 70 & 70 & 279.5 \\
\hline $3 \cdot 5,, 4$ & 625 & 362 & $18: 2$ & 14 & 31 & 43 & $125 \%$ \\
\hline $3 \cdot 0,, 3 \cdot 5$ & 309 & 173 & 84 & 3 & 26 & 34 & 629 \\
\hline $2 \cdot 9$ & 28 & 15 & ij & $\ldots$ & 6 & 4 & 59 \\
\hline $2 \cdot 8$ & 25 & 15 & 7 & $\cdots$ & 1 & $\tilde{5}$ & 53 \\
\hline $2 \cdot 7$ & 21 & 8 & 7 & $\ldots$ & 2 & 3 & 41 \\
\hline $2 \cdot 6$ & 16 & 10 & 2 & $\ldots$ & 2 & l & 31 \\
\hline $2 \cdot 5$ & $\overline{5}$ & 5 & $\ldots$ & $\ldots$ & 1 & $\ldots$ & 11 \\
\hline $2 \cdot 4$ & 8 & 5 & $\dddot{l}$ & 1 & $\ldots$ & l & 16 \\
\hline $2 \cdot 3$ & 5 & 1 & $\ldots$ & $\ldots$ & $\ldots$ & 2 & 8 \\
\hline $2 \cdot 2$ & 2 & $\ldots$ & $\ldots$ & $\ldots$ & $\ldots$ & 1 & 3 \\
\hline $2 \cdot 1$ & 5 & I & $\ldots$ & $\ldots$ & $\ldots$ & 1 & 7 \\
\hline $2 \cdot 0$ & 2 & & $\ldots$ & 1 & $\ldots$ & $\ldots$ & 3 \\
\hline $1 \cdot 9$ & 2 & 1 & $\ldots$ & $\ldots$ & $\cdots$ & $\cdots$ & 3 \\
\hline $1 \cdot 8$ & $\ldots$ & $\ldots$ & 1 & $\ldots$ & $\ldots$ & $\ldots$ & 1 \\
\hline $1 \cdot 7$ & $\ldots$ & $\ldots$ & $\ldots$ & $\ldots$ & $\ldots$ & 1 & 1 \\
\hline $1 \cdot 6$ & 1 & $\ldots$ & $\ldots$ & $\ldots$ & $\ldots$ & $\ldots$ & 1 前 \\
\hline $1 \cdot 5$ & $\ldots$ & $\ldots$ & $\ldots$ & $\ldots$ & $\ldots$ & $\ldots$ & ... \\
\hline $1 \cdot 4$ & $\ldots$ & $\ldots$ & $\ldots$ & $\ldots$ & $\ldots$ & 1 & 1 \\
\hline $1 \cdot 3$ & 1 & $\ldots$ & $\ldots$ & $\ldots$ & $\ldots$ & $\ldots$ & 1 \\
\hline $1 \cdot 2$ & $\ldots$ & $\ldots$ & $\ldots$ & $\ldots$ & $\ldots$ & $\ldots$ & $\ldots$ \\
\hline $1 \cdot 0$ & 1 & $\ldots$ & $\ldots$ & $\ldots$ & $\ldots$ & $\ldots$ & 1 \\
\hline
\end{tabular}

The analysis of the samples showing the highest and lowest fat was

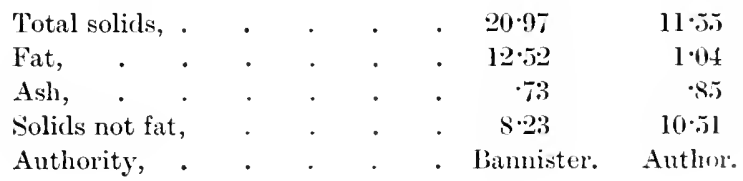


TABLE XVIII.-Composition of MiLK of Differext Breeds of Cattle (Solids yot Fat).

\begin{tabular}{|c|c|c|c|c|c|c|c|}
\hline $\begin{array}{l}\text { Percentagc } \\
\text { of solitls } \\
\text { weot rat. }\end{array}$ & $\begin{array}{l}\text { bairy } \\
\text { shorthorn. }\end{array}$ & $\begin{array}{l}\text { Peligree } \\
\text { Shorthorn. }\end{array}$ & kerry. & $\begin{array}{c}\text { Iersey. } \\
\text {. }\end{array}$ & $\begin{array}{c}\text { Red } \\
\text { Polled. }\end{array}$ & $\begin{array}{l}\text { Other } \\
\text { Breeds. }\end{array}$ & Total. \\
\hline Alove 10 & 21 & & 6 & 13 & 2 & 7 & 51 \\
\hline 9.5 to 111 & 112 & 37 & 88 & 91 & 16 & 47 & 391 \\
\hline דים , & 972 & 390 & $7+4$ & 200 & 69 & 114 & 2489 \\
\hline $8 \%,, 9 \cdot 0$ & $1+91$ & 734 & 594 & 91 & 76 & 59 & 3045 \\
\hline 54 & $10 s$ & 70 & 23 & 2 & 6 & 6 & 215 \\
\hline$s: 3$ & 62 & 30 & 2.2 & 2 & 7 & 2 & 125 \\
\hline$s \because 2$ & 36 & 9 & 6 & 2 & $\ldots$ & 1 & 54 \\
\hline$s \cdot 1$ & 12 & 9 & 3 & 1 & $\ldots$ & 1 & 26 \\
\hline$s \cdot 11$ & $1 j$ & 7 & $\ldots$ & $\ldots$ & 3 & & 25 \\
\hline $7 \cdot 9$ & 10 & 2 & 2 & $\ldots$ & 1 & 1 & 16 \\
\hline $7 \cdot 4$ & $\bar{J}$ & 1 & $\ldots$ & $\ldots$ & $\ldots$ & $\ldots$ & 6 \\
\hline $7 \cdot 7$ & 3 & 2 & $\cdots$ & $\ldots$ & 2 & $\ldots$ & 7 \\
\hline $7 \cdot 6$ & 2 & 1 & 1 & $\ldots$ & $\ldots$ & $\ldots$ & 4 \\
\hline $7 \because$ & $\ldots$ & $\ldots$ & $\ldots$ & $\ldots$ & 2 & $\ldots$ & 2 \\
\hline $7 \cdot 3$ & $\ldots$ & $\ldots$ & $\ldots$ & $\ldots$ & 1 & $\ldots$ & 1 \\
\hline$T \cdot 1$ & $\ldots$ & $\ldots$ & $\ldots$ & $\ldots$ & 1 & $\ldots$ & 1 \\
\hline $6 \cdot 6$ & $\ldots$ & $\ldots$ & 1 & $\ldots$ & $\ldots$ & $\ldots$ & 1 \\
\hline $6 \cdot 2$ & $\ldots$ & $\ldots$ & l & $\ldots$ & $\ldots$ & $\ldots$ & 1 \\
\hline$i \cdot 1$ & $\ldots$ & $\ldots$ & 1 & $\ldots$ & $\ldots$ & $\ldots$ & 1 \\
\hline $4 \cdot 9$ & $\ldots$ & $\ldots$ & 1 & $\ldots$ & $\ldots$ & $\ldots$ & 1 \\
\hline
\end{tabular}

The samples yielding below 7 per cent. of solids not fat were all obtained from one cow.

The following are analyses on different dates of her milk :-

$$
\begin{aligned}
& \text { TABLE XIX.- Variations IN Solids not Fat in Milk } \\
& \text { Fron the salle Cow. }
\end{aligned}
$$

\begin{tabular}{|c|c|c|c|c|c|c|c|c|}
\hline & $=$ & 语 & $\begin{array}{l}= \\
= \\
=\end{array}$ & $=$ & $=\frac{10}{0}$ & 资 & $\begin{array}{l}=0 \\
=\end{array}$ & $=\frac{x}{0}$ \\
\hline Total solirts, & $\begin{array}{l}\text { Peret. } \\
\text { ] } 4.11\end{array}$ & $\begin{array}{c}\text { Perct. } \\
12.8\end{array}$ & $\begin{array}{c}\text { Peret. } \\
14: 3\end{array}$ & $\begin{array}{l}\text { Perct. } \\
16.7\end{array}$ & $\begin{array}{l}\text { Perct. } \\
\text { II } 0\end{array}$ & $\begin{array}{c}\text { Perct. } \\
14: 8\end{array}$ & $\begin{array}{c}\text { Perct. } \\
1.5 \cdot 1\end{array}$ & $\begin{array}{c}\text { Peret. } \\
1.2 \cdot 1\end{array}$ \\
\hline Fat. . & +9 & $3 \cdot s$ & $9 \cdot 4$ & 111.5 & $4 \cdot 9$ & $8 \% 2$ & $6: 3$ & $3 \%$ \\
\hline Milk-sugare, & $\cdots$ & $\ldots$ & ․ & & $1 \cdot 91$ & $3 \cdot 26$ & $\ldots$ & ... \\
\hline l'roteirls, & .. & ... & & & $3 \cdot 3.5$ & $3 \cdot 3 \cdot 2$ & .. & $\ldots$ \\
\hline Ash, . & & & T & 76 & 80 & 76 & & \\
\hline Folids not fat, & 1 & !) 11 & $4 \cdot 9$ & $(i \cdots 2$ & $6 \cdot 1$ & $6 \cdot(i$ & s' & 89 \\
\hline
\end{tabular}

Table XX. gives the maximum, minimum, and average percrentigges of total solids, fat, and solids not fat in the milk of cows of different breeds, obtained from analyses of the milk of cows kept on the Ayleshury Daily Company's Estate at Horsham. 
TABLE XX.-Solids in Milk of Cows of Differext BreEds (Vieth).

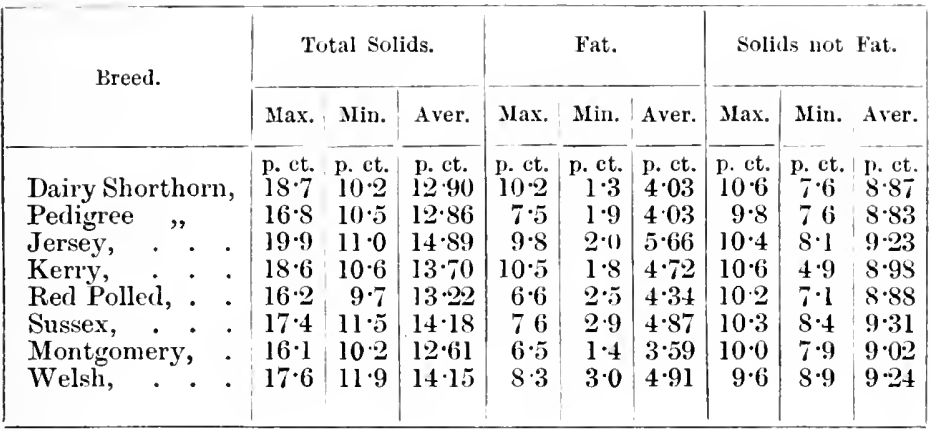

The figures below (Table XXI.) were obtained at the New Jersey State Agricultural Experiment Station.

\section{TABLE XXI.-Composition of Milk of Different Breeds of Cattle.}

\begin{tabular}{|c|c|c|c|c|c|c|}
\hline Breed. & & Total Solids. & Fat. & Milk-sugar. & Proteids. & Ash. \\
\hline $\begin{array}{l}\text { Ayrshire, } \\
\text { Guelnsey, : } \\
\text { Holstein, : } \\
\text { Jersey, . } \\
\text { Shorthorn, }\end{array}$ & 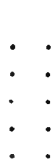 & $\begin{array}{c}\text { Per cent. } \\
12 \cdot 70 \\
14 \cdot 48 \\
12 \cdot 12 \\
14 \cdot 34 \\
12 \cdot 45\end{array}$ & $\begin{array}{c}\text { Per cent. } \\
3 \cdot 68 \\
5 \cdot 02 \\
3 \cdot 51 \\
4 \cdot 78 \\
3 \cdot 65\end{array}$ & $\begin{array}{c}\text { Per cent. } \\
4 \cdot 84 \\
4 \cdot 80 \\
4 \cdot 69 \\
4 \cdot 85 \\
480\end{array}$ & $\begin{array}{c}\text { Per cent. } \\
3 \cdot 48 \\
3 \cdot 9.2 \\
3.28 \\
3.96 \\
3 \cdot 27\end{array}$ & $\begin{array}{c}\text { Per cent. } \\
.69 \\
.75 \\
.64 \\
.75 \\
.73\end{array}$ \\
\hline
\end{tabular}

Fleischmann also gives the following figures :-

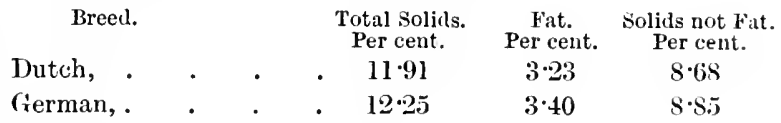

Liverseege gives, using analyses by James Bell, figures for the composition of the milk yielded by cows of different breeds; he notes that in some cases the number of samples is too small to be of inuch use. 


\section{TABLE XXII.-Solids IN Milk of Differest Breeds of Cattle (Bell).}

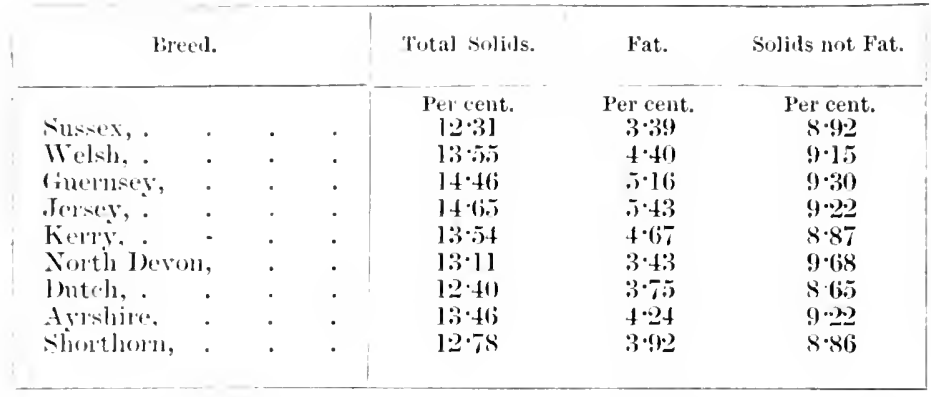

It is difficult to give the probable percentages of fat that may bee expecterl to be found, as the amount of fat in a milk is not mly dependent on that yielded by the cow, but is influenced by the fact that, owing to its not being in solution, it raries according to the conditions under which the milk is kejt.

Variations of Fat in Different Churns.-When the mixed milk of a herd of cows has been examined, the fat has not been found to fall below 2.98 per cent.; when the milk is divided into portions, as is the ease when it lias to be transported by railwas, considerable variations in fat are sometimes noticed. As examples, the following analyses may be quoted :-

Series 1.

\begin{tabular}{|c|c|c|c|}
\hline - pecitic glavity, & & $1 \cdot 0.340$ & $1 \cdot 0: 3: 21$ \\
\hline Total solirls, & $\begin{array}{l}\text { li. ct. } \\
11.28\end{array}$ & $\begin{array}{l}\text { P. et. } \\
11 \cdot(6 t)\end{array}$ & $\begin{array}{l}\text { P. ct } \\
]+16\end{array}$ \\
\hline & $2 \cdot 10$ & $2 \cdot 50$ & $5 \cdot 111$ \\
\hline olids unot fite. & $! 1 \cdot 10$ & $! \cdot 16$ & $1 \cdot 06$ \\
\hline
\end{tabular}

Series II

\begin{tabular}{|c|c|c|}
\hline & 1.0320 & $1 \cdot 0$ \\
\hline $\begin{array}{l}11 . c t . \\
11 \cdots 2.2\end{array}$ & $\begin{array}{l}\text { p. ct. } \\
12+42\end{array}$ & 13. \\
\hline $2 \cdot(60)$ & $3 \cdot 70$ & $4 \cdot 80$ \\
\hline $6: 2$ & 8.72 & $8 \cdot 62$ \\
\hline
\end{tabular}

Seasonal and Monthly Variations.-Distinct variations according to season are found; these will be shown by Table XXIII., which gives the mean monthly averages of milk for the last sixteen years.

Thr year, roughly speaking, can be divided into four periods:-

(1) November, Decemler, and January; the mills is rich, both in fat and solids not fat.

(2) liebruary, Mareh, and April; the solids not fat to not show appreciable dininution, but the fat becomes less in quality.

(:3) Nay, June, July, and August; the fat is low, though there is a tendency to rise at the end of the period. In July and August the solids not fat are below the average.

(4) September and Octoher : an improvement in quality both in fat and solids not fat is noticerl.

These periods correspond approximately to the seasons; winter 
milk is of very good quality, while summer milk is the poorest; the spring and autumn are transition periods.

The quality varies in an inverse ratio to the quantity yielded.

In the analyses below (Table XXIII.) the specific gravity has always been determined by a lactometer; the total solids were estimated from 1881 to February 1894 , since when, fat determinations have been made. The total solids or the fat have been calculated by the formula devised by Hehner and the author.

TABLE XXIIT.-Mean Monthly Averages of Milk.

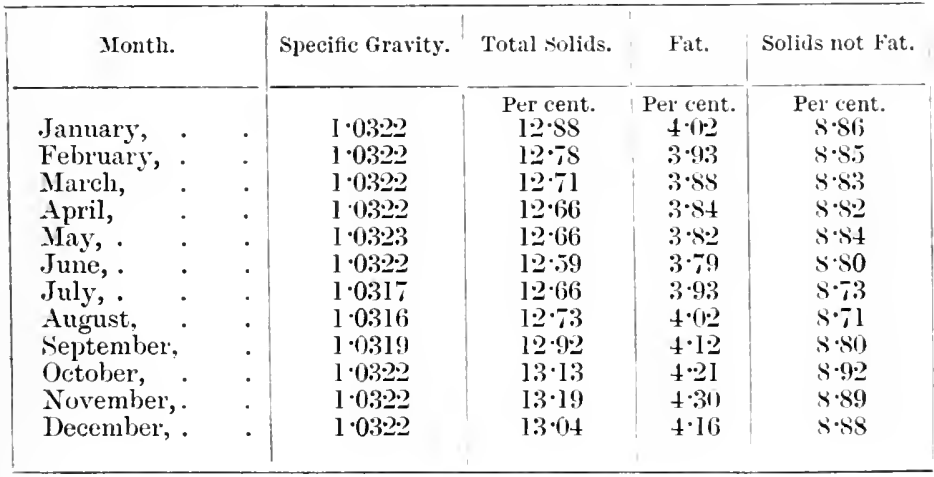

Daily Variations. - It has leen found that the percentage of fat varies slightly according to the day of the week, as is shown by the following figures:-

$\begin{array}{cccccccc}\text { Day, } & \text { Mon. } & \text { Thes. } & \text { Wed. } & \text { Thurs. } & \text { Fri. } & \text { sat. } & \text { sm. } \\ \text { Per cent. Fat, } & 3 \cdot 70 & 3 \cdot 78 & 3 \cdot 75 & 3 \cdot 75 & 3 \cdot 75 & 3 \cdot 73 & 3 \cdot 74\end{array}$

It is seen that Monday's milk is the lowest in fat; this is probably due partly to a disturbance in the quality arising from the interval between milking on Sunday night and Monday morning not being identical with the usual interval, and partly to the influence of the Sunday holiday on the wilkers, rendering them rather more careless about stripping the cows on Mondays than on other days.

Morning and Evening Variations.-In England it is the custom to milk cows twice a day; the quality is not the same at both meals, the evening milk being almost invariably richer in fat than the morning milk. In dairies where it is the custom to leave an interval of twelve hours between the inilkings this is far less noticeable than in those where there is an interval of nine to ten hours between the morning and the cvening meal, 
and fourteen to fifteen hours between the evening and the morning meal.

Table XXIV., giving the montlly average of morning and evening milk respectively during 1896 , will show the averige difference.

\section{TABLE XXIV.-Conposition of Morisg axd Evenisg Milk.}

\begin{tabular}{|c|c|c|c|c|c|c|c|c|c|}
\hline \multirow{2}{*}{ Nonth. } & & \multicolumn{4}{|c|}{ Morning Milk. } & \multicolumn{4}{|c|}{ Evening Milk. } \\
\hline & & $\begin{array}{l}\text { Specific } \\
\text { Gravity. }\end{array}$ & $\begin{array}{l}\text { Total } \\
\text { Solids. }\end{array}$ & Fat. & $\begin{array}{l}\text { Solids } \\
\text { nulE'tt }\end{array}$ & $\begin{array}{l}\text { Specific } \\
\text { Gravity. }\end{array}$ & $\begin{array}{l}\text { Total } \\
\text { Solids. }\end{array}$ & Fat. & $\begin{array}{l}\text { Solids } \\
\text { notFat }\end{array}$ \\
\hline January, & 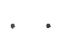 & 0327 & $12 \cdot 76$ & 371 & $9 \cdot 05$ & 1.0324 & $13 \cdot 16$ & $4 \cdot 10$ & $9 \cdot 06$ \\
\hline February. & . & 0327 & $12 \cdot 63$ & $3 \cdot 61$ & & & 13 & & $9 \cdot 02$ \\
\hline March, & . & $1 \cdot 0327$ & $10 \cdot 63$ & $3 \cdot 6 l$ & $9 \cdot 0 \cdot 2$ & 0323 & $12 \cdot 96$ & 95 & $9 \cdot 01$ \\
\hline April, . & . & & & $3 \cdot 56$ & 90 & & & & $9 \cdot 03$ \\
\hline May, & . & $1 \cdot 0328$ & $12+2$ & $3 \cdot 40$ & $9 \cdot($ & 23 & $12 \cdot 76$ & & $8 \cdot 97$ \\
\hline June, & - & $1 \cdot 0323$ & $12 \cdot 31$ & $3 \cdot 42$ & $8 \cdot 89$ & 318 & $12 \cdot 55$ & & $8 \cdot 83$ \\
\hline July. . & . & $1 \cdot 0316$ & $12 \cdot 24$ & $3 \cdot 50$ & $8 \cdot 74$ & $1 \cdot 0312$ & $12 \cdot 50$ & $3 \cdot 80$ & $8 \cdot 70$ \\
\hline Augrust. & . & $1 \cdot 0315$ & $12 \cdot 40$ & $3 \cdot 65$ & $8 \cdot 75$ & $1 \cdot 0313$ & 1269 & $3 \cdot 96$ & $8 \cdot 73$ \\
\hline tember, & . & $1 \cdot 032 !$ & 1261 & $3 \cdot 7$ & & 318 & & & $8 \cdot 92$ \\
\hline October. & . & $1 \cdot 0328$ & $12 \cdot 83$ & 375 & $9 \cdot 1$ & $1 \cdot 0324$ & $13 \cdot 23$ & $4 \cdot 1$ & $9 \cdot 06$ \\
\hline Novemlier, & . & $1 \cdot 0329$ & $1: 2 \cdot 89$ & $3 \cdot 78$ & $9 \cdot 11$ & $1 \cdot 0325$ & $13 \cdot 27$ & $4 \cdot 17$ & $9 \cdot 10$ \\
\hline Decemher, . & . . & $1 \cdot 0327$ & $12 \cdot 87$ & 380 & $9 \cdot 07$ & $1 \cdot 0324$ & $13 \cdot 24$ & $4 \cdot 17$ & 907 \\
\hline & . & 1·03.5 & $12 \cdot 60$ & 363 & $8 \cdot 97$ & l 0321 & $12 \cdot 95$ & $3 \cdot 99$ & $8 \cdot 96$ \\
\hline
\end{tabular}

Variations on Partial Milking.-CThe quality of the milk first drawn from the udder is very different from the last portions. Boussingault has recorded the following analyses of milk drawn from a cow in portions:-

\begin{tabular}{|c|c|c|c|c|c|c|}
\hline Purtion & 1 & 2 & 3 & 4 & 5 & 6 \\
\hline $\begin{array}{l}\text { Total solids, } \\
\text { Fat, : } \\
\text { forlinls not fat, }\end{array}$ & $\begin{array}{c}\text { Per cent. } \\
10 \cdot 47 \\
1 \cdot 711 \\
s \cdot \frac{7}{6}\end{array}$ & 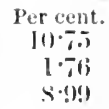 & $\begin{array}{c}\text { Per cent. } \\
10.8 .5 \\
2.10 \\
5.5\end{array}$ & $\begin{array}{c}\text { Per cent. } \\
11 \cdot 23 \\
2 \cdot 54 \\
5 \cdot 6 !\end{array}$ & $\begin{array}{c}\text { Per cent. } \\
11 \cdot 6 ; 3 \\
3 \cdot 14 \\
8 \cdot 49\end{array}$ & $\begin{array}{c}\text { Per cent. } \\
12.67 \\
4 \cdot 0 s \\
s \cdot 5 !\end{array}$ \\
\hline
\end{tabular}

Heaton has also given a remarkible analysis of a pirtial milking; it contained only 26 per cent. of fitt.

It is sometimes noticed that a $\mathrm{cow}$, through restlessness or nervonsness, holds hack her milk, especially if the surroundings are strance. Thus Dyer has recoriled an amalysis of milk obtained from a cow at an agricultural show which contained 1.85 per cent. of fat ; the next day the milk was normal, containing $3 \cdot 6.4$ per 
cent. of fat. Many, if not all, of the very low fats recorded in Table XVII. on p. 123 are due to this cause.

Variations of Fat with Solids not Fat.-Speaking very generally, a high percentage of fat is accompanied by a high percentage of solids not fat. Vieth gives the following table:-

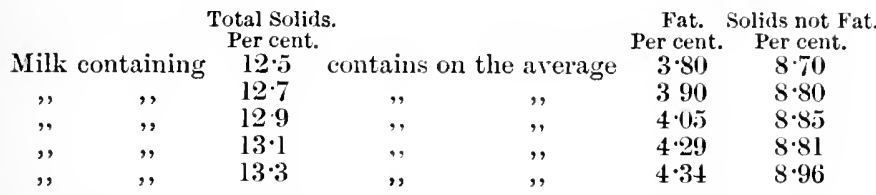

There are, however, very many exceptions to this rule.

Fore Milk and Strippings. - The first portions drawn from the udder are known as "fore milk," the last portions as "strippings"; it is not unusual to find more than 10 per cent. of fat in strippings.

Colostrum.-The name "colostrum" is applied to the secretion of the udder before (and immediately atter) parturition. Lassaigne pointed out that an albuminous liquid commenced to form sometimes two months before parturition. This secretion, according to Houdet, often appears under two forms - a brownish, viscous, honey-like product, and a lemon-yellow, non-viscous liquid; the two often co-exist in the same animal, the earlier milkings furnishing the tirst, and the later the second.

The viscous secretion is curdled by heat, and precipitated by acetic acid, mercuric chloride, and alcohol, but not curdled by rennet. The analysis is

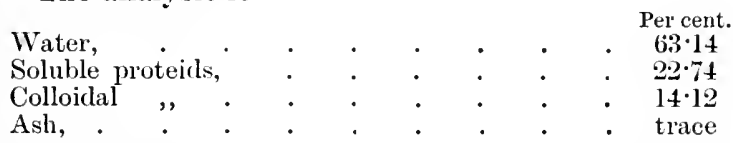

The non-viscous secretion contained more water and less soluble proteids than the viscous secretion, and gave a barely appreciable precipitate with mercuric chloride and alcohol, but was coagulated by heat and acetic acid and unaffected by rennet.

One hundred cubic centimetres containerl

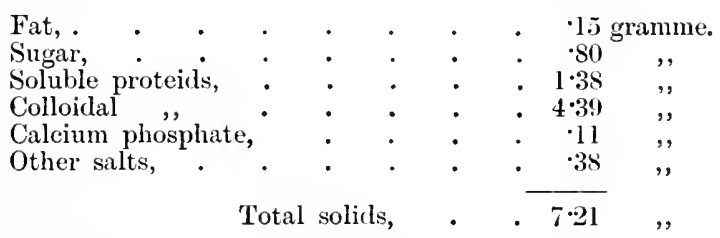

The composition of the fluid secretion approaches more nearly to that of milk.

Four or tive days before parturition the secretions are replaced by colostrum proper. 
True colostrum is an opaque yellow liquid of pungent taste; sometimes bloor is present, which shows its presence by a reddish colour.

It is curdled by heat, acetic acid, mercuric chloride, and rennet (though the action of this is not so rapid as with milk). It has a slimy, viscous appearance, and, if left to stand, has a tendency to separate into two layers.

The proteids probably consist of casein, albumin, nuclein, and globulin, while lecithin, cholesterol, tyrosine, and urea are present. Albumoses and peptones have been found.

The sugar of colostrum consists of milk-sugar, dextrose, and, possibly, other sugars.

The fat ditfers from that of milk; the melting point is high $\left(40^{\circ}\right.$ to $44^{\circ}$ C.), and the amount of volatile acids low. Pizzi found that a few hours ( 3 to 6 ) before parturition the Reichert-Wollny figure of the fat was $4 \cdot 4$ to $4 \cdot 7$, and six hours after calving $6 \cdot 2$ to $6 \cdot 3$; a rapid increase was noticed, and in from three to six days a normal figure was reached.

The ash of colostrum has, according to Fleischmann, the following composition :-

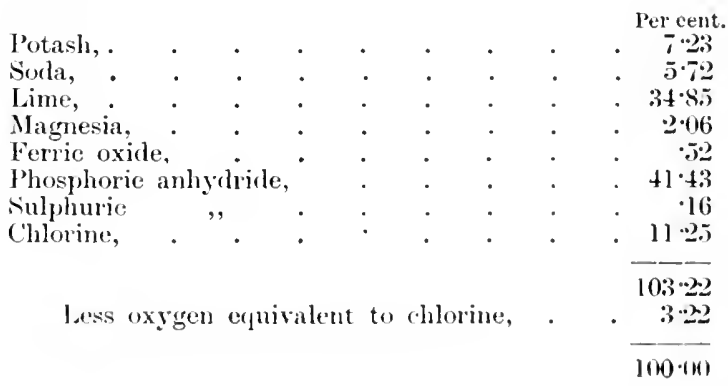

The best defined characteristic of colostrum is the presence of the "corps granuleux" of Donné, which consist of clusters of cells like bunches of grapes. These are from 005 to 025 millimetre in diameter, and are easily detected under the microscope. They do not disappear entirely from milk till three weeks after calving, according to Henle.

The specific gravity of colostrum is from 1.046 to 1.079 at $15^{\circ} \mathrm{C} .\left(59^{\circ} \mathrm{F}.\right)$, and arerages 1.068 .

Fugling gives the following composition :-

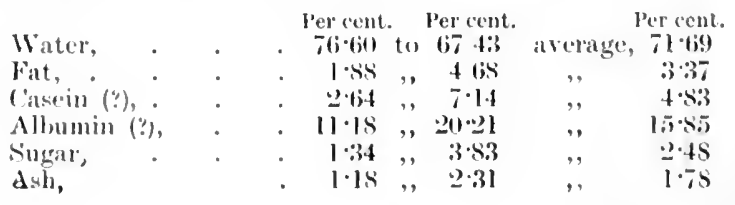


Change of Colostrum to Normal Milk.-The composition of colostrum changes rapidly after parturition. Houdet gives the following figures as illustrating the change :-

\begin{tabular}{|c|c|c|c|c|c|c|}
\hline & Fat. & Sugar. & $\begin{array}{l}\text { Soluble } \\
\text { Proteids. }\end{array}$ & $\begin{array}{l}\text { Colloidal } \\
\text { Proteids. }\end{array}$ & $\begin{array}{c}\text { Calcium } \\
\text { Pliosphate }\end{array}$ & $\begin{array}{l}\text { Other } \\
\text { Salts. }\end{array}$ \\
\hline $\begin{array}{l}\text { Six days before calving, } \\
\text { Four ,, , , } \\
\text { Immediately after,", }\end{array}$ & $\begin{array}{c}\text { Per ct. } \\
50 \\
3 \cdot 01 \\
3 \cdot 14\end{array}$ & $\begin{array}{c}\text { Per ct. } \\
2 \cdot 35 \\
3 \cdot 17 \\
2 \cdot 70\end{array}$ & $\begin{array}{c}\text { Per' ct. } \\
\cdot 47 \\
\cdot 45 \\
\cdot 25\end{array}$ & $\begin{array}{c}\text { Per ct. } \\
17 \cdot 43 \\
12 \cdot 08 \\
14 \cdot 53\end{array}$ & $\begin{array}{c}\text { Per ct. } \\
\cdot 44 \\
\cdot 47 \\
\cdot 46\end{array}$ & $\begin{array}{c}\text { Per ct. } \\
\quad 36 \\
\cdot 40 \\
\cdot 42\end{array}$ \\
\hline
\end{tabular}

These figures show a sudden increase in the amount of proteids over that contained in the fluid secretion described above. Houdet ascribes this to a diversion to the udder of nutritive material which up to this time had been supplied to the foetus. An increase of fat and a decrease of soluble proteids are also observed.

The colostrum from another cow was examined at intervals after parturition with the following results (Table XXV.), which show the gradual transition into normal milk :-

Table XXV.-Change of Colostrum to Normal Milk.

\begin{tabular}{|rl|c|c|c|c|c|c|c|}
\hline \multicolumn{2}{|c}{ Date. } & & Fat. & Sugar. & $\begin{array}{c}\text { Soluble } \\
\text { Proteids. }\end{array}$ & $\begin{array}{c}\text { Colloidal } \\
\text { Proteils. }\end{array}$ & $\begin{array}{c}\text { Calcium } \\
\text { Phosphate }\end{array}$ & $\begin{array}{c}\text { Other } \\
\text { Salts. }\end{array}$ \\
\hline & & & & & & \\
\hline
\end{tabular}

Vaudin gives the following figures (Table XXVI.) as showing the composition of colostrum :-

TABLE XXVI.-Conposition of Colostrum.

\begin{tabular}{|c|c|c|c|c|c|}
\hline Date. & Fat. & Sugar. & Proteils. & $\begin{array}{c}\text { Calcium } \\
\text { Phosphate }\end{array}$ & $\begin{array}{l}\text { Other } \\
\text { Salts. }\end{array}$ \\
\hline $\begin{array}{l}\text { Evening before calving, } \\
\text { Immediately after } \\
\text { calving ( } 4 \text { cows), } \\
\text { Five days after calving, }\end{array}$ & $\begin{array}{l}\text { Per cent. } \\
1 \cdot 30 \\
6 \cdot 32 \\
3 \cdot 84 \\
1 \cdot 36 \\
2 \cdot 42 \\
5 \cdot 18\end{array}$ & $\begin{array}{l}\text { Per cent. } \\
1 \cdot 52 \\
2 \cdot 17 \\
2 \cdot 37 \\
1 \cdot 02 \\
2 \cdot 86 \\
4 \cdot 07\end{array}$ & $\begin{array}{l}\text { Per cent. } \\
2370 \\
14 \cdot 91 \\
20 \cdot 10 \\
19 \cdot 02 \\
17 \cdot 68 \\
4 \cdot 35\end{array}$ & \begin{tabular}{|l} 
Per cent. \\
$\cdot 62$ \\
$\cdot 63$ \\
$\cdot 66$ \\
$\cdot 61$ \\
$\cdot 87$ \\
$\cdot 38$
\end{tabular} & $\begin{array}{c}\text { Per cent. } \\
\cdot 47 \\
\cdot 46 \\
\cdot 39 \\
\cdot 46 \\
\cdot 34 \\
\cdot 49\end{array}$ \\
\hline
\end{tabular}


Colostrum differs from milk in containing less sugar, a fat which is very poor in volatile acids, and a high amount of nitrogenous compounds. The nitrogenous eompounds differ from those of milk. As methods for their separation are not known, this accounts for the discrepancy between the results of Engling and Houdet.

Milk containing colostrum is not usel for dairy purposes; at least four days should be allowed to elapse after parturition before the milk is employed for consumption.

Generally speaking, the milk of newly-calvel cows is poorer in fat than that of cows towards the end of their period of lactation. Kühn's experiments have shown that the casein also increases as the period of lactation advances, while the milksugar decreases; the mineral matter also increases towards the end of lactation. Nost of the analyses in p. 122 which slow a high percentage of proteids were oltained from cows which were getting dry.

The milk of cows in ill-health may have a very abnormal composition. Wynter Blyth las collated the information concerning these in his Foods, their Composition and Aralysis (q. v.). They are, however, of interest from a pathological point of view, rather than of practical importance in dairying.

Limits and Standards of Milk - Society of Public Analyst's Standard.-The Society of Public Analysts have adopted as lower limits for fat and solids not fat respectively, 3.0 per cent. hy weight and 8.5 per cent. by weiglit, and these limits have been accepted as satisfactory hy the great majority of analytical chemists of the country. These limits do not represent the absolute ininima yet found, as will be readily seen by referring to the figures previously quoted, but are limits below which mixed milk of a lierd of cows may he reasonably expected not to fall. Vieth in discussing the question how fal they conlal he applied to all milks has written: "My object is by no means to riise the cry that the standard alopted by the society is ten ligh; on the contrary, I think it is very judiciously fixed, but, in upholding the standard of purity, it should not be forgotten that the cows have never been asked for, nor have given their assent to it, and that they will at times produce milk holow standard. A bad season for hay-making is, in my experience, almost invariably followed by a particularly low dppression in the quality of the milk towards the end of the winter. Shruld the winter be of unusual severity and length, the depression will he still more narked. Long spells of cold and wet, as well as of heat and drought, luring the time when cows are kept on pasture, also unfavourahly influence the quality and, I may add, quantity of milk."

According to the author's experience the limit of 3.0 per cent. for fat is certainly reasonable for the mixed milk of a whole 
herd; such milk very rarely, if ever, falls appreciably below this limit. It is far more frequent, as is shown by Table XVI. on p. 122 , for milk to contain less that 8.5 per cent. of solids not fat; in the whole of these cases, the author has found that at least .50 per cent. of total nitrogen and 70 per cent. of ash was present, and this experience has received much confirmation. Smetham and some American observer's have, however, found that even these limits are somewhat too high for the milk of Dutch or Holstein-Frisian cows. At the present time this breed of cows does not form a majority of English milch-cattle; on farns where they are kept other breeds yielding milk of higher quality are also milked.

Triple Standard. - For all practical purposes the triple standard of 8.5 per cent. of solids not fat, .50 per cent. of total nitrogen, and .70 per cent. of ash may be adopted for the purpose of judging whether a milk is of genuine composition or not. The figure for the ash is, lowever, liable to be increased by the addition of mineral substances added to the milk; thus boric acid and borax, used as preservatives, and salt, added to mask the addition of water, would raise the ash; estimation of the boric acid, which is absent in genuine milk, or of the chlorine, which does not exceed 10 per cent., will show additions of this nature. The amount of ash insoluble in hot water is also a useful figure; it amounts in milk to at least 50 per cent. and is very nearly equal to the total nitrogen.

A milk should never be pronounced as watered on the evidence of the solids not fat alone, unless this is well below 8.0 per cent.; a determination of the total nitrogen and of the ash at least should be made in addition; a judgment formed on the three determinations will be in all probability correct.

Variations of Fat in Milk on Standing.-Were milk a homogeneous solution there would be no trouble in employing the limit of 3.0 per cent. of fat to detect the addition of skim milk, in the same rigid manner that the limits mentioned can be used to detect watering; the fat globules of milk have, however, a natural tendency to rise to the surface and to thus cause an unequal distribution of fat in different portions of the milk.

Table XXVII. will give an idea of the rate at which appreciable change in the composition of the milk occurs ; 12 gallons of well-mixed milk were placed in a churn with a tap at the bottom at 11.25 a.m., and a measure holding 7 quarts was drawn out every half-hour till 2.25 p.m.; each of these quantities was analysed, as also the residue left in the churn (5 quarts); the milk was undisturbed throughout. 
TABLE XXVli.-Variations in Composition of Milk oN Standing (Large Churs).

\begin{tabular}{|c|c|c|c|c|}
\hline Time. & Specific Gravity. & Total solids. & Fat. & Solids not Fat. \\
\hline $\begin{array}{l}11.25 \text { a.m. } \\
11.55 \quad . \\
12.25 \text { p.m. } \\
12.55 \quad ., \\
1.25 \text {. } \\
1.55 \quad, \\
2.25 \quad, \\
\text { Resirlue. }\end{array}$ & $\begin{array}{l}1 \cdot 0.324 \\
1 \cdot 0.325 \\
1 \cdot 0.324 \\
1 \cdot 01331 \\
1 \cdot 13334 \\
1 \cdot 0334 \\
1 \cdot 0.334 \\
1 \cdot 0.253\end{array}$ & $\begin{array}{c}\text { Per cent. } \\
12 \cdot 691 \\
12 \cdot 68 \\
12 \cdot 3.5 \\
12 \cdot 13 \\
12 \cdot 113 \\
11 \cdot 92 \\
1192 \\
16 \cdot 155\end{array}$ & $\begin{array}{c}\text { Per cent. } \\
3 \cdot 71 \\
3 \cdot 6 \times \\
3 \cdot 34 \\
3 \cdot 10 \\
2 \cdot 95 \\
0 \cdot 90 \\
2 \cdot 90 \\
7 \cdot 57\end{array}$ & $\begin{array}{c}\text { Per cent. } \\
8 \cdot 98 \\
9 \cdot 00 \\
9 \cdot 01 \\
9 \cdot 03 \\
9 \cdot 08 \\
9 \cdot 07 \\
9 \cdot 06 \\
5 \cdot 78\end{array}$ \\
\hline
\end{tabular}

In another experiment two small churns, such as are used in restaurants, each holding 12 quarts, were stood side by side; every quarter of an hour 1 quart was drawn from the tap and the amount of fat in each portion was estimated (Table XXVIII.).

\section{TABLE XXVIII.-Variations in Composition of Milk on Staydisg (Siall Cilurss).}

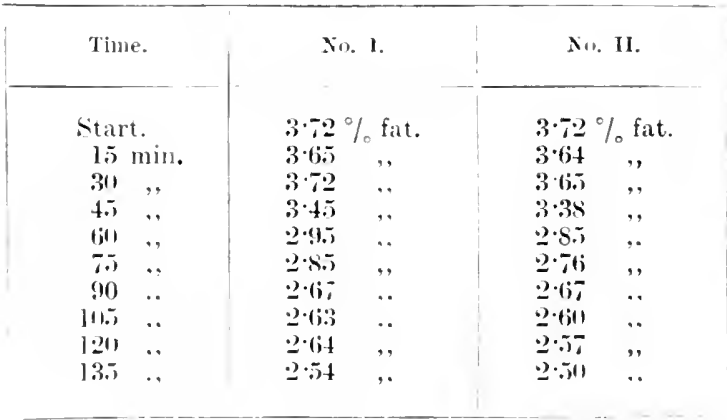

It is seen from the results of these experiments, which are typieal of many, that milk left to stand remains approximately of the same composition for short periods only--not exceeding half an hour; hy continually drawing of the bottom layer, samples are ohtained which hecome poorer and pooser in fat till the upper layer of cream is reached.

A similar phenomenon is observerl, if the milk is dipped from the top of a counter pan, as the following figures will show:-

Three quasts of milk were placed in a pan: every half-hwur one pint was removed by dipping from the surface; and each portion was analysed (Table XXIX.). 
TABLE XXIX. - Variations in Composition of IILK on Standing (PaN).

\begin{tabular}{|c|c|}
\hline Time. & Percentage of Fat. \\
\hline & \\
\hline Start. & $3 \cdot 6.5$ \\
$30 \mathrm{~min}$. & $3 \cdot 75$ \\
$60,$, & $4 \cdot 40$ \\
$90,$, & $4 \cdot 15$ \\
$120,$, & $3 \cdot 75$ \\
Residue. & $2 \cdot 80$ \\
\hline
\end{tabular}

Here again it is seen that the milk does not remain practically constant in composition for more than half an hour.

Court of Queen's Bench Decision.-These figures were obtained under conditions which need never occur in practice; indeed, the decision of the Court of Queen's Bench in the case of Dyke $v$. Gower makes it necessary that they must not occur, as it has been decided that a vendor is bound to sell milk in its natural state; it is equally an offence against the law to sell milk which has been deprived of its cream by natural rising when the milk is undisturbed, and to sell that wilfully adulterated with skim milk.

Practical Allowances for Fat Variation.-It is, however, fortunately not a matter of extreme difficulty for a vendor to comply with the spirit of this judgment; for instance, in the sale of milk from a counter pan it is easy to stir the milk every half hour, or, what is preferable, before serving each customer. When milk is delivered in the streets the churn can be fitted with one of the numerous arrangements for automatically keeping the cream mixed; the action of these is, too, materially aided by the motion the milk receives from the movement of the cart or barrow when drawn along the streets. To ensure that the composition of the milk will not vary the minutest fraction perhaps demands more skill and attention than the average milk distributor possesses, but a practical compliance with the judgment mentioned above can and ought to be obtained. It is probably owing to the consideration of the natural tendency of cream to rise that the chemists of the Board of Inland Revenue, who are referees under the Sale of Food and Drugs Act, have adopted the limit of 2.75 per cent. of fat in milk, while their limit for solius not fat is the same as that adopted by the Society of Public Analysts.

The difference between the two limits. $-3 \cdot 0$ and $2 \cdot 75$-is certainly ample to cover any changes which may take place in the milk during sale, and the referees have not, in the author's opinion, erred on the side of stringency. 
It cannot be too strongly insisted on that these limits apply only to the mixed milk of a number of cows; the milk of a single cow may be below to a serious extent these figures. As this case is one which but rarely occurs-the sale of milk being almost entirely confined to the production of herds-it is not necessary to make any allowance for the greater variations of quality of the milk of individual cows.

Appeal to the Cow.- In cases of doubt it is advisable to resort to what is known as "appeal to the cow," or the "stall or byre test." This consists in having the cow-or cowsmilked in the presence of a responsible witness who can certify to the absolute genuineness of the milk, which is analysed and compared with the suspected sample. It is desirable, it possible, that the milk of the morning and evening meals should both be examined. To make the test as fair as possible, the cows should be milked by their usual milkers at the same time of day, and under the same conditions; the test should be carried out at as early a date as convenient, and care should be taken that the meteorological conditions are nearly alike, as a poorer milk is yielded in warm, damp weather than if it is clear and frosty. The test should not be carried out on a Sunday or Monday, or on a public holiday or its morrow, unless the previous sample was taken on a similar day, as it has been shown that the irregularity in the time of milking-which oceurs on such days -affects the quantity and quality of the milk; any serious divergence from the average quantity of milk yielded may be looked upon as throwing cloubt on the reliability of the test. The witnesses must be specially careful in seeing that the cows are milked out, and that nothing occurs likely to disturb the equaninity of the cows, such as undue commotion or noise. If the milk is cooled, it is the duty of the witnesses to satisfy themselves that the refrigerator cloes not leak, as well as to see that all vessels into which milk is received are clean and drr.

'This test, if properly carried out by competent witnesses, is very reliable: if the suspected sample were genuive, mills will be yielded of approximately the same composition at the appeal to the cow; crerything, however, depends on the competency of the witnesses.

Adulterations of Milk.-The chief adulterations of milk are-

(1) The addition of water, which is sometimes masked by the use of a solid substance which is soluble.

(2) The addition of skim or separated milk, or the removal of cream.

Calculation of Added Water.-Watering is detected by the depression of the solids not fat, total nitrogen, and ash; if all three are below the limits given above, the milk may be con- 
demned as watered. The amount of water added is best ealculated from the solids not fat by the formula-

where $\mathrm{S}=$ solids not fat.

$$
\text { Water }=100-\frac{S}{8.5} \times 100 \text {, }
$$

This formula will give the minimum percentage of water added. It is only correet if the criginal milk contained 8.5 per cent. of solids not fat.

The probable amount can be calculated by using the mean figure for solids not fat $8 \cdot 9$, instead of $8 \cdot 5$, in the above formula.

Another excellent method for ealculating percentage of added water is to use the sum of the degrees of speeific gravity and the fat as a datum.

$$
\text { Water }=100-\frac{(\dot{x}+\mathrm{F}}{34 \cdot 5)} \times 100,
$$

where $G=$ degrees of gravity, and $F=$ the pereentage of fat.

This will likewise give a minimum figure, and the probable amount can be obtained by substituting 36 for 34.5 .

The latter formula has the advantage that it is applicable without correction to milk whieh contains an excess or defieiency of fat, while the percentage of solids not fat is affected to some extent by variations in the fat; the table on p. 134 will make this clear. The solids not fat vary from $s \cdot 78$ to $9 \cdot 0 s$, a differenee of $\cdot 30$ or $3 \cdot 3$ per eent. of the solids not fat; the sum of the degrees of specifie gravity and fat only varies from $36 \cdot 11$ to $36 \cdot 35$, a differenee of $\cdot 24$ or 7 per cent. of the sum.

Adulterations by Cane Sugar, \&s.- Sometimes substances such as cane sugar, dextrin, or other earbohydrates or glycerine are added to mask the addition of water by raising the solids not fat; these will be detected by the sweet taste, the deficieney in total nitrogen and the ash. . Cane sugar, dextrin, \&c., ean be detected by the diserepancy between the milk-sugar estimated by polarisation and that determined by Fehling's solution.

Glycerine, if added to any appreciable extent, will render the total solids sticky, and on analysing the sample the water, fat, milk-sugar, proteids, and ash will in the aggreqate be seriously below 100 per cent. It can be detected, and approximately estimated, by evaporating 25 e.e. of milk to a pisty consisteney, treating with a mixture of alcohol and ether, and following the procedure of the "Somerset House" method of analysis; the aleohol-ether extract is evaporated and the residue exhausted with a little water and this again evaporated. If $\mathrm{gl}$ ycerine be present, a residue having a stieky consistency when cold will be left; the weight of this, less that of the ash left on ignition, will approximately give the amount of glyeerine.

Starch has also been used; this is detected by a blue coloration being obtained with a solution of iodine in potassium iodide (see p 89). 
Brains and mammary tissue are said to have been used; this is doubtful, but they would be shown at once by the large deposit obtained on centrifugalising the milk.

Mineral adulterants have been employed. The use of chalk, which is popularly supposed to enter into the composition of adulterated milk, is probably hypothetical, as its insolubility would defeat the object of its use. Salt is detecterl in the ash by an increase in the chlorides above $\cdot 10$ per cent.; an estimation of sodium should also be made, as milk does not contain more than 05 per cent.; carbonate or bicarbonate of soda is also detected by the increased alkalinity of the soluble ash; this does not exeeed in genuine milk an amount equal to $02 . j$ per cent. $\mathrm{Nin}_{2} \mathrm{CO}_{3 ;}$; an amount appreciably exceeding this is due to addition of alkali. The alkalinity of the ash should be estimated by titrating with $\frac{\mathrm{N}}{10}$ acil, using phenolphthalein as indicator; 1 c.c. of the acid is with this indicator equal to 0106 gramme of $\mathrm{Na}_{2} \mathrm{CO}$...

Other mineral additions, such as boric acid, borax, fluorides, icc., may be addled as preservatives, and not to mask the addition of water; the methods of detecting these will be given later.

It has heen alleged that salts of ammonia have been added to raise the total nitrogen. These would be detected by rendering alkaline with magnesium carbonate, distilling the milk, and testing the distillate with Nessler's reagent (an alkaline solution of mercuric chloride in potassium iodide).

Calculation of Fat Abstracted.-The detection of adulteration by removal of cream can only be effected with certainty by the estimation of fat; if this falls below 2.75 per cent., cream has certainly been abstracted, and any percentage below 3.0 is extremely suspicious. From the table on $1 \% 1 \geq 7$ it is seen that the mean percentage of fat varies at different times of the year; a limit of $3 \cdot 25$ per cent. conld be used from October to January with as much justification as a limit of $3 \cdot 1)$ for the other months.

The percentige of cream alstracterl is calculated by the formulit

$$
\text { (ream abstralcted }=160-\frac{\mathrm{F}}{3} \times \ln (\mathrm{n})
$$

wher $\mathrm{F}=$ percentage of fat.

This formula wives a minimum percentage of fat abstracted; the figure 2.75 should not be used insteat of 3 in the ealculation, as this is used as a limit in oreler to allow for cream abstraction by the natural rising of cream in milk. The figure thus calculated is almost always seriously below the truth; the probable amount can be ealeulated by substituting 3.75 for 3, or, better still, the monthly average figure given in lable XXIII. on p. 1.2 for the month in which thro analysis is made.

If "appeal to the cow" has been made, or if the mean compo- 
sition of the milk was approximately or exactly known, the figure representing the actual composition should be substituted for 3 .

The colour of the fat is of some aid in judging the amount of cream abstracted; if it is very yellow, the milk is very likely yielded by Jersey cows, and a high figure-e.g., 4-may be substituted for 3.

The colour of the milk itself is no guide, as it is frequently artificially coloured to give it an appearance of richness. Annatto was the colouring-matter chiefly used, but this is now somewhat largely replaced by coal-tar colours. Artificial coiouring-matters generally may be detected by precipitating the casein with acetic acid, washing well with water, and digesting with strong alcohol; the casein carries down the colouring-matter and gives it up to the alcohol; on evaporating this, and taking up with a little water, the colour can be detected. Annatto is unchanged by mineral acicis, while many of the coal-tar colours turn pink.

Preservatives.--In order to check the growth of microorganisms in milk; and thus make it keep for id longer time than it otherwise would, preservatives are frequently added. The most common additions for this purpose are boric acid and its sodium salt, borax; salicylic acid, either alone or mixed with borax and boric acid, and sometimes in alcohol or glycerol solution; fluorides, such as sodium fluoride; fluosilicates and flnoborates; and formaldehyde. Benzoic acid and potassium nitrate have also been recommended, but they are comparatively weak antiseptics and are little, if at all, used.

Objections. - The practice of adding preservatives is by many considered highly reprehensible, while others are warmly in favour of this course. Evidence that any well-marked injurious effect follows the consumption of milk containing small amounts of preservatives is not forthcoming. Hehner, Leffmann and Beam, and Cripps have shown that boric acid, even in considerable quantities, has no appreciable inlibitive effect on enzymes such as pepsin, trypsin, and ptyalin, which exist in the alimentary tract, and to which a part of the digestive process is due. They have none of them, however, ventured to claim that their experiments have more than a partial bearing on the question whether boric acid is injurious or not. On the other hand, the author has found a general consensus of opinion among medical men, who are specialists in infant feeding, that the presence of boric acid or its compounds tends to cause feeding troubles in young children. Salicylic acid is in rather a different category ; it is a well-known drug, and, when taken in moderate quantity, has been proved to cause injurious symptoms; its use is forbidden in France as a preservative; it has also an inhibitive effect on enzymes. Formaldehyde is of considerable activity as a chemical agent and comlines with proteids 
to form compounds of a different nature; there is considerable evidence that it render's the casein of milk less digestible, according to the experiments of Weigle and Nerkel, and Cassal.

The Lamet has elicited the opinions of a selection of scientists, who may claim to be authorities on phrsiology; the general view was that there was not enough evidence to justify the forldidlance of preservatives in food, but that the fact of their presence should be notified; many were in favour of limiting the quantities allowable to linits not stated, but to be defined after full in restigition.

To snm up, it seems that while healthy adults can take small doses of the preservatives usually employed in milk, there is evidenee that young children are not unaffecterl. The practice must, therefore, be considered undesirable. The author's expelirnce has shown that in London, the use of preservatives in milk is entirely unnecessary; no difficulty has been found, even in summer, in delivering milk to customers in a fresh condition. Cream and butter are on in slightly different footing to milk. While the last is chiefly consumed for its food ralue, cream and butter are chiefly taken to improve the taste of other foods, and are consumed in comparatively small quantities; being, moreover, high in price, they may be considered as luxuries, and are expected to keep for a longer time than is naturally possible. Jt is readily seen that, under these circumstances, there is far more to be said in farour of the use of preservatives in cream and butter, than can be said when they are added to milk.

Butter is defined by the Margarine Act as "the substance usually known as butter . . . with or without preservatives," and the use of preservatives is therely legalised; the Sale of Fond and Drugs Act, lowever, contains no such clause, and, in a case recently (Jan. 12th, 1898 ) decided at Pontypridd, the presence of an amount of boric acid beyond that necessary for preserving the butter has been held to be in adulteration.

Advantages. - The advantages of using preservatives to the veulor are olvious; they enable a perishable article to he maintained in a marketalile condition for a longer time than it would otherwise remain so. As change from the action of microorganisms is not entirely stopperl, the advantage to the purchaser is by no means so appiarent, and there appears to be a wellfornded public opinion against the use of preservatives.

\section{Detection of Preservatives.}

The detection and estimation of horic acid have already been deseribed (p. 75$)$.

Some iriea as to whether boric acid or borax has heen added an be olstained hy applying the turmeric test (1) to a solution of ash of milk in water, and (2) to a solution of the ash in dilute 
hydrochloric acid. If test (1) gives no reaction, while test (2) gives a strong reaction, borax has been adderl; if test (2) gives a reaction no stronger than that obtained by test (1), boric acid has been used; while if test (1) gives a reaction, while test (2) gives a stronger reaction, a mixture of the two is probable. These tests are far from absolute, owing to the difficulty of judging the strength of a reaction, and, further, owing to the fact that the ash of milk is usually feebly alkaline, which would cause some of the boric acid to be reckoned as borax. Occasionally, the ash of milk is acid, and some of the borax would then appear as boric acid. Nothing more than rough approximate results are claimed for this method.

Farrington has shown that when boric acid is added to milk its acidity to phenolphthalein is four times as great as its acidity in aqueous colution; if a milk is found to have a high acidity, say $40^{\circ}$, and does not smell or taste sour or curdle on boiling, it is highly probable that boric acid is present

Salicylic acid is best detected in the filtrate produced by adding mercuric nitrate to milk; if much salicylic acid be present this will acquire a red colour after some time, and when shaken with a little amyl alcohol, the colour will pass to the amyl alcohol.

A very much better test is to shake the filtrate at once with ether, and evaporate the ethereal solution. 'The residue is taken up with water, and divided into three parts; to one a drop of dilute ferric chloride solution is added, and a violet coloration is developed in the presence of salicylic acid; a second is tested with bromine water, a curdy yellowish precipitate is produced by salicylic acid, and the characteristic smell of halogen phenol derivatives produced; the third part is evaporated to dryness with strong nitric acid, and the residne taken up with a few drops of water; a yellow coloration is produced on adding ammonia if salicylic acid be present

These reactions are not absolutely characteristic of salicylic acid, as phenol (carholic acid) and other hydroxy-benzene derivatives behave in a similar mamner.

Fluorides are thus detected in the ash of milk. At least 25 c.c. of milk should be taken, and the ash treated in a platinum basin with a little strong sulphuric acid. Over the top of the basin a watch giass coated with paraffin wax, through which a few lines are scratched, is placed, and a piece of ice or sone cold water is put into the concave depression. The basin is then gently warmed and the watch glass exposed to the action of the funes evolved for ten minutes. In the presence of fluorides it is seen that the glass has been etched, after removal of the wax. If a drop of water is placell on the paraffin, away from the lines scratched through it, a white film of silica will be formed on its surface, if fluosilicates be present. If fluoborates. 
be present, this drop of water will give a boric acid reaction; in the presence of fluoborates both a fluoride and a boric acid reaction are given by the ash of the milk.

Formaldehyde, which has been introduced of late years, is now frequently employed as a milk preservative.

It is generally added as a 1 per cent. solution in water, which is made ly diluting the 40 per cent. solution known as "Formalin," "Formal," "Formol," or "Formine." When tirst introduced it was claimed that it could not be detected in milk, but a very large number of reactions for this substance have been workerl out.

The most characteristic test is that known as Hehner's test, which is best carried out as follows:--The milk is diluted with an equal rolume of water, and a little 91 per cent. sulphuric acid run in so that it forms a layer at the bottom. In the presence of formaldehyde a violet-blue colour appears at the junction of the two liquids, and the colour is permanent for two or three days. This test will deteet, easily, 1 part of formaldehyde in 200,000 of milk. Milk, in the absence of formaldehyde, gives a slight greenish tinge at the junction of the two liquids, and on standing a brownish colour is developed, not at the junction of the two liquids, but lower down in the acid. This test is absolutely characteristic of formaldehyde, but is not given in the vresence of litrge amounts of this body. Leonard has pointed out that pure sulphuric acid gives no reaction, but the presence of an roxidising agent is necessary ; he found that a trace of ferric chloride gave the best results; it is better to use commereial acid than a purer form, as the necessary oxidising agent is present.

As a confirmatory test, $s$ me of the milk may be curdled by dilute sulphuric acid and a little Schiff's reagent-a solution of rosaniline bleached by sulphurous acid-added to the filtrate in a test tuhe, which is corked and allowed to stand. In the presence of an aldehyde a violet-pink colour is produced after a short time. Excess of sulphurous acid must be aroided in preparing the reagent, or the test may fail with small amounts.

There ar: onany confirmatory tests, which are best applied to the clear solution obtained by distilling the filtrate obtained by curdling the milk with sulphurie acid. Smith and Leonard have shown that when milk containing formaldehyde is distilled, but a small fraction can he ohtained in the distillate; if the milk be made alkaline, still less is obtained; but a very much larger proportion is obtained by distilling from an acid solution. This is probalily due to the fact that formaldehyde combines with the froteids of the milk; the more perfectly these are in a state of solution, the faster is the rate of combination. Combination is mor" rapid at high temperatures, hut takes place at ordinary temperatures, and the total quantity anded is never obtained; 
after a lapse of some time-several days-the formaldehyde disappears, and can no longer be detected.

If Schiff's test is applied to the distillate, it must be rendered faintly acid beforehand with hydrochloric acid; Hehner has shown that the distillate of milk gives a faint pink colour with Schiff's reagent after some time, but this disappears on the addition of a drop or two of sulphurous acid, while the colour due to the presence of formaldehyde does not. He ascribes this to oxidation, but as it is equally well prevented by a little hydrochloric acid, it appears that this explanation is not correct; it is probably due to traces of alkali dissolved from the glass.

The following tests are a selection from the miny which have been devised :-

(1) To the distillate add one drop of a dilute aqueous solution of phenol, and pour in some strong sulphuric acid down the sides of the tube. In the presence of formaldehyde a bright crimson zone appears at the junction of the two liquids. This test, which is also due to Hehner, is as delicate as the test previously described, and has the further advantage that it is obtained by formaldehyde solutions of all strengths. If there is more than one part of formaldehyde per 100,000, a white turbidity is obtained in the solution above the sulphuric acid, while in strong solntions a white or pinkish curdy precipitate is obtained. Many hydroxy-derivatives of benzene, such as salicylic acid, resorcinol, and pyrogallol may be substituted for phenol. Quinol, however, gives not a red colour, but an orange-yellow one. Acetaldehyde gives an orange-yellow colour with phenol and sulphuric acid.

(2) Boil the distillate with a solution of hydrazine sulphate, made strongly alkaline with caustic soda; a white precipitate suddenly appears if formaldehyde is present.

(3) To a decigramme of diphenylamine add 2 c.c. of water, and sufficient sulphuric acid to dissolve it, and pour some of the distillate into the warm solution. In the presence of formaldehyde, a white turbidity or precipitate is obtained, on further warming if necessary. The precipitate rapidly turns green. This test, like the last, is characteristic of formaldehyde, but is not of such great delicacy as the former ones, and may not be obtained with inilk containing only a small amount.

(4) Heat some of the milk for thirty minutes on the water bath with a little sulphuric acid and a drop of dimethylaniline; filter; render alkaline with caustic soda; and boil till the smell or dimethylaniline has disappeared. Filter; moisten the filter paper with acetic acid, and sprinkle lead peroxide on it. A blue colour is developed if formaldehyde is present.

(5) To the distillate add a 3 per cent. solution of aniline. Formaldehyde produces a white precipitate, which is dissolved on boiling, but is deposited again on cooling. 


\section{Preservation of Milk Samples.}

Where any special importance is attached to the analysis of any sample, it is an advantage to preserve the sample for reference and further corroborative analysis. Preservatives are added to eflect this. The following substances have been used :-

Alcohol - Allton has suggested adding to the milk to be kept twice its weight of alcohol; his experience and that of Hehner show that analytical data can be obtained on the preserved milk (naking allowince for the alcohol added) which agree with the original sample The objection to this method is that a large amount of a volatile substance is adfled, and a correction, the correctness of which depends on the amount of alcohol present, must be made.

Chloroform. When added in the proportion of 1 c.c. to 100 c.c. of milk it keeps the milk well for a short time. It has the advantage of dissolving in the fat and keeping the cream in an easily miscible condition. As Babcock and Russell have shown, it does not stop enzymic action; hence changes in the Iroteirls, due to this canse, proceed as if no chloroform had been added. The correction to be applied is small. For keeping samples for a short period, say ten ditys, this method is good.

Ether.-This preservative is nearly as good as chloroform; it is, however, not quite so good a preservative and is more volatile.

Terpenes, Thymol, Dichlorophenol, and Salicylic Acid.These keep the milk, bnt allow the cream to rise to the surface, where it sets in a firm layer and is not easily redistributed.

Hydrofluoric Acid and Fluoboric Acid.-The anthor has prover that these substances, when added to fresh samples in the propurtion of $\frac{1}{2}$ c.c. to 100 c.c. of milk, keep them in good condition, ind, after a year. analysis gives the same figures as those previously found. They curdle the milk, however, so that the sample must be well shalien to hring the precipitated casein into a tine state of division: a little of the bottle is dissolved and the ash is therely slightly increased. The anthor has found this metheri to be one of the best.

Formalin.--The ardition of formalin has many advantages. A very minute amonnt of the 10 per cent. solution need be added (2 (loups per 100 c.c.), and no correction is necessary for so small a quantity. The formaldehyde, hwwerer, combines with the proteids, and raises the apprirent percentage of total solids and solids not fat. lievin hits also suggested that the milk-sugar is hydrolysed into dextrose and galactose, as he found the increase in total solids more than the total amount of formaldelivele adderl.

Potassium Bichromate, Mercuric Chloride, and Solid Antiseptics.-Thess: and considerably to the weight of the 
total solids and solids not fat, and cannot, therefore, be recommended. If fat only is to be determined they are efficient.

Sterilisation may be resorted to. Certain changes take place, which do not usually interfere with the analysis. The crean rises and clots on the surface, so that it is not easy to obtain an average sample.

Cold Storage.-Samples may be frozen and kept in a cold chamber, if one is available; they keep for an indefinite period thus, but require carefully remelting and remixing. This method, which is not always available, is superior to all others, and should be resorted to in those dairies which possess a freezing plant and cold storage room.

The Action of Heat on Milk.-When milk is heated the following changes occur:-At about $70^{\circ} \mathrm{C}$. a cliange takes place in the albumin; it is not precipitated, but is converted into a form which is precipitated by acids, magnesium sulphate and other precipitants of casein.

At about $80^{\circ} \mathrm{C}$. certain organised principles, the nature of which is not fully known, undergo a change. The presence of these principles in an unchanged form is shown by the following reactions :- They cause an evolution of gas from hydrogen peroxide in the cold and give a blue colour with para-phenylenediamine (para-di-amido-benzene), and hydrogen peroxide. Other substances may be substituted for the para-phenylene-diamine, but, according to Leffmann, this substance is the most characteristic.

Near $100^{\circ} \mathrm{C}$. calcium citrate is deposited, and, by keeping at this temperature for some time, slight oxidation sets in, with the production of traces of formic acid and a marked reduction of the rotatory power of the milk-sugar; a brown colour is produced at the same time. A deposition of salts and, perhaps, also of albumin takes place on the fat globules, which increases their mean density, causing them to rise slowly to the surface, when the milk is afterwards cooled; during the heating the fat globules are expanded and may somewhat coalesce.

If the surface of the milk is freely exposed to the air, a skin forms at temperatures exceeding $60^{\circ} \mathrm{C}$. This has been stated to consist of casein, but has not the properties of this substance ; it is certainly of a proteid character, and there is some reason to suppose that it is an oxidation product. The taste and smell of milk are changed by heating to above $70^{\circ} \mathrm{C}$.

It is not known how far the action of heat on milk affects its digestive qualities. Milk which has been heated is curdled less readily by rennet than fresh milk, but there are good grounds for the view that this is due to the deposition of calcium salts rather than to any change in the casein. It has been claimed that sterilised or boiled milk is more easy of digestion than unboiled milk, but this, again, is possibly lie to the fact that it 
is not curdled so easily in the stomach and does not produce so firm a clot. There appears to be no evidence that healthy adults digest boiled milk either more or less readily than unboiled milk. In one respect boiled milk is less to be preferred than fresi milk. From the evidence adduced by Barlow, it seems that children fed exclusively on sterilised milk have a scorbutic tendency. It has long been known that the absence of fresh food of any description is a predisposing cause of scurvy, but no substance has yet been identified as the agent which confers anti-scorbutic properties.

It is of considerable importance to be able to distinguish between fresh milk, on the one hand, and "frasteurised" or "sterilised" milk, on the other.

\section{Condensed Milk.}

For convenience of transport, milk is deprived of the bulk of its water by evaporation under diminished pressure in a vacuum apparatus fitted with a condenser; this is termed condensed or evaporated milk. It is made in two forms: sweetened condensed milk, which is a preparation of milk and cane sugar; and unsweetened condensed milk, which consists of milk evaporated per se.

The methods of manufacture are similar. In the manufacture of sweetened condensed milk $1 \frac{1}{4} \mathrm{lbs}$. of cane sugar are added to each gallon of milk, and the mixture heated to such at temperature that it will commence to boil at once on being admitted to the racuum pan. It is allowed to flow in slowly, the pump being kept working the whole tine, and no heat is applied till all the milk is in the pan. By this procedure the gases of the milk are drawn out, and on applying heat the milk boils without frothing over. By carefully regulating the supply of heat to the pan, and eold water to the condenser, the milk can be boiled at an even ripid rate till sufliciently concentrated, a point which can be easily told by an experienced operator. The whole operation is controlled by looking through a glass sight-hole let into the upper portion of the pan. The finished product has a density of ahout $1 \cdot 28$ and weiglis one-third of the original milk; it only occupies threceleventlis of the original rolume-i.e., 1 gallon of milk is evaporated to $2 \frac{1}{4}$ pints.

Commercial olucose is sometimes sulstituted for a part or the whole of the canc sugar.

Composition of Sweetoned Milk.-The following analyses ('Trulbe XXX.) will show the composition of swertened condensed milks :- 
TABLE XXX.-Composition of Sweethed Milk.

\begin{tabular}{|c|c|c|c|c|c|c|c|}
\hline Authority. & Water. & Fat. & $\begin{array}{l}\text { Milk- } \\
\text { Sugar. }\end{array}$ & $\begin{array}{l}\text { Cane } \\
\text { Sugar. }\end{array}$ & Proteids. & Ash. & Total. \\
\hline 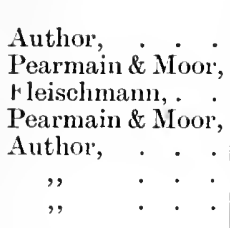 & $\begin{array}{l}\text { Per ct. } \\
24 \cdot 06 \\
26 \cdot 10 \\
25 \cdot 69 \\
29 \cdot 87 \\
29 \cdot 05 \\
29 \cdot 23 \\
28 \cdot 43\end{array}$ & $\begin{array}{r}\text { Perct. } \\
11 \cdot 23 \\
10 \cdot 94 \\
10 \cdot 98 \\
1 \cdot 17 \\
1 \cdot 28 \\
\cdot 64 \\
\cdot 36\end{array}$ & $\begin{array}{l}\text { Per ct. } \\
13 \cdot 97 \\
14 \cdot 68 \\
16 \cdot 29 \\
14 \cdot 68 \\
14 \cdot 91 \\
15 \cdot 50 \\
16 \cdot 88\end{array}$ & $\begin{array}{l}\text { Per ct. } \\
38 \cdot 31 \\
36 \cdot 93^{*} \\
32 \cdot 37 \\
41 \cdot 54^{*} \\
40 \cdot 07 \\
40 \cdot 19 \\
39 \cdot 27\end{array}$ & $\begin{array}{r}\text { Per ct. } \\
9 \cdot 36 \\
9 \cdot 55 \\
12 \cdot 33 \\
10 \cdot 74 \\
10 \cdot 63 \\
10 \cdot 73 \\
11 \cdot 73\end{array}$ & $\begin{array}{l}\text { Per ct. } \\
2 \cdot 13 \\
1 \cdot 90 \\
2 \cdot 34 \\
2 \cdot 00 \\
2 \cdot 33 \\
2 \cdot 633 \\
2 \cdot 58\end{array}$ & $\begin{array}{r}\text { Per ct. } \\
99 \cdot 11 \\
100 \cdot 00 \\
100 \cdot 00 \\
100 \cdot 00 \\
98 \cdot 27 \\
95 \cdot 92 \\
99 \cdot 25\end{array}$ \\
\hline
\end{tabular}

The first three are condensed whole milks-i.e., the milk has been evaporated without previous removal of the crean; the last four are condensed separated milk, the separated milk having been mixed with cane sugar and evaporated.

These milks are not usually steriliser, as the large amount of dissolved matter and the small amount of water renders them unsuitable for the revelopment of micro-organisms; they keep for a long time without appreciable change.

Composition of Unsweetened Milk.-Unsweetened condensed milks are prepared in a similar manner, excej,t that the addition of sugar is omitted.

The composition of this product is shown by the following analyses (Table XXXI.) :-

TABLE XXXI._Composition of Unsweetened Milk.

\begin{tabular}{|c|c|c|c|c|c|c|}
\hline Authority. & Water. & Fat. & $\begin{array}{l}\text { Milk- } \\
\text { Sugar. }\end{array}$ & Proteids. & Ash. & Total. \\
\hline $\begin{array}{c}\text { Author, . } . \\
\quad, \quad \cdot \\
\text { Pearmain \& Moor, } \\
\text { Aschmann, . }\end{array}$ & $\begin{array}{c}\text { Per cent. } \\
63 \cdot 47 \\
62 \cdot 40 \\
63 \cdot 07 \\
61 \cdot 96 \\
69 \cdot 35\end{array}$ & $\begin{array}{l}\text { Per cent. } \\
10 \cdot 22 \\
11 \cdot 91 \\
10 \cdot 86 \\
10 \cdot 67 \\
9 \cdot 2 \cdot 3\end{array}$ & $\begin{array}{c}\text { Per' cent. } \\
12 \cdot 98 \\
13 \cdot 04 \\
13 \cdot 38 \\
15 \cdot 50 \\
10 \cdot 98\end{array}$ & $\begin{array}{c}\text { Per cent." } \\
10 \cdot 30 \\
9 \cdot 68 \\
9 \cdot 80 \\
9 \cdot 57 \\
9 \cdot 41\end{array}$ & $\begin{array}{c}\text { Per cent. } \\
2 \cdot 07 \\
2 \cdot 14 \\
2 \cdot 21 \\
2 \cdot 30 \\
1 \cdot 63\end{array}$ & $\begin{array}{l}\text { Per' cent. } \\
99 \cdot 04 \\
99 \cdot 17 \\
99 \cdot 32 \\
100 \cdot 00 \\
100 \cdot 00\end{array}$ \\
\hline
\end{tabular}

These milks have all been sterilised by heat. T'hey have the analy tical characters of sterilised milk.

It is noticed that the totals of analyses of condensed milk almost invariably add up distinctly below 100 per cent.; it is probable that the milk-sugar is underestimated. In condensed milk the layer of solution which is attracted round the fat globules by surface energy has probably a composition which is identical with the composition of the liquid in which the globules are suspended. When condensed milk is diluted with

* By difference. 
water it is doubtful whether the liquid in this layer is diluted by the water, as it is held hy a great force, and acts as though separated by a semi-permeable membrane, through which the dissolved solids must pass hy osmose. As the milk is usually diluted with cold water, this process of osmose takes a considerable time, and the whole of the milk-sugar is not obtained in solution, but a portion is taken down by the fat globules, when they are removed previous to the estimation of the milk-sugar. The same cause can be assigned to the fact that the fat glohules in diluted condensed milk rise with sueh extreme slowness; a dense laver round the globules increases its mean density, and makes this nearly approach the density of the serum.

Dilution.-The directions on the label of sweetened condensed milk are often somewhat misleading. For some purposes-e.g., for infant feeding - the directions given are to dilute with five or even seven parts of water. Supposing that these dilutions are performed by volume, the composition will be as follows:-

\begin{tabular}{|c|c|c|c|c|c|c|}
\hline & & & \multicolumn{2}{|c|}{ Condensed Whole Milk. } & \multicolumn{2}{|c|}{ Condensed Skim Milk. } \\
\hline & & & $\begin{array}{c}\text { With } 5 \\
\text { Volumes of } \\
\text { Water. }\end{array}$ & $\begin{array}{l}\text { With } 7 \\
\text { Volumes of } \\
\text { Water. }\end{array}$ & $\begin{array}{l}\text { With } 5 \\
\text { Volumes of } \\
\text { Water. }\end{array}$ & $\begin{array}{l}\text { With } 7 \\
\text { Volumes of } \\
\text { Water. }\end{array}$ \\
\hline . Fat, . & . & . & $2 \cdot 02$ & $1 \cdot 51$ & .21 & $\cdot 16$ \\
\hline Nlilk-sugar, & . & . & $2 \cdot 57$ & $1 \cdot 93$ & $3 \approx 0$ & $2 \cdot 40$ \\
\hline Cane sugar, & . & . & $7 \cdot 33$ & 550 & $8 \cdot 53$ & 640 \\
\hline Protciels, & . & . & $1 \cdot 83$ & $1 \cdot 37$ & $2 \cdot 24$ & $1 \cdot 68$ \\
\hline Ash, . & . & . & $\cdot 411$ & 30 & $\cdot 53$ & $\cdot 40$ \\
\hline
\end{tabular}

Compared with the average composition of human milk (p. 323), which is

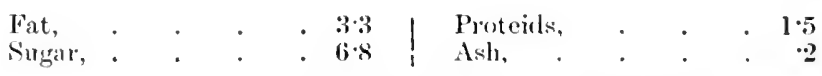

we see that there is a serious deficiency of fat, especially in the diluted condensed skim milk, and a great excess of total sugar.

Food Value. - Ruibners hits stated that as a food $2 \cdot 43$ parts of sugar are ecpual to l part of fat. Calculating the value of fat as sugar by this factor, we get the following values for the food value of fat and sugar:-

\begin{tabular}{|c|c|c|c|c|}
\hline \multirow[b]{2}{*}{ Нแนกล : } & \multicolumn{2}{|c|}{ C'mulenser] Whole Milk. } & \multicolumn{2}{|c|}{ Conlensed skim Milk. } \\
\hline & $\begin{array}{l}\text { With s } \\
\text { V(1) unne's. }\end{array}$ & $\begin{array}{l}\text { With } 7 \\
\text { Volumes. }\end{array}$ & $\begin{array}{l}\text { With 5 } \\
\text { Volumes. }\end{array}$ & $\begin{array}{l}\text { With ? } \\
\text { volumes. }\end{array}$ \\
\hline $14 \cdot 82$ & $1+\mid i l$ & $10 \cdot 96$ & $12 \cdot 34$ & 9 23 \\
\hline
\end{tabular}


Only in the case of the condensed whole milk diluted with 5 volumes of water does the food value approximate to that of human milk; it is doubtful, however, whether fat can be replaced entirely by cane sugar, especially for young infants.

Milk Powders.-To prepare these, milk is evaporated to dryness in vacuo, and granulated.

Two samples examined by the author had the following composition :-

\begin{tabular}{|c|c|c|c|c|c|c|c|c|}
\hline Fat, . & & & & & & . & $\begin{array}{c}\text { Per cent. } \\
15 \% 2\end{array}$ & $\begin{array}{c}\text { Per cent. } \\
13.5\end{array}$ \\
\hline Milk-sugar, & . & . & $\theta^{\circ}$ & . & . & . & 21.7 & $21 \cdot 3$ \\
\hline Cane sugar, & . & . & . & . & . & . & $42 \cdot 5$ & $40 \cdot 9$ \\
\hline Proteids, & . & . & . & . & . & . & $15 \cdot 1$ & $14 \cdot 9$ \\
\hline Ash, . & . & . & . & . & . & - & $3 \cdot 3$ & $3 \cdot 2$ \\
\hline
\end{tabular}

Both had a slightly rancid odour and taste. When dissolved in water some of the fat was not emulsified.

\section{Sterilised Milk.}

Milk is a product which affords all the necessary nourishment for the growth of micro-organisms ; these not only develop products which cause alteration of the milk-e.g., lactic acid and protenlytic enzymes-but also are in some cases injurious to health.

They are destroyed by heat. Hence milk is frequently "sterilised" by heat, the object being to bring about the destruction of the micro-orsanisms.

Many processes are used. Pasteur originally recommended heating to $70^{\circ} \mathrm{C}$. for a short time, a process which was sufficient to destroy all adult forms of pathogenic organisms and, practically, all others. The spores, however, were left untouched and retained their vitality; on cooling to the mean air temperature these developed into the adult forms and resumed their activity. To destroy the spores, a process of continued "pasteurisation" has been used. This consists of alternately heating to $70^{\circ} \mathrm{C}$. for, say, twenty minutes; cooling to a lower temperature and keeping at this temperature for a sufficient length of time to allow the spores to develop; again heating to $70^{\circ}$; and repeating this process many times. By this process, which is very tedious, the taste and composition of the milk undergoes but little alteration.

It has been found that most spores can be killed by continued exposure at higher temperatures. The temperature of boiling water is one much used, as it can be easily attained, but higher temperatures are sometimes resorted to by heating the milk under pressure; the higher the temperature, the shorter the time necessary to kill all microbial life. Another method 
adopted is to alternate successive short periods of heating to high temperatures with intervals during which the milk is kept at the ordinary temperature. Numerous modifications of these methods have formed the subjects of patents.

Analytical Characters.-As, practically, no milk sterilised by successive heating to a temperature not exceeding $70^{\circ} \mathrm{C}$. is sold comnercially, it will be sufficient to describe the methouls for characterising milk which has been heated above the coagulating point of albumin.

The most marked characteristic distinguishing sterilised milk from new milk is the state in which the albumin exists. As previously stated, it is probable that albumin exists in milk in combination with a base; on heating milk, no coagulation of albumin takes place, but on acidifying, or saturating with magnesium sulphate, the albumin separates with the casein. The albumin appears to be changed from a soluble to a colloidal form. (Not more than 1 per cent. of albumin is found in sterilised milk in the solnble form.) The casein separates on acidifying in a more finely divided st:ite.

If the milk has been heated to $100^{\circ} \mathrm{C}$. or a higher temperature for any length of time, the rotatory power of the milk-sugar undergoes a scrious reduction, the cupric reducing power not changing to any appreeiable extent. The milk also assmes a slight hrownish colour, due probably to the formation of a "caramelised" body of low rotatory power.

The citric acid of the milk is partially deposited as calcium citrate, in the form of gritty particles; both calcium and citric acid undergo reduction in quantity.

The cream rises with extreme slowness; in three hours, practically no cream is observed on the surface of the milk; and after six hours, the layer is only about one-tenth of that given by new milk. If stcrilised milk be allowed to stand for twentyfour hours or more the bulk of the cream will rise to the surface, but the quantity will be less than that yielded by new milk; the cream will, howerer, contain a distinctly larger percentage of fat. about 40 per cent., as against less than 30 per cent. in the eream yielded by new milk.

The following figures, which, together with those in Table XXXVI., were obtained ly Boseley and the anthor ('Tables XXXII, XXXIII, XXXiv.) will illustrate the above facts:- 
TABLE XXXII.-Composition of Sterilisei Mili.

Sterilised Milk allowed to stand for Six Hours.

\begin{tabular}{|c|c|c|c|c|}
\hline No. & Fat in Milk. & Cream. & Fat in Cream. & Fat in Skim Milk. \\
\hline & Per cent. & Per cent. & Per cent. & Per cent. \\
\hline 1 & $4 \cdot 30$ & $1 \cdot 3$ & $23 \cdot 3$ & $4 \cdot 05$ \\
2 & $3 \cdot 80$ & $0 \cdot 7$ & $2 \cdot 2 \cdot 3$ & $3 \cdot 67$ \\
3 & $4 \cdot 25$ & $1 \cdot 5$ & $20 \cdot 6$ & $3 \cdot 95$ \\
4 & $4 \cdot 10$ & $1 \cdot 9$ & $24 \cdot 7$ & $3 \cdot 70$ \\
5 & $5 \cdot 35$ & $2 \cdot 8$ & $31 \cdot 4$ & $4 \cdot 60$ \\
6 & $3 \cdot 62$ & $0 \cdot 3$ & $\ldots$ & $\ldots$ \\
\hline
\end{tabular}

\section{TABLE XXXIII.—Composition of Sterilised Milk.}

Sterilised Milk allowed to stand for Twenty-four Hours.

\begin{tabular}{|c|c|c|c|c|}
\hline No. & Fat in Milk. & Crean. & Fat in Crean. & Fat in Skim Milk. \\
\hline & Per cent. & Per cent. & Per cent. & Per cent. \\
\hline & $4 \cdot 30$ & $7 \cdot 0$ & $46 \cdot 8$ & $1 \cdot 10$ \\
2 & $3 \cdot 80$ & $6 \cdot 0$ & $41 \cdot 5$ & $1 \cdot 37$ \\
3 & $4 \cdot 25$ & $8 \cdot 8$ & $39 \cdot 0$ & $\cdot 90$ \\
4 & $4 \cdot 10$ & $8 \cdot 7$ & $41 \cdot 0$ & 58 \\
5 & $5 \cdot 36$ & $11 \cdot 1$ & $41 \cdot 4$ & 85 \\
6 & $3 \cdot 62$ & $0 \cdot 8$ & $\ldots$ & $3 \cdot 48$ \\
\hline
\end{tabular}

\section{TABLE XXXIV.-Composition of New Milk.}

New Milk allowed to stand for Six Hours.

\begin{tabular}{|c|c|c|c|c|}
\hline No. & Fat in Milk. & Cream. & Fat in Crean. & Fat in Skin Milk. \\
\hline & Per cent. & Per cent. & Per cent. & Per cent. \\
\cline { 1 - 3 } 1 & $4 \cdot 05$ & $9 \cdot 2$ & $17 \cdot 4$ & $2 \cdot 70$ \\
2 & $4 \cdot 20$ & $11 \cdot 2$ & $16 \cdot 5$ & $2 \cdot 65$ \\
3 & $3 \cdot 90$ & $9 \cdot 8$ & $15 \cdot 9$ & $2 \cdot 60$ \\
4 & $3 \cdot 70$ & $9 \cdot 8$ & $18 \cdot 0$ & $2 \cdot 15$ \\
5 & $4 \cdot 45$ & 135 & $16 \cdot 5$ & $2 \cdot 30$ \\
\hline
\end{tabular}

Table XXXIV. showing the behaviour of new milk is produced here for the sake of comparison. The samples 1 to 5 are from the same cows which respectively yielded the samples with corresponding numbers in the tables illustrating the behaviour of sterilised milk. 
Condensed unsweetened milk, which has been diluted to the original volume with water, has all the analytical characteristics of sterilised milk. This is in no way due to the fact that it has been condensed, but is owing to the sterilising process that it has undergone. There appears to be no good method of discriminating between condensed milk diluted with water and sterilised milk. If a water containing large amounts of nitrates bas been used for diluting the condensed nilk, a strong diphenyl. anine reaction will indicate the probability that water has been added; this test is not of a sufficiently absolute character to be relied on. This is to be regretted. The subject has been considered of sufficient importance by the British Dairy Farmers' Association to induce them to offer a gold medal for the discovery of such a method.

Detection of Sterilised Milk in New Milk.-To distinguish new milk on the one hand from milk which has been sterilised on the other, the following methods may be employed :--

(1) Place 100 c.c. of milk in a graduated cylinder (or fill a "creamometer") and allow it to stand for six hours at a temperature of $60^{\circ} \mathrm{F} .\left(15.5^{\circ} \mathrm{C}\right.$.) ; note the percentage of cream. If less than 2.5 per cent. of cream for each 1 per cent. of fat in the milk has risen to the surface, the milk may be considered suspicious. If the quantity of cream falls markedly below 2 per cent. for each 1 per cent. of fat, it is highly probable thit sterilised milk is present.

(2) Estimate the albumin by the method of Hoppe-Seyler or, better, those of Sebelein or Duclaux. If less than 35 per cent. is found, sterilised milk may be considered to be present.

(3) Estimate the milk-sugar by the polariscope, and also sravimetrically in duplicate; if the difference between the two estimations be more than 2 per cent., it will be corroborative evilience of the presence of sterilised milk.

(4) To about 5 c.c. of milk adil as much powdered paraphenylene-diamine as will lie on the point of a knife: and shake well; on the addition of a drop or two of a 10-volume solution of hydrogren peroxide fresh milk gives a blue coloration; "pasteurised" milk grives a similar reaction, nol, however, so marked; while "sterilised" milk gives no coloration within lo minutes. A mixture of "sterilised" and fresh milk will give the characters of "pasteurised" milk.

The hydrochloride of meta-phenylene-diamine may be substituted with advantage for the para-compound. The coloration is paler, and not quite so quickly developed. By shaking with an equal volume of anyl alcohol the hlue substance is dissolved in the alcohol layer, and the test is thus rendered more reliable in the presence of sulsstances which modify the tint (e.g., formaldehyde). 
A cultivated palate may also detect a boiled taste ; this will certainly be noticed with "sterilised" milk.

No good method for the estimation of citric acid is at present worked out, nor are there sufficient data to make an estimation of value. An estimation of lime is also not of much value in atfording evidence of the presence of sterilised milk, as the variations of this constituent are too great, and the difference too small between the amount in new milk and that in sterilised milk to allow of reliable deductions being drawn.

It is doubtful whether a proportion of sterilised milk much below 30 per cent. could be detected with certainty when mixed with new milk.

The proportion of sterilised milk should be deduced from the percentage of soluble albumin by the following formula :--

$$
\text { Percentage of sterilised milk }=\frac{\cdot 4-\text { percentage of soluble albumin }}{\cdot 4} \times 100 \text {. }
$$

This is based on the supposition that new milk contains 4 per cent. of albumin, while in sterilised milk the albumin has been removed.

'The estimation of albumin is the mosc reliable test. There are many causes which influence the rising of cream, such as the temperature to which the milk has been warmed or cooied; the size of the fat glıbules, which varies with the stage of lactation; and the acidity of the milk. No quantitative deductions can be drawn from observations of the rate of the rising of cream. The fall in specific rotatory power of milk-sugar is by no means constant, as milks sterilised side by side may show very appreciable variations in this respect.

Tests other than the estimation of albumin must be considered as merely corroborative and of qualitative value only.

It must be remembered, however, that no sharp distinction can be drawn between milk which has been raised to a temperature over $70^{\circ} \mathrm{C}$. for a sliort period, and which is naturally not sterilised in the true sense of the term, and milk which has been heated for a sufficient length of time to destroy all microbial life. For this reason, a milk should not be reported as sterilised, solely on the result of a very low percentage of albumin, if neither the "creamometer" nor the para-phenylene-diamine nor "milksugar" tests give corroborative indications. It is probable that the milk, in this case, has been merely scalded.

The following. figures (Table XXXV.) by C. H. Stewart show the percentage of albumin found in milk raised to various temperatures :- 
TABLE XXXV.-Percestage of Albumin in Milk at Various Templiratures.

\begin{tabular}{|c|c|c|c|c|c|c|}
\hline \multicolumn{5}{|c|}{ 'Time' of Heating. } & $\begin{array}{c}\text { Soluble Albumin in } \\
\text { Fresh MIilk. }\end{array}$ & $\begin{array}{l}\text { Soluble Albumin in } \\
\text { Heated NIilk. }\end{array}$ \\
\hline \multicolumn{3}{|c|}{10 minutes at $60^{\circ} \mathrm{C} .}$. & 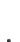 & . & $\begin{array}{l}\text { Per cent. } \\
\text {. }\end{array}$ & Per cent. \\
\hline 30 & , &,,$\quad$, & . & . & $\cdot 43.5$ & 427 \\
\hline 10 & .. &., $65^{\circ} \mathrm{C}$ & . & . & 39.5 & $\cdot 362$ \\
\hline 30 & .. & $., \quad,$. & . & . & 39.5 & 333 \\
\hline 10 & .. &,, $71^{\circ} \mathrm{C} .$, & . & . & 422 & 269 \\
\hline$\therefore 0$ & .. & .. , , & . & . & 421 & 253 \\
\hline 10 & ., & , 椾C., & . & . & 380 & $\cdot 07$ \\
\hline 30 & , , &,,$\quad$, & . & - & $3 s$ & .05 \\
\hline 10 & .. &., $80^{\circ}()$. & . & . & דיני & none \\
\hline 30 & , & , & · & . & 37.5 & none \\
\hline
\end{tabular}

The following analyses (Table XXXVI.) will show to what extent the metliods above described can be depended on :--

\section{TABLE XXXVI.-Comparative Axalyses of Mixed Fresh and Sterilised Milks.}

\begin{tabular}{|c|c|c|c|c|c|c|c|c|c|}
\hline \multirow[b]{2}{*}{$\bar{z}$} & \multirow[b]{2}{*}{ 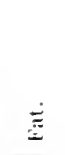 } & \multirow[b]{2}{*}{ 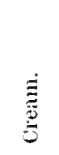 } & \multirow[b]{2}{*}{ 泀 } & \multirow[b]{2}{*}{ 竎 } & \multirow[b]{2}{*}{ 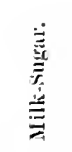 } & \multirow[b]{2}{*}{ 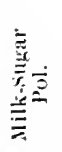 } & \multicolumn{3}{|c|}{ Percentage Sterilised. } \\
\hline & & & & & & & 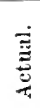 & 吾离 & 豆主 \\
\hline 1 & $\begin{array}{l}\mathrm{p}, \mathrm{c} \\
3 \times 60\end{array}$ & $\frac{1}{7} \cdot c$ & 7.c. & \begin{tabular}{l} 
P. c. \\
\hdashline 30
\end{tabular} & $\begin{array}{l}\text { f. c. } \\
4.8 .5\end{array}$ & $\begin{array}{l}\text { P. c. } \\
+6.5\end{array}$ & 33 & 29 & 25 \\
\hline 2 & +10 & $9 \mathrm{t}$ & $2 \cdot 34$ & $3+4$ & 479 & $4 \cdot 68$ & & Genmine & \\
\hline 3 & $3 \cdot 911$ & $7 \cdot 5$ & $1 \cdot 92$ & 29 & 479 & $4 \cdot 64$ & 25 & 26 & 27 \\
\hline 4 & 370 & 43 & $1 \cdot 16$ & $\cdot 16$ & $47 \pi$ & 4.57 & 56 & (i) & 60 \\
\hline 5 & $4 \cdot 10$ & 7.4 & 1.81 & $\ddot{2} 6 ;$ & $\ldots$ & $\ldots$ & 30 & 31 & $3 \pi$ \\
\hline 6 & $4 \cdot 0 \times 1$ & $7 . \overline{5}$ & $1 \cdot k$ & 27 & $\ldots$ & $\ldots$ & 30 & 25 & 32 \\
\hline 7 & 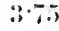 & 7 & $2 \cdot 11$ & 3. & $\ldots$ & $\ldots$ & & Gemmine & \\
\hline
\end{tabular}

The Action of Cold on Milk-Composition.-When milk is exprosed to al low temperature it partially freezes. Like other agueous solutions the freczing point is below that of water, and is ab.ut - $5.5^{\circ} \mathrm{C}$. (31 $1^{\circ} \mathrm{F}$ ), estimated in the Beckmann upparatus. The frozen portion has not the same composition as the milk from which it was prepaurel, but contains a larger quantity of water. The following analyses (Tahle XXXVII.) will show the composition of the ice and liquid portion respectively:- 
TABLE XXXVII.-Conposition of the Solid axd Liquid Portions of Frozen Milk.

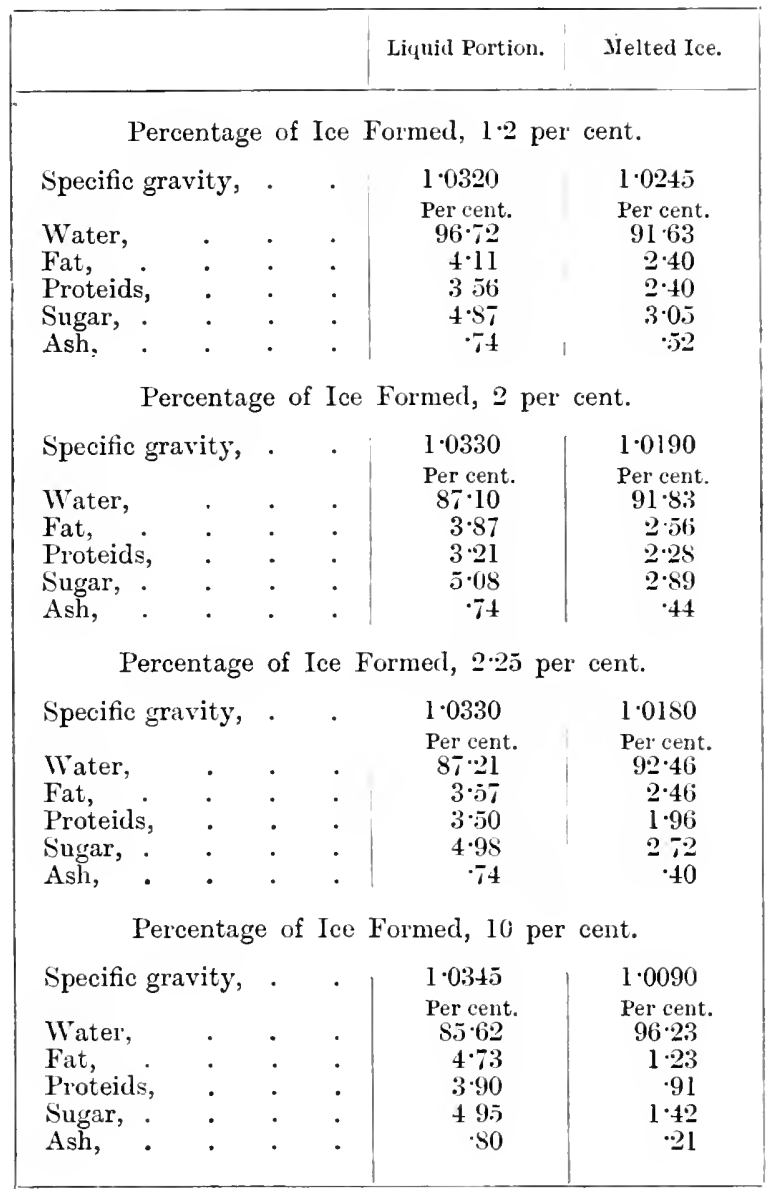

It is seen that no appreciable difference between the ratio 'of the sugar to the proteids and the ash is found in the two series of analyses, showing that no separation of any constituent except water takes places during freezing.

It is seen that the greater the percentage of the ice selarated, the more dilute is the melted ice ; this is best seen by calculating the solids not fat (Table XXXVIII.). 
TABLE XXXViII.-Composition of Frozen MiLk.

\begin{tabular}{|c|c|c|c|c|}
\hline $\begin{array}{l}\text { Pereentage of ice, } \\
\text { Solids not fat, } \\
\text { Erpual to percentage of } \\
\text { water (approx.), }\end{array}$ & $\begin{array}{l}1 \cdot 2 \\
6 \cdot 17 \\
30\end{array}$ & $\begin{array}{l}2 \cdot 0 \\
5 \cdot 61 \\
38\end{array}$ & $\begin{array}{l}2.25 \\
5 \cdot 08 \\
43\end{array}$ & $\begin{array}{r}10 \\
2 \cdot 64 \\
70\end{array}$ \\
\hline
\end{tabular}

As all these samples were taken from churns in which milk was brought up to London, the percentage of ice may be taken as roughly indicating the temperature below freezing point to which the milk was exposed, the time of exposure to the low temperature having been approximately the same in all cases. It appears that the lower the temperature to which milk is exposed the more dilute will be the ice after melting.

Composition of Melted Frozen Milk.-The difference in composition between frozen and unfrozen milk may have some importance. should samples be taken under the "Sale of Food and Drugs Act," in very cold weather; should an excessive proportion of ice be present in the portion sold to the inspector the sample may, though originally genuine, have the composition of watered milk.

Vieth has recorded an interesting experiment on the freezing of milk:-Two gallons of milk were exposed to a temperature of $-10^{\circ} \mathrm{C} .\left(14^{\circ} \mathrm{F}\right.$.) for three hours; longer time than this did not render any more milk solid. Ice was formed on the bottom and sides of the vessel employed to contain the milk and a funnelshaped carity in the centre was filled with liquid. The ice was found to consist of two layers, one of eream, and the other of skim milk; these were separated as completely as possible and the liquirl portion also poured off.

The results of analysis were :-

TABIE XXXIX.-Conposition of Frozen MiLK (Vieth).

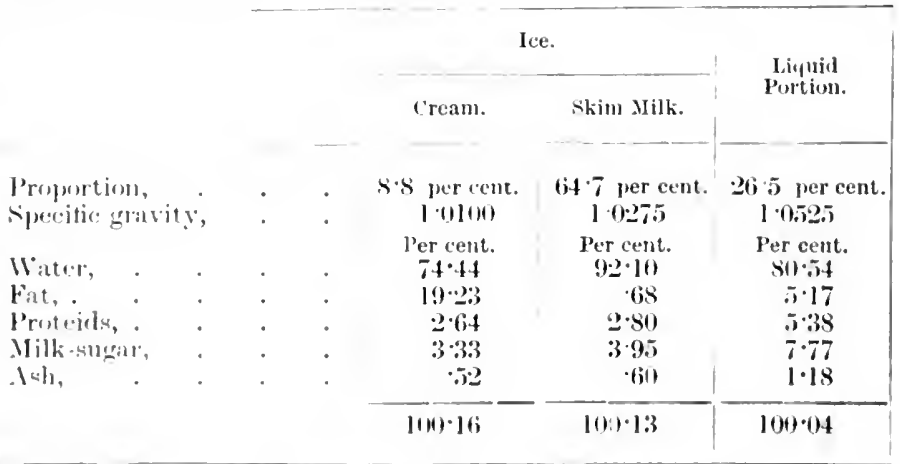

Another experiment gave almost irlentical tigures. 
It is probable from these experiments that milk exposed to a temperature of $-10^{\circ} \mathrm{C}$. will always give a liquid portion having the composition given above. The tigures also show that milk cannot be frozen in blocks, from which pieces can be cut off and melted for use, without modifying the composition to a serious extent.

The author has had the opportunity of examining three samples of milk which had been frozen for transport and remelted (Table XL.).

The samples were taken under such conclitions as would represent the retailing of the milk.

TABLE XL.-Conposition of Frozen MiLK.

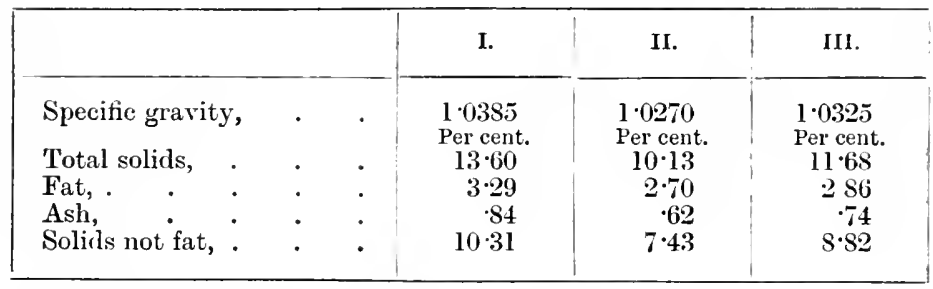

No. I. has the composition of concentrated milk, No. II. of a watered milk, and No. III. of a slightly skimmed milk.

Attempts are being made to introduce frozen, or partially frozen milk, into the English market from Holland and other foreign countries. The above figures show what may be sometimes the composition of milk as retailed, unless extreme care be taken in melting the imported product. 


\section{CHAPTER IV.}

THE CHEMICAL CONTROL OF THE DAIRY.

Costexts. - Juties of the Dairy Chemist-The Testing of Milk-Determination of Specific Gravity-Estimation of Total Solirls-of Fat and Butter - The Control of Milk during Delivery - The Solution of Analytical Problems-Cause of low and high Specifie Gravityof Sweet Taste- of "Poor" Milk-of unnsual Taste and Smell-of Nilk being Curdled_of Milk being Thick-Nature of Sediment_Skim Milk-Cream.

Duties of the Dairy Chemist.-The duties of the dairy chemist consist in the following :- -

(1) To see that the milk at or from the farms is of good quality, containing a full percentage of cream, is not tampered with by the employes, and is in good condition.

(2) If milk is sold by retail, to see that the milk sent out is of good quality, and, by analysing samples taken without notice from the employe in charge of the milk, to ascertain that it is delivered in the same condition as it left the dairy.

(3) To see that cream separators, churns, dce, are worked in the most efficient manmer, by examining the various products, and to obtain such figures rejresenting their composition as will allow of accounts being kept of the man ufacturing processes.

(t) To ensure that all products derivid from milk are of good quality.

(5) To specially investigate products decmed unsatisfactory, and to elucidiate the cause for dissatisfaction.

(6) To make ehemical exminatims of water supplies, disinfectants, de., so als to ansure that sanitation is carried out by relialle means.

(i) To advise on chemical questions that may arise-e.g., the suitability of metals for the construction of dairy apparal us, the examination of waters on boiler compositions for ste:m production, the analysis of feeding stuft's and fertilisers, ite.

A leseription of the dnties of a dairy cheni-t must necessarily be somewhat hypothetical, as the conditions in diflerent daries differ rxceedingly from ratch other. In large dairies the chemist is an ofticial wholly responsible for his own department, and under the control of no one exept the proprietor. It is not adrisable that he should have any direct control of the business, 
his functions being those of a scientific adviser; a good dairy chemist should have had a practical experience in dairying, so that he may be able to apply his scientific knowledge to the various points that may arise from time to time. In smaller dairies, the manager or other person may undertake the functions of chemist, and these must be arranged so as to interfere as little as possible with his other duties; this may introdnce variations in the plan of work described, by curtailing it, but the general procedure will remain the same.

The main duties of the dairy chemist are to see that the milk received from the farms and supplied to the public is pure and contains its due proportion of cream; that the cream and butter are of good quality and of uniform composition; that the skimmed or separated milk is as poor as possible in fat; and that the water used is free from pollution; as also to elucidate the complaints of the customers by examining the product complained of.

Samples and Sampling.-The main difficulty in keeping a uniform quality of milk is due to the rising of cream whenever milk is allowed to be at rest. The attention of the chemist should be devoted to studying the conditions under which the milk is distributed in the dairy to which he is attached, and to discover how to prevent this separation of eream during distribution. For the proper performance of his duties he must be provided with samples of milk at all possible stages, from the entrance of the milk into the dairy till the final return of the small quantities of milk left after distribution; these samples should, if possible, be examined at once and before the milk has passed to the next stage of delivery. This is only practicable in large dairies where the ehemist has no other functions. It is advisable that the persons employed in sampling the milk should be under the control of the ehemist as far as this duty is concerned, as upon the proper sampling of the milk the whole value of his work depends. In certain cases where more value thin usual is attached to the examination, the chemist should personally supervise, or eve's perform, the sampling.

The samples may be divided into two kinds, bulk-samples and samples taken during delivery. In the former case, the object to be attained is to take a sample in which the various constituents shall bear the same relative proportion in the sample as in the bulk. In the latter, the bulk from which the sample is taken will be of known composition, and the object of taking the sample is to test the person from whom it is taken; no attempt must then be made to take an average bulk sample, but the person giving the sample should furnish it in the same manner as he would furnish milk for sale. The taking of the latter class of samples presents no difficulty; the only precaution to be observed is that the bottle into which the sample is poured is clean and dry, and that 
it has a well-titting cork. The proper sampling of a large bulk of milk is by no means easy; the bulk to be sampled will be, in most cases, a churn, and these may be sampled as follows. The sampler stands at the side of the churn and places one foot against the bottom for greater power; he then inserts a stirrer (a flat board 6 inches wide and long enough to reach to the bottom of the churn, and provided with a handle) into the churn, keeping it against the side towards him; he pulls the handle towards him, so that the end is moved along the bottom to the other side of the churn, and raises the stirrer, keeping the end against the side of the churn and the handle as near to himself as possible in such fashion as to lift up the lower layer of the milk; this operation should be repeated :tgain and again. The stirring should be brisk, and should continue for half a minute or more. An iron rod carrying a perforated tin jlate is often used for the purpose of stirring the milk; the stirring is performed by working the stirrer up and down.

The "milk thief," a trough with a small opening in it, is also employed. The milk to be simpled is made to pass along the trough, and a little trickles out of the hole into a convenient recepticle beneath. This method gives fairly representative samples and requires no labour.

Small quantities of milk may be mixed by pouring to and fro from one vessel to another.

The sample should then be taken by means of a dipper or, better, hy a sampling tube. This consists of a long tube open at both ends, the lower being flat; a flat plate is attached to a rod which runs down the middle of the tube, so that by raising the rod the plate can be pressed against the hottom of the tube enabling it to contain liquid. To take the sample the tube is lowered slowly into the churn, the plate being kept away from the bottom to allow the milk to rise; when the milk has completely filled the tube the rod should be raised, and the tube withdrawn to prevent the exit of the milk; the sample can then le transforred to a convenient receptacle by placing it uncler the tube and depressing the rod.

Another method of sampling bulks of milk, which is seareely less exact than the preceding, is to tip the contents of the churn into a strainer with sides, the slope of which causes the milk to be thrown from side to side at an angle of $45^{\circ}$. The milk finds an exit through the wire gamze at the sides of a circular well, which should dip into a small tank of such size that the milk rises to the top of the wire garze; a hool at the back prevents spilling and facilitates mixing. The sample should be taken from the tank with a dipper or sampling tube. This method of sampling has the advantage of removing any partieles of straw, dust of ford, de, that may be found in the milk. If the tank be provided with a taj the milk can then be run ofl. 
The most convenient receptacles for the samples from bulk are ordinary half-pint milk cans. In large dairies, the milk is received from different farms, and it is convenient to legibly stump the name of the farm on its own sample can; sample cans should be provided and marked for all the samples it is desired to take regularly, and the use of unmarked cans, cans marked with paper labels, and cans marked with another designation should be avoided, if possible.

Testing.-The tests applied to milk should be of two kinds, simple tests done in the dairy, and a more extensive examination in the laboratory. The only test sufficiently convenient for use in the dairy is the estimation of the specific gravity. This will be sufficient to detect any gross adulteration. The taking of the specific gravity of every churn shonld be invariably performed, as this indication alone will be sufficient to detect gross adulteration, and it will also give a rough indication of the quality of the milk. For this purpose it is most convenient to employ a thermo-lactometer, or lactometer and thermometer combined in one instrument; the specific gravity should be corrected to $60^{\circ} \mathrm{F}$. by means of Table LXXIII. It is not generally necessary that the chemist should personally take these specific gravities. This may be left to a foreman or other intelligent person who has been trained to this work under the supervision of the chemist. The instructions given to the foreman should be, to pass all milk of a specific gravity lying between certain limits, unless special instructions to the contrary in certain cases are given; these limits may be from 1.034 to $1 \cdot 031,1 \cdot 0305$, or $1 \cdot 030$, according to circumstances; but in special cases higher or lower limits may be used. Sbould the specific gravity of any churn fall outside these limits, the foreman should be instructed to take samples with special care, and send them at once to the laboratory to be further tested; the milk in this case should be put on one side and not used until the report of the chemist has been received. As it is possible that a dispute, perhaps in a law court, may arise with respect to these special samples, the foreman should be instructed to seal both the sample, and the churn from which it was taken, so as to prevent any possibility of the milk heing tampered with. This preliminary testing lias been found to give satisfactory results in the author's experience. In all cases where adulteration of milk before arrival at the dairy has been refinitely proved, the specific gravity test revealed that the milk was not of normal quality. As an example of a case in which it was necessary to depart from the usual instructions given to the foreman, the author has found, in the case of the milk received from one particular farm, that the milk had a specific gravity as low as 1.029 . As the genuineness of this milk was proved beyond a doubt, the lower limit for the milk derived from this farm was fixed for a certain period at this 
figure. It will not be necessary to teach the foreman to read the lactometer eloser than half a degree, as this is an approximation quite sufficient in practice.

Undoubtedly, the most perfect control over the mill: would consist in the analysis of the milk in every churn before it is used, and the rejection of those ehurns in which the milk does not come up to the standard of purity adopted. This is, however, hardly practicable in a large dairy, as the milk must be dealt with and sent out as soon as it arrives, and the time for analysis is short. It has been found that the time required for handling a churn of milk-i.e., straining and transferring to the vessel in which it is sent away from the dairy-is about 35 seconds, and the quickest analysis, other than the taking of the specific gravity, occupies at least two minutes; so that to test eacli churn in this way would mean lelaying the handling of the milk to an extent which is incompatible with the proper working of the dairy. The testing of the milk in the laboratory that has passed the specitic gravity test, must, therefore, be done after the milk has been disposed of. It has been found that it is not necessary in this case to test the milk in every churn, as the results are for guidance as to the quality of milk that may be expected from different sources, and one sample per day from each farm is sufficient for this; the morning and evening meal should be sampled alternately. If adulteration is detected, or if the milk is of abnormal quality, the whole of the churns from that particular farm should be tested. It is also desirable to test the whole of the churns from each farm at intervals, say once a month. in order to see that the difference between them is not excessive. No strict rule can be laid down for the taking of samples; the chemist must use his discretion, based on experience, as to what samples he will have taken.

Sample Cans. - It has been found most convenient to put the samples in half-pint cans. One of these should be provided for eacli sample that is regularly taken, and the designation of the sample should be legibly stamped on it in full, abbreviations being avoided as much as possible, as they are liable to create confusion. The lids of these cans should tit well, and they should not be filled more than three-quarters full, to obviate as far as possible the risk of spilling in transit. The samples, after being taken, should be placed in a box or tray made to contain twenty-four cans, or any other convenient number, in which they can be transported to the laboratory. The trays should have a strong handle in the middle, and it is desirable that they be also furnished with a lirl which can be locked or sealed, so as to prevent any tampering with the samples in transit. The duty of conveying the samples should be entrusted to one man who should be made responsible for any spilling of the contents. A tray holding twenty-four cans is not too heary to be carried 
steadily, and there is no reason why any of the milk should be spilt. If the sampling is performed at a distance from the laboratory, the use of 6-ounce bottles is more reliable; a case to contain these should be provided. It is, of course, necessary for the chemist to see that the sample cans are in good repair; any which leak, or have ill-fitting lids, should be replaced at once. The cans or bottles before being handed over to the samplers should be quite clean and dry; the cans should be washed with hot water and dried, and when not in use, kept with the lids open. If bottles are used a large stock should be kept, and they should be well washed with warm water and allowed to drain for a couple of days; this will be found to dry them sufficiently.

Analysis of the Tamples.-The cans should be brought at once to the laboratory and the lid of the tray opened; the samples are then to be arranged in alphabetical or numerical order, or in any way that may be most convenient; a methodical system in this respect will be found to ninimise any chance of error in dealing with large numbers of samples. The procedure must vary in different dairies; if the samples are very few, the samples taken at different times of the day may be left till a sufficient number have accumulated and all examined at once. In this case, it is necessary to preserve them in a cool place, especially in summer; but where the time can be found it is preferable to make two or three series of analyses a day. An examination of the lids of the cans should be macle to see if any of the milk has been splashed upon them, and if it is not possible to obtain a new sample the portion adhering to the lid should be washed down into the can with some of the sample. The analysis should comprise the following data:-Specitic gravity, fat, aud total solids, and (by difference) solids not fat. The specitic gravity should be estimated by means of a lactometer. The fat may be estimated by the Leffmann-Beam or similar methods, or may be calculated from the total solids and specific gravity. The total solids may be estimated by evaporation, or may be calculated from the fat and specific gravity. The choice of how the analysis is to be conducted will depend upon the time available. The most reliable mode of work is to estimate both fat and total solids, but it requires a considerable amount of time; the quickest method is to estimate total solids and specific gravity, and to calculate the fat, while it is, perhaps, more satisfactory to estimate the fat and to calculate the total solids, as the fat is the most valuable constituent of the milk, and also because the accuracy of this estimation by the Leffmann-Beam method is rather greater than the accuracy of the total solid determination. In some dairies payment is made according to the amount of fat in the milk; in this case, the fat estimation should certainly be made. 


\section{The Testing of Milk.}

In this chapter methods requiring less attention in detail, and suitable for the use of persons who have not had a thorough analytical training, are described. The results obtained by these methods have not the rigid accuracy which can be obtained by the best gravimetric methods, but determinations approximating sufticiently nearly to the truth can be made, to enable them to be used in practical work.

\section{Determination of Specific Gravity.}

Lactometers. - This is invariably done in nilk-testing by lactometers (see p. 54); the lactometers used in dairy work are of two kinds, the thermo-lactometer and the ordinary lactometer.

The thermo-lactometer (Fig. 4) consists of a stem on which is marked a double scale, one part reading the specific gravity, and the other the temperature on the enclosed thermometer; a cylindrical borly; and two bulbs, the npper one being the bulb of the thermometer, and the lower one (containing mercury or shot) serving for the adjustment. By its means the temperature and specific gravity can be read off from the same instrument.

The ordinary lactometer consists of a stem carrying a scale on which the specific gravity is read; a cylindrical, or globular, body ; and a bulb containing mercury or shot.

Soxllet's lactometer (Fig. 5) contains a scale from $25^{\circ}$ (1.025) to $35^{\circ}(1.035)$ divided up into suitable divisions $\left(\frac{1}{2}\right.$ or $\left.\frac{1}{10}\right)$.

Vieth's lactometer has a globular borly ; it requires a smaller bulk and depth of milk than Soxhlet's, and is suitable for taking the specitic gravity in a half-pint can. The scale reads from $25^{\circ}$ to $35^{\circ}$.

Qucvenne's lactometer has a scale from $15^{\circ}$ to $40^{\circ}$, and is marked to show proportions of water added to milk and skim milk respectively. This auxiliary scale is useless.

Another form of lactometer, the name of whose inventor is deservedly lost in oblivion, has a scale from 0 to 100,0 being equal to a specific srarity of 1.000 (water), and 100 being equal to a specific gravity of 1029 . It is of no practical use in nilk testing.

Still annther form is markerl II at $1 \cdot 029$, and W at $1 \cdot 000$, the intermediate space being divided into quarters; this form is a mere toy.

An instrument has lately been put on the market, which consists of a chlass tube in which is enelosed a bulb of specific gravity 1.0.29, which lloats in milk above this specific gravity, but sinks when the specific aravity is reducen below this tigure by watering, by warming, or ly exerss of cream. It provides a harmless form of amusement, hut is of no practical use. 
The best lactometer's for use in milk testing are the thermolactometer, Soxhlet's, I and Vieth's.

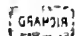

The thermo-lactometer cannot be made very small nor very delicate on account of the enclosed thermometer, and requires a comparatively large bulk of milk; it is thus more suitable for testing in the dairy than in the laboratory, where samples are often limited. It has, however, the advantage of not requiring a separate thermometer and a separate operation to determine the temperature.

Vieth's lactometer can be used in a can and, if the samples are received in cans, as is often the case in a dairy laboratory, no transference of the sample is necessary.

soxhlet's lactometer has a wider seale, and may be conveniently used when greater accuracy is required.

Galaine's self-correeting lactometer has a metal ball completely filled with chloroform attached to the bottom, the object being to obviate the necessity of correction of the speeific gravity for temperature; the expansion of the chloroform was supposed to compensate the expansion of the milk. Though excellent in theory, it has proved disappointing in practice.

The following direetions are due to Vieth:-

Use of Lactometer. - In order to determine the specific glavity, the milk is poured into a vessel at least $\frac{1}{4}$ in. greater in diameter than the widest part of the lactometer, and deep

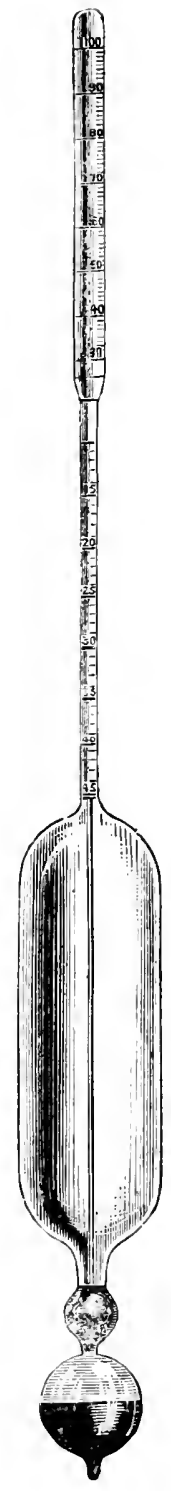

Fig. 4.

Thermo-

lactometer.

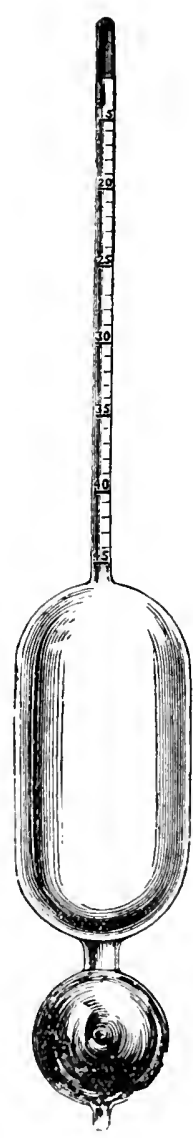

Fig. 5. Soxhlet's Lactometer. 
enough to allow the instrument to float. A cylindrical glass jar (Fig. 6), with foot, is the most suitable vessel for the purpose if Soxhlet's lactometer or the thermo-lactometer be used; Vietli's lactometer may be used in a can or tin cup. The lactometer is gradually lowered into the milk to the 25th degree,

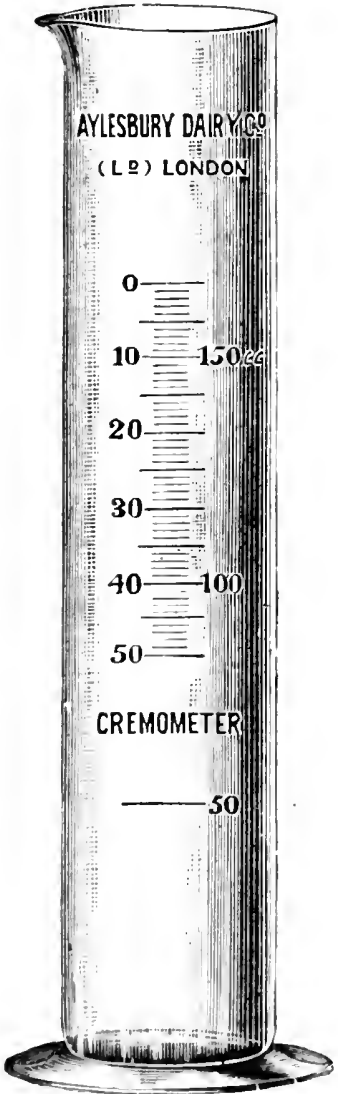

Fig. 6.

(iliks Jar. care being taken that the instrument is entirely wetted by the milk and that no air adheres to it. When released, the lactometer will move up and down, and after a little while become stationary. That degree of the scale which coincides with the surface of the milk is then noted. It will be observed that, where the milk tonches the vessel and the stem of the lactometer, the surface is not level, but, in consequence of the adhesion of the milk to the glass, forms a curve. There is no difficulty, however, in ascertaining the extension of the curve sufficiently near, and this has to be allowed for in reading off the specific gravity. When using instruments of ordinary size, the curve will be found to extend to about one-lialf degree.

Lactometers indicate the exact specific oravity at a temperature of $60^{\circ} \mathrm{F}$. It is, therefore, necessary, as soon as the position of the lactometer las been noted, to remove the instrument from the milk, immerse a thermometer, and ascertain the temperatirie.

If the temperature is found to be $60^{\circ} \mathrm{F}$., the observed specific gravity is correct, but should the temperature of the milk be higher or lower than $60 \mathrm{~F}$., the specific gravity must be corrected by the aid of the 'Table in the Appendix which is used as follows:Find the temperature of the milk in the upermost horizontal line. and the ohserved specitic gravity in the first or last vertical column; in the sane line with the latter, and under the tempriature, is wiven the corrected specific sravity. For example-sirposing the trmperature to be $51^{\circ}$ and the specific eravity $: 31^{\prime \prime}$. the specific sratrity corrected to $60^{\circ} \mathrm{F}$. is $32.5-1.0329$; or if the temperature is $60^{\circ}$ and the 
specific gravity $29^{\circ}$, the corrected specific gravity is $29 \cdot 8^{\circ}$ $=1.0298$.

Never take the specific gravity of a milk without also noting the temperature and correcting to $60^{\circ}$ Fahrenheit.

Instead of reading from the bottom of the curve and making a mental allowance, the lactometers may be read from the top of the curve and a definite figure (ascertained by a few carefullyconducted experiments) added on.

As soon as the specific gravity and temperature have been taken, the corrected specific gravity from the table should be entered in the book provided for the purpose of recording the results. It is not necessary to enter the specific gravity in full, but only the three significant figures; thus a specific gravity of 1.0325 may be entered simply as 325 or 32.5 .

Though the determination of specific gravity has been described first, it is found that it is convenient in practice to proceed as soon as work is commenced with the estimation of total solids, as this is an operation which proceeds alone. Only in those cases where the sample is so small that the lactometer will not conveniently float, if the quantity necessary for total solid estimation has been removed, is it usually convenient to take the specitic gravity first.

\section{Estimation of Total Solids.}

A number of dishes or capsules, each marked with a separate number and previously weighed, and a pipette marked to discharge 5 grammes of milk of a specific gravity $1.03 \mathrm{Z}$ at a temperature of $60^{\circ} \mathrm{F}$, are necessary. The dishes should be, if possible, of platinum, and at least $1 \frac{1}{2}$ inches internal diameter, flat bottomed, and with a rim about $\frac{1}{8}$ of an inch wide; this rim should be considerably wider at one side so as to form a lip on which the number should be legibly stamped. These dishes weigh about 12 grammes and cost about $2.5 \mathrm{~s}$. each. They may, however, be replaced by porcelain dishes of about $2 \frac{1}{2}$ inches diameter, glazed all over; these may be marked by scratching the number on the side with a new file, painting this over with a solution of platinum chloride, wiping off the excess, and igniting the capsule; the number will be marked in platinum.

The dishes must be previously weighed on a balance accurate to 1 milligramme, and the weights recorded on a table which should be kept in tbe balance case. It has been found in practice that, if the dishes be carefully cleaned, monthly weighings of the dishes are sufficient, the average loss in this period for dishes used daily having been found to be about 1 to 2 milligrammes.

The dishes should be arranged in a shallow tray-a photographic dish is suitable-according to their numbers from left 
to right, six or seven in a row, beginning at the bottom-i.e., the side nearest the operator. This arrangement is ehosen so that any milk accidentally dropped from the pipette will not fall into a dish which has been previously filled, but into an empty dish which can be easily wiped. The tray eoutaining the dishes should be on the left of the tray in which the samples are placed. 'The samples should be arranged in order in rows, beginning at the lett-hand bottom corner and going upwardsi.e., away from the operator-and should, if in cans, have their lids turned back over the next sample can. The taking of samples for the estimation of total solids is much facilitated by having an assistant to stir the milk. The measurement of the quantities of milk for analysis is done as follows :-The assistant stirs No. l can, and when the eream has been mixed the chemist plunges the pipette into the milk and sueks it up till it enters the mouth; it is advisable to throw away this first quantity. The milk is again sueked up, the finger placed over the end of the pipette, and the milk allowed to run down to the mark, eare being taken that air bubbles are not ineluded in the portion measured. The pipette is held over dish No. 1 and the finger removed; the milk runs into the dish, and the drop adhering to the end is removed by touching it against the side of the dish; the last drops must not be removed by blowing. Meanwhile the assistant has elosed can No. l and stirred can No. 2, from which 5 -rammes are measured in a similar manner, without, however, washing out the pipette; this is transferred to dish No. 2, and the whole of the samples are taken similarly.

The next step is to enter the designation of the samples and the number of the dish into which each lias been placed in a look provided for that purpose; the tray containing the dishes is then conveyed to the water-lath. The water-bath should be of copper, alout 6 inehes deep, and provided with a lid containing a suitalle number of hole's in which the dishes can rest; the number of these will vary with the number of samples to be daily examined: it is convenient to lave a projecting collar about a quarter of an inch deep round each hole, as this facilitates the putting on and removal of the dishes, and each should be provided with a lid. If stean is laid on, the bath should be heated by means of a coil laid in the bottom, through which the steam circulates; the exit of this eoil should be eonnected with a condenser, and the condensed steam serves to supply the libboratory with distilled water. If steam be not laid on, the bath must be supported on an irom support at such height as to allow of a burner heing placed underneath; in either case an arrangement for keeping the water lowel constant in the liath is uncessary.

After the dishes have been for ahout an hour on the bath, provided it has been boiling briskly, it will be notieed that a 
distended skin lias formed on the surface of the milk; this must be broken with a needle mounted in a handle, care being exercised that no portion of the skin is brought away on the needle. The object of this is to prevent the milk drying in flakes, which may be blown away by draughts, and the estimation lost. Should the dishes be forgotten, or should any other reason prevent the stirring being done at the proper moment, a few drops of water may be added to the milk residue, which will have the effect of making the flakes settle down and adhere to the dish. When the dishes liave been on the water-bath for three hours, they should be taken off, placed on a tray having two or three thicknesses of blotting-paper on the bottom to remove adhering drops of water, and transferred to a water-oven or air-bath. The important point about the water-oven is that it has an even draught passing through it; the form of air-bath devised by Dr. Adams of Maidstone is suitable, though the cover is a little troublesome to remove. The dishes are placed upon wire shelves one above the other, and it is convenient to have ten or twenty dishes on each shelf. If a good draught be maintained in the water-oven or air-bath, it is not necessary or advisable to keep this at a higher temperature than $90^{\circ}$ to $95^{\circ} \mathrm{C}$. After three hours drying in the air-bath, the dishes should be weighed.

Weighing.-Ten basins (or any number that can be conveniently placed in the balance case at one time) should be removed from the bath, placed on a tray and conveyed to the balance case, and there allowed to cool for a few minutes. Platinum basins cool very much faster than porcelain, and much time is saved by their use; when cool, they should be weighed to the nearest milligramme, the weight entered in the book opposite to the number of the dish; the weight of the empty dish (from the table of weights) should be subtracted, and the weight of the milk residue will be the difference between the two weights; this also should be entered in the book. As 5 grammes of milk were taken, the residue, multiplied by 20 , will give the percentage of total solids in the milk.

If the samples arrive in the laboratory in sample bottles and not in cans, a somewliat different mode of procedure must be adopted. A number of cylindrical tins without lids (of such a size as to hold the contents of a sample bottle) and a lactometer are necessary. The bottles and dishes are arranged in their proper order and entered in the book, as before. As many bottles as there are tins are shaken, so as to mix the cream, and emptied into the tins; 5 grammes are taken from each and placed in the dishes, but before the milk is poured back into the bottle or otherwise emptied from the tin, the temperature and specific gravity should be taken; the remaining samples are then similarly treated in their proper order. The drying and weighing is performed as before. 
Stokes' Rapid Method.-Stokes recommends a modification of Gerber and Radenhausen's method. A pipette is used which delivers $2 \cdot 5$ grammes of milk, and the milk is run into flatbottomed porcelain basins about 3 inches in diameter. The numbers are marked on the basins with copper paint, which paint, on ignition, forms an indelible blue mark. When all the basins are tilled, two or three drops of a 10 per cent. solution of acetic acid in alcohol are sprinkled over each. The alcohol sprearls itself over the surface of the milk, and the acid precipitates the casein. Under these cireumstances, drying proceeds very rapidly. The basins are placed on the water-bath till apparently dry, a matter of a few minutes only, and are fiurther dried for about an hour in the water-oven or air-bath. They are then weighed, as before. The difference between the weight of the basin with the residue and the weight of the basin alone, multiplied by 40 , gives the percentage of total solids.

In the author's experience this method has a tendency to give results slightly above the truth; it has, however, the advantages of rapidity and of requiring very little attention.

\section{Estimation of Fat.}

For the estimation of fat in a rapid manner, with an accuracy sufficient for milk control, a centrifugal method must be used. The Leffmann-Beam, the Babcock, and the acido-butyrometric methorls, together with Soxhlet's areometric method, will be described in detail.

The Babcock Method.-This method was the pioneer of the methods chiefly employed at the present day. It was devised by S. M. Balocock, and it depends on the solution of the casein and other solids not fat of milk in sulphuric acid, and on the subscquent separation of the fat by centrifugal force.

'l'his method lias proved to be one of the greatest advances in practiral milk testing yet made, and the name of Babcock must be placed high anong dairy chemists, the more so because, unlike most other inventors, he sought no personal protit from his diseovery, hut gave it freely for the use of all. Though the methor is being supplanted by methods on the Lellmann-Beam princifle, the lustre of liabcock's name suffers no diminution from this fact, these nucthods being but the legitinate ollspring of a worthy parent.*

'I'he only machine on the English narket for performing the biabcock methor is the listor-Pabcock. Embrey, Tichborne

* The author fonds that a dereriphtion of the baheock methorl would be

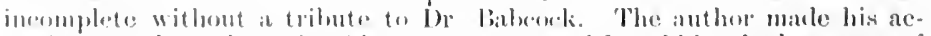

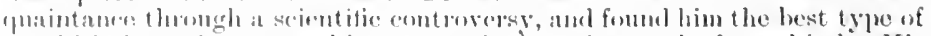
Insolfish insestigatom, senking not gain hint the genel of mankind. His

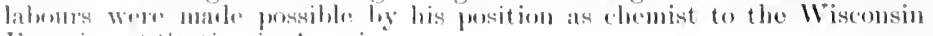
lixprement stittion in Americait. 
and Wilkinson have investigated the method with this machine and find the results somewhat low, but Woll has shown that the speed of whirling recommended by the makers of the machine must be increased from 600 revolutions per minute to from 700 to 1200 ; when this is done the results are accurate and no arbitrary correction need be made.

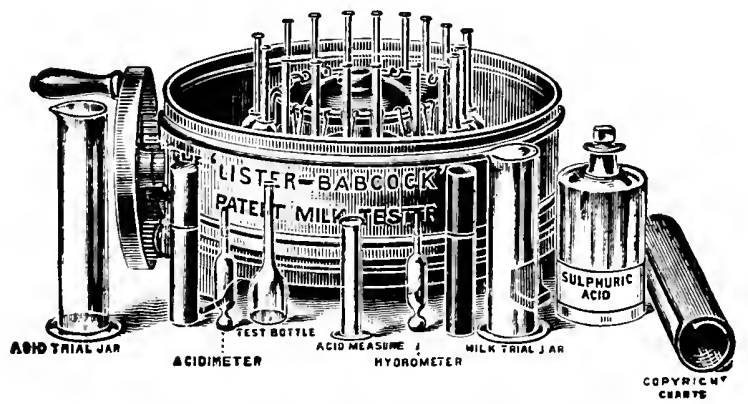

Fig. 7.-Lister-Babcock Milk Tester.

The machine is tigured in Fig. $i$, and is of strong and simple construction. It is provided with a cover to prevent accidents in case of the bottles breaking.

The following directions for the Babcock process are those supplied with the Lister-Babcock machines :-

"Measuring.-If the pipette is not dry when used it should be filled with the fluid to be tested, and this thrown away before taking the test sample.

"If several samples of the same are taken for comparison, the samples should be poured once from one vessel to another after each sample is measured. Neglect of this precaution may make a perceptible difference in the results, through the separation of cream, especially when the sample examined is rich.

"Persons who have had no experience in the use of a pipette will do well to practise a short time by measuring water into a test bottle before attempting to make an analysis. The manipulation is easily acquired, and with a little practice fluid may be measured nearly as rapidly with a pipette as with a measuring glass, and with much greater accuracy.

"When the samples have been sufticiently mixed, the pipette is filled by placing its lower end in and sucking at the upper end until the fluid rises above the ring round the neck; then remove the pipette from the mouth and quickly close the tube at the upper end by firmly pressing the end of the index finger, first wetted, upon it to prevent access of air; so long as this is done the fluid cannot flow from the pipette. Holding the pipette in a perpendicular position, with the mark on a level with the eye, carefully relieve the pressure on the finger so as to 
admit air slowly to the space above the fluid. When the upper surface of this coineides with the ring round the stem or neck, the pressure should be renewed to stop the flow. Then proceed as follows for

"New Milk.-Place the point of the pipette in the mouth of a milk test bottle held in a slightly inclined position so that the milk will How down the side of the tube leaving a space for the air to escape without elogging the neck, and remove the finger, allowing the milk to flow into the bottle. After waiting a short time for the pipette to drain, blow into the upper end to expel the milk held by capillary attraction in the point.

"Measure 17.5 eubic centimetres of pure sulphuric acid of speeitie gravity between 1.831 and 1.834 by means of a small glass measure, and pour into test bottle, giving the bottle a turn so as to wash down any milk which may adhere to the neck of bottle, shake gently till all curd is dissolved, then place in machine and whirl 10 minutes at speed denoted on machine. Fill up bottle to mark $i$ with hot water from water ean, then pour hot water (temperature about $200^{\circ} \mathrm{F}$.) into bottom of $\mathcal{C}$ machine about half an ineh deep, and whirl again for 2

$\mp$ minutes. Place bottle in hot water can (temperature $150^{\circ} \mathrm{F}$. to $200^{\circ} \mathrm{F}$.), allow this to stand a few minutes and measure extreme limits of fat column. Each complete division of 5 lines $=1$ per cent. of fat, and the single lines $=\cdot 2$ per eent., the percentage being denoted by figured long lines.

"Cream.-Take a pipette full of cream up to line round neck, and let this quantity run into a small glass or jar, and then take exactly the same quantity of pure water of about the same temperature as the eream and thoroughly mix the two together, after which a pipette full of this mixture should be taken and put into one of the eream test bottles (the remainder may be used for another test or thrown away). Great care should be taken to get this mixture eorrect.

" Measure 17.5 enbic eentimetres of pure sulphuric acid of specific gravity between 1.831 and $1 \cdot 34$ by means of a small glass measure, and pour into test bottle, giving the bottle a turn so as to wash down any eream which may allhere to the neck of hottle, shake ently till all enrd is dissolved, then place in machine and whirl 10 minutes at speed denoted on machine. Fill uy bottle to mark 25 with hot water from water can, then pour hot water (temperature about $200^{\circ}$ F.) into bottom of C michine about half an ineh deep, and whirl again for 2 - $†$ minutes. ['lace lottle in hot water can (temperature $150^{\circ} \mathrm{F}$, to $200^{\circ} \mathrm{F}$ ), allow this to stand a few minutes and measure extreme limits of fat column. Each complete 1 division of 5 lines $=2$ per cent. of fat, and the single lines $=4$ per cent, the pereentage being denoted by 
figured long lines, or for cream read double-that is, if the fat is from 2 to 24 , leaving 22 , the fat would be double that per cent. - that is, 44 per cent.

"Separated Milk. - To test skimmed milk it is necessary to take 2 pipettes filled up to the ring, and place it in a skim milk test bottle, and to this add 2 measures each $17 \cdot 5$ cubic centimetres of pure sulphuric acid of specitic gravity between 1.831 and 1.834 by means of a small glass measure, and pour into test bottle, giving the bottle a turn so as to wash down any milk which may adhere to neck of bottle, shake gently until all curd is dissolverl, then place in machine and whirl 10 minutes at speed denoted on machine. Fill up bottle to mark 2 with hot water from water can, then pour hot water (temperature about $200^{\circ} \mathrm{F}$.) into bottom of machine about half an inch deep, and whirl again for $\dagger 2$ minutes. Place bottle in hot water can (temperature $150^{\circ}$ F. to $200^{\circ} \mathrm{F}$.), allow this to stand a few minutes and measure extreme limits of fat column. Each complete 1 division of 5 lines $=1$ per cent. of fat, and the single lines $=\cdot 10$ per cent., the percentage being denoted by figured long lines.

"Acid. - The best method of obtaining sulphuric acid of suitable strength is to take 1 measure of water in an earthen jug, and then pour in very gradually 9 measures of the strongest sulphuric acid (pure) procurable, then on allowing mixture to cool to $60^{\circ} \mathrm{F}$., and putting in the acidimeter provided, it should so float that the surface of the liquid is between the two red lines on the stem, which lie close together, and encircle the scale, the upper line corresponding to a specific gravity of 1.831 , and the lower one 1.834 .

"Cleaning the Test Bottles. - The bottles should be emptied while hot, afterwards rinsed twice with cold water, and then inverted to allow of draining. They are then ready for another test.

"Working and Oiling Machine-Turning. - This should be commenced gradually, and increased until the speed as indicated on revolving disc is attained.

" Oiling.-The oil must be of good quality. The vertical spindle and surfaces are oiled from the cup on top of lisc. The bearing close to bevel wheels is oiled through tube which will be found in casting under revolving disc. The other bearings are in plain sight. A drop or two of oil is sufficient. Do not flood it.

" Revolving Disc. - This must be well fixed to spindle by set pin, the spindle at the same time being pushed up from underneath the frame so as to prevent the bevel wheels trom engaging too deeply one in the other. Should the machine work a ittle hard at any time, this will most likely be the sole cause." 
The Leffmann-Beam Method, and Modifications.-Leffmann and Beam, realising that the time of whiring necessary in Babcock's method was a serious objection, experimented with a view to shortening this. They finally decided on the use of amyl alcohol as a means of assisting the fat to rise, and were thereby enabled to reduce the time of whirling. The same idea was also independently worked out at the Vermont Experiment Station, but it appears that Leffmann and Beam were the pioneers in this direction.

It is usually employed in conjunction with the Beimling machine.

The method has been sulijected to a close investigation by the author, aur is of considerable accuracy.

The Beimling Machine.-This consists of a cast-iron framework carrying a vertical spindle; on this is a small bevelled cogwheel, which engages a larger bevelled cog-wheel on a horizontal spindle turned by means of a handle. In the larger machines a sccond spindle and set of cogs is introduced (Fig. 8).

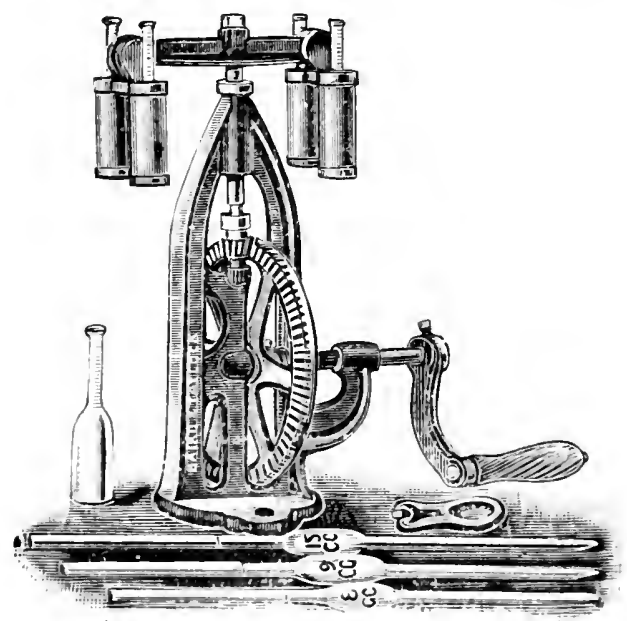

Fig. 8.- Beimling's Separator.

On the top of the rertical spinile two, three, or six arms extending radially are fixed. 'To the cnds of each of these are piroted one or usially two enps, in which the bottles are placed.

When the handle is turnerl, the cogs cause the spindle and the arms carrying the eups to rotate. For one turn of the handle, the vertical spindle turns cleven times. Centrifugal force causes the cups to assume a horizontal position when rotating, and they return to the vertical when the machine is at rest.

The bearings are all plain, which causes a considerable 
amount of friction; the centre of gravity of the rotating system is placed very high, which causes vibration, due to imperfect balancing, to be marked. The air resistance at high speeds is somewhat great.

These are serious faults but are capable of improvement. The two-bottle Beimling machine is the only machine on the market, to the author's knowledge, in which the hottles assume a horizontal and radial pusition when rotating; in the larger sizes the bottles are nearly, but not quite, radial. This position is advantageous, as it allows of the most rapid separation of the fat from the acid liquid.

Apparatus.- The test bottles consist of flat-bottomed flasks with a sloping upper portion terminating in a graduated neck. The bottles (English make) hold 29 c.c.; the necks are made of glass tube $5.96 \mathrm{~mm}$. in internal diameter, and are so graduated that 80 divisions $=1.475$ c.c. These dimensions are according to a specification laid down by the anthor, and differ slightly from those prescribed by Leffmann and Beam. The pipettes used are-

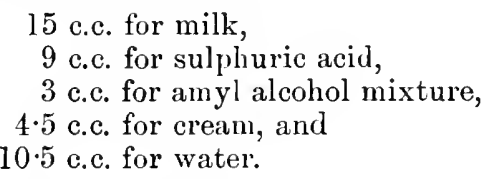

Automatic measuring apparatus and burettes may be also used for measuring the acid and anyl alcohol.

The author has devised a burette specially for the measurement of sulphuric acid and other corrosive liquids. It has been found, in practice, that ordinary burettes are liable to be filled to overflowing, and that considerable inconvenience is caused by spilling strong sulphuric acid.

An ordinary burette with a three-way tap is used, and to the tube, for filling from the bottom, a wider tube, 1 in. in diameter and 3 ins. long, is fused. An india-rubber cork is inserted in this, and through it is passed a long glass tube bent as a syphon, which serves to convey the acid from a stock bottle above.

In the top of the burette an india-rubber cork is fixed, through which passes a tube going almost to the top of an air chamber of glass; to the bottom of the air chamber a glass tube of small bore passes upwards so far as just to enter into the stock bottle.

The illustration (Fig. 9) will make the construction clear.

The conditions necessar'y for satisfactory working are :-

1. The capacity of air chamber and tube leading to stock bottle must not be more than $\frac{1}{5}$ of the capacity of the burette.

2 . The bottom of the stock bottle must be well above the top of the tube leading into the air chamber.

The tube leading in to the air chamber must be adjusterl to the mark on the burette equal to its capacity. 


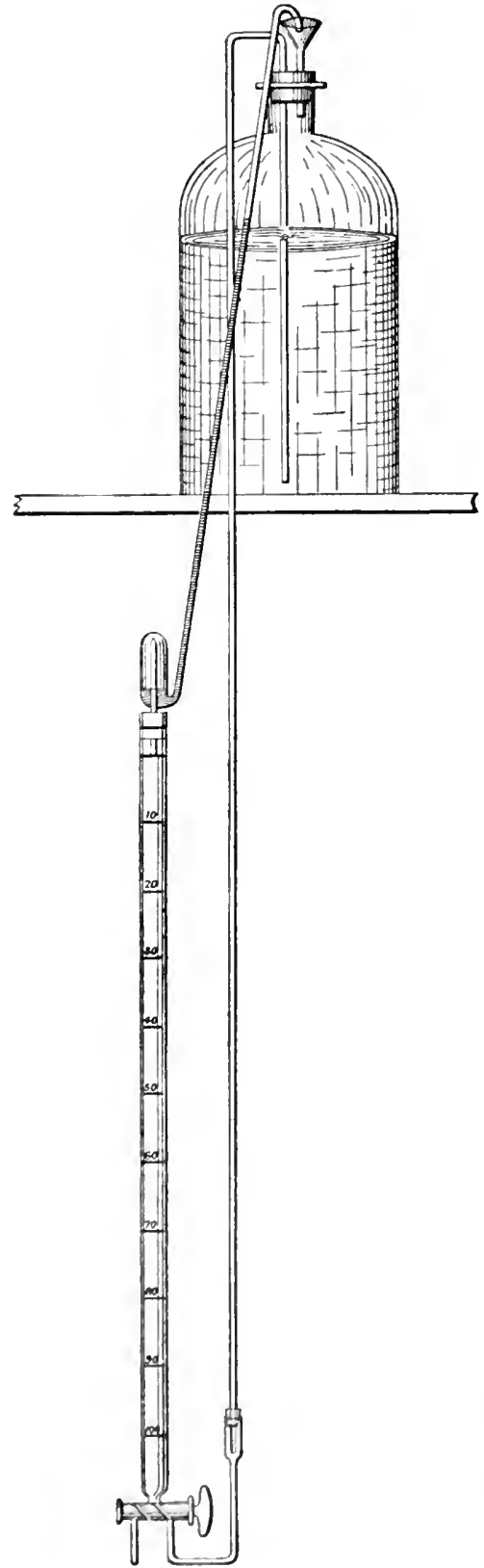

The burette is used as follows:- The tap is turned so that the liquid enters and fills the burette. As it reaches the upper portion, it passes up the tube and overflows into the air chamber, from which it is forced up the tulie leading to the stock bottle. When the liquid reaches a height corresponding to the level of the liquid in the stock bottle, the liquid ceases to run, and the burette is automatically filled to the zero point. When the tap is turned the liquid runs out, air bubbling in from the stock bottle, and measured quantities may be taken. After the liquid has been run out as far as desired, the tal is turned, and the liquid enters the burette.

The liquid in the air chamber is torced back into the stock bottle, and the burette automatically fills itself.

The burette can he made of 9 c.c. capacity, but it is. much quicker to +mploy a graduated burette of much larger capacity than any form of automatic measuring ipparatus.

The advantages claimed for this burette are-

(1) Antomatic filling to zero point.

(2) One turn of the tap mly reguined to fill and to measure.

(3) Impossibility of spilling (nrosive liquids.

(4) Siaving of time, as the filling is done while other operations are conducterl.

Fig. 9.-Antomatic Burette. 
Chemicals. - Commercial sulphuric acid containing 96 per cent. $\mathrm{H}_{2} \mathrm{SO}_{4}$, which has a specitic gravity of 1.842 at $15.5^{\circ} \mathrm{C}$. $\left(60^{\circ} \mathrm{F}\right.$.). Owing to the fact that strong sulphuric acid has a somewhat anomalous specific gravity, it is not advisable to test the specific gravity directly. 'The following test will give good results :- . Measure accurately $200 \mathrm{c}$ c. of acid into a large flask, and to it add cantiously 15 c.c. of water, cooling the flask by immersion in cold water. 'Take the specific gravity of this diluter acid, either with an accurate hydrometer or by other means. If the temperature be not exactly $15.5^{\circ}\left(60^{\circ} \mathrm{F}\right.$.), add on .001 for each degree Centigrade above $15.5^{\circ}$, or 00055 for each degree Fahrenheit above $60^{\circ} \mathrm{F}$. (or subtract for temperatures below).

The following table will give the strength of acid :-

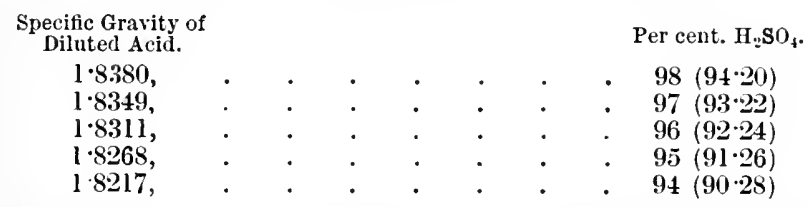

The figures in parentheses give the percentage of sulphuric acid in the diluted acid, the other figures referring to the percentage of acid before dilution.

Another method of determining the strength of acid is to weigh about 1 gramme of acid in a basin and, after diluting with water, to add an excess of strong ammonia. The solution is evaporated on the water-bath and, when nearly dry, a little more strong ammonia is added; it is then dried to constant weight at $100^{\circ} \mathrm{C} .\left(212^{\circ} \mathrm{F}\right.$.) and weighed. The weight divided by 1.347 will give the weight of sulphuric acid in the sample; this, divided by the weight taken and multiplied by 100, will give the percentage.

Puritied amyl alcohol, specific gravity 815 to 818 at $15 \cdot 5^{\circ} \mathrm{C}$. $\left(60^{\circ} \mathrm{F}\right.$.), which completely dissolves to a clear liquid when mixed with an equal bulk of hydrochloric acid; this mixture must not become darker than sherry in three days.

Conmercial hydrochloric acirl.

The amyl alcohol is mixed with an equal bulk of hydrochloric acid for use; it is best not to keep this mixture longer than a few days.

The Process-Testing of Milk, Skim Milk, Buttermilk, and Whey.-Measure 15 c.c. each of the well-mixed samples into test bottles, holding the point of the pipette against the side of the neck, so that the liquid may run down, allowing room for the air to escape. Add 3 c.c. of the mixture of amyl alcohol and hydrochloric acid. Pour in, with care, 9 c.c. of sulphuric acid, so that it washes down any particles of milk on 
the neck of the bottle. Mix the contents of the bottle with a rotatory motion; a little practice is required to do this without the liquid boiling over, owing to the heat evolved on mixing sulphuric acid with water, but when the way is once learned there is no difficulty in doing this. Fill up the bottles to the zero mark with a mixture of one part of sulphuric acid to two volumes of water, and place the bottles in the machine; rotate by turning the handle at 100 revolutions per minute for about one minute, when the fat will separate in a clear layer.

Read the fatty layer as follows:-Note the

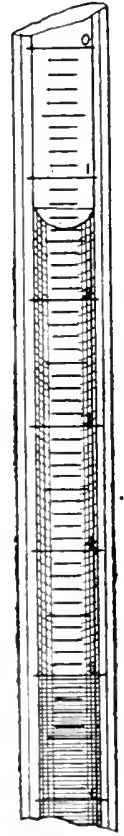

Fig. 10.

Neck of Bottle. position of the lower surface of the fat (it is convenient to wait till it has fallen to one of the main graduation lines), then immediately note the position of the lowest point of the eurve on the upper surface; the difference between the two will give the percentage of fat; repeat this once or twice; the results should be identical (Fig. 10).

Each small division is $\frac{1}{10}$ per eent. fat ; if, then, the fatty layer oceupies thirty-six of these, the percentage is $3 \cdot 6$. Half or a quarter of a division may easily be read with practice.

Should the fatty layer have sunk below the lowest graduation, a little more diluted acid may be added, and the bottle whirled for a few seconds.

In very cold weather the fat may solidify in the neek; in such case it should be warmed slightly before reading; it is not otherwise necessary to warm the bottles be fore reading.

skim milk and buttermilk should be whirled as soon as possible after mixing; in very hot weather, or if the bottles stand very long after the acid has been added, the fat may be of a dark colour.

It is advisable to compare the results given by this method with those given by the Adams or other good gravimetric process, whenever a new stock of sulphuric acid or amyl alcohol is used, and, if necessary, to work out a detinite correction to be added to or subtracted from the results. With acid and atcohol corresponding to the speeification above, no correction should be necessiry.

The diflerence between the results by the Leffmann-Beam methor and those by gravimetric analysis very rarely exceed 1 per cent. of fit.

Testing of Cream.-If the cream contains less than 32 per cent. of fat it can he measured direct by the 4.5 c.e. pipette; if it is thicker than this, it must be diluted with separated inilk. Two beakers or tin pots are counterbalanced on a rough balance 
turning to 01 gramme; in one of them, about 25 grammes of cream are placed, and separated milk is run into the other till the weights are equal. The cream and separated milk are mixed together, and the mixture can be measured.

The measurement is performed as follows:-Fill the pipette with cream by sucking at the top, and close it with the finger; hold the pipette vertically, and allow the cream to run down till the upper surface is on a level with the mark; turn the pipette to a horizontal position and wipe the stem; then return it to the vertical and, holding the point orer the neck of a test bottle, allow the cream to run out freely ; after the quick succession of drops has ceased allow three more drops to run. Add 10.5 c.c. of water and proceed as in analysing milk.

Calculate the results from Table XLI., using column 3 for undiluted cream and column 2 for diluted cream.

TaBLE XLI.-For Estimating Fat in Creay.

\begin{tabular}{|c|c|c|c|c|c|}
\hline Reading. & Diluted. & Indiluted. & Reading. & Diluted. & Endiluted. \\
\hline$s \cdot \tilde{J}$ & $63 \cdot 8$ & $32 \cdot 0$ & 6.7 & $49 \cdot 8$ & $25 \cdot 0$ \\
\hline $8 \cdot 4$ & $63 \cdot 0$ & $31 \cdot 6$ & $6 \cdot 6$ & $49 \cdot 0$ & $24 \cdot 6$ \\
\hline $8 \cdot 3$ & $62 \cdot 2$ & 312 & $6 \cdot 5$ & $48 \cdot 2$ & $24 \cdot 2$ \\
\hline $8 \cdot 2$ & $61 \cdot 4$ & $30 \cdot s$ & $6 \cdot 4$ & $47 \cdot 4$ & $23 \cdot 8$ \\
\hline $8 \cdot 1$ & $60 \cdot 6$ & $30 \cdot 4$ & $6 \cdot 3$ & $46 \cdot 6$ & $23 \cdot 4$ \\
\hline $8 \cdot 0$ & $59 \cdot 9$ & $30 \cdot 0$ & $6 \cdot 2$ & $45 \cdot 9$ & $23 \cdot 1$ \\
\hline $7 \cdot 9$ & $59 \cdot 1$ & $29 \cdot 6$ & $6 \cdot 1$ & $45 \cdot 1$ & $22 \cdot 7$ \\
\hline $7 \cdot 8$ & $58: 3$ & $29 \cdot 2$ & $6 \cdot 0$ & $44 \cdot 4$ & $22 \cdot 3$ \\
\hline $7 \cdot 7$ & $57 \cdot 6$ & $28 \cdot 9$ & $5 \cdot 9$ & $43 \cdot 6$ & $21 \cdot 9$ \\
\hline $7 \cdot 6$ & $56 \cdot 8$ & 28.5 & $5 \cdot 8$ & $42 \cdot 8$ & $21 \cdot \tilde{5}$ \\
\hline $7 \cdot \overline{3}$ & $56 \cdot 0$ & $28 \cdot 1$ & $5 \cdot 7$ & $42 \cdot 1$ & $21 \cdot 1$ \\
\hline $7 \cdot 4$ & 5.53 & $27 \cdot 7$ & $5 \cdot 6$ & $41 \cdot 4$ & $20 \cdot 8$ \\
\hline $7 \cdot 3$ & 54.5 & $27 \cdot 3$ & $5 \cdot 5$ & $40 \cdot 6$ & 20.4 \\
\hline $7 \cdot 2$ & 537 & $26 \cdot 9$ & $5 \cdot 4$ & 39.5 & $20 \cdot 0$ \\
\hline $7 \cdot 1$ & $52 \cdot 9$ & $26 \cdot 5$ & $5 \cdot 3$ & $39 \cdot 1$ & $19 \cdot 6$ \\
\hline $7 \cdot 0$ & $52 \cdot 1$ & $26 \cdot 1$ & $5 \cdot 2$ & $35 \cdot 3$ & $19 \cdot 2$ \\
\hline $6 \cdot 9$ & $51 \cdot 4$ & $2.5 \cdot 8$ & $5 \cdot 1$ & $37 \cdot 5$ & $18 \cdot 9$ \\
\hline $6 \cdot 8$ & $50 \cdot 6$ & $25 \cdot 4$ & $5 \cdot 0$ & $36 \cdot 7$ & $18 \cdot 5$ \\
\hline
\end{tabular}

Testing of Sour Milk.-Weigh in a small beaker about 15 grammes of the sample which has been previously well mixed by whisking with a brush formed of fine wires; pour as much as possible into a test bottle and re-weigh the beaker; the difference will give the weight of the milk taken; add sufficient water to make up to $15 \cdot 25$ grammes and proceed as in analysing milk.

Calculate as follows:-Multiply the reading by $15 \cdot 25$ and divide by the weight taken; the result will be the percentage of fat in the sour milk. 
Testing of Clotted Cream, Cheese, and Butter.-Weigh the bottle and transfer to it about 1 to 1.5 gramme of butter, 2 grammes of clotted cream or 3 grammes of cheese, and weigh again. Butter should be melted in a closed vessel at a temperature of $40^{\circ} \mathrm{C} .\left(104^{\circ} \mathrm{F}\right)$, and, after shaking, about $1 \frac{1}{2}$ c.c. sucked up in a tube which will just enter the neck of the bottle; the butter should be blown in as completely as possible. Clotted cream should be well mixed and sucked up in a tube in the same way as butter, and either blown or pushed in with a wire. Cheese shonld be cut up into small pieces, which can be dropped in. Add sufficient water to make up the weight to $15 \cdot 25$ grammes and proceed as in analysing milk. Cheese requires rather longer shaking than other products, but gives equally good results.

If desired, cream may be weighed instead of being measured.

The calculation is performed as for sour milk.

The above directions differ in some respects from those given by Leffimann and Beam. The author has had, however, some years practical experience of the methods described and is convinced of their accuracy. A stind for the bottles is to be recommended; this may conveniently be made of wire rings into which the bottles fit, with a flat plate for a bottom; the bottles can then be easily carried about.

To clean the bottles: empty while hot in a convenient receptacle, and wash twice thoroughly with hot wate $r$; if necessary, run a brush down the neck. They are conveniently washed in the stand. Never leave pipettes dirty.

Failures and their Probable Causes.-The only failures likely to happen are :-

1. Dark laver of fat.

2. Fluffy layer under the fat.

1. If the acid be too strong, or the temperature too high, or the mixture left too long before whirling, the fat may be dark. The remedy is obvious.

2. A fluffy layer under the fat is often caused by allowing the milk and acid to stand too long unmixed. It may sometimes be due to a bad quality of amyl alcohol.

Grit on the bottom of the bottles may cause fractnre while in the machine. Fracture may also occur from too sudden a stoppage after the whirling is completed.

Modifications of the Leffmann-Boam Method.-The Leffmann-Bean method has bern subjected to eonsiderable modification; thus Paterson and, later, Gerber liave used amyl alcohol alone without hydrochloric acid.

Gerbor's Acido-butyromotric Mothod.-This is essentially the Inffmann-Beam mothod, the chemical principles of which have been adopted. The use of hydrochloric acid as a solvent 
for the amyl alcohol has been, however, discarded, following Paterson.

Gerber employs a test bottle, which he terms an "acidobutyrometer," which differs from that employed by Leffmann and Beam; it is a modified form of Marchand's lacto-buty rometer and, like this, is closed with a cork.

A definite strength of sulphuric acid is prescribed (90 to 91 per cent.), and rules for testing the acid and amyl alcohol used are laid down.

Gerber has shown considerable ingenuity in adapting the method of Marchand to that of Leffmann and Beam, and the method is reliable.

The acido-butyrometers are usually whirled in Gaertner and Hugershoff's machine or in that of Lister, which are practically identical, but no reason exists, except trade interests, for not employing any other form of machine.

The following comparative statement will show the differences of detail between this and the Leffmann-Beam method:-

\section{LEFFMAN-BEAM.}

1. Test bottles are flasked-shaped.

2. 96 per cent. sulphuric acid is used.

3. A mixture of amyl alcohol and hydrochloric acid employed.

4. Fat read off cold.

5. Bottles are used open.
Gerber.

Test bottles are butyrometer-shaped. 90 to 91 per cent. sulphuric acid is used.

Amyl alcohol alone employed.

Fat read off at $60^{\circ}$ to $70^{\circ} \mathrm{C}$.

Bottles are stoppered.

There is no practical advantage in either method. The original Leffmann-Beam is somewhat more rapid, while the Gerber modification requires rather less skill. Both are equally accurate.

I. The Tester with Catgut Action for Four and Eight Samples (Gaertner and Hugershoff's Patent). Description.A steel spindle, running in two ball bearings, the upper with ten balls and the lower with seven, is supported in a well-stayed frane, which can be fixed to any table by means of a screw clamp. On top of the spindle is a boss, on which two dises with screw threads are fastened, which hold the disc-plate for the reception of four or eight samples. The cover is screwed on to the spindle by means of a loose milled-headed nut and the machine is ready for use. If the machine is destined for frequent use, it will be best to fix it to a strong bench and not to a movable table; to further strengthen it, two screws may be put in through the holes in the frame and the tester will ther not bo transportable (Fig. 11).

The bearings can be adjusted by means of the brass collar in the upper one which is held in place by two screws; this should be so arranged that the spindle runs easily without play, and when this is found to be the case, the screws should be tightened 
to hold the collar in place. The bearings should be oiled with good machine oil, care being taken that the oil which runs down the spindle is wiped off.

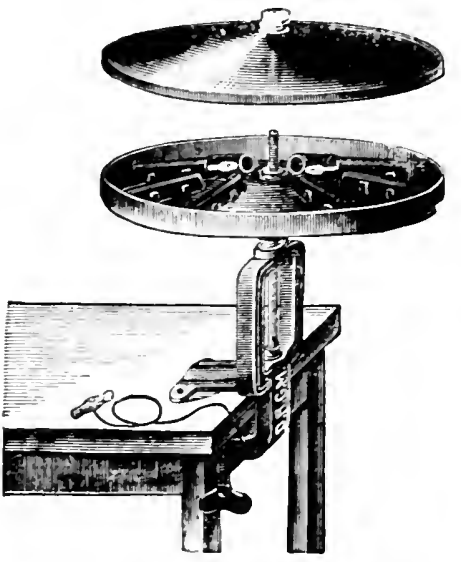

Fig. I1._-Gaertner and Hugershoff's Milk Tester.

To rotate the machine, put the metal end of the catgut into the hole in the spindle, wind the string around, by turning the disc plate backwards till the handle is close to the spindle. Pull the handle with full strength, the whole weight of the body being brought to bear, and as the string unwinds the machine is rotated; when all the string is unwound the end comes out of the hole, and the machine rotates freely. If clean and well oiled it will run for ten minutes.

To stop the machine, take hold of the milled-hearled nut of cover firmly and it will screw itself off; then press the edge of the under disc-plate gently with the finger till it stops. Do not stop it with a jerk.

II. The "Excelsior" Gearing. - This can be fitted to 8- or 24-sample machines. It consists of a hollow cylinder fixed to the frame carrying a hollow double pulley, inside which the spindle can rotate without touching. Round the lower

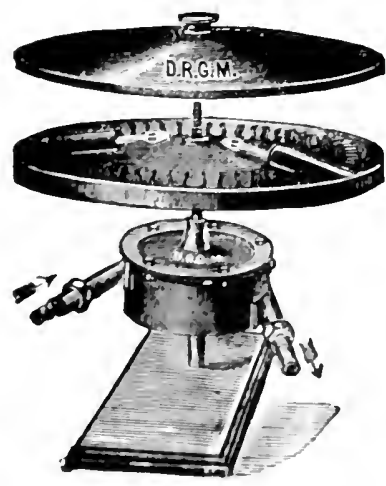

Fig. 12. Milk Tester (steam driven). portion of the pulley is coiled a spring, and in the opposite direction round the upper a strap is wound, which passes through an oppening in the cylinder; on the strap is clamped a stop-plate. which serres a double purpose-(1) to prevent the spring from pulling the strap too far, and (2) to lift the pulley, which is capable of a slight vertical morement, when the strap is wound home. At the bottom of the pulley is a jawl, which, when the stop-plate is pulled out, engrares a ratchet wheel on the spindle and which is lifted with the pulley when the stop-plate is 
home so that the spindle runs freely. The machine is rotated by pulling the handle on the end of the strap rapidly to and fro tifteen to twenty times, when a high velocity is obtained; the strap and stop-plate are then allowed to go home and the machine runs alone. If the speed slackens, it can be increased by a few further pulls. This gearing is only recommended for 24-sample machines.

Large machines are made to run by steam power (Fig. 12).

III. The "Rapid" Gearing.-In this, a loose pulley surrounds the spindle; it runs on a separate bearing and is, when not in use, kept up by a spring. A strap passes round the loose pulley, and when this is pulled (in a slightly downward direction) the pulley is brought downwards; two bevelled teeth engage two similar teeth on the spindle and cause the machine to rotate.

When the strap is pulled back (in a slightly upward direction) the spring forces the pulley up and the machine rotates freely. By pulling the strap rapidly backwards and forwards, a high rate of speed can be obtained.

The 2-bottle machine differs in construction from the others in not having the disc-plates, which are replaced by two arms, carrying cups; these cups are larger than the cups used in the larger machine and have a cover; the test bottles fit completely into them and are surrounded by warm water.

The machine is fitted with the "Rapid" gearing and has plain bearings; this causes continual driving to be necessary. The machine cannot be left to run alone.

None of the methods of driving the Gaertner-Hugershoff machine are satisfactory. The catgut requires a strong pull and is liable to soon wear out, if the metal end comes off; if it is required to rotate a second time, the machine must be stopped.

The "Excelsior" gearing has a weak point in the spring, which breaks and is difficult to repair ; the strap also sometimes breaks, and cannot be replaced without some trouble.

The "Rapid" gearing makes an unpleasant noise, and a great deal of the power employed to drive the machine is wasted in friction.

It is far better to discard the methods of driving sold with the machine and to employ a yard of blind cord (of the best quality), one end of which is fixed into a wooden handle. This is givell one or two complete turns round the spindle; the handle is held in the right hand and the loose end in the left. The cord is pulled with the right hand, just sufficient tension being kept on the end with the left to make it bite. At the end of the stroke, the left hand is brought up near the machine to loosen the cord round the spindle, otherwise there is danger of the cord winding up. 
The cord is now pulled back with the left hand keeping it quite loose-i.e., letting the right hand go back quite freely. 'The pulling with the right land is repeated, and continued till the speed is high enough.

It is advisable to stop up the hole in the spindle, as it causes the cord to wear. Should the cord wear out and break, it can easily be replaced at an infinitesimal cost. This method of driving was worked out in the author's laboratory by Boseley and Rosier.

The Lister Machine.-This has practically the same form as the Gaertner-Hugershoff machine, but cloes not include the "Excelsior" or "Rapid" gearings, which are covered by patents.

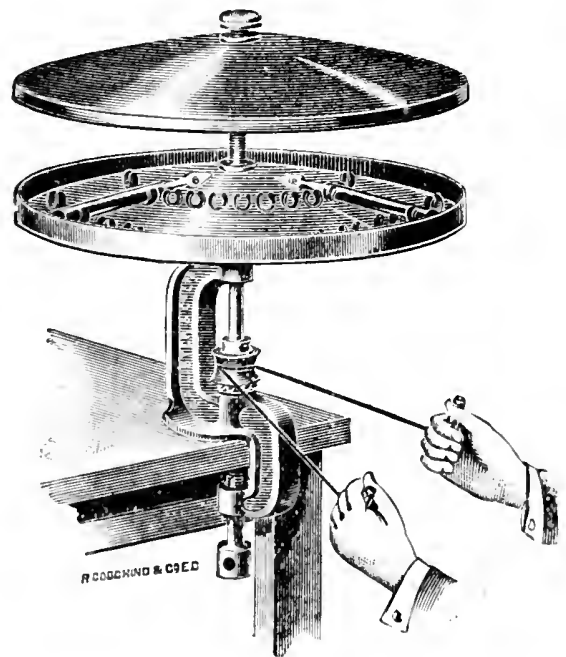

Fig. 13.- The Lister Machine. The frame is of different construction and is S-sluaped. Round the spindle a small brass pulley is fixed * (in the 24-bottle machine a ratchet is added), and it is driven by a string wound round this by Boseley and Rosier's method, which, however, was independently applied by Lister (Fig. 13).

It has the following advantages over the Gaertner - Hugershoff machine :-

(1) Lower frame and, therefore, less vibration.

(2) Better metal used for bearings; therefore lasts longer.

(3) Is easier to drive.

The 2-bottle machine has the arms hinged, and clanped in place by a screw, instead of having throu in one piece; it is more easily portahle.

Apparatus, \&c.-l. 'The acido-butyrometer is a grass ressel closed by an india-rubber cork, and with a graduated neck divifled into ninety divisions; one division $=0 \cdot 1$ per cent. fat. Every tenth division is longer than the others, and the intermerliate fifth divisions are also slightly lengthened to facilitate realing.

"In practice it is better to take off this mulley, stop up the bole, and drive on the spindle direre. The machines have also been marle without the pulley. 
2. The acido-hutyrometer for cheese, \&c., is open at both ends, and the lower cork carries a small glass cup.

3 . The author's butyrometer stand consists of a metal plate pierced with 4,8 , or 24 holes, and an india-rubber plate with 4, 8 , or 24 corresponding holes so cut that the butyrometers are slid easily in and out and yet are retained when inserted.

4. 11 c.c. pipettes for milk with, or without, automatic measurement.

$4 a .3$ c.c. pipettes for cream.

5. 1 c.c. pipette for amyl alcohol.

6. A water pipette, 10 c.c. in $\frac{1}{10}$ c.c.

$6 a$. A water pipette for cream, delivering $8 \cdot 2$ c.c.

7. 10 c.c. bulb pipette for acid. The bulbs prevent the acid. from being drawn into the mouth.

s. Automatic measuring apparatus, or burettes, as an alternative means of measurement.

Chemicals.-Commercial sulphuric acid, specific gravity of 1.820 to 1.825 at $15^{\circ}$ C. $\left(59^{\circ} \mathrm{F}\right.$.) (contains 90 to 91 per cent. $\left.\mathrm{H}_{2} \mathrm{SO}_{4}\right)$. The specific gravity may be taken with a hydrometer. Should the temperature not be exactly $15^{\circ} \mathrm{C} .\left(59^{\circ} \mathrm{F}\right.$.) the specific gravity may be corrected by adding on 001 for each degree Centigrade (or 00055 for each degree Fah:enheit above $59^{\circ}$ ) above $15^{\circ}$, and by subtracting 001 for each degree below $15^{\circ}$ : thus, if the temperature be $20^{\circ}$ and the specific gravity $1 \cdot 818$, the corrected specific gravity will be $1.818+5 \times \cdot 001=1.823$; and if the temperature be $11^{\circ}$ and the specific gravity 1.827 , the corrected specific gravity will be $1.827-4 \times .001=1.823$.

Pure amyl alcohol--specific gravity, 815 to .818 at $15^{\circ}\left(59^{\circ} \mathrm{F}\right.$.); boiling point, $124^{\circ}$ to $130^{\circ} \mathrm{C}$. - should polarise in a $200 \mathrm{~mm}$. tube from $1.5^{\circ}$ to $2 \cdot 7^{\circ}$ to the left-should give a clear solution with an equal volume of strong hydrochloric acid; and this solution should not become darker than a pale brown after twenty-four hours.

It is advisable to have a bottle of ammonia handy in case acid is spilt on the clothes; should this happen an application of a few drops of ammonia at once will prevent damage.

If strong acid is spilt on the skin, wash copiously with cold water without delay and the white swellings formed will soon disappear.

\section{Mode of Operation.}

Milk, Skim Milk, Whey and Buttermilk.-Place a sufficient number of acido-butyrometers in the stand, open end upwards, and run 10 c.c. of acid into each. Well mix the samples to be tested and measure with the milk pipette, 11 c.c. of each into the bottles; add 1 c.c. of amyl alcohol.

Measuring liquids by means of pipettes is done as follows :Hold the pipette near its upper end between the thumb and 
the middle finger of the right hand, insert the lower tapering end into the liquid, and fill it by exhausting the air with the mouth, then remove the lips and quickly close the upper end by means of the tirst finger. The pipette is then removed from the liquid, and by raising the first finger slightly, so much of the contents are allowed to escape, drop by drop, until the lowest point of the curve forming the surface of the liquid coincides with the mark on the upper part of the instrument. The contents are then discharged, the pipette being allowed to run out.

Insert the corks, slightly damping them at the ends if necessary; place the hand over the corks and shake with an up and down motion until the curd is dissolved; invert the stand to allow the acil in the lower bulb to mix with the rest, and thoroughly mix the contents by inverting three

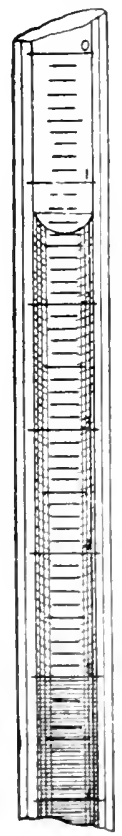

Fig. 14.

Neck of bintle. or four times. Take the bottles out of the stand one by one and allow the contents to run into the larger portion, push up the cork, if necessary, so that the graduated neck is full, and place the bottles in the cups of the machine, screw on the cover and spin it for two or three minutes. Place a Bunsen burner, with a flame just high enough to touch the bottom of the disc-plate, underneath to prevent cooling. If the fat is not in a clear limpid layer in the neck, or if the upper portion is frothy, the rotation has not been sufficient and must be repeated. After taking out the bottles, Gerber directs that they be placed in the water-bath for about a minute, which must be kept at a temperature of from $60^{\circ}$ to $70^{\circ} \mathrm{C}$. ; they are then ready for reading. The waterbath may, without sacrificing accuracy, be dispensed with. It is an adrantage to use a flame, as the corks have a tendency to come out in the bath, thereby spoiling the estimation.

Reading the Fatty Layer.-Hold the butyroneter up to the light, and by slight pressure on the cork adjust the bottom layer to one of the larger lines on the scale; count up the number of divisions between this and the lowest curved line at the top; each of the larger divisions is equal to 1 per cent. of fat, and the smaller $\frac{1}{10}$ per cent. of fat ; every fifth smaller division is also made somewhat longer to facilitate reading. In the illustration the pereentage of fat shown is $3 \cdot 6$; observe that the lower layer is coincident with one of the longer lines, and that the lower curved line at the top is thirty-six smaller divisions above that (lig. 1.1). 
All pipettes are graduated to run out; therefore the liquids must not be blown ont.

Separated milks require to be whirled for a somewhat longer time and at the highest attainable speed, and 05 per cent. must be added to the reading.

Condensed milks, both sweetened and unsweetened, may be tested by weighing about 20 to 25 grammes, making up to 100 c.c., and treating as a milk; a higher speed or longer whirling is, however, necessary to get up all the fat. The percentage of fat found must be multiplied by 100 and divided by the weight taken.

Cream.-Cream containing not more than 32 per cent. of fat can be measured with great accuracy. In the case of thin cream-i.e., one with not more than 32 per cent. of fatafter the acid has been added, add 8.2 c.c. water, measure the cream with a 3 c.c. pipette, filling it up accurately to the mark while in a vertical position, turn the pipette in a nearly horizontal position, and wipe the stem perfectly dry; hold it over the bottle in a vertical position and, removing the finger from the top, let the cream run out freely; after the quick succession of drops has run out, allow three more drops to enter the bottle; add 1 c.c. of amyl alcohol, and then proceed as in analysing milk.

Calculate the results from Table XLII., column?.

TABLE XLII.-For Calculating Fat in Cream.

\begin{tabular}{|c|c|c|c|c|c|}
\hline Degrees. & Undiluted. & Diluted. & Degrees. & Undiluted. & Diluted. \\
\hline $8 \cdot 5$ & $33 \cdot 2$ & $66 \cdot 2$ & $6 \cdot 7$ & $25 \cdot 9$ & $51 \cdot 6$ \\
\hline $8 \cdot 4$ & $32 \cdot 8$ & $65 \cdot 4$ & $6 \cdot 6$ & $25 \cdot 5$ & $50 \cdot 8$ \\
\hline $8 \cdot 3$ & $32 \cdot 4$ & $64 \cdot 6$ & 6.5 & $25 \cdot 1$ & 50.0 \\
\hline $8 \cdot 2$ & $32 \cdot 0$ & $63 \cdot 8$ & $6 \cdot 4$ & $24 \cdot 7$ & $49 \cdot 2$ \\
\hline $8 \cdot 1$ & $31 \cdot 6$ & 629 & $6 \cdot 3$ & $24 \cdot 3$ & $48 \cdot 4$ \\
\hline $8 \cdot 0$ & $31 \cdot 2$ & $62 \cdot 1$ & $6 \cdot 2$ & $23 \cdot 9$ & $47 \cdot 6$ \\
\hline $7 \cdot 9$ & $30 \cdot 7$ & $61 \cdot 3$ & $6 \cdot 1$ & 235 & $46 \cdot 8$ \\
\hline 7.8 & $30 \cdot 3$ & $60 \cdot 5$ & $6 \cdot 0$ & $23 \cdot 1$ & $46 \cdot 1$ \\
\hline $7 \cdot 7$ & $29 \cdot 9$ & $59 \cdot 7$ & $5 \cdot 9$ & $22 \%$ & $45 \cdot 3$ \\
\hline 7.6 & 29.5 & 58.9 & $5 \cdot 8$ & $22 \cdot 3$ & $44 \cdot 5$ \\
\hline $7 \cdot 5$ & $29 \cdot 1$ & $58 \cdot 1$ & $5 \cdot 7$ & $21 \cdot 9$ & 43.7 \\
\hline $7 \cdot 4$ & $=28 \cdot 8$ & $57 \cdot 3$ & $5 \cdot 6$ & 215 & $+2 \cdot 9$ \\
\hline $7 \cdot 3$ & $25 \cdot 3$ & $56 \cdot 4$ & $5 \cdot 5$ & $21 \cdot 1$ & $42 \cdot 1$ \\
\hline $7 \cdot 2$ & $27 \cdot 9$ & $55 \cdot 6$ & $5 \cdot 4$ & $20 \cdot 7$ & $41 \cdot 3$ \\
\hline $7 \cdot 1$ & 27.5 & $54 \cdot 8$ & $5 \cdot 3$ & $20 \cdot 3$ & $40 \%$ \\
\hline $7 \cdot 0$ & $27 \cdot 1$ & $54 \cdot 0$ & $5 \cdot 2$ & $19 \cdot 9$ & $39 \%$ \\
\hline $6 \cdot 9$ & $26 \cdot 7$ & $53 \cdot 2$ & $5 \cdot 1$ & $19 \%$ & $38 \cdot 9$ \\
\hline $6 \cdot 8$ & $26 \cdot 3$ & $52 \cdot 4$ & $5 \cdot 0$ & $19 \cdot 1$ & $38 \cdot 1$ \\
\hline
\end{tabular}

The cream should be as near $15.5^{\circ} \mathrm{C} .\left(60^{\circ} \mathrm{F}\right.$.) as possille, but the error due to temperature is very small and is less than the errors of reading, \&c. 
The pipette does not deliver the same weight of a cream with 20 per cent. of fat as of one with 30 per cent. of fat; this has been allowed for in the table.

Creams containing more than 32 per cent. of fat must be diluted. Take two beakers or tin pots and counterbalance them on a rough balance turning to 01 gramme, pour about 25 grammes of cream into one and add separates milk to the other till the weights are equal, mix the cream and separated milk and measure as before. Use column 3 for calculating the results.

It has been assumed in column 3 that the separated milk contains $\cdot 2$ per cent. of $f a t$; if no separated milk is at hand use milk with a known percentage of fat for diluting the cream: in this case subtract the amount of fat in the milk from column 3 and auld $\cdot 2$.

Somer Milk.-Well mix the sample by whisking for a few minutes with a brush made of fine wires; pour about 15 grammes into a small beaker and weigh; transfer from 10 to 11 grammes to the bottle and weigh again to get the weight added; add water to make up $11 \cdot 2 \cdot 2$ grammes. Proceed as before.

$$
\text { Calculate: Fat in sour milk }=\text { reading } \times \frac{11 \cdot 2 \cdot 2}{\text { wt. taken. }}
$$

An alternative method is to add to each 100 grammes 5 c.c. of strong ammonia and treat as a milk; increase the result by one-twentieth.

Clotted Cream, Butter, Cheese, \&c.-Well mix the sample (in the case of butter it is advisable to melt it in a closed ressel at about $40^{\circ} \mathrm{C}$. $\left(104^{\circ} \mathrm{F}\right.$.) and to shake violently till solid). Piace a few grammes in a sinall basin with a glass rod and weigh. After adding acid, transfer, with the rod, from 1 to 2 grammes (according to percentage of fat, 1 for butter, I 5) for elotted cream, and 2 for cheese); add water to make up to $11 \cdot 2 \cdot 2$ grammes and 1 c.c. of anyl alcohol, and proceed as before. Calculate as for sour milk.

To Clean the Bottles.-After reading, place the bottles in the stand, cork upwards; take out the corks and wash them several times with hot water. Do not use soda. Empty the bottles into a suitable vessel and fill them with hot water ; empty this out completely and repeat twice; if not quite clean l'm a brush down them and wish again. Invert the stand and let the bottles drain. Dry the corks after use. Never leave pipettes dirty.

Keep the stopper in the sulphuric acid bottle when not in nse. Cierber recommends a butyrometer with two openings for solid products; the lower cork carries a little glass cup of l e.c. capicity, and the product to be testerl is weighed into this. The author has not fouml this alvantageous. 
Cream and Clotted Cream. - Well mix from 50 to 100 grammes of the sample to be tested, fill the cup with this, dry the outsicle and weigh. Place the cork carrying the cup in the butyrometer, add 6 e.c. of clear hot water through the upper opening, then 1 c.c. of amyl alcohol and 6.5 c.c. of acid, and shake well; adil 6 c.c. more hot water, shake again and whirl in the machine. Read after one minute's standing in the water-bath.

Butter.--Meit about 10 to 20 grammes in a small closed bottle at $40^{\circ} \mathrm{C} .\left(104^{\circ} \mathrm{F}\right.$.) and shake violently till solid; fill the cup, and weigh. Add 12 c.c. of cold water, and 1 c.c. of amyl alcohol and 6.5 c.c. of acid. Shake well and proceed as before.

Cheese.-Mix 10 to 20 grammes in a mortar till of even consistency. Fill the eup and weigh; transfer the bulk of the cheese from the cup to the butyrometer, by inserting the cork and shaking gently; add 6 c.c. of hot water and 6.5 c.c. of acid and shake till the cheese is dissolved. Now add 7 c.c. of hot water and 5 drops of amyl alcohol (from the pipette), shake well and whirl in the machine. Stop the machine after about two to three minutes, take out the butyrometer, add a further 1 c.c. of amyl alcohol, and place for a minute in the water-bath at $60^{\circ}$ to $70^{\circ}$ (say $150^{\circ}$ to $160^{\circ} \mathrm{F}$.) ; whirl again and read after a minute's standing in the water-bath.

For Skim Cheeses whirl three times and add 8 c.c. of hot water instead of 7 c.c.

Calculation of Results. - The percentage of fat in the sample is found by dividing the number of degrees read off on the sten of the butyrometer by the weight taken, thus

Butter wt. 76 gramme. Reading $62^{\circ}$ Fat $=\frac{62}{76}=81 \cdot 6$ per cent.

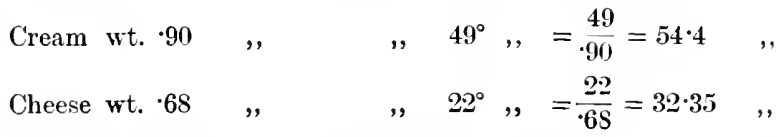

Water Estimation in Butter, Margarine, \&.c.-A special form of butyrometer is used for this; it consists of an elongated bulb 5 c.c. in capacity, connected by a graduated tube with a vessel in which a cork carrying a cup of 3 c.c. capacity is inserted. The only reagent necessary is diluted sulphuric acid, made by diluting commercial sulphuric acid (sp. gr. 1.820 to 1.825) with an equal bulk of water; before use this should be cooled to the ordinary temperature, and decanted from any deposit of lead sulphate.

Five c.c. of diluted sulphuric acid are measured into the butyrometer, which is placed open in the machine, and whirled for about two minutes, in order to bring all the liquid into the bulb; the level of the acid (at as near $60^{\circ} \mathrm{F} .\left(15.5^{\circ} \mathrm{C}\right.$.) as possible) is read off on the graduated scale. About $2 \frac{1}{2}$ to 3 grammes of 
butter are weighed into the cup, and after the cork has been inserted, the butyrometer is stood in the water-bath at $60^{\circ}$ to $70^{\circ} \mathrm{C}$. ( $\mathrm{say} 150^{\circ}$ to $160^{\circ} \mathrm{F}$.) to melt the butter; when this has been accomplished, the whole is well shaken till the contents form a uniform emulsion; after standing for a minute in the water-bath, the butyrometer is placed in the machine, and whirled three times, warming in the water-bath for about two minutes between each; after the third whiring, it is cooled to as near $60^{\circ} \mathrm{F}$, as possible, and the level of the aqueous liquid where it joins the fatty layer is read off. The difference between this reading and the level of the acid will give the percentage of water if exactly 3 grammes of bntter have been taken; should any other weight have heen taken it is necessary to multiply the result by 3 and divide by the weight taken; thus, in an experiment $2 \cdot 7<0$ grammes of butter were taken, the level of the acid was $2 \cdot 5^{\circ}$ and the level of the aqueous liquid $14.5^{\circ}$; the percentage of water indicated is, therefore,

$$
\frac{(1+.5-2 \cdot 5) \times 3}{2 \cdot 780}=\frac{12 \times 3}{2 \cdot 780}=12 \cdot 91 \text { per cent. water. }
$$

For the convenience of weighing out the cream, butter, \&c., in the cups, a balance of the steel-yard type can be obtained with the machine; it consists of a beam, with suitable supports, one end of which is longer than the other; from the shorter end, which also carries a pointer, a small wire cradle to support the cup is hung; the longer end is livided into 10 equal parts, each being indicated by a notch numbered 1 to 10 ; at the end of this is at fine screw earrying a counterpoise, which can be moved backwards or forwards by screwing round.

The weighing is accomplished by placing the cup in the cradle, and screwing the counterpoise back wards or forwards, as required, till the pointer is at zero in the middle of the scale; the cup is now removed and filled with the product to be tested, and the riders are put on the various notches in the beam in succession till equilibrium is restored. The largest rider indicates grammes, the medium tenths of a gramme, and the smallest hundredths of a granme.

Thus if the largest rider is in notch 2 , the medium 7 , and the smalle st 8 , the wright is $2 \cdot 780$.

If it be found that to restore equilibrium it is necessary to place the smallest rider intrmediate between two notehes, say between 2 and 3 , the reading is taken as 025 .

If it be found that two riders must be placed on the same moteh to restore equilibrium, the smaller should be hung from the upturned end of the larger.

The use of this balance, though convenient when many samples are being tested, is not necessary, as the weighings may be made, but slightly less expenitiously, with an ordinary balance. 
Stokes' Modification.-Stokes employs a modification of the acido-butyrometer; it is open at both ends, one being provided with an indiarubber washer kept in place by a screw cap, while the other can be closed with a cork. It is placed screw cap downwards : up to the zero mark of the graduations, the tube holds 1.5 c.c., and the neck is graduated to read percentages of fat; the upper portion consists of two bulbs; from the zero mark of the graduations up to a mark between the two bulbs the bottle holds 13.5 c.c., while from this mark to a mark above the second bulb the capacity is 15 c.c.

It may be used without a centrifugal machine as follows :1.5 c.c. of amyl alcohol are poured in to the zero mark, or, better, measured by means of a. pipette provided with a rubber teat of about 1.5 c.c. capacity; sulphuric acid is carefully poured in to the mark between the bulbs, and then the milk to be tested is poured in to the upper mark. An

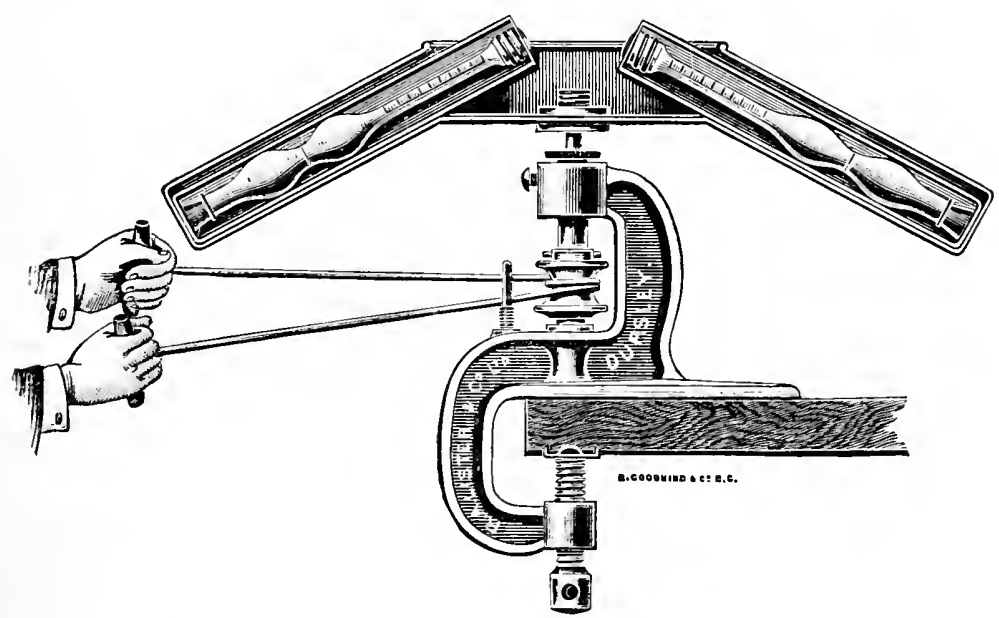

Fig. 15.-Lister-Stokes machine.

indiarubber cork is put into the upper opening, and the contents of the butyrometer well mixed by shaking and inversion. The tube is now stood, cork downwards, in hot water, the screw cap loosened, and left for an hour; the fat will have collected in a layer in the graduated neck, and can be read off in the same manner as previously described.

3This forms an extremely cheap method of estimating fat in milk, with an accuracy quite sufficient for most purposes, and can be recommended where only one or two samples per day are to be tested.

The apparatus can be used also for the more exact estimation 
of fat by measuring the milk. acid, and amyl alcohol by means of pipettes, or automatic measuring alparatus, and whirling in a centrifugal machine.

The Lister-Stokes machine is made to take these bottles; it differs ehiefly from the Lister-Gerber in the form of the disc. Insteal of having a lid, the dise is made double and open in the centre, the butyrometers being slid in to cardboard tubes in pockets, which are symmetrically arringed, radiating from the centre. This form of machine has the advantage of having the pockets comparatively large, and can be used for other purposes. The whole of the dise can be conveniently filled with hot water should it be desirable to prevent cooling during centrifugal separation.

Soxhlet's Areometric Process.-The following directions are due to Vieth :-

The apparatus (Fig. 16) consists of a stand, fitted with brackets for holding three pipettes, and a jacketed tube, in which a hydrometer-areometer-and thermometer combined is placed; a bottle of strong white glass fitted with a cork, and two glass tubes bent at right angles, a blower, and a piece of india-rubber piping, with a pinch-cock, also form part of the apparatus. The chemicals used in the process are pure washed ether and a solution of potassinm hydroxide of specitic gravity $1 \cdot 26$ to $1 \cdot 2 \bar{T}$, prepared by dissolving 400 grammes of fused caustic potash in one-half litre of water, the solution after cooling being made up, with water to one litre. The milk to be tested, as well as the ether and potash solution used for the examination, should be of a temperature of $61.5^{\circ}$ to $65.5^{\circ} \mathrm{F}$. $\left(16.5^{\circ}\right.$ to $18.5^{\circ} \mathrm{C}$.).

The examination is carried out as follows:-200 e.c. of milk are measured by means of the largest pipette, and run into the bottle; 10 c.c. of potash solution are added and mixed with the milk; 60 c.c. of ether are next added, the bottle closed with a cork or india-rubber stopper, and riolently shaken for half-aminute. The bottle is then placed in a ressel containing water at $63.5^{\circ} \mathrm{F} .\left(=17 \cdot 5^{\circ} \mathrm{C}.\right)$, and for a quarter of an hour very gently shak'n every half-minute. After that time it is left to rest standing in an upright, or, better, lying in all oblique, position in the water, until a clear layer has collected on th" top, consisting of a solution of fat in ether. $U_{j}$ to this time the bottle has been kept tightly corked, but now the stopper is removed and ruplaced be the cork fitted with the two bent tubes. 'T'o the shorter one of these tubes the howing apparatus is attached, while the longer one, which should reach down to the lower part of the cthereal solution, is connected by means of the indiarubber pipe learing the pinch-cock with the lower and of the jackreded tuhe. The jacket is next filled with water at $62.5^{\circ}$ to $645^{\circ} \mathrm{F} .\left(17^{\circ}\right.$ to $18^{\circ}(\mathrm{C})$, the cork of the inner tube loosened, the pinch-cock openol, and, by rery gently pressing the blowing apparatus, so much of the ithereal solution forced up into the 
SOXHLET'S AREOMETRIC PROCESS.

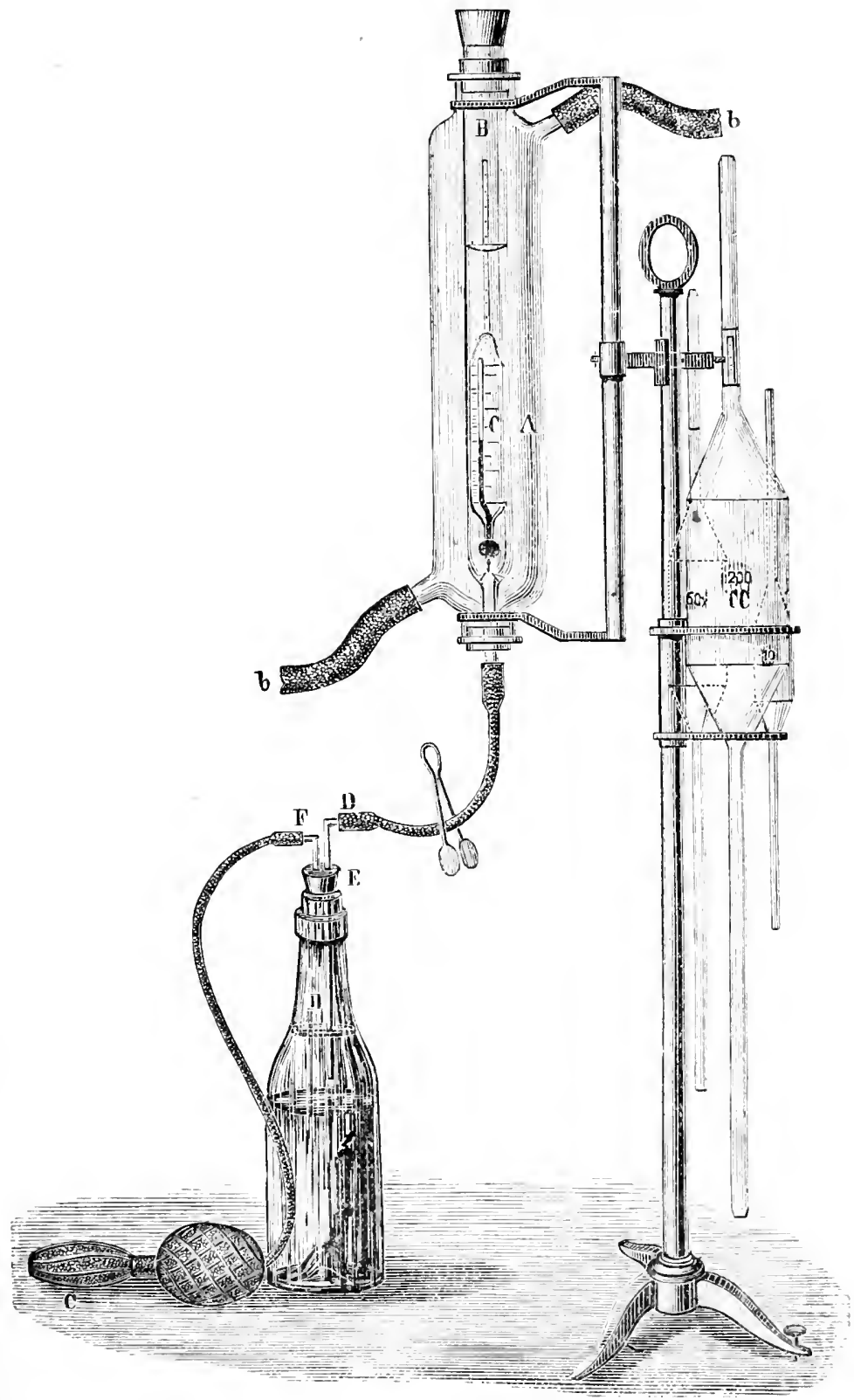

Fig. 16.-Soxhlet's Apparatus for Examination of Milk. 
jacketed tube as is required to float the areometer. The pinchcock is then closed again, the jacketed tube corked up rather firmly, in order to prevent the evaporation of ether, and the apparatus left to itself for two minutes, after which time the specitic gravity and temperature of the ethereal solution, as indicated by the areometer and enclosed thermometer, are read off and noted down, that degree of specific gravity being taken which eoincides with the lowest point of the eurved line forming the surface of the liquid. This done, the ethereal solution is run back into the bottle, the jacketed tube rinsed with a small quantity of pure ether, a washing bottle serving this purpose best, and dried by forcing a current of air through it hy means of the blowing apparatus. The apparatus is then ready for the examination of another sample.

Should the temperature of the ethereal solution be found to be exactly $63 \cdot 5^{\circ} \mathrm{F}$. $\left(17 \cdot 5^{\circ} \mathrm{C}.\right)$, the indicated specific gravity requires no correction; if, however, the temperature be higher or lower, the specific gravity must be corrected by simply adding to the indications of the areometer one degree of specific gravity for each degree of the thermometer above $17.5^{\circ} \mathrm{C}$, or subtracting one degree for each dearee below $17.5^{\circ}$. If, for instance, the specific gravity is found to be $47.6^{\circ}$ at $18.4^{\circ} \mathrm{C}$., the corrected specitic gravity is $48.5^{\circ}$, or if founr to be $58.9^{\circ}$ at $16.8^{\circ} \mathrm{C}$, the corrected specifie gravity is $58 \cdot 2^{\circ}$. The corrected specific gravity thus ascertained is then looked for in Table LXXIX, which shows the corresponding pereentage of fat.

It must here be remarked that the areometer, as well as the table, do not give the complete figures for the specific gravity of the cthereal solution, the first decimal place being onitted. Thus, the figure 43 appears instead of 7430 specifie gravity, and the firurts $65 \cdot 9$ instrad of $\cdot 7659$.

In the majority of cases, a sufficient quantity of the ethereal layer collects within a quarter of an hour, but sometimes rather more time should be allowed, and, in exceptional cases, one or two hours, or even longer, when the mixture acquires a yellowish or brownish tint, which, however, does not in the least interfere with the results. The rising of the ethereal solution is often accelerited by gfiving to the contents of the bottle a gentle circular motion. In such rare cases, in which the ethereal layer does not make its appearance within one hour, it is advisable to take another sumple of the milk which is being examined and shake it in the hottle hy itself, mutil the fat hegins to separate from the body of the milk in the form of small grains of butter, the examination to $\mathrm{i}_{\text {e }}$ then proceded with in the ordinary way.

If skim milk, containing less than 2 per eent. of fat has to be dealt with, the method has to he slightly molified by the addition of a small quantity of a sonj solution to the milk. This solution is prepared as follows:- Take 15 grammes stearic 
acid (genuine stearine candle), and put them in a suitable ressel containing 25 c.c. of alcohol and 10 c.c. of potassium hydroxide solution of specific gravity $1 \cdot 27^{\circ}-$ i.e., as used for the test. Keep, on a hot water-bath until a clear solution is effected, and make up with water to 100 c.c. When cold, some soap will separate from the solution, but will re-dissolve if the liquid is heated to $86^{\circ} \mathrm{F} .\left(30^{\circ} \mathrm{C}.\right)$.

Of this soap solution 0.4 to 0.5 c.c. $(=20$ to 25 drops) is mixed with the $200 \mathrm{c}$ c. of milk taken for examination, and otherwise the process carried out exactly as described above. In such cases, in which the ethereal fat solution takes an exceptionally long time to separate, the process may be repeated, with the extra addition of a small pinch of powclered sulphate of potash to the milk.

A special areometer, furnished with the apparatus, should be used for poor milks, but the readings are to be taken and the corrections to be made exactly in the same way as when richer milks are being tested.

\section{The Control of Milk during Delivery to Customers.}

A very important part of the work of the dairy chemist is the control of the men employed in delivering milk. It is evident that a man on a milk round, being under no supervision for a greater part of the time, has ample opportunities, should he be so disposed, to adulterate or "lengthen" the milk of which he has temporary charge. He may also, with the best intentions possible, unwittingly deteriorate the quality of the milk by allowing the cream to rise on the milk, and serving some customers with the richer portion, thereby leave a poorer quality for otliers. For the purpose of this control it is necessary to take three series of samples.

(1) Samples representative of the mixed bulk of milk that is placed in charge of the man.

(2) Samples taken in the streets in the course of delivery.

(3) Samples of the small quantities of milk returned.

The first and third samples should be taken by a foreman or other responsible person, preferably in the presence of the man ; the foreman should be responsible for their conveyance to the laboratory.

The second series should be taken by an intelligent and responsible person, who should receive instructions to take samples at irregular intervals, and to avoid any semblance of rotation, in order that the man shall not be able to form an idea when he may expect a visit. He may be, with adrantage, mounted on a bicycle if the area of delivery is large.

The first and third series may be conveniently taken in sample cans, while the second series may be taken in four-ounce 
bottles, which have been found to hold sufficient milk for analysis, while not being too large to be easily carried. A case holding a dozen bottles should be provided for this purpose.

The testing of these samples may be performed largely with a lactometer; in fact, it is in this work that the usefulness of the lactometer is most appreciated.

The specific gravity of the samples of series (2) and (3) should be carefully compared with those of series (1), which will form a standard by which the other's may be judged. In all cases the specific gravities must he corrected to $60^{\circ} \mathrm{F}$. Three cases may occur:

1. The specific gravity of a sample of series (2) or (3) is equal to the specitic gravity of the corresponding sample of series (1). In by far the greater number of cases this indicates that the composition of the samples is identical. It is possible, however, that the milk may have been skimmed, which would raise the speeific gravity, and then slightly watered, which would bring the specific gravity back to the original degree. It is, however, excessively unlikely that a milk carrier conld perform this feat with such accuracy as would be required, and an experienced olserver would have his suspicions aronsed by the thin appearance of the wilk. It is also patent that a man adulterating milk for the sake of profit, or with malice, would not confine himself to one isolated occasion, but would do so habitually; and only a skilled scientist cruld habitually remove cream from nilk, and reduce its specific gravity to the original degree by watering. For all practical purposes it may be taken that when the specitic gravities agree the milk has not been tampered with.

2. The specific gravity of the simple of series (2) or (3) is higler than the specific gravity of the corresponding samp.e of series (1). This indicates that it contains less cream than the original.

3. The specific gravity of the sample of series (2) or (3) is lower than the specific gravity of the corresponding sample of series (1). This may be the to two causes-either the milk contains more creim than the oriminal, or it has been watered. In some instances both causes may be responsible for the lowness of the sprecific gratrity.

If the second or third ases have oceurred, a further examination of thr milk shomll he proceeded with. Either the fat or total solirls shonlel be estimatrel, and the solids not fat calculated; the corresponding sample of series (1) should be simultaneously examined. It is adrisable that the samples-or a selected "Imuber of them-shonld he examined if it has been found that the specific oravities inree, as it aflords a means of checking the nceuracy of the spectic sravity determinations, and of detecting 
the somewhat hypothetical case of scientific skimming and watering.

A very important rule, which is of great use in the control work of the dairy chemist, may be enunciated as follows :-

The specific gravity of a milk in lactometer desrees added to the percentage of fat will remain constant, whether the cream his been diminished or increased. The sum of the two will be lowered by the aldition of water. For instance, the original milk had a specific gravity of 1.0325 or $32.5^{\circ}$, and contained 4 per cent. of fat. The sum is, therefore, 36.5 .

If a sample of (say) series (2) were found to lave a specific gravity of 1.0315 or $31.5^{\circ}$, and contained 5.0 per cent. of fat, the sum would be still 36.5 .

If the sample, however, contained only 3.8 per cent. of fat, and had a specific gravity of $31.5^{\circ}$, the sum would be only 35.3 ; and it conld then be concluded that the milk had been watered, and that it contained only $3 \overline{6 \cdot 5} \times 100=97$ per cent. of the original milk, or, in other words, 3 per cent. of water h $\iota d$ been adderl.

It has been found th it this rule holds with remarkable accuracy for any percentare of fat between 0 and 10, and it is not very far out with even higher percentages of fat.

If the simple had a specific gravity of 1.0335 or $33.5^{\circ}$, it will be found that the fat amounted to only 3.0 per cent., and the sum would be $36 \cdot 5$.

It must not be expected that the sum of the lactometer degrees and fat will al ways add up to the same identical figure, as there is a liability to error in both determinations; with care, however, the difference due to this cause should not exceed $0 \cdot 5$.

The value of the samples of series (3) lies in the fact that rising of cream is most easily detected by their percentages of fat being considerably different from that in series (1), as the total effect due to this canse is usually marked.

The Solution of Analytical Problems. - A dairy chemist is frequently called upon to solve the most diverse problems with regard to milk and its products. In the following paragraphs a few such problems are given, together with the analytical data from which the solution was deduced. They cover a fairly wide range, and may be taken as fairly representative of the questions a dairy chemist is called upon to elucidate. All are ctual examples.

Problem I.-To determine to what the low specific gravity of the milk is due.

Example a.-The analytical figures were :-

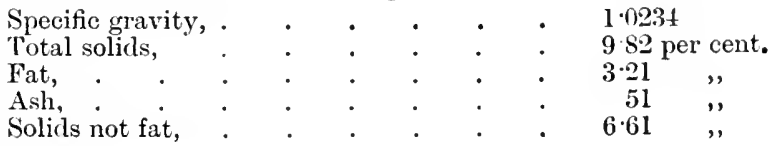


From the extreme lowness of all the figures it was concluded that 26 per cent. of alded water was present.

Example b.-The analytical figures were:-

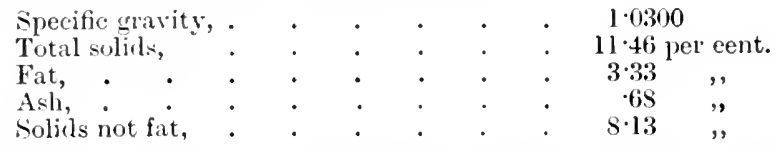

In this case it was concluded from the low solids not fat, and the correspondingly low ash, that a small amount ( 5 per cent.) of added water was present.

Example c.-Two samples of milk taken from two churns arriving at a station from a farm.

The analytical figures were:-

No. 1.

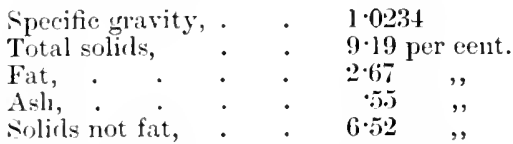

No. 2.

$1 \cdot 0298$

$11 \cdot 61$ per cent.

$3 \cdot 30$,

69,

In this case analyses of milk from the same farm had been made for some time previous, and the solids not fat had not been found to fall below $8 \cdot 6$ per cent. It was concluded that No. 1 contained 24 per cent. and No. 23 per cent. of added water. The conclusion about No. 2 would not have been justified had there not been evidence of the normal composition of this milk.

E.romple d.-The analytical figures were :-

Specific gravity,

'Total solids,

Fat,

Ash,

Solicls not fat,

\section{$1 \cdot 0291$}

$12 \cdot 78$ per cent.

$4 \cdot 36$

$73 \quad "$

$\mathrm{s} \cdot 42$,

Genuine anthenticated samples from the same sonree had been found to contain as little as $\$ .28$ per cent. of solids not fat. It was, therefore, concluded that this sample was genuine, but abmormally poor.

Exrmple e.-The analytical figures were:-

suecifir: erravity, .

lotal solirls,

lint,

Milk-sugar, .

Citsein, $\}$.

Ash,

solicls iost fat
$1 \cdot 0292$

$11 \% 5$ per eent.

$3 \cdot 31$

$3 \cdot+1$

$3 \cdot 54$

:il , ,

Sink , ,

It was concluded from the almormally low proportion of milksugal, and high amount of easein and ash, that this sample was genuine, though of abmormal character. 
Example f:-In this case the composition of the original milk was known.

The analytical figures were:-

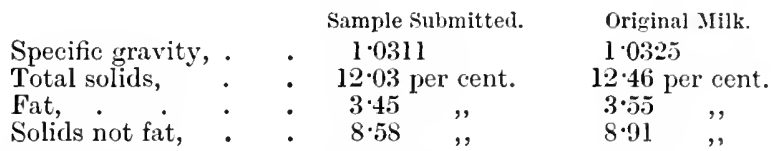

The sample contained 3 per cent. of added water.

Example g. - The analytical figures were :-

Specific gravity, . . . . . . 1.0287

Total solids, . . . . . $16 \cdot 75$ per cent.

Fat, Solids not fat, : : : : : $\quad$. $8 \cdot 10$,",

The low specific gravity was due to an excess of cream; this is shown by the high percentage of fat, and the comparatively high amount of solids not fat.

Example h.-The analytical figures were :-

Specific gravity, . . . . . . 10245

Total solids, . . . . . $16 \cdot 11$ per cent.

Fat,

Ash, $\cdot .450$

Solids not fat, . . . . . . $7 \cdot 90$ ",

This sample contained a large excess of fat, but had also received an addition of 8 per cent. of water, shown by the low solids not fat and small amount of ash.

Problem II.--To determine cause of high specific gravity of milk.

Example a.-The analytical figures were :--

Specific gravity, .

Total solids,

Fat,

Solids not fat,
$1 \cdot 0346$

10.95 per cent.

$1 \cdot 80$,

$9 \cdot 15$,

The low fat shows that this milk has been deprived of a portion (40 per cent.) of its cream.

Example b.-The analytical figures were :-

Specific gravity,
Total solids,
Fat.
Milk-sugar,
Proteids,
Ash,
Solids not fat,

$1 \cdot 0363$

$13 \cdot 86$ per cent.

$3 \cdot 62$

$4 \cdot 58$

$4 \cdot 62$

$\mathrm{S} 2$

$10 \cdot 24$

From the abnormal ratio of proteids to milk-sugar, it was concluded that this milk was genuine and of alnormal compo. sition. 
Example c.-The analytical tigures were :-

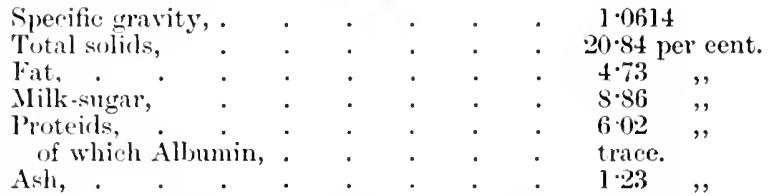

The practical absence of albumin showed that the milk had been boiled; the high figures shown by milk-sugar, proteids, and ash indicated that the milk had been concentrated, and that this was the cause of the high specific gravity.

Problem III.-C'To determine cause of sweet taste of milk.

Eample a.-The analytical figures were:-

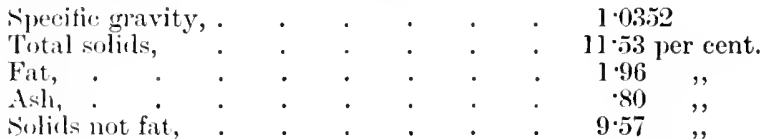

The normal ratio of ash to solids not fat and their excessive amount point to the milk having been concentrated.

Example b. - The analytical figures were :-

Total solids,

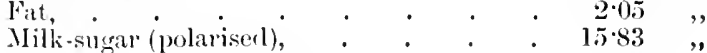

" (gravimetric), . • . $3 \cdot 12$,

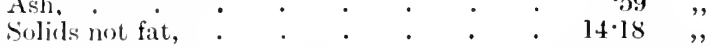

The extreme difference between the polarimetric and gravimetric tigures for milk-sugar points to the presence of added sugar, probably cane sugar in aqueous solution. This sample may pesibly lave been a diluted condensed milk.

Licample c.-The analytical figures were :-

simerific gravity, .

Tistal sorliels.

Fat,

Nilk-slloar,

Proteirls,

Ash,

Solicis not fit

The low aslo and proteids point to the presence of 35 per cent. of alded water; there has also heen an addition of milk-sugar, probably to mask the addition of water.

Problen IV.-Tho determine reason for milk being called "pror."

It is evident that either watering or abstraction of cream would canse the milk to apprar poor ; it is mmecessary to give furthrrexamples of this kind. 
Example a. - The analytical figures were :-

Specific gravity, . . . . . . $1 \cdot 0326$

Total solids, . . . . . . $13 \cdot 45$ per cent.

Fat, . . . . . . . $4 \cdot 30$,

Albumin, * . . . . . .

Ash, . . . . . . . 75 ,

Solids not fat, . . . . . . $915, "$

Cream in six hours, . . . . . 1*3,

This milk was normal in eomposition and contained a good percentage of cream. The low albumin and small imount of cream thrown up in six hours showed that it had been boiled. It was probably the slow rate of rising of cream, due to the milk having been raised to a high temperature, that caused a suspicion of "poorness."

Example b.-The analytical figures were:-

Specific gravity, . . . . . . 1.0325

Total solids,.$\quad$. . . . . $12 \cdot 70$ per cent.

Fat, . . . . . . . 378 ,

Solids not fat, . . . . . . 8.92, ,

Colour, . . . . . . . quite white.

The fat was also seen to be nearly colourless.

The milk was of good quality, but of a very white coloür, probably due to the cows having been fed on artificial food.

The "poorness" was here evidently judged by the colour. The widespread belief that absence of coluur denotes poorness has led to the artificial colouring of milk.

Example c.-The analy tical figures were :-

Specific gravity, . . . . . . 1.0317

Total solids, . . . . . . $14 \cdot 11$ per cent.

Fat, . . . . . . . $5 \cdot 04$,

Ash, . . . . . . . . .

Solids not fat, . . . . . . $9 \cdot 07$ ",

This milk was unusually rich; it is probable that it contained an excess of cream. It was the other portion of the milk (which naturally was deficient in cream) that was poor.

Problem V.- To determine reason of unusual taste and smell.

Example a.-The smell was faint and like stale fish, and the taste soapy and unpleasant.

The following were the analytical tigures:-

Specific gravity, . . . . . . 10364

Total solids, . . . . . . 1156 per cent.

Fat, . . . . . . .0939

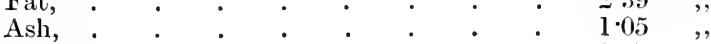

Solids not fat, . . . . . . $9 \cdot 17$,

The milk was alkaline and the ash titrated with phenolphthalein had an alkalinity equal to $\cdot 33$ per cent. of $\mathrm{Na}_{2} \mathrm{CO}_{3}$.

It was concluded that an addition of 3 per cent. of sodium carbonate had been added. 
Example b. - The milk smelt of vinegar and curdled on warming.

The analytical figures were:-

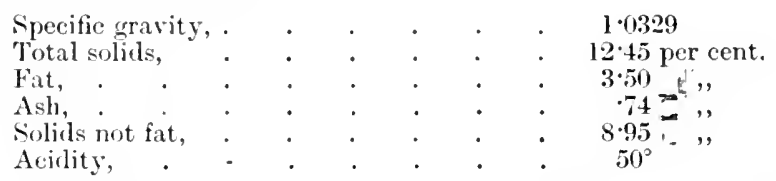

The milk was curdled by phosphoric acid; 60 c.c. of the whey were distilled :-

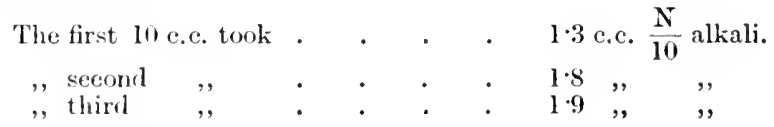

It wis evident that the milk contained an acid somewhat less volatile than water; this corresponds with acetic acid, and the whey distilled as a solution containing 11 per cent. of acetic acid, which is equivalent to 2 per cent. of vinegar.

Example c.-The milk had a faint burnt taste.

It contained 42 per cent. soluble albumin.

On centrifugalising, a deposit was obtained which appeared to consist of proteid matter; it was much browned. It was therefore concluded that the milk had been placed in a vessel, in which burnt milk had previously been kept.

Example d.-The milk tasted burnt.

The following analytical figures demonstrated that the milk had been boiled:-

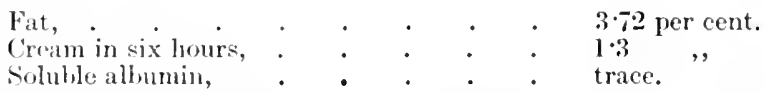

It was concluded that the milk had been burnt in boiling.

Fample e.-The smell and taste were unpleasant, but could not be identified.

The following analytical figures were obtained:-

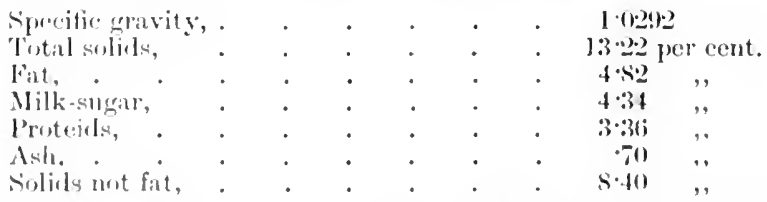

The sediment obtained ly centrifugalising contained much mucus and enlls from the udier.

It was conclurler that the milk was the product of a cow in ill health.

It is crident that if dirty water has heen added to milk, an 
evil smell and taste may occur; no further example nefd be given of this.

Turnips and other substances eaten by the cow or, what is more likely, handled by the milker, may communicate a taste to the milk. The action of certain organisms may have a similar effect. The author is unacquainted with chemical methods of identifying these causes.

Problem VI.-To determine reasons for milk being sour or curdled.

Example a.-The acidity was $17 \cdot 5^{\circ}$, and the cream in clots.

The analytical figures were:-

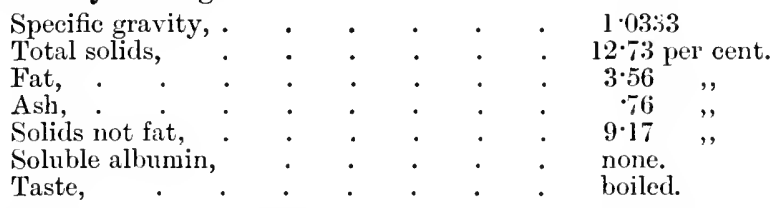

The milk had been boiled and the cream allowed to rise and clot, giving the milk a curdled appearance.

Example b.-The milk was curdled, and the whey was analysed.

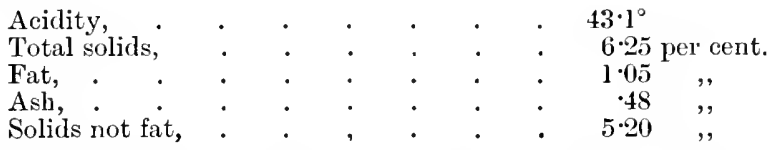

From the low percentage of solids not fat and ash of the whey, it was concluded that about 15 per cent. of water had been added, and there was some probability that this water contained an acid.

Example c.--The milk was curdled and the whey analysed.

The analytical figures were:-

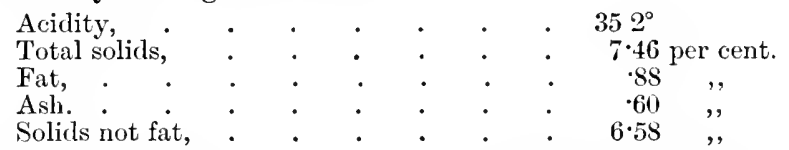

It was concluded from the normal percentage of solids not fat and ash of the whey, that nothing had been added and that the milk had become sour by natural causes.

Example d.-The milk was curdled and the whey analysed. It was slightly bitter and gave the biuret reaction.

The analytical figures were:-

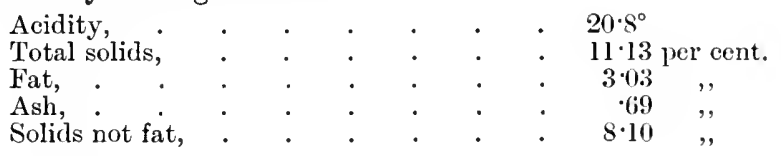


The alkainity of the ash to phenolphthalein was equal to .025 per cent. $\mathrm{Na}_{2} \mathrm{CO}_{3}$.

It was concluded that the milk had been peptonised, and was insufficiently alkaline.

Example e.-.'The milk was cumled and the whey analysed.

The following were the analytical figures:--

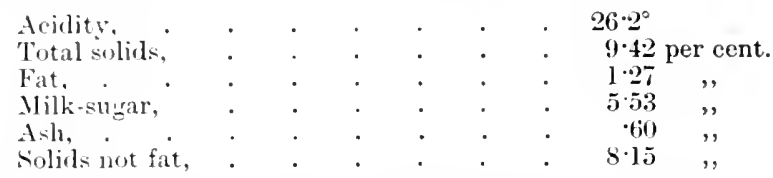

The milk was not bitter, but galve the biuret reaction.

It was concluded from the low acility and the high milksugar that lactic fermentation was not the cause of curdling; from the biuret reaction heing obtainerl, it was concluded that an enzyme was the cause.

Nilk is often alleged to he sour because when used for making milk puddings and custards with eggs, a clear whey runs out. The curdling of the milk is due to the coagulation of the large amount of albumin of the egg on baking. The following is an analysis of a whey from rice pudeling :-

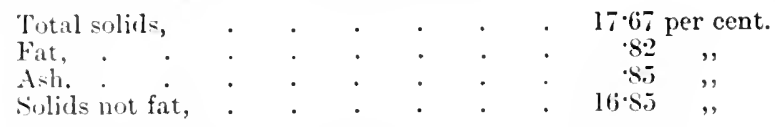

It was very sweet and contained much cane sugar.

Ploblex VII.-To determine the reason for mi!k being thick. Erample a.-The analytical tigures were:-

$$
\begin{aligned}
& \text { specific gravity, . . . . . . } 1 \cdot 0262 \\
& \text { Tiutal solids, }: \quad . \quad . \quad 1792 \text { per cent. } \\
& \text { Fat, } \\
& \text { A his, } \\
& \text { Solitis not fat, }
\end{aligned}
$$

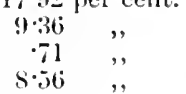

This sample contained an excess of ereim, which made it appear thick.

Limmle b.-The sample gave a blue colour on adding iodine solution. It was thickened with stilreh (or tlour).

Erremple c.- The milk was thick and, on dipping a glass rod inte it and liftine it ont, a stringy miss adhered to it. On putting the rod (which had heen sterilised) inte is bottle containine sterilised milk, the latter acquired the sime property in twenty-four hours. 'l'he milk wiss "ropy."

Probisu VIII. - To determine the nature of sediment.

In cises of this lescription, the mille shoule be placed in tubes and centrifugalised; as mueh milk as possible must be decanted, 
distilled water added, and the tubes again centrifugalised; this procedure should be repeated till the water is clear. The sediment is examined microscopically.

Vegetable cells, if clear and sharply clefined are usually due to the bark of hay and the dust of cake given to the cattle during feeding time. If indistinct and stained yellowish or brownish, these usually indicate cow-dung.

Small hairs, cotton and woollen fibres usually show the presence of household dust.

Crystalline particles usually indicate road dust. In this case a little of the deposit is placed on a slide and warmed with dilute hydrochloric acid, which is evaporated nearly off; a drop of water is added and also a drop of a solution of potassium ferrocyanide. A blue colour, due to iron, is obtained from road dust.

Skim Milk.-The term "skim milk" is applied to milk from which the bulk of the cream has been abstracted. Two ways of abstracting the cream are practised: (1) by allowing the milk to stand, taking advantage of the force of the earth's gravity to separate the cream; (2) by employing centrifugal force to attain the same object.

Distinction between Skimmed and Separated Milk.A distinction has been drawn between skim milk obtained by these two methods; that obtained by setting the milk being called "skimmed milk," and that obtained by centrifugal force "separated milk." The distinction is one of degree, not of kind, as, were it possible to keep milk without chemical change for an indefinite period, the same result would ultimately be obtained by either method.

The following are the characteristics of skimmed and separated milks :-

\section{Skimmed MilK}

Contains the solids not fat of the whole milk, partially changed by the action of micro-organisms.

Contains usually more than 4 per cent. of fat.

Contains a portion of the solid impurities of the milk.
Separated Milk

Contains the solids not fat of the whole milk, practically unchanged.

Contains usually less than 3 per cent. of fat.

Is free from the solid impurities of the milk.

Rising of Fat Globules.-The globules of fat rise through the milk because they are lighter than the milk serum.

If we have globules of fat of radius $r$, the force impelling it to rise will be proportional to the weight of an equal bulk of milk serum less the weight of the globule, or

$$
\phi=x \cdot \frac{4}{3} \pi r^{3} \cdot\left(d_{s}-d_{f}\right) \cdot g,
$$

where $x$ is a constant varying with the units adopted for $r, d_{s}$ and $d_{f}$.

$\pi$ is the ratio of the circumference of a circle to its diameter,

$r$ is the radius of the globule, and

$g$ is the acceleration due to gravitation. 
If the globule is acted on by centrifugal force, the expression $\frac{4 \pi^{2} v^{2} b}{3600}$ must be sulstituted for $g$.

$$
\begin{aligned}
& r=\text { velocity in revolutions per minute, } \\
& b=\text { distance of globule from the centre of revolution. }
\end{aligned}
$$

The glohnle loes not, however, rise freely; at the velocity at which the globules nove the resistance is very nearly proportional to the surface of the globule, which is equal to $4 \pi r^{2}$.

The time taken by a globule to pass through a given layer of milk is therefore inversely proportional to the square root of the culse of the radius.

It is eviclent that as the globules start from rest they must move with an accelerater motion. When a body falls freely, the space passel over in a given time is expressed by the formula $s=\frac{1}{2} a t^{2}$; the motion of small globules in a liquid is not expresserl by this formula as the resistance of the liquirl, which increases as the culde of the speed tends to rednce the velocity; it is crirlent that equilibrium will be after a short time established when the resisting force is equal to the impelling force, and if the latter be constant the motion will be uniform.

It is readily seen that the eyuation

$$
\begin{aligned}
& \frac{s}{t}=r^{*} \cdot\left(l_{s}-d_{j}\right) g \wedge k \text { will holl when the milk is at rest. } \\
& \therefore=\text { space passed over by a globule. } \\
& t=\text { time. } \\
& d_{k}=\text { specific gravity of the milk serum. } \\
& d_{f}=,, \quad, \quad, \text { fat. } \\
& y=\text { acceleration due to gravitation. } \\
& k=\text { coetlicient of viscosity. }
\end{aligned}
$$

If submitted to centrifugal force, it is evident that the speed of a globule cannot le constant, as the centrifugal force tending to move it varies with the distance of the fat globule from the centre of revolution.

If we assume that the resistance is very great (a condition nearly attainer with small globules), the equation for globules submitted to centrifugal force is

$$
\frac{d s}{d l}=r^{\frac{3}{2}} \times\left(l_{8}-l_{f}\right) \times k \times \frac{4 \pi^{2} r^{2} l}{3600} .
$$

The commertion between the space passerl over in the passage through the srparator and the time taken is given ly integrating this equation leet wern linits dronting the proint of entry anl exit from the separator.

The farctor $k$ vispes with the temperature, bering larger the hotter is the milk. In rentrifugal marhines the anse with which the cream cin escape hat also an influne on the fitctor, and this becomes especially important if the thickness of the cream is arljusted ly widening or nimowing the exit.

As thr amount of aream left in the separated milk is determined hy the amonnt of globules which travel a certain distance in a given time, we can Ierive the following formula, assuming the ratio of various sized glolules (1) Ixe constant. The percentage of fit left in the milk ly' any separator can be calculited hy the formula :- 


$$
f=a \times b^{(40-t)} \times c^{\mathbf{F}} \times \frac{m^{\frac{2}{3}}}{v^{2}},
$$

where $f=$ percentage of fat in separated milk,

$$
\begin{aligned}
\mathrm{F} & =\text { temperature in degrees Centigrade, } \\
t & =\text { cream, } \\
m & =\text { number of gallons per hour, } \\
v & =\quad, \quad \text { revolutions per minute. }
\end{aligned}
$$

$a, b$, and $c$ are constants for each separator.

$b$ usually varies from $1 \cdot 035$ to $1 \cdot 05$.

c , , from $1 \cdot 00$ to $1 \cdot 05$.

$c$ is appreciable, chiefly with separators in which the adjustment of the thickness of the cream is made at the cream outlet-e.g., in the Alpha

\begin{tabular}{|c|c|c|c|c|c|}
\hline $\mathbf{F}$ & t. & $m$ & $v$ & $f$. & $f$ calc. \\
\hline $\begin{array}{c}\text { Per cent. } \\
15 \cdot 5 \\
42 \cdot 0 \\
51 \cdot 0 \\
52 \cdot 6 \\
56 \cdot 3 \\
65 \cdot 0 \\
60 \cdot 4 \\
62 \cdot 1 \\
51 \cdot 0 \\
53 \cdot 0 \\
42 \cdot 0 \\
70 \cdot 0\end{array}$ & $\begin{array}{c}\text { Degrees. } \\
32 \\
32 \\
32 \\
32 \\
32 \\
32 \\
38 \\
38 \\
32 \\
27 \\
32 \\
76\end{array}$ & $\begin{array}{c}\text { Gallons. } \\
350 \\
350 \\
350 \\
350 \\
350 \\
350 \\
350 \\
350 \\
240 \\
350 \\
325 \\
120\end{array}$ & $\begin{array}{c}\text { Revolutions. } \\
5600 \\
5600 \\
5600 \\
5600 \\
5600 \\
5600 \\
5600 \\
5600 \\
5600 \\
5600 \\
5200 \\
5600\end{array}$ & $\begin{array}{c}\text { Per cent. } \\
\cdot 05 \\
\cdot 12 \\
\cdot 175 \\
\cdot 210 \\
\cdot 247 \\
\cdot 330 \\
\cdot 22 \\
.25 \\
\cdot 14 \\
\cdot 30 \\
\cdot 15 \\
\cdot 07\end{array}$ & $\begin{array}{c}\text { Per cent. } \\
\cdot 04 \\
\cdot 13 \\
\cdot 194 \\
\cdot 207 \\
\cdot 246 \\
\cdot 369 \\
\cdot 228 \\
\cdot 247 \\
\cdot 14 \\
\cdot 27 \\
\cdot 14 \\
\cdot 07\end{array}$ \\
\hline
\end{tabular}
separator, in which $c$ has the value $1 \cdot 04$ to $1 \cdot 05$.

The following results were obtained with a separator, for which the following formula was applicable:-

$$
* f=8155 \times 1.046^{(40-t)} \times 1 \cdot 0471 \mathrm{~F} \times \frac{m^{2}}{v^{2}}
$$

The constant $a$ depends on the following conditions :-

1. Size of drum and thickness of the layer of milk.

2. The specific gravity of the milk serum and of fat.

3 . The units in which the variables are expressed.

The constant $b$ chiefly depends on the viscosity (internal friction) of the milk serum ; also, to a slight degree, on the cubical expansion of milk serum and milk fat, and on the friction of the liquid against the drum.

The constant $c$ depends on the viscosity of cream and on the friction of the cream against the sides of the outlet.

It is naturally advantageous for $a, b$, and $c$ to be as low as possible.

To obtain $a$ low, the drum should be large and the layer of

* For temperatures above $40^{\circ}$ the expression $b\left(\frac{40-t}{2}\right)$, or $1 \cdot 046\left(\frac{40-t}{2}\right)$, should be used. 
milk thin; the dises placed inside the drum in the Melotte and Alpha separators make the layers of milk very thin and therefore decrease $a$.

'T'o obtain b low, the exits, and especially the eream exit, should be as large as complatible with the proper working of the separator; and the tubes, through which the skim milk and cream leave the drum, as short and as straight as possible.

To obtain $c$ low, cooling of the cream inside the drum should be avoided, and the cream exit large. Seprarators in which the adjustment of the thickness of cream is performed at the cream exit have a large $c$.

It is more difficult to express the results obtained by allowing milk to stand by a definite formula. Here we have not a definite space through which the globules of fat must pass, as in the cream separator, where the layer of milk is always of constant thickness; the space is determined by the depth of the layer of milk set.

In the formula

$$
\frac{s}{t}=r^{3} \times\left(d_{8}-d_{j}\right) g \times k
$$

it is apparent that $k, s$, and $\left(d_{8}-d_{f}\right) g$ are all constants for a given space provided the fat globules all have the same density and the equation may be written

$$
t=\frac{r}{r^{\frac{3}{2}}} \text {, where } c \text { is a eonstant. }
$$

Taking the diameter of the largest globules as $.01 \mathrm{~mm}$. and the smallest as $0016 \mathrm{~mm}$, we calculate that the smallest globules will take about fifty times as long to pass through a given space as the largest; the author deduces from his experiments that the largest fat globules move at the rate of $15 \mathrm{~mm}$. per hour. If we assume that the total weight of fat globules of any size, is equal to the total weight of tat globules of any other size, in an ordinary cream tube we may expect roughly the following figures :-

In 5 hours alout 35 per cent. of total fat will be found in the cream.

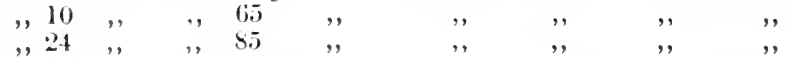

while from three to four days should clapse before the whole of the fat is found in the cream.

From the equation

$$
\dot{\imath}=r^{2} \times\left(l_{s}-l_{f}\right) ! \times 6
$$

it will be rearlily secen that it the density of the fat varies the time will he consicherally affected. The density of solid fat at $60^{\circ} \mathrm{F}$. (15.5 ( $)$ is about 9.3 ; the density of liquid fat is abont .y2 at the same temperature; and, as the experiments in 
Appendix A show, it is highly probable that the solidification of the fit is a process which takes time. The difference between the specific gravity of milk serum and milk fat is also accentuated at temperatures above $60^{\circ} \mathrm{F}$.; it is probable that when milk is rapidly cooled, the fat globules do not so easily attain the lower temperature as the serum. It would appear, theoretically, that there is a considerable advantage in setting milk for cream immediately after milking, and that the fat globules will rise at a much more rapid rate than if the milk is cooled and kept for some time. The experiments of Babcock completely substantiate this view; he finds that delaying the setting for even a short time materially affects the percentage of fat in the skim milk.

Composition of Skim Milk.-Skim milk differs practically from whole milk in the percentage of fat. In milk from which the cream has been removed by skimming very wide variations are found in the percentage of $t \mathrm{t}$; it varies from 4 per cent. to over 'ser cent. Huch lower percentages are found in separated milk, and the limits, 05 per cent. to $\cdot 3$ per cent., are very rarely overstepped. By the removal of the fat the percentage of other solid constituents are slightly raised in amount; this is caused by the constituents which were contained in 100 jarts being left in about $96 \frac{1}{2}$ parts, by the removal of $3 \frac{1}{2}$ parts of fat.

The following is the average composition of separated milk:-

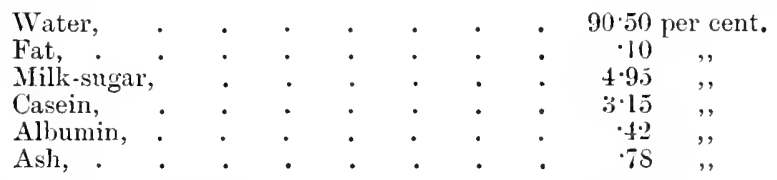

Control of Separators.-The most important point in the control of separators is the estimation of the fat left in the separated milk. A separator leaving a proportion of fat appreciably higher than that deduced from the formula given above is working badly, and the cause should be at once investigated. It is important that the speed is properly maintained, that the milk is at the right temperature, and that the exit tubes are not clogged up'; the chemist should make a practice of visiting the separators daily while they are running and of checking the speed and temperature of the milk. At least one sample of separated milk should be tested from each "run" of the separator; these samples should be taken from the skim outflow tube, at some period of the run, preferably not immediately after starting.

A further means of controlling the separators is to compare the total weight of the fat in the cream, separated milk, and the milk left in the drum after separating, with the total weight of the fat in the milk separater. This is done by weighing each 
product, multiplying the weight by the percentage of fat and dividing by 100 . The total weight of fat in the cream and separated milk should be nearly equal to that in the milk, the difference representing loss in separating; the average loss should not amount to more than 2 per cent. of the total fat in the niilk.

Separator Slime.-After running a separator a viscous substance is found on the insirie of the drum. It is usually of a dirty white colour; but if the milk contains much solid impurity, as happens most frequently in the winter, it may be distinctly brown.

This by no means consists, as is often considered, of dirt and cow-dung, though it naturally contains these impurities if present in the milk. Microscopical examination shows it to contain-

1. Inorganic impurities -i.e., dust gathered during transport, and earthy matters due to mncleanliness.

2. Vegetable matters derived from the dust of the food given to the cattle-e.g., bark of lay, fine particles of cake, d.c.; in many cases portions of leaves with stomata developed may be identified. Other portions of the vegetable matter have the cell watls considerably disintegrated; these have probably passed through the alimentary tract of the cow, and indicate the presence of cow-dung.

3. Substances derived from the cow ; hairs are often found ; much pavement epithelium from the udder of the cow, and possibly :I -0 from the hands of the milkers; and empty sacs (gland cells), which form a very large portion of the slime. (If the cow was in ill-health, mucus, blood, and pus may be present.)

Nicro-organisms are very numerous; should the cows be afflicted with tuberculosis of the ndder, Bacillus tuberculosis may be found here.

The following composition is assigned to separator slime by the author and by Fleischmann, respectively :-

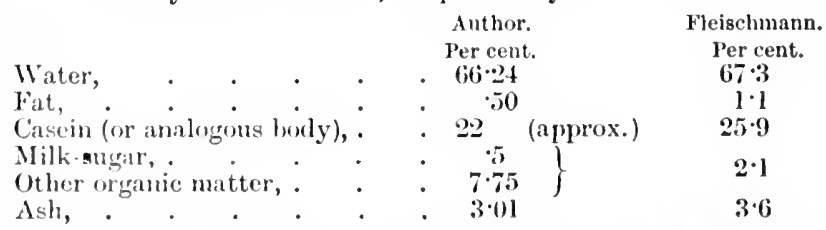

It is doubtful whether the substance returned as casein is really this body ; it is undoubtedly a mixture of several proteirls, including Storch's mucoid proteid.

The following is the composition of the ash :-

Total ash,

Soluble ash,

Insoluble ash,

3.01 per cent.

$\cdot 166$,

$2 \cdot 844$, 
consisting of

\begin{tabular}{|c|c|c|c|c|c|}
\hline \multirow{2}{*}{\multicolumn{2}{|c|}{ Silica, lron oxide and alumina, }} & & - & \multicolumn{2}{|c|}{$\cdot 171$ per cent } \\
\hline & & & & .012 & , \\
\hline Lime, . & . $\quad . \quad$. & . & . & $\cdot 654$ & , \\
\hline Magnesia, & . & . & . & $\cdot 225$ & , \\
\hline Alkalies, & . $\quad . \quad$. & . & . & 559 & , \\
\hline Phosphoric & anhydride, & . & . & $1 \cdot 233$ & ", \\
\hline
\end{tabular}

There are 675 equivalent of lime and $\cdot 325$ equivalent of magnesia to 1506 equivalents of phosphoric anhydride, showing that the insoluble ash consists chiefly of $(\mathrm{Ca}, \mathrm{Mg})(\mathrm{Na}, \mathrm{K}) \mathrm{PO}_{4}$ like the insoluble ash of milk.

The quantity of separator slime amounts to about 04 parts to 100 parts of milk separated, and varies within comparatively narrow limits-.02 to 08 --unless the milk is very dirty, when it may even reach 15 ; in the last case the slime was brown and very gritty.

It has been argued that the removal of the slime purifies the milk to such an extent, that its keeping qualities are enhanced. This opinion is probably founded on observations of the number of microbes contained in the slime; but though a greater relative quantity are found than in the milk, the numbers left in the cream and separated milk are not appreciably diminished. Practice has, however, shown that a nixture of cream and separated milk in their original proportions keeps no better than the milk from which they were separated.

Attempts have been made to remove the impurities in milk by filtration; straining through a fine wire sieve and through fine muslin or swansdown is always practised in dairies; this removes the grosser impurities-i.e., hairs, large vegetable fibres, \&c.-but the quantity removed in this way does not exceed .0025 per cent. In Denmark and Germany, and lately in a few dairies in England, filtration through layers of gravel and sand is practised; this method, which adds considerably to the labour of handling the milk, owing to the necessity of washing the gravel and sand with caustic soda, followed by water, sterilising, and drying, fails to remove any more from the milk than simple straining or upward filtration through muslin or swansdown.

Separators.-It is not within the province of this work to give a description of the various cream separators that are in use. A few points only, which may aid in the choice and use of separators, and which may be said to come within the province of the dairy chemist, are touched upon. (See table on p. 224.)

Before any advice on the choice of separators can be given, it must first be ascertained to what use they are to be put. A separator eminently adapted for producing cream destined to be churned into butter is not necessarily the best for making cream for sale as such; a separator may produce a good thin cream, and yet not work satisfactorily when thick cream is desired. 
When separating cream for churning a somewhat thin cream is made. The great point to be aimed at is to obtain the maximum percentage of fat in the cream, and to leave as little as possible in the separated milk. For this purpose frequent examinations of the separated milk should be made, and a standard of, say, $\cdot 5$ per cent. of fat should be fixed; if more is found, the cause should be enquired into.

If the cream is "pasteurised" as som as it is scparated, as is the case when it is to be "soured" by means of a pure ferment, no special attention need be paid to the temperature of the crean leaving the separator. If, on the other hand, it is to be

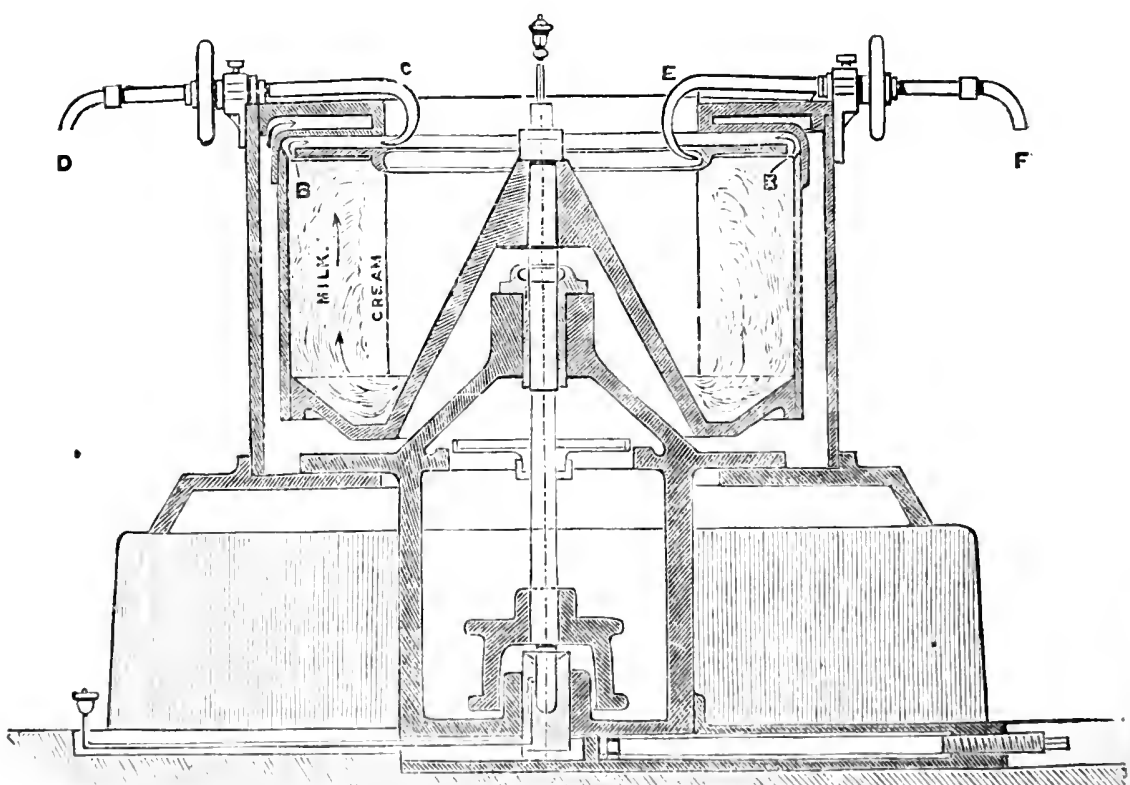

Fig. 15.-Bumeister and Wain heparater.

allowed to staml for some length of time at the lemperature at which it leaves the separator, it lecomes of importance to see that it is not too warm.

Closed separators-iee, those which have a cover over the whole of the upper part, leaviug mly an opening suflicient to allow the milk o entri--e.\%, the Alexandra (Fig. 1i) deliver crean, if anything, slightly warner than the milk which flows 


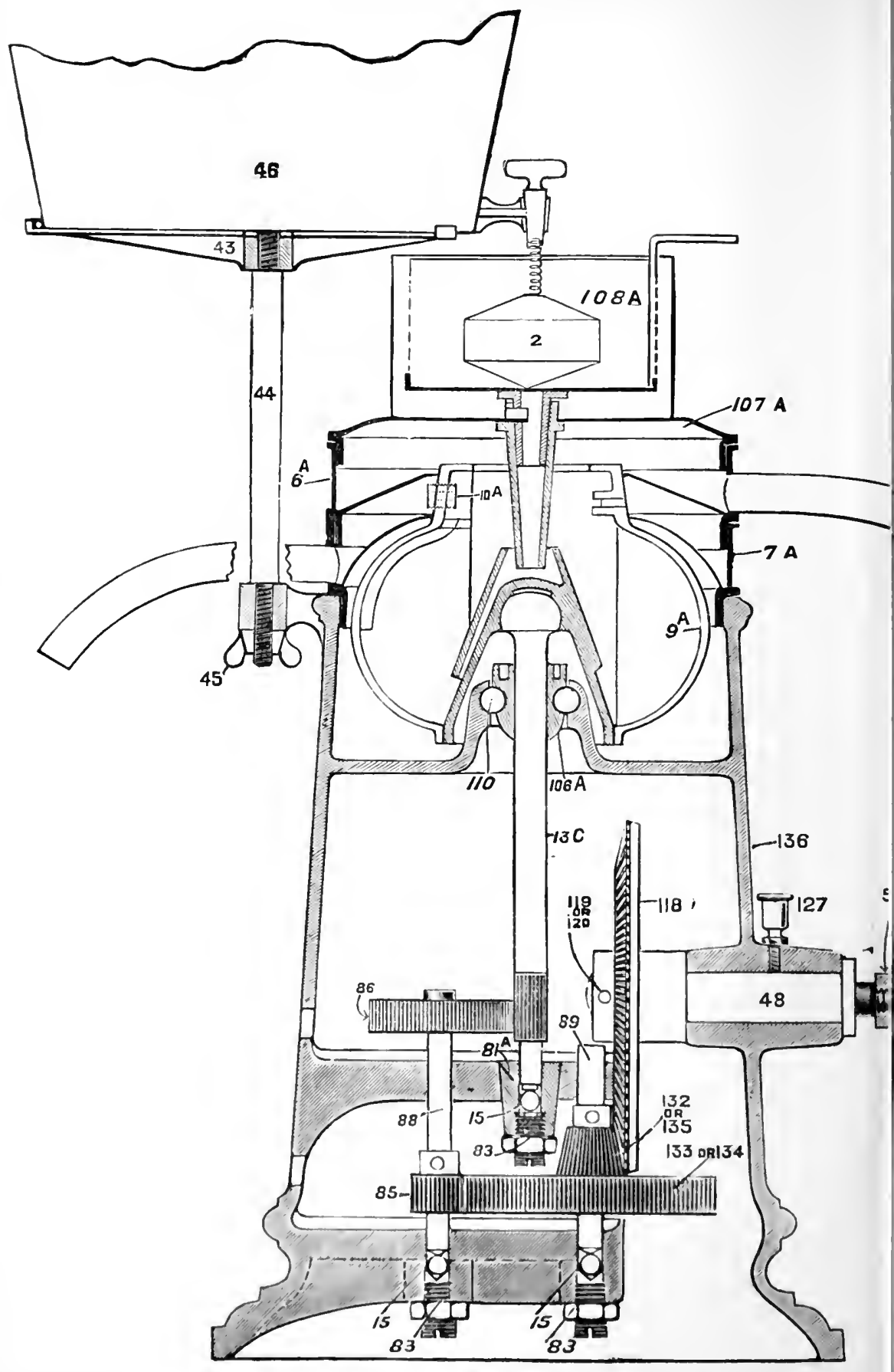

Fig. 17.-Alexandra Separator. 


\section{Explanation of Parts.}

2. Float for regulating inflow of milk from large receiving tin.

6A. Top tin cover with cream outlet.

7A. Bottom tin cover with skim milk outlet.

9A. Steel cylinder in which milk is separated.

$10 \mathrm{~A}$. Screw for regulating thickness of cream.

13c. Cast-steel spindle with ball-shaped head.

15. Steel ball for footstep bearings, on which spindles Nos. $13 \mathrm{c}, 88$, and 89 rest.

43. Receiving tin bracket.

44. Spindle for receiving tin bracket.

45. Thumb nut for receiving tin bracket.

46. Receiving tin with tap.

47. Handle spindle.

$50 \mathrm{~A}$. Steel pawl pin for handle.

51. Steel spring for handle.

53. Gun-metal ring for handle.

54. Steel grab screw for handle.

55. Iron quill pin and washer for handle.

56. Wood quill for handle.

57. Crank casting for handle.

$81_{\text {A. }}$ Footstep bearing for No. 13c.

83. Steel set pin with lock nut for bearing $81 \mathrm{~A}$.

85. Steel pinion on spindle carrying leather wheel.

86. Leather wheel on spindle No. 88 .

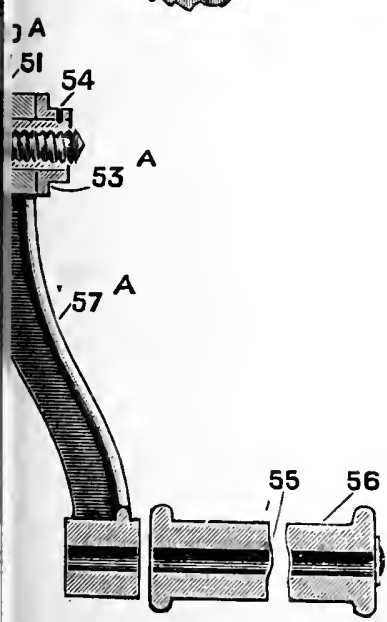

87. Steel pinion for main spindle 13c.

88. Steel spindle for carrying leather wheel and pinion.

89. Steel spindle for bevel pinion and spur wheel.

106A. Neck bearing.

$107 \mathrm{~A}$. Tin cover and inlet funnel combined.

$108 \mathrm{~A}$. Strainer and inlet regulator combined.

110. India-rubber ring for top bearing.

118. Bevel wheel on handle spindle.

119. Steel taper pin holding 118 to 47 .

127. Lubricator for handle.

130. Grub screw for holding 87 to $13 \mathrm{c}$.

132. Bevel wheel.

133. Spur wheel. 

in; a difference of $2^{\circ} \mathrm{F}$. has sometimes been noticel. Such separators are at an obvious clisadvantage.

Open separators-i.e., those which have no cover at all-e.g., the Burmeister and Wain machines (Fig. 18)-permit of a considerable cooling of the cream, owing to the currents of air produced; it is by no means unusual to find that the cream is from $12^{\circ}$ to $20^{\circ} \mathrm{F}$. cooler than the milk.

Semi-closed separators-i.e., those which have a cover over the upper part, bnt the opening of which is sufficiently large to allow of air being drawn in-e.g., the Alpha (Fig. 19)—stand intermediate in this respect between the other two classes, the cream being $4^{\circ}$ to $6^{\circ} \mathrm{F}$. cooler than the milk.

If the cream is to be pasteurised, the separator which gives the "smoothest" cream is to be preferred, as the "lumps" are liable to melt into a fatty layer, which prevent uniformity in the butter.

It cream is made for sale as such, the object to be aimed at is to obtain the most viscous or "thickest" product; smoothness should also be aimed at. The latter quality is obtained by taking off the cream as near to the centre of the separator as possible, and consequently as small an air space as practicable is allowed in the centre; for this reason the more modern separators are either of the closed or semi-closed varieties. The cream should also be allowed to flow out with as little friction as possible; the "open" separator" of Burmeister and Wain, in which the layer of cream is cut off from the interior by a sharp edged tube,

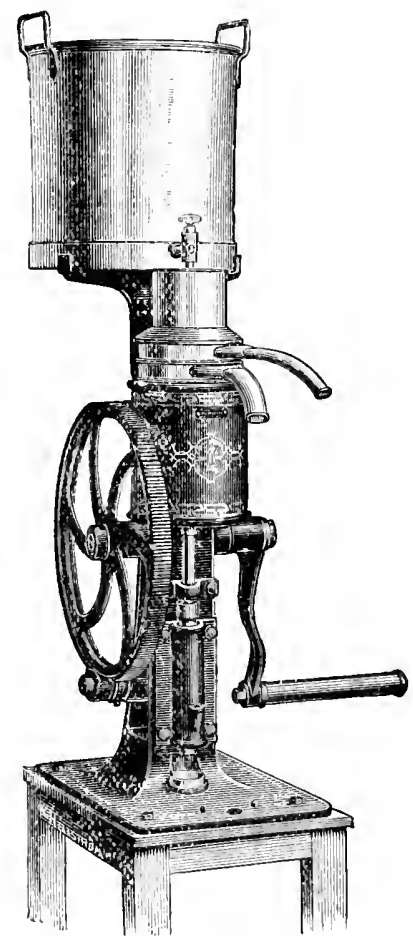

Fig. 19.-Alpha Separator. fulfils the last condition to the least extent; while those separators which allow the cream to flow out through a hole are in this respect the best.

Experiment points to the conclusion that cream is most viscous in proportion to its percentage of fat, when the largest quantity of fat is left in the separated milk; this is probably due to a difference in the mean size of fat globules, as it is 
the smaller globules that remain in the separated milk. It is not altogether an advantage to insist on a very small percentage of fat in the separated milk when cream is macle for sale. Cream, when used as such, is judged entirely by its taste and viscosity, and, other things being equal, that containing least fat is the most suitable for use ; for instance, cream low in fat is comparatively high in proteids and, when used in tea, combines with a greater proportion of tannin.

Separators, as a rule, do not work well if the cream amounts to less than 10 per cent. of the milk; if it be desired to take off less than this-i.e., to make a thicker cream-the quantity of milk that a separator will cream must be seriously reduced, if a low percentage of fat in the separated milk be desired. Thus, when taking off cream in quantity equal to $6 \mathrm{per}$ cent. of the milk, a separator of a nominal cajacity of 300 gallons per hour will not run more than 150 gallons per hour.

This is probably due to the fact that the viscosity of the cream is so great, and consequently the friction against the sides of the exit so much increased, that the cream does not all escape. As the pressure is great and the contents of the bowl must find an exit, a portion which should pass through the cream exit is obliged to flow out through the separated milk tube. Those separators in which the arljustment of the separator is performed by restricting the outlet of cream do their work less satisfactorily than those in which the flow of separated milk can be varied.

There are few, if any, separators on the market in which the cream outlet is sufficiently large to allow very thick cream to flow away with sufficient freeness. The closer the exit of creanr is to the midldle of the drum, in which the tube feeding the milk is placed, the worse they are for running thick cream.

The figures quoted in the table on p. 224 show this to a remarkable degree. Of steparators in which the adjustment is performed at the cream "xit, the Russian is closer built than the Alpha and shows a higher percentage of fat in the separated milk. The Alexandra and the modified Burmeister and Wain are adjusted by regulating the quantity of separated milk; they both show a low percentage of fat when running thick cream. The moditied Burmeister and $\mathrm{W}^{\mathrm{a}}$ in has the largest exit for cream, and will separate a fluantity of milk approximating closer to its nominal caparity than any of the others, when thick cream is made.

Cream-Composition.-The name croam is given to the layer which rises to the sur'are when milk is allowed to stand. This layer consists essentially of the fat globules, together with a proportion of the aquenus portion of milk.

Cualitatively, it has the sanc composition as milk: quantitatively, it contains a higher proportion of fat, the other constituents being correspondingly depressed. 
It is by many accepted as a fact that cream contains a larger proportion of solids not fat to water than the milk from which it was derived; and various explanations of this have been put forward. Thus a membrane round each fat globule has been alleged to exist by some (e.g., Storch and Béchamp); others have considered that the proteids are concentrated in the aqueous layer formed round each globule by surface tension. The author's experiments have indicated that the ratio of solids not fat to water in cream is the same as that in milk. It is true that in some cases a distinctly higher ratio has been found, but it has been noticed that in these cases ample opportunity for evaporation of the water has been afforded, either by leaving the cream on the surface of the milk for some length of time in a dry atmosphere, or by pasteurising it, without any precautions to prevent evaporation; indeed, evidence of evaporation has been obtained by noting the quantity of .cream before and after pasteurising. In cases where precautions have been taken to prevent evaporation, no evidence of a higher ratio has been obtained.

In the following analyses (Table XLIII.) the solids not fat have been calculated by dividing the percentage of water by 100 and multiplying by 10.2 (except in No. 2 where 10.0 , and No. 9 where 10.4 has been used), this being the average ratio in the milk from which these creams were prepared. The calculated ash is $\frac{1}{12}$ of the calculated solids not fat:-

TABLE XLIII.-CoMposition of Creas.

\begin{tabular}{|c|c|c|c|c|c|c|c|}
\hline No. & Total Solids. & $\begin{array}{l}\text { Solids not } \\
\text { Fat. }\end{array}$ & $\begin{array}{l}\text { Solids not } \\
\text { Fat, calc. }\end{array}$ & Diff. & Ash. & $\begin{array}{l}\text { Ash } \\
\text { calc. }\end{array}$ & Diff. \\
\hline & Per cent. & Per cent. & Per cent. & & Percent & Per cent & \\
\hline 1. & $32 \cdot 50$ & $6 \cdot 83$ & $6 \cdot 90$ & $+\cdot 07$ & 57 & 57 & $\ldots$ \\
\hline 2. & 37.59 & $6 \cdot 14$ & $6 \cdot 24$ & $+\cdot 10$ & 52 & 52 & $\ldots$ \\
\hline 3. & 50.92 & $5 \cdot 02$ & $5 \cdot 01$ & $-\cdot 01$ & $\cdot 42$ & 42 & $\ldots$ \\
\hline 4. & $55 \cdot 05$ & $4 \cdot 65$ & 459 & $-\cdot 06$ & $\cdot 3 s$ & $\cdot 3 s^{\prime}$ & $\ldots$ \\
\hline 5. & $55 \cdot 18$ & $4 \cdot 77$ & 4.57 & -20 & $\cdot 39$ & 38 & -01 \\
\hline 6. & $55 \cdot 97$ & $4 \cdot 47$ & $4 \cdot 49$ & $+\quad 02$ & $\cdot 38$ & $\cdot 37$ & -01 \\
\hline 7. & $56 \cdot 37$ & $4 \cdot 40$ & $4 \cdot 45$ & +.05 & $\cdot 38$ & 37 & $-\cdot 01$ \\
\hline 8. & 57.99 & $4 \cdot 17$ & $4 \cdot 28$ & $+\cdot 09$ & $\cdot 41$ & 36 & -.05 \\
\hline 9. & $68 \cdot 18$ & $3 \cdot 30$ & $3 \cdot 31$ & $+\cdot 01$ & 28 & 28 & $\ldots$ \\
\hline
\end{tabular}

In cream No. 1 the proteids were also estimated, and found to be 2.60 per cent., while the figure calculated on the assumption that they are 37.8 per cent. of the solids not fat, as in milk, is 2.58 per cent.

The statement that cream contains a higher proportion of solids not fat to water than milk, though to some extent due 
to the evaporation of water which takes place, is probably also due to the methods of analysis employed. Thus it is known that when butter fat is leated in contact with air for some hours an increase of weight is noticed As cream contains from 25 to 50 per cent. of fat, an apparent increment in the total solids of from 1 to $\cdot 3$ per cent. may be noticed. If the fat be estimated by a method which avoids i long heating, and the solids not fat deduced by difference, the increment will swell the amount of solids not fat. Many analyses of the fat in cream have been made by methods which do not completely extract the fat; the solids not fat are thus still further increased.

The following is an analysis of a thick cream :-

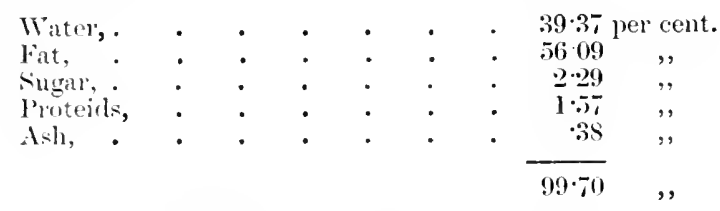

The following table will show the amounts of milk-sugar, proteids, and ash contained in 100 parts of water compured with those contained in milk ani separated milk (see L/ean Composition on !p. 120 and 209):-

\begin{tabular}{|c|c|c|c|c|c|c|}
\hline & & & & (rean. & Nilk. & Separated Iilk. \\
\hline $\begin{array}{l}\text { Milk-sugar, } \\
\text { Proteids, } \\
\text { Ash, }\end{array}$ & . & . & : & $\begin{array}{c}\text { Per cent. } \\
5 \cdot 81 \\
3 \cdot 99 \\
\cdot 97\end{array}$ & $\begin{array}{c}\text { Per cent. } \\
.5 \cdot 45 \\
3 \cdot 90 \\
\cdot 86\end{array}$ & $\begin{array}{c}\text { Per cent. } \\
5 \cdot 47 \\
3 \cdot 94 \\
\cdot 56\end{array}$ \\
\hline
\end{tabular}

It is impossible to give an average composition of cream, as the variation of the fat is enormons ; the author has obtained cream containing 9 per cent. of fat as a minimum, and 68 per cent., anf even slightly more, as a maximum. As milk has been known to contain as much as 12 per cent. of fat (from .Jerser cows), it follows that no sharp distinction between milk and crean can be drawn. Attempts haw been made to fix a standard for crean, but without success. Thus a London vestry, on the advice of their analyst, decided not to reognise as cream any product containing less than 25 per cent of fat; the absurdity of this is shown by the fact that, while much of the cream sold in london contains lew ween 40 and to per cent. of fat, being prepared hy a separator, crem male by the Swartz process bint rarely comes up to the stambind proposed.

Ash. - It has been alleged that the ash of eream is practically free from chlorides; this, however, is not in the authur's experi- 
ence correct; the ash of cream differs in no respect from that of milk.

The following is the composition of the ash of cream according to Fleischmann :-

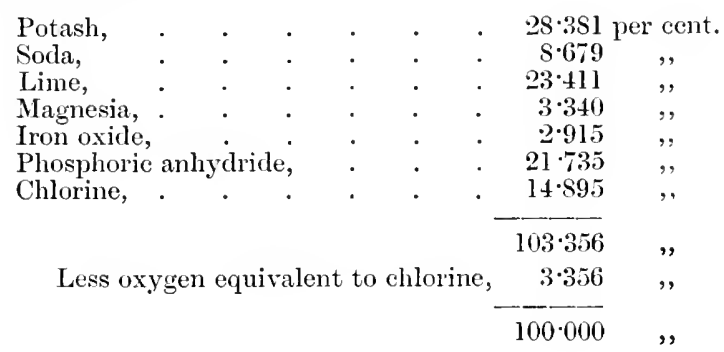

The percentage of fat varies inversely as the density of the cream.

A formula connecting the two can be deduced from the formula expressing the relation between specific gravity, fat, and total solids in milk.

$$
\mathrm{T}=2625 \frac{\mathrm{G}}{\mathrm{D}}+1 \cdot 2 \mathrm{~F} .
$$

Assuming that the solids not fat (S) are in the ratio to the water as $10^{\circ} 4: 100$,

then

$$
\frac{100-\mathrm{F}}{10 \cdot 615}=\mathrm{S}
$$

and

$$
\mathrm{T}=\mathrm{F}+\frac{100-\mathrm{F}}{10 \cdot 615}=\frac{100+9 \cdot 615 \mathrm{~F}}{10615},
$$

substituting in the formula

$$
\begin{gathered}
\frac{100+9 \cdot 615 \mathrm{~F}}{10 \cdot 615}-1 \cdot 2 \mathrm{~F}=\cdot 2625 \frac{\mathrm{G}}{\mathrm{D}} \\
3 \cdot 123 \mathrm{~F}=100-2 \cdot 786 \frac{\mathrm{G}}{\mathrm{D}} \\
\mathrm{F}=32 \cdot 0-.892 \frac{\mathrm{G}}{\mathrm{D}}
\end{gathered}
$$

Density.-It is impossible to test the specific gravity of a cream containing more than 30 per cent. of tat with a hydrometer direct; but if it is diluted with an equal weight of separated milk the hydrometer can be used as with a thinner cream.

Te calculate the specitic gravity of a thick cream from that of a mixture with an equal weight of separated milk, the following formula may be used :- 


$$
\begin{aligned}
& c=\text { specific gravity of eream. } \\
& s=, ", \text { of separated milk. } \\
& m=\quad, \quad, \quad \text { of mixture. } \\
& c=\stackrel{s \times m}{s-s-m} \text {. }
\end{aligned}
$$

Creau containing 25 per cent. of fat decreases in specific gravity 00027 or $27^{\circ}$ for each $1^{\circ} \mathrm{F}$. above $60^{\circ} \mathrm{F}$.

\begin{tabular}{|c|c|c|c|}
\hline Specific Gravity. & Fat Estimated. & \multicolumn{2}{|c|}{ Fat Calculated. } \\
\hline 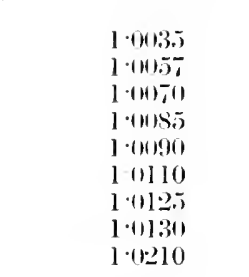 & $\begin{array}{c}\text { Per cent. } \\
29 \cdot 2 \\
27 \cdot 3 \\
26 \cdot 3 \\
26 \cdot 2 \\
24 \cdot 5 \\
24 \cdot 11 \\
2.2 \cdot 4 \\
21 \cdot 4 \\
211 \cdot 8 \\
13 \cdot 3\end{array}$ & & $\begin{array}{c}\text { Per cent. } \\
28 \cdot 9 \\
26 \cdot 9 \\
25 \cdot 8 \\
24 \cdot 5 \\
24 \cdot 1 \\
2 \cdot 2 \cdot 3 \\
21 \cdot 1 \\
20 \cdot 6 \\
13 \cdot 7\end{array}$ \\
\hline $\begin{array}{c}\text { siecific Gravity } \\
\text { of separaterl } \Delta l i l k=8 \text {. }\end{array}$ & $\begin{array}{l}\text { Specific Gravity } \\
\text { of Mixture = } m \text {. }\end{array}$ & Fat Estimated. & Fat Calculated. \\
\hline $\begin{array}{l}1 \cdot 0367 \\
1.0367 \\
10364\end{array}$ & $\begin{array}{l}1 \cdot 00,53 \\
1 \cdot 0041 \\
1 \cdot 0051\end{array}$ & $\begin{array}{c}\text { Per cent. } \\
55 \cdot 5 \\
57.7 \\
49.5\end{array}$ & $\begin{array}{c}\text { Per cent. } \\
54 \div \% \\
56 \cdot 3 \\
49 \cdot 0\end{array}$ \\
\hline
\end{tabular}

Table XLTV. shows the results obtained by calculating the fit from the specific gravity.

TABLE XLIV.-Calculation of Fat in Cream.

The specific gravity of cream is aflected by the state in which the fat globules "xist; if they are in the solid state, the specitic gravity will he very appreciably ligher than if liguid. The formula given above assumes that they are solid; if, however, the crean has heen separated at a temperature above the melting point of the fat, the stobules are liquefied, and do not at once issmue the solid state on cooling. For this reason the method of calculating the fat from the specitic gravity is liable to give at times very disuoment results.

These figures show that, though the estimation of the specific gravity of a croall is scarcely exact enough to serve as a means of analysis, it is a useful comoborative figurs. Considering the sourees of errol the agroement is rery good, and serves as a further prouf that eresum does not contain a larger proportion of solirls not fat to water than milk.

Vieth finls that cream containing 10 per cent. fat has, at a 
temperature of $175^{\circ} \mathrm{F}$., a specific gravity of 960 and gives the following table :-

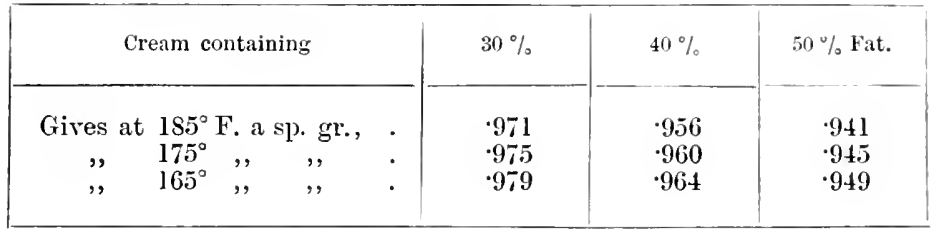

A sample of froth taken from the surface of cream running from a Burmeister and Wain separator had the following composition :-

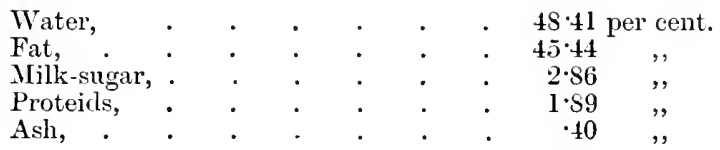

It does not differ in its chemical composition from cream. The froth, however, always contains more fat than the cream.

Clotted Cream, or cream prepared by the system practised in Devonshire and Cornwall, has been examined regularly in the Aylesbury Dairy Company's laboratory since 1886. Table $\mathrm{XLV}$. gives the average yearly results, together with the maxima and minima found.

TABIE XLV.-Conposition of Clotted Creay.

\begin{tabular}{|c|c|c|c|c|}
\hline Date. & Water. & Fat. & Ash. & Solids not Fat. \\
\hline $\begin{array}{l}1886 \\
1857 \\
1888 \\
1889 \\
1890 \\
1891 \\
1592 \\
1893 \\
1894 \\
1895 \\
1896 \\
1897\end{array}$ & $\begin{array}{c}\text { Per cent. } \\
36 \cdot 11 \\
36 \cdot 94 \\
35 \cdot 54 \\
36 \cdot 69 \\
35 \cdot 16 \\
33 \cdot 95 \\
35 \cdot 63 \\
30 \cdot 77 \\
31 \cdot 59 \\
33 \cdot 19 \\
32 \cdot 36 \\
33 \cdot 36\end{array}$ & $\begin{array}{c}\text { Per cent. } \\
57 \cdot 36 \\
55 \cdot 51 \\
57 \cdot 09 \\
56 \cdot 69 \\
55 \cdot 35 \\
59 \cdot 30 \\
56 \cdot 27 \\
61 \cdot 49 \\
60 \cdot 25 \\
55 \cdot 21 \\
59 \cdot 16 \\
55 \cdot 22\end{array}$ & $\begin{array}{c}\text { Per cent. } \\
.52 \\
.58 \\
.57 \\
5 \% \\
53 \\
52 \\
54 \\
.58 \\
.60 \\
.69 \\
.71 \\
.68 \\
.70\end{array}$ & $\begin{array}{c}\text { Per cent. } \\
6 \cdot 53 \\
7 \cdot 55 \\
7 \cdot 37 \\
6 \cdot 62 \\
6 \cdot 49 \\
6 \cdot 75 \\
7 \cdot 52 \\
7 \cdot 74 \\
8 \cdot 16 \\
8 \cdot 60 \\
S \cdot 48 \\
S \cdot 42\end{array}$ \\
\hline $\begin{array}{l}\text { Average, } \\
\text { Maximum, } \\
\text { Minimum, }\end{array}$ & $\begin{array}{l}34 \cdot 26 \\
4484 \\
21 \cdot 08\end{array}$ & $\begin{array}{l}58 \cdot 16 \\
71 \cdot 37 \\
44 \cdot 29\end{array}$ & $\begin{array}{r}\cdot 60 \\
1 \cdot 17 \\
\cdot 42\end{array}$ & $\begin{array}{r}7 \cdot 52 \\
11 \cdot 70 \\
5.03\end{array}$ \\
\hline
\end{tabular}

It is seen that the ratio of solids not fat to water is very much 
higher in clotted eream than in milk, due to the evaporation which takes place from the surface during heating.

Roughly speaking, the ratio of solicls not fat to water is double the average ratio in milk.

The ratio of ash to solids not fat is very neally the same in clotted cream as in milk; it is, however, slightly lower. This is partly, if not entirely, due to the fact that on heating milk certain salts of calcium, probably chiefly citrate, are deposited, leaving a smaller proportion in the milk and also in the cream derived from it.

For dairy control work it is but rarely neeessary to estimate the percentage of solids not fat, a determination of the fat being sutticient. This may be done by one of the centrifugal methods described, or it may be deduced from the percentage of total solids. For this purpose it is assumed that the proportion of solids not fat, to water in milk is constant, an assumption which causes no appreciable error in cream analysis. It is found that on the average 100 parts of water contain 10.4 parts of solids not fat (see 1. 217); we may assume that the water in cream contains the same proportion of solids not fat, and estimate the fat by deducting the percentage of water multiplied by 104 from the total solids.

The following formula will express this relation :-

Let

then
$\mathrm{T}=$ total solids and $\mathbf{F}=$ fat,

$\mathrm{F}=1 \cdot 104 \mathrm{~T}-10 \cdot 4$.

The following table (XIVI.) may be used:-

TabLE XI, VI.-Ratio of Fat to Total Solids in Crean.

\begin{tabular}{|c|c|c|c|c|c|}
\hline Toutal solisls. & Fat. & $\begin{array}{c}\text { Soljals not } \\
\text { Fat. }\end{array}$ & Total solids. & Fiat. & $\begin{array}{l}\text { Soljils not } \\
\text { Fat. }\end{array}$ \\
\hline $\begin{array}{c}\text { Per cent. } \\
\text { g(1) }\end{array}$ & Percent. & $\begin{array}{c}\text { Per cent. } \\
+\cdot ?\end{array}$ & Per cent. & $\begin{array}{c}\text { Per cent. } \\
: 35 \bullet\end{array}$ & $\begin{array}{c}\text { Per cent. } \\
5 \cdot \mathrm{S}\end{array}$ \\
\hline in & $54 \div$ & $4 \cdot 3$ & $\begin{array}{l}+7 \\
43\end{array}$ & $3 \pi \cdot 1$ & 5.9 \\
\hline $5 s$ & 536 & +4 & 42 & $36 \cdot 0$ & 60 \\
\hline 57 & $5: 2 \cdot 5$ & 4.5 & 11 & 349 & $6 \cdot 1$ \\
\hline .56 & $51+$ & $4.1 i$ & 411 & $3: 3 \cdot 5$ & $6 \cdot 2$ \\
\hline 5 & $511 \% 3$ & $4 \%$ & $3 ! !$ & $3: 3 \cdot 7$ & $6 \cdot 3$ \\
\hline it & $4 ! 1: 3$ & 1.8 & 38 & $31 \cdot 6$ & $6 \cdot 4$ \\
\hline 53 & $4 x \cdot 1$ & +9 & 37 & $311 \cdot 4$ & $6 \cdot 6$ \\
\hline 52 & 4.11 & $5 \cdot 11$ & $31 ;$ & $21 \cdot 3$ & $6 \cdot 7$ \\
\hline 5 & $6 \div 0$ & $5 \cdot 1$ & 35 & $2 \mathrm{~S} \cdot 2$ & $6 \cdot S$ \\
\hline 511 & $41 \cdot 8$ & $5: 1$ & 34 & $27 \cdot 1$ & 69 \\
\hline 49 & $1: 3 \cdot 7$ & $\pi 3$ & $3: 3$ & $2(i \cdot 0)$ & $7 \cdot 0$ \\
\hline is & $421 i$ & 54 & 32 & $24 \cdot 1$ & $7 \cdot 1$ \\
\hline 17 & 415 & $5 \div$ & 31 & $23 \cdot 5$ & $7 \cdot 2$ \\
\hline If; & 411.4 & $5 \cdot 1 i$ & 311 & 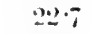 & $7 \cdot 3$ \\
\hline 45 & $31 \cdot 3$ & $5 \cdot 7$ & $2 ! !$ & $21 \cdot 6$ & $7 \cdot 4$ \\
\hline
\end{tabular}

'This table is not appliealle to clotted eream. 
The Thickness of Cream.-The thickness is the factor by which cream is usually judged when used for direct consumption. This can be quantitatively estimated by the method generally employed for the determination of "viscosity"-i.e., noting the time taken for a given volume of cream to flow through a tube of constant size. The viscosity of a liquirl depends on the internal friction-i.e., the friction of molecules passing each other ; the viscosity or internal friction of cream is not quite of the same order as that of a homogeneous liquid; in the latter case, the molecules are of equal size (or nearly so), and very small in comparison with the diameter of the tube through which the liquid passes. The viscosity of cream depends on two factors-the internal friction of the very small molecules of the milk serum, and the friction between the comparatively large fat globules.

As the fat globules have an appreciable size compared to the size of the tube, we cannot expect the laws to be of the same kind as those governing the viscosity of a liquid composed of molecules of infinitely small size. The actual and relative size of the globules will also have considerable influence; thus if we have two creams identical in chemical composition, in one of which the relative size of fat globules is much larger than in the other, the "viscosities" will differ.

It is not possible to compare the thickness of cream by making a determination of the percentage of fat in a sample. It is possible, however, to make a comparison of cream which contain globules of relatively the same size. For instance, if cream be diluted with the separated milk, which is practically free from fit, the thickness can be deduced by making determinations of fat.

The law connecting thickness or viscosity and amount of fat is expressed by the following empirical formula-

where $\mathrm{V}=$ the viscosity,

$$
\mathrm{V}=10^{x \mathrm{~F}^{3}},
$$

$\mathrm{F}_{2}=$ the volume of fat in 100 volumes of cream,

and $x=a$ faetor dependent on the mits in whieh the viseosity is expressed, and on the relative size of fat globules.

The volume of fat in 100 volumes of cream may be calculated from the percentage of fat (by weight) by the following formula-

$$
\mathrm{F}_{i}=\frac{1 \cdot 07527 \mathrm{~F} \times 100}{0 \cdot 11 \mathrm{~F}+96 \cdot 5} .
$$

This is true at a temperature of $60^{\circ} \mathrm{F} .\left(15.5^{\circ} \mathrm{C}.\right)$, and may be used withont appreciable error at other temperatures.

The following two series will illustrate the exactitude with which the formula agrees:- 
SEKIES 1 .

\begin{tabular}{|c|c|c|c|c|c|}
\hline $\begin{array}{l}\text { Fer cent. Fat } \\
\text { by Weight. }\end{array}$ & $\begin{array}{l}\text { Per cent. Fat } \\
\text { ly Volume. }\end{array}$ & Viscosity. & $\begin{array}{l}\text { Calc. } \\
\text { Viscosity. }\end{array}$ & $\begin{array}{l}\text { Calc. } \\
\text { Per cent. Fat } \\
\text { by Volume. }\end{array}$ & $\begin{array}{l}\text { Calc. } \\
\text { Per cent. Fat } \\
\text { by Weight. }\end{array}$ \\
\hline $\begin{array}{l}629 \\
6 \div 1 \div 3 \\
57 \cdot 7 \\
52 \cdot 6\end{array}$ & $\begin{array}{l}6.5 \cdot 4 \\
6020 \\
60 \cdot 3 \\
5.5 \div 3\end{array}$ & $\begin{array}{r}151 \cdot 6 \\
58 \cdot 0 \\
55 \cdot 2 \\
21 \cdots 2\end{array}$ & $\begin{array}{r}157 \cdot 6 \\
90 \cdot 3 \\
52 \cdot 7 \\
21 \cdot 4\end{array}$ & $\begin{array}{l}653 \\
1 ; 2 \cdot 8 \\
60 \cdot 6 \\
55 \cdot 3\end{array}$ & $\begin{array}{l}62 \cdot 8 \\
60 \cdot 2 \\
58 \cdot 0 \\
52 \cdot 6\end{array}$ \\
\hline & \multicolumn{5}{|c|}{ FEnies II. } \\
\hline $\begin{array}{l}61 \cdot 4 \\
53 \cdot 7 \\
46 \cdot 0\end{array}$ & $\begin{array}{l}63 \cdot 9.5 \\
56 \cdot 4 \\
48 \cdot 7\end{array}$ & $\begin{array}{r}170 \\
31 \cdot 5 \\
9 \cdot 5\end{array}$ & $\begin{array}{r}165 \cdot 5 \\
33 \cdot 3 \\
9 \cdot 6\end{array}$ & $\begin{array}{l}64 \cdot 05 \\
56 \cdot 1 \\
45 \cdot 9\end{array}$ & $\begin{array}{l}615 \\
53 \cdot 4 \\
46 \cdot 2\end{array}$ \\
\hline
\end{tabular}

The agreement is within the limits of experimental error.

Instead of the formula given above, which inchudes a calculation of the percentinge by volume of fat, the following approximate formula may lee used-

$$
\mathrm{V}=10^{x, \mathrm{~F}^{2.8}}
$$

where $\mathrm{F}$ is the percentage of fat by weight. For small differences the results by the two formulie agree sufficiently well.

A practical methor for the dilution of cream to constant thickness may le founded upon the above formula. To take the viscosity of a cream, a 10 c.c. pipette with a fairly wide opening, marked with distinct lines both above and below the bulb, may be employed; it should be surrounded by a water jacket made of glass to ensure a constant temperature; and the end should not project fal heyond the jacket. Care must be taken that its position is always vertical during the test; this may usually be ensured by clamping the jacket firmly in position and fixing the pipette by rubler corks. The position should be tested by a plumb line", marle of cotton, passing through the pipette.

The "viscosity" of the cream is represented by the number of secon's that the cream in the pipette takes to flow from the mark above the bulb to that below, which can be determined with sufficient accuracy by any watch with a seconds hand, though it is proferable to use a stop watch. Care must be taken that the cream is free from lumps, or solid particles, and it may advantagcously be filtered through muslin. The pipette should be clean and dry, and the cream should be allowed to remain in the pipette a few minutes before making the test, in order to ensure that its temperature is that of the jacker.

It will be found in practice that it is better to use water of the man daily temperatur in the jacket than water at any constant temperature, lecause a purchase $r$ is not in the habit of reducing cream to a temperature of $(\mathrm{say}) 60^{\circ} \mathrm{F}$. before passing judgment on its thickness. 
At the same time that the viscosity is estimated a determination of the fat should be made by one of the methods recommended (pp. 178 and 187).

The relation between viscosity and fat can be calculated by the formula given above, which may be expressed, for practical use, as

$$
\log (\log \mathrm{V})=3 \log \left(\frac{107 \cdot 527 \mathrm{~F}}{11 \mathrm{~F}+96 \cdot 5}\right)+\log x
$$

Or,

$$
\log (\log \mathrm{V})=2 \cdot 7 \log \mathrm{F}+\log x_{i}
$$

A standard viscosity must be tixed, which evidently must be deterinined by each operator to suit his apparatus, and the conditions under which it is necessary to work; the value of $\log x$ or $\log x^{\prime}$ having been found from the determination of viscosity and fat, the percentage of fat which will correspond to the standard viscosity can readily be calculated.

If $a$ be the percentage of fat found in the cream, and $b$ the percentage of fat which will be contained in the cream of standard viscosity, the cream may be reduced to standard viscosity by adding to each 100 parts $100\left(\frac{a-b}{b}\right)$ parts of separated milk, or $100\left(\begin{array}{l}a-b \\ b-f\end{array}\right)$ parts of milk containing $f$ per cent. of fat. The figure 3.5 may generally be used for $f$ without appreciable error.

As an example the following result may be taken:-

$$
\begin{aligned}
\mathrm{V} & =170 \\
\log v & =2 \cdot 23045 \\
\log (\log v) & =\log 2 \cdot 23045=\cdot 34539 \\
\mathrm{~F} & =61 \cdot 4 \\
107 \cdot 527 \mathrm{~F} & =63.95 \\
\cdot 11 \mathrm{~F}+96 \cdot 5 &
\end{aligned}
$$

$\log 63 \cdot 95=1 \cdot 80584$, and $3 \log 63 \cdot 9 \overline{5}=5 \cdot 41752$

then

$$
5 \cdot 41751=\cdot 34839+5 \cdot 06913
$$

Now let the standard viscosity be 25 .

$$
\begin{array}{lrl} 
& \log 25=1 \cdot 39794, \text { and } \log 1 \cdot 39794=\cdot \mathbf{1 4 5 5 0} \\
\text { therefore, } & 5 \cdot 21463=\cdot 14550+5 \cdot 06913 \\
\text { now } & 5 \cdot 21463=3 \times 1 \cdot 73821=3 \log 54 \cdot 7,
\end{array}
$$

and the percentage of fat in cream reduced to standard viscosity is 52.0 per cent. by weight, or $54 \cdot \tau$ per cent. by volume.

Now

$$
a=61 \cdot 4 \text {, and } b=52 \cdot 0
$$

then

$$
100\left(\frac{a-b}{b-3 \cdot 5}\right)=19 \cdot 4
$$

that is, to each 100 parts of cream 19.4 parts of milk must be added to reduce it to standard thickness.

By the formula $\mathrm{V}=10^{x, \mathrm{~F}^{2 \cdot 7}}$ the percentage of fat calculaterl in the cream of standard viscosity is $51 \cdot 7$, which is a figure sufficiently close for practical purposes. 
Artificial Thickening of Cream.-Cream has been artificially thickened by the addition of varions foreign substances; thus, gelatine, isinglass, and snbstances of like nature have been employed, but withont great success, as the cream thus treated has an appearance markedly different to that of genuine cream. The following method, due to Stokes, may be apjlied to detect gelatine in cream :- To 10 grammes (approximately) of cream add 25 c.c. of water and 2 c.c. of Wiley's acid mercuric nitrate solution (p. 78), and shake well; filter through a dry filter. In the presence of much selatine the filtrate cannot be obtained clear, and it is not essential that it should be so. On adding a saturated aqueous solution of picric acid a yellow precipitate is formed in the presence of gelatine; if the quantity of grelatine be but small, the precipitate does not form at once, but the solution becomes turbid, and precipitates after a lapse of some minutes. Starch, which has been gelatinised bv heating, has also been used; this, of course, is readily detected by the characteristic blue coloration siven with tincture of jodine. Of comparatively recent introduction is "viscogen," which is a solution of lime in cane-surar syrup; the addition of a small amount of this substance has a remarkable effect in increasing the thickness of cream.

The following table shows the results obtained with various types of separators; the experiments with thin cream were made by Vieth in Hameln, and those with thick cream by the author at the Aylesbury Dairy Company. The Balance and the Alexandia separators are very similar, and the two serjes are comvaralsle:-

\begin{tabular}{|c|c|c|c|c|c|c|c|c|}
\hline \multirow[b]{2}{*}{ 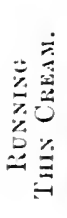 } & Name of separator. & 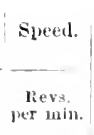 & $\begin{array}{l}\begin{array}{l}\text { Capa- } \\
\text { cily. }\end{array} \\
\text { (ialls, } \\
\text { ber hir. }\end{array}$ & $\begin{array}{c}\text { Yield of } \\
\text { Crean. } \\
\text { Per ct. }\end{array}$ & \multicolumn{4}{|c|}{$\begin{array}{l}\text { Percentage of Fat in } \\
\text { separaled Milk. }\end{array}$} \\
\hline & $\begin{array}{l}\text { Burmeister \& Wain, } \\
\text { AA, } \\
\text { Mlphail. : } \\
\text { Bilance, : }\end{array}$ & $\begin{array}{l}\text { Revs. } \\
\text { ret min. } \\
2700 \\
5600 \\
7000\end{array}$ & $\begin{array}{l}\text { Galls. } \\
\text { fer lir. } \\
247 \\
2.77 \\
169\end{array}$ & $\begin{array}{l}\text { Per et. } \\
12 \cdot 15 \\
12 \cdot 97 \\
13 \cdot 51\end{array}$ & $\begin{array}{l}\text { No. of } \\
\text { sanples. } \\
274 \\
343 \\
267\end{array}$ & $\begin{array}{l}\text { Max. } \\
\cdot 15 \\
\cdot 0.5 \\
.05\end{array}$ & $\begin{array}{l}\mathrm{Min} . \\
\cdot 50 \\
\cdot 25 \\
\cdot 30\end{array}$ & $\begin{array}{l}\text { Aver } \\
\text { age } \\
\cdot 24 \\
\cdot 10 \\
\cdot 15\end{array}$ \\
\hline 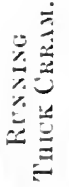 & $\begin{array}{l}\text { Burmeister \& Wain, } \\
\text { B (modified), . } \\
\text { Alexandra I., } \\
\text { Alpha I, . } \\
\text { lussian, . }\end{array}$ & $\begin{array}{l}4000 \\
6000 \\
51000 \\
7800\end{array}$ & $\begin{array}{r}80 \\
1 \leq 0 \\
250 \\
120\end{array}$ & $\begin{array}{l}6 \cdot 0 \\
6 \cdot 0 \\
6 \cdot 0 \\
6 \cdot 0\end{array}$ & $\begin{array}{l}115 \\
233 \\
177 \\
12\end{array}$ & $\begin{array}{l}.05 \\
.0 .5 \\
.05 \\
.15\end{array}$ & $\begin{array}{r}30 \\
30 \\
\cdot 34 \\
35\end{array}$ & $\begin{array}{l}15 \\
.14 \\
.19 \\
.28\end{array}$ \\
\hline
\end{tabular}




\section{CHAPTER V. \\ BIOLOGICAL AND SANITARY MATTERS.}

Contents. - The Decomposition of Milk-Micro-organisms-Action on Milk-Pathogenic Organisms-Conveyance of Disease-Water Supply -Inspection of Source-Analysis of Water-Bacteriological Examination - Summary of Sanitary Precautions - Products formed from Milk by Micro-organisms.

The Decomposition of Milk-Micro-organisms. - The decomposition of milk is due to the action of micro-organisms. The description of their life-history, and the means of sepratating and identifying them belong to the science of Bacteriology. The following slight sketch will, however, be found of use to the dairy chemist:-

Classification. - Micro-organisms belong to the vegetable kingdom and are classed among the fungi; they are divided into

Schizomycetes or fission-fungi.

Saccharomycetes or yeasts.

Hyphomycetes or moulds.

The Schizomycetes are again divided into families according to their shape and mode of growth :-

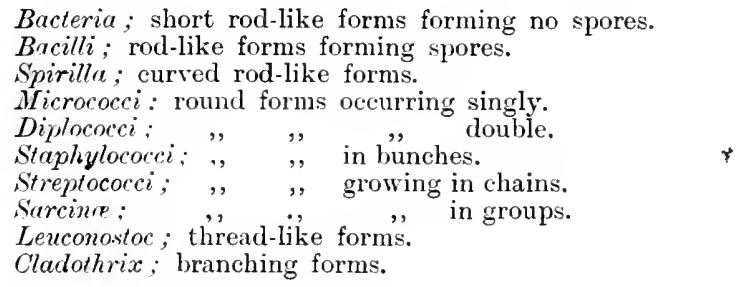

The distinction between these forms is by no means absolutely defined; thus many species forming spores with difficulty or only under certain conditions, which were formerly classed as Bacteria, are now called Bacilli. Some organisms grow as micrococci, streptococci, spirilla, and leuconostoc.

\section{Action on Milk.}

For the purposes of the dairy chemist micro-organisms may be classed according to their action on milk, as follows :- 
Those acting on milk-sugar $(a)$ producing lactic acid;

(l) ,, butyric acid ;

(c) ,, alcohol.

Those acting on proteids (a) curdling milk without acidity and not dissolving the curd;

(b) curdling milk without acidity and afterwards dissolving the curd ;

(c) peptonising the proteids without curdling the milk.

Those producing coloured substances.

Those having no action on milk.

We may also place in another class those which are pathogenic.

Milk is a model food for micro-organisms, for it contains in an assimilable form all those compounds which are necessary for the sustenance of life.

It has been shown by experiment that it is possible to obtain milk which is quite free from micro-organisms. It is necessary, however, to reject the first portions drawn, as these contain micro-organisms which have found their way down the duct of the teat. The last portions are practically sterile, and it is highly probable the few organisms found were due to accidental contamination of the milk during its passage from the teat into the sterilised bottle into which it was drawn. Practically speaking, all the organisms found in milk fall in after milking; in certain diseases-e.g., tuberculosis of the uddel-the Bacillus of tuberculosis is not derived from external sources, but passes from the diseased tissue into the milk.

Generally speaking, micro-organisms only develop between the temperatures of $4^{\circ} \mathrm{C} .\left(39^{\circ} \mathrm{F}\right.$.) and $50^{\circ} \mathrm{C} .\left(122^{\circ} \mathrm{F}\right.$.) ; each organism has an optimum temperature-i.e., one at which its development and action are most rapid this varies from $12^{\circ} \mathrm{C}$. $\left(53.6^{\circ} \mathrm{F}\right.$.) to $40^{\circ} \mathrm{C} .\left(104^{\circ} \mathrm{F}\right.$.) in different species; the optimum temperature of pathogrenic organisms and of most of those acting on milk is about blood-heat. Among other conditions which regulate their development are (1) the amount of acid present in the milk-thus the organisms which produce lactic acid are paralysed in their functions when more than about 1 per cent. has bern produced; and (2) the presence or absence of oxygen. Some organisms can do without oxygen, and are called anëerobic; others roquire it for their life processes, and are designated rerobic.

Lactic Fermentation.-The most commonly observed effect of the action of micro-organisms is the souring of milk. This is clue to a numerous elass of organisms, chiefly bacteria and bacilli, which convert the milk-suenr into lactic acid. The chemical equation for this change usually given is

$$
\mathrm{C}_{12} \mathrm{H}_{22} \mathrm{O}_{11}+\mathrm{OHI}_{2}=4 \mathrm{C}_{3} \mathrm{H}_{6} \mathrm{O}_{3} \text {. }
$$

'The change, howerer, never proceeds in this delightfully simple manner, crrtain quantities of carbon dioxide being 
always produced; by keeping up a free supply of oxygen a very large proportion of carbon dioxide can be obtained. Some lactic ferments give an amount of lactic acid agreeing approximately with the above equation; others produce notable amounts of alcohol and other products. Other organisnis, again, produce very small quantities of lactic acid and large amounts of other sulistances. Hueppe has studied this class of organisms minutely and has described many species; few of these form spores and are destroyed with comparative ease by heat; generally speaking, their optimum temperature is about $35^{\circ} \mathrm{C} .\left(97^{\circ} \mathrm{F}\right.$.).

Butyric Fermentation.-When this takes place the milk coagulates without the development of acidity, but the milk becomes alkaline; a bitter taste is acquired, the precipitated casein is redissolved, and butyric acid is formed; an unpleasant smell is usually developed. This fermentation, which does not readily occur if lactic acid is developed, appears to be also caused by many micro-organisms, which attack both milk-sugar and casein. When this fermentation takes place, the solid portion of the milk is reduced to a very much greater extent than by the lactic fermentation.

Alcoholic Fermentation.-This does not readily occur in milk. As already mentioned, small quantities of alcohol are produced as bye-products by some organisms; ordinary yeasts Saccharomyces cerevisice, \&c., do not cause fermentation of milksugar, but one species of Saccharomyces is known which converts the bulk of the milk-sugar into alcohol ; this is found in kephir grains, together with organisms producing lactic acid and others acting on the proteids.

Curdling Organisms.-These organisms act on the casein by the secretion of an enzyme, which resembles rennet in its action; these are usually bacilli, which readily form spores and are difficult to kill by heating.

Organisms which Curdle without Acidity and Redissolve the Curd.-This class is a very large one; the organisms act by the secretion of enzymes having proteolytic functions analogous to pepsin and trypsin. Many of the organisms producing butyric acid belong to this class; among the most noticeable of which are the hay- and potato-bacilli.

Organisms which Peptonise the Milk without Curdling. -This class is probably more numerous than has been described; they also act by the secretion of a proteolytic enzyme. It is rare to find milk which shows their characteristic behaviour, as there are generally other organisms present which curdle the milk. When cultivated in sterile milk, no action is at first apparent, but the milk gradually becomes more and more transparent till it assumes an appearance like a liquid jelly. "The author has separated an organism of this class from "mazoum," an Armenian preparation. 
Chromogenic Organisms-Milk "out of Condition."Several organisms have the property of producing coloured substances: these, and one or two other elasses, are the chief causes of milk being "out of condition."

Blue Hilk.- Sometimes the formation of dark blue patches on the surface of milk, having the appearance of a drop of blueblack ink which has fallen in, is noticed. This is due to an organism called B. syncyanus or B. cyanogenus; when cultivated alone a grey colour is produced, which turns an intense blue on the addition of acids; the blue colour is only noticed if the milk be sour with lactic acid.

Red Mill.-This is occasionally due to the action of microorganisins; it is usual to aseribe the formation of red milk to Micrococcus prodigiosus, which forms an intense blood-red substance, but it is doubtful whether this organism is commonly the cause. The colour is usually of a far more pinkish tinge, and is due to the pink yeast, Micrococcus rosaceus, Bucillus lactis erythrogenes, or Sarcinc rosea. The organisin causing a red colour varies aceording to the distriet, and only one organism is usually found in any distriet.

A red colour in milk may be due to the presence of madder in the food eaten by the eattle, but far more frequently arises from the presence of blood; this is produced by a diseased state of the udder, but far more frequently by some slight local damage, through a kick or a blow resulting in the breaking of a small blood-vessel in the udder.

Yellow Hilk.-An organism which curdles milk and redissolves the eurd to form a yellow liquid has been described as Bacillus synxantlus ; there are probably several organisms which jroduce a yellow colour; all seem to have proteolytic functions. Yellow milk is very rare, thouglı it is very common to see dirty vessels which have contained milk become quite yellow.

G'reen milk, riolet milk, and litter milk have been found to be prodnced by micro-organisms. Bitter principles may be derived from the food of the cattle, and some, though not all, of the butyrie ferments give rise to a bitter taste. l'eptones produced from easein may also be the cause of bitterness.

Ropy Milk.-Milk oceasionally, instead of remaining liquid, lecomes a thick slimy mass; if a glass rod is dipped into milk which has become ropy and withdrawn, a portion of the milk adheres and can be drawn out in long threads. Sometimes this action is confinml to the cream on the surface, but with other organisms the whole milk beeomes ropy.

Soapy Milk.-After a fow hours milk has been known to acquire a fishy orlour, alkaline renetion, and soaly taste. Herz regards this as due to a discase of the cow. and has found that such samples have a high specitic gravity; Wrigmann has identified an organism, which he also found in the straw used as a litter, which gave a soapy taste to milk. 
Moulds.--White mould (Oidium lactis) is very commonly found on sour milk; it forms a tough white skin on the surface, which is entirely formed by the hyphre and mycelium of the mould. A brown mould, which penetrates down into the milk, is sometimes observed. Green mould, Penicillium glaucum, also grows on milk and is the colouring agent of some cheeses-e.g., Roquefort and Gorgonzola.

Pathogenic Organisms-Conveyance of Disease through Milk.- If, as already mentioned, a cow is suffering from tuberculosis of the udder, the bacillus passes into the milk. It has been proved that the organism retains its toxic properties, and to this cause the bulk of cases of infantile tubercular intestinal disease can be traced. Tuberculosis is by no means an uncommon disease iu cows. Evidence was given before the Royal Commission on Tuberculosis that in Copenhagen and Berlin, where all animals before being slaughtered are systematically examined by veterinary experts, the percentage of oxen and cows affected with tuberculosis was $17 \cdot 7$ and $15 \cdot 1$ per cent. respectively of the total number examined. In many herds the number exceeds this; on one farm as many as 80 per cent. of the cattle were affected.

In a large proportion of the cattle the disease did not affect the milk-producing organs, and in these the milk did not contain the tubercle bacillus; in a very noticeable proportion the milk was, however, affected. As there is no certainty that the disease may not spread to the udder, even though the bacillus be not detected in the milk, the presence of tuberculosis in a cow shonld always be taken as a sign of danger.

On the Continent and in America this subject has received much more attention than in this country, but now that the report of the Royal Commission on Tuberculosis is completed, it may be expected that legislation will follow, which will minimise this cause of infection.

An obvious means of preventing infection by tuberculosis is to remove the diseased cattle, and only use healthy cows as the source of milk supply. As the tubercle bacillus is comparatively easily destroyed by heat, pasteurisation of milk may be resorted to to destroy the organisms; keeping the milk for a quarter of an hour at $70^{\circ} \mathrm{C}$. $\left(162^{\circ} \mathrm{F}\right.$.) will practically remove the source of infection. Another, but less satisfactory means, is to mix the milk with that of healthy cows and trust to Providence for the presence of sufficient lactic acid organisms to destroy the tubercle bacilli; even if they are not destroyed, they are sometimes so diluted that they have no toxic effect on healthy adults, though children and persons weakened by disease or predisposed by heredity to consumption may be affected.

Other diseases-pleuro-pneumonia, foot and mouth disease, and scarlatina (or an analogous skin disease)-may be derived 
from the cattle. These are much less common than tuberculosis and less insidious, as the symptoms can be detected with comparative ease in the cows. Practically speaking, tuberculosis is the only disease which needs to be guarded against by systematic veterinary inspection.

Conveyance of Disease through Contamination of the Milk.-The labours of the late Ernest Hart in collecting statistics have conclusively shown that typhoid, cholera, scarlet fever, and diphtheria can be conveyed through milk.

There are practically two causes: (1) the occurrence of the disease in the milkers and those handling the milk and their families; and (2) the presence of the organisms to which the malady is due in water used for "cleansing" the utensils or for adulterating the milk.

The epidemics of scarlet fever and diphtheria which have been spread through milk have almost all been due to the milk being handled, shortly after milking, by those either affected with the disease, or living in the same house with sufferers. The remedy is, of course, obvious; a rule should be made in every dairy that all employes who feel unwell should absent themselves from their work, and pay an immediate visit to a medical man; if any members of their families be ill, medical advice should be similarly ol,tained; and if the clisease be infectious, the employé must be at once suspended from duty, and not aliowed to go near the dairy.

It is found in practice that this regulation can be carried out

(1) By the employer providing for the services of a medieal man.

(2) By the payment of full wages to any employe who is suffering from infectious discase, and suspended from duty.

(3) by a distinct understanding that the breaking of the regulation by an employe means instant dismissal without notice.

Water-borno Diseases.-Typhoid and cholera, which are essentially water-borne diseases, have, in the majority of cases investigatet, been lue to the use of contaminated water for the cleansing (sic) of dairy utensils; the small amount of water left on the sides of the vessel is suflicient, if the water contain virulent germs, to infect the milk ; even more so does this occur if the practice of washing out the dairy vessels with a little water after milking, and adtling this to the milk, prevails. The precantions against this form of infection are also obvious, though more difficult to carry out in practice than those mentioned above.

\section{Water Supply.}

$\Lambda$ water supply which is not contaminated, or liable to contamination, and a gond system of sanitation is necessary. Before milk is supplied from a farm or dairy the water supply must be 
rigidly investigated. The investigation may be conveniently divided into three parts.

(1) Inspection of source.

(2) Chemical analysis.

(3) Bacteriological examination.

\section{Inspection of Source.}

The following sources of supply are almost always satisfactory :-

(1) Deep artesian borings.

(2) Deep wells passing through an impervious stratum-e.g, chalk.

(3) Springs fed by an uninhabited watershed-e.g., springs in the sides of hills.

Public water supplies, mountain rills, and wells sunk in open ground remote from habitations are very frequently-but by no means always - of a satisfactory nature.

On the other hand, shallow wells near dwellings, ponds, small brooks, and wells in pervious strata-e.g., corrl ragstone-are usually unsatisfactory.

The following points must be considered to be highly unsatisfactory :-The proximity of privies, cowsheds, \&c.; the trend of the lands from habitations to the source; faulty conditions of the sides of a well (otherwise satisfactory), which may allow surface drainage to enter ; and, except in the case of springs on the sicles of uninhabited hills, a marked diminution of the supply after drought, and increase after rain.

It is advisable to ascertain the geological formation, and whether artificial fertilisers are much used in the vicinity; if this is done to a large extent, some of the chemical evidence may be discounted.

\section{Chemical Analysis.}

Taking of Samples.-At least half a gallon of water must be taken for the analysis; a "Winchester quart" bottle is convenient for this purpose. The first portions-say, 10 to 20 gallons-should invariably be rejected, and the bottle should be rinsed with the water, filled nearly full, care being taken to avoid undue aëration, and despatched to the laboratory as quickly as possible.

The following data should be obtained :-

Colour. - This should be observed in a layer at least 12 inches in length; a yellowish-green tint is always suspicious, and points to sewage contamination; a brownish or brownishyellow indicates vegetable products, not necessarily harmful, but usually undesirable. A nearly colourless water, with a faint blue or bluish-green tinge, is shown by most good waters.

Smell.-A small wide-necked bottle is half filled with the 
water, which is warmed to about $60^{\circ} \mathrm{C} .\left(140^{\circ} \mathrm{F}.\right)$; the water is shaken, the stopper removed, and the smell noted. Foul smells show badly polluted waters; a peculiar sweetish unpleasant odour is often given by waters containing sewage. Few waters are absolutely devoid of smell when tested thus; for instance, waters from the Oxford clay sometimes smell of petroleum, and a smell of pines is not uncommon in wooded distriets.

Analytical Figures-Total Solids. -250 c.c. (or 100 c.c.) are evaporated in a weighed basin, and dried to constant weight in the water-bath.

Loss on Ignition.-The resiclue is ignited over a very small flame; the swell of the rapours given off should be noted, as polluted waters often give an unpleisant smell. Much blackening indicates a large amount of organic matter; if nitrates are abundant, red nitrous fumes may be observed.

Chlorine. -100 c.c. of the water are placed in a white porcelain basin, 1 e.e. of a 1 per cent. solution of pure potassium chromate added, and silver nitrate ( 4.7887 grammes $\mathrm{AgNO}_{3}$ per litre) run in till a faint reddish colour is produced. The quantity of silver nitrate required to give a similar tint with 100 c.c. of distilled water is subtracted, and the difference represents milligrammes of chlorine.

Free and Albuminoid Ammonia. - 250 c.c. of water are placed in a stoppered Würtz flask, to the delivery tube of which a condenser is conneeted; the condenser must be a good one, and drawn out at the end, so that the diameter of the opening does not exceed 1 millimetre. If the water be distinctly alkaline to methyl orange, nothing need be added; but if not, a little freshly ignited sodium carbonate must be dropped in. A flame is placed under the flask, and about 1:5 c.c. of the water distilled and collected in a stoppered bottle. As soon as the flame is placed muder the flask, about 250 c.c. of distilled water are placed in a Hask and brought to the boil (or nearly so) ; the flask is renroved to the bench, 10 grammes of caustic soda added, and, when dissolution of this is complete, about 1 gramme of potassiun permanganate dropped in. 'This solution of alkaline permanginate is hoiled, while the distillation is proceeling, at such a rate, that its bulk, when 125 e.c. have distilled from the flask, should be just ahout suflicient to make up the original volume.

The alkaline permanganate solution is alded to the Wuirtz thask ; and a further 1.5 e.e. are distilled off; and collected in a second stoppered lootile.

The first bottle continins the free (or salime) ammonia, and the second the alhuminoil (or ormanic) ammonia.

The contents of the luttles are well mixed, and 50 c.e. of each are placed in a Nessler cylincler, 2 c.c. of Nessler solution added, and the tint in each of them matehed hy placing a known volume 
of standard ammonium chloride solution in a Nessler cylinder, making up to 50 c.c. with distilled water free from ammonia, adding 2 c.c. of Nessler solution. The waters must be allowed to stand for five or ten minutes before the final comparison is made, as the colour does not develop instantaneously.

After a little practice, it will be found easy to make an approximate match of tints at the first trial. It is not necessary to do this exactly. If the cylinder which contains the distillate is of approximately the same depth of shade as the standard, a little may be poured from the darker cylinder till the colours are matched; the positions of the cylinders should be several times reversed before finally deciding that they are eyual, as a shadow may be cast on one cylinder more than the other and nake it appear darker than it really is.

If the cylinder containing the distillate is the darker, and some of the solution has been poured from it, the calculation is performed as follows :-Let $x=$ the weight of ammonia equal to the amount of standard ammonia solution taken, $y=$ the amount of solution poured out, and $z=$ the total amount in the cylinder; then the weight of ammonia in 50 c.c. of the distillate $=x \times \frac{z}{z-y}$, and the amount of ammonia obtained from 250 c.c. of water is found by multiplying by the total volume of the distillate, which should be measured, and dividing by 50 .

If the cylinder containing the distillate is the lighter, and some of the solution bas been poured from the standard, the calculation is slightly different:-Let $x=$ the weight of ammonia equal to the amount of standard ammonia solution taken, $y=$ the anount of standard solution poured out, and $z=$ the total amount in the cylinder containing the standard solution; then the weight of ammonia in 50 c.c. of the distillate $=x \times \frac{z-y}{z}$.

Nessler Solution.-Dissolve 35 grammes of potassium iodide in 100 c.c. of water; next dissolve 17 grammes of mercuric chloride in 300 c.c. of water; reserve a little of the potassium iodide solution and add the mercuric chloride solution to the rest, till a permanent precipitate is formed; then add the remainder of the potassium iodide solution and cautiously drop in mercuric chloride solution, till a faint permanent precipitate is left. Dissolve 160 grammes of potassium hydroxide in water, add this solution to the mercury potassium iodide solution and make up to 1 litre. The solution is more sensitive if a little more mercuric chloride solution is added. The solution is left to settle and the clear portion decanted for use.

Standard Ammonium Chloride Solution. - Weigh out $\cdot 3146$ gramme of pure ammonium chloride, and dissolve in 100 c.c. of 
ammonia-free water; dilute 10 c.c. of this to 1 litre with ammoniafree water for use. 1 c.c. $=\cdot 00001$ gramme $\mathrm{NH}_{3}$.

Ammonia-free Water. - Boil ordinary distilled water in a flask to half its bulk and cool in an atmosphere free from ammonia.

Nitric Acid.-Place about 01 gramme of diphenylamine in a poreelain basin, ardd 1 c.e. pure sulphuric acid, and mix; run two or three drops of the water down the sides of the basin, so that they will flow over the surface of the acid. In the presence of nitrates a blue colour will be developed. From the amount and depth of enloration produced a rough illea of the amount of nitric acid present can be formed, which will be useful in the quantitative estimation.

Measure 1 c.c. of the water by an exact pipette into a poreelain basin and evaporate to dryness on the water-bath; measure also a knewn volume of the standard potassium nitrate solution into a porcelain basin and evaporate to dryness. To each add 1 c.c. of a sulphuric acid solution of salicylic acid ( 2 grammes of salicylic acid dissolved in 100 c.c. of pure sulphuric acid) and heat for five minutes on the water-bath. Dilute to about 20 c.c. with distilled water, make alkaline with ammonia, and dilute to 50 c.c. Compare the colours produced in Nessler cylinders and calculate in the same manner as directed under Free and albuminoid ammonia.

Standard Potassium Nitrate Solution.-Dissolve 1.85 grammes of pure potassium nitrate in 1 litre of water; dilute 10 c.c. to 1 litre for use. 1 c.e. $=00001$ gramme $\mathrm{N}_{2} \mathrm{O}_{5}$.

It the chlorine be high, the nethod just deseribed gives results seriously below the truth and the following method miny be used :-

Place about 200 c.c. of water in a wide mouth stoppered bottle with three pieces of copper-zinc couple. Leave for twenty-four hours in a warm place; then take 100 c.c. and distil off 50 c.c. of this, after making alkaline with sodium carbonate. Estimate the ammonia in the 50 c.c. (or an aliquot part, 5 or 10 c.c. diluted to 50 c.c. ale often sufficient) in the manner previously directed. The ammonia found (less the free ammonia present) multiplied by $3 \cdot 2$ will give the nitric acid (as $\mathrm{N}_{2} \mathrm{O}_{5}$ ).

Preparation of Copper-Zine Couple.-Cut a number of pieces of shert zinc $4^{\prime \prime} \times 1$ ", and immerse them successively in 2 por cent. caustic sola solution, distilled water, 2 per cent. sulphuric acid solution, and distilled water, keeping them for ahont two minutes in each solution and agitating them. Place them in 3 per cent. solution of erystallised copper sulphate till a firm black deposit is obtained; well rinse them in listilled water, without undur handling; and preserve in a stoppered lwottle filled with strong alcoliol.

Nitrites.-Dissolw: about 0.5 gramme of meta-phenylene- 
diamine in dilute sulphuric acid ( 10 c.c.); add 10 c.c. of water and allow the mixture to stand. A pink coloration is produced, if nitrites be present.

Oxygen absorbed from Permanganate.-Clean out a stoppered bottle with chromic acid and rinse well with distilled water. Take 250 c.c. of water, add 10 c.c. of dilute sulphuric acid and 10 c.c. of standard potassium permanganate solution, mix, and keep at a temperature of about $80^{\circ} \mathrm{F} .\left(27 \cdot 4^{\circ} \mathrm{C}\right.$.) for four hours. Add a crystal of potassium iodide and titrate with standard sodium thiosulphate solution till only a faint yellow colour remains; then add a little starch solution and continue the titration till the blue colour disappears. To 250 c.c. of distilled water ald 10 c.c. of sulphuric acid and 10 c.c. of potassinm permanganate; and titrate with standard sodium thiosulphate solution (2 grammes per litre).* The difference between the amounts of sodium thiosulphate solution used, divided by the amount of sodium thiosulphate used for the sulphuric acid, potassium permanganate and distilled water, and multiplied by 001 will give the weight of oxygen absorbed by 250 e.c. of water.

Dilute Sulphuric Acid.-Mix 100 c.c. of pure sulphuric acid cautiously with 300 c.c. of water, cool to $80^{\circ} \mathrm{F}$, and add so much potassium permanganate solution that a faint pink tinge remains after four hours.

Standard Potassium Permanganate Solution.-Dissolve .395 gramme of pure potassium permanganate in 1 litre of distilled water. 1 c.c. $=\cdot 0001$ gramme oxygen.

Starch Solution.-Make an emulsion of $5 \mathrm{gramme}$ of starch in 2 c.c. of water and add this to 50 c.c. of boiling water. Boil for tive minutes and cool.

Phosphates.-Dissolve the ignited resiclue from the total solid estimation in a little dilute nitric acid; evaporate the solution to dryness in a porcelain dish, and take up with 1 c.c. of dilute nitric acid, filter the solution, and wash the filter paper with very small amounts of water. Add to the filtrate, which should not exceed 2 or 3 c.c., an equal bulk of ammonium molybdate solution and warm to $60^{\circ} \mathrm{C}$. $\left(140^{\circ} \mathrm{F}\right.$.). A yellow coloration is called a "very faint trace" of phosphates, and a distinct precipitate a "very heavy trace."

Ammonium Molybdate Solution.-Mix 14 c.c. of strong ammonia (sp. gr. $\cdot 880$ ) with 28 c.c. of water, and add 10 grammes of molybdic acid and stir till all is dissolved. Add this solution, slowly and with constant stirring, to 125 c.c. of nitric acid (sp. gr. 1.2); stand the solution in a warm place for a few days and decant the clear solution for use. A slight deposit may form on keeping.

* The addition of a little, say 05 gramme, salicylic acid will render this solution permanent. 
Interpretation of Results of Water Analysis.-Good waters contain, renerally speaking:-

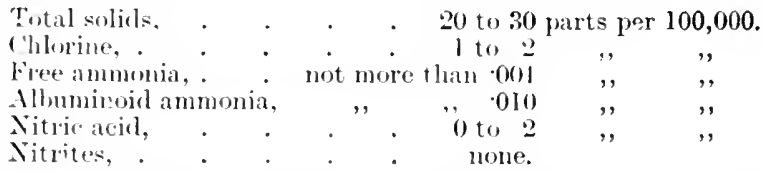

"They" ahsort, less than 'l part per 100,000 of oxygen, and are practically frece from plosphates.

The total solids may be higher than the limits named, in chalk waters and in mineral water.

A high chlorine content may be due to beds of rock salt-e.g., in Cheshire-or to admixture with salt derived from the sea (near the coast); it is, however, usually due to sewage.

Deep well waters often contain large amounts of free ammonia; and water which has passed through iron pipes may also contain free ammonia and nitrites.

A high albuminoid ammonia is usually very undesirable, thoush not conclusive of pollution by sewage; pools into which dead leaves fall may give rise to high albuminoid ammonia.

Nitric acid is a most reliable datum; any amount above 3 or 4 parts per 100,000 is ertainly due to pollution.

The presence of nitrites is always unfavourable, except when the water has passed through iron pipes.

The amount of oxygen absorberl does not give much information as to whether a water is polluted with sewage; high figures are often due to vegetable matter. The proportion of oxygen absorbed to albuninoid ammonia is otten a useful datum. Where vegetable contamination has taken place the oxygn absorbed is ten times (or more) the albuninoid ammonia; in polluted waters it is usually less.

The presence of phosphates is usually regarded as an unfavourable symptom ; this may, however, be due to the use of artifieial fortilisers; the nitrie acil may be increased from this earls'.

If waters known to be pure from the same district and from the same geological formation can be obtained, the water can be compares with them; any marked increase in the figures fomm nust be regarded as evidence of pollution. By this means "vidence of contamination is often obtained which wonld be diffienlt, or almost impossible, to acequire from chemical analysis alone.

It must lo rememlered in emmpring waters with a "distriet stanclard" that in the autumn the figures for free and albuminoid ammonia, nitrie aciol, and oxygen aborbed usually are slightly higher than at other times of the ran. 
For further information on the subject works on "Water Analysis" must be consulted. It must be borne in mind that the judging of water supplies is not a subject that can be learnt from books entirely, but that prolonged experience is necessary to properly interpret the results obtained.

\section{Bacteriological Examinations.}

A very simple examination is all that is usually necessars. A sample of the water for bacteriological examination must be taken in a sterilised bottle; a six-ounce stoppered bottle is plugged with cotton wool, and the stopper is wrapped in cotton wool and tied to the neck; the bottle is sterilised for three hours at a temperature of $150^{\circ} \mathrm{C} .\left(350^{\circ} \mathrm{F}\right.$. $)$. The sample is best taken directly after the sample for analysis has been obtained; the plug of cotton wool is removed and the bottle filled with water without being rinsed; then the stopper is quickly removed from its cotton wool wrapping and inserted in the bottle. The examination must be commenced with as little delay as possible; and, if the sample has to be forwarded by post or rail, it should be packed in ice.

The examination usually corsists in making a gelatine cultivation at $22^{\circ} \mathrm{C}$. and an agar cultivation at $37^{\circ} \mathrm{C}$.

Preparation of Nutrient Media-Nutrient Gelatine.-120 grammes of gelatine (Coignet's Extra Gold Label) are dissolved in 1 litre of water on the water-bath; 5 grammes of Liebig's extract of meat and 10 grammes of peptone are added, and dissolved by further heating; the whites and shells of two eggs, stirred up together to make an intimate mixture are next added, and the heating on the water-bath continued till the liquid is cleared. Small quantities of sodium carbonate are now added, with constant agitation, till, on testing with delicate litmus paper, a faint alkaline reaction is obtained. The liquid is now filtered, the filter being kept warm, and the clear filtrate is ready for use. Portions of 10 c.c. are placed in tubes 4 inches long, $1 \frac{1}{4}$ inches in diameter, with a neck $\frac{5}{8}$-inch in diameter, which have been previously plugged with cotton wool and sterilised by heating for three hours at $150^{\circ} \mathrm{C}$. $\left(350^{\circ} \mathrm{F}\right.$.). The nutrient gelatine in these tubes is sterilised by heating to $100^{\circ} \mathrm{C}$. $\left(212^{\circ} \mathrm{F}\right.$.) in steam for fifteen minutes on four successive days.

Nutrient Agar.-Seventeen grammes of finely divided agar are substituted for the gelatine. The preparation is otherwise conducted in the same manner. The filtration is, however, much more difficult and the agar is never so brilliantly clear as the gelatine. If a steam turbine tester is available, it is better to centrifugalise the agar, in tubes of sufficient size to fit into the machine, at the highest rate of speed that the tubes will 
bear, for un hour. The solid matters are removed by centrifugal force, and the agar is clearer than can be olhtained by filtration.

Prepare also a number of test tubes, each containing 9 c.c. of distilled water; plug these with cotton wool; and sterilise. The tubes containing nutrient media and sterilised water must be covered with a rubber eip to prevent evaporation.

Procedure.-Sterilise a pipette delivering 1 c.c. by heating to $150^{\circ} \mathrm{C} .\left(350^{\circ} \mathrm{F}\right.$ ), or by heating all over in the flame of a Bunsen burner. As soon as this is cool, open the bottle containing the sample, and take out 1 e.c. Add this to one of the tubes containing sterilised water and replace the plug immediately. Take out another 1 c.c. and add this to a tule of nutrient agar, which should have been previously liquefied and allowed to cool to $50^{\circ}$ C. $\left(122^{\circ}\right.$ F.). Replace the plug of cotton wool, mix the water and the nutrient agar, and cool under the tap, rolling the tube between the fingers so that the agar is solidified in an even layer wrer the sides.

With another sterilised 1 c.c. pipette add 1 c.c. of the mixture of water with sterilised water to a tube of nutrient gelatine, which has been previously liquefied by heating and cooled to about $27^{\circ} \mathrm{C}$. $\left(80^{\circ} \mathrm{F}\right.$.). Replace the plug of cotton wool, mix the water and the nutrient gelatine, and cool under the tap if the water he cold enough, or by rolling on a block of ice. The gelatine must be spread in an even layer over the sides of the tube.

Place the agar cultivation in an incubator kept at about $37^{\circ} \mathrm{C}$ ( or $100^{\circ} \mathrm{F}$.), and the gelatine cultivation in an incubator kept at about $22^{\circ} \mathrm{C}$. (or $72^{\circ} \mathrm{F}$.) : after two and a-half days the number of colonies that have developed are counted. The best method of comnting is to hold the tubes over a black surface; mark each colony with a dot of red ink, and count the dots. It is usually advisable to divide the surface of the gelatine tube into sections by lines drawn in red ink and to count the colonies in the section separately.

If the water is suspected to be bad, a smaller amount of water may be taken, 5 c.c. or even $\cdot 2$ e.c. If it is supposed that the water is good, the amomnts taken may be increased. The quantities given will, lowerer, usually serve. Many of the colonies on the gelatine will he found to have liguefied the medium, and, if the counting is delayod, the liquid may run down and contaminate the other jurtions. The anthor has found that if the colonies are counted in two and a-half days, no practical inconvenience is found from this sourer.

Interprotation of Rosults. - The grow th of any large number of colonies on the agrar, cultivated at $37^{\circ} \mathrm{C}$. (or $\left.100^{\circ} \mathrm{F}\right)$, must be considered as a very unfavourable sign, as the ordinary water organisms are almost all destroyed at this temperature, while 
the organisms found in sewage, including pathogenic organisms, grow well under these conditions. A few colonies, say 5 to 10 jer c.c., may, however, be found in good water.

The colonies liquefying gelatine are usually those of putrefactive organisms, and any great proportion is undesirable. The number of organisms growing on gelatine varies greatly with the source of the water. Water from deep wells should be almost sterile and certainily should not give more than 100 colonies per c.c.; any number exceeding this may be taken as indicating contamination with surface water. Surface waters which are not contaminated may contain many more organisms, as many as 2,000 per c.c., and often a large number of these (25 per cent.) liquefy gelatine; such waters are generally found to contain organic matter derived from decaying leaves and other vegetable matter.

All waters giving an appreciable number of organisms on nutrient agar and a number of organisms running into many thousands on gelatine may be condemned as unsatisfactory.

By the combined information from inspection of the source, chemical analysis and bacteriological examination, a usually reliable opinion can be made of the purity of the water ; it is even more reliable, if the data are compared with those obtained on waters of known purity from the same district and of the same character.

For other methods of bacteriological examination and for the separation and identification of individual species, works on bacteriology must be consulted.

Summary of Sanitary Precautions.-The following recommendations were made by a commission held under the auspices of the British Medical Journal :-

1. That all milking be carried on in the open air, the animals and operators standing on a material which is capable of being thoroughly washed, such as a floor of concrete or cement. Such a floor could be easily laid down in any convenient place which can be found. The site chosen should be removed from inhabited parts as far as possible, and should be provided with a plentiful [and pure] water supply.

2. That greater care be expended on the personal cleanliness of the cows. The only too familiar picture of the animal's hindquarters, flanks, and sides being thickly plastered with mud and fæces is one that should be common no longer.

3 . That the hands of the milker be thoroughly washed before the operation of milking is commenced, and that, after being once washed, they be not again employed in handling the cow otherwise than in the necessary operation of milking. Any such handling should be succeeded by another washing in fresh water before again commencing to milk.

4. That all milk-vendors' shops should be kept far cleaner 
than is often the case at present. That all milk-retailing shops should be compelled to provide proper storage accommodation, and that the counters, \&c., should be tiled.

With reference to the last recommendation, it may be mentioned that the regulations of the London County Council provide that all places where milk is stored shall have an impervious floor, and the walls shall be tiled or cemented for a height of 6 feet trom the floor.

The following additional recommendations are chiefly taken from the system arlopted by the Aylesbury Dairy Company :-

1. The cows should be systematically examined by veterinary surgeons; and those in ill-health removed, and their milk not utilised.

2. The sanitaly arrangements of the dairy and health of the employés should be systematically examined by a medical officer, who should be empowered to insist on all unsatisfactory arrangements being instantly remedied, and, in default of this, should have the power to stop the milk supply.

3 . To ensure the proper carrying out of these regulations guarantees should be given that no tinancial loss should result from suspension of the milk supply owing to infectious disease, while very heary penalties should be inposed for contravention of sanitary regulations.

4. All water used for cleansing dairy utensils should be previously boiled, to destror disease germs if accidentally present; and, if possible, the vessels themselves should be steamed.

If the only available water supply be not abore suspicion, an immunity from the consequences of its use may be attained by filtration through a Pasteur-Chamberland filter. This consists of one or more tubes of unglazed porcelain of a special quality, through which water will pass, but which keeps back microorganisms. It has been found that in course of time that certain micro-organisms will grow through the filter, but it appears to he firmly established that pathogenic germs are not among these. 'To secure eflicient working, these filters should be frequently cleaned, and it is advisable to sterilise them by steaming from time to time. They have the advantage of being easily tested, as when efticient they will not, when wet, allow ail under a pressure of $10 \mathrm{ll}$ s. per spuare inch to pass; while, if defective, a passage is afforded at any place which will allow miero-organisms to traverse the filter.

Products formed from Milk by the Action of MicroOrganisms. - Besides butter and cheese, in the manufacture of which micro-organisms play an important part, several preparations are made from milk; among these may be mentioned koumiss, kephir, and mazoum. 
Koumiss.- This preparation was originally made from mare's milk by the Tartars. It is a product of combined alcoholic, lactic, and proteolytic fermentations on milk. Its production first from mare's milk is probably due to the fact that the sugar of this milk very easily undergoes alcoholic fermentation.

The following analyses of mare's milk koumiss are by Vieth :-

\begin{tabular}{|c|c|c|c|c|c|c|}
\hline & & & & I Day old. & 8 Days old. & 22 Days Old. \\
\hline $\begin{array}{l}\text { Water, } \\
\text { Alcohol, } \\
\text { Lactic acid, } \\
\text { Sugar, · } \\
\text { Casein, . } \\
\text { Albumin, . } \\
\text { Albumoses, } \\
\text { Fat,. : } \\
\text { Ash, . . }\end{array}$ & $\begin{array}{l}\dot{0} \\
\dot{\circ} \\
\dot{\circ}\end{array}$ & : & $\begin{array}{l}\cdot \\
\cdot \\
\cdot \\
\cdot\end{array}$ & $\begin{array}{c}\text { Per cent. } \\
91 \cdot 43 \\
2 \cdot 67 \\
\cdot 77 \\
1 \cdot 63 \\
\cdot 77 \\
\cdot 25 \\
\cdot 98 \\
1 \cdot 16 \\
\cdot 35\end{array}$ & $\begin{array}{c}\text { Per cent. } \\
92 \cdot 12 \\
2 \cdot 93 \\
1 \cdot 08 \\
\cdot 50 \\
\cdot 85 \\
\cdot 27 \\
\cdot 76 \\
1 \cdot 12 \\
\cdot 35\end{array}$ & $\begin{array}{c}\text { Per cent. } \\
92 \cdot 07 \\
2 \cdot 98 \\
1 \cdot 27 \\
\cdot 23 \\
\cdot 83 \\
\cdot 24 \\
\cdot 77 \\
1 \cdot 30 \\
\cdot 35\end{array}$ \\
\hline
\end{tabular}

Koumiss is now very largely made from cow's milk by the selection of special organisms.

The following analyses of various kinds of koumiss have been made by Vieth on the preparations of the Aylesbury Dairy Company. The carbonic acid present has not been taken into account; it is, however, always present (except in the earlier stages) in sufficient amount to render the koumiss highly effervescent; hence, the preparation has been termed "milk champagne" on this account.

The term "casein" includes dys-caseoses.

Fule Koumiss.

\begin{tabular}{|c|c|c|c|c|c|c|}
\hline & & & & 1 Day old. & 8 Days Old. & 22 Days Old. \\
\hline $\begin{array}{l}\text { Water, } \\
\text { Alcohol, : } \\
\text { Fat, } \\
\text { Casein, : } \\
\text { Albumin, : } \\
\text { Albumoses, } \\
\text { Lactic acid, } \\
\text { Sugar, } \\
\text { Ash, soluble, } \\
\text {, insoluble, }\end{array}$ & $\begin{array}{l}\dot{:} \\
\dot{5} \\
\dot{5} \\
\dot{.}\end{array}$ & . & $\begin{array}{l}\dot{5} \\
\dot{5} \\
\dot{5} \\
\dot{5} \\
\dot{5} \\
\dot{5}\end{array}$ & $\begin{array}{r}\text { Per cent. } \\
88 \cdot 90 \\
\cdot 15 \\
1 \cdot 35 \\
2 \cdot 01 \\
\cdot 30 \\
\cdot 34 \\
\cdot 34 \\
6 \cdot 03 \\
\cdot 17 \\
\cdot 41\end{array}$ & $\begin{array}{c}\text { Per cent. } \\
90 \cdot 35 \\
.94 \\
1 \cdot 36 \\
1.96 \\
\cdot 23 \\
.53 \\
\cdot 96 \\
3 \cdot 10 \\
\cdot 23 \\
\cdot 34\end{array}$ & $\begin{array}{c}\text { Per cent. } \\
90 \cdot 57 \\
1.04 \\
1.38 \\
1.58 \\
\cdot 20 \\
\cdot 77 \\
1 \cdot 40 \\
2 \cdot 18 \\
\cdot 23 \\
.35\end{array}$ \\
\hline
\end{tabular}


WheY Koumiss.

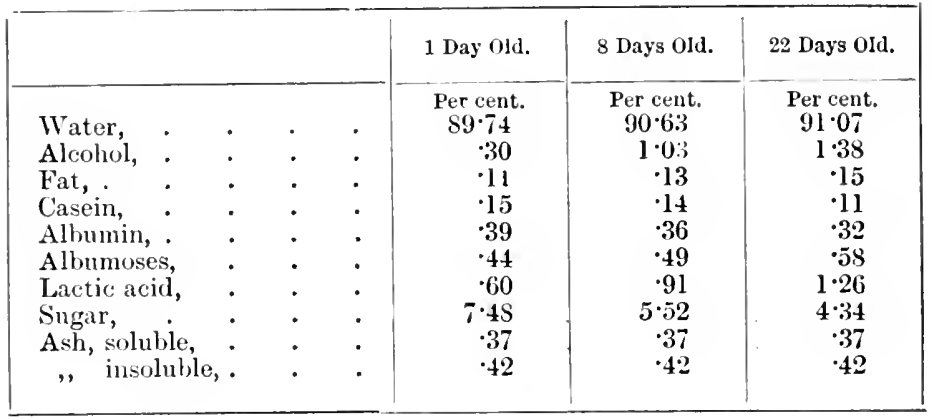

Mediua Koumiss.

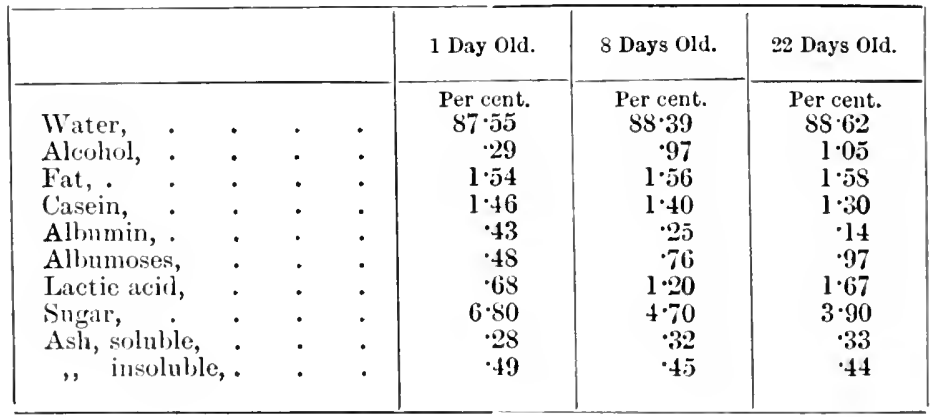

Diabetic Koumiss.

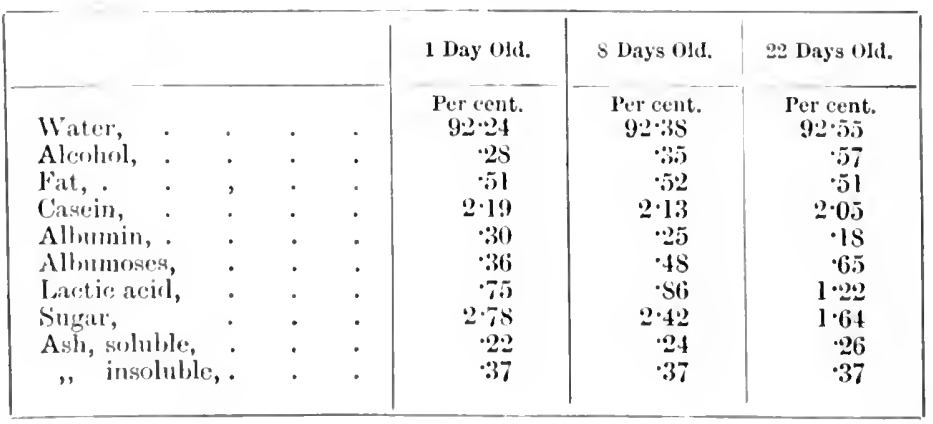




\section{Russian Koumiss.}

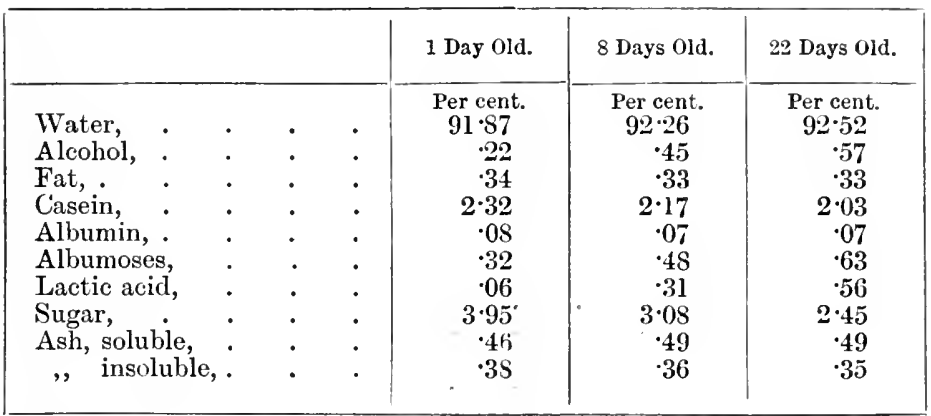

The last preparation-made from skim milk-is not an article of commerce now.

Wiley gives the following mean composition of koumiss prepared in America :-

\begin{tabular}{|c|c|c|c|c|c|c|c|c|}
\hline Water, & & • & $\cdot$ & $\bullet$ & * & & \multicolumn{2}{|c|}{$89 \cdot 32$ per cent. } \\
\hline Carbon diox & de, & - & $\theta$ & $\cdot$ & $\bullet$ & $\cdot$ & $\cdot 83$ & \\
\hline Alcohol, . & . & . & ${ }^{\circ}$ & . & - & . & $\cdot 76$ & \\
\hline Lactic acid, & - & . & - & . & . & - & $\cdot 47$ & , \\
\hline Proteids, & . & - & - & - & - & • & $2 \cdot 56$ & , \\
\hline Fat, . & . & - & - & - & - & - & $2 \cdot 05$ & , \\
\hline Sugar, & . & . & . & . & . & . & $4 \cdot 38$ & ," \\
\hline
\end{tabular}

Koumiss has the advantage of being a food and a stimulant at the same time; and is, for this reason, often prescribed by the medical faculty in cases of disease (e.g., gastritis) when no other food can be retained.

Kephir.-This is a preparation of a similar nature to koumiss and is produced from milk by means of kepliir grains.

The following is the composition of kephir according to various authorities :-

\begin{tabular}{|c|c|c|c|c|c|c|}
\hline & & & & König (mean). & Hammarsten. & $\begin{array}{c}\text { Vieth } \\
\text { (an old sample). }\end{array}$ \\
\hline $\begin{array}{l}\text { Water, · } \\
\text { Alcohol, } \\
\text { Lactic acid, } \\
\text { Fat, . . } \\
\text { Sugar, . } \\
\text { Casein, . } \\
\text { Albumin, . } \\
\text { Albumoses, } \\
\text { Ash, . }\end{array}$ & $\begin{array}{l} \\
\\
0\end{array}$ & $\begin{array}{l} \\
0 \\
\end{array}$ & $\begin{array}{l}0 \\
0 \\
0\end{array}$ & $\begin{array}{c}\text { Per cent. } \\
91 \cdot 21 \\
\cdot 75 \\
1 \cdot 02 \\
1 \cdot 44 \\
2 \cdot 41 \\
2 \cdot 83 \\
\cdot 36 \\
\cdot 30 \\
\cdot 63\end{array}$ & $\begin{array}{r}\text { Per cent. } \\
88.915 \\
.720 \\
.727 \\
3.088 \\
2 \cdot 685 \\
2 \cdot 904 \\
\cdot 186 \\
.067 \\
.708\end{array}$ & $\begin{array}{c}\text { Per cent. } \\
90.09 \\
.64 \\
\cdot 44 \\
1 \cdot 82 \\
1.87 \\
2.90 \\
.07 \\
.45 \\
\ldots\end{array}$ \\
\hline
\end{tabular}


Kephir differs from koumiss chiefly in the comparatively small amount of albumoses it contains, showing that, although the alcoholic and lactic fermentations have taken place, the proteolytic fermentation is very weak.

Struve found in kephir grains :-

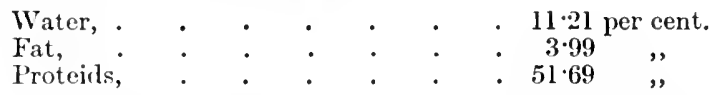

The author has exanined a "kephir powder," which had the following composition :-

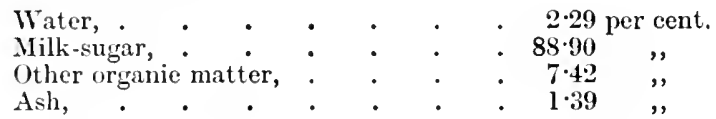

It appeared to be a mixture of milk-sugar with pulverised kephir grains.

Mazoum.-This preparation, lately introduced from Armenia, where it has been made for c $\in$ nturies, has somewhat the appearance of clotted cream; on warming, it separates into a liquid whey and an insoluble curd.

The author has determined the following figures:-

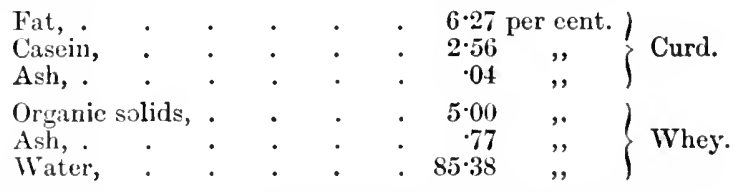

There was no evidence of albumoses in the whey.

Miazoum appears to have been produced by the lactic fermentation of milk enriched with cream; the sample examined was very fresh and proteolytic fermentation was not appreciable.

An organism was separated from mazoum which gave colonies rapidly spreading on the surface of gelatine to $1 \mathrm{c.m}$. or more in diameter, and which produced a slight putrid smell. This organism, which was a bacillus, slowly peptonised milk without curdling it, and finally transformed it into a semi-transparent liquid jelly. 


\section{OHAPTER VI.}

BUTTER.

Contenrs.-Definition of Butter-Composition-Theory of ChurningThe Proximate Analysis of Butter-The Analysis of Butter FatPreparation of the Fat for Analysis-Recapitulation of Properties -Estimation of Volatile Fatty Acids-Saponification EquivalentSoluble and Insoluble Fatty Acids-Colour Tests for Adulterants -Behaviour of Butter Fat with Solvents - Iodine and Bromine Absorption-Heat Evolved by Sulphuric Acid-Physical Examination of Butter Fat-Microscopic Examination-Density-Refractive Index -Viscosity-Melting Point-Detection of Adulteration of ButterInfluence of Keeping on Butter-Buttermilk-Chemical Control of Churning Operations.

Definition.-Butter is the substance produced by churning milk or cream, during which process the fat globules coalesce to form granules; when freshly churned, butter has the appearance of a fine spongy mass; but, after being worked, this assumes a structure homogeneous to the naked eye.

Composition.-Storch gives the following mean composition to butter :-

\section{TABLE XLVII.-Composition of Butter.}

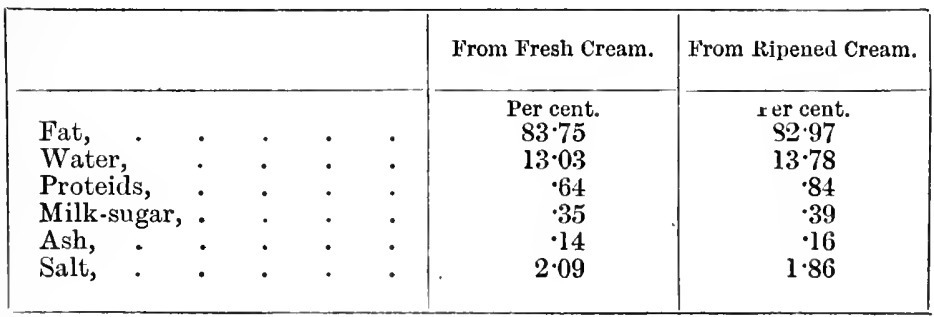

He further argues that the milk-sugar must all belong to the buttermilk, which fills the spaces between the fatty portion; and, from the composition of the buttermilk, calculates the proportion of water, proteids, and ash belonging to this. 
TABLE XLVIII.-Composition of Butter.

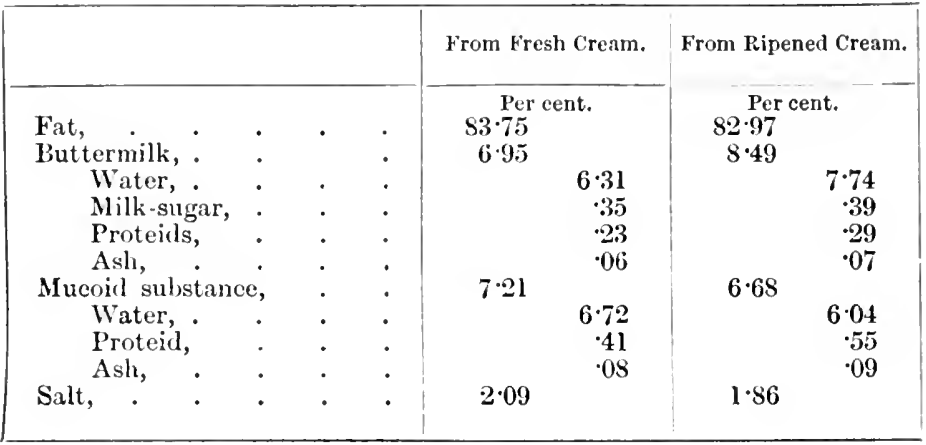

Proportion of Solids not Fat to Water.-Vieth has shown that in butter the proportion of solids not fat to water remains, so long as no water is added, the same as that in milk-i.e., 100 to 10 ; he gives the following average analyses:-

\section{Composition of Different Kinds.}

\section{TABLE XLIX.-Composition of Butters.}

\begin{tabular}{|c|c|c|c|c|c|}
\hline Designation. & Fat. & Water. & Curd. & Salt. & $\frac{\text { Curd }}{\text { Water }} \times 100$. \\
\hline $\begin{array}{l}\text { English, . } \\
\text { French, fresh, } \\
\text {,' salt, } \\
\text { German, salt, } \\
\text { Janish, ,, } \\
\text { Swedish, ", }\end{array}$ & $\begin{array}{c}\text { Per cent. } \\
86 \cdot 85 \\
84 \cdot 77 \\
84 \cdot 34 \\
85 \cdot 24 \\
83 \cdot 41 \\
82 \cdot 89\end{array}$ & $\begin{array}{c}\text { Per cent. } \\
11 \cdot 54 \\
13 \cdot 76 \\
12.05 \\
1.2 .24 \\
13 \cdot 42 \\
13 \cdot 75\end{array}$ & $\begin{array}{c}\text { Per cent. } \\
: 59 \\
1: 38 \\
1 \cdot 60 \\
1 \cdot 17 \\
1 \cdot 30 \\
1 \cdot 33\end{array}$ & $\begin{array}{c}\text { Per cent. } \\
1 \cdot 02 \\
\cdot 09 \\
2 \cdot 01 \\
1.35 \\
1 \cdot 57 \\
2 \cdot 03\end{array}$ & $\begin{array}{l}5 \\
10^{*} \\
13 \\
10 \\
10 \\
10\end{array}$ \\
\hline
\end{tabular}

The following analyses by the author show the average composition of French fresh butter (giving the amount of preservative), and of Australian butter :-

Designation. Fat. Watcr. Curl. Salt. Anlydrous Anhydrous Commercia

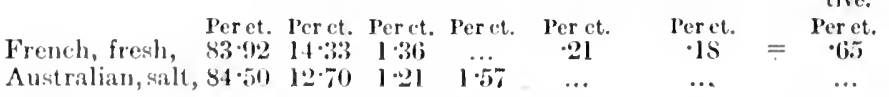

Table J. will grive the number of samples in which the water falls between the percentages named. The analyses were made by Virth, Sehnepel, lioseley, livett, O'Shaughnessy, and the author in the Aylesbury Dairy Company's laboratory.

- Container boric acid. 
TABLE L.-Variations of Water in Butter.

\begin{tabular}{|c|c|c|c|c|c|}
\hline \multirow{2}{*}{\multicolumn{2}{|c|}{$\begin{array}{l}\text { Percentages of } \\
\text { Water. }\end{array}$}} & \multicolumn{2}{|c|}{ English Butters. } & \multicolumn{2}{|c|}{ Foreign Butters. } \\
\hline & & No. of Samples. & Percentage. & No. of Samples. & Percentage. \\
\hline $\begin{array}{c}7 \text { to } 8, \\
8,, 9, \\
9,, 10, \\
10,, 11, \\
11,, 12, \\
12,, 13, \\
13,14, \\
14,, 15, \\
15,, 16, \\
16,, 17, \\
17,, 18, \\
18 \cdot,, 19, \\
19 ., 20, \\
\text { Total, }\end{array}$ & & $\begin{array}{r}2 \\
5 \\
14 \\
26 \\
65 \\
151 \\
182 \\
97 \\
50 \\
21 \\
4 \\
3 \\
2 \\
625\end{array}$ & $\begin{array}{r}\cdot 3 \\
\cdot 8 \\
2 \cdot 2 \\
4 \cdot 2 \\
10 \cdot 4 \\
24 \cdot 6 \\
29 \cdot 1 \\
15 \cdot 5 \\
8 \cdot 0 \\
3 \cdot 4 \\
\cdot 6 \\
\cdot 5 \\
\cdot 3 \\
\ldots\end{array}$ & $\begin{array}{r}\cdots \\
5 \\
13 \\
51 \\
78 \\
115 \\
395 \\
373 \\
241 \\
71 \\
21 \\
1 \\
\ldots \\
1364\end{array}$ & $\begin{array}{r}\ldots \\
\cdot 4 \\
1 \cdot 0 \\
3 \cdot 7 \\
5 \cdot 7 \\
8 \cdot 4 \\
29 \cdot 0 \\
27 \cdot 4 \\
17 \cdot 7 \\
5 \cdot 2 \\
1 \cdot 5 \\
\cdot 1 \\
\ldots \\
\ldots\end{array}$ \\
\hline
\end{tabular}

The above table contains butters of all kinds-fresh, salt, preserved, unpreserved, fresh from churning, and samples which had been kept for various periods.

Variations in Percentages of Water.-The following table (LI.) is taken from a paper by Faber on "Water in Danish Butter":-

TABLE LI.-Variations of Water in Butter (Faber).

\begin{tabular}{|c|c|c|c|c|c|}
\hline \multirow{2}{*}{\multicolumn{2}{|c|}{$\begin{array}{l}\text { Percentages of } \\
\text { Water. }\end{array}$}} & \multicolumn{2}{|c|}{ No. of Samples. } & \multicolumn{2}{|c|}{ Percentage of Total. } \\
\hline & & Summer. & Winter. & Summer. & Winter. \\
\hline $\begin{array}{c}9 \text { to } 10, \\
10,, 11, \\
11,, 12, \\
12,, 13, \\
13,, 14, \\
14,, 15, \\
15,, 16, \\
16, " 17, \\
17,, 18, \\
18,, 19, \\
\text { Above } 19, \\
\text { Total, } \\
\text { Average, }\end{array}$ & 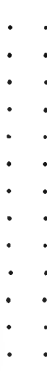 & $\begin{array}{r}1 \\
16 \\
136 \\
335 \\
534 \\
512 \\
287 \\
124 \\
39 \\
13 \\
4 \\
2001 \\
14 \cdot 03 \%\end{array}$ & $\begin{array}{r}1 \\
8 \\
20 \\
138 \\
431 \\
562 \\
447 \\
205 \\
95 \\
20 \\
3 \\
1930 \\
14.41^{\circ} \%\end{array}$ & $\begin{array}{r}\cdot 0 \\
\cdot 8 \\
6 \cdot 3 \\
16 \cdot 8 \\
26 \cdot 7 \\
25 \cdot 7 \\
14 \cdot 4 \\
6 \cdot 2 \\
2 \cdot 0 \\
\cdot 7 \\
\cdot 2 \\
\ldots \\
\ldots\end{array}$ & $\begin{array}{r}\cdot 1 \\
\cdot 4 \\
1 \cdot 0 \\
7 \cdot 2 \\
22 \cdot 3 \\
29 \cdot 1 \\
23 \cdot 2 \\
10 \cdot 6 \\
4 \cdot 9 \\
1 \cdot 0 \\
\cdot 2 \\
\ldots \\
\ldots\end{array}$ \\
\hline
\end{tabular}


Table LII. shows the effect of keeping on the percentage of water contained in the butter; fresh and salt butters, which were all prepared at the Aylesbury Dairy Company, are kept separate.

\section{TABLE LII.-Variations of Water in Butters on Keeping.}

\begin{tabular}{|c|c|c|c|c|c|}
\hline \multirow{3}{*}{$\begin{array}{l}\text { Percentages } \\
\text { of Water. }\end{array}$} & \multicolumn{5}{|c|}{$\begin{array}{l}\text { Percentages of the Total Number falling between } \\
\text { the Limits Named. }\end{array}$} \\
\hline & \multicolumn{2}{|c|}{ Fresh Butters. } & \multicolumn{3}{|c|}{ Salt Butters. } \\
\hline & $\begin{array}{l}\text { Less than } 12 \\
\text { hours old. }\end{array}$ & $\begin{array}{l}24 \text { to } 48 \\
\text { hours old. }\end{array}$ & $\begin{array}{l}\text { Less than } 12 \\
\text { hours old. }\end{array}$ & $\begin{array}{l}24 \text { to } 48 \\
\text { hours old. }\end{array}$ & $\begin{array}{l}10 \text { to } 30 \\
\text { days old. }\end{array}$ \\
\hline $\begin{array}{c}18 \text { to } 19, \\
17,, 18, \\
16,, 17, \\
15,, 16, \\
14,, 15, \\
13, " 14, \\
12,, 13, \\
11,, 12, \\
10, .11, \\
9, " 10, \\
\text { Average } \\
\text { percentage } \\
\text { of water, }\end{array}$ & $\begin{array}{r}\ldots \\
\ldots \\
1 \cdot 7 \\
10 \cdot 3 \\
31 \cdot 3 \\
32 \cdot 8 \\
20 \cdot 7 \\
3 \cdot 4 \\
\cdots \\
\cdots \\
13 \cdot 79\end{array}$ & $\begin{array}{r}\ldots \\
\ldots \\
10.0 \\
15 \cdot 0 \\
35 \cdot 0 \\
40 \cdot 0 \\
\ldots \\
\ldots \\
\ldots\end{array}$ & $\begin{array}{r}1 \cdot 3 \\
2 \cdot 5 \\
15 \cdot 0 \\
22 \cdot 5 \\
25 \cdot 0 \\
25 \cdot 0 \\
7 \cdot 5 \\
1 \cdot 3 \\
\ldots \\
\ldots\end{array}$ & $\begin{array}{r}\ldots \\
\cdots \\
3 \cdot s \\
5 \cdot 1 \\
12 \cdot 6 \\
34 \cdot 1 \\
38 \cdot 0 \\
5 \cdot 1 \\
1 \cdot 3 \\
\ldots\end{array}$ & $\begin{array}{r}\ldots \\
\ldots \\
3.6 \\
10.7 \\
28 \cdot 6 \\
42 \cdot 9 \\
10 \cdot 7 \\
3.6\end{array}$ \\
\hline
\end{tabular}

Taking butters from twenty-four to forty-eight hours old to represent commercial butter, it is seen that salt butter contains rather less water than fresh butter. The contrary is usually stated; but this is not according to the author's experience.

Fresh butter loses its water chiefly by evaporation, and it is seen that this loss is small; salt butter also loses water by brine running out. It will usually be noticed that salt butter looks wet on being cut, while fresh butter rarely has this appearance.

Action of Salt. - The action of salt, which is added both to give a flavour and as a preservative, seems to be as follows:-It first dissolves in the buttermilk left in the butter, and forms a strong solution, which curdles the buttermilk, giving an insoluble precipitate of proteid matter and a clear whey. 'The salt solution has a smaller viscosity than the buttermilk; hence, a smaller layer is condensed rouml the particles by surface energy, so that there is liquid which is very loosely held in the butter; this gralually runs out, and gives rise to the wet appearance of salt butter. It is noticed that the liquid which runs out, or is 
squeezed out, of salt butter is always clear and transparent, while the liquid squeezed out of fresh butter is usually milky.

By warming to a temperature near the melting point of the fat considerable quantities of water can be mixed with butter. In the preparation of "pickled" butter this fact is taken advantage of to add large amounts of salt by working in warm brine. Buttel treated in this way does not lose its water easily, as an emulsion of fat and water is thus produced.

Storch has slown that by the action of certain micro-organisms such a condition (of the proteids?) is produced, that large amounts of water are retained and cannot be worked out. In this case an emulsion is produced, which contains large numbers of very minute water globules. These butters are designated "thick," and are rare in England.

Theory of Churning.-Several theories have been put forward to account for the phenomenon of churning. Tlius, Fleischmann holds the view that the globules of fat in milk are in a superfused condition, and that churning is simply the phenomenon of solidification; with the recognition of the fact that the globules are solid at low temperatures this view is untenable. Soxhlet holds that churning consists in the rupture of a solid membrane, which he believes exists round the fat globules; as the existence of such a membrane appears hypothetical, this view cannot be accepted. Storch attributes churning to the gradual rubbing off of a semi-solid membrane of "mucoid substance," and this hypothesis has much to recommend it; the whole of the evidence points to the existence of a layer, which is not solid, round the fat globules. As previously stated, the author cannot reconcile Storch's theory that this layer consists of "mucoid substance" with known facts; but it appears very highly probable that there is a layer, the composition of which is for the present purpose immaterial, round each fat globule. As it is improbable that this layer is elastic, the effect of the impact of one fat globule on another will be to squeeze out the layers between them, and bring the globules witlin the sphere of each other's attraction. In this way nuclei will be formed, which will, on continued churning, increase in size; as the nuclei get larger and larger, the resistance, owing to fluid friction on their surfaces, will gradually bear a smaller and smaller proportion to the force tending to bring them to the surface, and, at a given moment, the butter will "come." This theory is in accord with all the known facts. By microscopical examination of cream during churuing the formation of nuclei of irregularly shaped masses of fat globules is noticed. As an irregular mass will occupy a greater apparent volume than a sphere, the transformation of splherical globules into irregular nuclei should be attended with thickening of the cream, which is in accord with the facts; as the nuclei increase in size, the 
layer condensed by surface energy round them will rapidly become less, so that the cream will gradnally decrease in thickness; this decrease in thickness of the crean should take place later than the increase mentioned above, which is also the case.

When the butter is taken from the churn it is in fine grains, which are the nuclei referred to. On working, the fat globules are brought still closer to each other, and the butter is formed into a nearly homogeneous mass; small amounts of liquid are, however, left distributed throughout the mass, and as these liquid globules are very small and contained in a medium which, though solid, is still viscous, they are by surface energy transformed into spheres. The microscopical examination of butter shows a number of spherical globules of aqueous liquid in a nearly homogeneous medium consisting of fat; there are, however, many fat globules left, which, by careful examination with little light (best by dark stage illumination), can be made out. The whole of the globules usually seen, which are of all sizes, consist of aqueous hiquid; in many cases where the globules are of sufficient size for the surface energy to become small, they cease to be spherical.

The reason that butter always does, and must, contain water is that the aqueous liquid present is finely divided, and assumes a spherical condition. It is impossible by pres. sure from the outside to remove small spheres from a lomogeneous medium.

It appears certain, from the experiments of Storch on the density of butter, that the density of the fat is the same as that of butter fat in the solid state; it is, therefore, solid in butter. This view is nearly universally accepted. Vieth, however, holds that it is liquid, becanse all the globules which are visible are spherical; it appears probable that he has overlooked the fact, only recently pointed out by Storch, that all the globules visible by the usual microscopical examinations are water globules.

With the recognition of the faet that butter is an approximatcly homogeneous fatty substance, the reason for its change of consistency by alteration of temperature at once becomes apparent. To churn butter of the right consistency it is necessary that the fat in the cream shall be of that consistency. As pointel out in Alymeli.r $\Lambda$, the fit in cream which has been warmed very slowly solidilies. If the crean has been kept at a high temperature, as in summer, it is necessary to churn at a lower temperature than if the cream has been kept at a lower temperature, as the collect on the consistency of the fat of cream of cooling for a long time at a fairly low temperature is the same as that of cooling for a shorter time at a lower temperature. 
Temperature of Churning.-The best temperatures for churning are as follows :-

Recently separated cream (quick churning), about $8^{\circ} \mathrm{C} .\left(46 \cdot 4^{\circ} \mathrm{F}\right.$.)

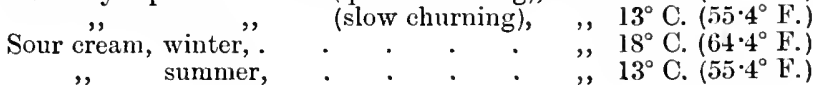

If the butter is churned at too high a temperature, it will contain more water than at medium temperatures. Butter churned at very low temperatures also contains more water than at medium temperatures; this appears to be due to the fact that in the one case the fat is too liquid, and in the other too solid, for the maximum effect of squeezing out the watery portion on working to be attained. Butter which is quickly churned by violent impact also has a tendency to contain more water than that churned more slowly. This nay be explained by the hypothesis that if the nuclei are quickly formed several globules. of fat may coalesce simultaneously and enclose more buttermilk than if they coalesced singly.

When the cream churned is very sour the solids not fat may contain precipitated casein; in this case the ratio of solids not fat to water is high.

If the temperature at which the butter is churned and worked be too high, very large percentages of water (up to 50 per cent.) may be found this may be very materially reduced by cooling the butter for several hours and re-working.

Various substances-rennet, pepsin, sodium carbonate, dc.have been used to increase the yield of butter; this effect is attained by increasing the water contained in the butter.

Preservatives in Butter.-Besides salt, various other substances are used as preservatives; the most usual are mixtures of borax and boric acid, though formalin, salicylates, sulplites, and potassium nitrate have also been employed.

The Proximate Analysis of Butter.-The proximate analysis of butter indicates, not whether the sample is genuine or otherwise, but its condition, and affords some clue as to its mode of preparation.

The usual data to be determined are water, solids not fat, fat, and salt. Preservatives are usually only tested for qualitatively, but sometimes a determination may be made. It is also occasionally of interest to determine the actual curcl.

Water.-The most important datum is the percentage of water. As the water is not always equally distributed throughout the mass of butter, especially in butters which have been salted, it is necessary to take precautions to obtain a fair sample - a matter of some difficulty. It is not advisable to use a scoop, as water is liable to be squeezed out while forcing it into the lump. Perhaps the fairest way of sampling is to cut the lump' 
in two halves, and to take a piece near (not at) one top corner, a second piece in the middle, and it third near the opposite bottom corner. The three pieces should be placed in a widemouthed stoppered bottle, melted at as low a temperature as possible, and violently shaken till the mass is nearly solid. If the analysis is to be commencel at once, suitable quantities may be poured out while the butter is still in a semi-liquid condition, and weighed as soon as possible. The water by this means is equally distributed throughout the sample, and a small quantity will be representative of the whole sample. In the case of wellmarle fresh butter the differences in the distribution of water is small, and a single sample taken from any part of the lump will represent with fair accuracy the whole bulk. Where extreme accuracy is not desired, the melting and shaking of samples of fresh butter may be omitted.

The water in butter may also he mixed by warming to such a temperature that the butter begins to lose its consistency, and stirring vigorously with a stout glass rod. The mixing of salt butter should not be omitted if accuracy is a desideratum.

The following methods are used for the determination of the water:-

1. About 10 grammes are weighed out into a small porcelain basin provided with a glass stirrer. This is place 1 over a very small flame, or on a sand-bath, and the butter carefully, but vigorously, stirred till all signs of frothing cease. The temperature must be so regulated that spirting is aroided, and that the "curl" does not become appreciably browned by the heat. The basin and its contents are, after cooling, weighed; the loss of weight indicates water.

$\therefore$. A basin is filled with pumice, which is broken in pieces about the size of a small pea, wished, and ignited; 2 or 3 grammes of well mixed butter are weighed in, and the basin placerl in a drying oven at $100^{\circ}$ C. $\left(212^{\circ}\right.$ F.), through which a good lraught passes. At the expilation of an hour the basin is coolen and weigherl, and then replaced in the oven for a further half hour; weighings are matle at the expination of succeeding half hours till the weight ccases to diminish. 'The lowest weight obtained is taken as that of the dry butter. The difference between this weight and that of the original butter is taken as water.

$\therefore$ Four to five armmos of butter are woinhel into a wirlemouthed tlat-bottomed conical flask, which is placed in a water oven and shaken every ten minutes for the first half hour, after which it is shaken every half hour. It the expiration of four hours it is coroled, weinherl, and returnes to the lath for another hour: if there be any loss, the drying is continued till an hour's drying dres not cause any diminution of weight.

4. From 2 to 212 grammes of well mixed butter are weighed 
into a flat-bottomed basin about $2 \frac{3}{4}$ inclies diameter. This is placed in the water-oven till just melted, and 1 to $1 \frac{1}{2}$ c.c. of strong alcohol are added; the basin is replaced in the wateroven, and weighed alter two hours. The loss represents water.

Of the four methods, the first is the most expeditious, and is nearly as accurate as the others; the second is the most accurate ; the third is the most convenient if solids not fat and salt are also estimated; while the fourth is fairly accurate, rapid, and requires no attention. No one of the four methods has, however, any great advantage over the others.

Solids not Fat and Salt.-For the estimation of solids not fat and salt the residue from the determination of water is taken and melted at a low temperature. A solvent for the fat, of which ether is perhajs the best, though chloroform, anyl alcohol, and others may be also used, is poured on, the whole well mixed, and allowed to stand in a warm place till the solvent is quite clear. The solution is carefully decanted and a fresh portion of the solvent poured on the residue, and, when clear, poured off. Four or five successive treatments are sufficient to remove the whole of the fat. With a little practice the operation may be so performed that none of the solids not fat are poured away with the solvent. The residue is placed in the water-oven, and dried to constant weight; the weight represents solids not fat and salt.

Salt. - To estimate the salt the residue is treated with hot water and filtered, the filter together with the residue washed, and the filtrate, or an aliquot portion of it, is titrated with a standard silver nitrate solution, using potassium chromate as indicator. It is essential that the solution should be cold before titration, and the silver nitrate solution should be standardised on pure sodium chloride. The strength should not be deduced from the amount of silver nitrate present, as Hazen, and, later, W. G. Young, have pointed out that the amount of silver used is always greater than that theoretically required to combine with the chlorine From the amount of silver nitrate solution used the weight of salt is readily calculated. It is convenient to make the silver nitrate solution of such strength that 1 c.c. $=.005$ granme of sodium chloride.

Solids not Fat.-The weight of salt found by titration is subtracted from that of the residue left after the extraction of the fat, and the difference represents the solids not fat.

Fat.-The fat is best estimated by subtracting the total of the water, salt, and solids not fat from 100; though the solvent may be evaporated and the fat actually weighed, if desired.

Curd.-An estimation of the actual curd present can be made by subnitting the residue, left after estimation of the fat, to Kjeldahl's process for the estimation of nitrogen (p. 105), and multiplying the nitrogen found by $6 \cdot 38$. The milk-sugar may 
be estimated in a portion of the solution used for the titration of the salt by one of the methods given for the determination of milk-sugar (p. 82). These determinations are rarely required.

Ash.-In place of an estimation of the salt, an ash determination is often made, and the ash taken as salt. The results are, however, always slightly above those obtained by titration, as butter itself, to which no salt has been added, gives a small ash; preservatives, such as borax, will also swell the weight of the ash.

Preservatives.-The preservatives most largely used in butter consist of a mixture of borax and boric acid; sulphites and nitrates have also been used, usually in conjunction with borax or horic acid; formalin has been recommended, but appears to be rarely used. These should be tested for in the aqueous portion which sinks to the bottom on melting the butter at a low temperature. The reaction with turmeric paper applied to the liquid direct will show the presence of free borie acid. If no reaction or a feehle one be obtained, a little of the liquid may be acidified with very dilute hydrochloric aeid, and tested with turmeric paper. A pinkish-brown coloration, turned greenish-black by dilute alkali, will show the presence of boric acid in combination (as borax). It will usually be found, if the butter is preserved in this way, that a reaction is obtained from the liquid itself, and a much stronger one after acidifying. The presence of sulphites may almost always be detected by the smell of sulphurous acid developed on acidifying. Nitrates may be found by the diphenylamine test. For the quantitative estimation of preservatives 50 grammes of butter should be placed in a stoppered crlinder, 50 c.e. of chloroform added, and the mixrure gently warmed till perfect mixture takes plaee. A quantity of water, which will, with that present in the butter, make up 50 grammes, is added, and, after shaking, the cylinder is put aside to allow the aqueous portion to separate. Each cubic centimetre of the solution will contain the preservative in 1 gramme of hutter.

For the estimation of boric acid Thompson's method is the most convenient (1) 76). As butter is practically free from phosphates, the process for their removial may be omitted, and the titration porformed on the solution without any treatment; the result will be the total boric acid, free and combined. If it be desired to "stimate borax and horie acid separately, it is best tr evaporate an aligunt portion of the liquid to dryness several times with methyl alcohol, and to titrate the boric acid in the resirue; 1 part $\mathrm{B}_{0} \mathrm{O}_{3}$ in the residue equals 2.886 parts of dry borix. The results" obtained do not necessirily indicate the guantity of horax and boric acid originally alded, is the presence of acid and alkali in the butter may cause the formation of borax or boric acid in situ. A more useful result maty be obtained by 
dividing the total $\mathrm{B}_{2} \mathrm{O}_{3}$ by 56 , a figure based on the fact that commercial preservatives contain approximately about 56 per cent. of boric anhydride.

Another method of estimating borax is to calculate the total alkalinity to methyl orange as borax, but this method is liable to be erroneous should other substances-alkaline to methyl orange-be present.

An estimation of the total sulphurous acid may be made by distilling a portion of the liquid with dilute hydrochloric acid, passing the gas evolved into decinormal iodine solution, and titrating with sodium thiosulphate; 254 parts of iodine convert 64 parts of $\mathrm{SO}_{2}$ into sulphuric acid. The gas evolved may also be passed into bromine water, and the sulphuric acid formed estimated as bariun sulphate, of which 233.5 parts represent 64 parts of $\mathrm{SO}_{2}$. The solution from which the sulphurous acid has been distilled may be advantageously evaporated to dryness after making alkaline and ignited, and the sulphuric acid estimated in this; the sulphuric acid present is probably due to the oxidation of the sulphite.

Nitrates may be estimated by one of the methods described under "Water Analysis." If much salt be present, the copperzinc couple method, or Crum's method, should be employed.

Formalin cannot be estimated with any degree of exactitude, as it gradually enters into combination with the proteids present, and only the residue of uncombined formaldehyde, which gives no clue to the original amount, can be determined.

If adulteration is suspected, it may be of interest to microscopically examine the residue left after removal of the fat; adulterants, such as starch, mineral matters, dtc., which it is alleged have been used, would be thus detected. This form of adulteration is of extreme rarity.

The Interpretation of Results.-There is a general concensus of opinion among authorities that butter at the time that it is placed on the market should not contain more than 16 per cent. of water; in many cases where this figure has been markedly exceeded successful prosecutions under the "Sale of Food and Drugs Act" have been instituted. There is only one class of butter in which there is the slightest difficulty in getting the water down to 16 per cent.-the Irish pickled butter. This butter, though considered unappetising by the majority, finds considerable favour among the town workers of the Mlidlands and North. From its mode of preparation-the working in of strong brine at a somewhat elevated temperature-it is necessarily liable to contain a somewhat large percentage of water. Seeing that warm brine is worked into the butter, with the object of producing an article for which there is a public demand, it is doubtful whether such a proceeding can be considered an adulteration, though were water worked in in the same manner 
it would undoubtedly be a contravention of the law. It, therefore. behoves us to distinguish between them.

It is advisable to always calculate the solids not fat and salt, not only as percentares, but also as parts per 100 parts of water present. The following table will show the characteristics of various classes of butter :-

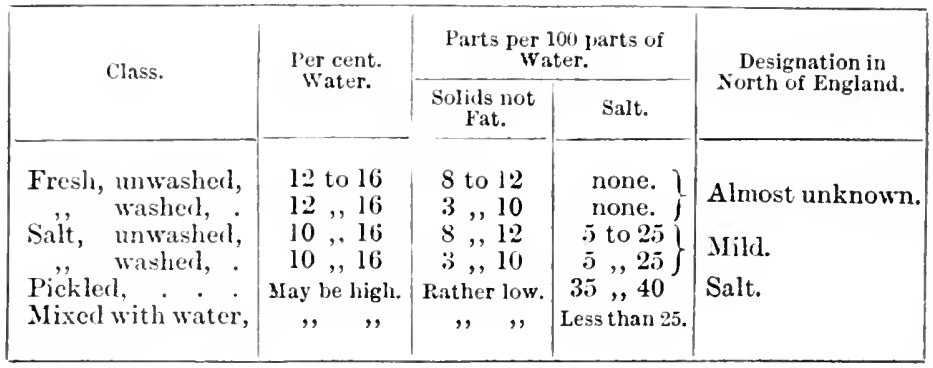

The figures given are not intended as absolute limits, but rather as indicating the composition of by far the greater number of samples met with. It is seen that the pickled butters contain a very large amount of salt in proportion to the water present. This fact is of great use in distinguishing them from samples which have been purposely watered.

It is frequently stated, even by "experts," that salt butter contains more water than fresh. Unless the term "salt butter" is appliect exclusively to piekled butter, this statement is contrary to fact, as it is found that if, after cluurning, the butter is divided into two part.s, one being worked as fresh, and the other immediately salted, the percentage of water is almost identical in the two samples; after standing, the salt butter will be found to lose water by rumning out, while the fresh butter undergoes no such loss. It will be found that salt butter when placed on the market contains on the average less water than fresh butter.

A high percentage of water does not appear to have any effect on the kreping yualities of the butter; a large percentage of solids not fit or curd seems to be distinctly inimical to its good preservation.

speaking broally, butters containing about $13 \frac{1}{2}$ per cent. of water have the hest Hitrour. When the limits of 12 per cent. on one hand, and 15 per cent. on the other, are passed, a distinet falling-oft in quality is usually found. To this rule, however, exceptions are numerous.

During very hot wather, if the butter is very soft when taken ont of the churn, there is a diflienlty in working the water out to a suflicient extent ; during very cold weather the butter may be so hard that it cannot he ethiciently worked. In both these cases the water may some what execed 16 per cent. An organism 
has been described which produces changes in the cream which prevent the water from being worked out, but it is fortunately not frequently met with.

The Analysis of Butter Fat-Preparation of the Fat for Analysis.-A portion of the butter is placed in a beaker and melted by exposing to a temperature not exceeding $50^{\circ} \mathrm{C}$. $\left(122^{\circ} \mathrm{F}\right.$.). The water, with a considerable amount of the other constituents, sinks to the bottom, leaving the fat (containing, however, particles of curd in suspension) as an upper layer. If the butter be genuine, fresh, and well made, the melted fat will usually appear transparent; while if it be mixed with butter substitutes, rancid, or churned at a high temperature, or if it has been melted and re-emulsified, the fat frequently has a turbid appearance.

The fat, with as little as possible of the other constituents, is poured upon a dry filter, which is kept at a temperature sufficient to prevent the fat from solidifying; the clear fat, separated from all the other constituents of butter, except a trace ( 2 per cent.) of water and lactic acid, if present, is collected in a dry vessel. It is sometimes of importance to prepare the butter free from water. This may be done by shaking it with a little calcium chloride (free from lime) and filtering again. Chattaway proposes to remove the water by stirring in a number of pellets of filter paper, which have been dried in the water-oven. The author has found that, as far as the proportions of the volatile acids, insoluble acids and saponification equivalent are concerned, the fat is entirely unaffected by this treatment, though certain properties-e.g., rise of temperature with sulphuric acid-are slightly affected, owing to removal of the water.

After filtration, the fat is rapilly cooled, so as to prevent partial soliditication and to ensure the homogeneous nature of the sample.

Recapitulation of Properties.-The following recapitulation of the essential differences between butter fat and other fats likely to be used as substitutes or for adulteration will serve to show the basis of the methods employed in the analysis of butter. Butter fat is characterised by the presence, in considerable amount, of glycerides of the fatty acids of low molecular weight. The lowest and most important is butyric acid, but the whole of the members of the series $\mathrm{C}_{n} \mathrm{H}_{2 n+1} \mathrm{COOH}$, in which $n$ is an odd number from 3 to 17 , are present in butter fat. A considerable amount of acids of the oleic series, of which not much is known, is also present; of this series, the lower members are certainly absent, and the unsaturated acids are of a higher mean molecular weight than the saturated acids: it is probable that oleic acid is the chief representative of the series, and, possibly, higher homologues occur. It is not known with 
certainty whether acids of other series occur in butter fat. The alcohol present is almost entirely glycerol.

The pioneer in butter analysis was Otto Hehner, who demonstrated in 1872 that upwards of 5 per cent. of the fatty acids were volatile, and that the quantity of insoluble fatty acids was very much less than that yielded by nearly all other fats. The bulk of the methods at present in use are the legitimate outcome of Hehner's work. Perhaps the only method which is not derived from the first investigation of Hehner is that of ron Hiibl, who showed that, by the action of an alcoholic solution of iodline and mercuric chloride, a quantitative addition of halogen could be made to unsaturated glycerides, but in the simplification of this method Hehner has had a lirge share.

\section{Estimation of Volatile Fatty Acids.}

Reichert Process.-Hehner and Angell, after showing that butter contained more butyric acid than was (then) generally supposed, attempted to estimate this by distillation, but finally relinquished the method on account of discordant results, due largely to the bumping of the liquid and the use of too strong an acid.

Perkins published a method for distilling the volatile acid; he used oxalic acid to decompose the saponified butter, and distilled to dryness. Probably he did not obtain the whole of the acid.

In the same year Reichert proposed to saponify 2.5 grammes of butter with caustic soda and alcohol, evaporate off the alcohol, add 50 c.c. of water and 20 c.c. dilute sulphuric acid, and to distil 50 c.c. in a weak current of air. 'This method, though Reichert himself calls it Hehner's method, is now known as the Reichert process. He showed that butters took a constant amount of deci-normal alkali for neutralisation, while fats and artificial butters took very smill quantities- $0.3 \mathrm{c}$ c., and cocoanut oil took about 3 c.c. ; he proposed 140 c.c. as the mean for genuine butters, and 13.0 c.c. as a limit; he showed also that mixtures of butter and margarine took quantities of $\frac{N}{10}$ alkali equivalent to the amount of butter they contained.

Noore in 1884, and Caldwell in 1886, hoth spoke farourably of the methol, the former drawing especial attention to the fact that coconunt oil, which is not detected hy other methods, is shown by the Rerichert method.

Medicus and sicherer used this method to show that butter, on being melted and allowed to cool, separates into portions containing more and less volatile acids respectively.

Allen showed that the distilling ressel did not exercise any influence on the results, but that there was a considerable loss on saponification in an open basin, and recommended a closed 
flask; this loss was due to the formation of butyric ether, as had been already pointed out by Hehner and Angell. Wanklyn and Fox actually estimated the butyric ether formed by saponifying with a barely sufficient quantity of soda, but naturally always fell far below the total quantity.

Munier proposed the use of an alcoholic potash solution for saponification and phosphoric acid to liberate the acids.

The results found by various observers are given in the following table :-

Name.

Reichert,

Caldwell, : :

Schmitt, . .

Allen,

Ambuhl,

Munier, .

Reichardt,

Beckhurts,

Merckling,

IVoll,

Cornwall and Wallace. .

Nilson, . . .
No. of Samples.

13

(?)

(?)

66

35

10

so

(?)
Limits.

13.0 to 14.95 c.c.

$127,15.5$,

$13 \cdot 0,14 \cdot 3$,"

$12 \cdot 5,15 \cdot 1$,

$14.05,, 15.55$,

$9 \cdot 2$, 14.05 ,

$13.8,, 14.7$,

$156,, 17.5$,

$13 \cdot 2,13.55$,

$12 \cdot 0,14.9$,

$11.3,15 \cdot 1$,

$9 \cdot 27,20.5$,

Too much importance must not be attached to these figures, as they were obtained by the original form of the method (or very slight modifications); Munier's low results have been criticised by Wollny (post), and Nilson's have also been doubted, though on no very strong grounds.

Nilson showed that disease may seriously reduce the volatile acids; one cow whose butter gave 16.85 c.c., after a few days' illness yielded butter taking only $10 \cdot 1$ c.c. of $\frac{\mathrm{N}}{10}$ alkali. His lowest result- 9.27 c.c.-was obtained from butter prepared from the milk of a cow directly after parturition, and he shows that the quantity of volatile acids rapidly increases, and becomes normal a very short time after calving. Figures as low as 9.27 c.c. can then hardly be considered normal for commercial butter.

Meissl proposed to saponify 5 grammes of butter-fat in a flask of about 200 c.c. capacity with 2 grammes of caustic potash and 50 c.c. of 70 per cent. alcohol, and to drive off the alcohol on the water-bath. The resulting soap is dissolved in 100 c.c. of water, and 40 c.c. of dilute sulphuric acid ( 1 to 10 ) are added and the solution distilled with a few small picces of punice; 110 c.c. are collected, filtered, and 100 c.c. titrated with deci-normal alkali. In common with Reichert and the earlier experimenters, he used litmus as an indicator, but the superiority of phenolphthalein for this purpose soon became apparent to many. To the number of cubic centimetres of $\frac{N}{10}$ alkali used one-tenth is 
added; he found thus that butters gave from $26 \cdot 6$ to 31.8 c.c., and fats and artificial butters about $3 \cdot 0$ c.c.

Sendtner, as early as 1883 , proposed 23 c.c. as the lowest limit.

Hansenn proposed blowing into the flask in order to drive away the last traces of alcohol, and was one of the earliest to use phenolphthalein as indicator.

This method was adopted $b y$ the Congress of Bavarian Analytical Chemists at Monaco in 1883; Meissl's limit of 26 c.c. was, however, considered not to be universally applicable, and 23 c.c. were taken. The Paris M unicipal Laboratory also adopt it with the modification of saponifying in an open basin, transferring the soap to a flask, and washing the basin with 100 c.c. of hot water ; their limits are stringent -26 to 335 c.c.

The following figures are published :-

\begin{tabular}{|c|c|c|c|}
\hline Name. & & No. of Samples. & Limits. \\
\hline Meissl, . & & . $\quad 52$ & 26.6 to 31.8 c.c. \\
\hline Sendtner, & & 5.5 & $24 \cdot 0,32 \cdot 8$, \\
\hline Hager, & - & $(\because)$ & $26 \cdot 0,31 \cdot 0$, \\
\hline
\end{tabular}

Wollny, in a now classic memoir, studied the errors of the Reichert-Mleissl process ; these are :-

(1) Error due to the absorption of carbonic acid during the saponification (may amount to +10 per cent.).

(2) Error due to the formation of ethers during saponification (niay amount to -8 per cent.).

(3) Error due to the formation of ethers during the distillation (may amount to -5 per cent.).

(4) Error due to the cohesion of the fatty acids cluring distillation (may in extreme cases amount to - 30 per cent.).

(5) Error due to the shape and size of the distilling vessel and to the time of distillation (inay vary the results \pm 5 per cent.).

To avoid these errors he lays down the following method of working :-

Five grammes of butter-fat are weighed into in round flask of about 300 c.c. capacity, with a neck $2 \mathrm{c} . \mathrm{m}$, wide and 7 to $8 \mathrm{c.m}$. long : 2 c.c. of a 50 per cent. soda solution and 10 c.c. of 96 per cent. alcohol are added, and the llask heated for half an hour on the water-bath under a slanting inverted condenser; between the centre and the flask is a $T$ piece, which is closed, the limb being turned upwirls. At the expiration of half an hour the limb of the $T$ piece is oprned and turned downwards, and the alcohol distilled off during a suartor of an hour; 100 c.c. of briling water are adrled by the T pirce, and the flask heated on the watcr-hath till the soap is dissolved. The solution is allowed to cool to $50^{\circ}$ or $60^{\circ}, 40$ c.c. of dilute sulphuric acid (25 c.c. to a litre; 2 c.c. of sonla solution should neutralise about 35 c.c. of this), and two pieces of pumice the size of peas are added. 
The flask is at once furnished with a cork carrying a tube $0 \cdot 7 \mathrm{c} . \mathrm{m}$. in diameter having, $2 \mathrm{c} . \mathrm{m}$. above the cork, a bulb 2 to $2.5 \mathrm{c} . \mathrm{m}$. in diameter; above this the tube is bent at an angle of $120^{\circ}$, and 5 c.m. further on again at an angle of $120^{\circ}$; this tube is joined to a condenser by an india-rubber tube. The flask is heated by a very small flame till the fatty acids are all melted, and the flame is then turned up and 110 c.c. distilled off in from twenty-eight to thirty-two minutes. The distillate is well mixed, and 100 c.c. are filtered off through a dry filter, 1 c.c. of a 0.05 per cent. solution of phenolphthalein solution in 50 per cent. alcohol added, and the solution titrated with $\frac{\mathrm{N}}{10}$ baryta solution. To the figure thus obtained one-tenth is added, and the amount found by a blank experiment subtracted; the blank should not exceed 0.33 c.c.

In order to render this method more sensitive, if possible, for the detection of small quantities of butter in margarine, Hehner proposed the use of 5 c.c. only of alcohol, saponifying (almost instantaneously) in a closed flask, warming for five minutes with occasional shaking, and driving off the alcohol through a narrow tube in a cork, reduced pressure being applied towards the end, and the addition of 100 c.c. of water which has boiled at least half an hour. He finds the blank figure thus to be less than $0 \cdot 1$ c.c., and the same as that given by 100 c.c. of boiled water filtered through a dry filter; other fats and oils give less than 0.06 c.c., and no increase is observed in heating them on the water-bath with the soda solution for two hours.

In order to facilitate the melting of the fatty acids, the author proposes lengthening the bulb tube, used by Wollny for distillation, above the bulb to $15 \mathrm{c.m}$. and placing on it a small condenser, through which water is kept running during the melting of the acids, this being removed during distillation; the same results are obtained by the use of this apparatus as by Wollny's.

Mansfeld saponifies in a closed flask for two hours on the water-bath with a solution of 56 grammes of potash in 100 grammes of water, no alcohol being used; he operates otherwise as Wollny. His method gives the same results as that due to Wollny. His blank is 4 c.c., and the extremes are 24.42 to $33 \cdot 15$ c.c. for butters and 0.59 to 0.96 c.c. for margarines.

Goldman distils the whole of the volatile acids in a current of steam, collects 600 c.c. of distillate, and titrates with $\frac{N}{10}$ baryta. He finds as limits $36 \cdot 24$ to $43 \cdot 20$ c.c. for butter, and 0.80 to 0.92 c.c. for margarine; duplicates do not differ by more than 0.2 c.c. Two samples gave by this method $36 \cdot 24$ and $36 \cdot 28$ c.c., and by the Reichert-Wollny-Mansfeld process 27.00 and 28.04 c.c. respectively. 
Leffmann and Beam saponify with 2 c.c. of caustic soda solution in 10 c.c. of glycerine, heating over a naked flame with constant sliaking. As in the reaction heat is evolved, care must be exercised ; they otherwise operate as Wollny. The results are about $0 \cdot$ e. c.c. higher than Wollny's.

The Reichert-Wollny method is largely anlopted in every country, and may be considered as a standard method.

In England the proportions of the Reichert method with Wollny's precautions are much used ; the author has determined the ratio between figures obtained thus and by the ReichertWollny method, and finds it to be $2 \cdot 21$ to $2 \cdot 27$, mean $2 \cdot 23$.

The following limits have been found by various observers:-

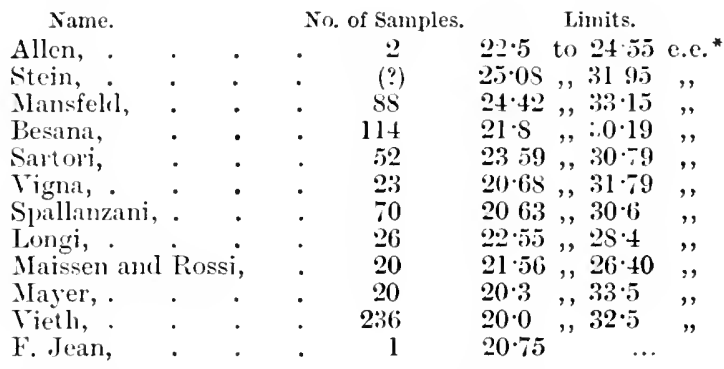

Vieth and Spallanzani have also founci in samples obtained under exceptional circumstances, which cannot be considered as commercial butter, amounts as low as $14 \cdot 7$ and $14 \cdot 3$ c.c. respectively.

The average of the results of different ouservers (excluding Vieth, who searched for low samples) shows that out of 100 samples-

$$
\begin{aligned}
& 3 \text { will probably give over } 30 \text { e.e. } \\
& \text { Sj , ", between } 30 \text { and } 26 \text { c.c. } \\
& \text { \& , , , , , } 26, \text {, } 25 \text {, } \\
& 3 \text { " ", unter 25 е.е." }
\end{aligned}
$$

The absolute lower limit must be tixed at 20 c.c. for butters, but all samples giving helow 2:5 c.c. may he looked upon as suspicions, and with in probalibity of 3 to 100 of such simples being genuine, 25 c.c. may be adepted as a commercial limit.

fefluamn and bean's modifieation has the advantages over the Reichert-Wolly methol of yiekling a clear distillate and giving a sharper end reaction.

Kreis' Modification of Roichert's Mothod.-Kreis has substituted for sapmnitication ly means of alkali, hydrolysis with strong sulphuric acid. Five ammes of fat are treated with 10 c.c. of stroms sulphuric acid atud gently warmed.

* These were sery "xreptional samples, ant bence the figures are not representative of the ordinary enmpustion of hut ter-fat. 
Saponification rapidly proceeds and the fatty acids are liberated; the unsaturated acids are attacked, with the formation of sulphurous acid. 100 c.c. of water are added; then a solution of potassium permanganate is added till a pink colour remains for a minute or two; and the bulk is made up to 140 c.c. 110 c.c. are distilled and titrated as in the Reichert-Wollny process.

This method offers no advantages over saponification by means of alkali, and its adoption can be in no case recommended.

The Theory of the Reichert Process. - The total amount of volatile acids contained in butter is not obtained in the Reichert process, but a nearly constant fraction - certainly constant for the same sample when distilled under standard conditions. The work of Duclaux has led to the explanation of the reasons why the amount is so constant, and has elucidated the real significance of the Reichert figure.

In the flask from which the butter is distilled there are (1) an aqueous liquid containing volatile acids in solution and (2) a layer of non-volatile fatty acids, also containing volatile acids in solution. From the experiments of Duclaux, the author has deduced the general formula expressing the rate of distillation of volatile fatty acids (see p. 46),

$$
(100-y)=\frac{100(100-x)^{a}}{100^{a-1}},
$$

if no condensation take place in the retort. For values of a greater than 1 condensation in the retort causes the apparent rate of distillation to be faster. As $a$, in the case of hutyric and caproic acids, is respectively 2 and 4 , it follows that increased condensation, either by exposing a greater condensing surface or by increasing the time of distillation, will give higher results; this is in strict accord with the experiments of Wollny. The author has found that if, instead of merely collecting 50 or 110 c.c. and titrating the total distillate, smaller fractions are collected and titrated sepalately, the results do not accord with the general formula given above. That the disturbing influence is due to the solubility of caproic acid in the layer of insoluble fatty acids is shown by the experiments cletailed below :-

(1) Pure butyric acid was distilled as in the Reichert process; the fraction distilled over was very nearly that deduced from the rate of distillation of this acid $(96.9$ per cent. when 110 c.c. out of 140 were distilled).

(2) The experiment was repeated, with the addition of 2.2 or 4.4 grammes of well-washed fatty acids of butter, which, when distilled alone, gave a mere trace of volatile fatty acids; the results obtained were practically equal to those obtained in experiment (1) $(97 \cdot 2$ per cent ). 'This shows that insoluble fatty acids clo not retard the distillation of butyric acid, and that the 
solubility of butyric acid in water is great compared with its solubility in insoluble fatty acids.

(3) Numerous samples of butter were fractionally distilled. The following are the mean results obtained expressed as percentages of the total, the variations being small, not exceeding 1 per cent. :-

Volume Distilled

from 75 c.c.

$\begin{array}{ll}20 & \text { c.e., } \\ -2 \cdot 2 \cdot 2.5 & ,, \\ 40 & ,, \\ 711 & ,, \\ 60 & ,, \\ 7.5 & ,\end{array}$

Percentage of Volatile

Acid in Distillate.

$46 \cdot 3$

$50 \cdot 8$

$74 \cdot 9$

$84 \cdot 4$

$91 \cdot 1$

$100 \cdot 0$

(t) Experiments by Wollny, which agreed with those performed hy the author, showed that on the average $\delta i$ per cent. of the total volatile acids were found in the distillate in the Reichert-Wollny process.

(5) Duclaux has shown that when eight-elevenths (practically the same proportion as obtained in the Reichert-Wollny method) of the bulk of liquid are distillerl, that the composition of the distillate is 1.8 molecules of kutyric acid to 1 of caproic acid.

Now, from experiments (1) and (2) we see that 97 per cent. of the total butyric acid is in the distillate; therefore, the total butyric acid is equal to $\frac{1.8}{.97}=1.856$ molecules for each 1 of caproic acid in the distillate.

From experiment (4) we see that 87 per cent. of the total acids are in the distillate; each $2 \cdot 8$ molecules in the distillate correspond to $\frac{2 \cdot 8}{87}=3.218$ molecules of total volatile acid; of these, 1.856 molecules are butyric acid, and, therefore, 1.362 molecules caproic acid-i.e. the volatile fatty acids of butterhave the following average percentage composition :-

Butyrie acil, . . 57.7 molecules or 51.7 per cent. by weight.

Caproic , . . 42:3 , $45 \%$,, ,"

The following talle gives the percentage of acid distilled, the calculated percentage of acid that should be distilled if it were all butyric acid, and the presentage of caproic acid distilled (this is obtained by multiplying the percentage of butyric acid that should be distilled by 57.7 , subtracting it from the figures in column 2 and dividing by $\frac{1 \div 3}{100}$ ):- 


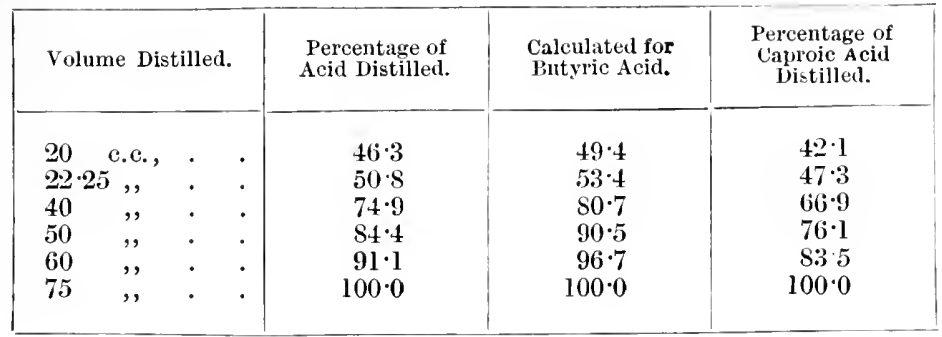

By interpolation in column 4 of the table above, the composition of the vapour at the moment when each fraction was completed, is expressed as percentages of the strength of the liquid at the commencement of distillation (column 2). By dividing this by 4 (the ratio of strength of liquid to strength of vapour for caproic acid) the composition of liquid can be calculated (column 3). By multiplying this by the amount of liquid left in the flask, and dividing by 75 , the percentage of total caproic acid in the liquid at the end of each fraction is found (column t). The total percentage of acid in the flask is found by subtracting the percentage distilled from 100 (column 5). The difference between column 4 and column 5 will indicate the percentage of caproic acid dissolved in the insoluble fatty acids (column 6).

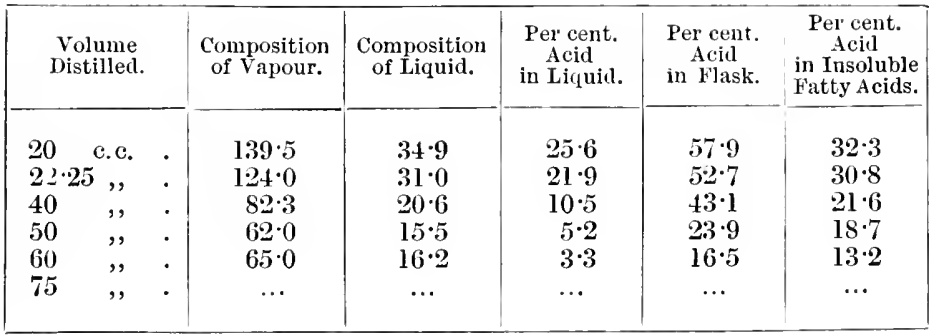

As the volume of insoluble fatty acids is constant throughout, the percentage of caproic acid dissolved therein is always proportional to the composition of the aqueous liquid.

It is seen that the figures in columns 3 and 6 are sensibly identical, proving that the caproic acid is distributed between the aqueous and fatty layer's respectively in a definite proportion. 75 c.c. of the aqueous liquid dissolve sensibly as much caproic acid as 2.2 grammes of insoluble fatty acids, while the solubility of butyric acid in insoluble fatty acids compared to that of water is small -in fact, negligible.

This explains why the apparent rate of distillation of volatile 
acids in the Rieichert process is less than the rate of the less volatile acid-butyric.

It also explains satisfactorily why Wollny found more volatile acid in proportion distilled from 2.5 grammes of butter than from 5 grammes, the other conditions as to volumes of water, \&c., bein identical. There was a smaller proportion of insoluble fatty acids, and, consequently, a larger proportion of caproic acid in the distillate. In the case of mixtures of butter and other fats. where the amount of insoluble fatty acids is raried but slightly from that found in butter, it is found, in accord with the present view, that the volatile acid rlistilled over is very nearly proportional to the percentage of butter present.

As so large a percentage of volatile acids are li-tilled under the conlitions of the Reichert process, the effect of condensation is practically small; still it cannot be entirely neglected, and the practice of Wollny in laying down exact conditions of working has a sound theoretical basis. 'To illustrate this fact it may be mentioned that the author has found that the ratio of the figures obtained in the Reichert process (where $2 \cdot 5$ grammes of butter are dissolverl in 75 c.c., and 50 c.c. distilled) to those of the Peichert-Wollny process (where 5 grammes of butter are dissolved in 140 e.c.) is on the average $2 \cdot 23$. The ratio of the figures obtained by the Reichert process to those obtained by dissolving 25 grammes of butter in 70 c.c. and distilling 55 c.c.

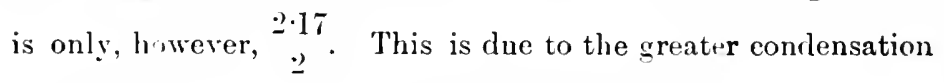
$\mathrm{n}$ the flask used for listiling the larger quantity.

Estimation of Saponification Equizalent, or alkali necessary for complete saponification.

Kœttstorfer's Method.-Kettstorf $r$ proposed to utilise the fact that butter required a greater amount of alkali for its complete saponification than most other fats.

The method is performed as follows:-A standard aleoholic solution of sodium hydroxide is prepared by dissolving 2.5 c.c. of the 50 per cent. solution of caustic soda recommended by Wollny (p. 260) in 1 litre of strong alcohol; after a clay's repose, during which a little salt sittles ont, the solution is clear and fit for use. This solution, which should he approximately seminormal, is stanflardised anainst semi-normal hydrochloric acid. A bout 2 wrammes of the fat are weighed out into a small flask, 25 c.c. of the alcologlic sorla solution rum in from a pipette, the flask connected with an invirterl conrlenser, and the eontents gently boiled for fifteen minntes. During the boiline the alcoholic soda solution is standardised: 25 c.c. of the solution are measured from the same pilutte, which is allowed to frain for the same longth of time as before. and titraterl with semi-normal hydrochloric acis-a little phenolphthalein being added as indicator. 
The number of cubic centimetres of hydrochloric acid solution should be noted. It is advisable to perform this operation in duplicate. The flask containing the saponified fat is disconnected from the condenser, a few drops of phenolphthalein solution added, and the liquid titrated with semi-normal hydrochloric acid till the pink colour just disappears. The number of cubic centimetres used, subtracted from the number required by the 25 c.c. of soda solution alone, will give the equivalent of the alkali required for saponification; this, multiplied by $\cdot 02805$, will give the weight as alkali calculated as potassium hydroxide, $\mathrm{KOH}$; and the figure thus obtained multiplied by 100 and divided by the weight of fat taken will express the "potash absorption" as percentages. It is also advisable to calculate the "saponification equivalent" (a term due to Allen), which is really an expression of the mean molecular weight. This is calculated from the number of cubic centimetres of normal acid, the definition of a normal solution being that it contains, or is equivalent to, in 1 litre a weight in grammes equal to the equivalent of a substance. It is, therefore, necessary to calculate the weight of fat which would be saponified by alkali equal to 1 litre of normal hydrochloric acid.

Let $W=$ the weight of fat taken.

And $V=$ the number of cubic centimetres of semi-normal hydrochloric acid equivalent to the alkali required for saponification. Then the saponification equivalent is expressed by

$$
\frac{2000 \mathrm{WV}}{\mathrm{V}} \text {. }
$$

The relation between "potash absorption per cent." $(K)$ and "saponification equivalent" (S) is expressed by the formula

$$
\mathrm{S}=\frac{5610}{\mathrm{~K}} \text {. }
$$

Instead of a pipette, the alcoholic alkali may be measured from a burette or automatic measuring apparatus, and the saponification may be conducted in a closed Hask. An open flask or basin should not be used, as ethyl butyrate, an intermediate product of saponification (p. 36), is volatile; this would cause a low value to be obtained.

According to Kottstorfer, the potash absorption varies from $22 \cdot 15$ to $23 \cdot 30$ per cent. in genuine butters, with an arerage of 22.70 per cent. His experience has been confirmed by numerous observers. The saponification equivalent raries from $253 \cdot 3$ to $240 \cdot 8$, the average being $247 \cdot 1$.

Other oils and fats have a potash absorption of 19.0 to $19 \cdot 9$ per cent., with an average of about 19.5; or a saponification equivalent of $295 \cdot 3$ to $282 \cdot 0$, with a mean of $287 \cdot 6$.

Cocoa-nut and palm-nut oils yleld, however, figures which are very different, $24 \cdot 62$ to $26 \cdot 84$ per cent. 
Estimation of Soluble and Insoluble Fatty AcidsHehner and Angell Method.-Hehner and Angell, having relinquished the distillation of the volatile fatty acids (see p. -58), turned their attention to the estimation of the insoluble acills. At the date at which the process was devised the use of alcohol for the saponification of fats was unknown, and they saponified the butter by heating for a considerable length of time with a strong solition of eaustic potash in water. This method was inconvenient, as it was found that the molten fat floated on the surface of the solution, and, being attacked with difficulty, required long boiling before saponification was complete. It was difficult to boil such a mixture, because bumping occurred, and this cansed a certain amount of loss. Hehner and Angell's original figures were somewhat lower than those now generally accepted.

T'urner, shortly after the publication of the method, suggested that alcoholic alkali should be substituted for the aqueous solution formerly used. The method is performed as follows:$A$ bout 3 grammes of the fat are weighed ont into a large basin, and saponified by about $l$ gramme of potash (or its equivalent of soda) dissolved in alout 10 c.c. of alcohol. On gently warming, an odour of ethyl butyrate is noticed, and saponitication rapidly proceeds. When, on addition of a few drops of water, no cloudiness is seen, the alcohol is evaporated on the water-bath, the soap is dissolved in 50 to 100 c.e. of hot water, and hydrochloric acid is added to slight excess. The iusolnble fatty acids which are liberated float on the surface in a curdy mass, and the basin is gently heater till these melt and bceome clear. A filter, which has been previously dried in the water-oven, is placed in a weighing tube and weighed, the weight of the empty tube being sulstracter from the total. This is placed in a funnel, wetted with hot water, and the insoluble fatty acids filtered through this. The basin can be washed quite clean by means of a jet of boiling water and the fatty acils entirely transferred to the filter. The washing is contmued on the filter, care being taken to direet the jet of boiling water so that the liquid acids are well stirrerl up; at least a litre of witer should he used in the washing. If the filter paper is of good quality, and thoroughly wetted heforehand, none of the fatty acids will run through; if, however, it is noticed that oily drops float on the surface of the filtrate, these may, if not too numerous or larec, be allowed to solidify, and can then he pieked ont and alded to the main quantity. When the washing of the fotty acids is completed, the funnel, with the filter, should he immersed in cold water up to the level of the top of the futty aciols to solidify them. The filter and its contents shomlil then be taken out. placed in a wrighed hasin, and dried in the water-oven. After two hours the basin shonld be weighed, replaced in the water-oven for half 
an hour, and again weighed. If a loss is found to have taken place, a further half hour's drying should be given. It is important not to prolong the drying ton much, as the fatty acids have a tendency to oxidise and to increase in weight at a temperature of $100^{\circ} \mathrm{C}$. The weight of the basin and the filter subtracted from the total weight will give the weight of the insoluble fatty acids.

This method has been submitted to numerous modifications; Muter prefers to conduct the whole operation in a flask. Instead of washing the fatty acids on a tilter, he allows them to solidify in the flask, and pours off the aqueous solution. Hager proposes to add a known weight of wax, picks out the lump, dries, and weighs it. Fleischmann and Vieth advise that the washing should be continued till at each succeeding washing the coloration produced by the addition of a few drops of litmus solution to a few cubic centimetres of the filtrate is not changed. Cassal has devised an ingenious flask, which has a tap at the bottom so that the liquid can be run off, leaving the fatty acids in the flask; washing can be thus much expedited, as hot water can be added, the fatty acids shaken up with the water, and the water run off.

Modification by the American Association of Official Agricultural Chemists. - The following method has been adopted by the American Association of Official Agricultural Chemists :-

Reagents required.-Decinormal sodium hydroxide.

Alcoholic potash. Dissolve 40 grammes of good caustic potash, free from carbonates, in 1 litre of $9 \tilde{j}$ per cent. redistilled alcohol. The solution must be clear.

Semi-normal hydrochloric acid accurately standardised.

Indicator.-One gramme of phenolphthalein in 100 c.c. of alcohol.

About 5 grammes of the sample are weighed into a saponification flask (250 to 300 c.c. capacity of hard, well annealed glass, capable of resisting the tension of alcohol vapour at $100^{\circ}$ C.), 50 c.c. of the alcoholic potash solution added, and the flask stoppered and placed in the steam-bath until the fat is completely saponified. The operation may be facilitated by occasional agitation. The alcoholic solution is always measured with the same pipette, and uniformity further secured by allowing it to drain the same length of time (thirty seconds). Two or three blank experiments are conducted at the same time. In from five to thirty minutes, according to the nature of the fat, the liquid will appear perfectly homogeneous. Saponification being then complete, the flask is removed and cooled. When sufficiently cool, the stopper is removed and the contents of the flask rinsed with a little 95 per cent. alcohol into an Erlenmeyer flask of about 200 c.c. capacity, which is placed on the steam 
bath, together with the blanks, until the alcohol is evaporated. Titrate the blanks with semi-normal hydrochlorie acid. Then run into each of the flasks containing the fatty acids 1 c.c. more of the hydrochloric acid than is required to neutralise the alkali in the blanks. The flask is then connceted with a condensing tube, 3 feet long, made of small glass tubing, and heated on the steam-bath until the separated fatty acids form a clear stritum. The flask and contents are then cooled in ice-water.

The fatty acids having quite solidified, the liquid contents of the flask are poured through in dry filtel into a litre flask, care being taken not to break the eake.

Between 200 and 300 c.c. of water are next brought into the flisk, the cork with its condenser tube re-inserted, and the flask heated on the steam-bath until the cake of fatty acids is thoroughly melted. During the melting of the cake of fatty acids, the flask shonld occasionally be agitated with a revolving motion, but so that its contents are not made to touch the cork. When the fatty acidis have again separated into an oily layer, the flask and its contents are coolol in ice-water and the liquid filtered throush the same filter into the same litre flask. This treatment with hot water, followed by cooling and filtration of the wash water, is repeated three times, the washings being added to the first filtrate. The mixed washings and filtrates are next made $u$, to 1 litre, aliqnot parts titrated with the deeinormal sodium hydroxide, and the total aeidity calculated. The number so obtained represents the volume of decinormal sodium hydroxide noutralised by the soluble acids of the butter fat taken, plus that corresponding to the excess of the standard acid used-viz., l c.c. The number is, therefore, to be diminished by 5, corresponding to the excess of 1 c.c. of semi-normal acid. This corrected volume, multiplied by $008 s$ gives the weight of (fatty acils calculated as) butyric acid in the amount of butter fat saponifiert.

The flask eontaining the cake of insoluhle acids and the paper through which the soluble acils were filtered are allowed to drain and dry for twelve hours, when the eake, together with as much of the acils as ean be removed from the filter paper, is transferred to a weigherl glass dish. The funnel and filter are then set in an Erlenmeyer flask and the tilter washer thoroughly with alsolnte alcohol. The llask is rinsed with the washings from the filter paper, then with pure alcohol, and these transferred to the erlasi dish, which is placel in the steam-bath. After the alcohol has exaporated, the resilue is dried for two hours in an air bath at $100^{\circ} \mathrm{C}$., cooled in a desiceator, and weighed. It is heated in the air-hath for two hours more, cooled and weighed. If the two weighines are deciledly difforent, a further lieating for two hours must be made. The resiclue is the total insolul, acirls of the sample. 
Johnstone's Modification.-A method for the estimation of soluble fatty acids which the author has found to work very well is one which was first suggested by Johnstone, though in an imperfect form. 4 to 5 grammes of butter fat are weighed out and saponified, as directed under the estimation of saponification equivalent, by a sutficient excess of alcoholic alkali. The excess of alkali is titrated with semi-normal hydrochloric acid and the potash absorption calculated. The soap solution is washed out of the flask into a basin and the alcohol evaporated. Acid is adcled and the insoluble fatty acids filtered and washed, as previously directed (an unweighed filter paper being used). Instead of cooling down the fatty acids, they are washed by warm alcohol into a 100 c.c. flask, and, after cooling, the bulk is made up to 100 c.c. with alcohol and well mixed. 25 c.c. of this solution are pipetted into a weighed bisin, the alcohol evaporated and the fatty acids dried and weighed; 50 c.c. are titrated with alcoholic alkali solution, using phenolphthalein as indicator, till a faint pink colour appears. The alkali used is calculated into its equivalent of semi-normal solution; this multiplied by 2 is subtracted from the amount of semi-normal acid equivalent to the alkali used for saponification. This figure multiplied by $4 \cdot 4$ and divided by the weight of butter taken will give the percentage of soluble fatty acids calculated as butyric. This method has the advantage of taking but little time, and gives, besides determinations of the saponification equivalent, insoluble, and soluble fatty acids, an estimation of the mean combining weight of the insoluble fatty acids; a figure which is occasionally of value. This is calculated in the same way as the saponification equivalent of a fat.

Blunt's Modification -Blunt uses the fitty acids left in the flask after a distillation by Reichert's process for the estimation of the insoluble fatty acids. It is necessary, however, to wash out the condenser, as some of the insoluble acids are slightly volatile, and to add these, and the acids which are found in the distillate, to the quantity left behind in the flask.

Morse and Burton's Modification.-Morse aud Burton, instead of weighing the insoluble fatty acids, titrate them with alcoholic alkali very much in the manner above described, and express both the soluble and insoluble fatty acils in terms of the alkali necessary to combine with them calculated as percentages of the total alkali necessary for saponification of the butter. This method has the advantage of rapidity and of not necessitating that the strength of the alkali solution shall be accurately known, but it is a decided advantage to know the weight of the insoluble fatty acids.

Attempts have been made to measure the volume of the insoluble fatty acids, but, owing to the difference in clensity and difficulty of making accurate measurements, this method has not proved satisfactory. 
The variation of insoluble fatty acids is from 85.5 per cent. (Bell and Menozzi) to 90.0 per cent. (Reichardt, Cornwall, and others) in gemuine butters; the soluble fatty acids calculated as butyric vary from $7 \cdot 0$ per cent. to $4 \cdot 0$ per cent. Most other fats give about 95.5 per cent. of insoluble fitty acids and traces only of soluble fatty acids. Cocoa-nut and palm-nut oils are, however, exceptions to this, yielding from 82 to 85 per cent.

\section{Specific Colour Tests for Adulterants.}

Baudouin's Test for Sesamé Oil.-This test consisted, originally, in shaking the melted fat with a solution of cine-sugar in hydrochloric acid. Villavecchia and de Fabris have modified this by using a solution of 2 grammes of furfuraldehyde in 100 c.c. of alcohol to replace the sugar; 10 c.c. of the melted fat are shaken thoroughly with 10 c.c. of hydrochloric acid and $\cdot 1$ c.c. of the reagent; a red coloration indicates the presence of sesamé oil. This reaction is very delicate, but is not entirely conclusive. Certain colouring matters-e.g., turmeric and certain aromatic dyes-give a red coloration with hydrochloric acid alone, and, in the presence of these, sesamé oil cannot be detected, as the colour due to sesamé oil would be masked by that yielded by the dye. Furfuraldehyde and hydrochloric acid alone, after some time, yield a reddish colour; hence a slight pinkish tinge criulually ippearing must not be taken to indicate sesamé oil. Spampani and Daddi have shown that the milk of goats fed with sesamé oil yields butter which qives this test. Hehner and Faber were, however, unable to obtain it with butter prepared from the milk of cows fed on sesimé cake.

Becehi's Test for Cottonseed Oil.-This test was originally performed by heating the fat with a solution containing silver nitrate, alcoliol, ether, nitric acirl, amyl alcohol, and rape oil. The reagreut has been frequently modified. Bevan prepares the reagent by boiling silver nitrate with amyl alcohol, and cooling the solution. Equal parts of this solution and of the fat are heated in a test tube on a boiling water-bath for ten minutes; a brow or black coloration indicates cottonsed oil. This test is by no means conclusive of the presence of addel cottonseed oil, as the milk of cows feel on larige proportions of eotton cake yiolus butter which will give a brown coloration.

Wellmann's Test for Vegetable Oils. - The reagent consists of a solution of sodium phospho-molyblate. It may be preparen by saturating 5 grammses of molylidic neid with sodium carbonate solution, adding I grammo of sorlinm phosphate, evaporating to hryess and fusing. 'Tlu mass is dissolved in boiling water, and concentrated nitric acid (5 to 7 e.e.) is added till the yellow shate is permanent. The solution is then made up to 100 c.c. 
One gramme of fat is dissolved in 5 c.c. of chloroform and shaken with 2 c.c. of the reagent for one minute. A green coloration (changing to blue on addition of ammonia) is formed in the aqueous layer when vegetable oils are present. Cocoa-nut oil is not, however, detected by this means.

\section{Behaviour of Butter Fat with Solvents.}

Critical Temperature of Solution.-Crismer recommends that several drops of the melted and filtered fat be introduced into a small tube several millimetres in diameter by means of a capillary pipette. A slightly greater volume of alcohol is added and the tube sealed and fastened by a platinum wire to the bulb of a thermometer; it is then heated in a bath of sulphuric acid till the meniscus separating the two layers becomes a horizontal plane. At this point the thermoneter is withdrawn from the bath, and turned sharply two or three times until the liquid becomes homogeneous, after which it is replaced and the temperature allowed to fall slowly, the thermometer and tube being constantly shaken. The temperature at which a marked turbidity is produced in the liquid is the critical temperature of dissolution. If absolute alcohol be employed an open tube may be used.

When examining butter fat it is necessary to estimate also the acidity by titrating 2 c.c. with $\frac{\mathrm{N}}{20}$ alkali and adding the figure thus obtained to the critical temperature.

Crismer has shown that the critical temperature varies with the percentage of insoluble fatty acids. The following table will show the variations:-

\begin{tabular}{|c|c|c|}
\hline $\begin{array}{c}\text { Critical Temperature. } \\
\text { Alcohol '8195 sp. gr. }\end{array}$ & $\begin{array}{c}\text { Critical Temperature. } \\
\text { Absolute Alcohol. }\end{array}$ & Insoluble Fatty Acids. \\
\hline Below $100^{\circ}$ & Below $54^{\circ}$ & 86 to 88 \\
$100^{\circ}$ to $105^{\circ}$ & $54^{\circ}$ to $62^{\circ}$ & $88,, 90 \cdot 5$ \\
$108^{\circ}, 118^{\circ}$ & $62^{\circ}, 72^{\circ}$ & $90,, 93 \cdot 3$ \\
$118^{\circ}, 124^{\circ}$ & $72^{\circ}, 78^{\circ}$ & $93,, 95 \cdot 5$ \\
\hline
\end{tabular}

The Reichert-Wollny figure may be calculated by the formula

$$
\begin{aligned}
\mathrm{R}-\mathrm{W} & =129^{\circ}-\text { critical temperature (with alcohol of sp. gr. } \\
& =33 \cdot 5195 \text { ). }
\end{aligned}
$$

Valenta's Method-Solubility in Acetic Acid.-Valenta showed that there was an enormous difference in the temperatures at which varions fats and oils dissolved without turbidity 
in acetic acid. By the work of Allen and Hurst it was shown that the strength of acid made a considerable difference. Chattaway, Pearmain, and Moor have investigated the subject and recommend the following procedure for hutters:2.7.) grammes of butter fat which has been previously tried (preferably by mixing with lied pellets of tilter paper and filtering through a iried filter) are weighed into a test tube provided with a stopjer; $3 \mathrm{cc}$ accurately measured of acetic acid (containing 995 per cent. $\mathrm{C}_{2} \mathrm{H}_{4} \mathrm{O}_{2}$ ) are run into a tube, and this is placed in a beaker of water. The water is gradually heated and the tube shaken till the solution is clear; the water is then allowel to cool gradually and the temperature at which a turbidity appears in the tube is measured by a thermometer held in close proximity. By slightly warming up and cooling down again, a second determination can be obtained.

Undue heating of the sample should be avoided, both in the preparation of the fat for analysis and during the performance of the test.

They gire figures as follow :-

$\begin{array}{lrrr} & \text { Maximum. } & \text { Minimum. } & \text { Average. } \\ \text { Butter fat, } & \quad 39 \cdot 0^{\circ} \mathrm{C} . & 290^{\circ} \mathrm{C} . & 36.0^{\circ} \mathrm{C} \text {. } \\ \text { Margarine, } & .97 \cdot 0^{\circ} \mathrm{C} . & 94.0^{\circ} \mathrm{C} . & 95.0^{\circ} \mathrm{C} \text {. }\end{array}$

E. W. 'T. Jones prefers, instead of using an acid of estimated strength, to test it against a stanclard sample of butter, and to dilute the arid so that it gives a temperature of turlidity of $60^{\circ}$. Margarine then gives ahout $100^{\circ}$.

Hehner has found that this test depends almost entirely on the glicerides of the saturated fatty acids present, as these are almost completely deposited on allowing the acotic acid to cool.

\section{The Iodine and Bromine Absorption.}

Von Hübl's Mothod and its Modifications.-This method depends on the fict that acids of the oleic, linolic, and linolenic series contain unsaturated bonds, and, under suitahle conditions, combine with iefline and bromine.

For the indine alsomption, it has been shown by von Hiabl that it is necessary to haw mercurie chloridr present. His process has received numerous modilications, but tew, if any, are real inprovements.

The process is worked as follows:-

lieagmts - Iodine solution. Iissolve 25 grammes of iodine in 500 c.c. of 95 per cent. alcohol.

Mercuric chloride solution. Dissolve 30 grammes of mereuric chloride in 500 c.c. of 95 ju. cent. alcohol, and decant from the insoluble residuc, or filter, if necessary. 
Equal volumes of the two solutions are mixed at least twentyfour hours before the test is made.

Decinormal sodium thiosulphate solution. Dissolve 25 grammes of pure sodium thiosulphate solution and l gramme of salicylic acid in 1 litre of water. Allow this to stand a few days and filter. This solution is permanent and does not alter in strength. To standardise the solution, abont $\cdot 25$ gramme of resublimed iodine is accurately weighed in a small stoppered flask, about 2 grammes of potassium iodide and 2 c.c. of water are added, and the flask gently shaken till the iolline is dissolved. The iodine solution is diluted with water, transferred to a larger flask, and titrated with the sodium thiosulphate solution till the yellow colour just disappears. This operation is repeaterl two or three times. The nean strength of the iodine deduced from these experiments is noted on the label of the bottle.

A 10 per cent. (approximate) solution of potassium iodide and a starch paste solution, made by pouring an emulsion of 1 gramme of starch in a little cold water into 200 c.c. of boiling water, and boiling for ten minutes; if a little mercuric iodide be added, this solution is permanent.

The process is performed as follows :- A bout 5 gramme of the fat is accurately weighed in a glass stoppered flask holding at least 100 c.c. ; 10 c.c. of chloroform or, better, carbon tetrachloride are added, and the flask gently rotated till the fat is dissolved; 20 c.c. of the mixed iodine and mercuric chloride solutions are next added and the whole well mixed. The flask is now put aside in the dark for three hours. At the sime time one or more blanks-i.e., flasks containing 10 c.c. of chlorotiorm or carbon tetrachloricle and 20 c.c. of mixed iodine and mercuric chloride solutions should be put aside with the tests.

After three hours, 10 c.c. of potassium iodide solution are added to each flask, and the contents are "ashed out into a larger stoppered bottle with distilled water. The standard thiosulphate solution is run in with continued shaking till only a faint yellow colour remains; a little starch paste is added, and the thiosulphate solution run in, drop by drol', till the blue colour disappears. The quantity of thiosulphate solution used for the flask in which the sample was placed subtracted from the mean of the blanks will give the equivalent of the iodine absorbed. This, multiplied by the strength of the solution, will give the weight of iodine. By multiplying this by 100 and dividing by the weight of fat, the percentage of iodine absorbed is oltained.

The following examples will make the mode of calculation clear :- 
Experiment 1. Weight of fat taken, 5006 gramme.

Titrited with 26.48 e.e. of thiosulphate solution.

2. Weight of fat taken, 4991 gramme.

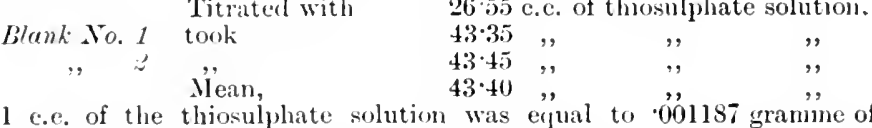
iocline.

Therefore 5006 gramme absorbed $(43.40-26 \cdot 48) \times \cdot 001157$ gramme of iodine.

$$
\begin{aligned}
& =\cdot 2008 \text { gramme or } 40.11 \text { per cent. } \\
& .4991 \text { gramme absorbed }(43 \cdot 40-26 \cdot 55) \times \cdot 001187 \text { granme of } \\
& \text { iolline. } \\
& =\cdot 2000 \text { gramme or } 40 \cdot 07 \text { per cent. }
\end{aligned}
$$

Bromine Absorption.-- Instead of using a mixture of the iodine and mercuric chloride solutions, a solution of bromine in chloroform, or, what is far preferable, carbon tetrachloride may be used.

Four c.c. "f dry bromine (this is best dried by shaking bromine with anhydrous calcium chloride, decanting, and distilling from a small stoppered Würtz Hask fitted with a good condenser) are rissolved in l litre of iry chloroform or carbon tetrachloride. The process is performed as above described, except that there is no need to wait three hours before titrating; this may be performed at once. 20 c.c. of the bromine solution are substituted for the 20 c.c. of mixed iodine and mercuric chloride solutions. It is advisable also to increase the amount of potassium iodide solution added to 20 c.c. or more.

Gravimetric Method of Hehner.-Hehner has proved that the bromine absorled may be estimated gravimetrically. The fat is weiglsed in a small bisin. dissolved in carbon tetrachloride, a solution of bromine in carbon tetrichloride added, and the excess of bromine and the carbon tetrachloride evaporated on a water-bath in a good draught cupboarl. The residue is freed from the last traces of bromine by adding several successive portions of carbon tetrachloride and evaporating them, and, finally, ly drying in an air-bath maintained at a temperature somewhat above $100^{\circ} \mathrm{C}$. The increase in weight multiplied by $\frac{127}{80}=1.5075$ will give the iodine absorption.

Thermomotric Method.-Hehner and Mitehell have also devised a most ingenious moans of rapidly and accurately caleulating the indine absorption, foumbre on the fact that when l motrenle of lonemine combines will 1 motecule of mosturated fint a definite anomul of heat is liberated.

Onc olmumb ol fiat is worghed into a jacketerl test tube about 1 inch in dianetre and finches long, from the jacket of which the air has heen ixhaustud. 10 e.e. of cluloroform are added, and tho temperature noted; 1 c.c. of bromine is added, the 
mixture stirred with the thermometer, and the highest point to which the temperature rises is recorded. The difference between the initial and the highest temperatures multiplied by a factor will give the iodine absorption. The factor must be found empirically, as it varies slightly with each ipparatus, thermometer, \&c. It can be easily ascertained by submitting a few fats of known and varying iodine absorption to this test, and taking the mean relation between the difference of temperatures noticed and the iodine absorption. Hehner and Mitchell found in their experiments that the temperatures multiplied by 5.5 gave the iodine absorption. The thermometer used should be a good one, capable of reading to $\frac{1}{1}^{\circ} \mathrm{C}$.; the same thermometer and test tube should always be used. When the apparatus has been once standardised this method forms a rapid means of estimating the iodine absorption.

The bromine should be measured in a 1 c.c. pipette, having a bulb filled with soda lime in its upper portion; unless this is done, the fumes of the bromine are apt to prove very unpleasant.

\section{Heat Evolved by Hydrolysis by Sulphuric Acid.}

The Maumené Test.-When fats are acted on by strong sulphuric acid a series of reactions takes place. The fat is first split up to fatty acids and glycerol, which combines with the sulphuric acid. The saturated fatty acids (stearic series) are not further affected, but the unsaturated fatty acids undergo sulphonation and cther changes. Of these, the oleic series, which has only one saturated bond, is acted on to a less degree than the linolic and linolenic series, which contain two or three bonds respectively. Each of the actions which takes place evolves heat, and, by measuring the rise of temperatures which takes place, an index of the total amount of heat evolved is obtained.

Modification by Thompson and Ballantyne.-This test is due to Maumené, who measured the heat evolved on mixing 10 c.c. of sulphuric acid with 50 grammes of an oil or fat. $\mathrm{His}$ original method was faulty, in that he did not rigidly prescribe any strength of acid nor form of apparatus. Thompson and Ballantyne propose to compare the heat evolved on mixing 10 c.c. of sulphuric acid with 50 grammes of oil or fat with that evolved by unixing 10 c.c. of the same acid with 50 granmes of water in the same vessel. Taking the heat evolverl by the water as 100, they term the figure obtained the "Specitic Temperature Reaction" of the oil or fat. This method gives a very fair means of correcting for the differences of temperature observed when working with acids of differing strength and in different apparatus, and is convenient in practice.

The author has examined with some care the results obtained by the use of acicls of different strengths. The following series 
will show that the effeet of strength of acid ean be corrected by a very simple calculation. These results were obtained with a pure olive oil.

\begin{tabular}{|c|c|c|c|c|}
\hline \multicolumn{3}{|c|}{ strength of Acid. } & \multirow{2}{*}{$\begin{array}{l}\text { Rise of Tempcrature. } \\
\qquad \begin{array}{l}47 \cdot 2^{\circ} \\
41 \cdot 1^{\circ} \\
39 \cdot 3^{\circ} \\
35 \cdot 6^{\circ} \\
32 \cdot 6^{\circ} \\
31 \cdot 4^{\circ} \\
29 \cdot 0^{\circ}\end{array}\end{array}$} & $\begin{array}{c}\begin{array}{c}\text { Calculated for } 100 \\
\text { per cent. }\end{array} \\
47 \cdot 2^{\circ} \\
410 \cdot 0^{\circ}\end{array}$ \\
\hline $\begin{array}{r}100 \cdot 00 \\
97 \cdot 50 \\
96 \cdot 64 \\
94 \cdot 93 \\
93 \cdot 49 \\
9 \cdot 2 \cdot 55 \\
9 \cdot 2 \cdot 04\end{array}$ & $\begin{array}{l}\mathrm{ec} \\
, " \\
, " \\
, " \\
, " \\
, "\end{array}$ & $\begin{array}{l}{ }_{2} \mathrm{SO}_{4}, \\
, \\
, \\
, \\
, \\
, \\
,\end{array}$ & & $\begin{array}{r}47 \cdot 2^{\circ} \\
46 \cdot 6^{\circ} \\
466^{\circ} \\
46 \cdot 1 i^{\circ} \\
46 \cdot 8^{\circ} \\
469^{\circ} \\
46 \cdot 3^{\circ} \\
\overline{46 \cdot 7^{\circ}}\end{array}$ \\
\hline
\end{tabular}

The results ealculated for 100 per cent. aeid were obtained by the following formula :-

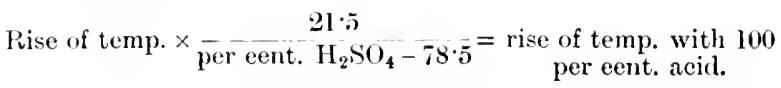

Richmond Modification.-The author caleulates the "Relative Molecular Mammené" fignre by the following formula:-

$$
\text { R.M.M. }=\mathrm{R} \times \frac{215}{x-75.5} \times \frac{20+h}{20} \times \frac{19.5}{\mathrm{~K}} \text {; }
$$

where

$$
\begin{aligned}
& \mathrm{R}=\text { observer rise of temperature. } \\
& x=\text { percentage of } \mathrm{H}_{2} \mathrm{SO}_{4} \text { in acid. } \\
& h=\text { heat eapaeity of apparatus. } \\
& \mathrm{h}=\text { potash absorption (per cent.). }
\end{aligned}
$$

25 grammes of oil were used and 5 c.e. of acid.

The method is performed as tollows:- $A$ beaker abu ut 11 inches in diameter and 3 inclies leep is fitted, by means of a ring of cork, insirle a slightly larger heaker; this is placed in a third still larger beaker, and the intermediate spaee packed with cotton wool. The heat eilpacity of this apparatus is next determined; about 10 grammes of water are placed in the imnermost beaker and the temperature noted ; abont 2.5 grammes of water of higher temperatme are added, and the final temperature noted. 'The heat equivalent of the apparatus is calculated by the formulit-

$$
h=\frac{! n \times(b-c)}{r-a}-x:
$$

where

$h=$ heat capacity of apparatus.

$x=$ wright of witer phared in beaker.

$y=$ weight of hot witer alked.

$a=$ emperature of apparatus.

$b=$ temperatur of hot water.

$r=$ final temperature after mixing. 
The following experiments will show the nature of the value of $h:-$

\begin{tabular}{|c|c|c|c|c|c|}
\hline $\begin{array}{c}x . \\
\text { grammes. }\end{array}$ & $a$. & $\begin{array}{c}y . \\
\text { rammes }\end{array}$ & $b$. & c. & $\begin{array}{c}l . \\
\text { grammes. }\end{array}$ \\
\hline $10^{\circ} 0$ & $16 \cdot 0^{\circ}$ & $26 \cdot 5$ & $39 \cdot 0^{\circ}$ & $31 \cdot 2^{\circ}$ & $3 \cdot 60$ \\
\hline $10 \cdot 0$ & $17 \cdot 5^{\circ}$ & 235 & $50 \cdot 5^{\circ}$ & $38 \cdot 5^{\circ}$ & $3 \cdot 43$ \\
\hline $0 \cdot 0$ & $20 \cdot 0^{\circ}$ & $35 \cdot 1$ & $42 \cdot 0^{\circ}$ & $40 \cdot 0^{\circ}$ & $3 \cdot 51$ \\
\hline
\end{tabular}

When the innermost beaker lolds about double the volume of the oil and acid, its weight multiplied by $\cdot 15$ will give its heat capacity with considerable accuracy; the beaker used above weighed $23 \cdot 2$ grammes; this multiplied by $\cdot 1.5$ gives $3 \cdot 48$.

Twenty-five grammes of filtered and dried fat are weighed into the beaker, and the apparatus with thermometer, together with the acid to be used in a small bottle, and a 5 c.c. pipette, are placed in an incubator kept at $30^{\circ} \mathrm{C}$. for at least half an hour, and the temperature noted. 5 c.c. of acid are added, and the mixture well stirred with the thermometer, till the temperature ceases to rise. The difference between the initial temperature and that finally attained is taken as the rise of temperature, and the Relative Molecular Maumené figure is calculated from this.

The R.M.M. of butters varies from $330^{\circ}$ to $34 \cdot 5^{\circ}$, with a mean value of $34.0^{\circ}$. The ratio $\frac{\text { R.M.M. }-10}{\text { iodine absurbed }}$ has been about $\cdot 633$, varying from 615 to 649 . Any increase in this ratio may be taken to indicate aduiteration by vegetable oils.

This method is occasionally useful, but is rather troublesome, and cannot be well recommended, except as an additional test in cases of donbt. It is very important that the fat be well dried.

The Physical Examination of Butter Fat. - The most important physical properties are microscopic eximination under polarised light, density, refractive index, viscosity, and behaviour on melting.

Microscopic Examination under Polarised Light.-This method is founded on the fact that when a crystalline substance is placed between two crossed Nicol prisms the light undergoes rotatory polarisation; the rays that would normally vibrate in the plane, which would caluse total reflection, are caused to vibrate in a plane inclined to this, and the light consequently passes through the second $\mathrm{Nicol}$ prism. Substances which have no crystalline structure do not cause any interference with the plane of vibrations.

This method was first applied by Campbell Brown to detect adulteration of butter with foreign fat. The fat of milk when churned into butter is devoid of crystalline structure. The fats of which margarine is composed, having been melted and cooled, usually acquire a more or less pronounced crystalline form.

It has been studied by Taylor, Pizzi, and others, and is fairly 
reliable. The following are the sources of error:-The presence of salt, salicylic acid, and other crystalline substances added to butter as preservatives, or accidentally mixed with it, will cause the liglit to pass, and may be mistaken for crystalline fat; but a simple microscopical examination will usually reveal the nature of particles of this nature, and an experienced observer will rarely be misled. Butter which has been melted, re-emulsified, and rechurned will behave to this test as margarine, though no similar appearance is noticed in butter which has beeu kept just below the melting point for some length of time. Margarine which has been prepared by emulsifying the fat with skim milk with a good emulsor, separating the cream, and churning this with ordinary cream, beliaves as butter, and Pizzi has succeeded in alding 30 per cent. of foreign fat to butter in this way without being able to distinguish it. Finally, rancid butter, and butter which has been at once churned from pasteurised cream at a low temperature, may sometimes give an appearance resembling margarine.

It is apparent that this test must be used with reservation, but it is without doubt of use as corroborative evidence in cases where other analytical data are not absolutely conclusive.

The method is carried out as follows:--The outer portions of a piece of butter are removed, and a piece about the size of a pin's liead is transferred from the freshly exposed surface to a clean microscope slide. A cover glass is placed on the top, and the hutter spread out by gentle pressure on the upper surface of the cover. The slicle is placed on the stage of a microscope titter with erossed Nicol prisms, and examined with a l-inch objective. To exclude light from the upper surface a blackened cardboard tube may be placed over the slide in such a manner that the ohjective dips into it, and the light falling on the upper portion of the slicle is cut off. When pure butter is examined the field is uniformly dark, and only with the greatest difliculty can any structure be distinguished. When margarine is present cortain portions of the field have a bright appearance, and indistinct crystalline forms can be made out. If any distinct and bright crystals are seen, the Nicol prisms should be turned parallel, and the slicle exanined in that spot in order to see whether salt or other crystalline matter is present; there is not much difliculty in distinguishing this owing to its great refractive power. 'The slide should he movel about to examine all parts of it, is, in cases of small amounts of achulteration, the margarine is not equally distributed throughout, and two or more portions from different parts of the sample may be examined.

As a chrck, a selenite plate (a crystalline form of calcium sulphate, which possesses the property of rotatory lispersion to a large extent) is next placed under the slinte, the microseope 
focussed, and the sample again examined. In this case the slide will be uniformly illuminated when the prisms are crossed, but will appear coloured; the colour depends on the thickness of the selenite and the position of the Nicol prisms, but when pure butter is examined the whole of the field appears of one colour. When margarine is under observation certain parts of the field are seen to be of a different colour.

This modification is, when used by persons of absolutely normal vision, quite as delicate as the examination without selenite, but it cannot be generally recommended, as the perception of colour is a sense in which many people--more than is commonly supposed-are somewhat deficient, though not absolutely colour blind. The usual colours which selenite plates are constructed to give-red and green-are those which are least easily distinguished by the majority of those who suffer from weak colour perception. It is advisable, therefore, never to omit the examination without a selenite plate.

It is, of course, essential to ernploy a good microscope, as any illumination of the slide, except by light which has passed through the polariser, will prevent the extinction of the field on crossing the Nicol prisms. Though it is impossible in practice to secure an absolutely dark field, this can be done with a good instrument and a cardboard tube over the slide with a near approach to completeness. Any marked illumination of the field when the Nicol prisms are crossed will greatly impair the delicacy of the test.

\section{The Density of Butter Fat.}

Butter fat, on account of the presence of glycerides of low molecular weight, has a greater clensity than the fats used for its adulteration. As it is more convenient and exact to take the density of a liquid than of a solid, the fat is almost invariably melted and the density determined at a temperature above its melting point.

The methods of estimating the density have already been discussed under the "specific gravity of milk" (p. 51), and (except that for butter a temperature considerably higher than that at which the density of milk is taken is employed) the same methods are employed.

Expansion.-Two questions arise: At what temperature shall the density of butter be taken? How shall the results be expressed? The experiments of Skalweit have indicated the most favourable temperature. He took the densities of butter and margarine at various temperatures from $35^{\circ} \mathrm{C}$. to $100^{\circ} \mathrm{C}$., using Koch's incubator to keep a constant temperature. 
His figures are as follow:--

\begin{tabular}{|c|c|c|c|}
\hline Temperature & Butter. & Margarine. & Difference. \\
\hline $\begin{array}{c}35^{\circ} \mathrm{C} . \\
50^{\circ}, \\
60^{\circ}, \\
70^{\circ}, \\
80^{\circ}, \\
90^{\circ}, \\
1011^{\circ},\end{array}$ & $\begin{array}{l}\cdot 91 \cdot 21 \\
.9017 \\
\cdot 8945 \\
\cdot 8579 \\
\cdot 8810 \\
.8741 \\
.8672\end{array}$ & $\begin{array}{l}9017 \\
\cdot 89.21 \\
.8857 \\
\cdot 8793 \\
\cdot 87.29 \\
.8665 \\
\cdot 8601\end{array}$ & $\begin{array}{l}.0104 \\
.0096 \\
\cdot 0091 \\
.0086 \\
.0081 \\
.0076 \\
.0071\end{array}$ \\
\hline
\end{tabular}

Mode of Expressing Results.- These figures clearly show that its the temperature rises the densities of butter and margarine tend to approach one another; the widest difference occurs at $35^{\circ} \mathrm{C}$.; he, therefore, recommends that this temperature be adopted as the temperature at which the densities of butter should be determined.

In England a larce number of determinations have been made by J. Bell, Allen, Muter, and others at a temperature of $100^{\circ} \mathrm{F}$. $\left(37.8^{\circ} \mathrm{C}.\right)$, and this temperature is very near that found by Skalweit to give the largest difference.

In Americit the temperature of $40^{\circ} \mathrm{C}$. is used to a considerable extent. and the anthor has taken a large number of densities at $39.5^{\circ} \mathrm{C}$. (owing to the use of a thermometer which read $\cdot 5^{\circ}$ too high).

Estcourt proposed to use the temperature of boiling water (which he found to raise the butter fat to $97 \cdot 8^{\circ} \mathrm{C} .\left(208^{\circ} \mathrm{F}\right.$ )), as being easily attained. Allen and others have warmly recommended this temperature, and find no difficulty in bringing the temperatur. up to $\$ 99^{\circ} \mathrm{C}$.

There is a certain amount of confusion as to the manner in which densities are expressed. 'To ascertain the true density, the weight of a certain volume of fat should be divided by the weight of the same volume of water at the same temperature and multiplien by the density of water at that temperature. This is very rarely done, so that few published figures are true densities.

Muter gives the term "actual density" to the weight of a certain volume of fat divided lyy the weight of the same volume of water at the san. timperature; densities expressed thus are usually denoted hy the symbol D $\frac{37 \cdot 5^{\circ}}{37 \cdot 5^{\circ}}$ for density at $37 \cdot 8^{\circ}$, or $D \frac{35^{\circ}}{3.5^{\circ}}$ for density at $35^{\circ}$, and the true density is often expressed in $\mathrm{D} \frac{37 \cdot 8^{\circ}}{4^{\circ}}$ or $\mathrm{D}^{3 .} 4^{\circ}$. 
It is usual when densities are taken at the temperature of boiling water to express them in a different way. 'T'he weight of a certain volume of fat is divided by the weight of water displaced by a piece of glass which occupies the same volume at the same temperature, when it is cooled clown to $60^{\circ} \mathrm{F}$. $\left(15.5^{\circ} \mathrm{C}\right.$.). This mode of expression may be denoted by the formula $D \frac{100^{\circ}}{15 \cdot 5^{\circ}}$ in glass. Though aplarently cumbersome this method of expressing results has certain advantages, as the instrument with which the densities are taken can he standardised at $60^{\circ} \mathrm{F} .\left(15.5^{\circ} \mathrm{C}\right.$.), and can then be used at any temperature without requiring to be restandardised. It must be remembercd that though the expansion of glass is very nearly constant it is not quite so, and over a range of $85^{\circ} \mathrm{C}$. appreciable differences may occur in the expansion of different instruments. If the glass be not well annealed, internal strains are set up, and these may be so accentuated at high temperatures as to cause distortion and change of volume. It will be readily seen that the method of taking the apparent density in glass at the temperature of boiling water is liable to greater experimental error than determinations at lower temperatures, and, as the experiments of Skalweit have shown, that the effect of experimental error is magnified at $100^{\circ} \mathrm{C}$, , owing to there being a smaller difference between the densities of butter and margarine at this temperature than at lower ones. It is desirable not to adopt this method where accuracy is, as it al ways should be, a clesideratum.

On the whole, it seems desirable to aclopt $100^{\circ} \mathrm{F} .\left(37 \cdot 8^{\circ} \mathrm{C}\right.$.) as the standard temperature at which determinations should be made, because it is sufficiently near Skal weit's minimum to give a large difference between butter and margarine, and because a large number of experiments on genuine butters have already been made at this temperature.

Determination.--The density of butter is best determined by the pycnometer. This is filled with distilled water, and the weight of water which it liolds at $37.8^{\circ}$ determined. After drying, by placing in the water oven and drawing a current of air through it, it is filled with the fat and placed in water at $37.8^{\circ} \mathrm{C}$. till the volume is constant; the temperature must be accurate to $\cdot 1^{\circ} \mathrm{C}$. if the result is required to be exact to the fourth place of decimals. The weight of fat divided by the weight of water will give the density at $37 \cdot 8^{\circ}$.

The Westphal halance may be employed, the apparent density of water at $37.8^{\circ}$ must be determined, and the density of fat indicated by the instrument divided by this to obtain the density at $\frac{37 \cdot 8^{\circ}}{37 \cdot 8^{\circ}}$ 
The ilensity is also sometimes iletermined by a hydrometer. If this instrument be usel, it should be tested in fats of known density, and its indieations thus controlled. A. Meyer states that the height of the meniscus depends somewhat on the harometric pre-sure, but the rror lue to this eause is not likely to exeed the experimental error of reading. Should the temperature not be exactly $37 \cdot 8^{\circ} \mathrm{C}$., a correction of .0007 for each dingree mav be added for temperatures above, and subtracted for temperatures below, $37 \cdot 8^{\circ} \mathrm{C}$.

It it be desired to take apparent densities at $\frac{100^{\circ}}{15 \cdot 5^{\circ}}$ in glass, the instruments should he standardised at $15.5^{\circ}$, and the density determined as above.

The author has used a bulb of specific gravity 865 at $15.5^{\circ}$ for the purpose of rapidly determining an approximate density. A test tuhe is filled with the fat, the bulb dropped in, and the tube placed in boiling water. If the bulb floats at the top, the density is above 865 ; and if it sinks, it is below. This has proved a fairly good rough test.

The limits observed for pure butter are :-

$\begin{array}{cccc} & \text { Maximum. } & \text { Ninimum. } & \text { Mean. } \\ \text { At } \frac{37 \cdot 8^{\circ}}{37 \cdot 8^{\circ}} & .9140 & .9094 & .9118 \\ \text { At } \frac{100^{\circ}}{15 \cdot 5^{\circ}} \text { (in glass) } & .8685 & .8650 & \end{array}$

The fats usually employed as adulterants have a density at $37 \cdot 5^{\circ}$ of $\cdot 901$ to 905 , mean 903 ; and at $\frac{100^{\circ}}{15 \cdot 5^{\circ}}$ (in glass) of 860 to $: 6.3$, mсan 86 l.

Certain oils have, however, a higher deusity; thus, at $\frac{100^{\circ}}{15.5^{\circ}}$ (ii) glass) -

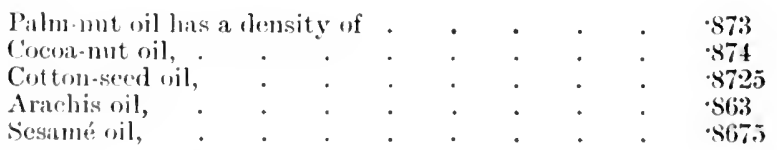

Of these oils, falm-nut and cocoa-nut oils can be realily frofeted (ste frat), while the other oils eannot be used alone, but must be mixed with fats of less density to ohtain the necessary consistency. With the reservation that the oils mentioned above would cause somrwhat ahmormal results, the dremination of thre rensity of luter is a very useful test, and, though not reliable as a single lest, is of aruat use for eorroborative purposes. 
Molecular Specific Volumes.-A method of calculating which will sometimes be of use is to deduce the specific volume by dividing the density into 1 , and to multiply the figure thus. obtained by the potash absorption and to divide the result by $19 \cdot 5$.

The nean figure thus obtained for butter is 1.2766 , and for margarine $1 \cdot 1641$ at $37 \cdot 8^{\circ} \mathrm{C}$. If the butter is adulterated with beet or other animal fat, the percentage of adulteration calculated with this figure will agree fairly well with that calculated from other determinations. If vegetable oils have been used, the percentage deduced thus is considerably more.

\section{Refractive Index.}

The Oleo-refractometer. - When light passes from one nedium to another it only passes in a straight line when it falls perpendicular to the surface separating the two media. If it passes through at an angle to the surface, it is bent or refracted, and the ratio between the angle made by the path of the ray with the perpendicular to the surface in the first medium and the angle made by the path in the second medium with the perlendicular is a constant; the ratio of the sines of the two angles is known as the index of refraction. As the sine of an angle of $90^{\circ}$ is 1 , it is seen that the ratio between the sine of the angle at which light is first reflected and 1 is the index of refraction; this angle is termed the angle of total reflection. As it is more convenient to measure this than to measure the two. angles, and deduce the ratio of the sines, in practice the angle of total reflection is frequently measured.

Müller was the first to apply the determination of the refractive index to the analysis of butter. He allowed the butter to solidify slowly, absorbed the liquid portion with filter paper, extracted this with ether, and examined it in Abbé's refractometer, an instrument which measures the angle of total reflection. Skal weit examined this method and showed that it was inıportant to operate at a fixed temperature.

Owing to the difficulty of maintaining a fixed temperature in A bbé's refractometer, this method was not nuch used till special instruments were devised.

A magat and Jean have devised an oleo-refractometer for determining the refractive index of oils and fats (Fig. 20); it consists of a collimator, a hollow prism with sides inclined at an angle of $107^{\circ}$, and a telescope furnished with an arbitrary glass scale placed in the focus of the eye-piece. In the collimator is placed a piece of opaque substance, which cuts off the light from onehalf of the field. If the prism and the space outside between the collimator and the telescope are filled with the same liquid, there will be no refraction. If, however, the prism contains a 
different liquid, the refraction will he indicated (in arbitrary degrees) by the position of the junction between the light and dark halves of the field on the seale.
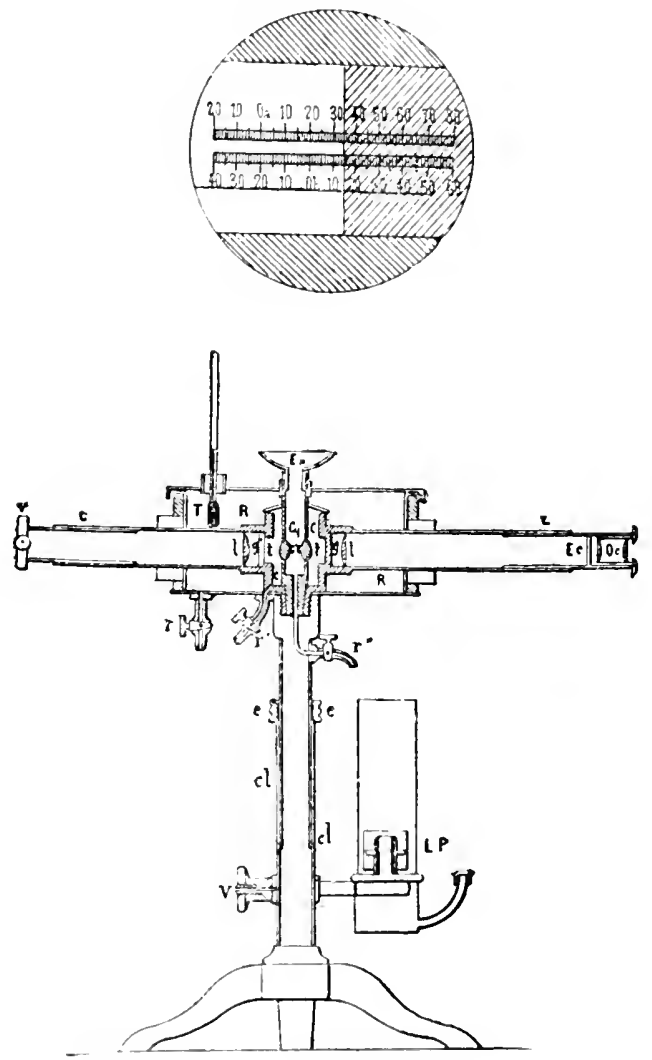

Fis. 20. - Oleo-refractometer.

A standard oil (herile eype)* is supplied with the instrument, and the seale is so adjusted as to reach zero when this is placed in the instrument. The oil on fat to be tested is placed in the lollow prosm and the position of the dividing line read off on the scale. 'l'he temprature is kept constant by means of a jacket, and is usually $45^{\circ} \mathrm{C}$.

Jean gives the following method for testing butter:-Melt from 25 to 30 grammes of the lutter in a porcelain dish at a

"This is usulally translated as "typical oil"; the word "standard" is more nearly oquivalent to the French "'ype," than is "typieal." 
temperature not exceeding $50^{\circ} \mathrm{C}$; stir well with a jinch or two of gypsum, and allow to settle out at about the same temperature. Then decant the supernatant fat through a hot water tunnel plugged with cotton wool, and pour (while warm) into the prism. Observe the deviation at $45^{\circ}$. Genuine butter gives a deviation of about $30^{\circ}$ to the left, while margarine gives about $15^{\circ}$, and cocoa-nut oil about $59^{\circ}$. Libry de Bruyn has shown that genuine butters may show a deviation of $25^{\circ}$ to the left.

It is evident that the addition of a mixture of cocoa-nut oil and margarine would give a figure equal to that of butter. Muter has, however, shown that the figure given in the oleorefractometer has a relation to the Reichert figure, which would be much disturbed by such a mixture.

Muter's relation is expressed by the following table :-

A deviation of $-36^{\circ}$ is accompanied by a Reichert figure of 16.0 .

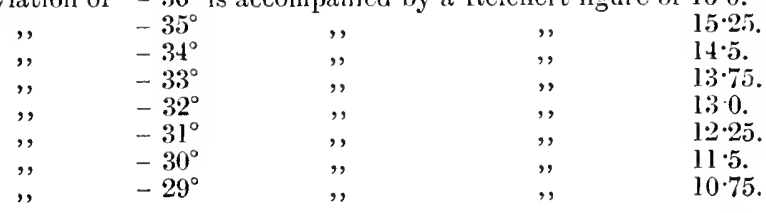

Butyro-refractometer.-Zeiss' butyro-refractometer (Fig. 21) measures the angle of total reflection and is a modification of the well-known Abbé refractometer. It consists of two prisms of glass, hinged so that they can be separated. The light enters at the bottom, passes through the prisms, and is viewed through a telescope having a fixed scale in the focus of the eye-piece. The prisins are provided with a jacket, through which water, the temperature of which is indicated by a thermometer, is passed. A drop of the filtered fat is placed on the glass surface of the lower prism, spread evenly over it, and the prism closed the reflector is adjusted so as to reflect clear daylight or lamplight through the prisins, and the refractive index in scale degrees is read off.

This instrument is extremely rapid, as a determination, including reading of the temperature and scale degrees, does not take more than a minute. After use, the instrument should be cleaned by rubbing off the fat with a duster, and polishing the prisms with a clean linen cloth slightly moistened with alcohol.

Scale divicions mav be converted into refractive indices by the following table (p. 288).

There is a difference in the refractive index depending on the light used; this is corrected in the instrument by making the prisns of different kinds of glass, so that when used with butter ordinary white light behaves as if it were simple light. Other fats (and adulterated butters) may be tinged at the edge with blue or red. In this case it is not easy to read the dividing line 


\begin{tabular}{|c|c|c|}
\hline scale Division. & $\begin{array}{l}\text { Refractive Indices for the } \\
\text { D line. }\end{array}$ & Difference. \\
\hline 0 & 1.220 & \\
\hline 10 & $1 \cdot 4300$ & $8 \cdot 0$ \\
\hline 20 & 1.4377 & $7 \cdot 7$ \\
\hline 30 & 1.4452 & $7 \cdot 5$ \\
\hline 40 & 1.4 .524 & $7 \cdot 2$ \\
\hline 50 & 1.4593 & $6 \cdot 9$ \\
\hline 60 & $1 \cdot 4659$ & $6 \cdot 6$ \\
\hline 70 & $1 \cdot+723$ & $6 \cdot 4$ \\
\hline 80 & 1.4783 & $6 \cdot 0$ \\
\hline 90 & $1 \cdot 4540$ & 57 \\
\hline 100 & $1 \cdot 489.5$ & $5 \cdot 5$ \\
\hline
\end{tabular}

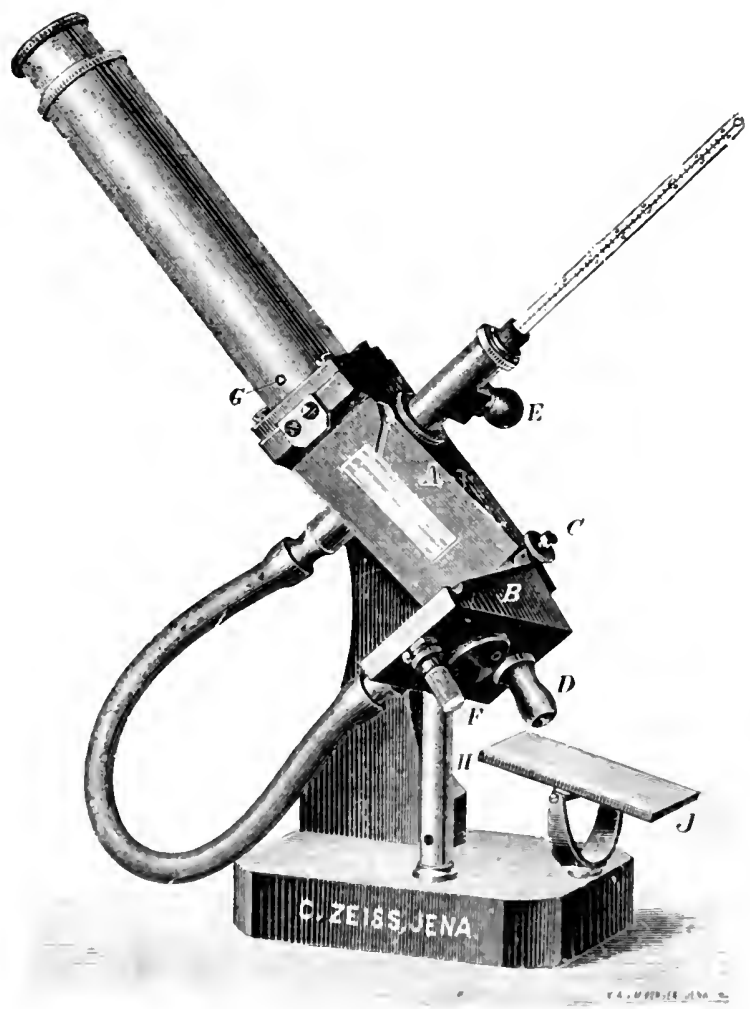

Fig. 2l. - Int yro refractometer. 
accurately. The author is in the habit of using the sodium flame, obtained by heating sodium chloride in a Bunsen burner, as the source of light, and finds that absolutely sharp readings can thus be always obtained. The readings with butters do not differ, whether white light or sodium light be used.

The refractive index varies .55 scale degree for each $1^{\circ} \mathrm{C}$, and can be corrected by means of this factor if the temperature differs from that adopted as normal.

The author has found that genuine butters vary from $43.7^{\circ}$ (in a sample giving a Reichert value of 16.0 c.c.) to $49.0^{\circ}$ (in a sample giving a Reichert value of 10.5 c.c.), and average $46.0^{\circ}$ at a temperature of $35^{\circ} \mathrm{C}$. The value $47.0^{\circ}$ has been proposed as a practical limit.

The equivalent at other temperatures of this limit is as follows :-

\begin{tabular}{c|c||c|c} 
Temperature. & Scale Division. & Temperature. & Scale Division. \\
$25^{\circ}$ & $52 \cdot 5^{\circ}$ & $40^{\circ}$ & $44 \cdot 2^{\circ}$ \\
$30^{\circ}$ & $49 \cdot 8^{\circ}$ & $45^{\circ}$ & $41 \cdot 5^{\circ}$ \\
$35^{\circ}$ & $47 \cdot 0^{\circ}$ & &
\end{tabular}

Some importance has been attached to the colour observed at the edge of the dividing line, and a blue colour has been alleged to be indicative of margarine. In the author's experience this property is valueless. Thus the sample giving a reading of $43.7^{\circ}$ was tinged red, and that giving $49.0^{\circ}$ was tinged blue, though both were authenticated as genuine butters.

Margarine has a value of about $52^{\circ}$ at $35^{\circ}$, cocoa-nut oil of $41^{\circ}$, and cotton-seed oil of $61^{\circ}$.

The remarks made upon the oleo-refractometer apply equally well to the butyro-refractometer, except that the actual values are not identical.

The author's experience confims that of Mansfeld, and shows that, while Muter's relation is, broadly speaking, correct, there are differences so large between the refractive index found and that calculated on the assumption that this property follows the Reichert value, that the rule cannot be depended upon. The refractive index is a property which is much more nearly related to the iodine absorption, or, in other words, to the unsaturated carbon atoms.

Though a very convenient test, it has but little value alone, unless the value is below the average, $46^{\circ}$ at $35^{\circ} \mathrm{C}$. When a butter is adulterated with vegetable oils-e.g., cotton seed-its indications are of some value. It is also useful in detecting cocoa-nut oil, but its value is chiefly corroborative.

A standard fluid (normal flüssigkeit) is supplied with the instrument, and the readings of the scale should be checked from time to time by its use. The point at which the dividing line should lie at $3 \overline{5}^{\circ} \mathrm{C}$. is marked in the instrument, and the 
scale should be brought to this point by means of a key just above the prisms.

Viscosity.-Killing proposes to take the viscosity of butter fat as a test by running it out of a pipette, marked above and below the bulb, and records the time taken for the melted fat to flow from one mark to another. The instrument must be graduated with butters and other fats of known purity.

He gives the following average times of flow:-

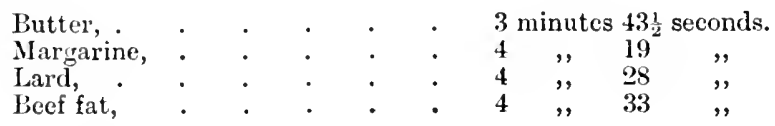

Wender uses an apparatus called a fluidimeter. This consists of a U-shaped capillary tube having at one end an enlargement holding 10 c.c., and at the other an enlargement holding 2 c.c.; the larger bulb is placed higher than the smaller; liquid, therefore, flows from it. A solution of the fat in chloroform is used; the upper bulb is filled with this, the solution allowed to flow into the lower bulb, and the time noted which it takes to pass from the lower mark to the upper one on the smaller bulb. The time taken for chloroform to flow is also noted, and this is taken as 100 .

The viscosity of the fat is calculated by the following formula :-

Let $\quad \mathrm{V}=$ viscosity of the fat,

$x=$ percentage of fat in chloroform solution by volume,

and $\mathrm{T}=$ the time taken divirled by the time taken by chloroform,

then $V=\frac{100 \mathrm{~T}-100(100-x)}{x}$.

The average time for chloroform to fill the lower bulb was 20.04 seconds.

Wender gives the following values as the mean figures at $20^{\circ} \mathrm{C}$. (chloroform $\left.=100\right)$ :-

Tiseosity of pure butter, . . . . . . $344 \cdot 3$

", nargarine, : $: \quad: \quad$ : 373.2

It does not appear that this test has any greater value than other physical determinations.

Behaviour of Buttor on Melting.-When butter is melted at a temperature of about $60^{\circ} \mathrm{C}$., the fat which flows from the arpeous portion is generally elear and transparent; when margarine is melted, the fat is almost always cloudy.

This has been used as a test for the purity of butter. It does not appear to depend on any property of the fat, but on the state in which the fat existed in milk, and the method of preparing the butter. Butters which have been overworked invariably melt in a cloudy manner. 
Druot has devised an apparatus for observing the behaviour on melting. It consists of a number of cups stamped in tin plate, in which pieces of the samples to be tested, about $1 \frac{1}{2}$ grammes in weight, are placed. A piece of iron heated to about $60^{\circ}$, and of sufficient thickness to retain enough heat to melt the samples, is placed over the top, and left till the butters are melted. The appearance of the fat is observed, the polished surface of the tin plate materially aiding the observation.

This method can only be classed as a rough means of determining the purity of butter.

Melting Point of the Fat.-Formerly some importance was attached to the melting point of the fat; this, however, depends to some extent on the method employed in determining it. Butter melts at about $33^{\circ} \mathrm{C}$.; and artificial butters are made up to melt at the same temperature.

Among other physical properties which have been proposed are the determination of the heat of combustion, which differs materially in butter and other fats, and the relative transparency to the $X$ rays. These methods are not, however, practical analytical methods.

Detection of Adulteration of Butter.-The most useful and rapid preliminary test is examination with the butyrorefractometer. Any sample showing a refractive index of less than $46^{\circ}$ at $35^{\circ} \mathrm{C}$. is most probably genuine, but may, however, contain cocoa-nut oil. The Reichert process should next be applied. Any sample requiring less than 9 c.c. of $\frac{\mathrm{N}}{10}$ alkali for 2.5 grammes, or 20 c.c. for 5 grammes (Reichert-Wollny method) may be taken as adulterated; samples requiring more than 12.5 c.c. or 28 c.c. respectively may be passed as genuine, though they cannot absolutely be certified as free from adulteration. Any sample taking a volume of $\frac{\mathrm{N}}{10}$ alkali between the limits given above must be further examined. Baudouin's, Becchi's, and Wellmann's tests should be applied. A wellmarked reaction with any or all of them will furnish strong presumptive evidence of the presence of margarine containing vegetable oils. 'The soluble and insoluble fatty acids, saponification equivalent, and especially the mean molecular weight of the insoluble fatty acids should be determined.

Cocoa-nut oil can be readily detected by the figures thus obtained. The ratio between the Reichert or Reichert-Wollny figure and the difference between the insoluble fatty acids and 95.5 is much depressed; in butter the ratio is about $\frac{\mathrm{R}}{95 \cdot 5-\mathrm{I}}=1.6$ or $\frac{\mathrm{R}-\mathrm{W}}{95.5-\mathrm{I}}=3.5 \quad(\mathrm{R}=$ Reichert figure, 
$\mathrm{R}-\mathrm{W}=$ Reichert-Wollny figure, and $\mathrm{I}=$ Insoluble fatty acids); while cocoa-nut oil gives values of $\cdot 35$ and $\cdot 75$ respectively. The mean nolecular weight of the insoluble fatty acids in butter is about 259 and varies but little from this figure, while the corresponding figure for cocoa-nut oil is about 200. The iodine alsorption of cocoa-nut oil is also low, about 9 per cent.; while butter absorbs about 34 per cent. of iodine.

It is far more diffieult to detect other adulterants, if present. in small quantities. Genuine butters which are below the average in the Reichert figure give high insoluble and low soluble fatty acids, a higl iodine absorption, and a low percentage of potash absorbed. In the few samples that the author has examined the mean combining weight of the insoluble fatty acids has not been so high as wonld be expeeted. Thus the mean combining weight of the insoluble fatty acids is about 259, while the mean combining weight of the insoluble fatty acids of most adulterants is about $27 \pi$. The Valenta test is also useful, and the density may be used as a corroborative test.

Margarine.- It is advisable to ealculate from the mean figures yielcled by genuine butters and margarine the apparent percentage of margarine present. If the percentage thus calculated from the mean combining weight of the insoluble fatty acids, the Valenta value, and the density be less than that ealeulated from the other determinations and, at the same time, the iodine absorption and refractive index are slightly high, it is probable that the butter is genuine. If the contrary is the ease, and the apparent percentages from all the methods give approximately the same value, it is probable that the butter is adulterated. If, in addition, the colour tests for veretable oils have given distinct reactions, the probability of adulteration is strengthened.

Though in the present state of science it is not possible to definitely certify many cases of small amounts of adulteration, for dairy control work the task is much simplified. The samples which must be regarded as suspicious can be reported as such, or even as adulterated, with a high degree of probability, and it will be frequently possible to trace such samples to their origin, by examining the fat of the milk of the eows which yiclded the butter.

Influence of Kooping on the Analytical Properties of Butter. - When butter is kept and beemes rancid very pronounced changes take place in the composition of the fat. These may he elassed under two heads-hydrolysis and oxidation. If butter fat be kept in the dark and out of contact with the air, it keeps indefinitely without change; but in the presence of light and air it becomes oxidised. 
The general course of change may be roughly indicated thus-

(1) The fat is partly hydrolysed into fatty acids and glycerol.

(2) The glycerol is oxidised to fatty acids of low molecular weight.

(3) The unsaturated acids are oxidised, forming hydroxy-acids.

The general effect of these changes is-

The volatile and soluble acids are increased, the soluble in greater proportion than the volatile.

The insoluble acids are decreased.

The iodine absorption is lowered.

The density and refractive index are increased.

The potash absorption is increased.

If the butter has been kept in its natural state, the butter fat obtained on melting may have properties materially differing from those indicated above, owing to the solubility of some of the products in the water still left in the butter. The soluble and volatile acids in the filtered fat may be lowered from this cause, and the insoluble acids increased.

The change is not very rapid, and in the course of several weeks the changes are often not very pronounced.

Bell has recorded the following figures for the changes in the insoluble fatty acids; the butter in this case was kept for the times indicated:-

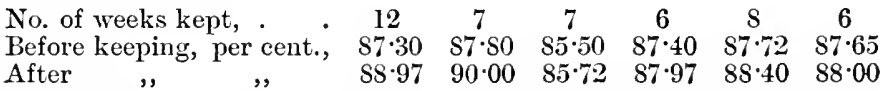

Vieth has made analyses showing the change in the insoluble fatty acids produced when butter fat is kept. In each case about a year had elapsed between the two analyses.

$\begin{array}{lcccc}\text { Original insoluble fatty acids, } & 87 \cdot 43 & 88 \cdot 33 & 87 \cdot 61 & 87 \cdot 72 \\ \text { Insoluble fatty acids, after keeping, } & \$ 5 \cdot 07 & \$ 5 \cdot 97 & 84 \cdot 41 & \$ 3 \cdot 82\end{array}$

The same observer has also examined old butter fat and old butter (kept for about ten years) which had not been previously analysed.

The old butter fat was divided into two portions-one, completely bleached, contained 83.52 per cent. of insoluble fatty acids; and the other, which still retained a trace of its natural colour, yielded 83.90 per cent.

The results with the old butter were as follows :-

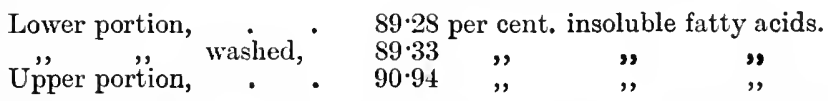

Allen and Moor have examined two samples of butter which had been kept for five and a half years. The following table gives their results :- 


\begin{tabular}{|c|c|c|c|c|c|c|}
\hline & \multicolumn{4}{|c|}{ L. } & \multicolumn{2}{|c|}{0.} \\
\hline & \multirow{2}{*}{ Fresh. } & \multicolumn{3}{|c|}{ Old. } & \multirow{2}{*}{ Fresh. } & \multirow{2}{*}{ old. } \\
\hline & & 1. & 2. & 3. & & \\
\hline Density $\frac{100^{\circ}}{15 \cdot 5^{\circ}}$ (in glass), & 8640 & $\cdot 8634$ & $\cdot 8696$ & $\cdot 8730$ & $\cdot 8641$ & $\cdots$ \\
\hline Rieichert-Wollny, . . & $2 \cdot 2 \cdot 51$ & $14 \cdot 43$ & $12 \cdot 02$ & $12 \cdot(0)$ & $24 \cdot 55$ & $22 \cdot 48$ \\
\hline Potash absolption, . . . . & $22 \cdot 16$ & $21 \cdot 99$ & $2 \cdot 55$ & $22 \cdot 88$ & $2 \cdot 2 \cdot 09$ & $23 \cdot 33$ \\
\hline Soluble fatty acids, per cent., & $4 \cdot 44$ & $3 \cdot 82$ & $5 \cdot 66$ & $5 \cdot 80$ & $4 \cdot 68$ & $5 \cdot 59$ \\
\hline Insoluble fatty acids, , , & $90 \cdot 44$ & $90 \cdot 73$ & $90 \cdot 70$ & $90 \cdot 00$ & $90 \cdot 10$ & $85 \cdot 78$ \\
\hline Iodine absorption, $\cdot{ }^{\cdot} \cdot \cdot$ & $40 \cdot 0^{*}$ & $30 \cdot 01$ & $27 \cdot 17$ & $25 \cdot 05$ & $?$ & $25 \cdot 57$ \\
\hline
\end{tabular}

Clayton has analysed a butter which in 1879 gave in Helıner's hands 87.75 per cent. of insoluble fatty acids. His results were :-

\begin{tabular}{|c|c|c|c|c|c|}
\hline & $\begin{array}{l}\text { Melting } \\
\text { Point. }\end{array}$ & $\begin{array}{c}\text { Density } \\
100^{\circ} \\
15 \cdot 5^{\circ} \\
\text { (in glass). }\end{array}$ & $\begin{array}{c}\text { Insoluble } \\
\text { Fatty Acils. }\end{array}$ & $\begin{array}{c}\text { Soluble } \\
\text { Fatty Acids. }\end{array}$ & $\begin{array}{l}\text { Reichert- } \\
\text { Wolluy. }\end{array}$ \\
\hline \multirow[t]{2}{*}{$\begin{array}{l}\text { January, } 189 \tilde{5}, \\
\text { October, } 1897,\end{array}$} & $33^{\circ} \mathrm{C}$. & $\begin{array}{c}8742 \\
\cdots\end{array}$ & $\begin{array}{l}\text { Per cent. } \\
85 \cdot 72 \\
\quad \ldots\end{array}$ & $\begin{array}{c}\text { Per cent } \\
\quad \because \cdot 36\end{array}$ & $\begin{array}{c}\text { c.e. } \\
22 \cdot 36 \\
\quad \ldots\end{array}$ \\
\hline & $\begin{array}{l}\text { Potash } \\
\text { alsorbed. }\end{array}$ & $\begin{array}{l}\text { Iodine } \\
\text { absorbed. }\end{array}$ & $\begin{array}{l}\text { Maumené } \\
\text { figule. }\end{array}$ & \multicolumn{2}{|c|}{ Rancidity. } \\
\hline $\begin{array}{l}\text { January, } 1895 \text {, } \\
\text { October, 1897, }\end{array}$ & $\begin{array}{c}\text { Per eent. } \\
\quad \cdots \\
23 \cdot 47\end{array}$ & $\begin{array}{l}\text { Per cent. } \\
25 \cdot 6 \mathrm{~S} \\
25 \cdot 09\end{array}$ & $22^{\circ} \mathrm{C}$ & \multicolumn{2}{|c|}{$\begin{array}{l}100 \text { grammes required } \\
\text { l(6):3 c.c. normal } \\
\text { alkali. }\end{array}$} \\
\hline
\end{tabular}

Besana has examined twenty samples after keeping for various periods of time; he estimated the Reichert-Wollny figure (Table LIII.).

Vieth has examined a butter which had been kept more than ten years; the fat then yielded the following Reichert-Wollny ficures-26.2, 25.6, $25 \cdot 7$, and $21 \cdot 2$ c.c. on different portions. He has also exammed butter fat which had been kept for eighteen inontlis.

The results werr:-

Fresh, . 29:2 c.c. $2 ! 9 ! 9$ c.c.

old, - 30.4 c.c. 2915 (.e. (dletermined by the anthor).

* This figure was determined by the author on a duplicate sample. 
THE RICHERT-WOLLNY FIGURE OF BUTtERS.

TABLE LiII.-The Reichert-Wollyy Figure of Butters.

\begin{tabular}{|c|c|c|c|}
\hline $\begin{array}{c}\text { No. of days } \\
\text { Netween first } \\
\text { and second } \\
\text { test. }\end{array}$ & \multicolumn{2}{|c|}{ Reichert-Wollny Figure. } & Difference. \\
\cline { 2 - 3 } & Fresh Butter. & Rancid Butter. & \\
\cline { 2 - 3 } 173 & $27 \cdot 70$ & $27 \cdot 42$ & $-\cdot 28$ \\
171 & $27 \cdot 28$ & $26 \cdot 98$ & $-\cdot 30$ \\
170 & $27 \cdot 50$ & $27 \cdot 28$ & $-\cdot 22$ \\
169 & $27 \cdot 51$ & $27 \cdot 64$ & $+\cdot 13$ \\
164 & $27 \cdot 43$ & $27 \cdot 75$ & $+\cdot 32$ \\
162 & $28 \cdot 49$ & $28 \cdot 30$ & $-\cdot 19$ \\
161 & $27 \cdot 90$ & $27 \cdot 65$ & $-\cdot 25$ \\
160 & $27 \cdot 54$ & $27 \cdot 40$ & $-\cdot 14$ \\
157 & $27 \cdot 72$ & $27 \cdot 31$ & $-\cdot 41$ \\
157 & $28 \cdot 49$ & $27 \cdot 97$ & $-\cdot 52$ \\
134 & $29 \cdot 15$ & $29 \cdot 40$ & $+\cdot 25$ \\
131 & $29 \cdot 48$ & $25 \cdot 74$ & $-\cdot 74$ \\
107 & $29 \cdot 48$ & $28 \cdot 96$ & $-\cdot 52$ \\
107 & 2970 & $29 \cdot 18$ & $-\cdot 52$ \\
84 & $29 \cdot 40$ & $28 \cdot 85$ & $-\cdot 55$ \\
84 & $29 \cdot 36$ & $28 \cdot 74$ & $-\cdot 62$ \\
79 & $27 \cdot 87$ & $27 \cdot 42$ & $-\cdot 45$ \\
47 & $28 \cdot 08$ & $28 \cdot 30$ & $+\cdot 22$ \\
46 & $27 \cdot 86$ & $27 \cdot 75$ & $-\cdot 11$ \\
46 & $28 \cdot 85$ & $28 \cdot 96$ & $+\cdot 11$ \\
\hline
\end{tabular}

Another example of butter fat well protected from the light gave in July, 1888, from $31 \cdot 6$ to $32 \cdot 1$ c.c. of $\frac{\mathrm{N}}{10}$ alkali. In-

\begin{tabular}{|c|c|c|}
\hline October, 1888, & it gave & $31:$ \\
\hline .January, 1889, & $"$ & $32 \cdot 1$ \\
\hline May, 1889 , & , & $32 \cdot 1$ \\
\hline September, 1859, & & $31 \cdot 8$ \\
\hline $\begin{array}{l}\text { December, } 1889 \text {, } \\
\text { April, 1890, }\end{array}$ & ", & $32:$ \\
\hline July, 1893, & ," & 33.9 \\
\hline
\end{tabular}

The last figure was determined by the author; the others by Vieth.

It is seen from the figures quoted above that the analysis of butter which has been kept for any length of time is a matter of considerable difficulty. Though in butter fat the volatile acids do not show any diminution, but rather an increase (due possibly to the oxidation of the glycerol), in butter the reverse is usually the case. It is by no means improbable that, besides the solubility of these in the water contained in the butter, a portion is destroyed by the action of micro-organisms. The most reliable datum would seem to be the determination of the volatile acids on the butter itself without separation of the fat, subsequent determination of the fat, and calculation of the 
Reichert figure on the actual fat present. The potash absorption does not appear to undergo much change.

Buttermilk-Definition.-The term buttermilk is applied to the aqueous portion left after churning. It differs only shightly in composition from skim milk. As the cream used for churning is usually slightly sour, the buttermilk contains appreciable amounts of lactic acid; it will also contain water or any other substance which has been added during churning. There is, in suspension, a considerable amount of Storch's mucoid proteid, which may be removed by passing it through a cream separator, when it is deposited on the sides of the drum.

Composition.-The following composition of buttermilk from sweet cream is given by Storch :-

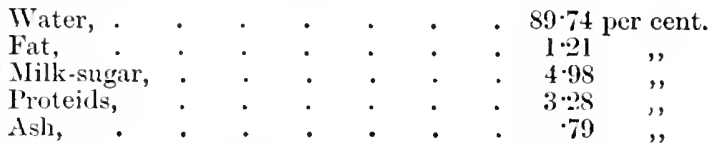

Buttermilk from ripened cream has the following composition :-

\begin{tabular}{|c|c|c|c|c|}
\hline Anthority, & . . & Storch. & Vieth. & Fleischmann. \\
\hline $\begin{array}{l}\text { Water, } \\
\text { Fat, . } \\
\text { Milk-sngar, } \\
\text { Lactic acid,. } \\
\text { Proteids, . } \\
\text { Ash, . . }\end{array}$ & $\begin{array}{l}\cdot \\
\cdot \\
\cdot \\
\cdot \\
\cdot \\
\cdot\end{array}$ & $\begin{array}{c}\text { Per cent. } \\
90 \cdot 93 \\
: 31 \\
4 \cdot 58 \\
(?) \\
3 \cdot 37 \\
.81\end{array}$ & $\begin{array}{r}\text { Per cent. } \\
90 \cdot 39 \\
50 \\
4.06 \\
.50 \\
3 \cdot 60 \\
.75\end{array}$ & $\begin{array}{c}\text { Per cent. } \\
91 \cdot 24 \\
.56 \\
4 \cdot 00 \\
3 \cdot 50 \\
\cdot 70\end{array}$ \\
\hline
\end{tabular}

Variations of Fat.-The author has found the amount of fat in buttermilk to vary from 15 per cent. to 5.60 per cent.; the last percentage is very unusual, and it is rare to find even as much as $2 \cdot 0$ per cent, percentages higher than this denoting that the churning has been inefliciently carried out.

Ash.-The following composition is given by Fleischmann to the ash of buttermilk :-

$$
\begin{aligned}
& \text { Potash, } \mathrm{K}_{2} \mathrm{O}, \text {. . . . . . . } 24.53 \mathrm{per} \text { cent. } \\
& \text { Sorlit, } \left.\mathrm{Na}_{2} \mathrm{O}\right), . \quad \text {. . . . } 1154 \text {," }
\end{aligned}
$$

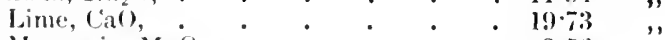

$$
\begin{aligned}
& \text { Magnesia, } .1100 \text {, . . . . . } 356 \text {,", } \\
& \text { Phosphoric acirl, } \mathrm{P}_{2} \mathrm{O}_{5}, . \quad \text {. . . . } 2989 \text { ", } \\
& \text { Chlorine, Cl, . . . . . . 13*27 ,", }
\end{aligned}
$$

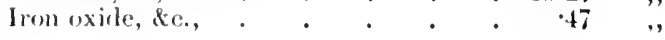

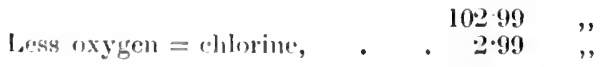

$$
\begin{aligned}
& \overline{100} \cdot \overline{0},
\end{aligned}
$$


Buttermilk has usually a slightly acid flavour; it does not, however, taste quite like sour skim milk, but has a distinctive smell and flavour of its own; it is not known to what this is due.

On microscopic examination it is seen that the fat left is not entirely in globules ; there exist many small nuclei consisting of two or more fat globules.

Chemical Control of Churning Operations.-The fat in the buttermilk from each churning should be estimated. Usually less than 1 per cent. of fat may be considered satisfactory, but if sweet cream is churned it is difficult to always keep within this limit. Any percentage of fat above 2 must be considered unsatisfactory, and the cause should be enquired into. This may be due to the use of cream which is too thick, mixtures of cream of different consistency and age, too high a temperature, or too rapid churning.

The fat in the cream to be churned should also be estimated. It has been found that cream containing from 25 to 30 per cent. of fat gives the most satisfactory results. If the cream contains more than 40 per cent. of fat, the buttermilk is very high in fat, and a larger percentage loss is obtained.

The weight of fat in the butter plus the weight of fat in the buttermilk should come within 2 per cent. of the weight of fat in the cream used. If a larger difference is found, a needless loss of fat is taking place, and the cause of this should be ascertained.

Table LXXXIV (Appendix) gives the weight in pounds of butter which may be expected to be produced on churning cream varying in percentage of fat from 15 to 50 . 


\section{CHAP'TER VII.}

OTHER IILK PRODUCTS.

Costerts. - Cheese-Rennet-Classification of Cheeses-CompositionThe Pipening of Cheese-Analysis of Cheese - Adulteration of Cheese -Other Products derived from Milk.

\section{Cheese.}

CHEEse is prepared by the action of renuet on milk; this separates it into whey and curd; the curd is finely divided, pressed to separate the whey and to consolidate it, and, usually, salted. From this, cheese is produced by ripening, which is due partly to the action of micro-organisms and fungi, partly (as Babcock and Russell have recently shown) to the action of an enzyme natural to milk.

Action of Rennet.-The action of rennet is to split up the casein into a dyscaseose, the calcium compound of which is insoluble and which forms curd, and a soluble caseose; the insolulble curd carries down with it a large proportion of the fat.

Composition of Curd and Whey.-.The following table will show the distribution of the various constituents of the milk when made into whey and curd:-

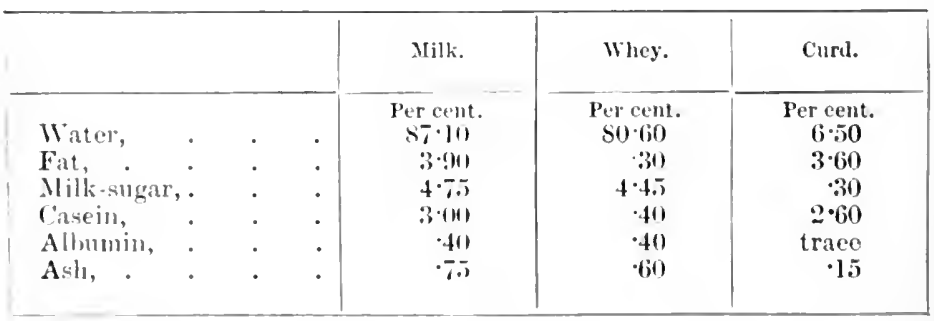

The following is the composition of whey according to various authorities:- 


\begin{tabular}{|c|c|c|c|c|c|}
\hline & & Fleischmaun. & $\underset{\text { (average). }}{\text { König }}$ & Snuetham. & $\begin{array}{l}\text { Vieth (from } \\
\text { skim milk). }\end{array}$ \\
\hline $\begin{array}{l}\text { Water, } \\
\text { Fat . } \\
\text { Milk-sugar, } \\
\text { Proteids, } \\
\text { Ash,. }\end{array}$ & . & $\begin{array}{c}\text { Per cent. } \\
93 \cdot 15 \\
\cdot 35 \\
4 \cdot 90 \\
1 \cdot 00 \\
\cdot 60\end{array}$ & $\begin{array}{c}\text { Per cent. } \\
93.38 \\
\cdot 32 \\
4 \cdot 79 \\
\cdot 86 \\
\cdot 65\end{array}$ & $\begin{array}{c}\text { Per cent. } \\
93 \cdot 33 \\
\cdot 24 \\
5 \cdot 06 \\
\cdot 88 \\
\cdot 49\end{array}$ & $\begin{array}{c}\text { Per cent. } \\
93 \cdot 00 \\
\cdot 09 \\
5 \cdot 45 \\
\cdot 92 \\
\cdot 54\end{array}$ \\
\hline
\end{tabular}

The author has found the fat in whey to vary from 04 per cent. (from skim milk) to 1.35 per cent., and the solids not fat to lie between 6 and 7 per cent., averaging 6.6 per cent., which contain-

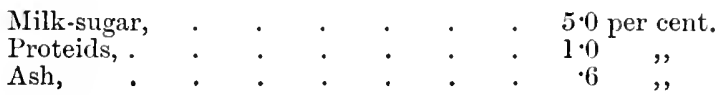

On adding an acid to whey, a slight proteid precipitate (which is difficult of filtration) is obtained. On heating the acid whey, a soft curd of little consistency is formed; this substance is a commercial article on the Continent.

The composition of the whey and the precipitated curd (after acidifying and boiling) are given :-

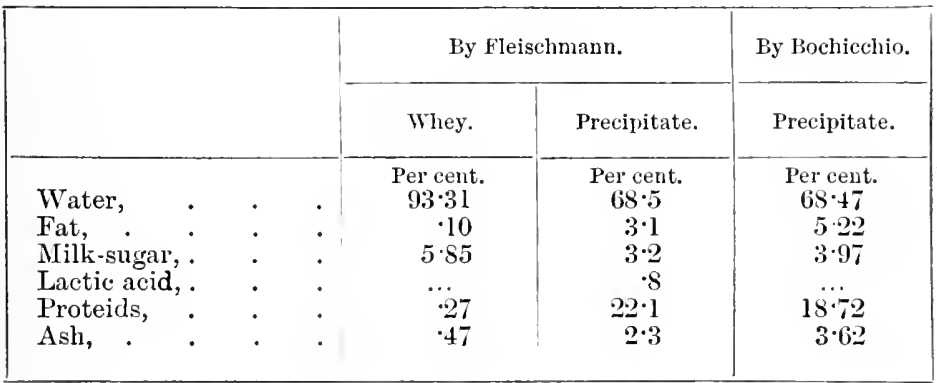

On boiling whey without acidifying, a precipitate of a similar nature also occurs; this appears to consist of coagulated albumin.

Cheese is sometimes prepared by allowing the milk to become sour spontaneously, salting and pressing the curd, and allowing it to ripen. This variety of clieese is not considered of such good quality as rennet cheese.

Fleischmann gives the composition of the whey thus obtained as follows :- 


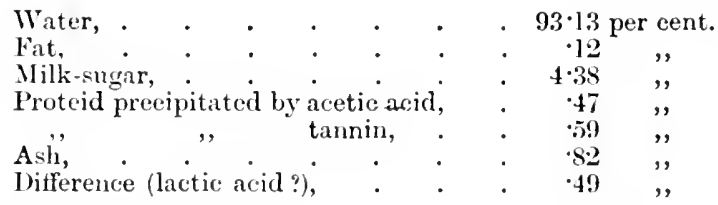

Vieth has shown that whey prepared in this way undergoes alcoholic fermentation much more readily than rennet whey.

Rennet.-This substance is an enzyme produced in the stomachs of mammals ; it occurs in the human stomach, and the curdling of milk when ingested is due to this; it is especially abundant in the young while still suckling.

Preparation.--It is usually prepared from the fourth stomach of the calf. The stomachs are dried and kept for some time; they are then cut up into small pieces and macerated in a 5 per cent. salt solution, usually containing boric acid, for some days; to the solution a further 5 per cent. of salt is added, and the liquid filtered; this forms extract of rennet. By adding more salt, the remet is precipitated, and "rennet powder" is produced; this consists, essentially, of the ferment, together with other organic matter, and a considerable amount of salt.

Properties.-Rennet acts on casein only in neutral or acid solution, and its properties are destroyed by alkalies. Like all enzymes it has an optimum temperature at which it acts best; this has been found by Fleischmann to be $41^{\circ} \mathrm{C}$. (105.8 F.). He gives the following table as showing the relative proportion of milk coagulated in a given time by the same quantity of rennet at different temperatures:-

\begin{tabular}{|c|c||c|c|c|c|}
\hline \multirow{2}{*}{ Temp. C. } & Proportion. & Temp. C. & Proportion. & Temp. C. & Proportion. \\
\cline { 2 - 3 } & & & & \\
\hline $20^{\circ}$ & 18 & $36^{\circ}$ & 59 & $44^{\circ}$ & 93 \\
$225^{\circ}$ & 44 & $37^{\circ}$ & 92 & $45^{\circ}$ & 59 \\
$30^{\circ}$ & 71 & $35^{\circ}$ & 94 & $46^{\circ}$ & 84 \\
$31^{\circ}$ & 74 & $39^{\circ}$ & 96 & $47^{\circ}$ & 78 \\
$32^{\circ}$ & 77 & $40^{\circ}$ & 95 & $48^{\circ}$ & 70 \\
$333^{\circ}$ & 80 & $41^{\circ}$ & 100 & $49^{\circ}$ & 60 \\
$34^{\circ}$ & 83 & $42^{\circ}$ & $99^{*}$ & $50^{\circ}$ & 50 \\
$35^{\circ}$ & 86 & $43^{\circ}$ & 96 & & \\
\hline
\end{tabular}

At the optimum temperature, and for several degrees on either side, the curd produced is very firm; at low temperatures, $15^{\circ} \mathrm{O}$. to $20^{\circ} \mathrm{C}$., the curd is quite soft and floceulent; and when the temperature is raised to $50^{\circ}$, the curd again becomes very goft.

* (iiven as 95 in original, but from the experinental data it appears that 99 is more correct. 
By heating rennet to temperatures much above $60^{\circ} \mathrm{C} .\left(140^{\circ} \mathrm{F}\right.$.) it rapidly loses its properties.

The action of rennet is affected by the acidity of the milk; the larger the amount of acid, the more rapid the action; the addition of water to milk causes it to be coagulated more slowly by rennet and the curd is less firm. By heating milk, the action of rennet is delayed, owing to the removal of some of the soluble calcium compounds. By the addition of soluble lime salts, the milk will be curdled by rennet in the usual manner.

Testing of Rennet.- It is important to know what the strength of rennet preparations are-i.e., the amount of milk that will be curdled by 1 part in a definite time at a definite temperature. This may be estimated as follows:-5 c.c. of a rennet extract or 5 gramme of a rennet powder are made up to. 100 c.c. with distilled water. After thorough mixing, 1 c.c. is measured out by means of a pipette and added to 100 c.c. of separated milk of acidity $20^{\circ}$, which has been brought to a temperature of $35^{\circ} \mathrm{C}$; the milk and rennet solution are immediately well stirred and the exact time at which the rennet was. added noted. The milk should be contained in a beaker, which is placed in a water-bath kept at $35^{\circ} \mathrm{C}$, and gently stirred with a thermometer till it is found, by the path becoming visible, that the milk has coagulated; the exact time which has elapsed from the addition of the rennet till the coagulation sets in is noted.

The strength of the rennet-i.e., quantity of milk that will be coagulated by 1 part in forty minutes-is calculated by the following formula :-

Let

$$
\begin{aligned}
x & =\text { quantity of milk coagulated. } \\
p & =\text { proportion between milk and rennet taken. } \\
t & =\text { the time. }
\end{aligned}
$$

Then

$$
x=\frac{40 p}{t} \text {. }
$$

The value of $p$ is 2000 when 5 c.c. was diluted to 100 c.c. and 1 c.c. taken, and 20,000 when ' 5 gramme was taken.

If the time taken is less than five minutes, or more than ten minutes, it is advisable to make another determination, using a smaller or larger proportion of rennet to milk.

Classification of Cheeses.-Cheeses may be divicled into the following classes:-

1. Soft Cheeses.-These are obtained by coagulating the milk with rennet at a low temperature (below $30^{\circ} \mathrm{C}$. or $86^{\circ} \mathrm{F}$.). The period of coagulation lasts a long time. As representative of these cheeses the following kinds may be mentioned:Gervais made from cream; Brie, Camembert, Pont l'Evêque, and Bondon (or Neufchâtel) made in France; and Stracchino made in Italy. 
2. Hard Cheeses. - These are obtained by coagulating at higher temperatures $\left(30^{\circ} \mathrm{C}\right.$. or $86^{\circ} \mathrm{F}$. to $35^{\circ} \mathrm{C}$. or $95^{\circ} \mathrm{F}$; ; they may be again divided as follows:-

(1) Cheese made from milk and cream-Stilton.

(2) Cheese malle from whole milk-Chedtar, Cheshire, Dunlop, and Wensleyrlale marle in England; Port de Salut made in France ; Emmenthaler or tirnyere made in Switzerland, Edam in Hollinnd, and Gorgonzola and Cacio Cavallo in Italy.

(3) Cheese male from partially skimmed milk - Parmesan in Italy; lerby, (iloncester, Leicester, and, sometimes, Cheddar in England; Edam (usually made in this way) in Holland, and Gruyère in Switzerlant.

Skim milk cheese and eheese made from skim milk enriched by margarine are also made.

A famous cheese, known as Roquefort, is prepared from sheep's milk; Besana has shown that many sorts of cheese may be made from sheep's milk.

Gaat's milk is also employed in cheese manufacture, but these cheeses are not important articles of commerce.

In addition to rennet cheeses, cheese made from the curd precipitated by warming milk which has been allowed to become sour is also used. The only cheese made in England is cream cheese; frequently an acid is added to the cream instead of allowing lactic fermentation to take place. A Swiss cheese, Glarner, and the German caraway cheese come under this category; the latter is mixed with caraway seeds.

Composition of Cheese.-But little is known of the composition of cheese. Most of the analyses made have included only water, fat, ash, and total nitrogenous substances either by difference or by estimation of the nitrogen and multiplication of this by a factor. In very few cases has the separation of the nitrogenous matters been attempted, and it is doubtful whether, where this has been done, much real information as to the character of the products has heen obtained. The chemical knowledge of cheese must be pronounced to be in a much less satisfactory conclition than that of other milk products.

The following tables (IIV. to IVII.) will give the proximate composition of various cheeses; they will be useful as showing the most striking differences. Thus soft eheeses contain large amounts of water, and small percentages of fat and proteids; cheeses made from whole milk contain an amount of fat at least equal to the proteids, while skim milk cheeses contain usually less fat than proteids; in cream cheeses the fat greatly exceeds the proteids :- 


\section{TABLE LIV.-Cream Cheeses.}

1. English cream cheese made without rennet.

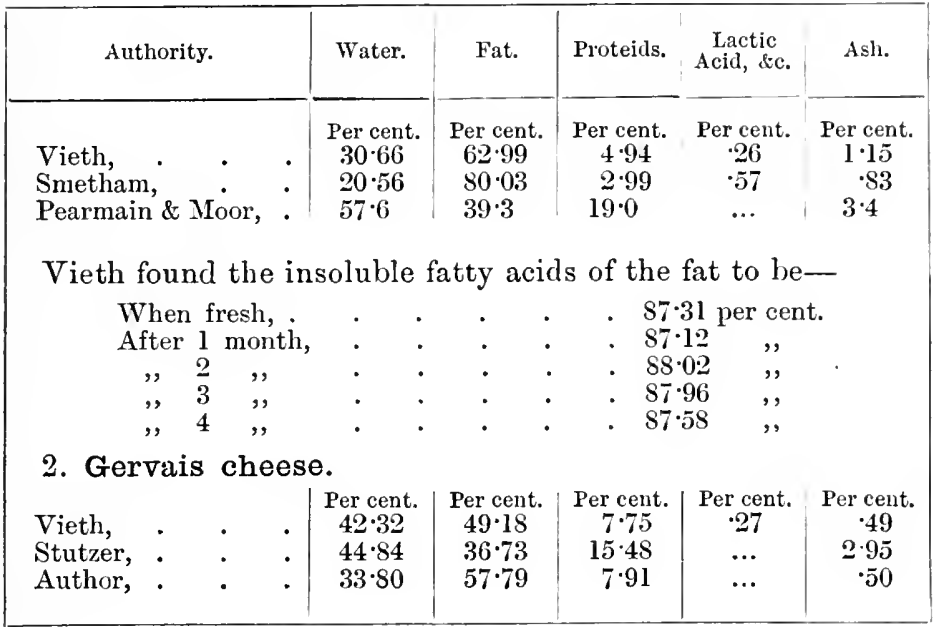

TABLE LV.-Soft Cheeses.

\begin{tabular}{|c|c|c|c|c|c|c|}
\hline Authority. & & Water. & Fat. & Proteids. & $\begin{array}{l}\text { Lactic } \\
\text { Acid, \&c. }\end{array}$ & Ash. \\
\hline & & Per cent. & Per cent. & Per cent. & Per cent. & Per cent \\
\hline Duclaux, . & - & $50 \cdot 04$ & $27 \cdot 50$ & $18 \cdot 32$ & $\ldots$ & $4 \cdot 12$ \\
\hline 2. Camembert. & & & & & & \\
\hline Duclaux, . . & . & $45 \cdot 24$ & $30 \cdot 31$ & $19 \cdot 75$ & $\ldots$ & $4 \cdot 70$ \\
\hline Stutzer, . . & . & $50 \cdot 90$ & $27 \cdot 30$ & $18 \cdot 66$ & $\ldots$ & $3 \cdot 14$ \\
\hline Cameron \& Aikman & & $51 \cdot 30$ & $21 \cdot 50$ & $19 \cdot 00$ & $\ldots$ & $4 \cdot 70$ \\
\hline Leffmann \& Beam, & . & $51 \cdot 90$ & $21 \cdot 00$ & $18 \cdot 90$ & $\ldots$ & $4 \cdot 70$ \\
\hline Pearmain \& Moor, & . & $45 \cdot 65$ & $22 \cdot 25$ & $23 \cdot 10$ & $\ldots$ & $4 \cdot 25$ \\
\hline Muter, . . & - & $48 \cdot 78$ & $21 \cdot 35$ & $19 \cdot 71$ & 36 & $9 \cdot 80$ \\
\hline $\begin{array}{l}\text { 3. Neufchâtel } \\
\text { (or Bondon). }\end{array}$ & & & & & & \\
\hline Fleischmann, . & . & $34 \cdot 5$ & $41 \cdot 9$ & $13 \cdot 0$ & $7 \cdot 0$ & $3 \cdot 6$ \\
\hline Pearmain \& Moor, & . & $39 \cdot 5$ & $24 \cdot 4$ & $9 \cdot 4$ & & $\cdot 7$ \\
\hline Muter, . & - & $55 \cdot 20$ & $20 \cdot 80$ & $15 \cdot 3 S$ & $1 \cdot 64$ & $6 \cdot 98$ \\
\hline $\begin{array}{l}\text { 4. Stracchino. } \\
\text { König (average), }\end{array}$ & . & $39 \cdot 21$ & $33 \cdot 67$ & $29 \cdot 32$ & $\ldots$ & $3 \cdot 80$ \\
\hline
\end{tabular}


TABLE I.VI.-Hard Cheeses.

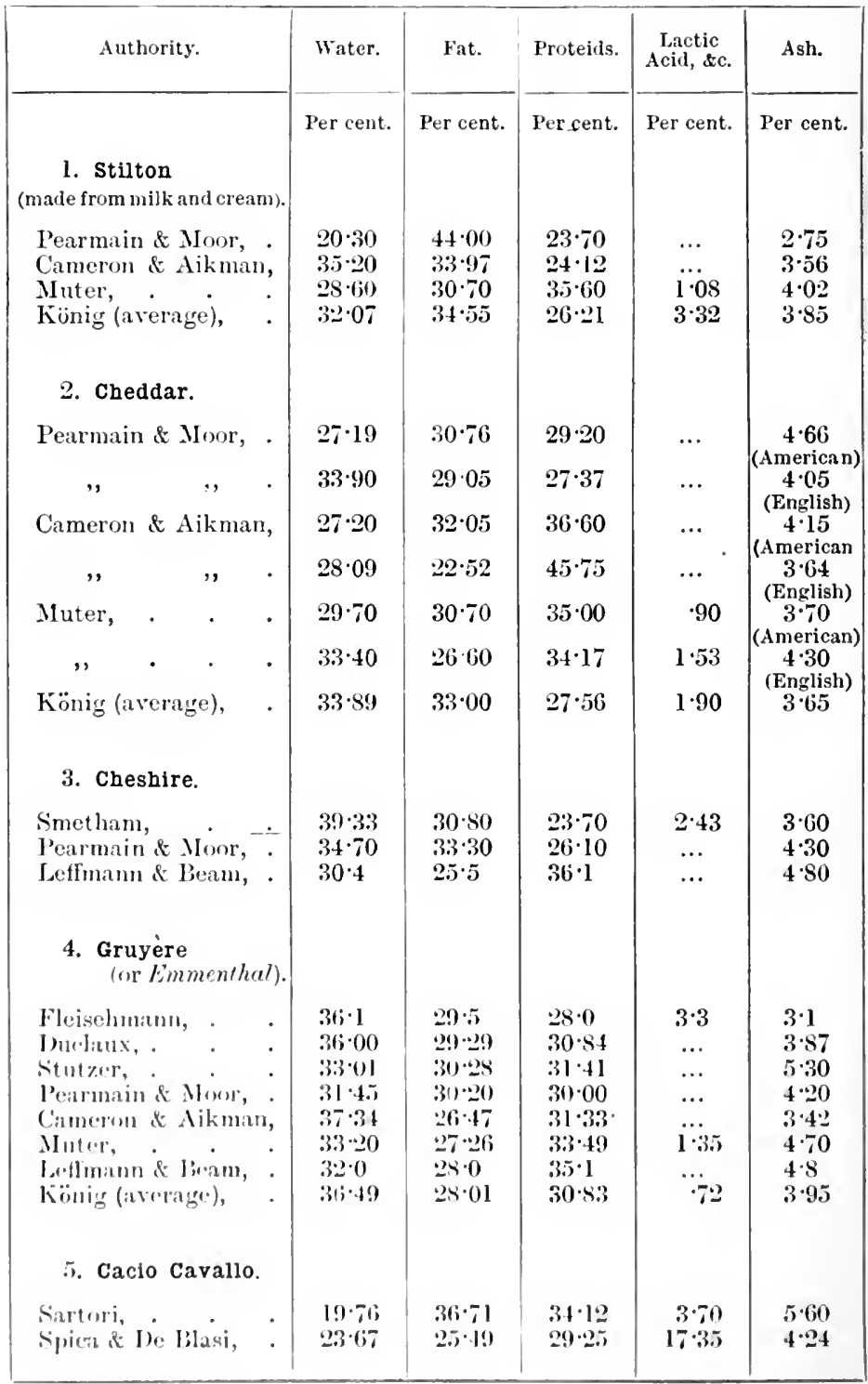


TABLE LVII.-_Skim Milk Cheeses.

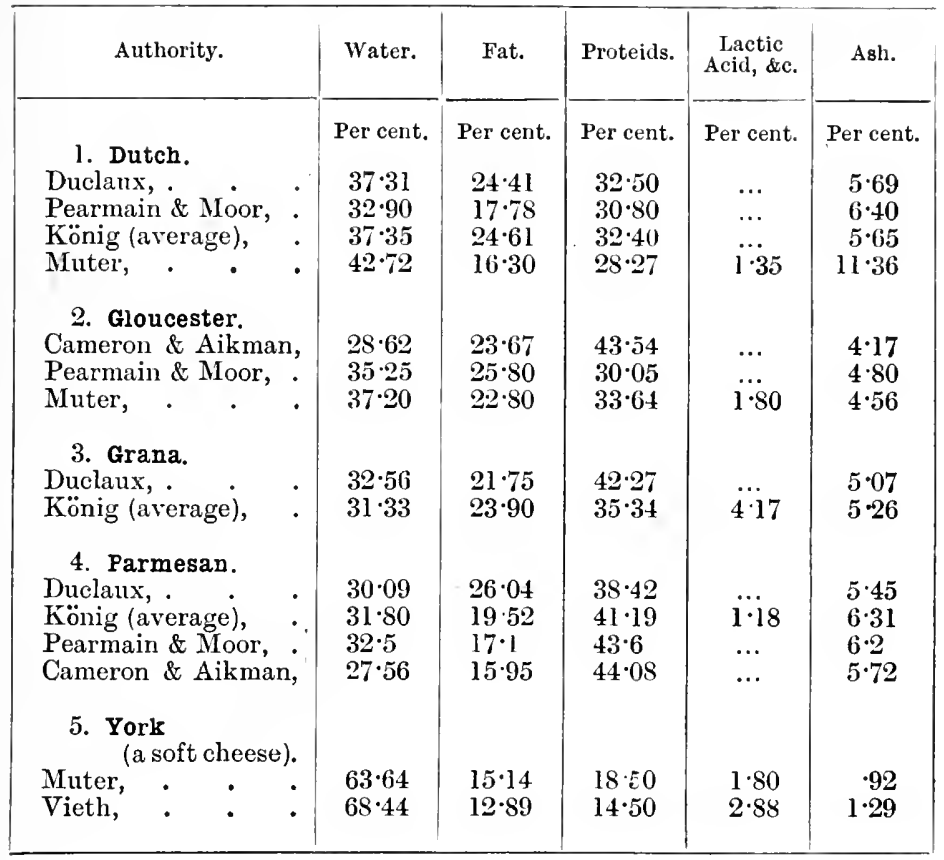

Besides these cheeses, which are all made from cow's milk, the famous Roquejort clieese, made from sheep's milk, must be mentioned. Its composition is-

\begin{tabular}{|c|c|c|c|c|c|}
\hline Authority. & Water. & Fat. & Proteids. & $\begin{array}{c}\text { Lactic } \\
\text { Acid, \&c. }\end{array}$ & Ash. \\
\hline $\begin{array}{l}\text { König (average), } \\
\text { Pearmain \& Moor, } \\
\text { Leffmann \& Beam, } \\
\text { Muter, . }\end{array}$ & $\begin{array}{l}\text { Per cent. } \\
36 \cdot 85 \\
29 \cdot 6 \\
26 \cdot 5 \\
21 \cdot 56\end{array}$ & $\begin{array}{l}\text { Per cent. } \\
30 \cdot 61 \\
30 \cdot 0 \\
32 \cdot 3 \\
35 \cdot 96\end{array}$ & $\begin{array}{l}\text { Per cent. } \\
25 \cdot 25 \\
28 \cdot 3 \\
32 \cdot 9 \\
24 \cdot 52\end{array}$ & $\begin{array}{c}\text { Per cent. } \\
1 \cdot 90 \\
\quad \ldots \\
\ldots .72\end{array}$ & $\begin{array}{c}\text { Per cent. } \\
5 \cdot 39 \\
6 \cdot 7 \\
4 \cdot 4 \\
10 \cdot 24\end{array}$ \\
\hline
\end{tabular}

In the above analyses the figures under the term "proteids" include true proteids and their products of ripening, and, frequently, also such products as lactic acid.

Proteids in Cheese.-Besides the analyses given on pp. 303-305, the following, in which an attempt has been made to distinguish between the various constituents, may be noticed. 


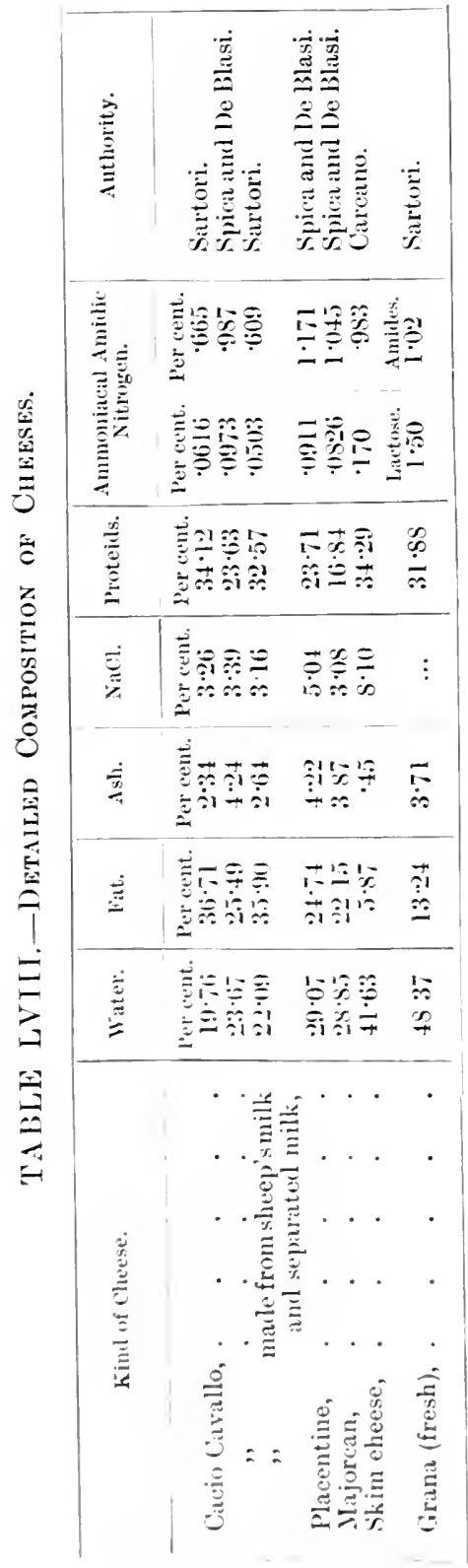

\begin{tabular}{|c|c|}
\hline 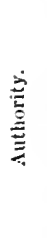 & 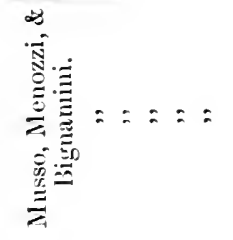 \\
\hline 我 & 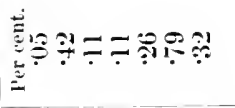 \\
\hline$\stackrel{\Xi}{\stackrel{\Xi}{\Xi}}$ & 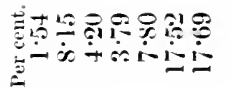 \\
\hline 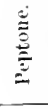 & 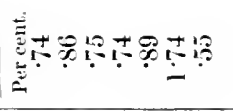 \\
\hline 昙 & 象 \\
\hline 离 & 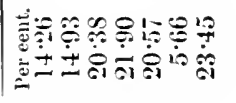 \\
\hline 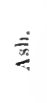 & 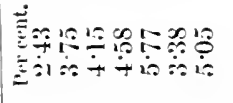 \\
\hline تُّنَ & 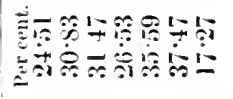 \\
\hline 这 & 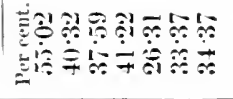 \\
\hline 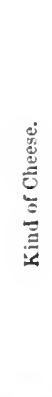 & 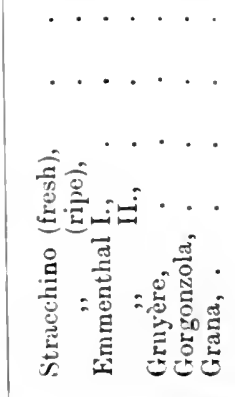 \\
\hline
\end{tabular}



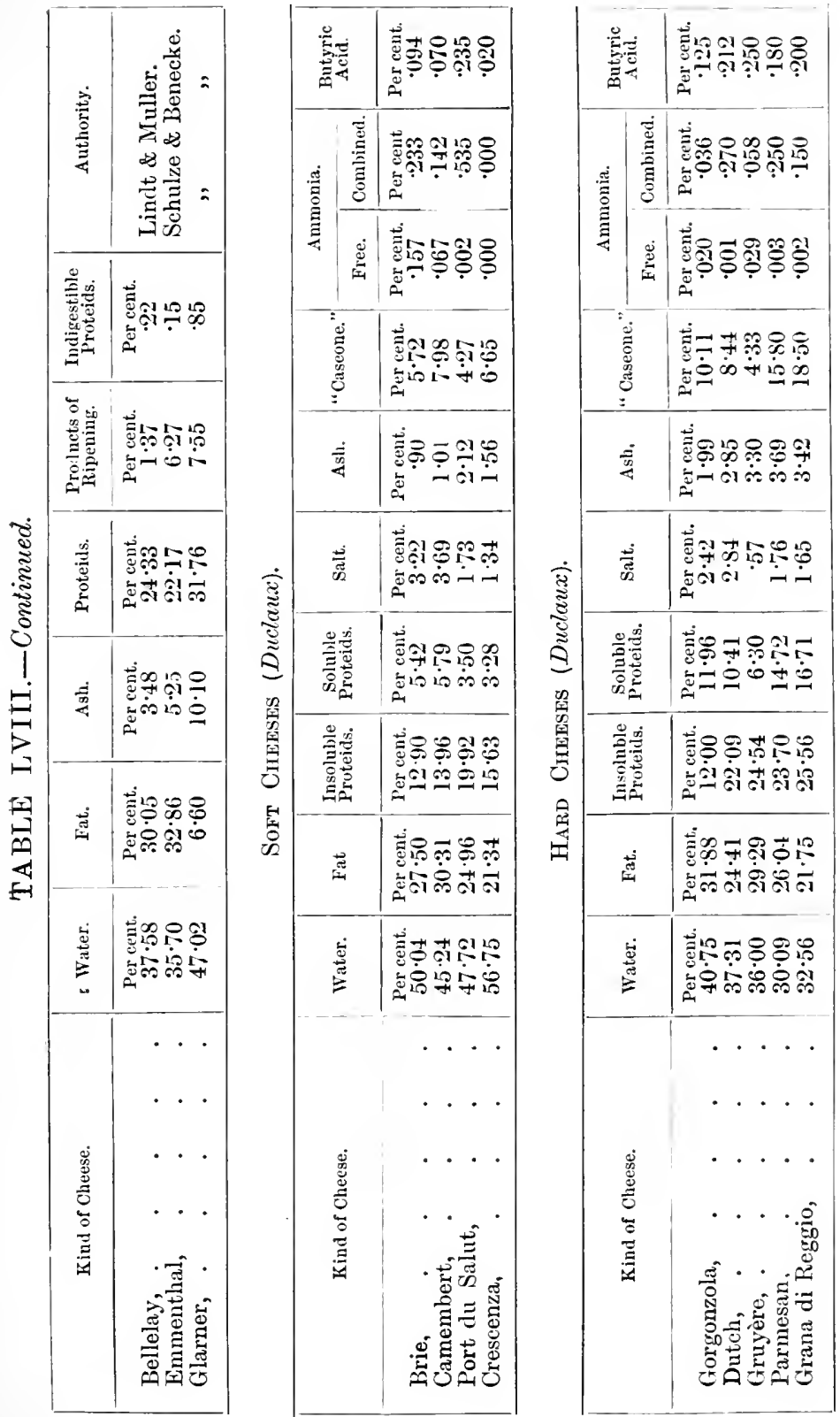
Steiben gives the following figures for Roquefort cheese :-

\begin{tabular}{|c|c|c|c|c|c|c|}
\hline & & Water. & Fat. & Ash. & $\begin{array}{l}\text { Insoluble } \\
\text { Proteids. }\end{array}$ & $\begin{array}{c}\text { Soluble } \\
\text { Proteids. }\end{array}$ \\
\hline $\begin{array}{l}\text { Fresh, } \\
\text { Month in cellar, } \\
\text { Old, }\end{array}$ & : & $\begin{array}{c}\text { Per cent. } \\
49 \cdot 66 \\
36 \cdot 93 \\
23 \cdot 54\end{array}$ & $\begin{array}{c}\text { Per cent. } \\
27 \cdot 41 \\
31 \cdot 23 \\
40 \cdot 13\end{array}$ & $\begin{array}{c}\text { Per cent. } \\
1.74 \\
4.78 \\
6.27\end{array}$ & $\begin{array}{c}\text { Per cent. } \\
13.72 \\
5.02 \\
8.53\end{array}$ & $\begin{array}{c}\text { er cent. } \\
6.93 \\
20 \cdot 77 \\
18 \cdot 47\end{array}$ \\
\hline
\end{tabular}

It is seen that comparatively few analyses are available, and that they are insufficient to allow any definite conclusions to be drawn as to the connection between chemical composition and degree of ripeness.

Heary Metals in Cheese. - The presence of copper has been noted in cheese by Besana ; it is derived from the use of copper vessels.

Studdart has found metallic lead in Canadian cheese; its presence appeared to be accidental.

Allen and Cox have drawn attention to the use of sulphate of zinc in cheese manufacture ; this is called "cheese spice," and is used to prevent the formation of gas in the cheese by fermentation.

The Ripening of Cheese.-The work of Freudenreich, Lloyd, Duclaux, Bochicchio, and Babcock and Russell has shed much light on the nature of ripening.

Role of Micro-Organisms. - When the curd is precipitated by rennet it carries down with it the bulk of the microorganisms present in the milk. The first of these to develop are the lactic acid organisms, which increase rapidly and transform the milk-sugar into lactic acid. Freudenreich and Lloyd have both come to the conclusion that these organisms are the chief, if not the only, factor in the ripening of cheese. While it cannot be denied thit they have some influence, it is hard to realise that lactic acid bacteria, which when grown in sterilised milk do not convert the proteids into albumoses and amidocompounds, should acquire this property in cheese. It appears to be an established fact, however, that the lactic acid organisms develop, rise to a maximum, and then graduilly diminish. The acid they produce appears to be inimical to the growth of other organisms. The ripening of cheese goes on concurrently with the srowth of the lactic aud organisms, and continues at an even rate while thr organisms are decreasing. This shows that the ripening of cheese is not due to the direct action of microorganisms.

Role of Enzymes.-Duclanx has recognised this, and attributes the rifening of cheese to enzymes (ealled by him "diastases") secreted by various organisms to which he gives the name Tyrothrix; the enzyme would remain and be active after the organisus liad died off. 
Babcock and Russell have quite recently shown that milk itself contains a peptonising enzyme. By treating milk with a quantity of an antiseptic, such as chloroform, to check all microbial action, they found that a digestion of the proteids was still going on. They have isolated the enzyme from milk, and, finally, have prepared cheeses, which have been ripened under aseptic conditions. Though perfectly sterile, these cheeses show that the proteids are converted into albumoses, peptones, and amido-compounds just in the same manner as in normal cheeses.

Babcock and Russell conclude that the action of the natural enzyme of milk is the chief factor in the manufacture of cheese, and consider that Freudenreich and Lloyd have been nisled.

The true part played by micro-organisms in cheese is probably the production of compounds in small quantities which give the characteristic flavours to the cheese.

\section{The Analysis of Cheese.}

A complete analysis of cheese includes determinations of the water, fat, ash, salt, proteids, primary products of ripening (as albumoses and peptones), secondary products of ripening (such as ainido-compounds, ammonia, and nitrates), and lactic and fatty acids; also, when present, milk-sugar. Few, however, of these determinations can be made with accuracy, though results which are of great utility can readily be obtained. In addition to the determinations mentioned, the fat may be examined as to its genuineness, and the proteids as to their digestibility.

The earlier methods of cheese analysis consisted of the estimation of water, by drying at $100^{\circ} \mathrm{C} .\left(212^{\circ} \mathrm{F}\right.$.) to constant weight; of fat, by extracting with ether; of ash, by ignition; and of casein, by difference; this method has the advantage of simplicity, but gives no information as to the changes that have taken place during ripening.

The following method will give fair results, and is easy of execution :-

Richmond's Method-Water, Fat, and Ash.-Three to five grammes of cheese are weighed into a wide platinum dish and dried in the water-oven till the fat begins to run away from the cheese. The basin is then turned up, so that the fat collects at one side, and the drying continued for an hour or so. It frequently happens that no fat runs away from the cheese; in this case the turning up of the basin may be dispensed with. The basin is then removed from the oven, and treated several times with ether to remove the fat. The ethereal solution is collected in a flask, the ether evaporated, and the fat dried and weighed. The basin and its contents are replaced in the wateroven, and the residue dried to constant weight. The combined weight of the fat and residue subtracted from the original weight 
gives the water. It will be found that the removal of the fat facilitates drying, but it is difficult to remove the whole of the fat in this manner. The residue may now be incinerated at a low red heat, and the ash weighed; in this the salt may be estimated by solution in water, and titration with silver nitrate solution, using potassium chromate as indicator.

It is advisable to make a separate estimation of the fat. This may be done by Short's method, which consists in grinding up a few grammes of cheese with twice its weight of anhydrous copper sulphate, and extracting the mixture with ether in a Soxhlet extractor. Schleicher and Schüll's thimbles are very convenient for holding the mixture. The Werner-Schmidt method is also applicable. To 2 or 3 grammes of cheese 5 c.c. of water and 10 c.c. of strong hydrochloric acid are added, and the whole boiled with constant shaking till all, except fat, is dissolved. The solution is cooled, about 25 c.c. of ether added, and the tube well shaken. After complete separation, as much as possible of the ether is drawn off, and a fresh portion added. After four or five repetitions of the same process, the extraction of fat is complcte. The combined ether extracts are then evaporated, and the fat weighed.

Proteids and the Products of Ripening.-About 10 grammes of cheese are well ground up in a mortar with ten successive portions of 20 c.c. each of hot water, the aqueous portions being poured off into a 250 c.c. flask. The grinding should be as thorough as possible, every lump of cheese being well crushed. After cooling, the solution should be made up to 250 c.c. and filtered.

Twenty-five c.c. of the filtrate should be evaporated in a platinum basin on the water-bath, and dried in the water-oven to constant weight. This may be termed the "total soluble extract." The residue may he incinerated at a low red heat, and the ash of the soluble extract weighed.

Twenty-five c.c. of the filtrate are diluted to abont 100 c.c., 5 c.c. of a solution of copper sulphate solution added (34.64 grammes to 500 c.c.), and canstic soda solution added, drop by drop, till the precipitate settles in the form of curd, and leaves the supernatant liquid quite clear. $\Lambda \mathrm{fter}$ standing for some time, the precipitate is collected on a Gooch erucible, washed with water, and dried at $120^{\circ} \mathrm{C}$. After weighing, the crucible is ignited, and the residue of copper oxide and phosphate weighed. The diflerence hetween the two weiglits may be taken as "primary products of ripening." The difference between this figure and that of the "total soluble extract," less tho ash, may bo taken as "secondary products of ripening." The difference between the "total soluble extract," less ash of soluble extract, and the "solids not fat," less total ash, may be taken as proteids. 
The above method will be found to be fairly rapid and to give an insight into the composition of the proteid matter of the cheese. The separations between the different classes of proteid substances are, however, arbitrary. Thus it is assumed that all the insoluble "solids not fat" consist of proteid, and that all the products of ripening (and nothing else) are soluble. The dis. tinction between primary and secondary products of ripening is based on the assumption that primary products are precipitated as basic copper compounds, while secondary products give soluble compounds under the conditions given above. In the present state of knowledge it is impossible to identify and separate all the products of ripening; therefore empirical methods which yield comparative results are necessary.

Stutzer's Method.-If it be desired to obtain further information, the method given above may be elaborated by some of the methods detailed below. Stutzer has recently published a study of the methods of cheese analysis, of which the following is an abstract.*

Ash and Mineral Matter.-From 10 to 15 grammes of the cheese are burnt (preferably in a muffle) in a platinum basin. The weighed ash is dissolved in 250 c.c. of water and an aliquot portion used for the determination of chlorine (calculated to sodium chloride). The portion insoluble in water may also be dissolved in dilute hydrochloric acid and made up to 250 c.c.; in a mixture of equal aliquot portions of each of these solutions the calcium and phosphoric acid may be determined.

Water.-A weighed quantity of the cheese is mixed with washed, ignited, and sifted quartz sand. For most cheeses the proportions of 100 grammes to 400 grammes of sand are satisfactory, but with very rich cheeses 500 grammes of sand are taken. This sand mixture is used in all the estimations. For the determination of the water, an amount of the mixture corresponding to about 3 grammes of cheese is dried to constant weight in the water-oven.

Fat.-The dry residue from the water-determination is extracted for twenty-four hours with water-free ether, which has been dried over sodium.

Nitrogen-I. Total Nitrogen.-Ten grammes of the sand mixture are analysed by Kjeldahl's method (p. 105).

II. Applicability of Copper Hydrate to the Precipitation of Albuminoids.-Formerly, Stutzer employed copper hydrate to separate proteids and their primary cleavage products from secondary products (amido-compounds, de.). He has since found that it only partially precipitates trypto-peptones (pancreaspeptone), and, extending his experiments to cheese, finds that there is sometimes a peptone present which is not completely precipitated.

* Taken, with but slight alterations, from The Analyst for January, 1897. 
III. Phospho-tungstic Acid as a Precipitant.-The conclusions of Bondzynski that phospho-tungstic acid is a suitable separating agent are confirmed. By its means the proteids and their primary cleavage products (albumuses and peptones) are separited from the secondary products (phenyl-amido-propionic acid, leucine. tyrosine, and other amides) and ammoniacal compounds, all of which Stutzer elasses as worthless. The substances belonging to the first group may be further divided into- $(a)$ Indigestible nitrogenous matters; $(b)$ Albumoses and peptones soluble in boiling water; and (c) Proteids insoluble in boiling water.

IV. Nitrogen in the Form of Ammoniacal Salts.-An amount of the sand mixture corresponding to 5 grammes of cheese is mixed with 200 c.c. of water and the ammonia distilled, after the addition of barium carbonate. Miagnesia and magnesium carbonate cause a partial decomposition of the amides. The author prefers to operate on a portion of the hotwater extract.

V. Nitrogen in the Form of Amides.-This is taken to be the nitrogen belonging to those compounds in the cheese which are not precipitated by phospho-tungstic acid, and which are not ammoniacal compounds. An amount of the sand mixture, corresponding to 5 grammes of cheese, is mixed with 150 c.c. of water, and well shaken for fifteen minutes in a closed vessel. After standing for fifteen hours at the ordinary temperature, 100 e.e. of dilute sulphuric acid (l vol.: 3 vols. water) are added, and phospho-tunustic acid so long as a precipitate results. The liquid is filtered, the precipitate washed with dilnte sulphuric acid until the filtrate amounts to 500 c.c., and the nitrogen is determined in 200 c.c. of this. By deducting from the amount that previously found as ammoniacal nitrogen, the nitrogen present in the form of amides is found.

VI. Indigestible Nitrogenous Substances. - The fresh mucous membrane of six pigs' stomachs is cut into small fragments and mixed with water and hydrochloric acid in a wide-necked flask in the proportion of 5 litres of water and 100 e.c. of 10 per cent. (hy weight) hydrochloric acid to each stomach. At the same time, 28 grammes of thymol dissolved in alcohol are added as a preservative. The mixture is left for twenty-four hours, with occasional shaking, and then filtered through flannel, coarse paper, and fine paper successively. If necessary, the amount of hydrochloric acid in the extract is brought to exactly 2 per cent. As thus prepared, the gastric juice remains unaitered for months.

Sand mixture, containing 5 grammes of cheese, is leprived of its fit hy extraction with ether, mixed with 500 c.c. of gastric juice in a heaker, and the mixture warmed for forty-eight hours in a thermostat at $37^{\circ}$ to $40^{\circ} \mathrm{C} .\left(99^{\circ}\right.$ to $104^{\circ} \mathrm{F}$.). At intervals 
of about two hours, 5 c.c. of 10 per cent. hydrochloric acid are added, until the acidity of the whole reaches 1 per cent. The liquid is filtered through paper or asbestos, the residne washed with water, and the nitrogen in it determined.

VII. Nitrogen in the Form of Albumose and Peptones.-A weighed quantity of the sand mixture, containing $\tilde{5}$ grammes of cheese, is extracted by boiling with successive portions (100 c.c.) of water, the liquid made up to 500 c.c. and filtered; and 200 c.c. of the clear filtrate (mixed with an equal volume of dilute sulphuric acid) precipitated by phospho-tungstic acid. The precipitate is collected on a filter, washed, and the nitrogen estimated by Kjeldahl's method.

Qualitative Test for Peptones.-A portion of the hotwater extract is concentrated by evaporation, saturated with zinc sulphate, and filtered. Concentrated sodium hydroxide solution is adiled to the filtrate until the zinc hydroxide dissolves, and a few drops of a 1 per cent. solution of copper sulphate added; a violet-red colour (the biuret reaction) points to the presence of-peptone. If desired, this may be estimated by evaporating 200 c.c. of the filtrate to 50 c.c., saturating with zinc sulphate, filtering, and washing with saturated zinc sulphate solution; the precipitate, which consists of albumoses, is treated by Kjeldahl's method. The nitrogen in the peptone is the difference between that in the albumoses and that in the precipitate formed by phospho-tungstic acid.

VIII. Proteids.- The nitrogen present in these substances, which are insoluble in boiling water, is obtained by subtracting from the total nitrogen the amounts found in IV., V., VI., and VII. It is not advisable to use the residue fron VII. for this purpose, on account of the large amount of sand present.

IX. Separation of the Proteids Digestible with Difficulty from those Readily Digestible.-Cheese contains only small quantities of completely indigestible nitrogenous substances, and it is, therefore, useful to determine the comparative digestibility of the proteids. For this furpose, a process of "interrupted digestion" is employed. In order to obtain comparable results, care is taken to have constant (l) the amount of nitrogen in the form of insoluble, but digestible, proteids ; (2) the amount of gastric juice; and (3) the acidity of the liquid, the temperature, and duration of digestion.

In each experiment so much of the sand mixture is taken as contains 15 gramme of nitrogen in the form of insoluble, but digestible, proteids, to which is added 150 c.c. of the gastric juice, with 343 c.c. of water and 7 c.c. of 10 per cent. hydrochloric acid. The acidity of the total hiquid ( $\frac{1}{2}$ litre) is exactly .20 per cent., the temperature is maintained at $37^{\circ}$ to $40^{\circ} \mathrm{C}$. $\left\langle 99^{\circ}\right.$ to $104^{\circ} \mathrm{F}$.), and the duration of the digestion is thirty to sixty minutes. The liquids are warmed to $40^{\circ} \mathrm{C}$. $\left(104^{\circ} \mathrm{F}\right.$.) 
before being measured and after mixing. At intervals of five minutes during the digestion the liquid is stirred with a glass rod; and at the conclusion the total liquid is placed in two large folded rapid filters, and the portion of the filtrate passing through in the first five minutes taken for the determination of the nitrogen. From the result a deduction must be made for the nitrogen contained in the gastric juice, and for the nitrogen in the cheese dissolving without the aid of the gastric juice (amidic, ammoniacal, albumose, and peptone nitrogen).

TABLE LIX.-Axalyses of Cheese (Stutzer).

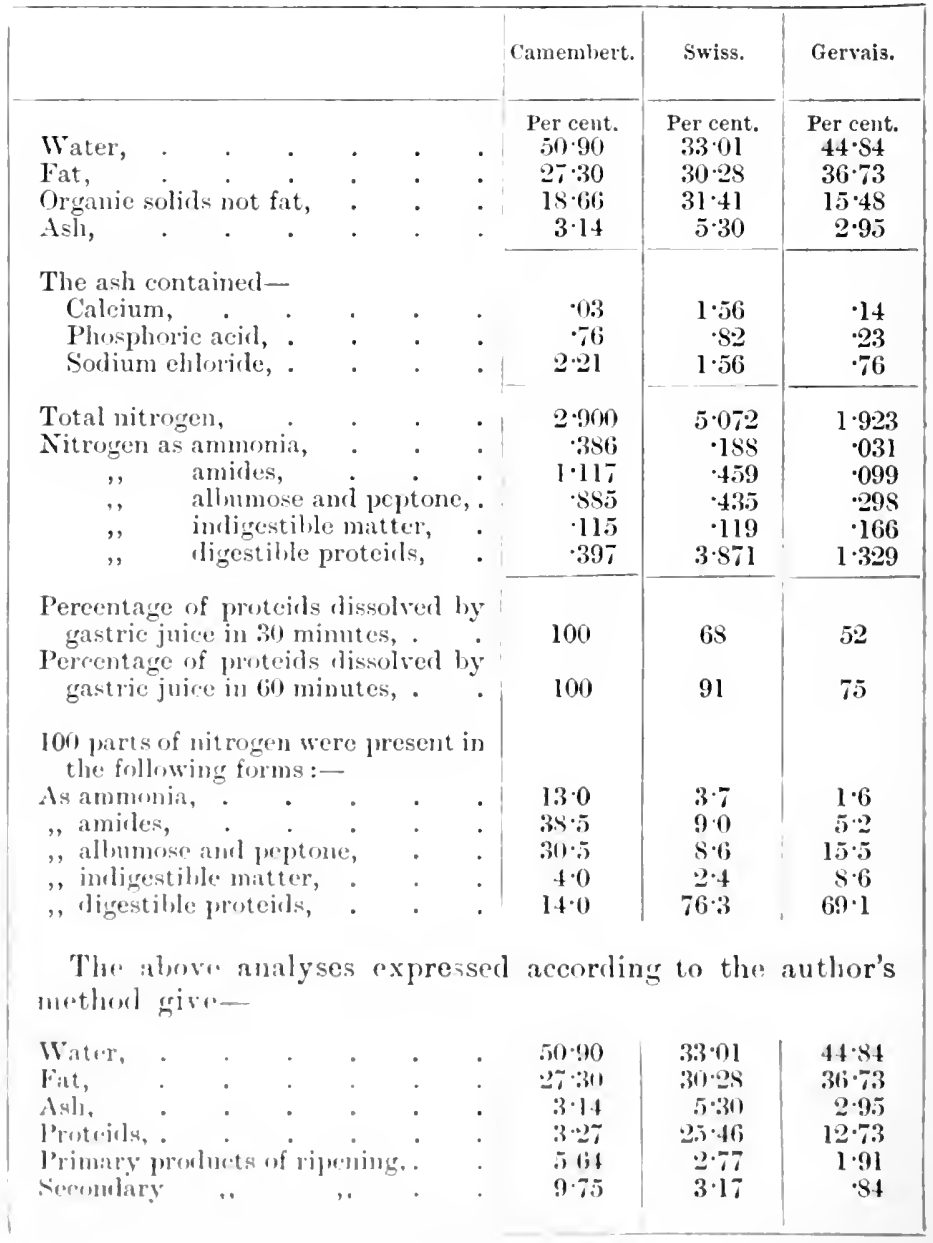


Table LIX. gives the results of the analysis of three varieties of cheese to illustrate the results of Stutzer's investigation. The nitrogen in the proteids multiplied by 6.38 will give, with fair accuracy, the amount of the proteids; the nitrogen of the albumoses and peptone multiplied by 6.38 will approximate ncarly to the amount of primary products of ripening. The author has calculated from the nitrogen given in Stutzer's analysis the proteids, primary and secondary products of ripening, in order to compare the method given above with that previously described.

For most practical purposes the author's method will give as much information as that of Stutzer, if the following facts are borne in mind:-(1) The ripening of a cheese is shown by the proportion of primary and especially secondary products; and (2) the digestibility of a cheese increases with its ripeness.

Duclaux's Method.-Duclaux has proposed the investigation of the fatty acids developed by ripening as a means of judging a cheese. The following are the methods used by him :-

Water, Fat, Alcoholic and Aqueous Extracts. - 20 grammes of sand which has been previously dried, sifted, and ignited, are weighed out, and about seven-eighths are placed in an enamelled mortar; 2 to 3 grammes of cheese, accurately weighed, are ground up with the sand to form a homogeneous mass, which should become nearly pulverulent. The mixture is introduced into a small calcium chloride tube, fitted with a plug of asbestos to prevent loss, and the basin rinsed out with the remainder of the sand. The tube with its contents are weighed, and placed in a bath heated to $50^{\circ}$ or $60^{\circ}$, and a current of dry air passed through for some hours. After cooling, the tube is weighed and the loss noted as water.

The fat is now extracted by carbon bisulphide (other solvents, such as ether or chloroform, may be used), the tube again dried and weighed, and the amount of fat deduced by difference.

The tube may be similarly exhausted by alcohol, hot or cold water, and the loss of weight noted after each extraction.

Ash and Salt.-A fresh portion of cheese is weighed out into a platinum basin, and ignited to obtain the ash; in this, the chlorine is titrated with standard silver nitrate, using potassium chromate as indicator.

Proteids and Products of Ripening.-About 10 grammes of cheese are weighed and intimately mixed in a mortar with about 10 c.c. of water; a very homogeneous paste is formed, and this is left for half an hour to ensure the perfect contact of the water with the solid matter. More water is added, little by little, the mixing in the mortar being continued till 100 c.c. has been added. The mixture is now filtered through a porous porcelain filter by means of reduced pressure; in several hours 60 to 70 c.c. can be obtained. 
Ten c.c. are evaporated in a platinum basin, the residue dried at $100^{\circ}$, weighed, then ignited, and the ash weighed. The difference will give the organic matter; this is termed by Duclaux "caseone," and represents the products of ripening. The percentige may b. calculated with approximate accuracy, by multiplying by 100 + the weight of water in the amount of cheese taken, and dividing by one-tenth of the weight of the cheese.

The remainler of the filtered liquid (50 c.c.) is brought, by the addition of water, to 150 c.c., and distilled into standard acid, to determine the free ammonia; this determination is not very exact as ammonia is gradually liberated as the distillation procerds; hence it is usual to stop the distillation when 75 c.c. have distilled over. A little calcined magnesia suspended in 25 c.c. of water is next added, and about 50 c.c are distilled into standard acid for the estimation of combined immonia.

The resillue in the distilling flask is rendered acid by the addition of a little sulphuric acid, and made up to 55 c.c.; 40 c.c. are distillerl off, and the volatile acid received in standard alkali. The acid is calculated as butyric by multiplying the number of c.c. of $\frac{N}{10}$ alkali used by the factor 00975 (this factor assumes that $90 \cdot 2$ per cent. of the total acid will be obtained under these conditions).

He gives the followin? analyses:-

\begin{tabular}{|c|c|c|c|}
\hline & $\begin{array}{l}\text { Cnrd Two Days } \\
\text { Old. }\end{array}$ & $\begin{array}{l}\text { Cantal cheese } \\
\text { in good } \\
\text { condition. }\end{array}$ & $\begin{array}{l}\text { Old Cantal } \\
\text { cheese. }\end{array}$ \\
\hline $\begin{array}{l}\text { Water, } \\
\text { Fat, } \\
\text { Proteirs (insoluble), } \\
\quad, \quad \text { (soluble lut not fil- } \\
\text { trable), } \\
\text { Salt, } \\
\text { Ammoniatrable), } \\
\text { Volatile acids (ats birtyric), }\end{array}$ & $\begin{array}{c}\text { Per cent. } \\
40 \cdot 7 \\
30 \cdot 1 \\
20 \cdot 0 \\
\\
4 \cdot 1 \\
4 \cdot 3 \\
\cdot 8 \\
\ldots \\
\ldots\end{array}$ & $\begin{array}{l}\text { Per cent. } \\
44 \cdot 4 \\
23 \cdot 9 \\
13 \cdot 7 \\
\\
5 \cdot 3 \\
7 \cdot 2 \\
2 \cdot 5 \\
\ldots \\
\ldots\end{array}$ & $\begin{array}{c}\text { Per eent. } \\
36 \cdot 26 \\
34 \cdot 70 \\
11 \cdot 09 \\
\\
13 \cdot 50 \\
2 \cdot 23 \\
.90 \\
\cdot 27\end{array}$ \\
\hline
\end{tabular}

Volatils Acids. - The following proportions of volatile acids per 100 of fat are instructive :-

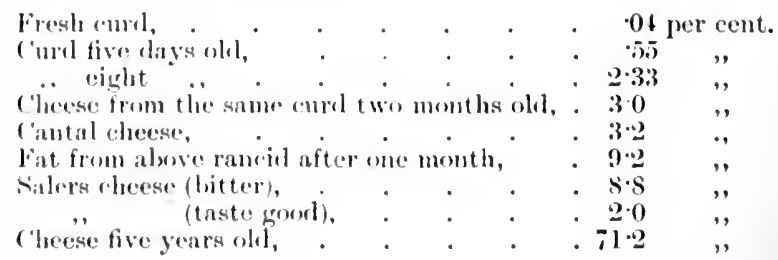


Devarda's. Method.-Devarda recommends for the determination of water that about 10 grammes of finely-divided cheese should be dried in vacuo over sulphuric acid for twentyfour to thirty-six hours, and then for two to six hours at $100^{\circ} \mathrm{C}$. until the weight becomes constant. In this way the bulk of water is removed at the ordinary temperature, and, whilst the method is fairly quick, there is no material loss of organic matter, such as occurs with long-continued drying at $100^{\circ} \mathrm{C}$. Complete drying in vacuo is too tedious and often impracticable.

The following examples show the accuracy of this process :-

\begin{tabular}{|c|c|c|c|c|c|c|}
\hline \multirow[b]{2}{*}{ Name of Cheese. } & \multicolumn{4}{|c|}{ Loss of Water per cent. } & \multicolumn{2}{|c|}{ Water per cent. } \\
\hline & $\begin{array}{l}24 \text { hours } \\
\text { in vacuo. }\end{array}$ & $\begin{array}{l}\text { A second } \\
\text {-4 hours } \\
\text { in vacuo. }\end{array}$ & $\begin{array}{l}3 \text { to } 6 \text { hrs. } \\
\text { at } 100^{\circ} .\end{array}$ & Total. & $\begin{array}{l}\text { Dried at } \\
100^{\circ} \mathrm{C} .\end{array}$ & $\begin{array}{l}\text { Dried in } \\
\text { racuo. }\end{array}$ \\
\hline Romadur, . & $46 \cdot 24$ & $2 \cdot 24$ & 311 & $51 \cdot 59$ & $51 \cdot 92$ & $51 \cdot 50$ \\
\hline Limburger, . & $37 \cdot 79$ & $1 \cdot 12$ & 09 & $39 \cdot 00$ & $39 \cdot 38$ & $38 \cdot 9 s$ \\
\hline Gervais,. . . & $47 \cdot 98$ & $\ldots$ & $1 \cdot 36$ & $49 \cdot 25$ & $49 \cdot 36$ & $49 \cdot 10$ \\
\hline $\begin{array}{l}\text { Limburger, } \\
\text { (air-dried). }\end{array}$ & $11 \cdot 10$ & $\cdots$ & $2 \cdot 17$ & $13 \cdot 27$ & $13 \cdot 46$ & $\ldots$ \\
\hline
\end{tabular}

Adulteration of Cheese.-The only forms of adulteration of any importance consist in the substitution of skim milk cheeses for whole milk cheeses, and the addition of fat not derived from milk to skim milk before making it into cheese.

The former adulteration is detected by the estimation of fat and total nitrogen. In a whole milk cheese the ratio fat

total nitrogen $\times 6 \cdot 37$ varies from 1 to 1.5 ; in a skim milk cheese it is usually less than 1 .

The addition of foreign fat is detected by an examination of the fat by the methods given under Butter Fat. The fat extracted durine the process of analysis may be used. The cheese may be boiled with water to which a little alkali has been added, or shaken with boiling water, and then with an equal bulk of sulphuric acid 1.820 specific gravity (as recommended in the Gerber process). If the cheese has been extracted witl water and wround up in a mortar, in most cases the bulk of the fat separates in the form of butter, and the fat can be readily separated from this.

Devarda recommends triturating 50 to 100 grammes of cheese with a little water in a mortar, mixing with 50 to 80 c.c. of water and 100 to 150 c.c. of ether in a stoppered flask and shaking with dilute potash till a red colour is shown with phenolphthalein. The ethereal layer is drawn off, the ether distilled, the fat dried at $100^{\circ} \mathrm{O}$, and filtered (if necessary). 
lt must be borne in mind that certain changes may take place in the fat, and that the limits of eomposition of butter fat do not apply quite so rigidly to cheese fat. As, however, any andition of tat is usually large relatively to the butter fat left in the chese, there is not much difficulty in detecting its presence.

\section{Other Products Derived from Milk.}

Commercial Milk-sugar-Preparation.-Where whey is a bye-product, in cheese making countries, it is treated for the manufacture of milk-sugar. 'This is done by allowing it to stand so that the crean present may rise to the surface, heating it, and removing the cream and a portion of the proteids. The whey is neutralised with lime, and a little alum adled, which preeipitates a further amonnt of proteids. The whey is then boiled down in vacuum pans, and the sugar allowed to crystallise out. Milk-sugar is purified by re-crystallisation from water or, where alcolnol is eleap, by dissolving it in water and preeipitating with alcohol.

The milk-sugar of commerce is usually in the form of fine powder, but it is also sold in crystals; it consists of essentially pure sugar, but may contain sensible amounts of lactic acid, ash, and, sometimes, proteids. Its chief uses are for the preparation of infants' food and the manufacture of penta-nitro-lactose which forms a part of some high explosives.

Examination of Commercial Milk-sugar.-Add 6 or 7 grammes of the finely-powdered sugar to alout 50 e.c. of distilled water; stir vigorously with a thermometer for ten seconds and all w w the solution to settle for twenty seconds; read the fall in temperature on dissolution and rapidly filter the solution. When sufficient elear filtrate is obtained, till a $200 \mathrm{~mm}$. polariscope tulbe, and polarise as soon as possible. Take polarimetric realings every minute till the specitic rotatory power begins to diminish. If the temperature at which the solution is polarised is kept at $15^{\circ} \mathrm{C}$, or below, ther is no difliculty in oltaining several reatings which are nearly constant, and the mean of these are taken as the initial rotation. Allow the tube to stand for twenty-four lowrs, and polarise again at the same temperature; this is the normal rotation. The initial rotation divided by the normal rotation will give the " birotation ratio." The amount of milk-sugar in 100 c.c. of this solution is estimated, either by drying 5 c.c. at $100^{\circ} \mathrm{C}$., when a residue of anhydrous sugar will be left; or be decheing it from the normal rotation. This is done by dividing the realing in angular dogrees by 1-106. The two tigures should anges closely.

Abrout 10 grammes of sugar are weighed out into a 100 c.c. flask and boiled with abent so c.e. of water for a few minutes. The solution is conlerl to $20^{\circ}$, marle up to 100 e.c., and polarised 
in a $200 \mathrm{~mm}$. tube. The reading in angular degrees multiplied by 100 and divided by the weight of sugar taken multiplied by 1.05 will give the percentage of milk-sugar in the sample.

Five grammes are weighed out in a platinum basin, ignited over a moderate flame and the ash weighed.

Ten grammes are dissolved in 100 c.c. of milk; this is brought to the boil ; the milk should not be curdled. If it is, the acidity should be estimated by titrating $\tilde{o}$ grammes dissolved in water with $\frac{\mathrm{N}}{10}$ alkali and calculated as lactic acid.

To a solution in water ( 10 per cent.) a little mercuric nitrate is added; the solution should not show more than the faintest turbidity.

Good commercial milk-sugar crystallised from water should give the following figures:-

\begin{tabular}{|c|c|c|c|}
\hline Milk-sugar per cent., & & & $99 \cdot 6$ to $99 \cdot 9$ \\
\hline Birotation ratio, . & & & $1 \cdot 6$ \\
\hline Fall of temperature, & & & $5^{\circ} \mathrm{C}$ \\
\hline Solubility at $15^{\circ} \mathrm{C}$. & & & $\begin{array}{l}7 \cdot 0 \text { grammes per } 100 \text { c.c. (anhy- } \\
\text { drous sugar), each } 1^{\circ} \text { increase of } \\
\text { temperature raises this figure } \\
\text { about } \cdot 1 \text { gramme per } 100 \text { c.c. } \\
\text { not more than } \cdot 05 \text { per cent. }\end{array}$ \\
\hline
\end{tabular}

Milk-sugars which have been precipitated with alcohol usually polarise slightly over 100 per cent.; have a birotation ratio below 1.6 and, usually, above 1.5 ; cause a slightly greater rise of temperature; and have a rather higher solubility in water.

Detection of Adulteration.-Milk-sugars which are adulteraterl with other sugars will show marked divergence from the above figures. Cane-sugar can be detected by treating a solution with a little yeast and keeping at $55^{\circ} \mathrm{C}$. for five hours; milksugar shows no change in specific rotatory power, while the presence of even 1 per cent. of cane-sugar will produce a marked alteration.

Dextrose is detected by an increase in the birotation ratio, by the solubility, and by a decrease in the fall of temperature.

Maltose and dextrin (present in commercial starch-sugar) are detected by a lowering of the birotation ratio, a great increase in the apparent percentage of milk-sugar, and in the solubility.

Mineral adulterants will be easily detected by the high percentage of ash.

The following are typical analyses :- 
TABLE LX. - Avalyses of Sugars.

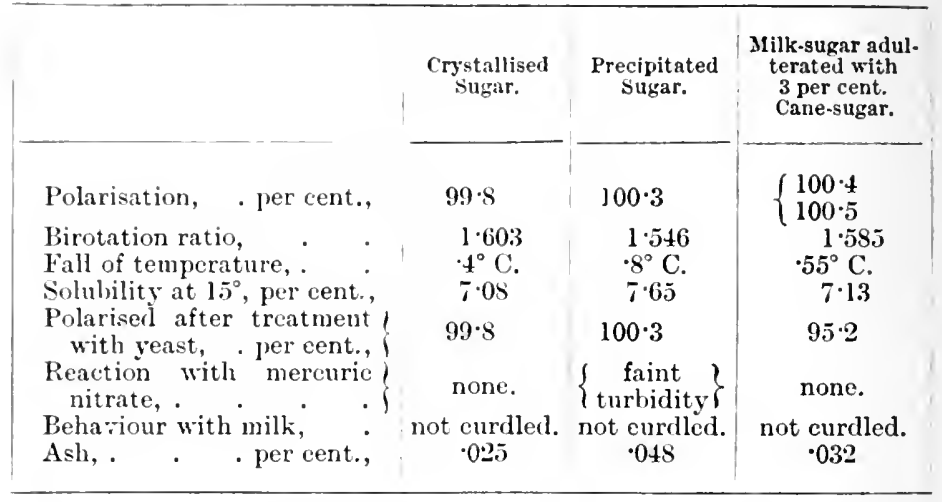

Junkets. - This preparation is made by adding cane-sugar to milk and curdling by rennet at a low temperature. It is a sweetish gelatinous substance, and is usually eaten with nutmeg and eream.

Proteid Compounds. - The following products derived from easein are commercial substances:-

Lacto-Somatose. - This consists of albumoses derived from easein by heating with superheated steam.

Sanose.-A mixture of 80 per cent. casein and 20 per cent. albumoses.

Nutrose. - The sodium compound of casein.

Eucasin.-The atmmonia compound of casein.

Argonin.-The silver compound of casein.

Lactoform consists essentially of easein precipitated by metallic salts and subsequently hardened by formaldehyde. It is employed in place of horn, ivory, ebony, amber, \&c. By painting walls twice with a 15 per cent. solution of casein and a 10 per cent. solution of zinc chloride, followed by an application of strong formaldehyde solution, they may be rendered dampproof.

Milk wine is producel by peptonising milk by means of special ferments or organisms, preeipitating with aeid, and fermenting, after the arldition of sugar.

Milk cocoa is a mixture of coeon with dricd milk solids. A sample cxanined by the author hat the following composition:-

\begin{tabular}{|c|c|c|c|c|c|c|}
\hline $\begin{array}{l}\text { Water. } \\
\text { Per rent. } \\
\text { 5.93 }\end{array}$ & $\begin{array}{l}\text { Fat. } \\
\text { Per cent. } \\
2.5 ! 11\end{array}$ & $\begin{array}{c}\text { Ash. } \\
\text { Per cent. } \\
5 \cdot 02\end{array}$ & $\begin{array}{l}\text { I'rot cids. } \\
\text { l'er cent. } \\
19.50\end{array}$ & $\begin{array}{l}\text { starch. } \\
\text { P'er cent. } \\
5.70\end{array}$ & $\begin{array}{c}\text { Milk-Sugar. } \\
\text { P'er cent. } \\
11 \cdot 70\end{array}$ & $\begin{array}{c}\text { Other } \\
\text { Substauces. } \\
\text { ler cent- } \\
\mathbf{2 6 \cdot 2 4 .}\end{array}$ \\
\hline
\end{tabular}


CHAPTER VIII.

\section{THE MILK OF MAMMALS OTHER THAN THE COW.}

Contents. -Classification of Milks-Human Milk-The Milk of the Buffalo - the Gamoose - the Ewe-the Goat-the Mare-and the Ass-Milk as a Food and a Medicine-As a Food for Infants.

Classification.-Broadly speaking, the milk of all mammals may be divided into classes as under :-

(1) Milks forming hard curds with rennet. This class includes the milk of the ewe, buffalo, goat, and cow.

(2) Milks forming a very soft, or no, curd with rennet. Included in this class are human milk, and those of the ass, mare, and mule.

The composition of milk of all mammals, on the whole, resembles that of cow's milk-i.e., they all contain fat in the form of globules, sugar, proteids, and mineral matter. Marked differences, however, occur in the composition of these bodies.

Comparison of the Fat of Different Animals.-(a) Size of Globules.-The following table (LXI.) gives the results obtained by Pizzi :

\section{Table LXI.—Size of Fat Globules in Mammalian Milks.}

\begin{tabular}{|c|c|c|c|c|c|c|c|c|}
\hline \multirow{2}{*}{$\begin{array}{l}\text { Name of } \\
\text { Mammal. }\end{array}$} & \multicolumn{8}{|c|}{ Relative Number of Globules of the Sizes Named. } \\
\hline & $.0127 \mathrm{~mm}$ & $0109 \mathrm{~mm}$. & $\cdot 0090 \mathrm{~mm}$. & $.0072 \mathrm{~mm}$ & $0054 \mathrm{~mm}$ & $.0033 \mathrm{~mm}$. & $.001 \mathrm{sm}$. & -0009 mm. \\
\hline $\begin{array}{l}\text { Woman, } \\
\text { Ewe, . } \\
\text { Goat, . } \\
\text { Cow,. * } \\
\text { Rabbit, } \\
\text { Ass, . . } \\
\text { Mare, . } \\
\text { Sow,. . } \\
\text { Bitch, . } \\
\text { Cat, . . } \\
\text { Mouse, *. }\end{array}$ & $\begin{array}{c}o \\
o \\
\text { v. few } \\
o \\
\text { many } \\
o \\
o \\
o \\
o \\
o \\
\text { many }\end{array}$ & $\begin{array}{c}o \\
\text { few } \\
\text { v. few } \\
o \\
\text { many } \\
\text { v. few } \\
, \\
o \\
o \\
o \\
\text { many }\end{array}$ & $\begin{array}{c}\text { many } \\
\text { o } \\
\text { few } \\
\text { medium } \\
\text { few } \\
\text { v. few } \\
\text { medium } \\
\text { v. few } \\
\text { many } \\
\text { few } \\
,,\end{array}$ & $\begin{array}{c}\text { many } \\
\text { medium } \\
\text { few } \\
\text { many } \\
\text { few } \\
\text { many } \\
\text { medium } \\
\text { v. few } \\
\text { many } \\
\text { few } \\
,,\end{array}$ & $\begin{array}{c}\text { medium } \\
,, \\
, " \\
\text { v. few } \\
\text { medium } \\
\text { few } \\
\text { v. few } \\
\text { medium } \\
,, \\
,,\end{array}$ & $\begin{array}{c}\text { few } \\
\text { medium } \\
, " \\
\text { v. few } \\
\text { medium } \\
\text { many } \\
\text { medium } \\
\text { few } \\
\text { v. few }\end{array}$ & $\begin{array}{l}\text { v. few } \\
\text { few } \\
\text { medium } \\
\text { v. few } \\
\text { v. few } \\
\text { v. many } \\
\text { many } \\
\text { v. many } \\
\text { v. few } \\
\text { ", } \\
\text { ", }\end{array}$ & $\begin{array}{c}\text { v. few } \\
, " \\
\text { ", } \\
\text { v. few } \\
, " \\
\text { many } \\
\text { v. few } \\
, " \\
, "\end{array}$ \\
\hline
\end{tabular}

* The milk of the rabbit and mouse contained globules up to $.0181 \mathrm{~mm}$. in diameter. 
(b) Composition of Fat.-The following table (LXII.) gives the comparative figures for the composition of the fat of various maumals :-

Table LXII.-Propertifs of Mammalian Fats.

\begin{tabular}{|c|c|c|c|c|c|}
\hline $\begin{array}{l}\text { Name of } \\
\text { Mammal. }\end{array}$ & $\begin{array}{l}\text { Melting } \\
\text { Point. }\end{array}$ & $\begin{array}{l}\text { Solidifying } \\
\text { Point. }\end{array}$ & $\begin{array}{c}\text { Reichert. } \\
\text { Wollny } \\
\text { Figure. }\end{array}$ & $\begin{array}{c}\text { Insoluble } \\
\text { Fatty } \\
\text { Acids. }\end{array}$ & $\begin{array}{l}\text { Refractive } \\
\text { Index. }\end{array}$ \\
\hline $\begin{array}{l}\text { Woman, : } \\
\text { Ewe, } \\
\text { Goat, } \\
\text { Buffalo, } \\
\text { Cow, } \\
\text { Rabbit, : } \\
\text { Ass, . } \\
\text { Mare, : } \\
\text { Sow, } \\
\text { Bitch, } \\
\text { Cat, . } \\
\text { Mouse, : } \\
\text { Porpoise, . }\end{array}$ & $\begin{array}{l}32^{\circ} \\
29^{\circ} \\
305^{\circ} \\
38^{\circ} \\
\ldots \\
\ldots \\
\ldots \\
\ldots \\
25^{\circ} \\
\ldots \\
\ldots \\
\ldots \\
\text { A sam } \\
\text { of v } \\
104 \\
\text { its } 1\end{array}$ & $\begin{array}{c}22 \cdot 5^{\circ} \\
12^{\circ} \\
31^{\circ} \\
2 y^{\circ} \\
\ldots \\
\ldots \\
\ldots \\
\ldots \\
12^{\circ} \\
\ldots \\
\ldots \\
\ldots \\
\text { examinc } \\
\text { atile acid, } \\
\text { and agree } \\
\text { pertics. }\end{array}$ & $\begin{array}{c}1 \cdot 42 \\
26 \cdot 7 \cdot 32 \cdot 89 \\
26 \cdot 1-28 \cdot 6 \\
25 \cdot 4-39 \\
20 \cdot 0-34 \\
16 \cdot 06 \\
13 \cdot 09 \\
11 \cdot 22 \\
1 \cdot 65 \\
1 \cdot 21 \\
4 \cdot 40 \\
2 \cdot 97 \\
\text { by Allen cc } \\
\text { aving a med } \\
\text { a with val }\end{array}$ & $\begin{array}{c}\text { Per cent. } \\
\ldots \\
\ldots \\
\ldots \\
\ldots \\
86 \text { to } 90 \\
. . \\
\ldots \\
\ldots \\
\ldots \\
\ldots \\
\ldots \\
\ldots \\
\text { tained } 5 \\
\text { combini } \\
\text { ic acid (m }\end{array}$ & $\begin{array}{c}51 \cdot 9^{\circ} \\
\ldots \\
\ldots \\
\ldots \begin{array}{c}43 \cdot 7^{\circ} \cdot 49 \cdot 0^{\circ} \\
\text { mean } 46 \cdot 5^{\circ}\end{array} \\
\ldots \\
\ldots \\
\ldots \\
\ldots \\
\ldots \\
\ldots\end{array}$ \\
\hline
\end{tabular}

Sugar.-The author has proved that the sugar of the milk of goat, the ass, and the gamoose (in summer) contains milk-sugar.

With Pappel the author obtained analytical figures which showed that the sugar of the milk of the gamoose in winter differed from milk-sugar, and with Carter that the sugar of human milk did not correspond with milk-sugar. It is probable also that the sugar of mare's milk is not identical with milksugar.

Proteids.-But little is known of the proteids of milk. It appears probable that the curd-forming milks contain the same proteids as cow's milk. The milks which do not form curd may differ in their proteids, but it is possible that the different reaction with rennet is due to a deficiency of lime, or to an alkaline reaction.

The following milks have an alkaline reaction:-Human milk, the milk of the mare, ass, rabbit, sow, and eat.

Composition of Milk.-Table IXIII. gives the mean composition of the milk of different mammals.

Of these milks those of the cow, goat, sheep, buflalo, mare, ass, and, in some countries (e.g., Spain), sow are used for human consumption, and, with the exeeption of that of the sow, are 
worthy of a more detailed notice. Human milk, the natural food of infants, will also be dwelt on.

TABLE LXIII.-Conposition of Mamialian Milk.

\begin{tabular}{|c|c|c|c|c|c|c|c|c|}
\hline & & & water. & Fat. & Sugar. & Casein. & Albumin. & Ash. \\
\hline $\begin{array}{l}\text { Cow, · } \\
\text { Goat, · } \\
\text { Ewe, · } \\
\text { Buffalo, } \\
\text { Woman, }\end{array}$ & $\dot{.}$ & 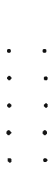 & $\begin{array}{c}\text { Per cent. } \\
87 \cdot 10 \\
86 \cdot 04 \\
79 \cdot 46 \\
82 \cdot 63 \\
88 \cdot 2\end{array}$ & $\begin{array}{c}\text { Per cent. } \\
3 \cdot 90 \\
4 \cdot 63 \\
5 \cdot 63 \\
7 \cdot 61 \\
3 \cdot 3\end{array}$ & $\begin{array}{c}\text { Per cent. } \\
4 \cdot 75 \\
4 \cdot 2 \cdot 2 \\
4 \cdot 25 \\
4 \cdot 72 \\
6 \cdot 8\end{array}$ & $\begin{array}{c}\text { Per cent. } \\
3 \cdot 00 \\
3 \cdot 49 \\
5 \cdot 23 \\
3 \cdot 54 \\
1 \cdot 0\end{array}$ & $\begin{array}{c}\text { Per cent. } \\
.40 \\
.56 \\
1.45 \\
.60 \\
.5\end{array}$ & $\begin{array}{c}\text { Per cent. } \\
\cdot 75 \\
\cdot 76 \\
.97 \\
\cdot 90 \\
\cdot 2\end{array}$ \\
\hline $\begin{array}{l}\text { Mare, . } \\
\text { Ass, }\end{array}$ & . & . & $\begin{array}{l}89 \cdot 80 \\
90 \cdot 12\end{array}$ & $\begin{array}{l}1 \cdot 17 \\
1 \cdot 26\end{array}$ & $\begin{array}{l}6 \cdot 89 \\
6 \cdot 50\end{array}$ & \multicolumn{2}{|c|}{184} & $\begin{array}{l}\cdot 30 \\
\cdot 46\end{array}$ \\
\hline $\begin{array}{l}\text { Mule, } \\
\text { Bitch, . } \\
\text { Cat, }\end{array}$ & . & : & $\begin{array}{l}91 \cdot 50 \\
75 \cdot 44 \\
81 \cdot 63\end{array}$ & $\begin{array}{l}1 \cdot 59 \\
9 \cdot 57 \\
3 \cdot 33\end{array}$ & $\begin{array}{l}4 \cdot 80 \\
3 \cdot 09 \\
4 \cdot 91\end{array}$ & $\begin{array}{l}6 \cdot 10^{1} \\
3 \cdot 12\end{array}$ & $\begin{array}{r}64 \\
5 \cdot 05 \\
5.96\end{array}$ & $\begin{array}{l}\cdot 38 \\
\cdot 73 \\
.58\end{array}$ \\
\hline $\begin{array}{l}\text { Rabbit, } \\
\text { Llama, }\end{array}$ & . & . & $\begin{array}{l}69 \cdot 50 \\
86 \cdot 55\end{array}$ & $\begin{array}{r}10 \cdot 45 \\
3 \cdot 15\end{array}$ & $\begin{array}{l}1 \cdot 95 \\
5 \cdot 60\end{array}$ & \multicolumn{2}{|c|}{1554} & $\begin{array}{r}2 \cdot 56 \\
\cdot 80\end{array}$ \\
\hline $\begin{array}{l}\text { Camel, } \\
\text { Elephant, } \\
\text { Sow, } \\
\text { Porpoise, }\end{array}$ & $\dot{.}$ & $\dot{.}$ & $\begin{array}{l}86 \cdot 57 \\
67 \cdot 85 \\
84 \cdot 04 \\
41 \cdot 11\end{array}$ & $\begin{array}{r}3 \cdot 07 \\
19 \cdot 57 \\
4 \cdot 55 \\
48 \cdot 50\end{array}$ & $\begin{array}{l}5 \cdot 59 \\
8 \cdot 84 \\
3 \cdot 13 \\
1 \cdot 33\end{array}$ & \multicolumn{2}{|c|}{$\begin{array}{r}4 \cdot 00 \\
3 \cdot 09 \\
7 \cdot 23 \\
11 \cdot 19\end{array}$} & $\begin{array}{r}\cdot 77 \\
.65 \\
1.05 \\
\cdot 57\end{array}$ \\
\hline Whale, & . & . & $48 \cdot 67$ & $43 \cdot 67$ & \multicolumn{3}{|c|}{$7 \cdot 11$} & $\cdot 46$ \\
\hline
\end{tabular}

Human Milk-Appearance.-In appearance human milk has usually a chalky white, somewhat watery appearance; some specimens, usually those ligh in proteids, have a marked yellowish tint. A red coloration, due to blood, has been noticed by Carter and the author.

Properties.--The fat globules, according to Pizzi, vary in size from $.009 \mathrm{~mm}$. to $.0009 \mathrm{~mm}$. Carter and the author have observed also that they are, on the whole, smaller than those of cows' milk.

The taste is rarely, if ever, sweet, but rather saline. The reaction to litmus paper is almost always alkaline.

Composition.-Human milk appears to be more variable in its composition than that of the cow. This is probably due to the fact that, while the cow is forced to adopt regular habits and leads a life which is very regular, the many occupations and duties of woman do not permit of this.

Table LXIV. gives the mean composition of human milk according to recent observers. 
TabLE LXIV.-Mean Composition of Human MiLK.

\begin{tabular}{|c|c|c|c|c|c|c|}
\hline & $\begin{array}{l}\text { Leeds. } \\
(64)\end{array}$ & $\begin{array}{l}\text { Pfeiffer. } \\
(160)\end{array}$ & $\begin{array}{l}\text { Luff. } \\
(12)\end{array}$ & $\begin{array}{c}\text { Johanssen. } \\
(25)\end{array}$ & $\begin{array}{l}\text { Carter and } \\
\text { Richmond. } \\
\quad(90)\end{array}$ & $\underset{(40)}{\text { Lehmann }}$ \\
\hline $\begin{array}{l}\text { Water, } \\
\text { Fat, . } \\
\text { Sugar, } \\
\text { Proteids, } \\
\text { Ash, . }\end{array}$ & $\begin{array}{c}\text { Per cent. } \\
\text { S6 } \cdot 69 \\
4 \cdot 16 \\
6 \cdot 95 \\
2 \cdot 02 \\
\cdot 22\end{array}$ & $\begin{array}{c}\text { Per cent. } \\
88 \cdot 2 \cdot 2 \\
3 \cdot 11 \\
6 \cdot 30 \\
1 \cdot 94 \\
\cdot 19\end{array}$ & $\begin{array}{c}\text { Per cent. } \\
85.51 \\
2 \cdot 41 \\
6 \cdot 39 \\
2 \cdot 35 \\
.34\end{array}$ & $\begin{array}{c}\text { Per cent. } \\
\begin{array}{c}3 \cdot 21 \\
4 \cdot 67 \\
1 \cdot 10 \\
\ldots\end{array}\end{array}$ & $\begin{array}{c}\text { Per cent. } \\
88 \cdot 04 \\
3.07 \\
6.59 \\
1.97 \\
.26\end{array}$ & $\begin{array}{c}\text { Per cent. } \\
87 \cdot 3 \\
3 \cdot 4 \\
6 \cdot 4 \\
1 \cdot 7 \\
\cdot 2\end{array}$ \\
\hline
\end{tabular}

TABLE LXV.-Variations in Composition of Hunan Milk During Lactation.

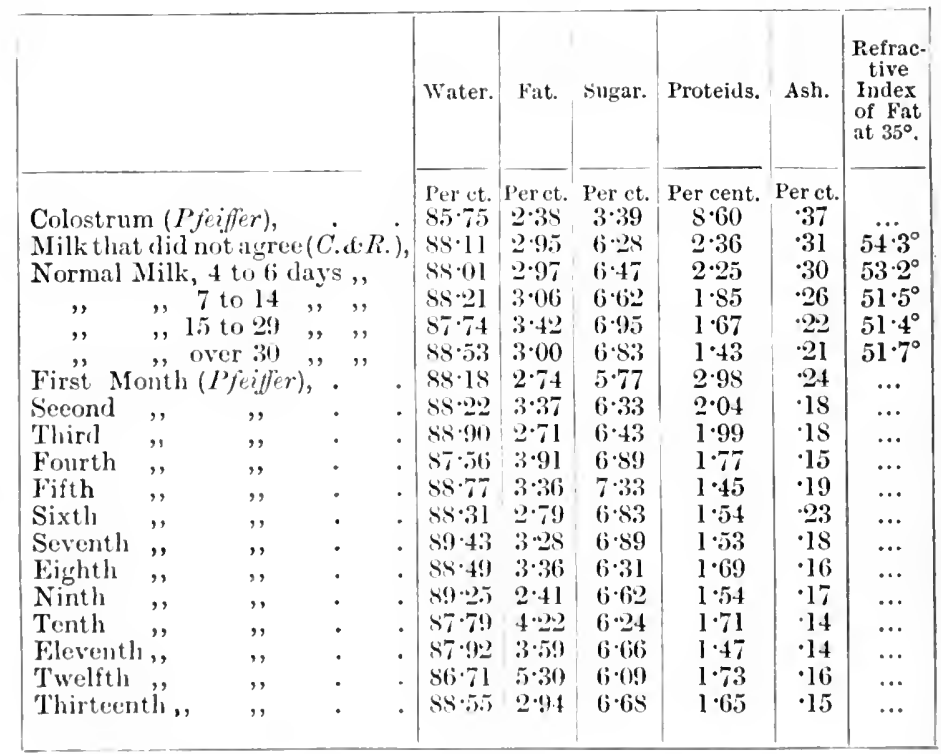

* Leeds gives the average eomposition as:-

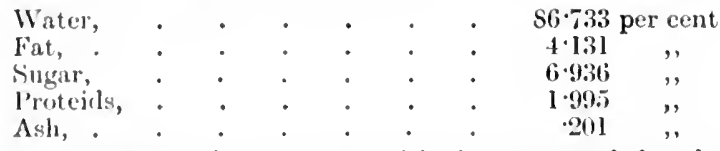

His figures, howover, do not agree with the average deduced from his: analyses. There is internal evidence that his analyses are not so reliable as the other series, and comparatively little weight must he given to his series. He exanined sixty-four samples derived from eighty women, some of his samples being the mixed milk of six women. 


\begin{tabular}{|c|c|c|c|c|c|}
\hline & Water. & Fat. & Sugar. & Proteids. & Ash. \\
\hline $\begin{array}{l}\text { 1st to I1th day (Leeds), } \\
\text { lith to } 31 \text { st ," ," } \\
\text { 31st to } 91 \text { st ," ," } \\
\text { Over } 91 \text { days, , ," }\end{array}$ & $\begin{array}{c}\text { Per cent. } \\
86 \cdot 49 \\
86 \cdot 60 \\
86 \cdot 99 \\
86 \cdot 51\end{array}$ & $\begin{array}{c}\text { Per cent. } \\
4 \cdot 28 \\
3 \cdot 90 \\
3 \cdot 97 \\
4 \cdot 44\end{array}$ & $\begin{array}{c}\text { Per cent. } \\
6 \cdot 67 \\
7 \cdot 06 \\
6 \cdot 99 \\
7 \cdot 09\end{array}$ & $\begin{array}{l}\text { Per cent. } \\
2 \cdot 32 \\
2 \cdot 01 \\
1 \cdot 50 \\
1 \cdot 76\end{array}$ & $\begin{array}{l}\text { Per cent. } \\
\cdot 23 \\
\cdot 20 \\
.21 \\
\cdot 22\end{array}$ \\
\hline
\end{tabular}

Variation with Lactation.-There exist several series of analyses in which the time which has elapsed since parturition has been noted. Of these, the results of Carter and the author represent normal milks, those which disagreed with the child in any way having been excluded. The Tables due to Pfeiffer and Leeds contain all the analyses made by them without any eliminations (Table LXV.).

Probable Mean Composition.-From the above results the following probable composition may be deduced for normal human milk after lactation has become regular :-

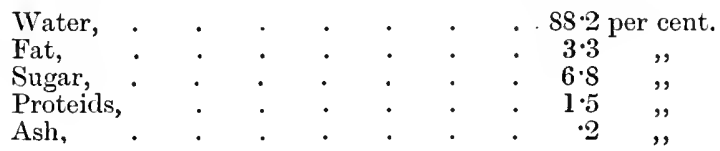

Variation of Constituents.-The following maxima and minima have been found:-

$\begin{array}{lccc} & & \text { Per cent. } & \text { Per cent. } \\ \text { Fat, . } & . & 9.05 \text { (Pfeiffer), } & .47 \text { (C. and R.). } \\ \text { Sugar, } & . & 8.89 \text { (C. and R.), } & 4.22 \text { (Pfeiffer). } \\ \text { Proteids, } & \text {. } & 5.56 \text { (Pfeiffer), } & .85 \text { (Leeds) } \\ \text { Ash, . } & . & .50 \text { (C. and R.), } & .09 \text { (Pfeiffer). }\end{array}$

Composition Before and After Suckling.-The average composition of 37 samples taken before and 37 sainples after suckling was found by Carter and the author to be--

\begin{tabular}{|c|c|c|c|c|c|c|}
\hline & & & & & Before Suckling. & After Suckling. \\
\hline $\begin{array}{l}\text { Water, } \\
\text { Fat, . } \\
\text { Sugar, } \\
\text { Proteids, } \\
\text { Ash, . }\end{array}$ & : & : & • & $\dot{0}$ & $\begin{array}{c}\text { Per cent. } \\
88.33 \\
2 \cdot 89 \\
6 \cdot 51 \\
1.99 \\
.28\end{array}$ & $\begin{array}{c}\text { Per cent. } \\
88 \cdot 04 \\
3 \cdot 1 \mathrm{~S} \\
6 \cdot 53 \\
1 \cdot 99 \\
\cdot 26\end{array}$ \\
\hline
\end{tabular}

In one case, where the secretion was excessive, the analyses before and after suckling were practically identical ; in another, where a very deficient supply was given, the fat differed greatly. 


\begin{tabular}{|c|c|c|c|c|c|c|c|}
\hline & & & & \multicolumn{2}{|c|}{ Excessive Secretion. } & \multicolumn{2}{|c|}{ Deficient Secretion. } \\
\hline & & & & $\begin{array}{c}\text { Before } \\
\text { Suckling. }\end{array}$ & $\begin{array}{c}\text { After } \\
\text { Suckliug. }\end{array}$ & $\begin{array}{c}\text { Before } \\
\text { Suckling. }\end{array}$ & $\begin{array}{c}\text { After } \\
\text { Suckling. }\end{array}$ \\
\hline $\begin{array}{l}\text { Water, } \\
\text { Fat, } \\
\text { Sugar, } \\
\text { Proteids, } \\
\text { Ash, }\end{array}$ & $\begin{array}{l}\cdot \\
\cdot \\
. \\
.\end{array}$ & $\begin{array}{l}\dot{ } \\
\dot{ } \\
. \\
.\end{array}$ & $\begin{array}{l}. \\
\dot{ } \\
. \\
.\end{array}$ & $\begin{array}{c}\text { Per cent. } \\
87 \cdot 40 \\
3 \cdot 12 \\
6 \cdot 68 \\
2 \cdot 49 \\
\cdot 31\end{array}$ & $\begin{array}{c}\text { Per cent. } \\
57 \cdot 33 \\
3 \cdot 12 \\
6 \cdot 70 \\
2 \cdot 51 \\
: 31\end{array}$ & $\begin{array}{c}\text { Per cent. } \\
90.59 \\
.98 \\
6.52 \\
1.71 \\
.20\end{array}$ & $\begin{array}{c}\text { Per cent. } \\
87 \cdot 65 \\
4.07 \\
6 \cdot 31 \\
1 \cdot 77 \\
.20\end{array}$ \\
\hline
\end{tabular}

In 15 cases the fat was higher before suckling than after suckling, and in 21 it was lower, while in 1 case it was identical. The cases in which the fat was higher before suckling than after were generally when the mother was in a prone condition, indicating that the separation of cream was largely mechanical.

Comparison with Cow's Milk.-The following differences in composition of the various constituents from that of the cow have been noticed:-

Fat.-This is very low in volatile acids (see p. 322). It appears to contain fiee fatty acids; Leeds noted that many of the fats extracted from the copper-proteid precipitate obtained by Ritthausen's process were tinted green; Carter and the author confirmed this, and found the following percentages of copper oxide $(\mathrm{CuO})$ in the fats thus extracted :-

$$
\begin{array}{lllll}
2 \cdot 80 & 1 \cdot 27 & \cdot 87 & \cdot 62 & \cdot 30
\end{array}
$$

The copper could be easily removed by shaking with dilute hydrochloric acid, and the fat behaved to copper salts in every way as if it contained free fatty acids.

Carter and the author found the refractive index to vary from $58.4^{\circ}$ (in a milk which upset the child, which finally died in convulsions) to $48 \cdot 2^{\circ}$ (in a milk on which the child throve remarkably well). The analyses of these two samples were:-

\begin{tabular}{|c|c|c|c|c|c|}
\hline Water. & Fat. & Sugar. & Proteisls. & Ash. & $\begin{array}{l}\text { Refractive } \\
\text { Index. }\end{array}$ \\
\hline $\begin{array}{c}\text { Per cent. } \\
89 \div 4 t \\
87.1\end{array}$ & $\begin{array}{c}\text { Per cent. } \\
\cdot 57 \\
3 \cdot 9 \overline{5}\end{array}$ & $\begin{array}{c}\text { Per cent. } \\
5.19 \\
7.11\end{array}$ & $\begin{array}{c}\text { Per cent. } \\
4 \cdot 0: 2 \\
1 \cdot 6 \cdot 4\end{array}$ & $\begin{array}{c}\text { Per cent. } \\
\cdot 38 \\
.20\end{array}$ & $\begin{array}{l}55 \cdot 4^{\circ} \\
45 \cdot 2^{\circ}\end{array}$ \\
\hline
\end{tabular}

Sugar.-Carter and the author fouml that the sugar crystallised in rhomboid plates (not the wedge-shaped crystals of milk-sugar), and had a specitic rotatory power of $[\alpha]_{1}=48 \cdot 7^{\circ}$.

'The sugiar was estimated by diflerence in the milk, as it was found that polarisation and estimation by Fehling's solution 
did not give satisfactory results. It was found that the gravimetric results were from $\cdot 56$ to 98 per cent. below the difference, and averaged $\cdot 71$ per cent. below, while the polarimetric results were from 85 to $2 \cdot 22$ per cent. below the difference, and averaged $1 \cdot 30$ per cent. below.

It was noted that by precipitating the sugar crystallised from water with dilute alcohol an amorphous substance separated, soluble in water. The $[\alpha]_{D}$ of the organic solids of the mother liquor from which the sugar was crystallised was $26 \cdot 8^{\circ}$. These facts seem to indicate that more than one sugar was present.

Proteids. - The proteids differ from those of cow's milk by not giving a curd with rennet, and by giving a much finer precipitate witl acids. By the addition of calcium phosphate they can be made to approach much more nearly in behaviour to those of cow's milk. The proteids of human milk are not precipitated by copper sulphate from a solution neutral to phenolphthalein, but require a further addition of alkali; the precipitate thus obtained yields a black ash, while the proteids of cow's milk precipitated from a neutral solution leave a green ash.

Mineral Matter.-Harrington and Kinnicutt give the following mean composition of the ash :-

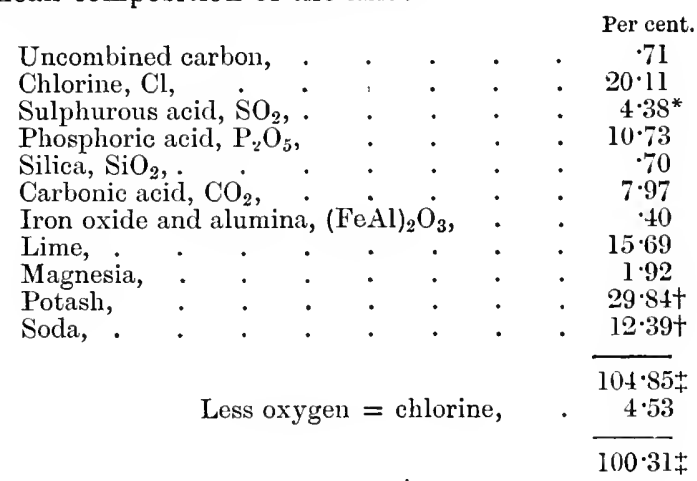

The presence of citric acid has been established, and is about $\cdot 1$ per cent.

Bèchamp describes a starch-hydrolysing enzyme. The author has established the presence of a proteolysing enzyme analogous to that described by Babcock and Russell in cow's milk.

The Milk of the Buffalo.-This has been examined in Europe by F. Strohmer, W. Fleischmann, and A. Pizzi.

Composition.- They give the composition as-

* Given in original as sulphur, 2*19.

† Given in original as potassium, $24 \cdot 77$; sodium, $9 \cdot 19$; oxygen, $6 \cdot 16$.

$¥$ The total is given in original as 100.54 . 


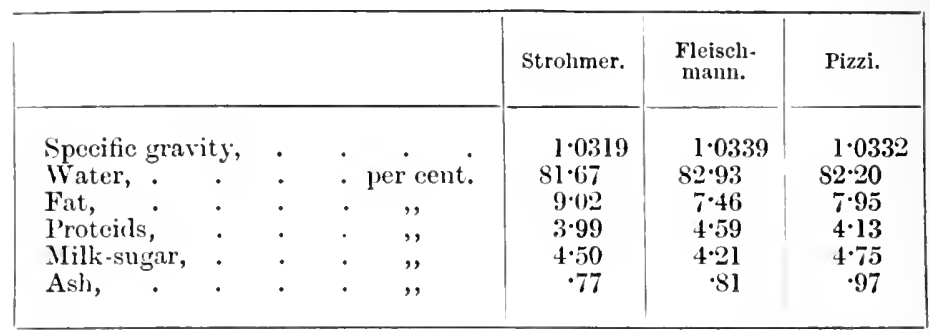

Strohmer draws attention to the high percentage of fat and the mush-like smell. It is white in colour, and the butter prepared from it has only a slight yellowish tinge.

Fat.-The analytical figures for the butter fat are given by Strohmer as-

$\begin{array}{ccccc}\begin{array}{c}\text { sfelting } \\ \text { point. }\end{array} & \begin{array}{c}\text { Solidifying } \\ \text { point. }\end{array} & \begin{array}{c}\text { Solidifying point } \\ \text { of fatty acids. }\end{array} & \begin{array}{c}\text { Potash } \\ \text { absorbed. }\end{array} & \begin{array}{c}\text { Reichert-Wollny } \\ \text { figure. }\end{array} \\ 31 \cdot 3^{\circ} & 19 \cdot 8^{\circ} & 37 \cdot 9^{\circ} & 22 \cdot 24 \text { per cent. } & 30.4 \text { c.c. }\end{array}$

and by Pizzi at melting point, $38.0^{\circ}$; solidifying point, $29.0^{\circ}$; Peichert-Wollny figure, $26 \cdot 2$.

Milk of the Gamoose-Composition.-The composition of the milk of the Egyptian gamoose or water-buffalo, which is the same as, or very closely allied to, that found in India, South Africa, Hungary, and Southern Europe, has been studied by the author and A. Pappel.

The average composition is-

\begin{tabular}{|c|c|c|c|c|c|}
\hline Specific g & ravity, & . $\quad 1 \cdot 035$ & & & \\
\hline Water, & .. & . $84 \cdot 10$ & $\mathrm{rec}$ & & \\
\hline Fat, . & . & . $\quad 5 \cdot 56$ &, & & \\
\hline Singar, & - & $5 \cdot 41$ &,, & & \\
\hline Casein, & . & $3 \cdot 26$ & , , & containing nitrogen, & $\cdot 511$ \\
\hline Allumin, & - & $\cdot 60$ & $"$ & ", & .094 \\
\hline Salts, & $\cdot \quad \cdot$ & 1.03 & " & $\begin{array}{ll}\text { asn, } \\
, & \text { citricacir }\end{array}$ & 30 \\
\hline Nitrogen & us bases, & $\cdot 09$ & ," & nitrogen, & 035 \\
\hline
\end{tabular}

A rise in specific gravity on standing was noticed, amounting to, in

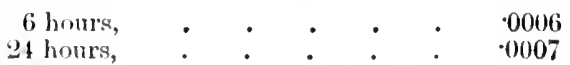

One sample, however, showed a decrease.

The fat was found to vary from $7 \cdot 35$ to $5 \cdot 15$ per cent., and the solids not fat from 10.67 to 10.07 per cent.

The average percentage composition of the solids not fat was-

\begin{tabular}{|c|c|c|c|c|c|c|c|c|}
\hline \multicolumn{7}{|c|}{. . . . . . 495 per cent. } & \multicolumn{2}{|c|}{495 per cent. } \\
\hline Proteirls, & . & . & 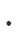 & • & 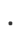 & . & $40 \cdot 8$ & , , \\
\hline Ash, . & . & . & - & . & • & . & s“2 & , \\
\hline Other sulset & tancess, & . & . & . & . & . & 1.5 & ," \\
\hline
\end{tabular}

Showing a ratio of sugar : proteids : ash $=6: 5: 1$. 
The following formula was found to be applicable to gamoose milk :-T $=\cdot 27 \frac{G}{D}+1 \cdot 191 \mathrm{~F}$., indicating that the fat had a density of $\cdot 934$, and the solids not fat had a density of 1.589 .

The formula

$$
\frac{\mathrm{G}}{\mathrm{D}}=-\cdot 76 \mathrm{l} \mathrm{F}+4 \mathrm{~L}+2 \cdot 5714 \mathrm{P}+7 \cdot 5715 \mathrm{~A} \text { (see p. 65) }
$$

was found to be applicable to the milk of the gamoose.

Two series of investigations into the constituents of the milk were made, one during the winter on milk yielded by a newlycalved gamoose, and the other during the summer on the milk of animals well on in their period of lactation. Notable differences were found.

Fat.-The fat gave the following figures on analysis :--

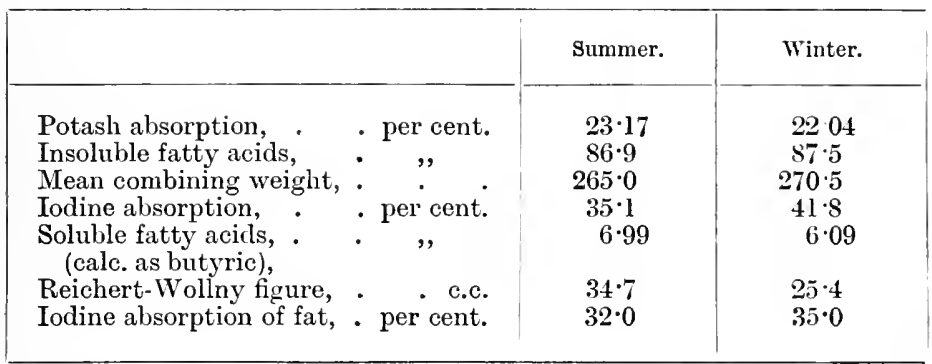

A winter sample of fat was found to contain 05 per cent. of sulphur and 01 per cent. of phosphorus.

Casein.-The casein was prepared from the winter milk. The purest preparation contained $2 \cdot 53$ per cent. of moisture and $\cdot 60$ per cent. ash, the nitrogen calculated to the pure substance being 14.66 per cent. and the phosphorus 85 per cent. Other preparations, which were less pure, gave about 14.4 to 14.5 per cent. of nitrogen.

Though this casein was precipitated three times, and thoroughly washed with water each time, and finally with alcohol and ether, it was perhaps not pure, as a solution was made in a minimum of caustic soda, and equivalent amounts of sodium phosphate and calcium chloride added; the nitrogen was estimated in this and in the precipitates obtained by (l) saturation with magnesium sulphate, (2) tannin, and (3) acetic acid at $40^{\circ} \mathrm{C}$.

Calling the nitrogen in solution 100 , the following amounts were obtained by

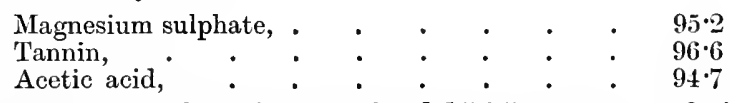

Albumin.-The albumin contained $15 \cdot 75$ per cent. of nitrogen, and is probably identical with that of cow's milk. 
Citrie acid was identified by isolating it and determining the percentage of calcium in the ealcium salt.

A yellow erystalline mercury compound was isolated from the winter milk in too small a quantity for identification, but was in all probability derived from a nitrogenous basie substance.

Sugar.-The sugar was prepared from the winter milk. Two preparations gave the following figures:-

$\begin{array}{cccc}\begin{array}{c}\text { Influence on } \\ \text { density. }\end{array} & {[\alpha]_{\mathrm{n}}} & \begin{array}{c}\text { Cupric reducing } \\ \text { power. }\end{array} & \begin{array}{c}\text { Water of } \\ \text { crystallisation. }\end{array} \\ 3 \cdot 94 & 48 \cdot 66 & 73 \cdot 6 & 4 \cdot 77 \\ 3 \cdot 94 & 49 \cdot 10 & 73 \cdot 9 & 4 \cdot 82\end{array}$

Mucic acid was not obtained by oxidation with nitric acid. On treatment with acid the following figures were obtained :-

$$
\begin{array}{cc}
{[a]_{\mathrm{D}}} & \text { Cupric reducing power, } \\
53.74 & 101 \cdot 0
\end{array}
$$

figures approaching those given by dextrose.

This sugar evidently differed from milk-sugar, and was named "Tewtikose."

A second preparation was made from the summer milk; it was examined by A. R. Ling and the author, and yielded the following figures. (For the sake of comparison figures yielded by milk-sugar, prepared by the same method, are given.)

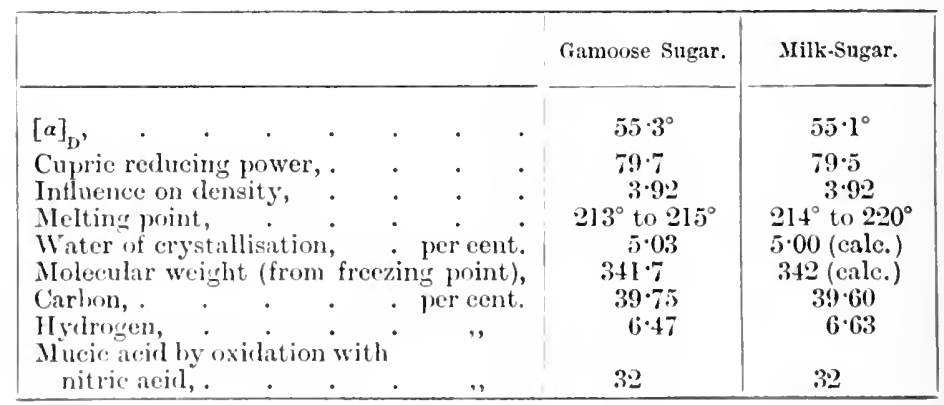

By heating with phenylhydrazine acetate two compounds were formed-one realily soluble in hot water (melting point, $197^{\circ}$ ), and the second almost insoluble in lot water, but soluble in hot dilute aleohel (melting point, $218^{\circ}$ to $219^{\circ}$ ). These compounds agree with phenyllactosazone and its anhydride.

The acetyl derivative prepared by heating with acetie anhydride and anhydrous sodium acetate, and crystallising from alcohol molted at $75^{\circ}$ to $80^{\circ}$. When crystallised from a mixture of $\$ 0$ per cent. alcohol ant chloroform it melted at $85^{\circ}$ to $95^{\circ}$.

The solution in chloroform was nearly optically inactive; if anything, slightly levo-rotatory. 
A determination of acetic acid in the acetyl derivative gave 71.46 per cent. as against 70.79 calculated for an octacetyl derivative.

The properties of the acetyl derivative agree exactly with octacetyllactose.

The birotation ratio was found to be $1 \cdot 6$.

All the properties without exception agree with those of ordinary milk-sugar.

It appears that the sugar of the summer milk is "lactose" and not "tewfikose."

Winter and Summer Milk.-There appears to be a distinct difference between the winter and summer milks, which may be summarised as follows :-

\section{Winter.}

Fat low in volatile acids.

Contains " tewfikose."
Summer.

Fat high in volatile acids.

Contains "lactose."

The author has tried to find evidence that the sugar called "tewfikose" was a product of the action of reagents used in the preparation of milk-sugar, but has been unable to do so, many preparations of milk-sugar having been made by the same method (including that from summer milk), always with the properties of milk-sugar. Analyses of the milk used to prepare "tewfikose" only added up to $99 \cdot 3$ per cent., when the polarisations were calculated as milk-sugar, but gave a satisfactory approach to 100 when calculated as tewfikose.

There appears to be no reason to reject the view that "tewfikose" is a separate entity.

The Milk of the Ewe.-The following composition is given by different authorities:-

TABLE LXVI.—Composition of Ewe's MiLK.

\begin{tabular}{|c|c|c|c|c|c|c|}
\hline Authority. & Water. & Fat. & Sugar. & Casein. & Albumin. & Ash. \\
\hline $\begin{array}{l}\text { Pizzi, : } \\
\text { Besana, : : } \\
\text { Vieth, : : } \\
\text { Bell, : } \\
\text { Fleischmann, } \\
\qquad,, \quad .\end{array}$ & $\begin{array}{l}\text { Per cent. } \\
\text { S0·42 } \\
78 \cdot 23 \\
81 \cdot 3 \\
75 \cdot 2 \\
83 \cdot 0 \\
75 \cdot 40\end{array}$ & $\begin{array}{c}\text { Per cent. } \\
9 \cdot 66 \\
9 \cdot 50 \\
6 \cdot 8 \\
11 \cdot 3 \\
5 \cdot 3 \\
11 \cdot 77\end{array}$ & $\begin{array}{c}\text { Per cent. } \\
4 \cdot 37 \\
5 \cdot 00 \\
4 \cdot 8 \\
36 \\
4 \cdot 6 \\
3 \cdot 65\end{array}$ & $\begin{array}{r}\text { Per } \\
4 \\
6 \\
6 \\
8 \\
4 \cdot 6 \\
6 \cdot 47\end{array}$ & $\begin{array}{l}1 \cdot 7 \\
1 \cdot 64\end{array}$ & $\begin{array}{c}\text { Per cent. } \\
1 \cdot 10 \\
1.01 \\
\cdot \mathrm{s} \\
1 \cdot 1 \\
\cdot \mathrm{s} \\
\text { (average) } \\
1 \cdot 06 \\
\text { Raden } \\
\text { herd) } \\
9 \cdot 3\end{array}$ \\
\hline \multicolumn{7}{|c|}{$\begin{array}{l}\text { The composition of colostrum of ewe's milk is given by } \\
\text { Voelcker as- }\end{array}$} \\
\hline & $69 \cdot 74$ & $2 \cdot 75$ & 8.85 & 17 & & $1 \cdot 29$ \\
\hline
\end{tabular}


The following figures are given by Weiske and Kennepohl :TABLE LAVII.-Composition of Ewe's MilK.

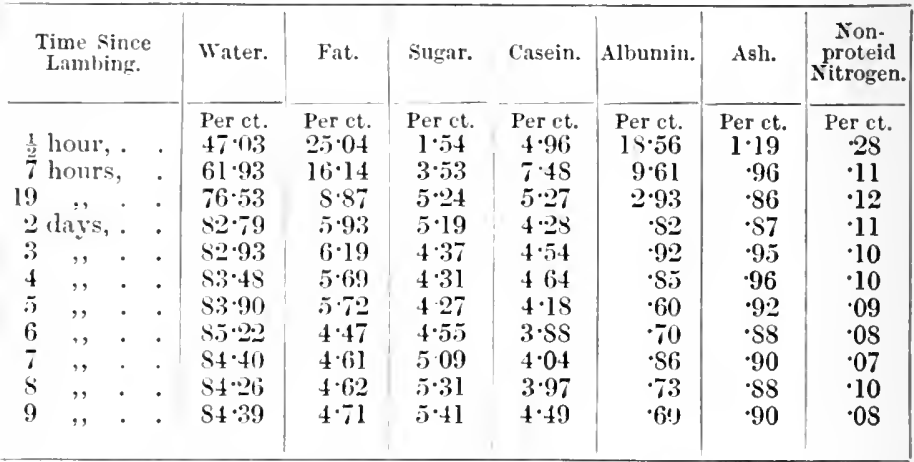

The specific gravity varies from 1.035 to $1 \cdot 043$.

Besana gives the following table for correcting the specific gravity to $15^{\circ} \mathrm{C}$. :-

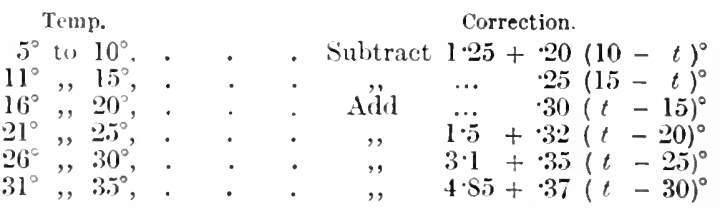

The fat globules vary in size, according to Besana, from $.0047 \mathrm{~mm}$. to $.0309 \mathrm{~mm}$. This is not in accord with Pizzi's observations (1.321). Sheep's milk throws up no cream if left to rest, owing to its great viscosity. The cream may, however, be removed by a separator, or by dilution with an equal bulk of water.

The action of rennet does not differ from that with cow's milk, but the curd is firmer.

The Milk of the Goat.-The following is the mean composition given by various authorities:-

TABLE LAVIII.-Composition of Goat's MiLK.

\begin{tabular}{|c|c|c|c|c|c|c|c|}
\hline Authority. & & Water. & rat. & Singar. & Casein. & Albuunin. & Ash. \\
\hline $\begin{array}{l}\text { König (average), } \\
\text { Yoser \& Suxhlet, } \\
\text { Pleischmam, }\end{array}$ & • & $\begin{array}{l}\text { Per ct. } \\
5.7 \% 1 \\
86.45 \\
5.5 \div \%\end{array}$ & $\begin{array}{c}\text { Per } 4.6 \\
4.6 \\
4.43 \\
4.4\end{array}$ & $\begin{array}{c}\text { l'er ct, } \\
4 \cdot 46 \\
4 \cdot 56 \\
4 \cdot 0\end{array}$ & $\begin{array}{c}\text { Per ct. } \\
3.20 \\
3.44 \\
3.4\end{array}$ & $\begin{array}{c}\text { Peret. } \\
1 \cdot 09 \\
\cdot 30 \\
1 \cdot 2\end{array}$ & $\begin{array}{c}\text { Perct. } \\
76 \\
79 \\
7\end{array}$ \\
\hline $\begin{array}{l}\text { l'izzi, } \\
\text { Author, }\end{array}$ & & $\begin{array}{l}56 \cdot 75 \\
46 \cdot 76\end{array}$ & $\begin{array}{l}5 \cdot 37 \\
378\end{array}$ & $\begin{array}{l}3 \cdot 60 \\
+4 \cdot 49\end{array}$ & & $\begin{array}{l}64 \\
10\end{array}$ & $\begin{array}{l}66 \\
\cdot 87\end{array}$ \\
\hline
\end{tabular}


None of the constituents differ sufficiently from those of cow's milk to need detailed notice.

The fat is, however, very white, and the milk and butter have a smell of the goat.

The Milk of the Mare.-Most of our knowledge of mare's milk is due to Vieth, who carried out an extencled series of observations on the stud of mares at the International Health Exhibition in London during 1884.

The following is an abstract of his results :-

TABLE LXIX.-Composition of Mare's Milk.

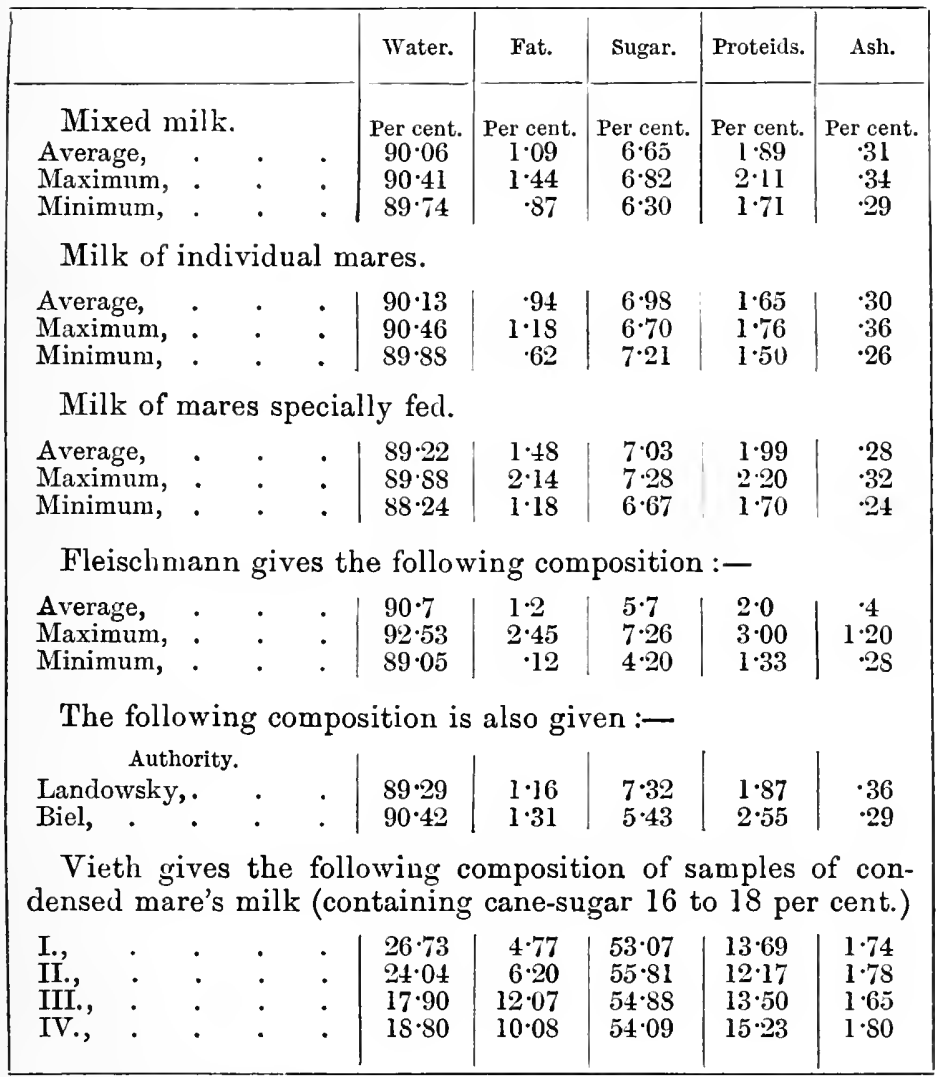

Vieth describes the milk as of a chalky white colour, of sweet, and at the same time somewhat harsh taste, and of aromatic flavour. It had usually an alkaline reaction, the very few exceptions being neutral. 
As this milk undergoes alcoholic fermentation very easily, while cow's milk loes not, there is reason to suppose that the sugar is not identical with milk-sugar.

The Milk of the Ass. - The milk of the ass is considered by some authorities (e.g., Tarnier) to ipproximate more in composition to human milk than that of any other animal; it is used to some extent for infant feeding.

The following is the composition given by various authorities:

\begin{tabular}{|c|c|c|c|c|c|c|}
\hline Authority. & Water. & Fat. & Sugar. & Casein. & Allymin. & Ash. \\
\hline Duclaux, & $\begin{array}{c}\text { Per cent. } \\
90 \cdot \% 0\end{array}$ & $\begin{array}{c}\text { Per cent. } \\
1.00\end{array}$ & $\begin{array}{c}\text { Per cent. } \\
6.54\end{array}$ & $\begin{array}{c}\text { Per cent. } \\
.99\end{array}$ & $\begin{array}{c}\text { Per cent. } \\
-34\end{array}$ & $\begin{array}{c}\text { Per cent. } \\
\cdot 43\end{array}$ \\
\hline Author, . & $59 \cdot 77$ & $1 \cdot 18$ & $6 \cdot 86$ & & 74 & $\cdot 45$ \\
\hline
\end{tabular}

Pizzi has shown that the fat is somewhat low in rolatile acids (see 1. 322).

The author has prepared the sugar and finds that it has a specific rotatory power $[\alpha]_{\mathrm{D}}=52 \cdot 5^{\circ}$ (for hydrated sugar), a birotation ratio of $1 \cdot 6$, and corresponds in every particular with milk-sucrar.

The milk has a very feeble alkaline reaction; rennet produces a very soft curd after a long time, and acids give a finelydivided precipitate. On hoiling, it has a tendency to curdle and deposit flakes (coagulated albumin?). It has a white colour and a sweet taste.

Milk as a Food and a Medicine.-In considering the food value of milk, two points must be borne in mind ; first, its value in relairing the waste of the tissues; and second, its value as a source of energy. As a food for infants it is required not only to repair waste of tissues, but to actually build them up.

Composition of Constituonts.-The following table gives the percentage composition of the three main constituents of milk :-

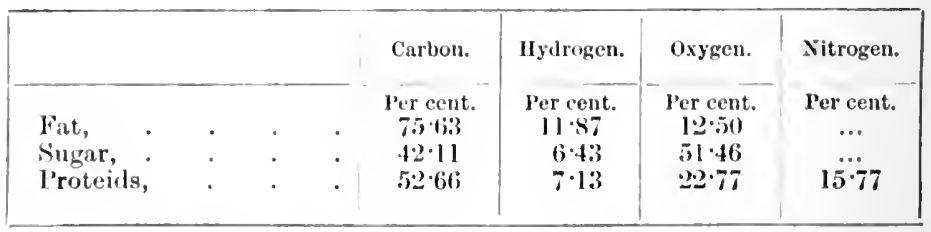

It is seen that fat is the richest in carbon and hydrogen, proteids next, while sngar oceupies the lowest place. Neither fat nor sugar ean replace protrids, as these compounds form the only source of nitrogen. Fat and sugar being composed of the same three elements may replace each other, but it is evident 
that in building up tissues containing high percentages of carbon and hydrogen, fat is a far more advantageous food than sugar. As a food for infants the value of milk largely depends on the fat present, and it is doubtful whether fat can be replaced by sugar without detriment to anabolic processes.

As a food for adults, where the tissues are ready formed, milk may be regarded chiefly as a source of energy. From this point of view fat may be replaced by the iso-dynamic quantity of milksugar.

Heat of Combustion of Constituents.-The following values for the heat of combustion of the constituents of milk are due to Strohmer:-

\begin{tabular}{|c|c|c|c|c|c|c|}
\hline Fats-Butter fat, & & & & $9231 \cdot 3$ & lor & gramme. \\
\hline Other fats, & & & & 9500 & , & ,", \\
\hline Sugar-Milk-sugar, & $\bullet$ & & & 3950 &, & ", \\
\hline $\begin{array}{l}\text { Cane-sugar, } \\
\text { Proteids }\end{array}$ & & & & $\begin{array}{l}3955 \\
5858 \cdot 3\end{array}$ & $"$ &,, \\
\hline Albumin, & . & . & . & $5735 \cdot 2$ & $"$ & , \\
\hline
\end{tabular}

These values assume that complete combustion takes place, and that carbon dioxide, water, and nitrogen are produced. In the case of fat and sugar it may be fairly assumed that an approach to complete combustion takes place in the human body, and that carbon dioxide and water are excreted. The nitrogen of proteids is not excreted as nitrogen, but as compounds, of which urea may be taken as the type.

Strohmer calculates that 1 gramme of average proteid yields -3428 gramme of urea, the heat of combustion of which is 2537 calories per gramme; the heat of combustion of the urea from 1 gramme of proteids is, therefore, $869 \cdot 7$ calories, or, in round figures, 15 per cent. of the total heat of combustion. It is necessary, therefore, to deduct 15 per cent. of the heat of combustion of proteids in calculating iso-dynamic metabolic ratios.

In round figures, the following will be the calories per gramme developed in combustion of the three constituents in the human body :-

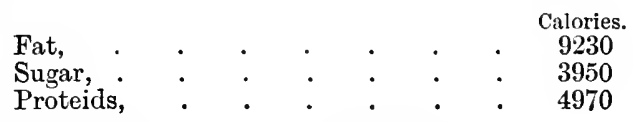

These figures are in the ratio of $2 \cdot 38: 1: 1 \cdot 26$.

The author proposes to calculate the ratio between the various constituents as follows :-

$$
\begin{aligned}
& \text { Anabolic ratio }=\text { fat }: \text { sugar }: \text { proteids. } \\
& \text { Metabolic ratio }=\frac{\text { fat } \times 2 \cdot 38+\text { sugar }+ \text { proteids } \times 1 \cdot 26}{\text { proteids. }} .
\end{aligned}
$$

Instead of the figures $2 \cdot 38$ and $1 \cdot 26$, the round figures $2 \cdot 5$ and 1.25 may be used without appreciable error. The author 
believes that the above ratios will give a truer idea of the proportionate value of different constituents than the usual nutritive ratio, which is $\frac{\text { fat } \times 2 \cdot 5+\text { sugar }}{\text { proteids. }}$.

Food Value.-We may now consider the food value of various milks.

The ratios for human milk are-

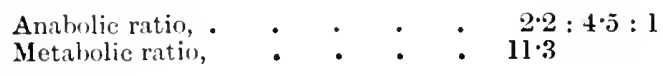

For cow's milk-

$$
\begin{aligned}
& \text { Anabolic ratio, . . . . . } 1 \cdot 15: 1 \cdot 4: 1 \\
& \text { Metaholic ratio, }: \quad \cdot \quad \cdot 5.54
\end{aligned}
$$

The marked difference of the two milks, due to the smaller amount of proteids in human milk, is very apparent.

It is assumed in calculating these ratios that the constituents are all digestible; this is approximately true with human milk. The same cannot be said of cow's milk, owing to a difference in the proteids; the action of rennet, one of the enzymes of the stomach, on cow's milk results in the formation of clots of curd, which are not digested. If the fat has been partially churned in the milk, this also is not perfectly digested.

Experiments have shown that children do not derive the most benefit from milk unless the anabolic ratio approximates to $2: 4: 1$, and the constituents are in such a form that they are as finely divided as possible in the stomach.

Milk as a Food for Infants-Artificial Human Milk.Many preparations of artificial human nilk, or humanised milk, are inade; they correspond in composition more or less exactly with human milk. The condition of the proteids necessary to produce a fine state of division in the stomach is attained-

(1) By simple dilution with water, and aldition of fat and sugar.

(2) By removal of casein, aml auddition of fat and sugar.

(3) By arting on the milk with a protcolytic enzyme-i.e., peptonising it, and addition of fat and sugar.

(4) By ardeling a preparation containing diastase and liluting it, and adding fat and sugar.

Various sugars are used, milk-sugar naturally being the most universally adopted; while cane-surar, and maltose, and other carbohydrates, resulting from the diisstatic conversion of starch are added.

The artificial freeding of children is to a large extent empirical. There is strong reason to belinve that few of the constituents of cow's milk are identical with those of human milk, though closely analogous; yet it has been found that cow's milk suitably modified is in excellent food. 
Again, it is found that human milk decreases in proteids as lactation advances. The best results have been obtained in artificial feeding by an exact reversal of this rule.

Peptonised Milk.-It is now conceded by the best authorities that the use of peptonised preparations is not an advantage, as, though the digestibility of the proteids is increased, it is at the expense of the development of the digestive organs.

The value of milk in the treatment of disease lies in the fact that it is readily digestible, especially if diluted or modified so that the formation of hard curd in the stomach is prevented. As an example, it may be mentioned, that during the epidemic of typhoid at Maidstone in 1897, the Aylesbury Dairy Company sent many hundreds of bottles of humanised milk to the hospitals, which gave most satisfactory results, and provided a food which was readily retained and assimilated.

Peptonised milk is also used in cases of gastric disorders. Vieth gives the composition of this product as :-

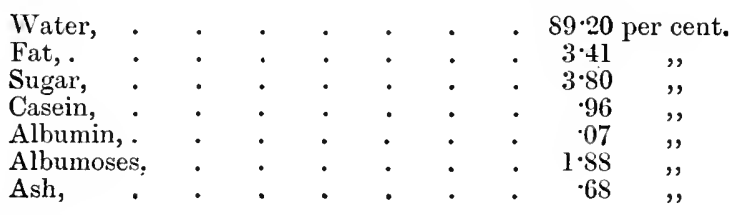

Diabetic Milk.-In cases of diabetes, Ringer has recommended a solution of casein in a mixture of salts approximating to those present in milk as supplying proteid nourishment; and Overend has used a diabetic milk in which the milk-sugar has been almost entirely replaced by lævulose with success.

The author found diabetic milk to have the following composition :-

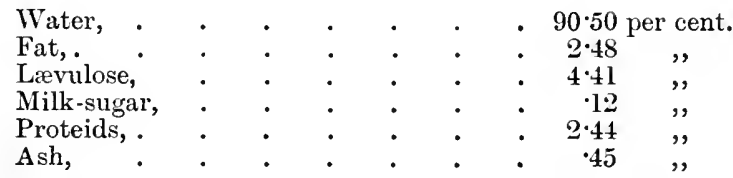

Koumiss is a remedial agent of great use in gastric disorders and many other diseases (see p. 243).

It owes its value to the fact that it is, first, a food of great digestibility; and, secondly, owing to the presence of alcohol, a stimulant. It is retained in cases where absolutely no other food can be given. 


\section{A P PENDIX A.}

\section{EXPERIMENTAL EVIDENCE THAT THE FAT IN CREAM IS SOLID AT LOW TEMPERATURES.}

As a means of determining this question the expansion of butter fat was studied, and the expansion of the fat in cream was compared with this.

The expansion of a sample of eream was found to be:-

\begin{tabular}{|c|c|c|}
\hline Temperature C. & True Densities D. $\frac{t^{2}}{4^{\circ}}$. & True Speeific Volumes. \\
\hline $14 \cdot 2^{\circ}$ & 10019 & .99802 \\
\hline $20.7^{\circ}$ & .99865 & $1 \cdot 00135$ \\
\hline $27 \cdot 9^{\circ}$ & .99400 & $1 \cdot 00604$ \\
\hline $38 \cdot 4^{\circ}$ & $\cdot ! 18763$ & $1 \cdot 01252$ \\
\hline $43^{\cdot} 1^{\circ}$ & 95.500 & $1 \cdot 01523$ \\
\hline $47 \cdot 7^{\circ}$ & $\cdot 98245$ & $1 \cdot 01786$ \\
\hline
\end{tabular}

The cream harl been left under the receiver of an air-pump for some time, and had stool for several hours at $14 * 2^{\circ} \mathrm{C}$. before the densities were determined.

The separated milk (which contained 08 per cent. fat) from the same milk from which the cream was prepared was also examined.

\begin{tabular}{|c|c|c|}
\hline Temperature C. & \multicolumn{2}{|c|}{$\begin{array}{l}\text { Apparent Specific Gravity in Glass } \\
\qquad 1 \frac{15 \cdot 5^{\circ}}{15 \cdot 5^{\circ}} \text { (in glass). }\end{array}$} \\
\hline $15 \cdot 3^{2}$ & $1 \cdot 0.375$ & * \\
\hline $21: 3^{\circ}$ & $1 \cdot 0361$ & \\
\hline $2 \cdot 2 \cdot 4^{\circ}$ & $1 \cdot 0358$ & $*$ \\
\hline $27 \cdot 5^{\circ}$ & $1 \cdot 0342$ & \\
\hline $29 \cdot 3^{\circ}$ & I 0.336 & * \\
\hline $3.7 \cdot 6^{\circ}$ & $1 \cdot 031 \overline{3}$ & * \\
\hline $45 \cdot 9^{\circ}$ & $1 \cdot 0276$ & \\
\hline $50 \cdot 0^{\circ}$ & $1 \cdot 0257$ & * \\
\hline
\end{tabular}

Care was taken to eliniuate nir hblles: the experinents marked with an * was taken while the temperature was rising, the others while it was falling, and it was taken again nt $15 \cdot 3^{\circ}$ after heating to $50^{\circ}$; no change was noticerl. 
From the above results the following true specific volumes were calculated :-

\begin{tabular}{|c|c|c|}
\hline Temperature C. & Specific Volumes. & Specific Volumes (calculated). \\
\hline & & \\
\hline $14 \cdot 2^{\circ}$ & $\cdot 96451$ & $\cdot 96452$ \\
$20 \cdot 7^{\circ}$ & .96600 & 96609 \\
$27 \cdot 9^{\circ}$ & .96824 & $\cdot 96819$ \\
$38 \cdot 4^{\circ}$ & .97191 & $\cdot 97185$ \\
$43 \cdot 1^{\circ}$ & .97371 & $\cdot 97373$ \\
$47 \cdot 7^{\circ}$ & .97570 & $\cdot 97571$ \\
\hline
\end{tabular}

The results were calculated by the formula :-

$$
\text { Specific volume }=\cdot 96203+\cdot 000127 t+\cdot 00000335 t^{2} .
$$

It is seen that the difference is within the limits of experimental error, and a curve nay be drawn (Fig. 22) with a bent lath which passes through all the points when temperatures and specific volumes are plotted against each other. It may be conchuled that the expansion is regular between $14.2^{\circ}$ and $50.0^{\circ}$, and shows no break in continuity.

From the specific volumes of cream and separated milk, that of the fat in cream may be caiculated by the following formula :--

$$
\text { Sp. vol. of fat }=\frac{\text { Sp. vol. of cream }-\cdot 664 \text { sp. vol. of separated milk }}{\cdot 336} \text {. }
$$

The following table gives the results thus obtained :--

\begin{tabular}{|c|c|c|}
\hline Temperature C. & True Specific Volume of Fat. & True Density of Fat. \\
\cline { 1 - 2 } $14 \cdot 2^{\circ}$ & $1 \cdot 0643$ & .9396 \\
$20 \cdot 7^{\circ}$ & $1 \cdot 0712$ & .9335 \\
$27.9^{\circ}$ & $1 \cdot 0807$ & .9253 \\
$38.4^{\circ}$ & 1.0928 & .9151 \\
$43 \cdot 1^{\circ}$ & 10973 & $\cdot 9113$ \\
$47 \cdot 7^{\circ}$ & $1 \cdot 1012$ & .9081 \\
\hline
\end{tabular}

On plotting out the temperatures against the specific volumes of cream and of fat it is seen that it is impossible to draw a single curve with a bent lath, which will include all the points, without far exceeding the experimental error. In both cases, however, two curves may be drawn, which cut each other at about $32^{\circ} \mathrm{C}$. ; the upper includes the three points above $32^{\circ} \mathrm{C}$, which lie in a straight line; and the lower, the three points below $32^{\circ}$, which do not lie in a straight line. No curve can be drawn which will include more than three points.

There is conclusive evidence that a change takes place in the density at about $32^{\circ} \mathrm{C}$., and that the expansion, which is perfectly regular above this temperature, is of a different character below. The melting point of butter fat lies at about $32^{\circ} \mathrm{C}$.

The densities of fat which have been calculated do not necessarily represent the real densities, as they are affected by any error in the fat determination or by evaporation of the cream when exposed in vacuo; these errors will not, however, affect the relative values appreciably. 


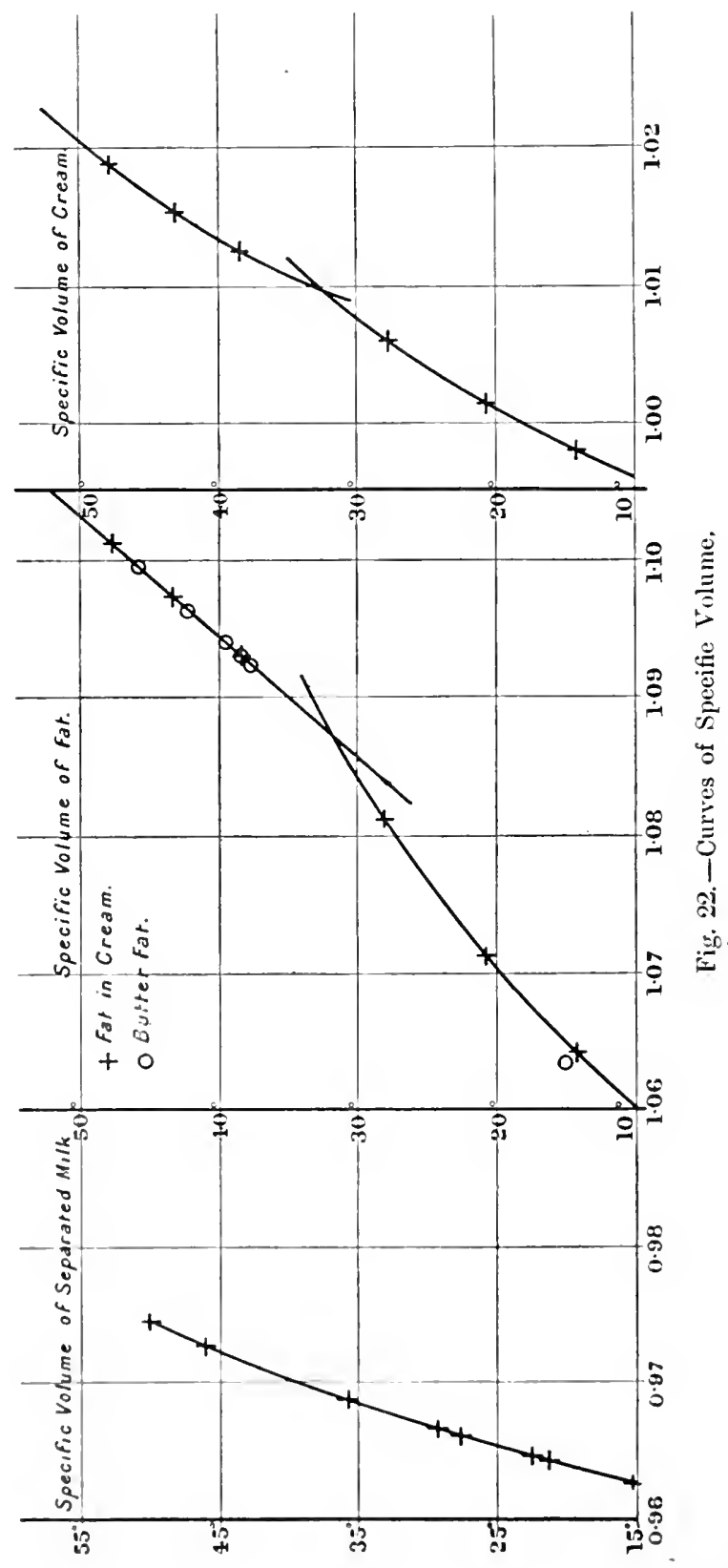


On p. 39 the densities and specific volumes of butter fat are given, and the specific volumes of the fat in cream are interpolated for comparison.

\begin{tabular}{|c|c|c|c|}
\hline Temperature C. & Sp. Vol. of Butter Fat. & Sp. Vol. of Fat in Cream. & Difference. \\
\cline { 1 - 2 } & & & \\
\hline $15.0^{\circ}$ & 1.0753 (solid) & $1 \cdot 0651$ & .0102 \\
$37.8^{\circ}$ & $1 \cdot 1041$ (liquid) & $1 \cdot 0922$ & .0119 \\
$39.5^{\circ}$ & $1 \cdot 1056$, & $1 \cdot 0937$ & 0119 \\
\hline
\end{tabular}

A series of experiments on the expansion of butter fat in the liquid state were carried out.

\begin{tabular}{|c|c|c|}
\hline Temperature C. & Volume (in degrees of dilatometer) & Sp. Vol. (calculated). \\
\hline $38 \cdot 5^{\circ}$ & $1566 \cdot 2$ & $1 \cdot 0928$ \\
$42 \cdot 3^{\circ}$ & $1571 \cdot 4$ & $1 \cdot 0965$ \\
$45 \cdot 5^{\circ}$ & $1575 \cdot 6$ & $1 \cdot 0995$ \\
\hline
\end{tabular}

The specific volumes were calculated by dividing by $1433 \cdot 07$, in order to give figures comparable with those determined for the fat in cream.

On plotting out these figures and those for the specific volume of butter fat (corrected by subtracting 0119 ), it is seen that the whole of those referring to liquid fat lie on the straight line which represents the results above $32^{\circ}$.

It is seen then that the expansion of fat in cream above $32^{\circ} \mathrm{C}$. corresponds exactly with the expansion of liquid fat.

It is seen also that the specific volume of fat in the solid state lies very close to the curve representing the points below $32^{\circ}$. Seeing that the densities of fat in cream correspond with the assumption that the fat is solid at temperatures below $32^{\circ}$ and that the very marked change in the expansion occurs at the melting point of butter fat, the evidence is very strong and, practically, conclusive.

Another sample of cream which had been treated in a similar manner was found to have a density of 1.0009 at $15 \cdot 6^{\circ} \mathrm{C}$. ; this was heated to $50^{\circ} \mathrm{C}$. and rapidly cooled, and its density after half-an-hour's cooling was found to be $\cdot 9976$ at $15 \cdot 5^{\circ}$. After a further two hours at this temperature it was found to have contracted very appreciably.

From this experiment it appears that when the fat in cream is liquefied it returns but very slowly to its original volume, and it is probable that it remains for some time in the superfused condition and only slowly solidifies. It is by no means improbable that the density of cream which was determined at $14 \cdot 2^{\circ}$ is slightly too low from this cause, and that the reason of the slight divergence of the specific volume of butter fat at $15^{\circ} \mathrm{C}$. from the curve is due to the curve being not correct owing to the fat at $14 \cdot 2^{\circ}$ not having assumed its real density. 


\section{A P P ENDIX B.}

\section{STANDARDISATION AND CALIBRATION OF APPARATUS.}

I. Weights.-A good set of weights is a sine quâ non in a laboratory; they shonld consist of the following :-

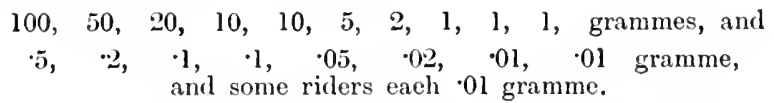

Select one of the weights, preferably a 10 gramme, as a standard ; mark one of the 10 grammes and one of the 1 gramme with a mark (') by means of a fine steel point; mark another l gramme with a mark ("); turn up one corner of a 1 gramme and of a 01 gramme. By this means the weights ean all be distinguished from each other.

See that the balance is in adjustment by swinging it withont any weights in the pans; if the pointer does not travel to an equal distance on both sides, alter the adjustment till this end is attained. After the adjustment, leave the balanee for at least one hour and see if it is still in adjustment; if not, repeat the process, handling the beam, \&c., as little as possible.

When the balance is in proper adjustment, plaee the 10-gramme weight on the right-hand pan, and the $10^{\prime}$-gramme weight on the left-hand pan; they should very nearly balanee, and the pointer should swing nearly equally on hoth sides; if they do not balance, place the rider so that the balance is restored. The value of the $10^{\prime}$-gramme weight can now be obtained in terms of the 10 -gramme weight, hy adding the readings of the rider, if on the right arm, and subtracting, if on the left arm. Now reverse the weights, placing the 10 -gramme weight on the left-hand pan, and the $10^{\prime}$-gramme weight on the right-hand pan, and repeat the weighing; the value of the $10^{\prime}$-gramme weight ean be obtained in terms of the 10.gramme weight by aldling the readings of the rider, if on the left arm, and subtracting, if on the right arm. Owing to minute differenees in the lengths of the arms it is not unusual to fiml a difference between the two values.

The true value may be found by adling the two valnes together and dividing by 2. (It is more correct, theoretically, to multiply the two values and take the sfunare root, hut the values thus obtained are practi. cally irlentieal with the arithmetical mean.)

I'lue total value of the $\overline{5}+2+1+1^{\prime}+1^{\prime \prime}$ weights are similarly obtained.

The value of the 20 -gramme weight is obtained in a similar manner by weighing it against the $10+10^{\prime}, 10+.7+2+1+1^{\prime}+1^{\prime \prime}$, or the $10^{\prime}+5+2$ $+1+l^{\prime}+1^{\prime \prime}$ or, preferal,ly, hy weighing against all three series and taking the mean of the three values (which should not difler appreeiably).

The value of the 50-gramme woiphe is obtitined by weighing it against the $20+10+10^{\prime}+5+2+1+1^{\prime}+1^{\prime \prime}$ weights.

Tho value of the 100 -gramme weight is olntained by weighing it against the $50+20+10+10^{\prime}+.5+2+1+1^{\prime}+1^{\prime \prime}$ weights.

The 5-gramme weight is now taker, temporarily, as a standard, and the $2+1+1^{\prime}+1^{\prime \prime}$ weights are wigherl against that, and the valuo of the series obtained in terms of the 5 -gramme weight. 
The true value of the 5-gramme weight is obtained by the following formula :-

Let $\quad 10+x$ be the value of the series $5+2+1+1^{\prime}+1^{\prime \prime}$,

$5 \times a+y$, the value of the series $2+1+1^{\prime}+1^{\prime \prime}$

in terms of the 5-gramme weight,

and

then

$5 \times a$ the true value of the 5 -gramme weight;

or

$$
\begin{aligned}
10+x & =2(5 \times a)+y, \\
5 \times a & =\frac{10+x-y}{2} .
\end{aligned}
$$

Now, temporarily assume that the l-gramme weight is the standard, and ascertain the values of the $l^{\prime}$ and $l^{\prime \prime}$ weights ; then ascertain the value of the 2 -gramme weight by weighing it against $1+1^{\prime}, 1+1^{\prime \prime}$ or $l^{\prime}+l^{\prime \prime}$ or, preferably, against all three.

The apparent values of the $2,1,1^{\prime}$, and $1^{\prime \prime}$ weights in terms of the l-gramme weight will now be obtained.

The true values are obtained as follows :-

Let $1 \times b$ be the true value of the l-gramme weight,

and $2(1 \times b)+z, 1 \times b+w, 1 \times b+u$, the values of the $2, \mathbf{1}^{\prime}$, and $\mathbf{1}^{\prime \prime}$ in terms of the l-gramme weight;

then

$$
2(1 \times b)+z+1 \times b+1 \times b+v+1 \times b+u=5 \times a+y,
$$

or

$$
1 \times b=\frac{5 \times a+y-z-w-u}{5} \text {. }
$$

From the true value of the l-gramme weight, the true values of the $2,1^{\prime}$. and $1^{\prime \prime}$ weights are obtained.

\begin{tabular}{|c|c|c|}
\hline Weight. & True Value. & Correction. \\
\hline 100 & $100 \cdot 0031$ & $+\quad 0031$ \\
\hline 50 & $50 \cdot 0028$ & $+\quad 0028$ \\
\hline 20 & $19 \cdot 9992$ & $-\quad .0008$ \\
\hline 10 & $10 \cdot 0000$ & 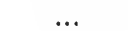 \\
\hline $10^{\prime}$ & $9 \cdot 9991$ & $-\quad .0009$ \\
\hline 5 & $5 \cdot 0002$ & $+\quad 0002$ \\
\hline 2 & $2 \cdot 0007$ & +0007 \\
\hline 1 & .9989 & -0011 \\
\hline $\mathrm{l}^{\prime}$ & •9993 & -.0007 \\
\hline $1^{\prime \prime}$ & $1 \cdot 0001$ & $+\quad 0001$ \\
\hline$\cdot 5$ & $\cdot 4997$ & -0003 \\
\hline$\cdot 2$ & 2002 & $+\quad .0002$ \\
\hline$\cdot 1$ & $\cdot 1001$ & +0001 \\
\hline$\cdot \mathrm{l}^{\prime}$ & .0993 & $-\quad .0002$ \\
\hline .05 & $\cdot 0497$ & $-\quad \cdot 0003$ \\
\hline$\cdot 02$ & $\cdot 0200$ & $\cdot 0000$ \\
\hline .01 & $\cdot 0097$ & -0003 \\
\hline$\cdot 01^{\prime}$ & .0099 & - .0001 \\
\hline Rider & $\cdot 0101$ & +.0001 \\
\hline
\end{tabular}

The values of the fractions of a gramme are obtained by the same process as the values of the $5,2,1,1$ ', and $1^{\prime \prime}$ weights.

TABLE LXX.--Valees of Weights. 
It is best to weigh the series $\cdot 5, \cdot 2, \cdot 1, \cdot \mathrm{I}^{\prime}, \cdot 05, \cdot 02, \cdot 0 \mathrm{I}$, and $\cdot 0 \mathrm{I}^{\prime}$ against the $1, l^{\prime}$, and $1^{\prime \prime}$ weights, and take the mean of the thrce values so obtained.

When the weights have been standardised, a table should be drawn up in the above fashion (Table I.X.).

II. Burettes. - Carefully clean out the burette with hot chromic acid mixture and rinse well with distilled water. Place it in a situation where sudden changes of temperature can be avoided, and fill it above the zero mark with distilled water ; note the temperature of this, which should be as near as possible $60^{\circ} \mathrm{F}$. $\left(15 \cdot 5^{\circ} \mathrm{C}\right.$. $)$.

Weigh an empty weighing bottle provided with a stopper; cut two parallel slits about 2 inches long and three-eighth of an inch apart in a card (a visiting earl answers armirably), and bend this so that the burette passes through the slits, the narrow strip being in front ; adjust this so that the upper edge of the narrow strip is coincident with the graduation next below the zero mark. Now carefully run out the water so that the lower edge of the meniseus coincides with the zero mark, cork np the burette and leave it for a few minutes; after making sure that no alteration in level has occurred, adjust the eard to the graduation next below the 5 e.c. mark, and run out slowly 5 e.c. into the weighing bottle. Weigh this and subtract the weight of the empty bottle; the difference will give the weight of water oceupying the volume between 0 and 5 .

After making sure that the level has not changer, adjust the card to the graduation next below the 10 c.e. mark and run out a further 5 c.c. into the weighing bottle; weigh again, and subtract the weight of the empty weighing bottle; the difference will give the weight of the water occupying the volume between 0 and 10 .

Repeat this process till the lowest mark on the burette is reached.

The ealibration of the burette shonld be repeated two or three times and the mean values tabulated.

With a finely-divided rule measure the lengths of the divisions 0 to 5 , 0 to 10 , \&c.; multiply each of these lengths by the total weight of water and divide by the total length, to obtain figures commensurate with the weights of water.

Now plot out on sfuared paper two curves, one taking the scale readings as ordinates, and differenees hetween scale readings and weights of water as alscisse; the other taking scale readings as ordinates, and differences between scale rearlings and lengths of scale corrected as described above as abscissae.

If hoth curves are nearly straight, it shows that the burette is made from a tube of uniform borc, and is correctly divided; if the two curves have a marked curvature, but eoincicle in form, it shows that the burette is made from a tube of uniform bore, but incenrectly divided; if the two curves do not coincicle it shows that the tube is not uniform in hore.

Now, oltain the value of the weights of water contained in each 5 c.c., 0 to 5,5 to 10 , \&c., hy subtrating the wcight contained in 0 to 5 from that contained in 0 to 10 , \&e., and the value of the lengthe in a similar manner; divide one value ly the other aud plot out the values so obtained on sruared paper, taking the mean scale readings (i.e., for the volume 0 to 5 take 2.5) us ordinates, and the values obtained by the division as abseisse. This will give the 'urve of irregularity of hore; if at any part of the curve it is notices that the irregularity is very gross, the rolume of cach 1 c.c. should be obtained ly weighing the water: if the curve is appreciably regular, it is evidlent that the errors of the burette must bo due to incorret clivision, and rery careful measmements of the lengths of divisions intermerliate betwern each 5 e.c. mark should be made; and if any very grave faults are found, the limette slonld he especially calilirated at that point. It is letter, however, wot to use a hurette of this description.

Talile LXXI. will give the figures ohtained on a burette of fairly even bore, but barly divided. 
TABLE LXXI.-Calibration of Burette.

\begin{tabular}{|l|c|c|c|c|}
\hline Scale. & $\begin{array}{c}\text { Weights of } \\
\text { Water. }\end{array}$ & Difference. & Length (inches). & $\begin{array}{c}\text { Difference } \\
\text { (corrected). }\end{array}$ \\
\cline { 1 - 4 } 0 to 5 & $4 \cdot 918$ & $-\cdot 082$ & $1 \cdot 752$ & $-\cdot 022$ \\
0 to 10 & $9 \cdot 940$ & $-\cdot 060$ & $3 \cdot 550$ & $+\cdot 016$ \\
0 to 15 & $14 \cdot 912$ & $-\cdot 085$ & $5 \cdot 329$ & $+\cdot 001$ \\
0 to 20 & $19 \cdot 896$ & $-\cdot 104$ & $7 \cdot 1095$ & $-\cdot 010$ \\
0 to 25 & $24 \cdot 850$ & $-\cdot 120$ & $5 \cdot 890$ & $-\cdot 023$ \\
0 to 30 & $29 \cdot 908$ & $-\cdot 092$ & $10 \cdot 683$ & -000 \\
0 to 35 & $34 \cdot 849$ & $-\cdot 151$ & $12 \cdot 436$ & $-\cdot 087$ \\
0 to 40 & $39 \cdot 817$ & $-\cdot 183$ & $14 \cdot 204$ & $-\cdot 135$ \\
0 to 45 & $44 \cdot 817$ & $-\cdot 183$ & $16 \cdot 982$ & $-\cdot 153$ \\
0 to 50 & $49 \cdot 877$ & $-\cdot 123$ & $17 \cdot 7775$ & $-\cdot 124$ \\
\hline
\end{tabular}

III. Pipettes.-Pipettes are used for measuring liquids by filling them to the mark and letting the liquid run out; the following points should be noticed :-

(a) The bottom of the meniscus should coincide with the mark.

(b) The pipette should be held vertically while it is rumning out.

(c) The liquid should always be allowed to run out in the same manner.

Perhaps the best manner of allowing the liquid to run ont is to allow it to flow as fast as possible, and, when empty, to touch the surface of the liquid with the point and to withdraw it at once. It may, however, be allowed to run out slowly, or a definite number of drops may be permitted to run out after the main portion is delivered. Whatever method is adopted during graduation must be strictly adhered to in practice.

The graduation of pipettes is very simple; they are filled with water as near $60^{\circ} \mathrm{F}$. $\left(15 \cdot 5^{\circ} \mathrm{C}\right.$.) as possible, the contents run into a weighing bottle and the water weighed.

The pipettes should be each etched with a number and the weight of water delivered tabulated for use.

Pipettes used exclusively for delivering known weights of milk should be graduated with milk of 1.032 specific gravity containing from 3.5 to 4.0 per cent. fat. In this case, the reading should be from the top of the meniscus, as the lower edge is invisible.

IV. Flasks. - Flasks of capacity sufficiently small to permit of being weighed when full, are filled with water as near $60^{\circ} \mathrm{F}$. as possible, and weighed. Each should be marked with a number, and the weight of water contained by each tabulated.

Larger flasks (e.g., litre flasks), if no balance sufficiently large is available, are graduated by the following method:-10 successive portions of a little less than 100 grammes of water at about $60^{\circ} \mathrm{F} .\left(15 \cdot 5^{\circ} \mathrm{C}\right.$.) are weighed into the flask (best from a 100 c.c. flask). A beaker containing a little water, and a pipette are now weighed, and the litre flask filled to the mark by water from the pipette ; the beaker, pipette, and remaining water are now weighed; the difference between the weights and the total weight of the ten portions added together will give the weight of water in the litre flask.

V. Leffmann-Beam or Gerber Bottles.-These can be graduated with sufficient accuracy by using each to make determinations of fat in several samples of milk, in which the fat has been carefully estimated by a good gravimetric method (e.g., the Adams method). Those bottles which show a marked difference (i.e., more than ${ }^{\prime} l$ per cent.) should be rejected.

The scale should also be measured with a finely-divided rule, and any bottles showing marked irregularities of graduation must be likewise rejected. 
VI. Lactometers.-Lactometers are graduated by taking the specifie gravity of several samples of milk which have had the density determined by a pyenometer; the range of specific gravities should be fairly wide; no lactometer showing differenees of more than $0002\left(\cdot 2^{\circ}\right)$ should be used, unless the differenees are eonstant, when a constant correction may be appliel.

YII. Thermometers. - One thermometer should be specially calibrated, and this will then serve as a standarl of comparison for others. The calibration is divided into two parts.

(a) Calibration of scale.

(b) Determination of fixed points.

(a) Calitration of sicule.-By means of a finely-divided rule the distances between the marks on the seale $(e . y ., 0$ to 10 , 10 to 20 , \&c.; or 0 to 5,5 to $10, \&$ e. ) are measured and tabulated.

The mereury is allowed to flow into the stem, and at a point, which should be as nearly as possible $10^{\circ}$ from the end, the tip of a fine flame is carefully applied; by a gentle jerk a thread about $10^{\circ}$ in length can be separated from the main portion, which is now allowed to flow back into the bulb. By gently tapping the tube, the thread is brought so that one end coineides with the zero mark, and the length of the thread is carefully measured ; the thread is next brought to the $10^{\circ}$ mark, and its length earefully measured again; and so on throughout the whole seale.

By dividing the lengths of the threal when it is between each pair of points (0 to 10,10 to $20, \& \mathrm{c}$ ) by the listanee between the same pair of points, the length of the threal in apparent degrees will be obtained; the average of these lengths will give the mean length of thread in mean degrees. By dividing the length of thread between each pair of points by the mean length, the value of a legree between each pair of points in terms of a mean legree will be obtained ; and, on multiplying by ten, the distance between each pair of points in mean degrees will be obtained. The values in mean degrees of the seale from 0 to 10,0 to 20 , \&e., should now be ealenlated, aml also the lengths of seale letween the same points. A curve of cronicality can be plotted for the thermometer in the same way that a similar curve was plotted for a burette $(q . v)$.

(b) Determination of fixed l'oints. - A flask with a long neck is partially filled with water and placed over a flame; a shallow cork, with two holes, is fitted to the neck, and through one of the holes the thermometer is passed : in the other a short bent tube to take the steam away from the operator is placel. The water is boiled briskly, and the thermometer pushed in till only the top of the mereury is visible, and left in this position for several minutes. The exact point on the seale where the top of the mercury rests is now noted ; the atmosplerie pressure is read, and, from the table below, the boiling point of water is taken; the difference between this and $100^{\circ}$ (or $212^{\circ}$ if a Fahrenheit thermometer is used) is now arlded to (or sulbtracted from) the scale realing of the thermometer, and the value thus obtained noted as the true value of $100^{\circ} \mathrm{C}$. $\left(01^{\prime} 212^{\circ} \mathrm{F}\right.$.).

The thermoneter is now removed, allowed to cool, and placed in melting ice; when the mercnly is statimary, the position of the top of the mereury is noted as the jreping point.

'I'he difference between the olserver] boiling and freezing points is taken, divided by 100 (or 180 if a Fhorenheit thermometer is used); the values in mean degrees of the senle from 11 to 10,10 to 20 , \&e., are multiplied by the value thus obtained, and the corrected value tahulated. The differences between these and the nominal values of the senle are now plotted on squared paper, and will serve ns a curve of eorrection of the instrument.

It is arlvisable to redetermine the loiling and freezing points from time to time, as they are liable to slight alteration.

Other thermometers may be stmmlarlised by eomparison with this one. 


\section{A P P E N D I C.}

USEFUL TABLES.

Table LXXII.-Boiling Point of Water Under Different Pressures (due to Regnault).

\begin{tabular}{|c|c||c|c|}
\hline Boiling Point. & $\begin{array}{c}\text { Pressure in Mrillimetres } \\
\text { of Mercury. }\end{array}$ & Boiling Point. & $\begin{array}{c}\text { Pressure in Millimetres } \\
\text { of Mlercury. }\end{array}$ \\
\cline { 1 - 2 } Centigrade. & $720 \cdot 15$ & $\begin{array}{c}\text { Centigrade. } \\
99 \cdot 5^{\circ}\end{array}$ & $746 \cdot 50$ \\
$98 \cdot 5^{\circ}$ & $722 \cdot 75$ & $99 \cdot 6^{\circ}$ & $749 \cdot 18$ \\
$98 \cdot 6^{\circ}$ & $725 \cdot 35$ & $99 \cdot 7^{\circ}$ & $751 \cdot 87$ \\
$98 \cdot 7^{\circ}$ & $727 \cdot 96$ & $99 \cdot 8^{\circ}$ & $754 \cdot 57$ \\
$98 \cdot 8^{\circ}$ & $730 \cdot 58$ & $99 \cdot 9^{\circ}$ & $757 \cdot 57$ \\
$98 \cdot 9^{\circ}$ & $733 \cdot 21$ & $100 \cdot 0^{\circ}$ & $760 \cdot 00$ \\
$99 \cdot 0^{\circ}$ & $735 \cdot 85$ & $100 \cdot 1^{\circ}$ & $762 \cdot 73$ \\
$99 \cdot 1^{\circ}$ & $738 \cdot 50$ & $100 \cdot 2^{\circ}$ & $765 \cdot 46$ \\
$99 \cdot 2^{\circ}$ & $741 \cdot 16$ & $100 \cdot 3^{\circ}$ & $768 \cdot 20$ \\
$99 \cdot 3^{\circ}$ & $743 \cdot 83$ & $100 \cdot 4^{\circ}$ & $771 \cdot 95$ \\
$99 \cdot 4^{\circ}$ & & & \\
\hline
\end{tabular}




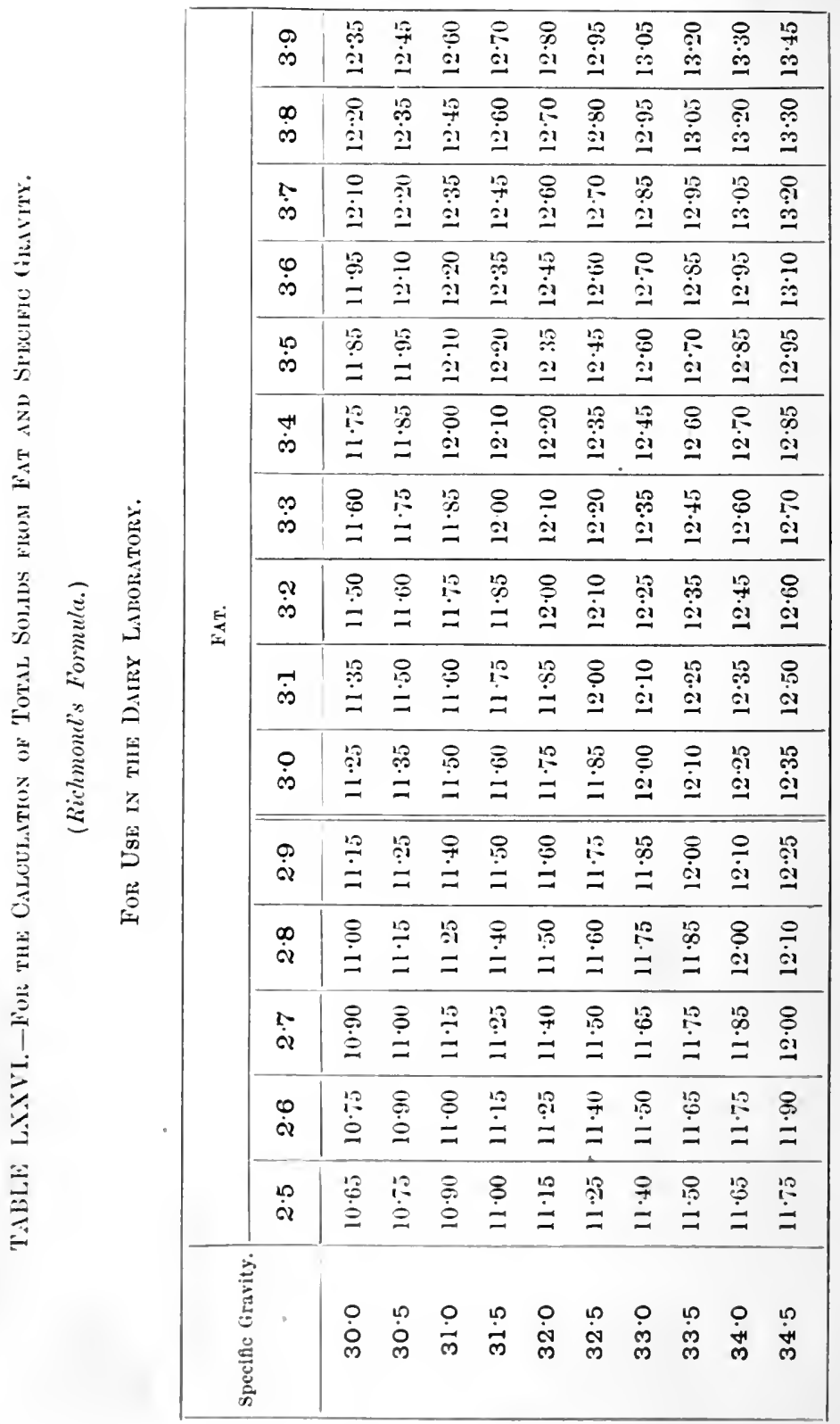


1029.5

\begin{tabular}{|c|c|c|c|c|c|c|c|c|c|c|c|}
\hline 75 & 76 & 77 & 78 & 79 & 80 & 81 & 82 & 83 & 84 & 85 & \\
\hline $21 \cdot 6$ & $\ldots$ & $\ldots$ & $\ldots$ & $\ldots$ & $\ldots$ & $\ldots$ & $\ldots$ & $\ldots$ & $\ldots$ & $\ldots$ & 20 \\
\hline $22 \cdot \pi$ & $\ldots$ & $\cdots$ & $\ldots$ & $\cdots$ & $\ldots$ & $\ldots$ & $\ldots$ & $\ldots$ & $\ldots$ & $\ldots$ & 21 \\
\hline $23 \cdot 7$ & $\ldots$ & $\ldots$ & $\ldots$ & $\ldots$ & $\ldots$ & $\ldots$ & $\ldots$ & $\ldots$ & $\ldots$ & $\ldots$ & 22 \\
\hline $24 \cdot 7$ & $\ldots$ & $\ldots$ & $\ldots$ & $\ldots$ & $\ldots$ & $\ldots$ & $\ldots$ & $\ldots$ & $\ldots$ & $\ldots$ & 23 \\
\hline $25 \cdot 7$ & $\ldots$ & $\ldots$ & $\cdot \ldots$ & $\ldots$ & $\ldots$ & $\ldots$ & $\ldots$ & $\ldots$ & $\ldots$ & $\ldots$ & 24 \\
\hline $26 \cdot 8$ & $\ldots$ & $\ldots$ & $\ldots$ & $\ldots$ & $\ldots$ & $\ldots$ & $\ldots$ & $\ldots$ & $\ldots$ & $\ldots$ & 25 \\
\hline $27 \cdot 8$ & 27.9 & $28 \cdot 0$ & $28 \cdot 2$ & $28 \cdot 3$ & $28 \cdot 4$ & $28 \cdot 6$ & $28 \cdot 7$ & 259 & $29 \cdot 0$ & $29 \cdot 2$ & 26 \\
\hline $28 \cdot 9$ & $29: 0$ & $29 \cdot 1$ & $29 \cdot 2$ & $29: 4$ & $29 \cdot 5$ & $: 29 \cdot 6$ & $29 \cdot 8$ & $30^{\circ} 0$ & $30 \cdot 1$ & $30 \cdot 3$ & 27 \\
\hline $29 \cdot 9$ & $30 \cdot 0$ & $30 \cdot 2$ & $30 \cdot 3$ & $30: 4$ & $30 \cdot 6$ & 30.7 & 308 & $31 \cdot 0$ & $31 \%$ & $31 \cdot 4$ & 28 \\
\hline $31 \cdot 0$ & $31 \cdot 1$ & $31 \cdot 3$ & $31 \cdot 4$ & 31.5 & $31 \cdot 7$ & 319 & $32 \cdot 0$ & $32 \cdot 2$ & $32 \cdot 3$ & $32 \cdot 5$ & 29 \\
\hline $32 \cdot 1$ & $32 \cdot 2$ & $32: 4$ & 32.5 & $32 \cdot 6$ & $32 \cdot 8$ & $33 \cdot 0$ & $33 \cdot 1$ & $33 \cdot 3$ & $33 \cdot 4$ & $33 \cdot 6$ & 30 \\
\hline $33 \cdot 2$ & $33 \cdot 3$ & 33.4 & 336 & $33 \cdot 7$ & $33 \cdot 9$ & $34 \cdot 0$ & $34 \cdot 2$ & $34 \cdot 4$ & $34 \cdot 5$ & 34.7 & 31 \\
\hline $34: 3$ & $34 \cdot 4$ & 34.5 & $34 \cdot 7$ & 348 & $35 \cdot 0$ & $35 \cdot 1$ & $35 \cdot 3$ & $35 \cdot 5$ & $35 \cdot 6$ & $35 \cdot 8$ & 32 \\
\hline 3 & 6 & $35 \cdot 6$ & 35.5 & $36 \cdot 0$ & $36 \cdot 1$ & $36 \cdot 3$ & 364 & $36 \cdot 6$ & $36 \cdot 7$ & 369 & 33 \\
\hline $36 \cdot 4$ & 36.5 & $36 \cdot 7$ & $36 \cdot 9$ & $37 \cdot 0$ & $37 \cdot 2$ & $37 \cdot 3$ & 37.5 & $37 \cdot 7$ & $37 \cdot 9$ & $38 \cdot 1$ & 34 \\
\hline $37 \cdot 1$ & $\ldots$ & $\ldots$ & $\ldots$ & $\cdots$ & $\ldots$ & $\ldots$ & $\ldots$ & $\ldots$ & $\ldots$ & $\ldots$ & 35 \\
\hline$\ldots$ & $\ldots$ & $\ldots$ & $\ldots$ & $\ldots$ & $\ldots$ & $\ldots$ & $\ldots$ & $\ldots$ & $\ldots$ & $\ldots$ & 36 \\
\hline
\end{tabular}

$1 \leqslant \infty$ 


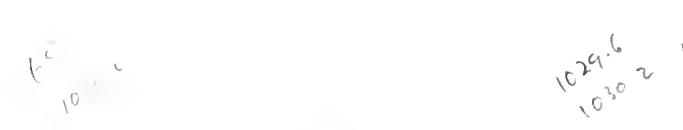

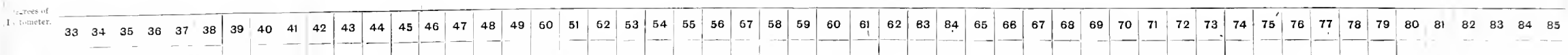

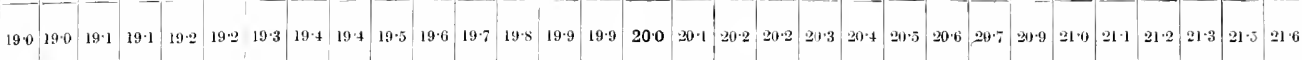

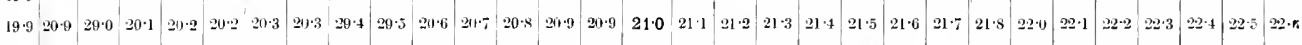

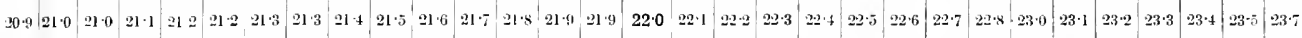

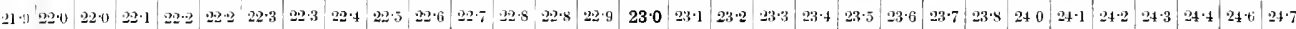

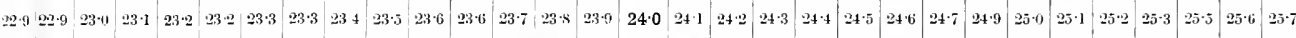

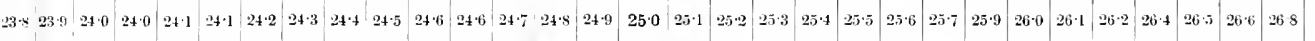

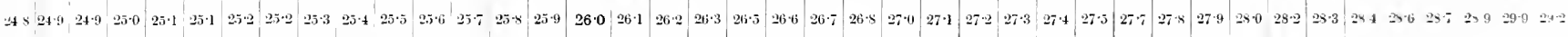

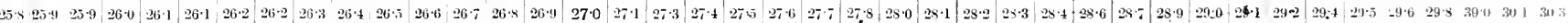
ت56

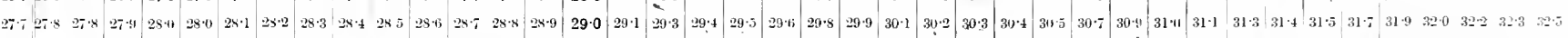

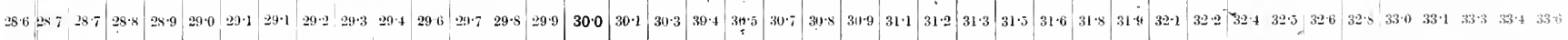

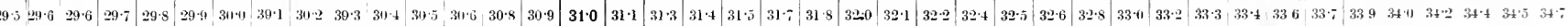
305

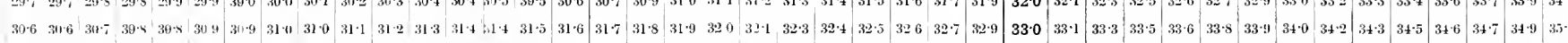

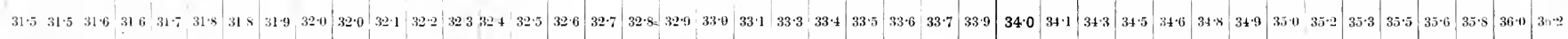

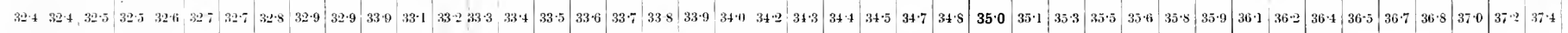

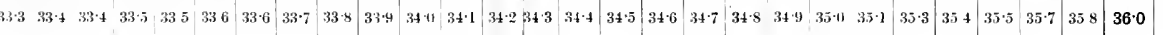

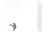




\begin{tabular}{|c|c|c|c|}
\hline 9 & 6.3 & 6.4 & 6.5 \\
\hline 8 & 7.56 & 7.68 & 7.80 \\
\hline
\end{tabular}

\begin{tabular}{|c|c|c|c|}
\hline 33 & $13 \cdot 21$ & $13 \cdot 33$ & $13 \cdot 45$ \\
\hline 46 & $13 \cdot 34$ & $13 \cdot 46$ & 1358 \\
\hline 58 & $13 \cdot 46$ & 13.58 & $13 \cdot 70$ \\
\hline 71 & 13.59 & $13 \cdot 71$ & $13 \cdot 83$ \\
\hline 83 & 1371 & $13 \cdot 83$ & 13.95 \\
\hline 96 & $13 \cdot 84$ & $13 \cdot 96$ & $14 \cdot 08$ \\
\hline 08 & $13 \cdot 96$ & $14 \cdot 08$ & $14 \% 0$ \\
\hline 21 & $14 \cdot 09$ & $14 \cdot 21$ & 1433 \\
\hline 33 & $14 \cdot 21$ & $14 \cdot 33$ & $14 \cdot 45$ \\
\hline 46 & $14 \cdot 34$ & $14 \cdot 46$ & $14 \cdot 58$ \\
\hline 58 & $14 \cdot 46$ & $14 \cdot 58$ & $14 \cdot 70$ \\
\hline 71 & 14.59 & 14.71 & 14.83 \\
\hline 83 & $14 \cdot 71$ & $14 \cdot 83$ & $14 \cdot 95$ \\
\hline 95 & $14 \cdot 83$ & 14.95 & 1507 \\
\hline 08 & $14 \cdot 96$ & $15 \cdot 08$ & $15 \cdot 20$ \\
\hline 20 & $15 \cdot 08$ & $15 \cdot 20$ & $15: 32$ \\
\hline 33 & $15 \cdot 21$ & $15 \cdot 33$ & 15.45 \\
\hline 4.7 & $15 \cdot 33$ & $15 \cdot 45$ & 15.57 \\
\hline 58 & $15 \cdot 46$ & $15 \cdot 58$ & $15 \cdot 70$ \\
\hline 70 & $15 \cdot 58$ & $15 \cdot 70$ & $15 \cdot 82$ \\
\hline 82 & $15 \cdot 70$ & $15 \cdot 82$ & $15 \cdot 94$ \\
\hline 94 & $15 \cdot 82$ & $15 \cdot 94$ & 1606 \\
\hline $0 \overline{7}$ & $15 \cdot 95$ & $16 \cdot 07$ & $16 \cdot 19$ \\
\hline 19 & 16.07 & $16 \cdot 19$ & $16 \cdot 31$ \\
\hline 31 & $16 \cdot 19$ & 16.31 & $16 \cdot 43$ \\
\hline 44 & $16 \cdot 32$ & $16 \cdot 44$ & $16 \cdot 56$ \\
\hline 56 & $16 \cdot 44$ & $16 \cdot 56$ & $16 \cdot 6 \mathrm{~S}$ \\
\hline 68 & $16 \cdot 56$ & $16 \cdot 68$ & $16 \cdot 80$ \\
\hline 80 & $16 \cdot 68$ & $16 \cdot 80$ & $16 \cdot 92$ \\
\hline 92 & $16 \cdot 80$ & 16.92 & $17 \cdot 04$ \\
\hline 0.1 & 16.93 & $17 \cdot 05$ & $17 \cdot 17$ \\
\hline 17 & 17.05 & $17 \cdot 17$ & $17 \cdot 29$ \\
\hline
\end{tabular}

DIFFERENCE TA B LE.

\begin{tabular}{|c|c|c|c|}
\hline G. & T. & F. & T. \\
\hline$\cdot l$ & 03 & $\cdot 01$ & $\cdot 01$ \\
\hline$\because 2$ & 05 & $\cdot 02$ & .02 \\
\hline 3 & $\cdot 08$ & $\cdot 03$ & $\cdot 04$ \\
\hline 4 & $\cdot 10$ & .04 & .05 \\
\hline$\ldots$ & $\ldots$ & $\cdot 05$ & $\cdot 06$ \\
\hline$\ldots$ & $\ldots$ & .06 & 07 \\
\hline$\ldots$ & $\ldots$ & .07 & $\cdot 08$ \\
\hline$\ldots$ & $\ldots$ & us & $\cdot 10$ \\
\hline$\cdots$ & $\ldots$ & $\cdot 09$ & $\cdot 11$ \\
\hline
\end{tabular}




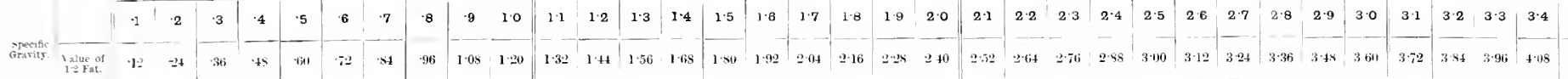

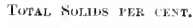

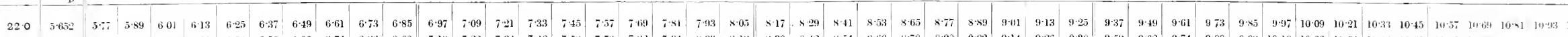

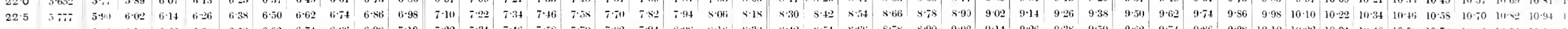

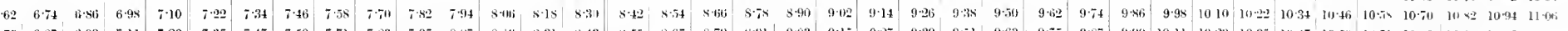

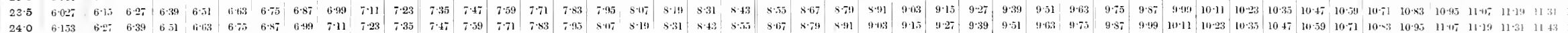

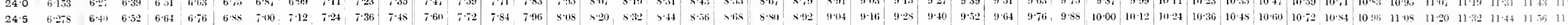

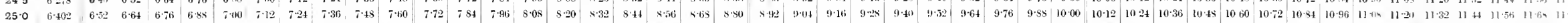

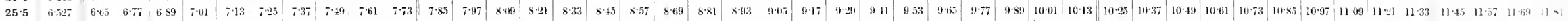

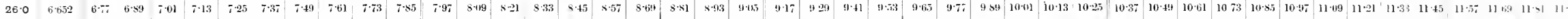

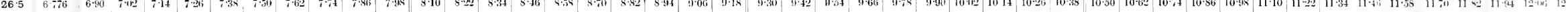

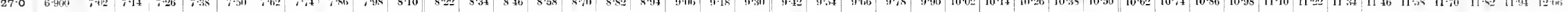

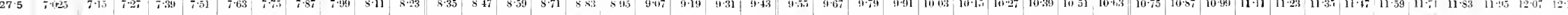

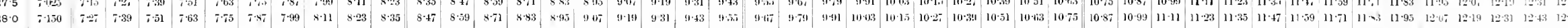

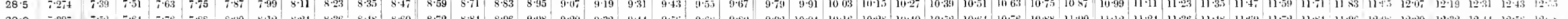

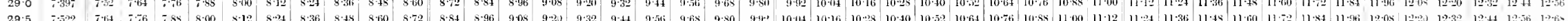

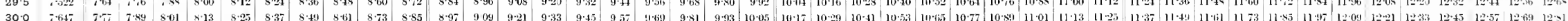

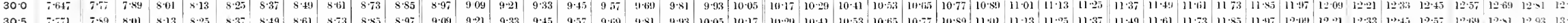

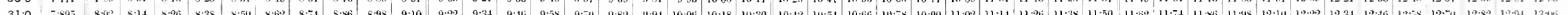

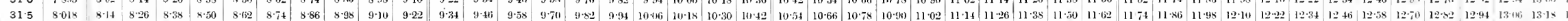

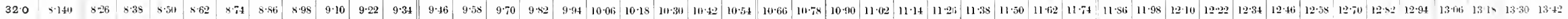
-

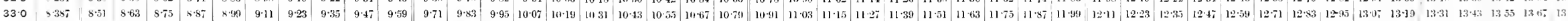

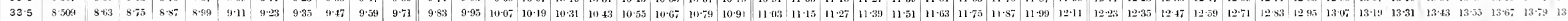

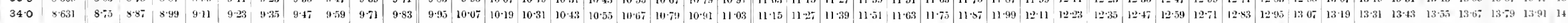

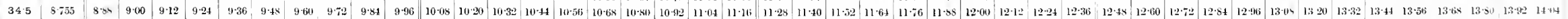

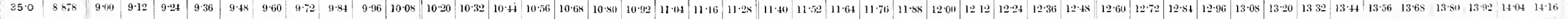

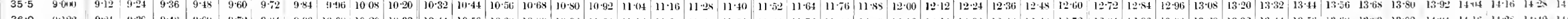

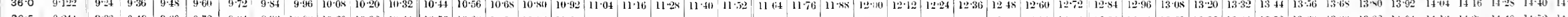

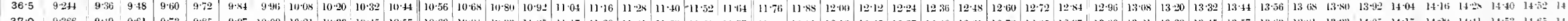

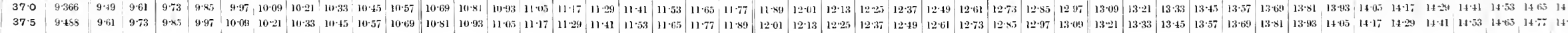




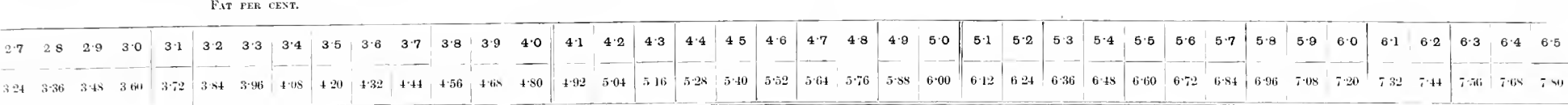
TUTAL SULATS FEk CEST.

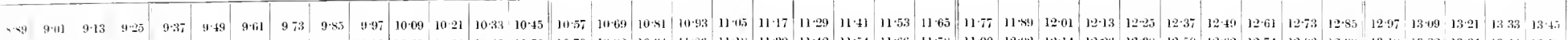

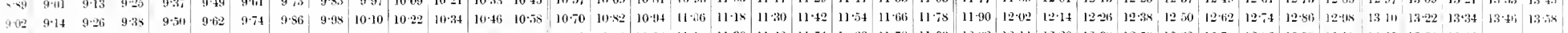

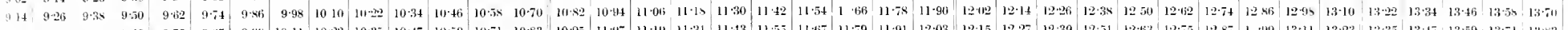

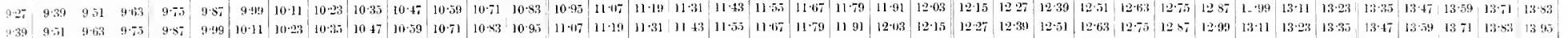

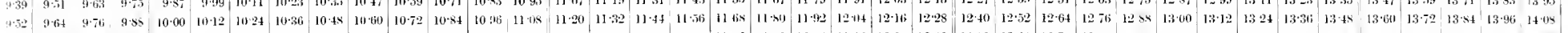

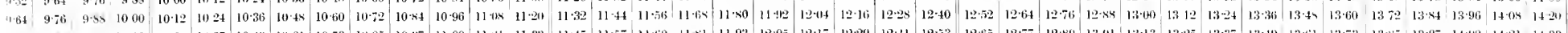

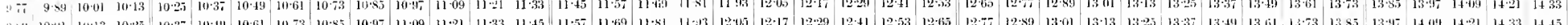

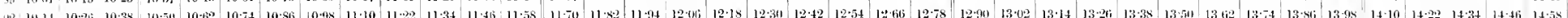

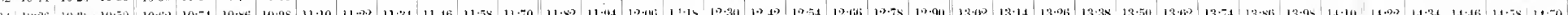

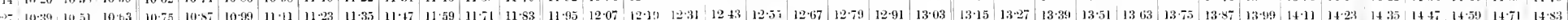

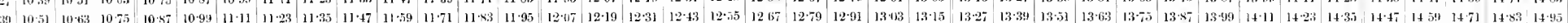

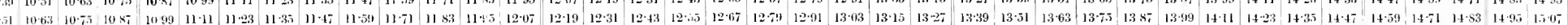

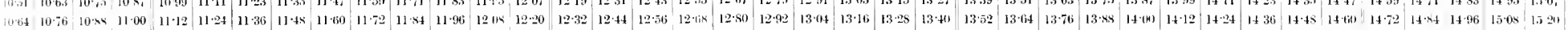

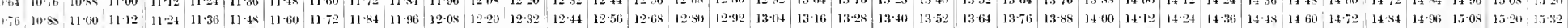

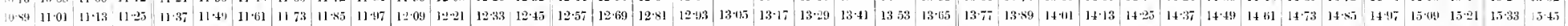

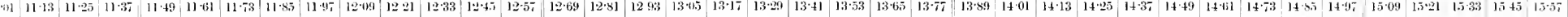

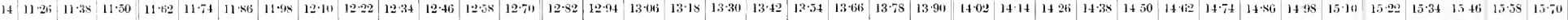

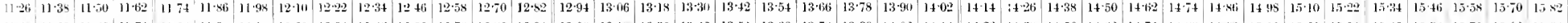

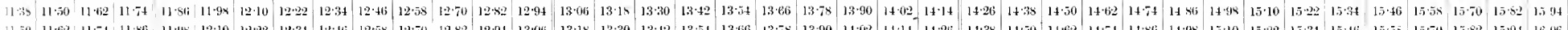

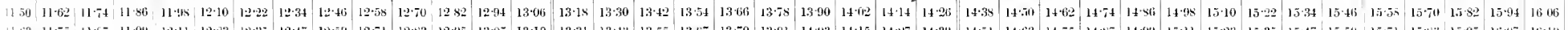

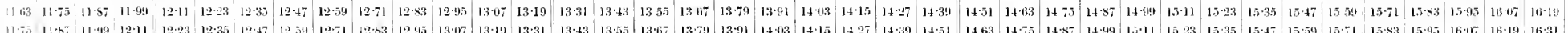

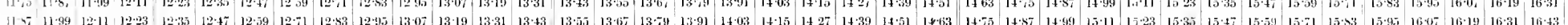

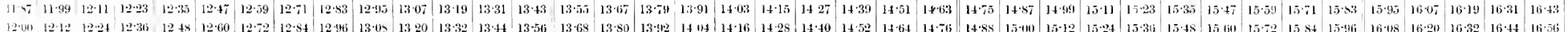

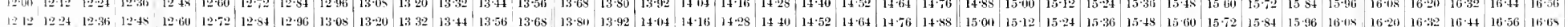
(12)

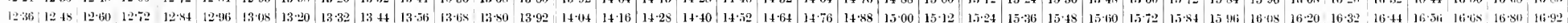

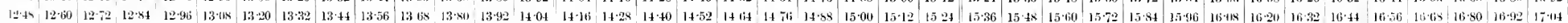

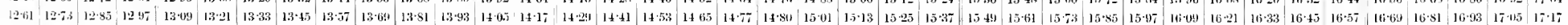

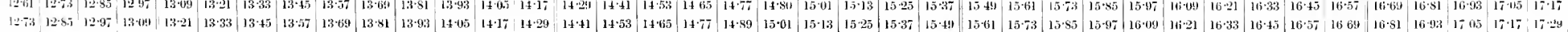

DIFFEREXCE TAELE.

\begin{tabular}{|c|c|c|c|}
\hline i: & I. & $\mathrm{F}$ & $\mathrm{r}$ \\
\hline 1 & 413 & 1" & -011 \\
\hline 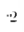 & S5 & $x_{2}$ & $t_{02}$ \\
\hline 3 & ox & 63 & $x_{14}$ \\
\hline \multirow[t]{6}{*}{4} & ויני & $\sqrt{14}$ & $4+5$ \\
\hline & & 0.5 & $+4+\infty$ \\
\hline & & $9 t^{\circ}$ & 07 \\
\hline & & דו" & $\pi$ \\
\hline & & $1+4$ & " ll \\
\hline & & 9 & I \\
\hline
\end{tabular}




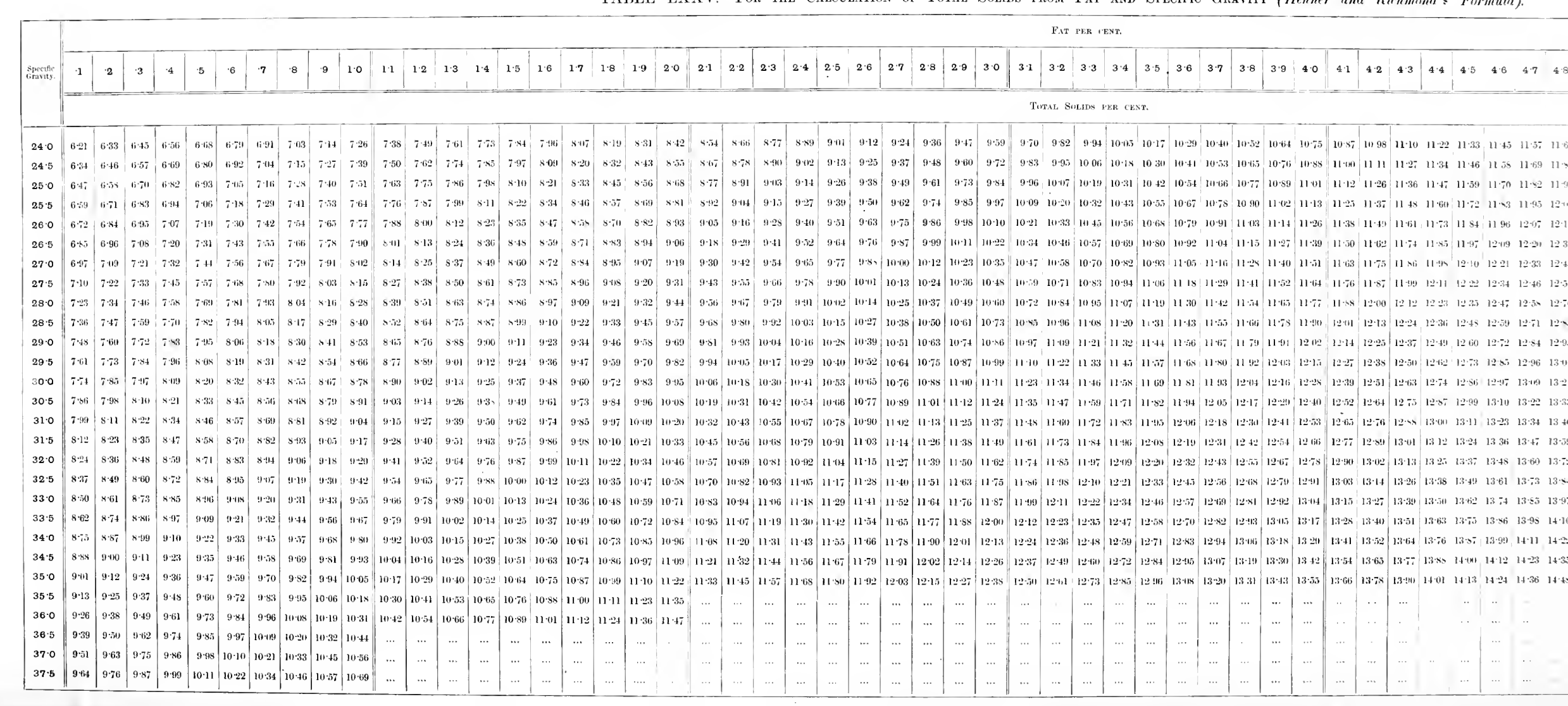




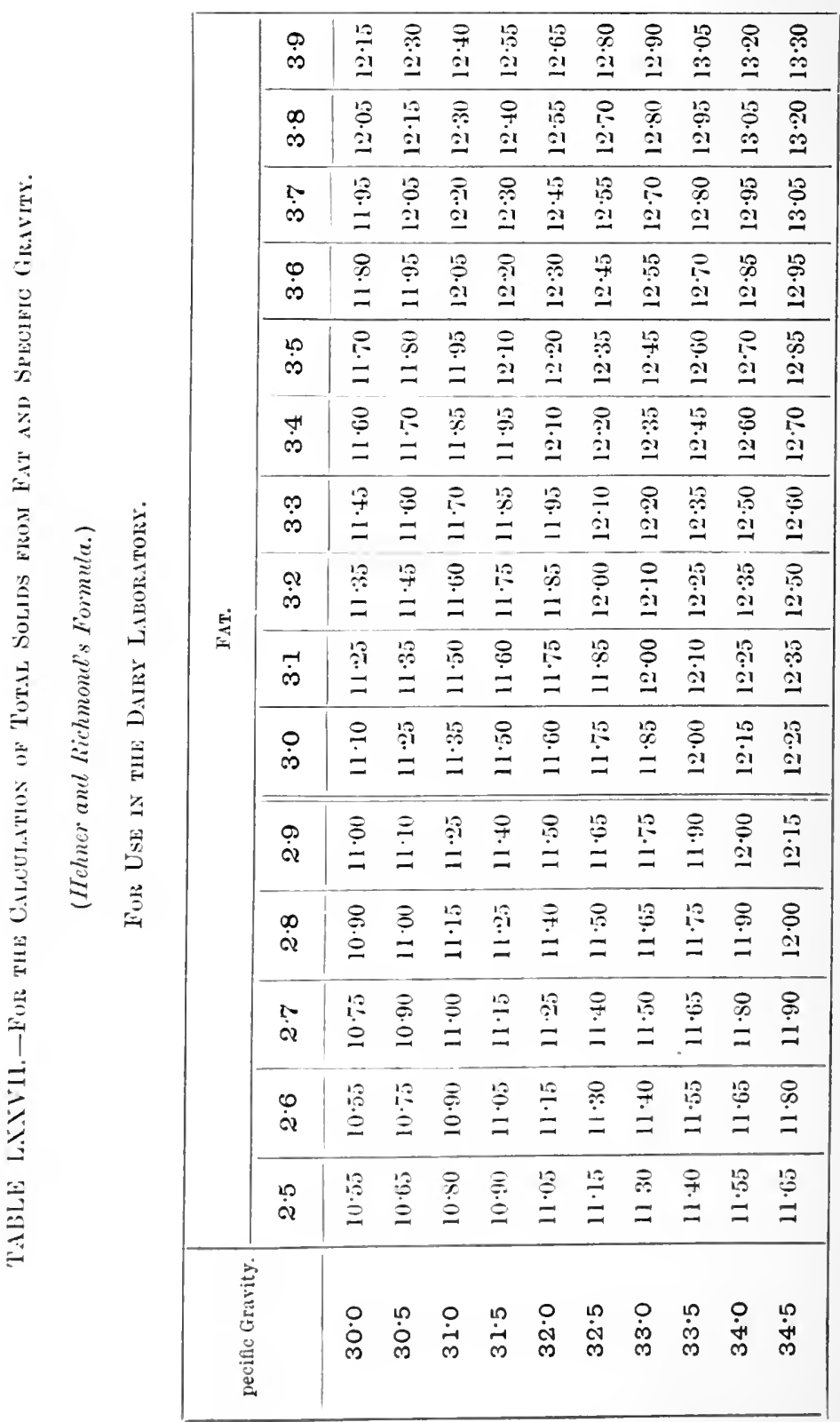




\begin{tabular}{|c|c|c|c|c|c|c|c|c|c|c|c|c|}
\hline \multirow{19}{*}{ 悹 } & مص & $\begin{array}{l}8 \\
\dot{+}\end{array}$ & $\stackrel{29}{\dot{\Xi}}$ & 品 & 吕 & $\begin{array}{l}\text { 号 } \\
\stackrel{+}{ \pm}\end{array}$ & 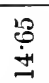 & $\begin{array}{l}\infty \\
\stackrel{\infty}{+}\end{array}$ & 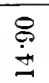 & $\begin{array}{l}9 \\
\text { ig }\end{array}$ & $\stackrel{10}{10}$ & \multirow{20}{*}{ 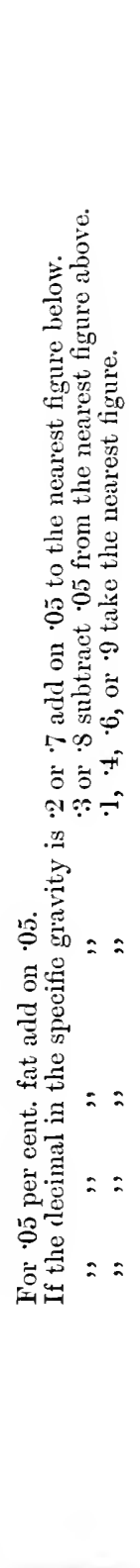 } \\
\hline & मे & $\begin{array}{l}8 \\
\stackrel{9}{9}\end{array}$ & 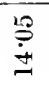 & 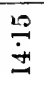 & $\begin{array}{l}\text { ↔ } \\
\stackrel{+}{+}\end{array}$ & 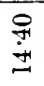 & 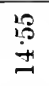 & $\begin{array}{l}\text { :8 } \\
\stackrel{8}{*}\end{array}$ & $\begin{array}{l}8 \\
\stackrel{\phi}{-} \\
\stackrel{-}{-}\end{array}$ & $\begin{array}{l}8 \\
\stackrel{9}{ \pm}\end{array}$ & 量 & \\
\hline & b & $\begin{array}{l}\phi \\
\stackrel{\infty}{2}\end{array}$ & $\begin{array}{l}\stackrel{\leftrightarrow}{9} \\
\stackrel{9}{2}\end{array}$ & 脶 & $\stackrel{10}{\stackrel{20}{4}}$ & 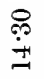 & 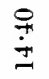 & 莒 & 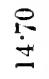 & $\begin{array}{l}8 \\
\stackrel{8}{ \pm}\end{array}$ & $\begin{array}{l}20 \\
\stackrel{2}{ \pm}\end{array}$ & \\
\hline & 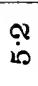 & $\begin{array}{l}\qquad 0 \\
\stackrel{10}{9} \\
\stackrel{9}{2}\end{array}$ & $\begin{array}{l}\not{\phi} \\
\dot{-1}\end{array}$ & 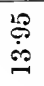 & 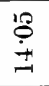 & 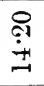 & $\begin{array}{l}\stackrel{\odot}{\oplus} \\
\stackrel{+}{ \pm}\end{array}$ & 号 & $\begin{array}{l}\text { 曷 } \\
\stackrel{ \pm}{ \pm}\end{array}$ & $\stackrel{P}{\stackrel{P}{Z}}$ & $\begin{array}{l}\infty \\
\dot{ \pm} \\
\dot{J}\end{array}$ & \\
\hline & is & 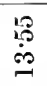 & $\begin{array}{l}\stackrel{P}{0} \\
\stackrel{9}{9}\end{array}$ & 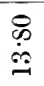 & $\begin{array}{l}\stackrel{2}{\stackrel{0}{0}} \\
\stackrel{9}{2}\end{array}$ & 㝵 & 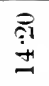 & $\begin{array}{l}\widetilde{\sigma} \\
\stackrel{\Xi}{*}\end{array}$ & $\begin{array}{l}\stackrel{9}{+} \\
\stackrel{+}{+}\end{array}$ & 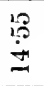 & $\underset{+}{\stackrel{P}{+}}$ & \\
\hline & ס̊ & $\stackrel{9}{9}$ & $\begin{array}{l}\stackrel{10}{9} \\
\stackrel{9}{9}\end{array}$ & $\begin{array}{l}\stackrel{P}{1} \\
\stackrel{9}{9}\end{array}$ & $\begin{array}{l}\stackrel{\leftrightarrow}{\leftrightarrow} \\
\stackrel{\leftrightarrow}{-}\end{array}$ & 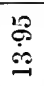 & 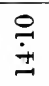 & 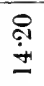 & $\begin{array}{l}\text { 号 } \\
\stackrel{9}{ \pm}\end{array}$ & $\begin{array}{l}\stackrel{9}{\rightarrow} \\
\stackrel{+}{+}\end{array}$ & $\stackrel{\stackrel{\rho}{ \pm}}{~}$ & \\
\hline & $\stackrel{\rho}{+}$ & $\begin{array}{l}\stackrel{8}{\oplus} \\
\stackrel{-}{9}\end{array}$ & $\begin{array}{l}19 \\
\stackrel{7}{9} \\
9\end{array}$ & 吕 & $\begin{array}{l}\stackrel{8}{9} \\
\stackrel{9}{9}\end{array}$ & 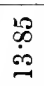 & 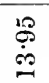 & $\stackrel{\vartheta}{ \pm}$ & 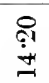 & $\begin{array}{l}\text { 営 } \\
\stackrel{ \pm}{ \pm}\end{array}$ & $\stackrel{20}{\stackrel{2}{ \pm}}$ & \\
\hline & $\stackrel{\infty}{\dot{f}}$ & $\begin{array}{l}\stackrel{\leftrightarrow \leftrightarrow \leftrightarrow}{\leftrightarrows} \\
\stackrel{\leftrightarrow}{\leftrightarrow}\end{array}$ & $\begin{array}{l}9 \\
90 \\
90\end{array}$ & 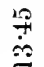 & $\stackrel{8}{\stackrel{0}{0}}$ & $\underset{\stackrel{\overbrace{}}{\leftrightarrow}}{R}$ & $\begin{array}{l}10 \\
\stackrel{0}{0} \\
-0\end{array}$ & $\begin{array}{l}\qquad 8 \\
\stackrel{0}{0}\end{array}$ & $\underset{\dot{+}}{\stackrel{\leftrightarrow}{+}}$ & $\begin{array}{l}\text { क्ष } \\
+1\end{array}$ & $\begin{array}{l}10 \\
\stackrel{20}{9}\end{array}$ & \\
\hline & $\underset{j}{j}$ & $\stackrel{\vec{\sigma}}{\therefore}$ & 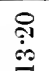 & $\begin{array}{ll}00 \\
0\end{array}$ & $\stackrel{19}{+9}$ & $\stackrel{\leftrightarrow}{\stackrel{\leftrightarrow}{\circ}}$ & $\begin{array}{l}\stackrel{10}{9} \\
\stackrel{9}{9}\end{array}$ & $\begin{array}{l}18 \\
30 \\
60\end{array}$ & $\stackrel{8}{\stackrel{\leftrightarrow}{+}}$ & $\stackrel{\odot}{\dot{\Xi}}$ & ?ר: & \\
\hline & $\stackrel{\varphi}{\dot{+}}$ & $\underset{: 0}{0}$ & $\stackrel{\circ}{\longrightarrow}$ & कैa & $\begin{array}{ll}10 \\
\text { ch }\end{array}$ & $\tilde{乛}$ & $\stackrel{8}{0}$ & 18 & $\begin{array}{l}10 \\
\infty\end{array}$ & $\stackrel{8}{i}$ & $\stackrel{\odot}{-}$ & \\
\hline & & & & & & & & $\because$ & $\because$ & $\pi$ & $\tau$ & \\
\hline & $\stackrel{\leftrightarrow}{+\infty}$ & 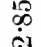 & $\stackrel{8}{\circ}$ & $\stackrel{\leftrightarrow}{\circ}$ & 禺 & ఝ & $\stackrel{\leftrightarrow}{0}$ & $\stackrel{\circ}{\circ}$ & 18 & 180 & $\stackrel{8}{8}$ & \\
\hline & 苟 & $\stackrel{12}{\stackrel{10}{c}}$ & $\begin{array}{l}10 \\
\infty \\
\dot{9}\end{array}$ & ְి & $\stackrel{\circ}{\stackrel{9}{\circ}}$ & & $\stackrel{9}{9}$ & 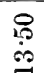 & \begin{tabular}{l}
30 \\
$\qquad$ \\
\hdashline
\end{tabular} & $\stackrel{8}{\stackrel{\circ}{\circ}}$ & 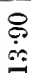 & \\
\hline & $\stackrel{0}{9}$ & 18 & $\stackrel{10}{10}$ & $\stackrel{\leftrightarrow}{.}$ & \& & $\stackrel{10}{-10}$ & 129 & $\stackrel{P}{P}$ & $\stackrel{P}{\sim}$ & 8 & 10 & \\
\hline & $f$ & 익 & 9 & 9 & $\stackrel{9}{-1}$ & $\stackrel{2}{-}$ & $\stackrel{2}{-1}$ & $\stackrel{2}{-1}$ & $\stackrel{2}{2}$ & 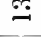 & $\stackrel{2}{9}$ & \\
\hline & $\underset{\dot{f}}{\stackrel{P}{H}}$ & 品 & $\begin{array}{l}38 \\
\stackrel{3}{9} \\
1\end{array}$ & 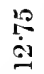 & 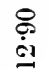 & 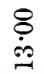 & $\stackrel{10}{\dot{\leftrightarrow}}$ & $\begin{array}{l}\stackrel{1}{\leftrightarrow:} \\
\stackrel{9}{9}\end{array}$ & $\begin{array}{l}\text { 우 } \\
\text { : }\end{array}$ & $\begin{array}{l}\stackrel{p}{0} \\
\stackrel{0}{\rightarrow}\end{array}$ & $\cong$ & \\
\hline & 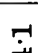 & 운 & $\stackrel{\circ}{\circ}$ & 8 & 19 & $\stackrel{8}{\circ}$ & ํㅗㅇ & $\stackrel{10}{=}$ & $\stackrel{\circ}{\circ}$ & $\stackrel{?}{-1}$ & 12 & \\
\hline & $H^{\prime}$ & 9 & I & $\cong$ & I & $\stackrel{9}{-1}$ & $\dddot{2}$ & $\stackrel{2}{9}$ & 92 & $\approx$ & $\approx$ & \\
\hline & 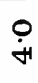 & $\begin{array}{l}\stackrel{0}{\circ} \\
\text { i }\end{array}$ & 움 & 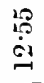 & $\begin{array}{l}\stackrel{10}{\grave{\leftrightarrow}} \\
\stackrel{\leftrightarrow}{\sim}\end{array}$ & 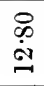 & $\begin{array}{l}\stackrel{\leftrightarrow}{\dot{\leftrightarrow}} \\
\stackrel{\sim}{\sim}\end{array}$ & $\begin{array}{l}\stackrel{\leftrightarrow}{9} \\
\stackrel{9}{9}\end{array}$ & $\stackrel{12}{\stackrel{\leftrightarrow}{\Im}}$ & $\begin{array}{l}\stackrel{9}{0} \\
\dot{\sim}\end{array}$ & - & \\
\hline \multicolumn{2}{|c|}{ 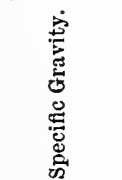 } & 品 & $\begin{array}{l}0 \\
\dot{\rho}\end{array}$ & $\underset{m}{\stackrel{P}{m}}$ & $\stackrel{\varphi}{\stackrel{\infty}{\infty}}$ & 酋 & ஸे & $\begin{array}{l}\dot{p} \\
\dot{m}\end{array}$ & $\begin{array}{l}\stackrel{L}{0} \\
\dot{m} \\
0\end{array}$ & $\underset{\stackrel{\leftrightarrow}{H}}{\stackrel{\rho}{H}}$ & $\infty$ & \\
\hline
\end{tabular}


Table LxyViII.-For tile Calculation of tile Total Solids of Skin Milk from tire Fat aNo Specific Gravity.

For Lse in the Dairy Lahoratory.

\begin{tabular}{|c|c|c|c|c|c|c|c|c|c|}
\hline \multirow{2}{*}{$\begin{array}{l}\text { Specific } \\
\text { Gravity. }\end{array}$} & \multicolumn{9}{|c|}{ FAT. } \\
\hline & $\cdot 1$ & 2 & $\cdot 3$ & 4 & 5 & 6 & 7 & 8 & 9 \\
\hline 33.5 & $s \cdot 65$ & 8.75 & $8 \cdot 85$ & $9 \cdot 00$ & $9 \cdot 10$ & $9 \cdot 25$ & $9 \cdot 35$ & $9 \cdot 45$ & $9 \cdot 60$ \\
\hline $34 \cdot 0$ & $8 \cdot 75$ & 8.85 & $9 \cdot 00$ & $9 \cdot 10$ & $9 \cdot 25$ & 9.35 & $9 \cdot 45$ & $9 \cdot 60$ & $9 \cdot \%$ \\
\hline 34.5 & 8.90 & $9 \cdot 00$ & $9 \cdot 10$ & $9 \cdot 25$ & $9 \cdot 35$ & 9.50 & $9 \cdot 60$ & $9 \cdot 70$ & $9 \cdot 85$ \\
\hline $35 \cdot 0$ & $9 \cdot 00$ & $9 \cdot 10$ & 9.25 & $9 \cdot 35$ & $9 \cdot 50$ & $9 \cdot 60$ & $9 \cdot 70$ & $9 \cdot 85$ & $9 \cdot 95$ \\
\hline 35.5 & $9 \cdot 10$ & 9.25 & $9 \cdot 35$ & $9 \cdot 50$ & $9 \cdot 60$ & $9 \cdot 70$ & $9 \cdot 85$ & $9 \cdot 95$ & $10 \cdot 10$ \\
\hline $36 \cdot 0$ & $9 \cdot 2.5$ & $9 \cdot 35$ & 9.50 & $9 \cdot 60$ & $9 \cdot 70$ & $9 \cdot 85$ & $9 \cdot 95$ & $10 \cdot 10$ & $10 \cdot 20$ \\
\hline 36.5 & $9 \cdot 35$ & $9 \cdot 50$ & $9 \cdot 60$ & $9 \div 0$ & $9 \cdot 85$ & $9 \cdot 95$ & $10 \cdot 10$ & $10 \cdot 20$ & $10 \cdot 30$ \\
\hline $37 \cdot 0$ & 9.50 & $9 \cdot 60$ & $9 \cdot 75$ & $9 \cdot 85$ & $9 \cdot 95$ & $10 \cdot 10$ & $10 \cdot 20$ & $10: 35$ & $10 \cdot 45$ \\
\hline $37 \cdot 5$ & $9 \cdot 60$ & 9.75 & $9 \cdot 85$ & $9 \cdot 95$ & $10 \cdot 10$ & $10 \cdot 20$ & $10 \cdot 35$ & $10 \cdot 45$ & 10.55 \\
\hline
\end{tabular}

TAlibe LAXX.-For tine Conversion of Thermonetric Scales.

For the Conversion of Degrees Fahrenheit into Degrees Centigrade.

Formula $\mathrm{C}=(\mathrm{F}-32) \times \frac{5}{9}$.

\begin{tabular}{|c|c|c|c|c|c|}
\hline $\begin{array}{l}\text { I)egrees } \\
\text { Fahrenheit. }\end{array}$ & $\begin{array}{c}\text { Degrees } \\
\text { Centigrade. }\end{array}$ & $\begin{array}{c}\text { Degrees } \\
\text { Fahrenheit. }\end{array}$ & $\begin{array}{c}\text { Degrees } \\
\text { Centigrade. }\end{array}$ & $\begin{array}{c}\text { Degrees } \\
\text { Fahrenheit. }\end{array}$ & $\begin{array}{c}\text { Degrees } \\
\text { Centigrade. }\end{array}$ \\
\hline 0 & $-17 \cdot 78$ & 51 & $10 \cdot 56$ & 78 & $25 \cdot 56$ \\
\hline 5 & $-15 \cdot 00$ & 52 & $11 \cdot 11$ & 79 & $26 \cdot 11$ \\
\hline 10 & $-1 \cdot 2 \cdot 2 \cdot 2$ & 53 & $11 \cdot 67$ & 80 & $26 \cdot 67$ \\
\hline 15 & -9.44 & 54 & 12.22 & 90 & $32 \cdot 22$ \\
\hline 20 & $-6 \cdot 67$ & $5 \tilde{5}$ & $12 \cdot 78$ & 100 & $37 \cdot 78$ \\
\hline 25 & $-3 \cdot 89$ & 56 & $13 \cdot 33$ & 110 & $43 \cdot 33$ \\
\hline 30 & $-1 \cdot 11$ & 57 & $13 \cdot 89$ & 120 & $48 \cdot 59$ \\
\hline 31 & -0.56 & 58 & $14 \cdot 44$ & 130 & $54 \cdot 44$ \\
\hline 32 & 0 & 59 & $15 \cdot 00$ & 140 & $60 \cdot 00$ \\
\hline 33 & 0.56 & 61! & $15 \cdot 56$ & 150 & $65 \cdot 55$ \\
\hline 34 & $1 \cdot 11$ & 61 & $16 \cdot 11$ & 160 & $71 \cdot 11$ \\
\hline 35 & $1 \cdot 6 i$ & 62 & $16 \cdot 67$ & 170 & $76 \cdot 67$ \\
\hline 36 & 222 & 63 & $17 \cdot 22$ & 150 & $52 \cdot 22$ \\
\hline 37 & $2 \cdot 78$ & 64 & $17 \cdot 78$ & 190 & $87 \cdot 78$ \\
\hline 38 & $3 \cdot 33$ & 6.5 & $18: 33$ & 200 & $93 \cdot 33$ \\
\hline 39 & $3 \cdot \$ 9$ & 66 & $18 \cdot 89$ & 210 & $98 \cdot 89$ \\
\hline 41) & $4 \cdot 44$ & 67 & $19 \cdot 44$ & 212 & $100 \cdot 00$ \\
\hline 41 & $5 \cdot 00$ & 68 & 2()$\cdot 00$ & 220 & $104 \cdot 44$ \\
\hline 42 & 5.56 & 69 & 20.56 & 230 & 110.00 \\
\hline 43 & $6 \cdot 11$ & 70 & $21 \cdot 11$ & 240 & $115 \cdot 55$ \\
\hline 4.4 & $6 \cdot 67$ & 71 & $21 \cdot 67$ & 250 & $121 \cdot 11$ \\
\hline 45 & $7 \cdot 22$ & 72 & $22 \cdot 22$ & 260 & $126 \cdot 67$ \\
\hline 46 & $7 \cdot 78$ & 73 & $2 \cdot 2 \cdot 78$ & 270 & $132 \cdot 22$ \\
\hline 47 & 8.33 & 74 & $23 \cdot 33$ & 280 & $137 \cdot 78$ \\
\hline 45 & $8 \cdot 89$ & 75 & $23 \cdot 89$ & 290 & $143 \cdot 33$ \\
\hline 49 & $9 \cdot 44$ & $i 6$ & $2.4 \cdot 44$ & 300 & 143.89 \\
\hline 50 & $10 \cdot 00$ & 77 & $25 \cdot 00$ & & \\
\hline
\end{tabular}


Percentage of Fat at $17.5^{\circ} \mathrm{C}$. (Soxhlet's Areometric Method.)

\begin{tabular}{|c|c|c|c|c|c|c|c|c|c|c|c|}
\hline $\begin{array}{l}\text { Spec. } \\
\text { Grav. }\end{array}$ & $\begin{array}{l}\text { Fat. } \\
\text { Per et. }\end{array}$ & $\begin{array}{l}\text { Spec. } \\
\text { Grav. }\end{array}$ & $\begin{array}{l}\text { Fat. } \\
\text { Per ct. }\end{array}$ & $\begin{array}{l}\text { Spec. } \\
\text { Grav. }\end{array}$ & $\begin{array}{c}\text { Fat. } \\
\text { Per ct. }\end{array}$ & $\begin{array}{l}\text { Spec. } \\
\text { Grav. }\end{array}$ & $\begin{array}{l}\text { Fat. } \\
\text { Per ct. }\end{array}$ & $\begin{array}{l}\text { Spec. } \\
\text { Grav. }\end{array}$ & $\begin{array}{l}\text { Fat. } \\
\text { Perct. }\end{array}$ & $\begin{array}{l}\text { Spec. } \\
\text { Grav. }\end{array}$ & $\begin{array}{l}\text { Fat. } \\
\text { Per ct. }\end{array}$ \\
\hline $48 \cdot 0$ & $2 \cdot 64$ & $51 \cdot 0$ & $3 \cdot 00$ & $54 \cdot 0$ & $3 \cdot 37$ & $57 \cdot 0$ & $3 \cdot 75$ & $60 \cdot 0$ & $4 \cdot 1 \mathrm{~S}$ & $63 \cdot 0$ & $4 \cdot 63$ \\
\hline $48 \cdot 1$ & $2 \cdot 66$ & $51 \cdot 1$ & $3 \cdot 01$ & $54 \cdot 1$ & $3 \cdot 3 \mathrm{~s}$ & $57 \cdot 1$ & $3 \cdot 76$ & $60 \cdot 1$ & $4 \cdot 19$ & $63 \cdot 1$ & $4 \cdot 64$ \\
\hline $48 \cdot 2$ & $2 \cdot 67$ & $51 \cdot 2$ & $3 \cdot 03$ & $54 \cdot 2$ & $3: 39$ & $57 \cdot 2$ & 3.78 & $60 \%$ & $4 \cdot 20$ & $63 \cdot 2$ & $4 \cdot 66$ \\
\hline $48 \cdot 3$ & $2 \cdot 68$ & $51 \cdot 3$ & $3 \cdot 04$ & $54 \cdot 3$ & $3 \cdot 40$ & $57 \cdot 3$ & $3 \cdot 80$ & $60 \cdot 3$ & $4 \cdot 21$ & $63 \cdot 3$ & $4 \cdot 67$ \\
\hline $48 \cdot 4$ & $2 \cdot 70$ & $51 \cdot 4$ & 3.05 & $54 \cdot 4$ & $3 \cdot 41$ & $57 \cdot 4$ & $3 \cdot 81$ & $69 \cdot 4$ & $4 \cdot 23$ & $63 \cdot 4$ & $4 \cdot 69$ \\
\hline $48 \cdot 5$ & $2 \cdot 71$ & $51 \cdot 5$ & $3 \cdot 06$ & $54 \cdot 5$ & $3 \cdot 43$ & $57 \cdot 5$ & $3 \cdot 82$ & $60 \cdot 5$ & $4 \cdot 24$ & $63 \cdot 5$ & $4 \cdot 70$ \\
\hline $48 \cdot 6$ & $2 \cdot 72$ & $51 \cdot 6$ & $3 \cdot 08$ & $54 \cdot 6$ & $3 \cdot 45$ & $57 \cdot 6$ & $3 \cdot 84$ & $60 \cdot 6$ & $4 \cdot 26$ & $63 \cdot 6$ & $4 \cdot 71$ \\
\hline $48 \cdot 7$ & $2 \cdot 73$ & $51 \cdot 7$ & $3 \cdot 09$ & $54 \cdot 7$ & $3 \cdot 46$ & $57 \cdot 7$ & $3 \cdot \$ 5$ & $60 \cdot 7$ & 4.27 & $63 \cdot 7$ & $4 \cdot 73$ \\
\hline $48 \cdot 8$ & $2 \cdot 74$ & $51 \cdot S$ & $3 \cdot 10$ & $54 \cdot 8$ & $3 \cdot 47$ & $57 \cdot 8$ & $3 \cdot 87$ & $60 \cdot 8$ & $4 \cdot 29$ & $63 \cdot 8$ & $4 \cdot 75$ \\
\hline $48 \cdot 9$ & $2 \cdot 75$ & $51 \cdot 9$ & $3 \cdot 11$ & $54 \cdot 9$ & $3 \cdot 48$ & $57 \cdot 9$ & $3 \cdot 8 s$ & $60 \cdot 9$ & $4 \cdot 30$ & $63 \cdot 9$ & $4 \cdot 77$ \\
\hline $49 \cdot 0$ & $2 \cdot 76$ & $52 \cdot 0$ & $3 \cdot 12$ & $55 \cdot 0$ & $3 \cdot 49$ & $58 \cdot 0$ & $3 \cdot 90$ & $61 \cdot 0$ & $4 \cdot 32$ & $64 \cdot 0$ & $4 \cdot 79$ \\
\hline $49 \cdot 1$ & $2 \cdot 77$ & $52 \cdot 1$ & $3 \cdot 14$ & $55 \cdot 1$ & $3 \cdot 51$ & $58 \cdot 1$ & $3 \cdot 91$ & $61 \cdot 1$ & $4 \cdot 33$ & $64 \cdot 1$ & $4 \cdot 80$ \\
\hline $49 \cdot 2$ & $2 \cdot 78$ & $52 \cdot 2$ & $3 \cdot 15$ & $55 \cdot 2$ & $3 \cdot 52$ & $58 \cdot 2$ & $3 \cdot 92$ & $61 \cdot 2$ & $4 \cdot 35$ & $64 \cdot 2$ & $4 \cdot 82$ \\
\hline $49 \cdot 3$ & $2 \cdot 79$ & $52 \cdot 3$ & $3 \cdot 16$ & $55 \cdot 3$ & $3 \cdot 53$ & $58 \cdot 3$ & 3.93 & $61 \cdot 3$ & $4 \cdot 36$ & $64 \cdot 3$ & $4 \cdot 84$ \\
\hline $49 \cdot 4$ & $2 \cdot 80$ & $52 \cdot 4$ & $3 \cdot 17$ & $55 \cdot 4$ & $3 \cdot 55$ & $58 \cdot 4$ & $3 \cdot 95$ & 614 & $4 \cdot 37$ & $64 \cdot 4$ & $4 \cdot 85$ \\
\hline $49 \cdot 5$ & $2 \cdot 81$ & $52 \cdot 5$ & $3 \cdot 18$ & $55 \cdot 5$ & $3 \cdot 56$ & $58 \cdot 5$ & $3 \cdot 96$ & $61 \cdot 5$ & $4 \cdot 39$ & $64 \cdot 5$ & 4.87 \\
\hline $49 \cdot 6$ & $2 \cdot \$ 3$ & $52 \cdot 6$ & $3 \cdot 20$ & $55 \cdot 6$ & $3 \cdot 57$ & $58 \cdot 6$ & $3 \cdot 98$ & $61 \cdot 6$ & $4 \cdot 40$ & $64 \cdot 6$ & $4 \cdot 58$ \\
\hline $49 \cdot 7$ & $2 \cdot 84$ & $52 \cdot 7$ & $3 \cdot 21$ & $55 \cdot 7$ & $3 \cdot 59$ & $58 \cdot 7$ & $3 \cdot 99$ & $61 \cdot 7$ & $4 \cdot 42$ & $64 \cdot 7$ & 4.90 \\
\hline $49 \cdot 8$ & $2 \cdot 86$ & $52 \cdot S$ & $3 \cdot 22$ & $55 \cdot 8$ & $3 \cdot 60$ & $5 \mathrm{~s} \cdot \mathrm{S}$ & 4.01 & $61 \cdot 8$ & $4 \cdot 44$ & $64 \cdot 8$ & $4 \cdot 92$ \\
\hline $49 \cdot 9$ & $2 \cdot 87$ & $52 \cdot 9$ & $3 \cdot 23$ & $55 \cdot 9$ & $3 \cdot 61$ & $58 \cdot 9$ & $4 \cdot 02$ & $61 \cdot 9$ & $4 \cdot 46$ & $64 \cdot 9$ & $4 \cdot 93$ \\
\hline 50.0 & $2 \cdot 88$ & $53 \cdot 0$ & $3 \cdot 25$ & $56 \cdot 0$ & $3 \cdot 63$ & $59 \cdot 0$ & $4 \cdot 03$ & $62 \cdot 0$ & 4.47 & $65 \cdot 0$ & $4 \cdot 95$ \\
\hline $50 \cdot 1$ & $2 \cdot 90$ & $53 \cdot 1$ & $3 \cdot 26$ & $56 \cdot 1$ & $3 \cdot 64$ & $59 \cdot 1$ & $4 \cdot 04$ & $62 \cdot 1$ & $4 \cdot 48$ & $65 \cdot 1$ & $4 \cdot 97$ \\
\hline $50 \cdot 2$ & $2 \cdot 91$ & $53 \cdot 2$ & $3 \cdot 27$ & $56 \cdot 2$ & $3 \cdot 65$ & $59 \cdot 2$ & $4 \cdot 06$ & $62 \cdot 2$ & $4 \cdot 50$ & $65 \cdot 2$ & 4.98 \\
\hline $50 \cdot 3$ & $2 \cdot 92$ & $53 \cdot 3$ & $3 \cdot 28$ & $56 \cdot 3$ & $3 \cdot 67$ & $59 \cdot 3$ & 4.07 & $62 \cdot 3$ & $4 \cdot 52$ & $65 \cdot 3$ & $5 \cdot 00$ \\
\hline 50.4 & $2 \cdot 93$ & $53 \cdot 4$ & $3 \cdot 29$ & $56 \cdot 4$ & $3 \cdot 68$ & $59 \cdot 4$ & 4.09 & $62 \cdot 4$ & $4 \cdot j 3$ & $65 \cdot 4$ & $5 \cdot 02$ \\
\hline $50 \cdot 5$ & $2 \cdot 94$ & $53 \cdot 5$ & $3 \cdot 30$ & $56 \cdot 5$ & $3 \cdot 69$ & $59 \cdot 5$ & $4 \cdot 11$ & $62 \cdot 5$ & $4 \cdot 55$ & $65 \cdot 5$ & $5 \cdot 04$ \\
\hline $50 \cdot 6$ & $2 \cdot 96$ & $53 \cdot 6$ & $3 \cdot 31$ & $56 \cdot 6$ & $3 \cdot 71$ & $59 \cdot 6$ & $4 \cdot 12$ & $62 \cdot 6$ & $4 \cdot 56$ & $65 \cdot 6$ & $5 \cdot 05$ \\
\hline $50 \cdot 7$ & $2 \cdot 97$ & $53 \cdot 7$ & $3 \cdot 33$ & 56.7 & $3 \cdot 72$ & $59 \cdot 7$ & $4 \cdot 14$ & $62 \cdot 7$ & $4 \cdot 5 \mathrm{~S}$ & $65 \cdot 7$ & $5 \cdot 07$ \\
\hline $50 \cdot 8$ & $2 \cdot 98$ & $53 \cdot 8$ & $3 \cdot 34$ & $56 \cdot 8$ & $3 \cdot 73$ & $59 \cdot 8$ & $4 \cdot 15$ & $62 \cdot 8$ & $4 \cdot 59$ & $65 \cdot 8$ & $5 \cdot 09$ \\
\hline $50 \cdot 9$ & $2 \cdot 99$ & $53 \cdot 9$ & $3 \cdot 35$ & $56 \cdot 9$ & $3 \cdot 74$ & $59 \cdot 9$ & $4 \cdot 16$ & $62 \cdot 9$ & $4 \cdot 61$ & $65 \cdot 9$ & $5 \cdot 11$ \\
\hline & & & & & & & & & & 66.0 & $5 \cdot 12$ \\
\hline
\end{tabular}




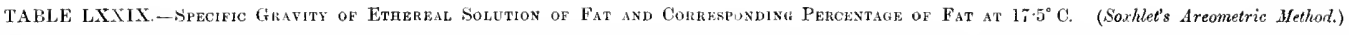

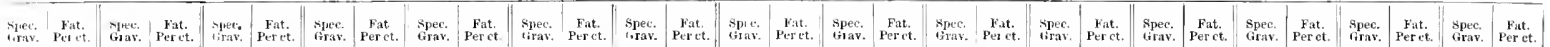

\begin{tabular}{|c|c|c|c|c|c|c|c|c|c|c|c|c|c|c|c|c|c|c|c|c|c|c|c|c|c|c|c|c|c|}
\hline & & & & & & & & & & & & & & & & & & & & & & & & & & & & & \\
\hline & & $24 \cdot 0$ & $11.2 \mathrm{~s}$ & 270 & 0.55 & 30.0 & $0 \circ 3$ & 330 & 1.1"1 & 360 & 137 & 390 & 167 & 420 & 197 & 450 & 230 & 48.0 & $2 \cdot 64$ & 510 & 300 & $54 \cdot 0$ & $3 \cdot 3 \bar{\jmath}$ & 57.0 & 3.55 & 60.0 & $4 \cdot 18$ & 630 & 463 \\
\hline $2 \mathrm{I} \cdot \mathbf{1}$ & $\theta 00$ & $24 \cdot 1$ & 1) 29 & ] & 0.56 & $30 \cdot]$ & 081 & $33 \cdot 1$ & $1 \cdot 11$ & $36 \cdot 1$ & $13 \mathrm{~K}$ & $39 \cdot 1$ & 1.6s & $42 \cdot 1$ & $1: 98$ & $45 \cdot 1$ & $2+31$ & $4 \times \cdot 1$ & $2 \cdot 66$ & $51 \cdot 1$ & 3.01 & $5 \cdot \cdot 1$ & $3 \cdot 38$ & $57 \cdot 1$ & 376 & $1 ; i \cdot 1$ & $4 \cdot 19$ & $63 \cdot 1$ & 4.64 \\
\hline $21 \cdot 2$ & $0 \cdot 01$ & 242 & $(1 \cdot 31)$ & 272 & 0.57 & $30 \cdot 2$ & 0.85 & 332 & $1 \cdot 12$ & 362 & 139 & 392 & 169 & 422 & $1.4 !)$ & $45 \cdot 2$ & $2 \div 2$ & $48 \cdot 2$ & $20 i$ & $51 \%$ & $3 \cdot 03$ & $54 \div 2$ & $3 \cdot 39$ & 572 & $3.7 \mathrm{~s}$ & $60 \cdot 2$ & $4 \cdot 20$ & $63 \cdot 2$ & $4 \cdot 66$ \\
\hline $21 \cdot 3$ & 11.02 & $24 \cdot 3$ & If:30 & $27 \cdot 3$ & 0.58 & $30 \cdot 3$ & $0 \times 6$ & $33 \cdot 3$ & $1 \cdot 13$ & $36 \cdot 3$ & $1+41$ & $\therefore 93$ & 170 & $4: 3$ & $2-04$ & $45 \cdot 3$ & $2+83$ & $48: 3$ & 268 & $51: 3$ & $3 \cdot 0.4$ & $54: 3$ & $3 \cdot 40$ & 573 & 3.80 & $60 \cdot 3$ & $4 \cdot 21$ & $63 \cdot 3$ & $4 \cdot 6 \bar{t}$ \\
\hline 214 & $v \cdot 03$ & $24 \cdot 4$ & 4.31 & $27 \cdot 4$ & 0.59 & $30 \cdot 4$ & $0 \cdot 87$ & $33 \cdot 4$ & $1 \cdot 14$ & 364 & $1 \cdot 41$ & $39 \cdot 4$ & 1.71 & 42.4 & $2 \cdot 01$ & 45.4 & 234 & 48.4 & 0 & $51 \cdot 4$ & $3 \cdot 05$ & 544 & $3 \cdot 41$ & 574 & $3 \cdot 81$ & 69.4 & $4 \div 13$ & 63.4 & $4 \cdot 69$ \\
\hline 215 & $0 \cdot 114$ & 24.5 & $0 \cdot 32$ & $2-5$ & $0 \cdot 60$ & 305 & 0.88 & 335 & $1 \cdot 15$ & $36 \cdot 5$ & 142 & 5'59 & 172 & $42 \cdot 5$ & $2 * 2$ & $45 \cdot 5$ & 233 & $48 \cdot 5$ & $2 \cdot 71$ & $51 \cdot 5$ & $3 \cdot 06$ & $54 \cdot 5$ & $3 \cdot 43$ & $57 \cdot 5$ & $3 \cdot 82$ & 60.5 & 4.24 & 63.5 & 4.70 \\
\hline 216 & $0+15$ & 246 & $0 \cdot 33$ & 276 & 0.60 & 306 & 0.88 & $33 \cdot 6$ & $1 \cdot 15$ & $36 \cdot 6$ & 143 & $3:-6$ & $1 \cdot 73$ & $42 \cdot 6$ & $2 \cdot 03$ & 456 & 236 & 486 & $2 \cdot 72$ & $51 \cdot 6$ & 3.08 & $54 \cdot 6$ & $3 \cdot 45$ & 576 & 3.84 & 606 & $4=26$ & $63 \cdot 6$ & $4 \cdot 71$ \\
\hline $21 \%$ & 0116 & $24 \cdot 7$ & $11 \cdot 34$ & 37.7 & 0.61 & 30.7 & $0 \times 9$ & $33 \cdot \bar{T}$ & $1 \cdot 16$ & 367 & 1.44 & $39 \cdot 7$ & $1 \cdot 74$ & $42 \cdot 7$ & 204 & $45 \cdot 7$ & $2 \cdot 3 \bar{\imath}$ & $48 \%$ & $2 \cdot 73$ & $51 \cdot 7$ & $3 \cdot 09$ & 547 & $3 \cdot 46$ & $5 \pi \cdot 7$ & $3 \cdot 65$ & 607 & $4=27$ & 63.7 & 4.73 \\
\hline $21 \times$ & 0.47 & $24 \cdot 8$ & 0.35 & $2 \pi x$ & 10.62 & 30.8 & $0 \cdot 90$ & $33 \cdot 8$ & $1 \cdot 17$ & $36 \times 8$ & 1.45 & $3+18$ & $1 \% 5$ & $42 \cdot 8$ & $2 \cdot 95$ & 45.8 & $2: 38$ & $48 \cdot 8$ & $2 \cdot 74$ & $51 \cdot 8$ & טינט 3 & $54: 8$ & $3 \cdot 47$ & $57 \times 8$ & 3.57 & 608 & 4.29 & 63.8 & 475 \\
\hline 21 & $0 \cdot 6$ & 249 & $0 \cdot 36$ & 29 & $11 \cdot 63$ & $30 \cdot 8$ & $0 \cdot 91$ & $33 \cdot 9$ & $1 \cdot 18$ & 3109 & $1+4 i$ & 3549 & $1 \cdot 76$ & $42 \cdot 9$ & $2 \cdot 060$ & $45 \cdot 9$ & $2 \div 39$ & $48 \cdot 9$ & $2 \cdot 75$ & $51 \cdot 9$ & $3 \cdot 11$ & $54 \cdot 9$ & $3 \cdot 48$ & 57.9 & 3.88 & 609 & $4: 30$ & 63.9 & $4 \cdot 7 \pi$ \\
\hline 220 & $0 \cdot 10 ! 1$ & 250 & 0.37 & 280 & $\theta \cdot 64$ & $31 \cdot 0$ & 0.92 & 340 & $1 \cdot 19$ & 370 & 147 & 400 & ה & 430 & $2 \cdot 07$ & 460 & $\because 40$ & $49 \cdot 0$ & $2 \cdot 76$ & $52 \cdot 0$ & $3 \cdot 12$ & 550 & $3 \cdot 49$ & 580 & $3 \cdot 90$ & 610 & 432 & 640 & $4 \cdot 79$ \\
\hline $22 \cdot 1$ & 0.111 & 1יזים & 0.38 & $2+1$ & 0.65 & $31 \cdot 1$ & 0.93 & $34: 1$ & $1 " 20$ & $37 \cdot 1$ & $1 \cdot 45$ & $411 \cdot 1$ & $17 \mathrm{~s}$ & $43 \cdot 1$ & $2 \cdot 18$ & $46 \cdot 1$ & $2 \cdot 42$ & $49 \cdot 1$ & $2 \pi$ & $52 \cdot 1$ & 3.14 & $55 \cdot 1$ & $3 \cdot 51$ & $58+1$ & $3 \cdot 91$ & $61 \cdot 1$ & $4 * 33$ & $64 \cdot 1$ & 4.80 \\
\hline $2 \cdot 2 \cdot 2$ & 0.11 & 252 & 0.39 & $28+2$ & $0 \cdot 66$ & $31 \% 2$ & 0.9 .9 & 34.2 & 1.21 & 372 & $1 \cdot 49$ & $40-2$ & $1 \cdot \% 9$ & $43 \cdot 2$ & $2 \cdot 60$ & $46 \cdot 2$ & $2 \cdot 43$ & $49 \cdot 2$ & 278 & $52 \cdot 2$ & $3 \cdot 15$ & 552 & $3 \cdot 52$ & 582 & $3 \cdot 92$ & $61 \cdot 2$ & $4 \cdot 35$ & $64 \cdot 2$ & $4 \times 2$ \\
\hline $22 \cdot 3$ & 0.12 & 253 & $0 \cdot 40$ & 263 & $0 \cdot 67$ & $31 \cdot 3$ & $0 \cdot 95$ & $34 \cdot 3$ & 1.22 & $37 \cdot 3$ & $1 \cdot 50$ & 403 & 1.80 & $43 \cdot 3$ & $2 \cdot 10$ & $+10 \cdot 3$ & $2 \cdot 44$ & $49 \cdot 3$ & 279 & $5: 3$ & $3 \cdot 16$ & 553 & $3 \cdot 53$ & 58.3 & $3 \cdot 93$ & $61: 3$ & $4: 36$ & $64 \cdot 3$ & 484 \\
\hline 224 & 01.3 & 254 & 0.40 & $2 \times 4$ & $11-68$ & $31 \cdot 4$ & 0.95 & $34 \cdot 4$ & $1 \cdot 2.3$ & $37 \cdot 4$ & $1: 51$ & $40 \cdot 4$ & $1 \times 1$ & $43 \cdot 4$ & $2 \cdot 11$ & $46 \cdot 4$ & $2 \cdot 45$ & $49 \cdot 4$ & 280 & $52 \cdot 4$ & $3 \cdot 17$ & 55.4 & $3 \cdot 5 \tilde{5}$ & $58 \cdot 4$ & $3: 05$ & $61 \cdot 4$ & 4.37 & 64.4 & 4.85 \\
\hline 2025 & $11 \cdot 14$ & 25.5 & $11-41$ & $2 \times 5$ & $0 \cdot 69$ & $31 \cdot 5$ & 0.96 & $34 \cdot 5$ & 1.24 & 375 & 1.52 & $40 \cdot 5$ & $1 \cdot 52$ & 43.5 & $2 \cdot 12$ & 46.5 & $\because 46$ & $49 \cdot 5$ & $2 \cdot 61$ & 52.5 & $3 \cdot 18$ & 555 & $3 \cdot 56$ & 585 & 3.96 & $61 \cdot 5$ & 439 & 64.5 & 4.87 \\
\hline $22 \cdot 6$ & $11 \cdot 15$ & $25+6$ & 0.42 & 286 & 0.70 & $31 \cdot 6$ & $(1.97$ & $34 \cdot 6$ & 1.24 & 376 & 1.53 & $40 \cdot 6$ & 1.83 & 436 & $2 \cdot 13$ & 466 & 247 & $49 \cdot 6$ & $2 \times 3$ & 526 & $3 \cdot 2 \theta$ & $55 \cdot 6$ & $3 \cdot 57$ & 586 & 3.98 & $61 \cdot 6$ & $4 \cdot 40$ & $64 \cdot 6$ & 4.88 \\
\hline $22 \cdot 7$ & 0.16 & $25 \%$ & 0.43 & -8.7 & 11.71 & 317 & 0.98 & 347 & 1.25 & $37 \%$ & $1 \cdot 54$ & 407 & 1.84 & 437 & $2 \cdot 14$ & 467 & $2+49$ & 457 & 284 & 527 & $3 \cdot 21$ & 557 & $3 \cdot 59$ & 58.7 & $3 \cdot 59$ & 617 & 4.42 & $64 \cdot 7$ & $4 \cdot 90$ \\
\hline 228 & $17 \cdot 17$ & 258 & $11 \cdot 44$ & $25 \cdot 8$ & $0 \% 2$ & $31 \cdot \mathrm{s}$ & 0.99 & 348 & $1 \cdot 26$ & 378 & $1.5 \overline{3}$ & $40 \cdot 8$ & 1.85 & 43.8 & $2 \cdot 16$ & $40 \cdot 8$ & $2 \cdot 50$ & $49 \cdot 6$ & $2 \cdot 86$ & $52-8$ & $3 \cdot 22$ & 558 & $3 \cdot 60$ & 58.8 & 4.01 & 61 's & 4.4 & $64 \cdot 8$ & 4.92 \\
\hline $22 \cdot 11$ & $0 \cdot 18$ & 25.9 & 045 & 259 & $11 \cdot 7 \cdot 3$ & $31: 1$ & $1 \cdot 60$ & 34.9 & $1{ }^{\prime \prime} 2 \bar{T}$ & 379 & 156 & $4 \theta \cdot 9$ & 1.86 & 439 & $2 \cdot 17$ & $46 \cdot 9$ & $2 \cdot 51$ & $49 \cdot 9$ & $2 \cdot 87$ & $52-9$ & $3 \cdot 23$ & $55^{-4}$ & $3 \cdot 61$ & $58 \cdot 9$ & 402 & $61 \cdot 9$ & $4 \cdot 46$ & $64 \cdot 9$ & $4 \cdot 93$ \\
\hline $23 \cdot 0$ & 11.19 & 26.0 & $10 \cdot 46$ & 290 & 0.74 & $32 \cdot 0$ & 101 & 35.0 & 1.28 & 38.0 & $1 \cdot 57$ & $4 \mathrm{I} \cdot 0$ & 1.87 & $44 \cdot 0$ & $2 \cdot 18$ & 470 & $2 \cdot 52$ & 500 & $2 \cdot 88$ & 53.0 & $3 \cdot 25$ & 56.0 & 363 & 590 & 4.03 & $62 \cdot 0$ & $4 \cdot 47$ & 650 & 4.95 \\
\hline$-3 \cdot 1$ & 1).20 & $26 \cdot 1$ & 11.47 & $29 \cdot 1$ & U. & $32 \cdot 1$ & 1.12 & $35 \cdot 1$ & 1.29 & $35 \cdot]$ & $15 x$ & $41 \cdot 1$ & 1.88 & 441 & $2 \cdot 1 !$ & 47.1 & $2 \cdot 54$ & $50 \cdot 1$ & 290 & $53 \cdot 1$ & $3 \cdot 26$ & $56 \cdot 1$ & $3 \cdot 64$ & $59 \cdot 1$ & 404 & $62 \cdot 1$ & $4 \cdot 48$ & $65 \cdot 1$ & $4 \cdot 97$ \\
\hline $23 \% 2$ & $10 \div 21$ & $26 \cdot 2$ & 0.48 & $29 \cdot 2$ & 0.76 & $32 \cdot 2$ & 1.03 & 352 & $1 \cdot 30$ & 38.2 & 1.59 & $41 \%$ & $1 \times 9$ & $44: 2$ & $2 \approx \theta$ & $47 \cdot 2$ & ע. & 50.2 & $2 \cdot 91$ & $53 \%$ & $3 \cdot 27$ & $56 \cdot 2$ & $3 \cdot 65$ & $59 \cdot 2$ & $4 \cdot 06$ & $62 \cdot 2$ & 4.50 & 652 & 4.98 \\
\hline $23 \cdot 3$ & 11.22 & $26 \cdot 3$ & $0 \cdot 49$ & $9 \cdot 3$ & $0 \cdot 77$ & $32 \cdot 3$ & $1 \cdot 0.4$ & $35 \div 3$ & $1 \cdot 31$ & $35 \cdot 3$ & $1 \cdot 60$ & $41 \cdot 3$ & $1 \cdot 90$ & 443 & $2 \cdots 2$ & 473 & 256 & $5 \theta-3$ & 242 & $53: 3$ & $3 \cdot 23$ & $56 \cdot 3$ & $3 \cdot 67$ & $59 \cdot 3$ & 4.07 & $62 \div 3$ & $4 \cdot 52$ & $65 \cdot 3$ & 5.00 \\
\hline $23 \cdot 4$ & $14 \div 2=3$ & $26 \cdot 4$ & 0.50 & $29 \cdot 4$ & $0.7 \mathrm{~s}$ & $32+4$ & 1.00 & $35 \cdot 4$ & $1 \cdot 32$ & 38.4 & $1 \cdot 61$ & 414 & $1+11$ & $44 \cdot 4$ & $2 \cdot 23$ & 474 & $2 \cdot 57$ & $50 \cdot 4$ & $2 \cdot 93$ & $53 \cdot 4$ & 3 & $56 \cdot 4$ & $3 \cdot 68$ & $59 \cdot 4$ & $4.0 y$ & $62 \cdot 4$ & $4 \cdot 53$ & $65 \cdot 4$ & $5 \cdot 02$ \\
\hline 235 & $1+2=1$ & 26.5 & 0.50 & ה:יום & 0.79 & $32 \cdot 5$ & 1.05 & $35 \%$ & $1 \cdot 33$ & 385 & $1 \cdot 62$ & 415 & 1.42 & $44 \cdot 5$ & $2 \cdot 24$ & 475 & $2 \cdot 58$ & 505 & $2 \cdot 94$ & $53 \cdot 5$ & $3: 30$ & 56.5 & $3 \cdot 69$ & $59 \cdot 5$ & $4 \cdot 11$ & $62 \cdot 5$ & 4.55 & $65 \cdot 5$ & $5 \cdot 04$ \\
\hline 236 & 10.25 & 266 & 1151 & $29 \cdot 6$ & 10.50 & $32-6$ & 1.06 & $35 \cdot 6$ & $1 \cdot 33$ & $38 \cdot 6$ & $1 \cdot 63$ & 416 & 1.93 & 416 & $2 \cdot 25$ & 476 & $2 \cdot 60$ & $50 \cdot 6$ & $2 \cdot 96$ & $53 \cdot 6$ & $3 \cdot 31$ & 566 & $3 \cdot 71$ & $59 \cdot 6$ & $4 \cdot 12$ & $62 \cdot 6$ & 4.56 & 65.6 & $5 \cdot 05$ \\
\hline 23.7 & 0.25 & 267 & 052 & $99 \cdot 7$ & 0.80 & $32 \cdot 7$ & 1.07 & 35.7 & $1: 34$ & $3 \times 7$ & $1 \cdot 64$ & $41 \cdot 7$ & 1.94 & 44.7 & $2 \cdot 26$ & 477 & 261 & 507 & 297 & 537 & $3 \cdot 33$ & 567 & 372 & 59.7 & $4 \cdot 14$ & 627 & $4: 58$ & $65 \cdot 7$ & $5 \cdot 07$ \\
\hline $23 \mathrm{~s}$ & $11 \cdot 26$ & 26.5 & 0.53 & $29 \cdot 8$ & $0 \cdot 81$ & 328 & 1.08 & $35 \cdot 8$ & $1 \cdot 35$ & $38 \cdot 8$ & 1.65 & $43 \cdot 5$ & $1 \cdot 95$ & 44.8 & 2.27 & 47.8 & $2 \cdot 62$ & $50 \cdot 5$ & $2 \cdot 45$ & $53 \cdot 8$ & $3 \cdot 34$ & 56.8 & $3 \cdot 73$ & 598 & $4 \cdot 15$ & $62 \cdot 8$ & $4: 59$ & $65 \cdot 5$ & $5 \cdot 09$ \\
\hline I! & $0.2 \overline{7}$ & $26 \cdot 9$ & 0.54 & $29-9$ & $0 \cdot 82$ & $32 \cdot 9$ & 109 & $35 \cdot 9$ & $1 \cdot 36$ & $38 \cdot 9$ & $1 \cdot 66$ & $41 \cdot 9$ & 1. $9 t i$ & 449 & $2 \cdot 25$ & 479 & $2 \cdot 63$ & $50 \cdot 9$ & $2 \cdot 09$ & $53 \cdot 9$ & $3 \cdot 35$ & $56 \cdot 9$ & $3 \cdot 74$ & 599 & $4 \cdot 16$ & $62 \cdot 9$ & $4 \cdot 61$ & $\begin{array}{r}65.9 \\
66.0\end{array}$ & $\begin{array}{l}5 \cdot 11 \\
5 ! 12\end{array}$ \\
\hline
\end{tabular}


TABLE LXXXI.-Weiritus aNd Measures.

\section{Linear Measure.}

1 inch. . . . . . . . $=0254$ metre.

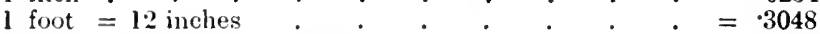

1 yard $=3$ feet $=36$ inches $\quad . \quad \cdot \quad \cdot \quad \cdot \quad \cdot \quad=-9144 \quad "$

1 metre $=10$ decimetres $=100$ centimetres $=1000$ millimetres.

1 metre $=39.37 \mathrm{l}$ inches $=3.281$ feet $\quad=1.094$ yards.

siquare Measure.

l square inch . . . . . . . $=000645 \mathrm{sq}$. metre.

l square foot $=144$ square inches $. \quad . \quad .=0929 \quad$ ",

1 square yard $=9$ square feet $=1296$ sq. inches $=8361 \quad$, ,

l sq. metre $=100 \mathrm{sq}$. decimetres $=10,000 \mathrm{sq}$. centimetres $=1,000,000$ sq. millimetres.

$1 \mathrm{sq}$. metre $=1550 \cdot 6 \mathrm{sq}$. inches $=10 \cdot 764 \mathrm{sq}$. feet $=1 \cdot 196 \mathrm{sq}$. yards.

Cubic Measure.

1 cubie inch . . . . . . $=00001639$ eub. metre.

1 cubic foot $=1728$ eubie inches $. \quad . \quad=0283$

l cubic yard $=27$ eubic $\mathrm{ft} .=46,656$ eubic ins. $=-7645$

1 cubic metre $=1000$ cubic decimetres $=1,000,000$ eubic centimetres $=1,000,000,000$ cubic millimetres.

1 cubic metre $=61,027$ cubic ins. $=35 \cdot 317$ cubie ft. $=1 \cdot 308$ eubic $y d s$.

Measures of Capacity.

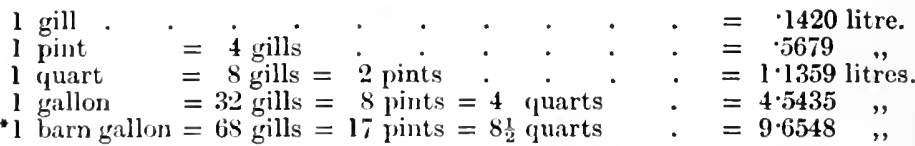

1 litre $=1000 \mathrm{cubie}$ centimetres $=1,000,000$ cubie millimetres.

1 litre $=7 \cdot 943$ gills $=1 \cdot 7605$ pints $=\cdot 9504$ quart $=\cdot 2201$ gallon $=\cdot 1036$ harn gallon. ${ }^{*}$

\section{Avoirdupois Weight.}

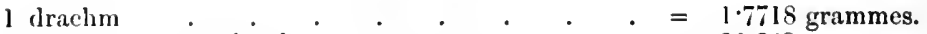

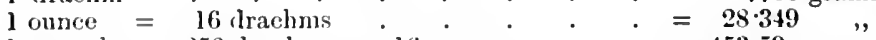

1 pound $=256$ drachms $=16$ ounces $.=453.59 \quad, "$

1 quarter $=7168$ drachms $=445$ ounces $=28 \mathrm{lbs} .=12700.5 "$,

1 hunlreolweight $=28,672$ drachms $=179207.8$

1 ton $=573,440$ drachms $=35,540 \mathrm{nzs}=2240 \mathrm{lbs} .=$

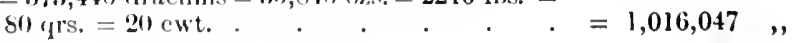

1 metricton $=1000$ kilnglammes.

1 kilogramme $=1000$ granmess.

1 gramme $=10$ decigrammes $=100$ centigrammes $=1000$ milligrammes.

1 gramme $=.5644 \mathrm{drachm}=\cdot 03527 \mathrm{0 \%}=002205 \mathrm{lb} .=00001968$

cwt. $=0000009 \mathrm{~s} 4$ ton

- The barn gallon is not a legal measure; all eontracts made in barn gallons are mull and voicl. It is, however, much used. 


\section{Useful Data.}

The gallon weighs $10 \mathrm{lbs}$. (of distilled water at $62^{\circ} \mathrm{F}$.).

The litre weighs 1000 grammes (of distilled water at $0^{\circ} \mathrm{C}$.).

1 gallon $=4 \frac{1}{2}$ litres approximately.

1 barn gallon $=10$

1 kilogramme $=2 \frac{1}{4}$ lbs. approximately.

1 hundredweight $=50$ kilogrammes approximately.

Note. - The metre and litre compared with the standard English measures are those defined by the Act of 1878, and are not the true metre and litre. The difference is due to the fact that the English measures refer to a temperature of $62^{\circ} \mathrm{F}$., and the metric measures to a temperature of $0^{\circ} \mathrm{C}$. In the Weights and Measures Act of 1878 the difference of temperature has not been allowed for.

The following table shows the comparison between the two systems :-

\begin{tabular}{|c|c|c|c|c|}
\hline & & Metre. & Litre. & Kilogramme. \\
\hline $\begin{array}{l}\text { True values at } 62^{\circ} \mathrm{F} \text {., } \\
\text { Adopted in Act, }\end{array}$ & $\dot{.}$ & $\begin{array}{c}\text { Inches. } \\
39 \cdot 38203 \\
39 \cdot 37079\end{array}$ & $\begin{array}{l}\text { Gallon. } \\
\cdot 22018 \\
\cdot 2200967\end{array}$ & $\begin{array}{c}\text { Lbs. } \\
2 \cdot 20462 \\
2 \cdot 20462\end{array}$ \\
\hline
\end{tabular}

TABLE LXXXII.-Barn Galloxs and Imperial Galloxs.

For the Conversion of Barn Gallons into Imperial Gallons.

\begin{tabular}{|c|c|cc|}
\hline \multirow{2}{*}{ Earn Gallons. } & Imperial Gallons. & Gallons. & Pints. \\
\cline { 2 - 3 } & $2 \cdot 1.25$ & 2 & 1 \\
2 & $4 \cdot 25$ & 4 & 2 \\
3 & $6 \cdot 375$ & 6 & 3 \\
4 & $8 \cdot 5$ & 8 & 4 \\
5 & $10 \cdot 625$ & 10 & 5 \\
6 & $12 \cdot 75$ & 12 & 6 \\
7 & $14 \cdot 875$ & 14 & 7 \\
8 & $17 \cdot 0$ & 17 & 0 \\
9 & $19 \cdot 125$ & 19 & 1 \\
10 & $21 \cdot 25$ & 21 & 2 \\
\hline
\end{tabular}

For the Conversion of Imperial Gallons into Barn Gallons.

\begin{tabular}{|c|c|c|c|}
\hline Imperial Gallons. & Barn Gallons. & Imperial Gallons. & Barn Gallons. \\
\cline { 2 - 3 } 1 & $\cdot 47$ & 10 & $4 \cdot 70$ \\
2 & .94 & 11 & $5 \cdot 17$ \\
3 & $1 \cdot 41$ & 12 & $5 \cdot 64$ \\
4 & $1 \cdot 85$ & 13 & $6 \cdot 12$ \\
5 & $2 \cdot 35$ & 14 & $6 \cdot 59$ \\
6 & $2 \cdot 8 \cdot$ & 15 & $7 \cdot 06$ \\
7 & $3 \cdot 29$ & 16 & $7 \cdot 53$ \\
8 & $3 \cdot 76$ & 17 & $8 \cdot 00$ \\
9 & $4 \cdot 23$ & & \\
\hline
\end{tabular}


TABLE LXXXiII. - Table of Weights of Dairy Products.

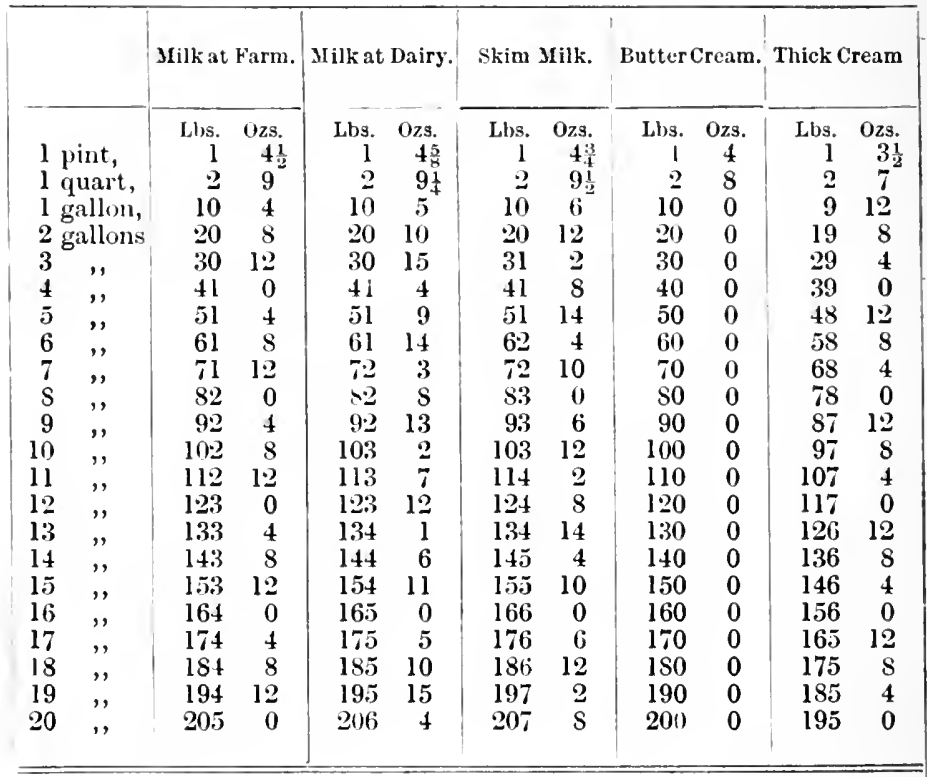

Difference Table.

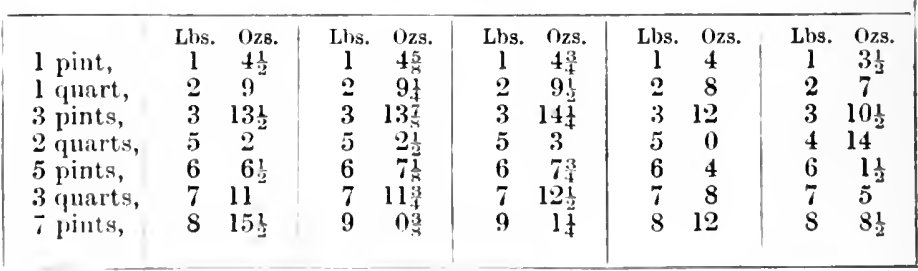

Note.-The milk at farm is assumed to be warm and freshly milked.

The milk at dairy is assumed to be at the average temperature $\left(60^{\circ} \mathrm{F}\right.$.) and a few hours oldt.

Skim milk is assumed to be at the average temperature $\left(60^{\circ} \mathrm{F}.\right)$.

Jutter cream is assumed to be at the average temperature $\left(60^{\circ} \mathrm{F}\right.$.) and to contain 30 per cent. fat.

Thick cream is assumed to be at the average tenuerature $\left(60^{\circ} \mathrm{F}\right.$.) and to contain 50 per cent. fat. 
He Weight of Butter in

Quarts of C'ream Churned.

\begin{tabular}{|c|c|c|c|c|c|}
\hline & 40 & 50 & 60 & 70 & 80 \\
\hline & $17 \cdot 4$ & $21 \cdot 8$ & $26 \cdot 1$ & $30 \cdot 5$ & 34.8 \\
\hline & $18 \cdot 6$ & $23 \cdot 3$ & $26 \cdot 9$ & $31 \cdot 6$ & $37 \cdot 2$ \\
\hline & 19.8 & $24 \cdot 8$ & $29 \cdot 8$ & & $39 \cdot 7$ \\
\hline & $21 \cdot 0$ & $26 \cdot 3$ & $31 \cdot 6$ & & 1 \\
\hline & $22 \cdot 3$ & $27 \cdot 9$ & $33 \cdot 4$ & 39. & $44 \cdot 6$ \\
\hline & $23 \cdot 5$ & $29 \cdot 4$ & $35 \cdot 2$ & $41 \cdot 1$ & $47 \cdot 0$ \\
\hline & $24 \cdot 6$ & 30.8 & 37.0 & $43^{\circ}$ & $49 \cdot 3$ \\
\hline & $25 \cdot 8$ & $32 \cdot 3$ & $35 \cdot 7$ & $4 \tilde{5}$ & $51 \cdot 6$ \\
\hline & $27 \cdot 0$ & & 40.5 & 47 & $54 \cdot 0$ \\
\hline & $28 \cdot 2$ & $35 \cdot 2$ & $42 \cdot 2$ & 49 & $56 \cdot 3$ \\
\hline & $29 \cdot 3$ & $36 \cdot 7$ & $44 \cdot 0$ & 51 & $58 \cdot 6$ \\
\hline & $30 \cdot 5$ & $38 \cdot 1$ & $45 \cdot 7$ & 53 & $61 \cdot 0$ \\
\hline & $31 \cdot 6$ & $39 \cdot 6$ & 47.5 & 55 & $63: 3$ \\
\hline & $32 \cdot 8$ & $41 \cdot 0$ & $49 \cdot 1$ & 57. & 65.5 \\
\hline & 33.9 & $42 \cdot 4$ & 50.9 & 59.4 & 67.8 \\
\hline & $35 \cdot 1$ & $43 \cdot 8$ & $52 \cdot 6$ & $61 \cdot 4$ & 70.2 \\
\hline & $36 \cdot 2$ & $45 \cdot 3$ & $54: 3$ & 63. & $72 \cdot 4$ \\
\hline & $37 \cdot 4$ & 46.7 & $56 \cdot 0$ & 65. & $74 \cdot 7$ \\
\hline & $38 \cdot 5$ & $48 \cdot 1$ & 57.7 & 67 & $77 \cdot 0$ \\
\hline & $39 \cdot 6$ & & $59 \cdot 5$ & 69. & $79 \cdot 3$ \\
\hline & 40.8 & $51 \cdot 0$ & $61 \cdot 1$ & $71 \cdot 3$ & $81 \cdot 5$ \\
\hline & $41 \cdot 8$ & $52 \cdot 3$ & $62 \cdot 8$ & 73.2 & 837 \\
\hline & $43 \cdot 0$ & $53 \cdot 7$ & $64 \cdot 4$ & $75 \cdot 2$ & $85 \cdot 9$ \\
\hline & $44 \cdot 0$ & $55 \cdot 1$ & $66 \cdot 1$ & $77 \cdot 1$ & $88 \cdot 1$ \\
\hline & 452 & $56 \cdot 5$ & 67.7 & $79 \cdot 0$ & $90 \cdot 3$ \\
\hline & $46 \cdot 2$ & 57.8 & $69 \cdot 4$ & 80.9 & $92 \cdot 5$ \\
\hline & $47 \cdot 3$ & $59 \cdot 2$ & $71 \cdot 0$ & 82.8 & $94 \cdot 6$ \\
\hline & $48 \cdot 4$ & 60.5 & $72 \cdot 5$ & $84 \cdot 6$ & 7 96 \\
\hline & $49 \cdot 4$ & $61 \cdot 8$ & $74 \cdot 2$ & $86 \cdot 5$ & $98 \cdot 9$ \\
\hline & $50 \cdot 5$ & $63 \cdot 1$ & $75 \cdot 7$ & $88: 3$ & $101 \cdot 0$ \\
\hline & $51 \cdot 6$ & $64 \cdot 5$ & $77 \cdot 3$ & $90 \cdot 2$ & $103 \cdot 1$ \\
\hline & $52 \cdot 6$ & $65^{\circ}$ & $78 \cdot 9$ & $92 \cdot 1$ & 105 \\
\hline & $53 \cdot 6$ & 67. & $50 \cdot 4$ & $93 ` S$ & $107 \cdot$ \\
\hline & $54 \cdot 6$ & $68 \cdot 2$ & $81 \cdot 8$ & $95 \cdot 5$ & $109 \cdot 1$ \\
\hline & $55 \cdot 5$ & 69.4 & $83 \cdot 2$ & $97 \cdot 1$ & 1110 \\
\hline & $56 \cdot 4$ & $70 \cdot 5$ & $84 \cdot 6$ & $98 \cdot 7$ & $112 \cdot 8$ \\
\hline
\end{tabular}


Table lxxxil-Fon the Calculation of the Weight of Butter in Pounds obtalned ex Cherning Cream.

\begin{tabular}{|c|c|c|c|c|c|c|c|c|c|c|c|c|c|c|c|c|c|c|c|c|c|c|c|c|c|c|c|c|c|}
\hline \multirow{2}{*}{$\begin{array}{c}\text { Percentase } \\
\text { of } \\
\text { Fat in Crestm. }\end{array}$} & \multicolumn{29}{|c|}{ Quarts of Creis Churned, } \\
\hline & 1 & 2 & 3 & 4 & 5 & 6 & 7 & 8 & 9 & 10 & 20 & 30 & 40 & 50 & 60 & 70 & 80 & 90 & 100 & 110 & 120 & 130 & 140 & 150 & 160 & 170 & 180 & 190 & 200 \\
\hline 15 & 44 & $3 i$ & $1: 31$ & 174 & $2 \cdot 10$ & $2 \cdot 61$ & $3 \cdot 0.5$ & $34 k$ & $3 \cdot 62$ & $4 \cdot 35$ & $8 \cdot 7$ & 131 & 174 & $21 \mathrm{~s}$ & $26 \cdot 1$ & $30 \cdot 5$ & $34 \cdot \mathrm{s}$ & $39 \cdot 2$ & $43 \cdot 5$ & 479 & $52 \because 2$ & 506 & 60.9 & $65 \cdot 3$ & $69 \cdot 6$ & $i+0$ & 783 & $\times 2 \div$ & 870 \\
\hline 16 & $4 i$ & $\cdot 93$ & 1.40 & $1 \cdot 8 i i$ & $2 \cdot 33$ & $2 \cdot 69$ & $3 \cdot 16$ & $3 \cdot 72$ & $4 \cdot 19$ & 465 & 93 & 140 & 18.6 & $23 \cdot 3$ & $26 \cdot 9$ & $31 \cdot 6$ & $37 \cdot 2$ & $41 \cdot 9$ & 46.5 & $51 \cdot 2$ & $5.5 \cdot 8$ & 605 & $65 \cdot 1$ & $69 \cdot 5$ & 73.4 & 78.1 & 537 & $s 8: 1$ & $93 \cdot 0$ \\
\hline 17 & 50 & 99 & $1 \cdot 4 !$ & 1.95 & $2 \cdot 45$ & $2 \cdot 95$ & 347 & $3 \cdot 97$ & 146 & 4.96 & $9 \cdot 9$ & $14 \cdot 9$ & $19 \mathrm{~s}$ & $24 \cdot 8$ & $29 \cdot 5$ & 347 & $39 \cdot 7$ & $44 \cdot 6$ & $49 \cdot 6$ & 546 & $50: 5$ & 64.5 & $69 \cdot 4$ & $74 \cdot 4$ & 29.4 & 543 & $89: 3$ & $94 \div 2$ & $49 \cdot 2$ \\
\hline 18 & .53 & $1 \cdot 05$ & 1.58 & $2 \cdot 111$ & 263 & $3 \cdot 16$ & $3 \cdot 6 \mathrm{~s}$ & $4 \cdot 21$ & 473 & $5 \because 6$ & 105 & 15.8 & 210 & $26: 3$ & $31 \cdot 6$ & 36.8 & $42 \cdot 1$ & $47 \cdot 3$ & 826 & $57 \cdot 9$ & $6.3 \cdot]$ & $6 \mathrm{~s} \cdot \mathrm{t}$ & $73 \cdot 6$ & 78.9 & 84.2 & $59 \cdot 4$ & 947 & $99-9$ & $1050-2$ \\
\hline 19 & 36 & $1 \cdot 11$ & $1 \cdot 6 \bar{i}$ & $2 \cdot 23$ & 279 & $3 \cdot 34$ & $3 \cdot 90$ & 446 & 5.01 & $\sqrt{257}$ & $11 \cdot 1$ & 16.7 & $22 \cdot 3$ & $27 \cdot 9$ & 33.4 & 390 & $44 \cdot 6$ & $30 \cdot 1$ & 557 & $61 \%$ & $61+8$ & 72.1 & $7 x \cdot 0$ & $\$ 3 \cdot 6$ & $89 \cdot 1$ & $94 \%$ & $100 \cdot 3$ & $105 \times$ & 1114 \\
\hline 20 & 59 & $1 \cdot 17$ & 1.76 & 235 & $2 \cdot 94$ & $3: 52$ & $4 \cdot 11$ & 470 & $5 \cdot 2 \mathrm{~s}$ & 587 & 117 & $17 \cdot 6$ & $23 \cdot 5$ & $2 ! \cdot 4$ & $35 \cdot 2$ & $41 \cdot 1$ & 470 & $.72 \cdot 8$ & $5 \times$ & $64 \cdot 6$ & $70 \cdot 4$ & 763 & $\mathrm{~S} 2 \cdot 2$ & N5.1 & $93 \cdot 9$ & $99 \cdot s$ & $105 \%$ & 1115 & $117 \cdot$ \\
\hline 21 & 62 & $1 \cdot 23$ & 1.85 & $2 \cdot 4 i$ & 3.08 & $3 \cdot 71$ & $4 \cdot 31$ & $4 \cdot 93$ & 5.54 & i. 16 & $12 \cdot 3$ & 18.5 & 246 & $30 \mathrm{~s}$ & $37 \cdot 0$ & 4.31 & 493 & .5 .54 & 61.6 & 1575 & $73 \cdot 9$ & $\mathrm{~s}(0) \cdot]$ & $\$ 6.2$ & 924 & $98 \cdot 6$ & 104.7 & $110 \cdot 9$ & $11 ; \cdot 0$ & $123: 2$ \\
\hline 22 & bje & $1 \div 3 !$ & 1.94 & $2 \cdot 53$ & 323 & $3 \cdot 87$ & 4.52 & $5 \cdot 16$ & $5 \cdot 81$ & 64.5 & 129 & $19 \cdot 4$ & $25 \cdot 5$ & $32 \cdot 3$ & $35 \%$ & $4.5^{2}$ & 516 & 58.1 & $64 . \tilde{5}$ & $71 \cdot 0$ & $\pi t$ & 83.9 & $90: 3$ & 96.8 & $103 \% 2$ & $109 \cdot \bar{\tau}$ & $116 \cdot 1$ & $12 \cdot 6$ & $1: 290$ \\
\hline 23 & $6 s$ & $1: 35$ & $2 \cdot 13$ & $2 \cdot 71$ & $33 x$ & $4 \cdot+1,5$ & $4-73$ & $5+0$ & 6.08 & 6.7 .5 & 135 & $20-3$ & 270 & $33 \times \mathrm{s}$ & $40: 5$ & 473 & 540 & tin $\times$ & $15 \div 3$ & $7 \pm 3$ & $81 \%$ & 878 & 94.5 & 2013 & 108.0 & $11+8$ & 121.5 & 1253 & 1350 \\
\hline 24 & 70 & $1 \cdot 41$ & $2 \cdot 11$ & $2 \times 4$ & $3 \cdot 52$ & 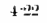 & 4.93 & $5 \cdot 63$ & $6: 34$ & $7 \cdot 14$ & $14 \cdot 1$ & $21 \cdot 1$ & $2+2$ & $3 \pi+2$ & +22 & $49 \cdot 3$ & $56 \div 3$ & ii:3.4 & 304 & $\pi 4$ & 84.5 & $91 \div 5$ & 986 & $105 \% 6$ & $112 \cdot 6$ & 1197 & $126 \%$ & $133 \times$ & $140 \times$ \\
\hline 25 & 73 & $1 \cdot 47$ & $2 \cdot 20$ & $2 \cdot 93$ & 367 & 4.40 & $5 \cdot 13$ & 5.86 & $(6 \cdot 60)$ & 733 & $14 \%$ & $22 \cdot 0$ & $29 \cdot 3$ & 367 & $44 \cdot 1)$ & $51 \cdot 3$ & $58 \cdot 6$ & $6 i t \cdot 0$ & $73: 3$ & 80 & $x+0$ & $9 \pi 3$ & $102 \cdot 6$ & 1100 & $117 \cdot 3$ & 1246 & 1.319 & $139-3$ & $14 r \cdot b$ \\
\hline 26 & 76 & 152 & $2 * 29$ & $3 \cdot 15$ & $3 \times 1$ & 4.57 & $5: 33$ & $6 \cdot 10$ & 6.86 & 762 & 152 & $22 \cdot 3$ & $311 . \overline{7}$ & $38 \cdot 1$ & 4.7 & 53.3 & 610 & 68.6 & 76.2 & $\$ 3 \cdot 8$ & $91 \cdot 4$ & $99 \cdot 1$ & 10667 & $114: 3$ & 121.9 & 129.5 & 1372 & 144.5 & $152+4$ \\
\hline 27 & 79 & $1.5 x$ & $2 \cdot 37$ & $3 \cdot 16$ & 3.96 & 4.75 & $5 \cdot 54$ & 633 & $7 \cdot 12$ & 7991 & $15 \times$ & $23 \cdot 7$ & $31 \cdot 6$ & $39 \cdot \mathrm{ti}$ & $47 \cdot 3$ & $53 \cdot 4$ & $63 \cdot 3$ & $71 \div 2$ & $79 \cdot 1$ & $87 \cdot 0$ & $94 \cdot 9$ & $102 \cdot 8$ & $110 \cdot 7$ & 1187 & 126.6 & 134.5 & $142 \div 4$ & $151 \cdot 3$ & $158-2$ \\
\hline 28 & -82 & 164 & $2 \cdot 46$ & 328 & $4 \cdot 10$ & $4 \cdot 91$ & $5 \cdot 73$ & 655 & $7 \cdot 37$ & $8 \cdot 19$ & 164 & 24.6 & $32 \cdot 8$ & $41 \%$ & $49 \cdot 1$ & 573 & 6.5 & 737 & $81 \cdot 9$ & $90 \cdot 1$ & $98 \cdot 3$ & 106.5 & 1147 & 12299 & 1310 & $139-2$ & 1474 & 1556 & 1638 \\
\hline 29 & $8 . \pi$ & 3.70 & 2.54 & $3: 39$ & $4 \cdot 24$ & 5.09 & $5 \cdot 94$ & 678 & $7 \cdot 63$ & 8.48 & 170 & 254 & $33 \cdot 9$ & $42 \cdot 4$ & $50 \div 9$ & $59 \cdot 4$ & 678 & $76 \div 3$ & 84.8 & $93 \cdot 3$ & $101 \cdot 8$ & $110 \%$ & 1185 & 1272 & $135 \%$ & $144-2$ & 15266 & $16 t \cdot 1$ & $169 \cdot 6$ \\
\hline 30 & 85 & $1 \cdot 75$ & $2 \cdot 633$ & 351 & 4.35 & $5 \cdot 26$ & 6.14 & $7 \cdot 02$ & $7 \cdot 59$ & 577 & $17 \cdot 5$ & $26 \cdot 3$ & $3 \tilde{a} \cdot 1$ & 43.8 & $52 \cdot 6$ & $61 \cdot 4$ & $70 \div$ & $7 * 0$ & $87 \%$ & 965 & $105 \% 2$ & 1140 & 122.5 & 1315 & $140 \cdot 3$ & $149 \cdot 1$ & 157.9 & $166 \cdot 6$ & 1754 \\
\hline 31 & 91 & $1 \cdot 81$ & 272 & 362 & 4.53 & $5 \cdot 43$ & $6: 34$ & $7 \because 24$ & $8 \cdot 15$ & 905 & 18.1 & 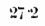 & 36.2 & 4.73 & $54 \cdot 3$ & 634 & 724 & $81: 5$ & 945 & 996 & 1056 & $117 \%$ & $1: 6 \%$ & $135 \cdot 5$ & 144.8 & $153 \cdot 9$ & $162 \cdot 9$ & $172+1$ & 1810 \\
\hline 32 & -93 & $1 \cdot 87$ & $2 \cdot 60$ & $3 \cdot 74$ & 4.67 & 560 & 6.54 & $7+7$ & 841 & $9 \cdot 34$ & 187 & $28 \cdot 0$ & $37 \cdot 4$ & 467 & $56 \cdot 0$ & 15.54 & 717 & $84 \cdot 1$ & $93 \cdot 4$ & 1027 & $112 \cdot 1$ & $121 \cdot 4$ & $130 \cdot 8$ & $140 \cdot 1$ & $149 \cdot 4$ & $158 \cdot 8$ & 168.1 & 175 & $186 \cdot 6$ \\
\hline 33 & 96 & 1.92 & 289 & $3 \cdot 8 \pi$ & $4 \cdot 81$ & 57 & $6 \cdot 73$ & $7 \cdot 70$ & $860^{\circ}$ & $9^{6} 62$ & 192 & $28 \cdot 9$ & 38.5 & 48.1 & $57 \cdot 7$ & $67 \cdot 3$ & 770 & $s_{6} \cdot 6$ & 96.2 & $105 \cdot 8$ & 115.4 & $125 \cdot 1$ & $134 \cdot 7$ & $144 \cdot 3$ & 153.9 & $16 i 35$ & 1732 & $182 \cdot 8$ & $192+4$ \\
\hline 34 & $\cdot 9 y$ & 1.98 & $2 \cdot 97$ & 3.96 & 4.96 & $5 \cdot 95$ & $6 \cdot 94$ & 7.93 & 8.92 & $9 \cdot 91$ & 198 & $29 \cdot 7$ & $39 \cdot 6$ & 4916 & $59 \cdot \hat{3}$ & $69 \cdot 4$ & $79 \cdot 3$ & $89 \cdot 2$ & $99 \cdot 1$ & 109.0 & 1189 & 128.8 & $138 \%$ & 1457 & $158 \cdot 6$ & 1685 & 1784 & $188 \cdot 3$ & $198-2$ \\
\hline 35 & 1.02 & $2 \cdot 04$ & 306 & 4 ' 18 & $5 \cdot 10$ & $6 \cdot 11$ & $7 \cdot 13$ & $8 \cdot 15$ & $9 \cdot 17$ & $10 \cdot 19$ & $\square 0.4$ & $30 \cdot 6$ & 40.8 & $51 \cdot 0$ & til. $]$ & $71: 3$ & $\$ 1 \cdot 5$ & 917 & 10199 & $112 \cdot 1$ & 1223 & $132 \cdot 5$ & 1427 & $152 \cdot 9$ & 1630 & $173-2$ & 1834 & 1936 & 203.8 \\
\hline 36 & $1 \cdot 05$ & $2 \cdot 199$ & $3 \cdot 14$ & $4 \cdot 18$ & $5 \cdot 23$ & 6.28 & $7 \cdot 32$ & $8 \cdot 37$ & $9 \cdot 41$ & $10 \cdot 46$ & $20 \cdot 9$ & 314 & 4) 8 & $52 \cdot 3$ & $62 \cdot 8$ & $73 \%$ & 837 & $94 \cdot 1$ & $104 \cdot 6$ & 115.1 & $125 \cdot 5$ & 1360 & 1464 & $156 \cdot 9$ & 1674 & $177 \cdot 8$ & $158 \cdot 3$ & $198 \%$ & $209-2$ \\
\hline 37 & 107 & $2 \cdot 15$ & $3 \cdot 22$ & $4 \cdot 30$ & $5 \cdot 37$ & 6.44 & 7.52 & 5.59 & 9.67 & $10^{\circ} 74$ & 215 & $32 \cdot 2$ & $43 \cdot 0$ & $53 \%$ & 6.1 .4 & $75 \%$ & $85 \cdot 9$ & $96 \cdot 7$ & 1074 & 118.1 & 128.9 & 1396 & 1504 & 161.1 & $171 \cdot 8$ & 1826 & $193: 3$ & $204 \cdot 1$ & $214 \cdot 8$ \\
\hline 38 & $1 \cdot 10$ & $2 \cdot 20$ & $3 \cdot 30$ & 4.40 & 551 & $6 \cdot 61$ & 7.71 & $8 \times 1$ & $9 \cdot 91$ & 11.01 & $22 \cdot 0$ & $33 \cdot 0$ & $44 \cdot 0$ & $5 \overline{5} \cdot 1$ & 66.1 & $7 \pi \cdot 1$ & $88 \cdot 1$ & $99 \cdot 1$ & $110 \cdot 1$ & $121-1$ & $132 \cdot 1$ & $143 \cdot 1$ & 1541 & $165-2 \mid$ & 176 & 187.2 & 198.2 & $209 \cdot 2$ & $2=20-2$ \\
\hline 39 & $1 \cdot 13$ & $2-26$ & $3 \cdot 39$ & 4.52 & 5.65 & $6 \cdot 77$ & $7 \cdot 90$ & $9 \cdot 103$ & $10 \cdot 16$ & $11 * 29$ & $22 \cdot 1 i$ & $33 \cdot 9$ & $45^{22}$ & 565 & 67.7 & 790 & $90 \cdot 3$ & $101^{\circ} 6$ & 112.9 & $124 \div 2$ & 135.5 & $146 \cdot 8$ & 158.1 & 1694 & $=180.6$ & 191.9 & 203.2 & 2145 & $225 \mathrm{~s}$ \\
\hline 40 & $1 \cdot 16$ & $2 \cdot 31$ & $3 \cdot 47$ & $4 \cdot 62$ & $5 \cdot 75$ & $6 \cdot 94$ & 8.09 & $9 \pm 5$ & $10 \cdot 40$ & $11^{\circ 5 t j}$ & $23 \cdot 1$ & $34 \cdot 7$ & $46 \cdot 2$ & 578 & $69 \cdot 4$ & $80 \div 9$ & $92 \cdot 5$ & $104 \cdot 0$ & $11.5 \cdot 6$ & 127.2 & $135 \%$ & $150 \cdot 3$ & 161.8 & 173.4 & 185.0 & 1965 & $208 \cdot 1$ & $219 \cdot 6$ & $231 \cdot 2$ \\
\hline 41 & $3 \cdot 18$ & 237 & $3 \cdot 55$ & $4 \cdot 73$ & 592 & $7 \cdot 10$ & 8.28 & $0 \cdot 46$ & $10^{\prime} 6 \bar{\theta}$ & $11 \cdot 83$ & $23 \cdot 7$ & 35.5 & $47: 3$ & $59 \div$ & $\pi 10$ & $82 \cdot 8$ & $94 \cdot 13$ & 1065 & 118.3 & $130 \cdot 1$ & 1420 & $153 \cdot 8$ & $165 \cdot 6$ & 1775 & $189-3$ & $201 \cdot 1$ & 2129 & $224-8$ & $23 t-6$ \\
\hline 42 & 1.21 & $2 \cdot 42$ & 363 & $4 \cdot 84$ & 645 & $7 \cdot 25$ & $8+16$ & $0 \cdot 67$ & 10.88 & $12 \cdot 09$ & $24 \cdot 2$ & $36 \cdot 3$ & 48.4 & 605 & $72 \cdot 5$ & $81 \cdot 6$ & 967 & 108.8 & $120 \div 9$ & 13.3 .0 & 145.1 & $15 \pi$ & 1693 & 1814 & 1934 & 21055 & $217^{\circ} 6$ & $2 \geq 97$ & 2418 \\
\hline 43 & 124 & $2 \cdot 47$ & 371 & $4: 94$ & $6 \cdot 18$ & $7+2$ & $8 \cdot 65$ & $9 \times 9$ & $11 \cdot 12$ & $12 \cdot 36$ & 247 & $37 \cdot 1$ & 49.4 & $61 \cdot 8$ & $7+2$ & 86.5 & $98 \cdot 9$ & $111 \% 2$ & 1236 & $136^{\circ} 0$ & 1453 & $160 \%$ & $173 \cdot 0$ & $185 \cdot 4$ & 197.8 & 210.1 & 20.35 & 2348 & $0.7 ;-2$ \\
\hline 44 & $1 \% 26$ & $2 \cdot 52$ & 379 & 5.05 & $6: 31$ & 757 & $8 \cdot 83$ & $100 \cdot 10$ & $11 \cdot 36$ & 1262 & $25 \cdot 2$ & 37.9 & 50.5 & $63 \cdot 1$ & 757 & $8 s: 3$ & 1010 & 113.6 & $124 i \cdots t$ & $138 \cdot \mathrm{s}$ & 1514 & 1041 & 1707 & $189 \cdot 3$ & 201.9 & 2145 & 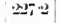 & 239.5 & $252 \cdot 4$ \\
\hline 45 & $1+20$ & $2 \cdot 5 \mathrm{~s}$ & $3 \cdot 87$ & $5 \cdot 16$ & $6 \cdot 45$ & 773 & 9.02 & $10: 31$ & 1160 & $12 \cdot 89$ & 258 & $38 \cdot 7$ & $51 \cdot 6$ & $6.4 \cdot 5$ & $77 \cdot 3$ & $90 \cdot 2$ & $103 \cdot 1$ & 1160 & $128 \cdot 4$ & 141.8 & 1547 & $167 \cdot 6$ & 180.5 & 1934 & $206 \cdot 2$ & $219 \cdot 1$ & 2320 & $244 \cdot 9$ & $257 \cdot 8$ \\
\hline 46 & $1 \cdot 32$ & $2 \cdot 63$ & 305 & 5.26 & $6: 58$ & 789 & $9 \cdot 21$ & 10.52 & $11 \cdot 84$ & $13 \cdot 15$ & $26 \cdot 3$ & $39 \pi$ & $52 \cdot 6$ & 65.8 & $78 \cdot 9$ & $92 \cdot 1$ & $10 \overline{2} 4$ & 118.4 & 1315 & $144: 7$ & 1578 & 1710 & 184.1 & $197 \cdot 3$ & 2104 & 2436 & 2367 & $249 \cdot 9$ & 263.0 \\
\hline 47 & $1 \cdot 34$ & $2 \cdot 68$ & +02 & $5 \cdot 36$ & $6 \cdot 70$ & $8 \cdot 04$ & $9 \cdot 38$ & $10 \cdot 72$ & $12 \cdot 06$ & 1340 & 26.8 & 40.2 & 53.6 & 650 & $80 \div$ & 93.8 & 1072 & $120 \cdot 6$ & $134 \cdot 0$ & $147 \cdot 1$ & $160 \%$ & $174 \cdot 2$ & $18 \div 6$ & 2010 & 2144 & 2278 & $241 \% 3$ & $234 \cdot 6$ & 2680 \\
\hline 48 & 136 & 273 & 4.09 & 546 & $6 \div 2$ & $8 \cdot 18$ & $9 \cdot 55$ & 10.91 & $12.2 \mathrm{~s}$ & 1364 & $27 \cdot 3$ & $10 \div 8$ & $54 \cdot 6$ & $68 \%$ & $81 \cdot 8$ & $95 \cdot 5$ & $109 \cdot 1$ & $12: 2 \cdot 8$ & $136 \cdot 4$ & 150.0 & 1637 & $177: 3$ & 1910 & $204 \cdot 6$ & 218.2 & $231 \cdot 9$ & 245.5 & $259 \div$ & 2725 \\
\hline 49 & 1839 & 277 & $4 \cdot 16$ & $5 \cdot 55$ & $6 \cdot 94$ & $8: 32$ & 971 & $11 \cdot 10$ & 12.48 & 13.87 & 277 & $41 \cdot 6$ & $55 \cdot 5$ & $69 \cdot 4$ & $83 \cdot 2$ & $97 \cdot 1$ & 1110 & 1248 & 1387 & 1526 & 1664 & $180-3$ & $194 \div 2$ & $20 \mathrm{~s} \cdot 1$ & 221.9 & 235 's & 2497 & 2635 & 274 \\
\hline 50 & $1 \cdot 41$ & 282 & $4: 23$ & $5 \cdot 64$ & $7 \cdot 05$ & 8.46 & $9 \cdot 87$ & 11.28 & 1269 & $1 \cdot 1 \cdot 10$ & $28 \div 2$ & $42 \cdot 3$ & 56.4 & $70 \cdot 5$ & 84.6 & 987 & 1128 & $126 \cdot 9$ & 141.0 & 155.1 & 169.2 & 183.3 & 1974 & 211.5 & $225 \cdot 6$ & $239 \cdot 7$ & 253.8 & 26799 & 2820 \\
\hline
\end{tabular}




\section{APPENDIX D.}

\section{LIST OF USEFUL BOOKS.}

(a) Chemistry.

Roscoe and Schorlemmer. A Treatise on Chemistry. 1898. London.

Beilstein. Handbuch der organischen Chemie. 1897. Hamburg and Leipsic.

Watts' Dictionary of Chemistry (edited by Morley and Muir). 1896. London.

(b) Analysis.

Fresenius. Quantitative Analysis. (Translated by C. E. Groves.) 1895. London.

Allen. Commercial Organic Analysis. 1898. London.

(c) Milk:

Wynter Blyth. Foods: their Composition and Analysis. 1898. London.

Bell. Foods. 1883. London.

Leffmann and Beam. Analysis of Milk and Milk Prodncts. 1897. Philadelphia.

Pearmain and Moor. Analysis of Food and Drugs. Part I. 1897. London.

Aikman. Milk, its Nature and Composition. 1899. London.

Konig. Chenie der Menschlichen Nahrungs- und Genussmittel. I893. Berlin.

Duclaux. Le Lait. 1894. Paris.

(d) Butter.

Zune. 'Traité d'analyses des beurres. Paris.

Besana. Sui metodi atti a distinguere il burro naturale dal burro artificiale e le loro miscegle. 1891. Lodi.

Benedikt and Lewkowitsch. Analysis of Oils, Fats, and Waxes. 1895. London.

Wright. Fixed Oils, Fats, Butters, and Candles. 1898. London.

(e) Wuter Analysis.

Leffmann. Water Analysis. 1895. Philadelphia. 
(f) Bacteriology.

Crookshank. A Text-Book of Bacteriology. 1898. London. Pearmain and Moor. Applicd Bactcriology. 1898. London. Lehmann and Neumann. Essentials of Bacteriology. 1897. London.

Lafar and Salter. Technical Mycology. 1898. London. Frankland (P. and G.). Nicro-organisms in Water. London. Slater and Spitta. An Atlas of Bacteriology. 1598. London.

(g) Periodiculs.

The Analyst.

The Experiment Station Record.

Milch-Zeitung.

Landwirthschaftliche Versuchsstationen.

The Journal of the Royal Ayricultural Society.

The Journal of the British Dairy Farmers' Association.

Stazioni sperimentali Agraric Italiane.

L'Industrie Laitière.

The Journal of the Chemical Society.

The Journal of the Socicty of Chemical Industry. 


\section{N D E X.}

\section{A}

AввÉ refractometer, 285, 287.

Abnormal milks, 121, 122.

Absorption-

Bromine, 276.

Iodine, 274.

Potash, 266.

Acetic acid and acetates, 7,41 .

Acetic acid, Solubility of butter fat in, 273 .

Acetyl-derivatives of milk-sugar, 17.

Acid-

Acetic, 7, 41.

Acrylic, 41.

Benzoic (as a preservative), 139.

Boric (as a preservative), $75,139$.

Boric, Detection of, $75,140$.

Boric, Estimation of, 76 .

Boric, Estimation of, Th ompson's method, 76.

Butyric, $35,43,46,47$.

Capric, $35,45,46,47$.

Caproic, 35, 44, 46, 47.

Caprylic, 35, 44, 46, 47 .

Citric, 7.

Citric, Estimation of, 77.

Elaidic, 48.

Formic, 41, 69, 145.

Galactinic, 16.

Gluconic, 8.

Glyceric, 40.

Glycollic, 41 .

Glyoxylic, 41.

Lactic (see also Lactic acid), 18-20.
Acid-

Lactic, Estimation of, $113,115$.

Lacto-bionic, 8, 16 .

Lauric, 45, 46, 47.

Linolenic, 48, 49.

Linolic, 48, 49.

Mucic, 16.

Myristic, 35, 45, 46, 47.

Nitric, Estimation of, 234 .

Oleic, 35, 47, 49.

Oxalic, 41.

Palmitic, 35, 45, 46,47.

Pecto-galactinic, 16.

Phosphoric, Estimation of, 74 .

Salicylic (as a preservative), 139,144 .

salicylic, Detection of, 141 .

Sarco-lactic, 19.

Stearic, 35, 45, 46, 47, 49.

Sulphuric, Estimation of, 74 .

Sulphuric, Estimation of strength of, 177.

Tartronic, 41.

Acidity-

Determination of, 113 .

Development of, 8 .

due to lactic acid, $1 \mathrm{~s}$.

Estimation of, in commercial milk-sugar, 319.

of sour milk, 114.

Acids, Action of-

on albuminoids, 21 .

on glycerol, 41 .

on milk-sugar, 8, 16.

on oleic acid, 47.

Acids, Fatty (see also

Soluble and insoluble

fatty acids), 1, 43-49.
Acids of series-

$\mathrm{C}_{n} \mathrm{H}_{2 n+1} \mathrm{COOH}, 43-46$.

$\mathrm{C}_{n} \mathrm{H}_{2 n-1} \mathrm{COOH}, 47$.

$\mathrm{C}_{n} \mathrm{H}_{2 n-3} \mathrm{COOH}, 4 \mathrm{~s}$.

$\mathrm{C}_{n} \mathrm{H}_{2 n-5} \mathrm{COOH}, 4 \mathrm{~s}$.

Acids, rolatile, Estima-

tion of, 117.

Acrolein, 40, 42.

Action-

General, of hydrolysts, 32.

of acids on-

albuminoids, 21 .

glycerol, 41.

milk-sugar, 8, 16.

oleic acid, 48.

of alkalies onglycerol, 41. oleic acid, 48.

of cold on milk, 154 .

157.

of enzymes on-

albuminoids, 21 .

milk-sugar, 17.

of heat on-

albumin, 27 .

albuminoids, 21.

fat, 37 .

lactic acid, 18 .

milk, 145-154.

milk-sugar, 9, 15.

of hyrlrolysis, 32.

of micro-organisms on milk, 225.

of micro-organisms on milk, Products formed by tle, 227 .

of rennet, 23,298 .

of rennct, Conditions influencing. :300.

of rennet, Intluence of tcmperature on, 300 .

of salt on butter, 248 .

Adulteration of-

butter, 291 .

Detection of, 291 . 
Adulteration of -

cheese, 31\%.

liy foreign fat, 317 .

liy skimming, 317 .

conmercial milksugar, 319.

cream, 216,224 .

milk, 136-143.

ly ammonium salts, 138.

by lirains and mammary tissue, l3s.

by cane-sugar, 137.

by dextrin, 137.

l,y glycerine, 137 .

by mineral matter, Alcoholic soda solution, 135.

by preservatives, 139.

by salt, 135 .

by starch, 137.

Adulteration of milk,

Detection of, 136-138, 140.

Advice on the choice of separators, 211.

Agar, Nutrient, 237.

Albumin (see also Lactallumin), 6, 23, 24, 27,28 .

as alkaline salt, 6,24 .

Composition of, $2 S$.

Estimation of, los. 112.

Densimetrie, 110.

Polarimetric, 112.

Heat of combustion of. 335.

in colostrum, 130 .

in gamoose milk, 329.

in sterilised milk, 150 , 152-154.

Preparation of, 28.

Properties of, 27 .

Action of heat on, $145,1501,154$.

Reactions of, 24. 28.

Albuninoid ammonia, 23:?.

Alhuminoils (see Proteirls), ], 6, 7, 2()-32.

Allumose and perton nitrogen, Estimation of, in rhecse, 313.

Albumeses, 21 .

in chcese, 309, 313.

in colustrum, 130.

in milk, 24.
Alcohol-

Behaviour of butter with, 273.

Estimation of, 11\%, 118.

in milk, 34 .

Micro-organisms producing, 226 .

Use of, for preserving milk samples, 144 .

Alcoholic extract in cheese, Estimation of, 315.

Alcoholic fermentation, 6.

266.

Aldehydes, $8,12,13$.

Aldehydrol, 8, 12, 13, 17.

Alloses, 8, 15, 17.

Alkali-

Salts of, 7 .

Alcoholic, 266.

Alkalies--

Action of, on glycerol, 41.

on oleic acid, 48.

Estimation of, 74, 75 .

Alkaline salts, 7 .

Alkalinity, Estimation of, in soluble ash. 73.

Alteration of specific gravity by change of temperature, $66,67$.

Amidic nitrogen, Fstimation of, in eheese, 312.

Amido-componnds, 22, 32.

in cheese, 306, 305, 312.

Anmonia-

Free and albuminoid, 232.

-free water, 234.

in rherse, Estimation of, $312,316$.

Amnonium-

chloriale solution, Staudarl, 233.

molylulate solution, 23.5.

salts. Arlulteration of milk l, 1,35 .

Amphioteris reaction, 8.

Anyl alcolool-

as a solvent, 115.
Amyl alcohol-

for milk testing, 177, 185.

Use of, in fat estimation, 115.

Anabolic ratio, $335,336$.

Analysis of -

butter fat, 257-291.

buttermilk, 119.

cheese, 309-317.

cream, 115, 179, 187, 189.

condensed milk, 116.

decomposed milk, 116 .

fermented milk, 117 .

kephir, 117.

koumiss, 117 .

milk products, 115.

samples, 163.

old butter, 295 .

skim milk, 116, 177.

water, 231-237.

Interpretation results of, 236.

whey, 119.

Proximate, of butter, 251-256.

Proximate, of butter, Interpretation of results of, $\mathbf{2 5 5}$.

Analytical--

characteristics of sterilised milk, 150.

problems, Solution of, 197.

properties of butter, Influence of keeping on the, 292-295.

Annatto--

Detection of, 139.

Use of, for colouring milk, 139.

Apparatus-

1)rying, 71.

for estimation of fat in milk, 99, 171,174, 1S1-184, 191, 19?.

for estimation of heat evolved ly the action of sulphuric acid on butter fat, 278.

for estimation of viscosity, 290.

for observing the behaviour of butter on melting, 291.

for sampling, 160 . 
Appeal to the cow, 136. Average specific gravity

Aqueous extract of of milk, 55 . cheese, Estimation of, Ayr'shire cows, Composi310.315 .

Arachis oil, Density of, 284.

Areometric method for the estimation of fat, 192.

Argonin, 320.

Artificial human milk, 336.

Artificial thickening of cream, 224.

Ass, Milk of, 834 .

Composition of, 323 , 334.

Sugar of, 322, 334 .

Asymmetric carbon atoms, 13.

Ash, 3.2.

Composition of, 32.

Density of, in milk, 65.

Estimation of, 73. in commercial milk. sugar, 319. in cream, 115.

in cream, Ratio between water, solids not fat, and, 215 .

Insoluble, 33.

Composition of, 33 . Estimation of, 73 .

of cheese, Estimation of, $310,311,315$.

of cream, Composition of, 217 .

of human milk, Composition of, 327 .

Ratio of milk-sugar, proteids, and, 121 .

Ratio of milk-sugar, proteids, and, in cream, 216.

Soluble, 33.

Estimation of, 73 .

Variations of, in milk, 121.

Attraction, Capillary (see Surface energy).

Automatic burette, 175.

Average composition of cow's milk, 120.

Average composition of milk fat, 35 .

Average specific gravities, Rules to, 64 . tion of milk of, 125, 126.

\section{B}

BACILLI, 2:25.

Hay and potato, 227.

Bacillus syncyanus or cyanogemes, :228.

lactis erythrogenes, 228.

tuberculosis, 220,229 .

Bacteria, 2:25.

Bacteriological examina. tion of water, 237 .

Bases, 7 .

Basic nitrogenous substances, 34.

Bath, Water-, 72.

Behaviour of butter on melting, 290.

Behaviour of fat with solvents, 273 .

Behaviour of milk with ether, 1, 2, 3 .

Bellelay cheese, 307 .

Bichromate, potassium, Use of, for preserving milk samples, $1+4$.

Biological and sanitary matter's, $2 \cdot 25-244$.

Birotation, 9, 10, 18.

Birotation ratio, Estimation of, 318.

Bitcl, milk of, Composition of, 323 .

Bitter milk, 228.

Blood, cause of red milk, 228 .

Blue milk. 22S.

Boiling points (see under names of substances). of acids of series $\mathrm{C}_{n} \mathrm{H}_{2 n+1} \mathrm{COOH}, 46$. of water, $3+7$.

Bondon cheese. 303.

Borax (as a preservative). $139,140$.

Borax, Estimation of, in butter, 254, 25.7.

Boric acid-Adulteration of milk with, $139,140$.
Bitter taste in milk, 227.
Boric acid-

as a preservative, 140.

Detection of, 75 .

Detection of, in butter, 254 .

Estimation of, 76 .

Estimation of. in but. ter. 2.54

Injurious effects of, 139.

Bottles, Gerlser, 184.

Leffmann-Beam, 175.

Standardisation of, 345.

Brains, Achlteration of milk with, 138 .

Brie cheese, 303,307 .

Bromhydrins, 4 l.

Bromineabsorption, 274, 276.

Buffalo-

Milk of (see also Gamoove), 327.

milk of, Composition of, $323,327,328$.

milk of, Fat of, 322, 328,329 .

Burette, Automatic, 175.

Burettes, Standardisation of, 344 .

Butter, 245-297.

Action of salt on, $2+8$.

adulteration with water, 2.5.

Characteristies of different classes of, 256.

Condition of globules in, 249.

Composition of, 245, 246.

Constitution of, 2,245 , 250.

l lefinition of, 245 .

Detection of formalin in, 255.

Detection of nitrates in, .255 .

Detection of preservatives in, 2.54, 255 .

Detection of sulphites in, 255.

Difference between fresh and salt, 248, 256.

Effect of keeping on water in, 248 . 
Butter-

Estimation of borie acid and horax in, 254.

Estimation of curd in, 253 .

Estimation of fat in, 2.53.

Estimation of preservatives in, 2.54, 255 .

Estimation of solids not fat in, 2.53.

Estimation of solids not fat and salt in, 253.

Estimation of total nit rogen in, 253 .

Estimation of water in. 2.52 .

Evidence of existence of mucoirl menbrane in, :2, 246.

Fresh, 246, 245, 256.

Influence of temperature on churning. 251.

Influence of temperature on proportion of water in, 2.5 l, 25j.

Interpretation of results of analysis, 255.

Piekledl, 255.

Preparat ion of samples of, for analy:is, 25], $25 \%$.

Preservatives in, 2.il.

Propurtion of water in, 247 .

Proximate analysis of, 25].25.

Salt, 246, 245, 2.56.

Stamlarl for water in, 20is.

Testing of, 180, 1s8. ls. 9 .

"Thick," "24!!

Variations of water in, $247,2+5$.

Working of, :29.

Butter-fat-

Analysis of, $257 \cdot 29.91$.

Bohaviour of on melt. ing. 290 .

Behaviomr of, with solvents, :273.

Jensity of, $37.39,291$. בx.5.
Butter-fat-

density of, Limits of, 284.

Detection of adulteration of, 291 .

Detection of cocoa-nut oil in, 291.

Detection of margarine in, 292.

Difference between, and other fats, 2.57 .

Estimation of bromine and iodine alsorption of, $27 t$.

Estimation of heat evolved by sulphu. rie acid hydrolysis of, $27 \%$.

Estimation of insoluble fatty acids in, 268 .

Estimation of molecular weight of. 267.

Estimation of refractive indlex of. 285.

Estimation of salonification efuivalent of, 261 .

Estimation of soluble and insoluble fatty acirls in, 268 .

Estimation of visensity of, $29 \%$

Estimation of volatile fitty atcicls of, 258 .

Intluence of keeping in analytical properties of, :(??.?

Microsenpical examination of, under wolurised light, 27!.

Plivsical examination of, 279.291.

Solubility of, in acetic acid. :-i:3.

Sperifie tests for adulteriuts of, :-7:2.

Buttermilk, :2!6-297.

Anilysis of. 119.

Ish of, 2eni.

ash of, Compusition if, :ali.

Compusition of, ?:96.

Definition of, es!ti.

Muroiel proteisl in, 29 it.

l'roperties of, 297.

'Testing of, 17\%, 15.5.
Buttermilk-

Variation of fat in, 296.

Butyrates (see Butyric acill).

Butyric acid, 35, 43.

Niero-organisms prolucing, 226, 22\%.

Ratio of, to caproic aeid in butter-fat, 264.

Butyrin, 35.

Butyro-refraetometer, 257.

Byre test, I36.

\section{C}

Cacio-cavallo (cheese), $302,304,306$.

Calcium, Estimation of, 73.

Calculation of-

arllerl separated milk, 138.

added water, 136 .

density of total solids, (i2.

fat, Formulae for, 58, $59,160,61$.

fat in cream from spccifie gravity. $21 \%$. pereentage of steri. lised milk in fresh milk, 153.

Camel, milk of, Composition of. 323.

Camembert cheese, 301, $303,307,314$.

Cane sugar-

Arldition of, to con. flensed milk, l4ti.

Arlulteration of milk hy, 137 .

Deteetion of, in milk, 89.

Estimation of, in milk, 87.

Heat of combustion of, 333.5.

siweetness of, 6.

Cans, sample, 16:.

Cantal rheese, :316.

Caprity, Heat of apparatus, 278.

('apillary attraction (see sinrface ener(ny).

Capric acil, 43. 
Caprin, 35.

Caproie acid, 44. Ratio of, to butyrie acid in butter-fat, 264.

Caproin, 35.

Caprylic aciol, 44.

Caprylin, 35.

Carbon dioxide-

Estimation of, 118.

In milk, 34.

Caraway elieese, 302.

Casein, 6, 25.

Action of rennet on, 25.

as a salt, 24 .

$\beta, 29$.

Behaviour of, with lime salts, 25 .

Combination of, with phosphates, 6, 25.

Composition of, 25,26 .

Estimation of, 112.

Estimation of, densimetric, 110.

Genuine, 26.

Heat of combustion of, 333 .

in eolostrum, 130.

Modifieations of, 26.

of gamoose milk, 329 .

Preparation of, 27 .

Properties of, 25 .

Reactions of, 24 .

Rotatory power of, 26.

State of, in milk, 6.

Caseinogen, 23.

Cat, milk of. Composition of, 323 .

Change-

(ehemical), Law of, 10.

in eomposition of eol. ostrum, 131

in eomposition of milk on standing, 133.

of rotatory power (see Birotation ; Nultirotation).

of $r$ tatory power of milk-sugar on heating, $15,150$.

of temperature, Alteration of specific gravity of milk by, 66

Characters of sterilised milk, Analytieal, 150.
Characteristics of skim- Cheesemed and separated milk, 20 j.

Cherldar eheese, 30:2, 304.

\section{Cheese-}

Adulteration of, 317 .

Analysis of, 309-317.

Classification of, 301 302 .

Compostion of, 302 $308,314$.

Difference between various kinds of, 301,302 .

Estimation of amidonitrogen in, 312.

Estintation of anmonia in, 312.

Estimation of albumose and peptone nitrogen in, 313.

Estimation of alcoholic extract in, 315 .

Estimation of agneous extract in, 315 .

Estimation of ash in, $30:), 311,315$.

Estimation of digestible proteids in, 313 .

Estimation of fat in, $309,311,315$.

Estimation of indigestilile proteids, 312 , 313.

Estimation of nitrogen in, 311 .

Estimation of primary products of ripening in, 310,315 .

Estimation of proteicls in, $310,313,315$.

Estimation of products of ripening in, $310,315$.

Estimation of salt in, $310,311,315$

Estimation of secondary products of ripening in, 310 , $310,316$.

Estimation of soluble extract, 310 .

Estimation of volatile acids, 316.

Estimation of water, $309,311,315,31 \%$.

Hard, :02, 304.
Heary metals in, 30 s.

Insolulble fatty acirls of cream , 30:3.

Moulds in, 2:29.

Preparation of, 298 .

Preparation of fat of, for analysis, 317.

Proteids of, 305-30-.

Qualitative test for peptones in, 313.

Rennet, 301, 302.

Ripening of, 308.

Soft, 301, 303.

Sour milk, 302.

Testing of, 180, 185, 189.

Chemical analysis of water, 231-237.

Chemical change, Law of, 10.

Chemical control of churning, 297

Chemical control of the dairy, 158-224.

Chemist, dairy, Duties of, 158 .

Cheslire ehcese, 302 , 304.

Chlorhydrin, 41.

Chlorides, 7 .

Estimation of, 75, 253.

Estimation of, in water, 232.

Chloroform, Use of, for preserving milk samples, 144.

Choice of separator's, Advice on, 211-214.

Chnlera, 230.

Cholesterol, 42. in colostrum, 130.

Chromogenic organisms, 228.

Chrysotile-

Use of, for total solids estimation, 70 .

Use of, for fat estiniation, 101.

Churning-

Chemical control of, 297.

Influence of temperiature on, 2.5].

of butter, 249 .

Theories of, 249.

Chymase (see Rennet).

Chyno-caseoses, 21, 30. 
Citric acir anel citrates, Composition ofi.

Citric acid-

Estimation of 77 . in liumau milk, 3:27. in gamoose milk, 330 . in sterilised milk, 150 .

Inversion of canesugar by, Ss.

Cladothrix, 225.

Classification of -

eheese, 301.

micro-olganisms, 2.25. milks, 3:l.

sehizomycetes, 225 .

Clotterl crean, 219.

Composition of, 219.

Ratio of solids not fat to water in, 2:0.

Testing of, 180, 188, 189.

Coagulation of alloumin by heat, 6,27 .

Coagulation ly salts of mercury. .5.

Coeoa, Milk, 320.

Cocon-nut uil, 25s, 267. $272,254$.

Detection of, in lintter, 291.

Cold, Action of, on milk, 154.

Cold storage for preserving milk samples, 145 .

Colloids. 7.

Colostrum, 129.

Colour of milk, 7 .

Colour of water, 231 .

Colour tests, Specific, for aclulterants of lintter, 272.

Colonred-sulistanessMiclo-organisms poroAucing 226, 2:25.

Colomring-matter of fat, 49.

Croloming - matter of milk, 34.

Colouring of milli, Arti. tirial. 13:4.

Combinstion, II 'at of (sece Herel af rom:ustion).

Commercial milk.sugar, 318.

Componition--

Chemiral, of milk, 1:20.

(ieneral, of milk, 1. albumin, 28.

albuminoids, 20.

ash of milk, 32 .

butter, $245,2+6$.

lutter, Influenee of keeping on the, :9:2$296^{\circ}$.

luttermilk, 296.

luttermilk, ash of, 296.

casein, 25,26 .

chees:, 302.30s.

clotted cream, 219 .

colostrum, 130.

colostrum, human, 324.

eonrlensed milk, 146 .

cream, $215,: 216$.

cream, ash of, 217 .

cream, frotl of, 219 .

eurd, 298 .

diabetie milk, 337.

fat of milk, 35

frozen nilk, 155, In6, 157.

human milk, 323, 324, $3: 5$.

human milk, ash of, 327.

insoluble ash, 33

kephir, 243 .

koumiss, 24]-243.

mazolnu. 244.

milk, l:20.

milk. Change of, on standing, 1:33.

milk-cocoa, 320.

milk of different animals, 3:23.

milk of different hreeds of catt le, 123, $1:-4,1: 5,1: 26$,

milk of the ass, 323, $3: 34$.

milk of the hutfalo, $3: 3,327$.

milk of the ewe, 3:3, 331 .

milk of the gamoose, $32 \mathrm{~s}$.

milk of the gamoose, fitt of, $3: 2 !$

milk of the goat, :3:3, $33: 2$

milk of the mate, 33:3, 3:33.

milk-puwlers, 149.
Composition of-

mueoid proteid, 28.

peptonised milk, 337.

produet s of hydrolysis

of easein, 29.

salts of milk, 33 .

separat or slime, 210.

separator slime, ash of, 2Il.

skim milk, 209, 216.

solicls not fat, 12l.

sour milk whey, 299 .

whey, 295, 299 .

Compounds, Amitlo-, 32 .

Conrlensed mare's milk, 333.

Condenserl milk, I 46 .

Analysis of, 116 .

Testing of, 187.

Condition, Milk out of, 228.

Condition of fat in butter, 250.

Conditions influencing action of rennet, 300 .

Conditions of development of micro-organisms, 226 .

Configuration of glieose and galactose, 18.

lactic acirl, 19 . milk-sugral, I2.

Constituents-

Nineral, 3:2.

of milk, $\mathrm{l}$.

of solids not fat, Density of, $6 \overline{5}$.

Other, 34 .

Constitution of albuminoiels, 20.

butter, $2, \mathbf{2 4 5}, 250$.

eream, 3,215

fat of milk, 34 .

glucose anil galactose,

Is.

lactic acid. Is.

milk-sugar, 1:2.

oleic and elaidic acids, 45.

Contamination of milk, $2: 30$.

Control, Chemieal, of churning, $29 \%$.

the dairy, 158 .

milk during delivery, 19.5.

separators, 209. 
Conveyance of -

disease by milk, 229.

disease by milkers, 230.

disease by water, 230 .

Cooling milk, Fractice of, in Denmark, 4

Copper solutions, Reduction of, 15, 82 .

Copper-zine couple, 234 .

Corps granuleux, 130 .

Correction of specific gravity for change of temperature 66 .

Cottonseed oil-

Density of, $28 t$.

Test for, 272 .

\section{Cow-}

Appeal to the, 136 .

Milk of, 1, 120, 321. 32:3.

milk of, Composition of, 120,323 .

Cow's milk koumiss, 24l 243.

Cream-

Analysis of, 115.

Artificial thickening of, 224 .

Ash of, $216,217$.

-cheese, 302, 303.

Clotted (see Clotted cream).

Composition of, 214216.

Constitution of, 3 .

Definition of, 214 .

Density of, 217-218.

Estimation of fat by measurement 102.

Estimation of fat from total solids, 2:20.

Evidence of existence of mucoid membrane in, 3 .

Formation of, 7 .

Froth of, 219.

Physical state of fat in, 218, 338.

Preservatives in, 140 .

Proportion of milksugar in. 3, 216.

Proportion of proteids in, 216.

Ratio of solids not fat to water in, 215, 220.
Cream-

Relation between fat and specific gravity in, 217 .

Relation between fat Decision of Court of and total solids in, 2.20.

Relation between milk - sugar, proteids, and $\mathrm{a}, \mathrm{h}$ in, 216

Rising of, 133, 151, 195.

rising of, Change of (omposition on, 134, 135.

lising of, Explanation of, 206,208 .

Rising of, in sterilised milk, 150,151 .

rising of, Precautions to prevent, 135.

Standard for, 216 .

Testing of, 178, 187, 189.

Thickness of (see Thickness of cream).

Creamometer, Use of, in detecting sterilised milk, 152 .

Crescenza cheese, 307 .

Critical temperature of butter fat, 273 .

Crystallised milk-sugar, 9.

Crystalloids. 7 .

Curd, 246,298 .

Composition of, 298.

Estimation of, in butter, 253.

Curdled milk-

Ash of. 33.

Determination of cause of, 203.

Curdling-

by acidity, 7 .

by heat, 7 .

by rennet, 298, 300 .

milk, Micro - organisms, 226,227 .

\section{D}

\section{DAIRY-}

Chemical control of, 158-2:4.

chemist, Duties of, 158.
Dairy-

shorthorns, Composi. tion of milk of, l:3. 125.

Queen's Bench that milk must be sold in its natural state, 13.5.

Decision of Justices at Pontypridd that boric acid is an adulterant of buttel 140 .

Decomposerl milk, Analysis of, 116 .

Decomposition of fat, $49,29 \cdot 2-296$

Decomposition of milk. $225 \cdot 225$

Decomposition products of fat, 49.

Definition of butter, $24 . \overline{5}$. buttermilk, 296. cream, 214.

Dehyrlrolactic acid, 18, 19.

Denmark, Practice of cooling milk in, 4.

Densimetric method of fat estimation, 103.

Density (see also Specific (jravity).

Alteration of, by change of temperature, 66 .

Determination of, 53 , $164,253$.

Modes of expression of, 51 .

of acids of series $\mathrm{C}_{n} \mathrm{H}_{y_{n+1}} \mathrm{COOH}, 46$. of ash in milk, 65. of bntter fat, 251-285. of butter fat, Estimation of, 83.

of cream, $217-218$. of fat of milk, 37-39. of fat and solids not fat in milk, 62 . of glycerol, 40 . of lactic acid, 1 ?. of liquid portion of fat, 37 .

of milk-sugar, 9,11 . of milk-sugar in milk, 65. of proteids in milk, 65 .
Definition of, 51 . 
Density-

of separated milk,33s.

of total solids of milk, 63.

of water at different temperatures, 51 .

if watered milks, 196 . 199.

Relation between Deutero-caseoses, 31 .

fat, solids not fat Development of microand, in milk, $56 \cdot 63$.

Derby eheese, 302 .

Detection of -

adiled water, 132,136 , 196-1!9.

adulteration of lutter, $255,2 ! 1,292$.

adult eration of cheese, 317.

adulteration of commercial milk-sugar, 319.

horic acid, 75 .

cane-sugar in milk, s9.

cocoa-nut oil in butter, 291 .

colouring-matter, 139.

fluorine compounds, $1+1$.

formaldehyile, 142.

gelatine in eream, 2024.

nitric acicl, 234,254 .

nitrites, $2: 34$.

phosphates, 235 .

preservatives, 140-143, 254.

silicylic acirl, $1+1$.

separated milk in milk, 132. 13\%.

starch, $89,13 \%$.

starch in cream, 224 .

steriliserl or diluted comblenserl milk in milk, 152.

Determination (see Estimation)-

of cause of high specitie gravity, $1 ! 99$.

of cause of low spereitic gravity, 197.

of eause of poor milk, 2010.

of ranse of solul or rimdled milk, 203.

of estuse of sweet taste., 200 .

of eause of mumsual taste or snell, 201 .
Determinationof clensity, 53, 164,283. of nature of seliment, 204.

of reason for milk leing thiek, 204.

Deutero-allumoses, 2l, 29,30 .

or wanisms, Conditions of, 2.26 .

Deronshire eream (see Clattel cream).

Dextrin, Ailulteration of milk by, 137 .

Dextrose (see Glucase).

Diabetie milk, 337.

Dichloro-phenol, Use of, for preserving milk samples, 144 .

Difference between butter fat and other fats, 257 .

Difference bet ween fresh and salt lutter, 24s, 25 is.

D ifferenee between various kinds of cheese, 301-30s.

Digestible proteids in checse, Estimation of, $31 \%$.

Digestibility of cheese, 315.

Iiluterl condensed milk, Composition of, 148 . Detectim of, in milk, 152.

Dilution of eream to 2.23.

I) pht heria, 230.

Diplucoeci, 2:5.

Dirretims foll use of lactometers, 164 .

Dise:se-

Converance of, by milk, 2.:-?.

Conveyanee of, by milkers, $2: 30$.

Comverance of, by water, 2:30.

Foot ambl muth, 2:9.

Distillation, Rate of (see linete of divfillation).

Districe stmmlard in water andlysis, :2:66. standard thickness,
Drving apparatus, 71 .

Dulcitol, 17.

Dunlop cheese, 302.

Dutch cheese, 302, 305, 307.

Iutch cows, Composition of milk of, 125, 126 .

Dysalloumoses (Dyspeptones), 2!, 29, 30 .

Dyscaseoses, 29, 30.

\section{E}

Enay cheese (Dutch), $302,305,307$.

Effects-

Injurious, of preservatives, 139.

of keeping on proportion of water in lutter, 248.

Elaidic acid, to.

Elephant, milk of, Composition of, :323.

Enmenthal cheese, 302, $304,306,307$.

Emulsion, Milk regarded as anl, 4.

Eudosmose and exos. mose, :-2.

Energy, Surface, of small partieles, 4.

Enzymes-

Aetion of, on milkslugar, 17.

Hydrolysis of albu. minoids by, 21, 29.

in eheese, 295, 305 .

in human milk, 327 .

in milk, 6, 24, 34, 298 .

Ripening of cheese by, 308.

Secretion of, hy mieroorganisms,

Equivalent, Saponification, 266 .

Estimation of acirlity, 113.

aciulity of commereial milk-sugar, 319.

:11minin, 108-112,152. albuminoid ammonia, 23:.

albumose in cheese, 313.

aleohol, 117. 
Estimation of-

alcoholic extract in cheese, 315 .

alkalies, 75 .

alkalinity of soluble ash, 73.

amidic nitrogen in cheese, 312 .

ammonia in cheese, $31: 2,316$.

aqueous extract in cheese, 315.

ash, 73 .

ash of cheese, 309 . 311,315 .

ash in commercial milk-sugar, 319.

birotation ratio, 318 . boric acid, 76 .

bromine absorption, 276.

calcium, 73 .

cane-sugar in milk, 87.

carbonic acid, 118.

casein, 108-113.

chlorides, 73, 75, 253.

chlorine in water, 232.

citric acid, 77 .

curl in butter, 253 .

density of butter fat, 283.

digestible proteids in cheese, 313.

fat, Areometric, 192.

fat, by measurement of cream, 102.

fat, Centifrugal, 170 $19 \cdot 2$.

fat, Densimetric, 103.

fat, Gravimetric, 90102.

fat in butter, 180, 188, $189,253$.

fat in cheese, 180,185, $189,309,311,315$.

fat in cream, 115, 172, $178,187,189$.

fat in cream from specific gravity, 217 .

fat in cream from total solids, 220.

fat, Indirect, 102-104.

fat, Optical, 103.

fat, Volumetric, 102, 170-192.

free ammonia, 232.
Estimation of -

heat evolved by the action of sulphuric acid on butter fat, 277.

indigestible nitrogenous substance, 312 . insoluble ash, 73 .

insoluble fatty acids, $268-272$.

iodine absorption, 274 . lactic acid, 113, 115 .

loss on ignition, 232.

magnesium, 74 .

milk-sugar by alcohol, 77.

milk-sugar by Fehling's solution, $82-86$.

milk-sugar by Pavy's solution, $\mathbf{8 6}$.

milk-sugar by polariscope, 78-82.

milk-sugar in commer. cial samples, 318 .

molecular weight of insoluble fatty acids, 271 .

nitric acid, 234.

nitrogen, 105 .

nitrogen in butter, 253.

nitrogen in cheese, 311.

uitrogen in cream, 116 .

oxygen absorbed from permanganate, 235 .

peptones in cheese, 313.

phosphoric acid, 74 .

potassium, 75 .

primary products of ripening in cheese, 310.

products of ripening in cheese, 310,312 , 315.

proteid nitrogen in cheese, 311 .

proteids, 105-113.

proteids in cheese, $310,313,315$.

reflactive index, 285 . 290.

salt in butter, 253 .

salt in cheese, 310 , $311,315$.

saponification equivalent, 266.
Estimation of-

secomlary prorlucts of ripening in cheese, $31 \%$.

sodium, 75 .

solids not fat, 9.5, 100, 115.

solids not fat in lutter, 253.

solubility of butter fat in acetic acid, 273.

solubility of butter fat in alcohol, 273 .

solubility of commercial milk-sugar,318. soluble ash, 73.

soluole fatty acids, $270,271$.

starch in milk, 89 .

strength of sulpluuric acicl, $17 \%$.

sulphuric acid, 74 .

total solicls, 68-70.

total solirls in water, $23: 2$.

total soluble extract in cheese, $310,315$.

viscosity of butter fat, 290.

viscosity of cream, 222 .

volatile fatty acirls, 258-266.

volatile fatty acids in cheese, 316.

water in butter, 252.

water in chees:, 309, $311,315,317$.

water in milk, 70 .

Ethel-

Behaviour of milk with, $1,2,3$.

Emulsification of mucoid by, 2 .

Preparation of, for fat estimation, 94.

Use of, for preserving milk samples, 144.

Ethoxide, Sodium -

Action of, on fat, 36.

Formution of, during saponification, 36 .

Eucasin, 3:0.

Evening milk, morning and, Variation of, 127 .

Evidence for and against existence of membrane round fat globules, 1-6. 
Ewe, Milk of, 322, 331.

Examination

Bateteriological, of water, 2.37 .

Microscopieal, under polatised light, 279 251.

of commercial milk. sugatr, 318.

Physical, of butter fat, $279-291$.

Expansion of

cream, :335.

fat of milk, 281, 3399. milk, (i6.

separated milk, 66), 335.

Explanation of rising of-

cream, 206.

fat glolules, 205 .

Extrate-

Alcoholic, of cheese, 31.5.

Anueous, of cheese, $310,315$.

Soluble, of cheese, 310 .

Extractor-

Soxhlet $\$, 93,94,97$, 9 s.

Simethaul's, 100.

\section{F}

Fat (see also Butler fru), $1-6,34-50,321,326$, 32 ?.

Adulteration of eheese with foreign, 317 .

Change of percentage of, on standing, 13\%. 135.

Composition of, of milk, 35.

Density of, in milk,6.i.

Difference bel ween but ter fat and other, 9.57 .

Fat, istimation of -

Aremetric, 192.

lyy mensurement of ('ream, 10:2.

Centrifural, 1;0-192.

Densimetric, 103.

Gravimetric, !(9-102.

in lintter, 181, 18s, 1.59, 2.53.
Fat, lstimation of -

in clicese, 180, 188, 189, 309, 311, 315.

in cream, 115, 172, $175,187,189$.

in cream from specific gravity, 217 .

in cream from total solids, 2:20.

Indirecet, 10:-104.

Optical, 103.

Volumetric, 102, 170. 192.

Fat in separated milk, l'ercentage of, 209, 224.

Fit. Limits for, 120 , $1.23,13.5$.

Fat of milk, 34-50.

Action of heat on, 37 .

Composition of. 35.

Density of, 37-39.

Expansion of, 39, 3:39.

Heat of combustion of. $39,335$.

of different animals, $3: 21,3: 2.2$.

Refractive index of 39.

Separation of, on soliclification, 37

Solulinlities of, 37 .

Fat, Plyysical state of, in butter, cream, and milk, 2, 5, 250, 338.

Fat, l'reparation of of cheese for analy'sis, 317.

Fiat, Relation betweenand specific gravity in cream, $21 \%$.

and thickness of eream, 2221.

total solidsand specific gritvity, iti-ti3.

Fat, Sime of globmles of, $34,321,323,332$.

Fat, Villiations of -

Ditily, 1:2.

in iditlerent churns, 126 .

in milk, 1:0, 1:3, lin.

in singlo (")ws, 123.

Monthly, 127.

on piltial milking, liz.

Seasonil. 126.
Fat, Variations of with solicls not fat, 129.

Fatty acids, 1, 43-49.

Fehling's solution, 82 . Estimation of milksugar ley, s2-86.

test, s2.

Fermentation-

Alcoholic, 6, 22\%.

Butrice, 227.

Lactic, 18, 226.

of milk-sugar, 1\%.

Felmonted milk, Analysis of, 117 .

Flasks, Standardisation of, 345 .

Fluoborates as preservatives, 139.

Detection of, 141 .

Fluoboric acid, Use of, for preserving milk samples, 144.

Fluorescence, 7 .

Fluoriles as preserva. tives, 139.

Detection of, 141 .

Fluosilicates as preservatives, 139.

Detection of, $1+1$.

Food, Milk as a, and a medicine, 334-337.

Foot and mont li discase, 229.

Fore milk, 129.

Formaldehyde as a preservative, 139

Detection of, 142 .

Deteetion of, in but. ter, 255 .

Injurious effects of, 140.

Formalin (Formine, Formal, or Formol), 142. in butter, 254 .

Use of, for preserving milk samples, 144 .

Formic acirl, 41, 69.

produced on heating milk, 145.

Formula for-

caloulnting fat m erenm from specitic gravity, 217 .

ealculating fat from cream solids, :-200.

calculating fat in milk, 56-65. 
Formula for-

calculating

Gernan cows, Composition of milk of, 125 . separated milk, 207. Gervais cheese, 301, 303, calculating proteids, 314 . $111,112$.

calculating thickness

Glarner cheese, 302,307 . of crean, 223 .

heat equivalent of apparatus, $27 \mathrm{~S}$

rate of distillation, $\because 63$.

relative molecular Maumené figure, 278.

Free ammonia, 232 .

Fresh butter, $\mathbf{2 4 6 , \mathbf { 2 4 7 }}$, 256.

Globules of fat, 1-6. in butter, 249 .

in condensed milk, 147.

in milk, 34 .

Microscopical appearance of, 2 .

Size of, $34,321,323$, 332.

Surface energy of, 4 .

butter, 250 .

Difference between, Globulin, 23, 28 .

and salt butter, 24S, 256.

Froth of cream, Composition of, 219.

Frozen milk, Composition of, $155-157$.

\section{G}

Galactin, 24.

Galactinic acid, 16 .

Galactose, 1\%.

Birotation of, 18.

Constitution of, 18.

Rotatory power of, 15.

Galacto-zymase, 24.

Gamoose, Milk of (see also Buffalo), 32S. 331.

Composition of, $3: 8$.

Fat of, 329.

Proteids of, 329 .

Sugar of, 330 .

Gelatine-

Detection of, in cream, 224 .

Nutrient, 237.

General-

action of hydrolysts, 32.

composition, 1 .

properties of acids of

series $\mathrm{C}_{n} \mathrm{H}_{2 n+1} \mathrm{COOH}$, 46.

Genuine casein, 26.

Genuine, Method of judging whether milk is, $133,135,136$.

in colostrum, 130 .

Gloucester cheese, 302, 305.

Gluconic acid, 8.

Glucose, 17.

Addition of, to condensed milk, 146

Birotation of, 18.

Constitution of, 18.

Rotatory power of. IS.

Glucosone, $\mathrm{S}$.

Glyceric acid, 40.

Glycerides, 1,34 .

Glycerine, Adulteration of milk by, 137.

Glycerol, 3it, 40-42.

Action of acids on, 41 . Action of alkalies on, 41.

Action of lieat on, 40 .

Density of, 40.

Oxidation of, 40

Properties of, 40.

Refractive index of, 40 .

Solubility of, 42 .

Glyceroxide, Formation of, during saponification, 36.

Glyceroxides, 36,4 :

Glycollic acid, 41 .

Glyoxylic acid, 4 l.

Goat, Milk of, 323,332 .

Cheese from, 302.

Composition of, 323 , 332.

Gorgonzola cheese, 302 , 306,307 .

Grana cheese, 305, 306, 307 .
Gravimetric methods for estimation of -

bromine alssorption, 276.

fat, 90-102.

milk-sugar, \$2.85.

Green milk, 228.

Gruyère cheese, 302 , $304,306,30 \%$.

Guernsey cows, Composition of milk of, $125,126$.

\section{$\mathrm{H}$}

Heat, Action of (see Action of he'et). capacity of apparatus, 278.

evolved by the action of brumine on fat, 276 .

evolved by the action of sulphuric acid on fat, $27 \%$.

Heat of combustion of fat, 39,335 .

proteid, 3335.

sugar, 335.

Heary metals in cheese, 308.

High specific gravity, Determination of cause of, 199.

Holstein cows, Composition of milk of, 125 .

Himan colostrum, 324.

Human milk, 3:3-327.

Artificial, 336.

Ash of, 3:2.7.

Citric acid in, 327.

Composition of. 324.

Enzymes in, 327.

Fat of, 322, 326 .

Fat globules of, 321.

Proteids of, 327 .

Reaction of, $: 23$.

Sugar of, 326 .

Taste of, 323.

Variations of, 324-326.

Humaniseri milk, 336 .

Hydrocarbon in fat of milk, 35.

Hydrofluoric acid, Use of, for preserving milk samples, 144.

Hydrolo-albumoses, 21. 
Hyclrolo-caseone, 21 .

Hydrolo-caseoses, 21, 30.

Hydrolysis-

Action of, 32.

of albuminoids, $21,22$.

of fat by alkalies, 35.

of fat "by sulphurie acid, 26.2.

of fat by sulphuric acid, Heat evolver by, $27 \%$.

of nilk-sugar, $S$.

Products of, of albuminoids, 21, 29, 30 .

Products of, of fat, 40-4?.

Hydroly'st, 22.

Hydrolyte, 2.2.

Hyphomycetes, 225.

Hypoxant hine, 34 .

\section{I}

I(xitios, Loss on, 232. Index of refraction (see Refirective index).

Indigestible nitrogenous substance in chcese, Fstimation of, 312 .

Indirect methorls for the estimation of fat, 102. 104.

Intluence of -

keeping on butter, 245, $292-296$.

temperat nue onchurn. inc, 251 .

temperature on water in butter, 249, 256. temperature, \&c., on pereentage of filt in separated milk. 20\%.

Injurious effects of borjc acirl, 139.

formaldehyole, 139. preservatives, 139. salicrlic acirl, 139. steriliserl milk, 146.

Insoluhle aslı of milk, 33.73.

Insoluble fatty acirs, 3.5.

Estimation of, 268 . 272.

Limits of, 272.

of cream chcese, 303.
Insoluble fatty acidsRelation between, and critical temperature, 273.

Inspection of source of water supply, 231.

Interpretation of results of -

bacteriological examination, 2:3S.

proximate analysis of butter, 255 .

water analysis, 236 .

Invertase, 17.

Estimation of canesugar by, S8.

Investigation of water supply, 230-239.

Iorline alssorption, 274.

Iodine solution, Hübl's, 274.

\section{J}

Jersey cows, Composition of milk of, 123 . 126.

Junkets, 320.

\section{K}

Kefris:, Effect of on butter fat, 292-296. on water in butter, 245.

Kephir, 243.

Analysis of, 117 .

Composition of, 24:3.

Kerry cows, Composition of milk of, 123126.

Ketoses, 1.5.

koumiss, 241-243.

Analysis of, 117 .

cow's milk, Composition of, $241-243$

mare's milk, 'om. position of, 241.

\section{L}

Lactalit Min (see also Altumin), 6, 22:2, 27.

Fstimation of, 108 . 112.
Lactase, 17.

Lactation-

Variations of human milk with, 324.

Variations of cow's milk with, 124, 131 .

Lactic acid, 19.20.

Estimation of, 113.

Lactic fermentation, 18, $2 \cdot 26$.

Lactide, 18, 19.

Lactobionic aeid. 8.

Lacto-caramel, 9, 15.

Lactoform, 320 .

Lacto-globulin (see also Globulin), 23, 28 .

Lactometers. .74, 164 167.

Determination of specific gravity by, 165-167.

Faults of, 54 .

Galaine's, 165.

Quevenne's, 164.

Soxhlet's, 164, 165.

Standardisation of, 346.

Thermo-, 165.

Vieth's, lit.

Lacto-protein, 23.

Estimation of, 109.

Lactoscope, 103.

Lactose (see $\mathbf{M} /$ ilk-sugar).

Lacto-somatose, $3: 0$.

Lauric acid, 35, 45, 46.

Lamrin, 3.5.

Law of ehcmical change, Harcourt's, 10.

Law of distribution of a substance between two solvents, 4.

Layer, wivilence of existence of a, round fat globules, 1-3.

Lecithiu, 49. in eolostrum, 130.

Leicester eheese, 302.

Lencine, 20, 2:2, 32.

Leuconostoc, 2:5.

Limlurg chese, 317.

Line (see Culcium).

lime-water as a standard solution, 113.

Limits forash, 133. chlorine, 133. density of butter fat, $38,284$. 
Limits forfat, 120, 132, 135 . potash absorption, 267.

Reichert process, 2.59, $260,262$.

refractive index, $2 ; 9$. solids not fat, 120 , $132,133$.

soluble and insoluble fatty acids, 272 . total nitrogen, 133 . Valenta figures, 274.

Limits of composition of human milk, 32.5.

Limits, Society of Public Analysts', 13:2.

Linolenic acid, 48.

Linolic acid, 48.

Liquid portion of fatComposition of, 37 . Specific gravity of, 37 .

Llama, Composition of milk of, 323 .

Loss on ignition, 232 .

Low specific gravity, De. termination of cause of, 197.

\section{M}

Mariesium, Estimation of. 74 .

Majorcan cheese, 306.

Mammalsmarine, Milk of, 1, $322,323$.

Milk of. 1.

other than the cow, Milk of, 32l-334.

Mammary tissue, Adulteration of milk by, $13 \mathrm{~s}$.

Mannitol, 17

Mare, Milk of, 333.

Composition of, 323, 333.

Sugar of, 6, 322, 334 .

Mare's nilk koumiss, 241.

Margarine-

Detection of, 292.

Properties of, 282, 290.

Mazoum, 244.

Organism from, 227 , 244 .
Medicine, Milk as a fool and a, 334-337.

Meltin -

Behaviour of butter on, 290 .

point of acids of series $\mathrm{C}_{n} \mathrm{H}_{2 n+1} \mathrm{COOH}, 46$. point of fat, 37,291 .

Membran-slim, 2. Composition of, 3. Properties of, 29.

Memlirane-

Mucoid, 2, 3.

round fat globules, 1-6.

Mercury salts-

Coagulation of proteids by, 5 .

Use of, for preserving milk samples, 144 .

Metabolic ratio, 335 .

Metals, Hcavy, in cheese, 308.

M eta - phenylene - diamine, 152, 234.

Meta-phosphoric acid, precipitant for proteids, 82.

Method for analysis of cheese-

Duclaux, 315, 316.

Richmond, 309, 311.

Stutzer, 311-315.

Method for detection of-

added water, 133, 197.

cane-sugar in milk, 137.

Cotton, 89.

separated milk, 13313.5.

sterilised milk, 152.

Method for dilution of cream to standard thickness, 222.

Method for estimation of-

acidity, 113.

acidity in commercial milk-sugar, 3।9.

albumin, 108-112, 152.

alluminoid ammonia, 232.

allumose, 313.

alcohol, 117.

alcoholic extract of cheese, 315 .
Method for estimation of-

amidic nitrogen, 312.

ammonia, 31:2, 316.

aqueous extract of cheese, $310,315$.

ash, 73 .

ash in checse, 309,311 , 315.

ash in commercial milk-sugar, 319.

birotation ratio, 318.

boric acid, Thompson, 76.

bromine absorption, 276.

Hehner, -76 .

Hehner \& Mitchell, 276.

calcium, 74 .

cane-sugar by invertase, 88.

Nuter, si.

Stokes and Bodmer, $8 S$.

carbonic acid, 118.

casein-

Densimetric, 110.

Duclaux, 110.

Frenzel and Weyl, $10 \mathrm{~s}$.

Hoppe-Seyler, 10 s.

Lehmann, 112.

Maissen and Musso, 109.

Richmond, 113.

Ritthausen, 108.

Schlossman, 113.

Sebelein, 109.

Van Slyke, 108. chlorides, 75 .

chlorine in water, 232 . citric acid, 77 .

curd in butter, 253

density, 53, 54, 165-

167 .

density of butter fat, $281,283$.

digestible proteir, 313.

extract in cheese, 310 , 315.

fat, Centrifugal-

Babcock, 170-173.

Gerber, 1s0.190.

Leffimann and Beam, $17+180$.

Stokes, 191, 192. 
Method for estimation of -

fat, Densimetric, 103. in cream, 217.

Soxhlet, 192-195.

fat, (iravimetricAdams, 91-94.

Babcock, 100.

Bell (Somerset House), 94-96.

Macfallane, 10I.

Ritthausen, 101.

Soxhlet, 98 .

Storch, 9 ;. 9\%.

Wanklyn, 101.

Verner-Schmia,95101).

fat in butter, 180, 185, $189,253$.

fat in cheese, 18s, 159, $309,311,315$.

fat in cream, 115,172 , $178,187,159$.

fat, Indirect, 102-104.

fat, Volumetric, 10:2, $170 \cdot 192$.

fat, Volumetric, Soxhlet's, 192-195.

frec ammonia, 232.

heat evolved by sulphuric acid- -

Maumené, 27.

Richmont, ㄱs.

Thompson \& Ballantyoue, 277 .

indigestible nitrogenous sulistanee, 312. insoluble ash, 73.

insoluble fatty acirls-

American Assoreiation of Ollicial Agrieult ur al ('lu'mists,

ileisilumam and Vireth, 2is!.

Helunr and Amedl, ㄴ.s.

ionline alsorption, 274.

lactic acisl, 113.

loss on ignition, 2:32. nagnesimn, it.

milk - slgatr, Gravi. metric-

O'sullivan, s3

Wein, 81.

milk-sllgariu commereial samples, 31 s.
Methor for estimation Method for estimation of-

milk-sugar, Polarimetric-

Deniges, $8 *$.

Richmond and Boseley, 81.

Vieth, so.

Wiley and Ewell, 7.

milk - sugar, Volumetric-

Felilingt, S.5.

Pary, st.

molecular weight of

insolulle fatty aciils, $2 ; 1$.

nitrie acid, 234. 255.

nitrogen, Kjeldahl's, 111.5 .

oxygen absorbed from permanganate, 235.

peptones, 313.

phosphorie acirl, it.

potassium, 75 .

products of ripening

in eheese, 3]1.

proteil nitrogen, 313.

proteids, 105-10s.

Deniges, 10\%.

Ritthausen, 106.

refractive index, 28\%290.

salt in butter, 253.

salt in rheese, 310 , $311,31.5$

saponification equivalent, $266,266 \%$.

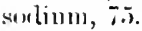

solirls not fat, 95, $100,115$.

solids not fat in but- Method for the examin. ter, 25i3.

soluble ash, 73 .

soluble fitty ardids,

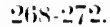

solubility of butter fat in acetio acisl, Chattaway, l'ealy. main, atril Hoor, 27.4.

solubility of butter fat in aleohol, 273.

solubility of rommer-
(iill milk-sugar, 31 s. starch, s!).

streugth of sulphoric ariil, $17 \%$. of -

sulphuric aeid, 74 .

total solicls-

Adams, 70 .

Babeock, 69.

Duclaux, 70.

Ganntner, 70 .

Gerber and Radenhausen, 70 .

Macfarlane, 70.

Pichmond, 69.

Society of Pullic Analysts 6 is.

Stokes, 170.

Wanklyn, (is.

in water, 232 .

total soluble extract in cheese, 310 .

viscosity of butter fat, Killing, 290.

Wender, 290.

viscosity of eleam, 222.

volatile fatty acirls-

fiolimann, 261.

Kreis, 262.

Leflmann and Beam, 262.

Mausfeld, 261.

Meissl, 259.

Perkins, 258.

Reichert. 2.55.

Wollny, 260, 261.

in cheese, 316.

water in hitter, 25.2.

water in ehcese, 309, $311,31.5$.

water in cheese, Devarda, 31\%.

water in milk, 70 . ation of -

but ter uniler polarised light, 279.281 .

com mereial milksugar, .31s, 319.

Methor for the remoral of proteirls in the estimation of milk-sugar, 7s, s.2. 5.3 .

Methorls of sampling, (i): 160 .

Micrueneci, 225.

Mierococeus prodigiosils, 22.5.

Micrococcus rosaceus, ?2.28. 
Micro-organisms, 225 . 230.

acting on milk-sugar, 226,227 .

acting on proteicls, $2 \cdot 26,22 \%$.

action of, on milksiggar, 18.

Classification of, 225.

Curdlıng, 226, 227.

Destruction of, by heat, 149.

in cheese, 29s, 308.

in separator slime, 210.

Pathogenic, 226, 229.

Peptonising, 226, 227. producing alcohol, $226,22 \%$.

producing butyric acid, 226, 227.

producing coloured substances, $2 \mathbf{2} 6, \mathbf{2} 28$.

producing lactic acid, 226.

Products derived from milk by the action of, $240-244$.

Microseopical examination of bulter under polarised light, 279281.

Milk-

Actioll of microorganisms on, 225229.

Action of rennet on, 万, 298 .

as a foor and a medicine, $331-33 \%$.

Bitter. 225.

Blue, 228.

Classification of, 321 .

-cocoa, 32!.

Constituents of, 1-5?

Conveyance of disease by, 229.

during delivery, Control of, 195-197.

General composition of, 1-8.

Green, 2:8.

of mammais other than the cow, 321334.

ont of condition, 228.

Precautions against conveyance of disease liy, 230 .
Milk-

Products derived from, by the action of micro-organisms, 240-244.

-powders, 149.

Red, 228.

regarded as an emulsion, 4.

Ropy, 228.

Soapy, 228.

Tuberculosis in, $\mathbf{2 2 9}$.

Violet, 2:28.

-wine, 320 .

Yellow, 228.

Milk-scale, 61.

Milk-sugar, 1, 6, 8-17.

Acetyl derivatives of, 17.

Action of acids on, 17 . enzymes on, 17 . heat on, 9,15 . nitric acid on, 16. phenylhydrazine on. $8,16$.

Birotation of, 9 .

Chemical properties of, $8-17$.

commercial, Adulteration of, 319.

commercial, Composition of, 320 .

commercial, Examination of, 318-320.

commercial, Preparation of, 17,318 .

Configuration of, 12 .

Crystallised, 11.

Density of, $9,11$.

Density of, in milk, 65 .

Estimation of, by alcohol, 77 .

Estimation of, by Fehling's solution, 8.2-86.

Estimation of, by Pavy's solution, 86.

Estimation of, by polariscope, 78-82.

Fermentation of, 17 , 227.

Formula of, 8.

Heat of combustion of, 335 .

in butter, 3, 245, 253.

Micro-organisms acting on, 226,227 .

Modifications of, 8-12.
Milk-sugar-

Multi-rotation of, 9, 10.

Nature of, 6 .

Oxirlation of, $\mathrm{s}, 16$.

Preparation of, 17 .

Products derived from, $18-20$.

Ratio between, proteirls and ash, 121.

Ratio between, proteids and ash in cream, 216 .

Reactions of, $8,15-17$.

Peduction of, 17 . copper solutions by, $15,82-\$ 6$.

Rotatory power of, 9-11, 80 .

change of, on heat. ing, 145,150 .

Solubility of, $9,15,318$.

Solution of, 318.

Thermal change on clissolving, 9,10 , $11,318$.

Milkers, Conveyance of disease by, 230 .

slineral -

analysis, 73-75.

constituents, 32, 33.

matter, Adulteration of milk by, 138 .

matter, Estimation of, 73-75.

Modes of expression of density, 52, 63.

Modifications of Adams' method--

Abraham, 93.

Allen and Chattaway, 91.

Pichmond, 93.

Thompson, 91.

Modifications of-

Leffmann - Be a m method, 180-192.

nilk-sugar, S-13.

Werner - Schmid method-

Allen, 99.

Richmond, 99.

Stokes, 99.

Molecular-

Manmené figure, Re. lative, 278 .

weight of acids of series $\mathrm{C}_{n} \mathrm{H}_{2 n+1} \mathrm{COOH}, 46$. 
Molecular-
weight of fat of milk, $40,26 \pi$.

weight of insoluble fatty aeids, $2-1$.

Molyblate, ammonium, Solution of, 235 .

Mont gomery eows. Composition of milk of, 125.

Morning and evening nilk, Variation of, 128.

Moulds, 225, 2:9.

Green, 2:9.

White, $2 \cdot 29$.

Mouth, Foot and, disease, 229.

Mreic aeis, 16.

Hucoid proteid, 2, 24, 28 .

Preparation of, 28, 29. ODorous substance, 7 , Propcrties of, 24, 28.

Mule, Milk of, 323 .

Multirotation, 9.

Myristic acil, 35, 45 , 46,47 .

Myristin, 3.5.

\section{N}

Nessrear solution, 233.

Neufchatel ehcese, 301, 303.

Nitrate-

Potassium, as a preservative, 139, 254 . potassium, Standarl solution of, 234 .

Nitrates, Estimation of, 234.

Nitrie acid-

Detection of, 234, 254 .

Estimation of, 234, 25.5.

Nitritas, Vetection of, 23.5.

Nitrogen-

anvilue, Estimation of, in cheese, 312.

alhumose. Estimation of, in rherse, 31:3.

Fistimation of, 10.).

peptone, Estimation of, in checse, 313.

34. 49.

Oidium lactis, 229.

Oil-

Arachis, 284.

Cocoa-nut and palmnut, 258, 267, 272, 284,291 .

Cottonseed, 272, 284.

Sesame. $272,284$.

Vegetalile, Tests for, $2 \div 2,292$.

Oleic acid, $3 \pi, 47,45$.

Olein, 3.5.

Oleo-refractometer, 285.

Optinum temperature of-

enzymes, 22.

micro-organisms, 2006. remet, 300 .

Organisms (sce Mirroortgumism.s).

Osones anl osazmes, 8 , 16.

Ovens, Mater, 71.

Oxalie acisl, 20 , 10.

Oxirlation of-

lutyrie acisl, 43.

glyerol, 40

milk-sugar, s, 16. olcior acold, 4 s.

Oxrgen alsonthed from jermanganate, Listimation of, 2:35.

proteirl, Eatimation Oxypropionie acjul (sees of, in cheese, 313. Lartir aciil).

\section{$\mathbf{P}$}

P.almitic acid, 35, 45, 46,47 .

Palmitin, 35 .

Palm-nut oil, 267, 272, 's4.

l'ara - phenylene - dia mine. Use of, for detecting sterilised milk, 145, 152.

Parmesan cheese, 302, $305,307$.

Partial milking, Variation of fat by, 128 .

Pasteurised milk, 146, 149.

Pathogenic organisms. $\therefore 26,229$.

Pecto-galactinic acidl, 6.

Perligree sliorthorns, Composition of milk of , 123-125.

Penicillium glaucum, 229.

Pepsin, 21, 23.

Pepto-albumrses, 21.

Pepto-caseone, $2 \mathrm{I}$.

P'pto-caseoses, 21, 23.

Peptones, 21.

in cheese, $306,309.313$.

in colostrum, 1:30.

Test for. 313.

Peptonised milk, 337.

Peptonising organisms, 226,227

Permanganate, potassium, Standarel solution of, 235 .

Phenylgalactosazone, $1 \mathrm{~s}$.

Phenylulucosazone. is.

I'lenylhydrazine, 8,16 , 18.

P'henyllactosazone, $\mathrm{s}, 16$.

l'hophates, 33.

Combination of, with ('asein, 6, 25, 26.

Deteetion of, 235.

l'hisical-

ixaminatim of butter fit. 27()$-290$.

stale of cascin in milk, i. .202, 2.5.

stateof fat in milk.?-ti. state of fat in eream, $338-341$,

Pickled hutter, 25.5, 256. 
Picro-carmine, Staining of membrane by, 2 .

Pipettes, Standardisa- Preselvatives, 139-145, tion of, 345 .

Placentine cheese, 306.

Pleuro-pneumonia, 229.

Polarised light, Microscopical examination of butter under, 279. 251.

Pont l'Evêque cheese, 301.

Poor milk, Determination of cause of, 200 .

Porpoise, Milk of, 323.

Port du Salut cheese, $302,307$.

Potash absorption, 266.

Potassium-

bichromate, Use of, for preserving milk samples, 144.

Estimation of, 75 .

nitrate as a preservative, $139, \mathbf{2 5} 4$.

nitrate, Standard solution of, 234 .

permanganate, Standard solution of, 235.

Powders, Milk, 149.

Practice of cooling nilk in Denmark, 4.

Precautions-

against conveyance of disease, 230 .

Sanitary, 239.

to prevent rising of cream, 135.

Preparation of -

albuminoids, 20.

butter fat for analysis, 257.

casein, 27.

cheese, 298.

condensed milk, 146.

copper-zinc couple, 234.

fat of cheese for analy. sis. 317 .

humanised milk, 336 .

lactalbumin, 28 .

milk-sugar, 17.

nutrient media, 237 .

rennet, 300 .

samples of butter for analysis, $25 \mathrm{l}$.

sterilised milk, 149.
Preservation of milk 254.

Adulteration of milk by, 139.

Advantages of, 140.

Detection of, 140-143.

Estimation of, 75, 76, $25 \overline{.}$.

in butter, 140,254 .

in cream, 140.

Injurious effects of, 139-140.

Objections to, 139 .

Principle -

Colouring, 7, 34, 49.

Odoriferous, $7, \quad 34$ 49.

Problems, Solution of analytical, 197-205.

Process, Reichert (see also Method), 258262.

Theory of, 263-266.

Products-

derived from milk. sugar, 18-20.

formed from milk by the action of microorganisms, 240-244.

of decomposition of fat, 49,50 .

of hydrolysis of fat, $35,36,40-49$.

of hydrolysis of proteids, 21.

of ripening of cheese, $305,310,312,315$, 316.

Other, derived from milk, 318-320.

Properties-

analytical, of butter, Influence of keeping on, 292-296.

General, of acids of the series $\mathrm{C}_{n} \mathrm{H}_{2 n+1} \mathrm{COOH}, 46-$ 47.

General, of linolenic acirl, 48, 49 .

General, of linolic acid, 48, 49.

Teneral, of oleic acid, 47,49 .

of buttermilk, 296 . samples, 144.

of albuminoids, 20 .
Properties-

of butyric and allied acids, 43-47.

of casein, 25,26 .

of glucose and galac. tose. 18.

of glycerol, 40-42.

of milk fat, $37-40,257$. of milk-sugar, 15-17.

Proportion of -

milk-sugar in cream, $3,215,216$.

proteids in creanı, 2, 215-216.

solids not fat to water in butter. 246 .

volatile acids to fat in cheese, 316.

water in butter, 246 248,256 .

Proteid-

nitrogen, Estimation of, $10 \overline{\text {, }, 313 .}$

-compounds, 320 .

Mucoid, 2, 24, 28.

Mucoid, in butter, 2, 246.

Proteids, 1, 6, 7, 20-32.

Coagulation of, by nitrate of mercury, $5,78,83$.

Composition of, 20, $25,26,28,3: 99$.

Density of, in milk, 6.5 .

Estimation of, 105-113.

Heat of combustion of, 335 .

Hydrolysis of, 21, 22.

in butter, 2 .

Micro-organisms acting on, $2: 26,: 2: 27$.

of cheese, $299,305$.

of colostrum, 130.

of human milk, 327 .

of milk, 6, 7, 20-32.

of milk of different mammals, 322.2 .

of whey, $30, \mathbf{2 9 9}$.

Proportion of, 2.

Proportion of, in cream, 2, 215, 216.

Ratio between, milksugar, and ash, 121.

Ratio between, milksugar, and ash, in cream, 216.

Reactions of, 20,26 , 27,2 . 
Proteids-

Removal of, in estimation of milk-sugar, $78,83$.

Yield of urea from,335.

Proto-alhumoses, 21 .

Proto-caseoses, :21, 29, 30,31 .

Comprosition of, 29,30 .

Reactions of, 31.

Proximate analysis of butter, $251 \cdot 255$.

Proximate analysis of butter, Interpretation of results of, $25 \overline{5}$.

Pseuclo-solution, 7 .

\section{$\mathbf{R}$}

Raleit, Milk of, 323.

Rancidity, 49, 50.

Rate of-

change in percentage of fat on stancling, $133-135$.

distillation of acids of the series $\mathrm{C}_{n} \mathrm{H}_{2 n+1} \mathrm{COOH}, 46$.

distillation of volatile fatty acicls, 263 .

flow, Influence of, on percentage of fat in Ratiosepiraterl milk. 207 .

Anabolic and meta. bolie, 33.5, 336 .

between milk-sugar, proteirls, and ash in milk, 121.

letween milk-sugar, proteirls, and ash in creatm, 216.

between lieichert and Peichert - Wollny figures. 2622 .

bet ween solicls not fat and water in butter, 246,256

liet ween solirls not fat and water in elotterl cream, 2:20).

betweon water, solids not fat, and ash in (ream, 215.

Reactions of-

humaı inilk, 323 .

milk, $s$.
Reaction ofmilk of different mammals, 322.

Reaction, Speeifie temperature, 277 .

Reactions of albuminoids, 20, 26, 27,28 .

caseones, 31 .

easeoses, 30, 31 .

cholesterol, 42, 43.

deutero-caseoses, 31 .

dys-caseoses, 30, 31.

milk-sugar, S, 15-17.

proto-caseoses, 31.

Reeknagel's phenomenon, $6 \bar{\tau}, 68$.

Red polled cows, Milk of $123-125$.

Recluction of copper solutions, 15, $\$:$.

Refractive inclexEstimation of, 285, 290.

of fat of milk, 39 .

of glycerol, 40 .

Relation between, and Reiclert figure, 287, 289.

Relation letween, and seale divisions of Butyo-refractometer, 2ss.

Refiactometer

Abbé, 285, 287.

Butyo-, $287 \cdot 290$.

Olen-, 25i-24.

Regulations against eonveyanee of discase, $23 i$.

Reiehert -

figure, Limits for, 259 . $260,262$.

figure, Relation between, and refrie. tive inclex, 28T, 2S?. process, $258-26$ (i3.

process, Theory of, $263-266$.

-Wolluy figure, 260.

- Wollny fisure, liclistion hetween, and critical temperature, 273.

Relation lxtweenericical temperature aurl insoluble fatty acids, 273.
Relation between-

critical temperature and Reieliert. Wollny figure, 273.

density, fat and solids not fat, 56-66.

density, fat and solids not fat, Formula for, 60 .

fat and specific gravity of eream, 217 .

fat and solids not fat, 129.

fat and total solids of cream, 220 .

milk-sugar, proteids, and ash, 121, 216.

potash absorption, and saponifieation equivalent, $26 \pi$.

refractive index and Reichert figure, $28 \%$, 289.

temperature, rate of flow, speed, thick. ness of cream and fat in separated milk, 207 .

thiekness of cream and percentage of fat, 221 .

volatile acids and fat of eheese, 316.

water and solids not fat in elotted cream, 219 .

water and solids not fat in ercam, 215 .

Relitive molecular Man. mené figure, 278.

Remedy for conveyance of clisense, 230 .

Renovial of proteirls in estimation of milksugar, 78, 83.

Remnct, 21, 23, 29S. 301.

Aetion of, on casein, 25, 29s.

Action of, on milk, 23 .

-eliceses, 301, 302.

Comlitions influeneing aetion of, 300 , 301.

Inlluence of temperature upon aetion of, $301,301$. 
Rennet-

Optimum ture of, 300 .

Preparation of, 300 .

Secretion by microorganisms of an enzyme resembling, 227 .

Testing of, 301.

Results of-

bacteriological cxamination, Interpretation of, $23 \mathrm{~s}$.

proximate analysis of butter, Interpretation of, 25.5 .

water analysis, Interpretation of, 236 .

Ripening of elieese, 308 . by micro-organisms, 308.

by enzymes, 30 .

Products of, 305,310 , $312,315,316$.

Rise of specific gravity of milk on standing, 67. 68 .

Rising of cream-

Change of composition on, 133-135.

Explanation of, 208.

in sterilised milk, $145,150$.

Precautions against, 135.

Romadur cheese, 317 .

Ropy milk, 228.

Roquefort clieese, 305, $30 \mathrm{~s}$.

Rotatory power, 14.

of casein, 26.

of glucose and galactose, 18 .

of milk-sugar, 10, 11.

Rule-

for averaging specific gravities, 64 .

of use in chemical control of milk dur. ing delivery, 197.

to prevent conveyance of disease, 230 .

\section{S}

Saccharonyces cerevisiz, $22 \%$.

Saccharonycetes, 225.
Salers cheesc, 316.

Salicylic acicl-

as a preservative, 139 .

Detection of, 141.

Use of, for preserving milk samples, 144 .

Salt-

Action of, on butter, 248.

Arlulteration of milk by, 138 .

butter, $246-24$, 256.

butter, Difference between fresh and, 248, 256 .

Estimation of, in butter, 253.

Estimation of, in cheese, $310,311,315$.

Existence of lactic acid as a, 20.

Salts-

Alkaline, 7 .

of calcium, 7 .

of casein, $6,7,24,25,26$.

of fatt $y$ acids, 44, 45, 46,48 .

of magnesium, 7 .

of milk, 7,33 .

of milk, Probable Separators, 209-2lt.

composition of, 33 .

of potassium, 7 .

of sodium, 7 .

Sample cans, 162 .

Samples-

of butter,, $\mathbf{s} l$.

of butter, Preparation of, for analysis, 250 , $25 \%$.

of water, 2:31.

of water for bacterio-

logical examination, 237.

Preservation of, 144 .

Taking of, 159, 160.

Sampling of-

butter, 251 .

milk, 159, 160 .

water, 231, 237.

Sanitary matters, 229, $230,239$.

Sanitary precautions, Summary of, 239 .

Sanose, 320.

Saponification, 3.5.

equivalent, Estimation of, 266

Explanation of, 36 .
Sarcina, 225.

rosea, 22s.

Sarcolactic acid, 19.

Scale for correction of specifiegravity of milk for temperature, $6 \overline{7}$.

Scale, Milk, 61 .

Sicarlatina, 229.

Scarlet fever, 230 .

Schizomycetes, 22.5.

Secretion, Normal, of manmals, 1.

Sediment, letermina. tion of cause of. $20 t$.

Separated milk, $205-209$.

Adulteration of milk with, 136.

Characteristics of, 205 . Detection of, in milk, 135.

Influence of temperature, rate of flow, speed, and thickness of cream on fat in, $20 \%$.

Testing of, 173, 17\%, 18 .

Separation of fat on solidification, 37 .

Arlvice on the choice of, $211-2014$.

Control of, 209.

Separator-slime, 210. Ash of, 211.

Sesamé oil-

Density of, 284.

lest for, 272.

Sheep, Milk of (see also Ewe), 32:3, 331.

Sheep, milk of, Cheese from, 302 .

Shorthorns, Milk of, 123. 126.

Size of globules, 34, 32], $323,332$.

Skim milk (see also separated milk), $205-209$.

Arlulteration of milk by, 136.

Analysis of, 116 .

cheese. $302-305$.

Detection of, 135.

Globules of fat in, $20 \mathrm{~s}$.

Testing of, 173,177 , 185. 
Skimmerl milk, Characteristies of, 205 .

s/im-memlran, 2.

Slime, Separator, 210.

Smell of water, 231.

Smell, unusual. Determination of cause of, 201.

Soapy milk, 228.

Society of Public Analy'sts' -

limits, 132.

method for total solid estimation, 68 .

Sodium, Estimation of, 75 .

Sodium thiosulphate, standard solution of, $235,275$.

Solid portion of fat, Composition of, is.

Soliclification, Śeparation of fat on, 37 .

Solidifying points (see under names of sulystances).

Solids not fat-

Comprosition of, 121.

Constituents of, 6.5, 121.

constituents of, Density" of, 6.5.

Density of, 60, 62.

Estimation of, in butter, 2.33.

estimation of, Somerset House method for, 9.5 .

Limits of, 120, 132, 133.

Ratio letween water and, in butter, 246.

Ratio hetween water ant, in crean, 215.

liatio betwcen water, and clotterl crean, 21 !)

Variations of, accorrling to season, 1:26.

Variations of, in milk, $1: 20-1: 2,1: 24-1: 25$.

Variations of, in wilk of single cows, 1:24.

Solide, Trotal (see Totrel solidis).

Solnbility of -

loutter fat in acetic acidl, 27:3.
Solubility of -

butter fat in alcohol, 273.

caleium salts of acirls of series $\mathrm{C}_{n} \mathrm{H}_{2 n+1} \mathrm{COOH}, 44$, 45,46 .

fat, $3 \bar{\tau}, 39$.

fatty acids in alcohol, $45,46,47$.

fatty acids in water, $43,44,45,47$.

glycerol, 42 .

lactic acid, 20 .

milk-sugar, 9, 12, 15.

milk - sugar, Estimation of, 31 s.

Solnble-

extract of cheese, Fstimation of, 310,315 .

fatty acils, $3 \overline{5}, 43,44$, 46,47 .

fatty acirls, Estimation of, $268-271$.

fatty acids, Limits of, Specific gravity$2 \div 2$.

Solution-

Fehling's, 82-86.

Nessler, 233.

of analytical problems, $197: 0.5$.

of milk-sugar, 9,318 .

Paryo, ab.

Stanidard, of ammonium chloride, 233.

Stamiari, of ammonium molylylate, 235.

Stanclarrl, of iodine, 274.

Standarl, of lime, 113.

Stamlard, of potassium nitrate, 234 .

Sitandard, of potas- speeifie rotatory power sinmpermanganate, 235.

Stamlard, of sodium thiosulphate, 235, 27.5 .

Stamblarl, of sulphurie acill, 23:5.

solveruts for fat, !10, 94, 11.5

Sonlerset House method for milk inalysis, 94. 96.
Sour milk-

Analysis of, by Somerset House method, 96.

cheese, 302.

Determination of cause of, 203.

Estimation of aeidity of, 113-115.

Source of-

error in determination of fat in cream from specific gravity, 218.

error in examination of butter under polariserl light, 280, 281.

water, Inspection of, 231.

Sow, Milk of, 323.

Specific colour tests for adulterants of butter, $2-2$.

as a test, 55 .

Change of, on rise of temperature, 66.

Determination of, 53$55,165-16 \bar{\imath}, 283$.

high, Determination of eause of. 199.

low, Determination of eause of, 197 .

of colostrum, 130.

of milk, 5l-68.

of milk, Average, 55.

of milk, Canse of, 56-

66.

of milk of individual cows. 55.

Relation between, and fat in cream, $21 \%$.

Rise of, on standing, $67,6 \mathrm{~s}$.

(see Rotutory pourer).

Specifie temperature reaction, $27 \%$

Sipred, Inlluenee of, on pereentage of fat in sejarated milk, 207.

spirilla, 2.2.5

Siprengel tube, $5 \%$.

staining of layer round globules by picro-carinine, :2.

sitall test, 136. 
Standard alcoholic soda, / Sterilised milk266.

Standard, District, in water analysis, 236 .

Standard solution (see Solution).

Standard thickness, Method of diluting cream to, 222.

Standardisation of bottles, 345 .

burettes, 344 .

flasks, 345 .

lactometers, 346 .

pipettes, 345 .

thermometers, 346. weights, 342 .

Standards for-

ash, 133.

chlorine. 133

cream, 216.

density of butter fat, 284.

fat, 132, 135 .

potash absorption, 267 .

refractive index, 287 , 289.

Reichert process, 259262.

solids not fat, 132 133. soluble and insoluble fatty acids, 272 .

total nitrogen, 133.

Valenta test, 274.

Standards, Society of

Public Analysts', 132.

Staphylococci, 225.

Starch-

Adulteration of milk by, 137 .

Detection of, 89,137 , 224.

Estimation of, 89, 90.

State of casein in milk, $6,22,25$.

State, Physical, of fat, 2-6.

Stearic acid, $35,45,46$, 47,49 .

Stearin, 35.

Sterilisation, for preserving milk samples, $1+5$.

Sterilised milk, 149-154.

Albumin in, 150, 153, 154.

Analytical characters of, $150-152$.

Citric acid in, $150,152$.
Detection of, in milk, $\begin{aligned} & \text { Sweetened contensed } \\ & \text { milk, 146, } 147,145 .\end{aligned}$ 152-154.

Injurious effects of, S'yntonin, 24 146.

Milk-sugar in, 150,152,

Preparation of, 149.

Rising of cream in, TAluLE (see List of $150-152$.

Tubles, p. xv.).

Stilton cheese, 302, 304. Tartronic acid, 41.

Stracchino cheese, 301, Taste$303,306$.

Streptococci, 225.

Strippings, 129.

Substance, indigestible nitrogenous, Estimation of, in cheese, 312 .

Suckling, Composition of human milk before and after, 325 .

Sugar, Cane-

Estimation of, 87-89.

Heat of combustion of, 333 .

Sweetness of, 6 .

Sugar-

Milk (see Milk-sugar). of human milk, 6,326 . of mare's milk, 6,334 . of milk of different mammals, 6, 32:2.

Sulphates, 7 .

Sulphites as preservatives in butter, 254, 2 อ๊.

Sulphur in casein, 25.

Sulphuric acid--

Estimation of, 74 .

Estimation of strength of, 177.

Hydrolysis of fat by, 262.

hydrolysis of fat by, Heat erolved on, $277-279$.

solution for water analysis, 235 .

Summary of sanitary precautions, 239.

Supply, Water, 230-239.

Investigation of, 231 .

Surface energy of small particles, 4, 250 .

Suspension, Substances in, 7 .

Sussex cows, Milk of, 12.).

Swcet taste, Determination of cause of, 200 .
Bitter, in milk, 227, 228.

of human milk, 323.

sweet, Determination of cause of, 200 .

unusual, Determination of cause of, 201 .

Terpenes, Use of, for preserving milk samples, 144.

Test-

Fehling's, 15, 92.

Hehner's, for formaldehyde, 142 .

Maumené, : $7 \%$.

Schiff's, 142.

Specific colour, for adulterants of butter, $\mathbf{2} 2 \mathbf{2}$.

Specific glavity as a, 55.

Stall or byre, 136.

Valenta, 273.

Testing of-

butter, 180, 188, 189.

buttermilk, 177,185 .

cheese, 180, 188, 1:9.

clotted cream, 180, 188,

189.

condensed milk, 187.

cream, $172,178,15^{\circ}$,

189.

milk, 161-163, 164-195.

rennet, 301 .

separated nilk, 173, $177,185$.

skim milk, 173, 17\%, 185.

sour milk, 179, $1 \mathrm{SS}$.

whey, 17\%, 185.

Tewfikose, 6, 330 .

Theory of eluurning, 249.

Theory of the Reichert process, 26:3-266.

Thermal change on dissolving milk-sugar, 318. 
Thermolact ometer, 164, 165.

Thermometers, standardisation of, 346 .

Thermometric methor for the extimation of bromine absorption, 276 .

Thick lintter, 249.

Thick, Determination of reison for milk being. 204.

Thickening of cream, Artificial, 2:2t.

Thickness-

Nethod for diluting eream to standard, 222.

of cream, -2.21 .

of cream, Influence of, on percentage of fat in separated milk, 207.

Thiosulphate solution, $23.5,273$

Thymol, Use of, for preserring milk sam. ples, 144.

Total nitrogen in eheese, Estimation of, 311 .

Total Solirls-

Density of, 6i3

Estimat on of, $6 \mathbf{6}-7$, $1(i 7-17)$.

Fstimation of, in eream, 115.

Estimation of, in water, $2: 32$.

Estimation of fat from, in cream, 2201.

Tutal solulule extract of cheese. 310, 315.

Trypsin, ‥

Trypto-illhumoses, $21,30$.

Trypto-easeone, 21, 30.

Trypto-easeoses, 21,30 .

Tuberculesis, 2029.

Truhoid, :230

'lyosine, 2:2, 2:2. in colestrum, 1:30.

Tyrothrix, 30s.

\section{U}

UXSWFETEXEN (.11 leomenel milk, 14ti, $1+7$.
Unsweetened conflensed milk -

Detection of, in milk, 152.

Unusual taste or smell,

Determillation of cause of, 201 .

Urea, 7.34.

in colcstrum, 130 .

Heat of combustion of, 33.5 .

Yield of, from pro. teitls, 335.

\section{V}

\section{Virtation of-}

analytieal properties of hutter on keep. ing, $29 \cdot 2-296$.

asl, 121 .

composition of human milk, 324.

composition of lumman milk with laetation, 324.

density uf butter fat with temperature, $2 \times 2$.

fat, 120,123 .

fat ant solids not fat, according to seisen, l:26.

fat and solids not fat, Daily, 1:27.

fat and soliuls not filt in buttermilk, 2!)6.

fat ancl solicls not fint in different elumrns, 1:21.

fat and solicls nut fat in milk, 1:20.

firl and soliels not fat in milk of gitlunese, 3엉.

fat allul solids mot fat in milk of single (1). 1:3, 1:4.

fat ancl solicls ont fat in wlyex, :2:!!

fat and soliels not fat inl pitrtial milking, l:בs.

fat with solicls not fat. 1:?!).

morning and exemings milk, las.
Variation of -

potash absorbed, 267 .

Reichert figures, 259, 2601,262 .

refractive index, 257 , 259.

refractive inclex with temperature, :-899.

solicls not fat, 120 , $122,124$.

soluble and insoluble fitty acicls, 272.

water in lutter, 247.

water in lutter on keeping, 24s.

Vegretable oils, Test for, 27.2

Violet milk, 22S.

Viscogen, 224.

Viseosity of acirls of the series $\mathrm{C}_{n} \mathrm{H}_{n+1} \mathrm{COOH}, 47$.

butter fat, 2000 .

crean, $221-2 \cdot 3$.

milk, 8 .

Volatile acirls in cheese, 316.

Volatile acirls in koumiss, Estimation of, $11 \%$.

Volatile fatty acids, listimation of, 255 . 263.

Volatility of lactic acid, 19.

Volumetric method for the estimation of milksugar, s5, si.

Volumetric method for the estimation of milk fat, $102,170.1922$

\section{W}

W.TEK-

Ailulteration of butter with, 25i.

Ammonia-free, 234 .

analysis, 231-235.

amlysis, lnterpretation of results of, 236.

batls, 72, Its.

lioiling points of, 347 .

Converance of disense by, 230. 
Water-

Water-

Conveyance of discase by, l'recautions against, 230 .

Density of, 51 .

Detection of added, $133,197$.

Detection of added, Method for, 197 .

Estimation of, in butter, 252.

Estimation of, in milk, 70 .

in butter, Effect of kesping on proportion of, 248 .

in butter, Influence of temperature on proportion, 249, 25 i.

in butter, Proportion and variations of, 246,247 .

in butter, standard for, 255 .

in cheese, Estimation of. 309, 311, 315, 317.

, as a standard Whey, 298-300. solution. 113 .

oven, 71,72

Ratio lietween, and solids not fat in butter, $: 246$

Ratio between, and solids not fat in clotted cream, 219.

Ration between, and solids not fat in cream. 217,220 .

supply, 230 .

supply, Investigation of, 230 .

Weights, Standardisaof, $34:$.

Welsh cows, Milk of, Yellow milk, $22 \mathrm{~S}$. $125,126$. 30:2

IT'estphal laalance, it.

Whale. Milk of, 32:3.

Analysis of, 119.

Sour milk. 299 293.

Wine, Milk, 320. Human milli).

\section{Y}

Yeast, Pink, 2028.

Yeasts, 2.25

York cheese, 305.

Wensleydale cheese,

Composition of, 299.

Proteids of. $30,299$.

Testing of, $17,18.5$

Variations of fat in,

Woman's milk (see

Working of butter, 25u.

\section{INDEX TO PROPER NAMES.}

A

А вве́, 285, 25\%.

Abraham, 93

Arlams, 70, 71, 90, 91, $93,96,98,99,100$, $101,102,169,345$.

Aikman (see Cameron).

Allen, 38, 87, 99, 44, $258, \quad 259,262,267$, $2 \pi 4,282,322$.

Allen and Chattaway, 91.

Allen and Cox, 308.

Allen and Homfray, 36.

Allen and Moor, 293.

Amagat and Jean, 28.5.

Ambuhl, 259.

American Association of Utticial Agricultural Chemists, 69, 100, 269.

Angell (see Hehner).

A schmann, 147 .

A shworth(see Smetham). Atwater, 39.
Aylesbury Dairy Com- Beckhurts, 259.

pany, 120, 124, 219, Beckmann, 154.

$24,240,241,246$, Behr.nd and Morgen, 60 .

248,337 .

B

B.ABCock, 24, 61, 67, 69, $100,170,171,174,209$.

Beimling, 174, 175.

Bell, 35, 91, 94, 96, 125, $126,272,282,293,331$.

Benecke (see Schulze).

Berkefeld, 110.

Besana, 34, 262, 294, $302,305,331,332$.

Babcock and Russell, 6, Bevan, 144. 24, 34, 144, 298, 308, Bicl, 24, 333. 309,327 .

Ballantyne (see Thompson).

Bannister, 120, 123.

Barlow, 146.

Baruch, 48.

Baudouin, 272, 291.

Baynes, 102.

Beam (see Leffmann).

Becchi, 272, 291 .

Béchamp, 1, 2, 3, 4, 6, $7,20,24,26,27,34$, 215,327 .
Bignamini (sec Mus:o).

de Blasi (sec Syricrt).

Blunt, 271.

Blyth, 24, is, 132 .

Bochicchio, 299, 308.

Bodmer, 120 (see also stolies).

Bondzynski, 312.

Boseley, 246.

Boseley and Richmond, $79, \$ 1,107,150$.

Boseley and Rosicr, 184.

Bourcart, 67. 
Boussingautult, 128.

Brown, (amphell, 279.

Brown, H., and Pickering, 9.

bown, J. K., 61.

Bronhl, 43.

de Bruyn, 287.

Burton (see Morse).

\section{C}

C.A.dweli, 2.55, 259 .

Cameron and Aikman, $303,304,305$.

Carcano, 306 (see also (íctelli).

Carter and Richmond, $6,322,323,324,325$, 326.

Cassal, 140.

Cassal and fierrans, 62.

Cazeneuve and Haddon, 69.

Chattaway, 257 (see also Allen).

Chattaway, l'earmain, and Noor, 274.

Chittenden and Painter, $23,26,29$.

Clauznitzer and Mayer, 60.

Clayton, :294.

Coignet, 237 .

Cornwall, 272.

Cormwall and Wallace, 2.).9.

Cottom, s!.

Cux (see Allen).

C'ripus, 139.

Crismer, 2073.

Crum, 2.55 .

\section{D}

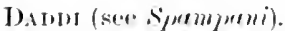

Dimilewsky (see Rerlenh(I) $\times$ (1).

Jeniges, $82,83,107$.

Jevaria, 317

Lomme, 130).

Dregendorff, 42.

Iroust, 29].

1)elnux, $22,23,70,102$, $110,152,26(3,26,2$, $303,3104,305,307$, $308,31 \%, 316,334$.
Duffy, 36.

Dumas, 106.

1)yer, 128.

Dyer and Roherts, 99.

Dyke $r$. Gower, 135.

\section{E}

EMPRET, 170.

Emery (see schueinits). Estcourt, 282.

Eugling, 130, 132.

Ewell (see Ifiley).

\section{F}

FABEK. 91, 103,247,272.

de Fabris (see lilla. recrhia).

Farrington, 67, 141 .

Fehling, 15, 28, 82, 83, S4, s5̃, 86, si, Ss, $13 \overline{\%}$, 320.

Fernandez-Krug and Hampe, 102.

Fischer, S, 15.

Fleischmann, 34, 38, 59, $60,61,125,130,147$, $210,217,249,296$, $299,300,303,304$, $327,331,332,333$

Fleischmann and $\mathrm{Hol}$ gen, 60.

Fleischmann and Vieth, 269.

Fox (nee Honk/yn).

Frenzel and Weyl. 10s.

Fremlenreich, : is, 309.

Foidevanx, jog.

\section{G}

GAFRTSER and Hugerslofl, IsI, 183, Ist.

Galaine, J65.

(iamutner. 70, 102.

Ciarelli and Careano, 40.

Gerher, 180, 181, isfo, Ist, 31 .

Giober and Radell. hausen, 70, 176.

Gerrans (ace Cressal).

Glusky, 94.

(ivilmaim, 26 .
| (Hooeh, 75, 83, 84, 85, $107,109,110,310$.

(rower (see Dyle).

Griffin, 71 .

(irunzweig, 43.

\section{$\mathrm{H}$}

Handos (see Cazeneure).

Hientselı (see sichmill).

Hager, $260,269$.

Halliburton, 23.

Hammarsten, 22, 23, 26, 30.

Hampe (see FernandezKं? $(n)$.

Hansenn, :260.

Hareourt, 10.

Harrington and Kinnientt, $32 \%$.

Hart, 230.

Hazen, 253.

Heaton, 128.

Helner, 40, 60, 76, 117, $118,139,142,143,144$, $258,261,272,274,276$, 294.

Helmer and Angell, 258, $259,268$.

Helmer and Nitehell, $45,46,276,27 \%$.

Hehner and Riehmond, (60, 61 .

Heilit\%, 45.

Henkel, 7.

Henle, 130.

Henniger, 40.

Henry, 19.

Her. 22S.

Hewlett, 23.

Hill. 99.

Homfriy (see Allen).

Hope-Seyler, 26, 102 , $108,1.5$.

Hourlet, 129, 131, 132.

ron Hiibl, 4s, $2.58,274$.

Huepe, 2:27.

Hugershoft see Gaert. ner).

llurst, 274 .

\section{J}

.JEsx, 262, 286 (see also Amatyal). 
Johanssen, 324.

\section{M}

$$
271 \text {. }
$$

.Jones, 39, 274.

\section{K}

KaHLBAUM, 43.

Kennepohl (see Weiske).

Killing, 290.

Kinnicutt (see Harrington).

Kjeldahl, 105, 106, 10s, $109,110,113,116,253$, 311,313 .

Koch, 281.

Koefoed, 44.

Koettstorfer, 266, 267.

Konig, 299, 303, 304, $305,332$.

Kreis, 262.

Kühn, 132.

\section{L}

LANDOWSKY, 332.

Lassaigne, 129.

Laurent, 81 .

Lesds, 324, 325, 326.

Leffmann, 145.

Leffmann and Beam, 110 , $117,139,163,170,174$, $175,178,180,181,262$, 303, 304, 305, 345 .

Leonard, 142 (see also Smith).

Lieben and Rossi, 43.

Liebermann, 92, 102.

Liebig, '237.

Lindenmeyer, 42.

Linder (see Picton).

Lindt and Muiller. 307.

Ling and Richmond,330.

Linnemam, 43.

List (see $W_{o h l}$ ).

Lister, Lord, 20.

Lister, R. A., \& Co., 184.

Liverseege, 125.

Livett, 246.

Lloyd, 122, 308, 309.

Longi, 262.

Lowe, 122.

Luck, 44.

Luff, 324 .

Macfarlane, 70, 101.

Maissen and Musso, 109.

Maissen and Rossi, 262.

Mannheim, 62.

Mansfeld, 261, 262,289.

Marchand, 181.

Marpmann, 102.

Maumené, 277, 278, 279.

Mayer, 262, 284 (see also Clanznitzer).

Merlicns and Scherer, 258.

Meissl, 259, 260.

Menozzi, 272 (see also MI (1.S.No).

Merckling, 259.

Merkel (see Ireigle).

Millon, 28.

Mitchell (see Hehner).

Mitscherlich, so.

Molinari, 99.

Moor (sec Allen, Chattaway, and Pearmuin).

Moore, 258.

Morgen (see Behrencl. and Fleischmann).

Morse and Burton, 271.

Morse, Pigott, and Burton, 102 .

Moser and Soxhlet, 332.

Müller, 285 (see also Lindt).

Munier, 259.

Musso and Menozzi, 23.

Iusso, Menozzi, and Bignamini, 306.

Musso (see also .1/ainsen).

Muter, 3s. 87, 269, 282, $287,289,303,304$, 305.

\section{$\mathbf{N}$}

Nessler, 13S, 232, 233.

Nicol, 279, 280, 281.

Nilson, 259.

Nitsche, 40.

\section{0}

O'ShaUghessy, 246.

O'Sullivan, S3.

Overend, 337.
P.inter (see Chitten(len).

Palnu, 24.

Pappei and Richmont, $6,322,32 \mathrm{~s}$.

Parker, 9:3.

Pasteur, 149, 240.

Paterson, 180.

Pavy, 86, s7, ss.

Pearmain and Noor, 147, 303, 304, 305.

Pearmain (see also Chattaway).

Perkins, 258.

Pfeiffer. 324, 325.

Piccardi, 331.

Pickering (seeH.Broun).

Picton and Linder, 6.

Pigott (see .1lorse).

Pizzi, 37, 39, 1:30, 279, 280, 321, 323, 327, 328, 331, 332, 334.

Pohl, 20.

Purdie, 18.

\section{Q}

Qunvesne, 164.

$\mathbf{R}$

RADENHACSEx and Danilewsky, 2:3.

Radenhausen (see also Gerber).

Raoult, 40.

Recknagel, 67, 68.

Regnanlt, 347 .

Reichardt, 259,272 .

Reichert, 258, 259, 260, $262,263,26+, 266,271$, $273,257,289,291,292$, $294,295,296,328$.

Ringer, 337.

Ritthausen. 26, 101, 102, $105,106,105,109,116$, 119,326 .

Roberts (sce Dyer).

Rosier (sce Bospley).

Rossi (see Lieben and Maissen).

Rübners, 148 .

Russell (see Babcock). 


\section{S}

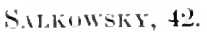

Sartori, 262, 304, 306.

sichecle, 40 .

suluerer (see Melieuss).

Schitf, 142, 143.

Schleicher and Seliull, (9), 93, 97, 310.

schlossmann, $1,3$.

Schninj, Werner (see Iferner-sirhmirl).

cielnuirlt and Hitnsch, is, sil.

Schmitt, 259.

sichnoeser, 10, 11, 12.

sichnepel, $2+6$.

scluulze and Benecke, $31 \%$.

Schweinitz and Emery, 39.

sebelein, $2: 2,27,2 s, 109$, 1.5 .2$.

Senitner, 260.

Shenstone, S6.

short, 310 .

Skalweit, 281, 283, 255.

suethan, dis, 100, 133, 2999, 30:3, 304.

sinethanand Asliworth, 114.

Smith and lecomatrl, 3, $1+2$.

Society of l'ullic Ana. lysts, (jl, 6s, 91, 101, 13:2.

xïllner, 7, 27, 33.

Sioxllet, $27,57,91,92$, $93,94,97,95,1100$, liki, Il:3, 164, 16.5, $170, \quad 1 ! 2, \quad 193,249$, $3] 0$ (ste also, Moser).

Siallanzani, : 602.

Sjumpini and Darlili, 272.

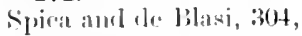
$31,6$.

siprenerrel. $\pi 3,54$.

viteiluen, :30s.

Sitein, :26?.
Stewart, 1.33.

stoddart, 30 s.

sitohmann, $26,39$.

Stokes, !18, 99, 170, 191, Voeleker, 331. 2024 .

stokes and Bodmer, si, sis.

Storch, $2,3.4,6,24,2 \mathrm{~S}$, $29,91,96,95,102$, 113, 2111, 215, 245, $249,250,296$.

strolimer, $327,325,335$.

Sitruve, 29, 244.

Stutzer, 303, 304, 311, $312,314,31 \%$.

Sykes, $\mathbf{6}_{2}$.

sizonlothy, 94.

\section{$\mathrm{T}$}

TANRET, 12.

Tarnier, 334.

Taylor, :279.

Thompson, R. T., 76, 254.

Thompson and Ballintyone, .377.

Thompsim, W., 91.

Tichlorme, 170.

Turner, 26s.

V

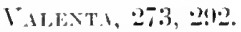

Van silyke, Jus.

Vareutrip, and lvill, 106.

Vaurliu, 1:3].

lentrke, SI.

Vietlı, (i.), $160,8 \%, 69$, :2, , $0,51,91,93, ! 14$, $113, \quad 121, \quad 1: 2, \quad 123$, l:5, l:!, 1.32, 1.36, Yox

lit, 11i, $112,215$.

$204,241,216, \quad 2511$,

"(i2, 2!1:3, 29)4, 29)5,

$2 !), 2 ! 9 !, 300, \quad 303$,

30., 3331, 333:3, 337, \% 1. 1मFk, 4:3, 41.

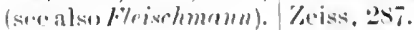

Vigna, 262.

Villarecchia and de Falbris, 272.

VI.ALACE(see Cornuall).

Waller, 92.

IVanklyn, 68, 101, 120 .

Wanklyn and Fox. 36, 25!).

Warringrton, 20.

Weigle and Nerkel, 140 .

Weignamn, 22S.

1Vein. $84,85,89,90$.

Veiske and Kennepolnl, 33:.

Wellnan, 27:2, 2!11.

Wender, 290.

Werner-Schmirl, 91, 9S, $99,116,117,310$.

IVestplial, 53, 54, 253.

Weyl (see Freñel).

Viley, 7s, 93, 2.24, 243.

IViley and Ewell, is, $79, \mathrm{~s} 0$.

Milkinson, 17].

Will (sec J (trrentrap).

Mislicenus, 19.

Woll and list, 18.

IVoll, 171, 209.

Wollux, 259, 260, 261, $26{ }^{2}, 263,264, \quad 266$. $273,291,292, \quad 294$, $29,5,320$.

11 ïrtz, 232,276 .

\section{$\mathrm{Y}$}

\section{Z}




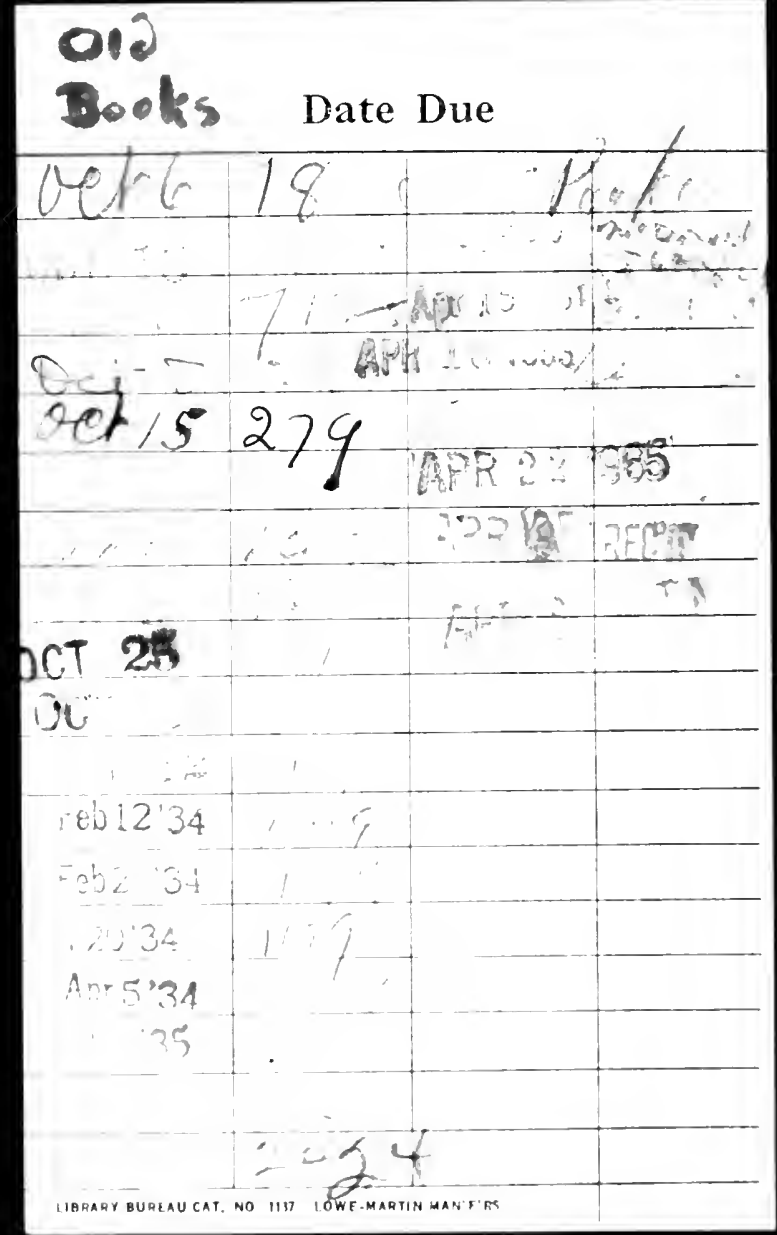


=-AGRICURTIRE

E- FORISTRY

- IIBRARY

$=$

$=$

$=$

$=$

1. 
